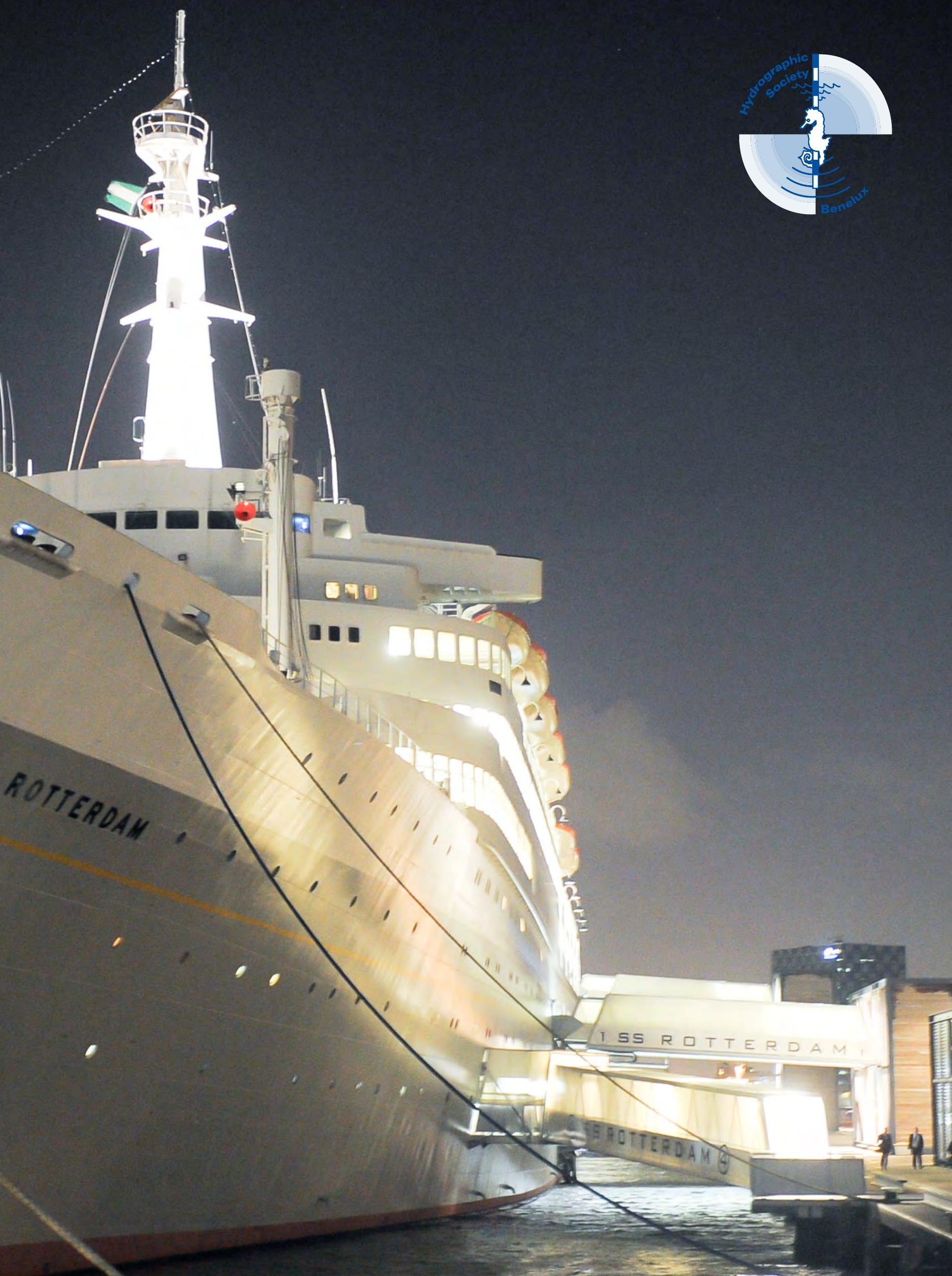

\title{
V
}





\section{Taking care of the sea}

Conference Proceedings of Hydro12

12-15 November 2012

SS Rotterdam, Rotterdam, the Netherlands

organised by the Hydrographic Society Benelux (HSB)

on behalf of the International Federation of Hydrographic Societies (IFHS)

editors:

Leendert Dorst

Thaiënne van Dijk

Rob van Ree

Joost Boers

Wilbert Brink

Niels Kinneging

Vera van Lancker

Alain de Wulf

Harm Nolte 
Published by the Hydrographic Society Benelux;

All copyrights: Hydrographic Society Benelux, 2012;

ISBN: 978-90-365-3470-3;

DOI: 10.3990/2.219;

This digital publication is permanently available online at proceedings.utwente.nl.

\section{2 | Hydrol 2}




\section{Contents}

$\begin{array}{ll}\text { J. Aardoom } & - \\ \text { A. Armstrong } & - \\ \text { O. Cantrill } & - \\ \text { R.M. Capperucci } & \\ \text { S. Claeys } & - \\ \text { C. Collins } & - \\ \text { R. Côté } & - \\ \text { M. Dauwe } & - \\ \text { D. Depreiter } & - \\ \text { T. van Dijk } & - \\ \text { J. Dumollin }\end{array}$

J. Dumollin -

J.B. Ferreira Fontes

C. Gautier

L. Gee

S. Harper

P.T. Harris

H. Hein

T. Hiller

T. Hiller

M. Hounjet

M. Journault

N. Kinneging -

S. de Kleermaeker

J.K. Klippen -

F. Köster

M. Kol

R. Longhorn

D. Mallace -

R.M. Malyankar

T. Mason

M. Mathys

M. van de Munt -

S. Murthy

H.O. Odunsi -

Y. Plancke

B.M.J. Possel -

J. Pötrönen -

V. Putans

B. Ruesink

S. Rütten

S. Salter

L. Schiller

N. Seube

N. Seube

N. Seube

C. Slobbe

B. Spelt

E. Stuifbergen

R. Thain

D. Ventura

E. Verfaillie

K. de Vries

C. Werner

A.P. Wiersma

A. de Wulf

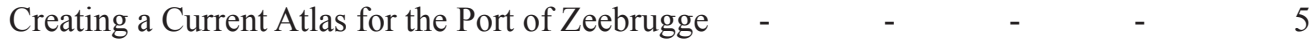

Towards New Standards of Competence for Hydrographers and Nautical Cartographers 11

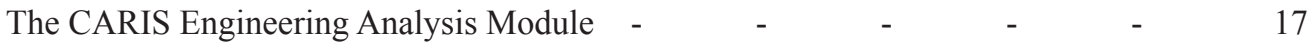

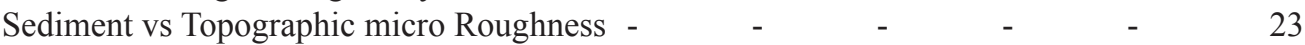

Fluid mud density determination in navigational channels $\quad-\quad{ }_{2} \quad-\quad-\quad 29$

The Progression of Multi-Dimensional Water Column Analysis $\quad-\quad 35$

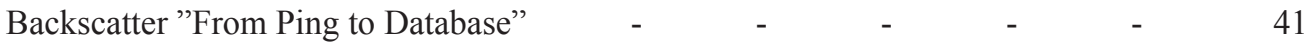

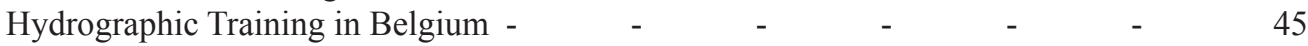

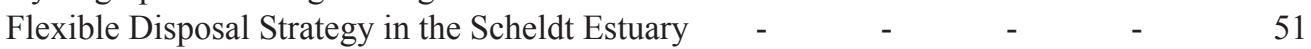

Quantified sea-bed dynamics of the Netherlands Continental Shelf $\quad$ - $\quad$ - $\quad 57$

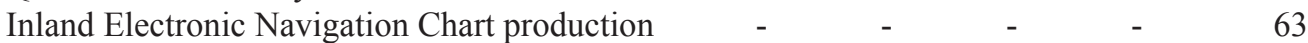

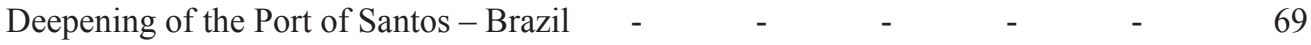

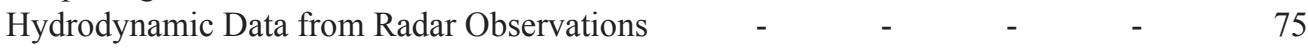

Is Multibeam Water Column Data Really Worth the Disk Space? $\quad$ - $\quad$ - 81

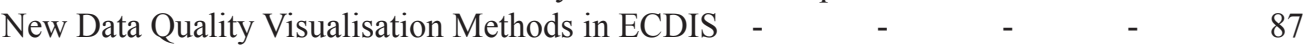

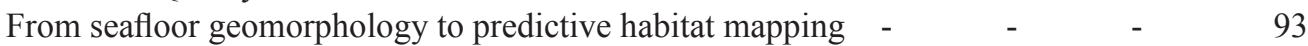

Computer-aided quality assurance of historic tide-gauge records $\quad-\quad$ - $\quad 99$

Measuring Bathymetric Uncertainty of the EdgeTech 4600 Sonar $\quad-\quad$ - $\quad 105$

Positioning Small AUVs for Deeper Water Surveys Using Inverted USBL $\quad$ - 111

$\begin{array}{lllllll}\text { Accurate water levels using PREMO } & - & - & - & - & - & 117\end{array}$

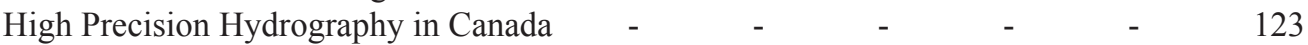

River bed classification using multi-beam echo-sounder backscatter data $\quad-\quad 129$

A New Coastal Flood Forecasting System for the Netherlands - $\quad$ - $\quad$ - $\quad 135$

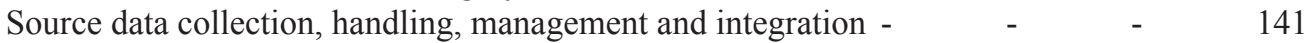

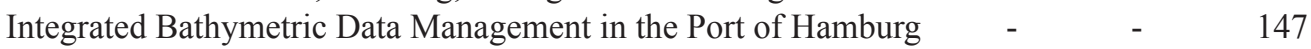

Determining rock quantities using swathe techniques on Maasvlakte 2 - $\quad$ - 153

Assessing the Impact of INSPIRE on Related EU Marine Directives - $\quad$ - 159

Managing bathymetric data in a hydrographic survey company- $\quad-\quad$ - $\quad 165$

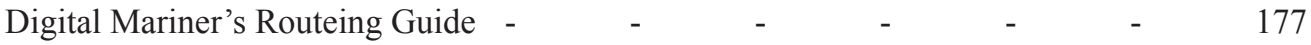

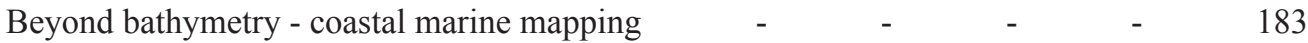

A lithological and morphological map of the Lower Scheldt estuary $\quad$ - $\quad$ - $\quad 189$

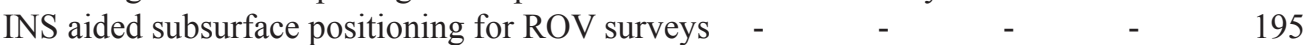

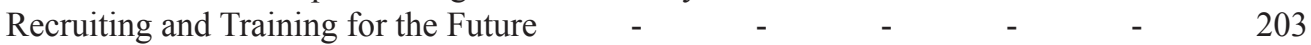

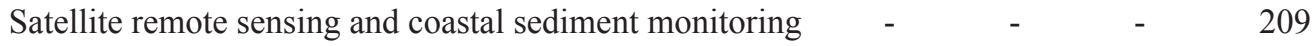

High resolution topo-bathymetric and flow measurements $\quad-\quad y_{2} \quad-\quad-\quad 215$

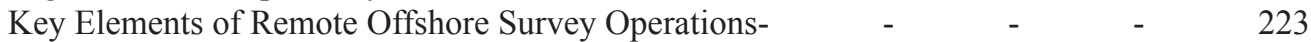

High Resolution Multibeam Survey and Mobile Laser Scanning $\quad$ - $\quad$ - $\quad 229$

$\begin{array}{llllllll}\text { Sediment waves: geohazard or geofeature? } & - & - & - & - & - & - & \end{array}$

Innovative Positioning System Integration for Tunnel Construction $\quad-\quad$ - $\quad 239$

Results of operational sea-wave monitoring with radar gauges - $\quad$ - $\quad$ - $\quad 247$

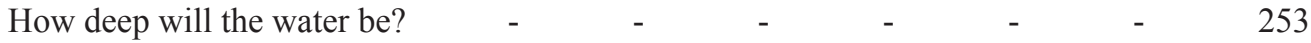

Comprehensive Definition and Systematic Subdivision of Hydrography - $\quad$ - $\quad 259$

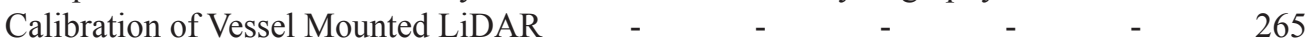

Hydrographic surveying course through international joint diplomas - $\quad$ - 277

International Cooperation in Education: The VASSIVIERE Program 2011-2013 - 281

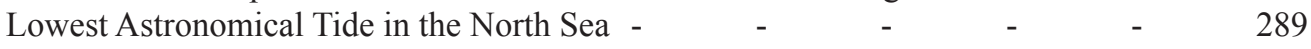

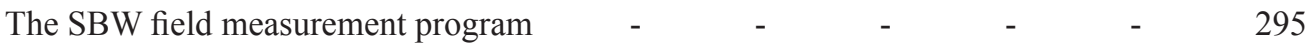

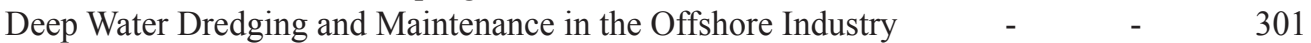

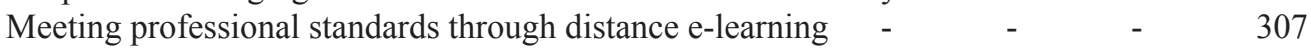

Utility of Airborne Lidar Bathymetry in Extreme Coastal Environments - $\quad$ - $\quad 311$

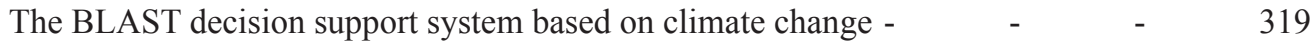

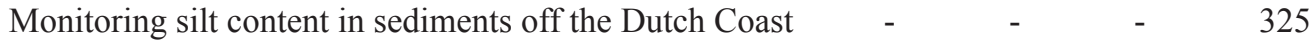

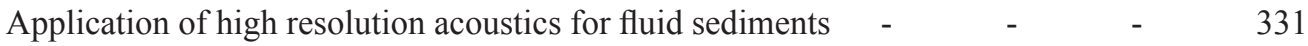

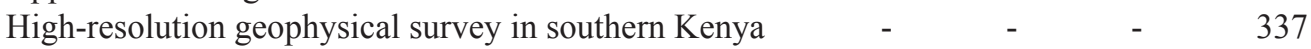

Grid Models versus TIN: Geometric Accuracy of Multibeam Data Processing - 343 
4 | Hydrol2 


\section{Creating a Current Atlas for the Port of Zeebrugge}

Jeroen AARDOOM, the Netherlands

Aqua Vision

Frans CLAEYS, Belgium

Eurosense

Hans POPPE, Belgium

Flemish Hydrography

Shauna NI FHLAITHEARTA and Pim VAN SANTEN, the Netherlands

Aqua Vision

Topic: Accurate hydrodynamics

\section{INTRODUCTION}

Current atlases are used in many ports around the world to assist shipping and increase safety on approach and within the port. For this reason the coast division of the Flemish government launched a tender to compile a new atlas for the port of Zeebrugge, which was appointed to Eurosense Planning and Engineering NV and subcontractor Aqua Vision BV
(Figure 1). The current pattern in the outer port of Zeebrugge is strongly influenced by the tidal cycle. As such, an accurate and detailed current atlas is of vital importance for the safe and effective navigation of shipping into the Port of Zeebrugge.

The current atlas was constructed for the outer port during spring, neap and average tides. To achieve this, a strict surveying scheme was created using

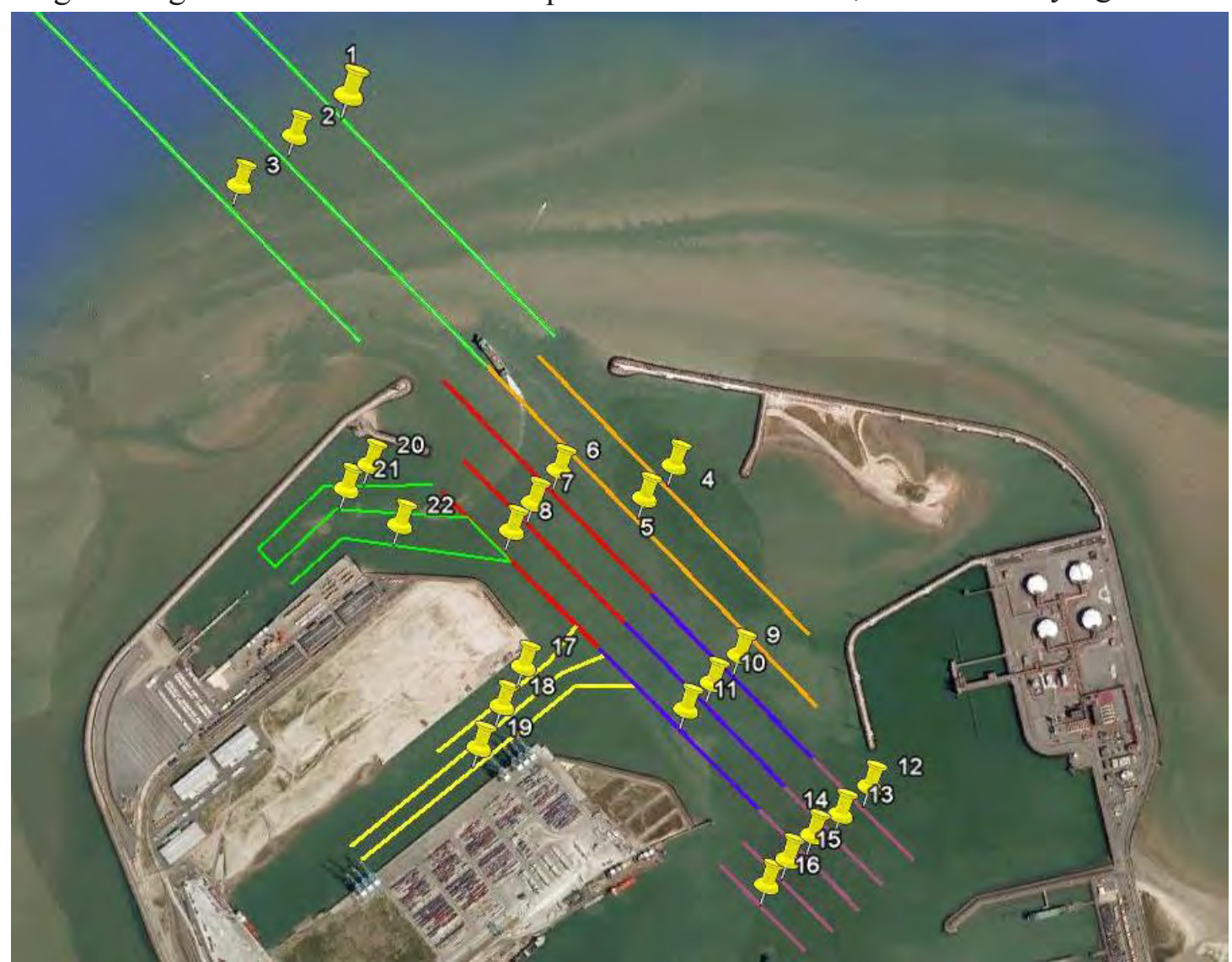

Figure 1: The outer Port of Zeebrugge with the survey zones marked by coloured stripes. Adapted from Verwerkingsrapport Stroming meetcampagnes Zeebrugge [2011]. 


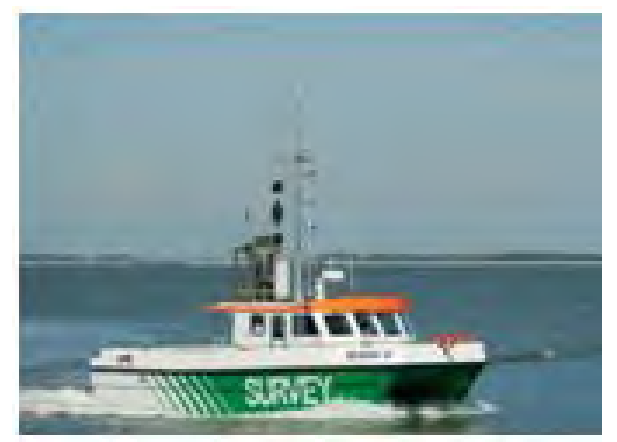

(a)

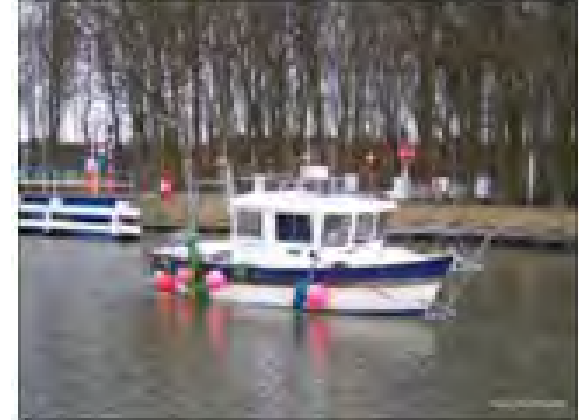

(b)

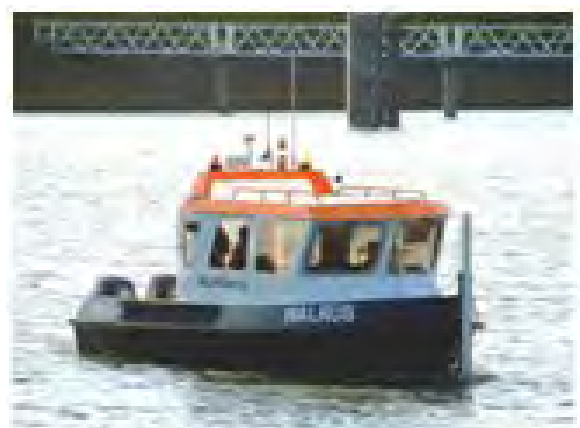

(c)

Figure 2: Survey vessels used for the ADCP measuring campaign, a) MS BEASAC VI, b) MS EB2, c) MS WALRUS. Adapted from Verwerkingsrapport Stroming meetcampagnes Zeebrugge [2011].

multiple vessels surveying simultaneously (Figure 2). All vessels were mounted with an Acoustic Doppler Current Profilers (ADCPs), which measured current speed and direction using broadband technology and bottom track functionality.

Low current speeds, a diffuse sediment layer and choppy wave conditions made measurements in the outer port of Zeebrugge a challenge. Furthermore, shipping activities in this busy port required survey vessels to veer off course, leading to gaps in the surveying scheme and a disruption to acoustic signals. To solve these challenges, Aqua Vision BV developed two novel solutions for port based surveying. First, a new data processing approach optimized data quality by using a combination of bottom tracking and dGPS. In this way, an optimum current speed solution could be derived, ensuring accurate and precise current speed and direction data. Second, a central surveyor station was set up using a remote desktop connection to all survey vessels, in order to optimize real-time planning and anticipation of shipping activities.

\section{METHODS}

The port was split into several distinct zones (Figure 1). Three survey vessels were equipped with ADCPs (Teledyne RD Instruments) and deployed to simultaneously survey during spring tide, neap tide and average tide. For each tidal type, three boats surveyed all zones in two days of 13-hour measurements. Data acquisition and reprocessing were performed using the data acquisition software package ViSea-

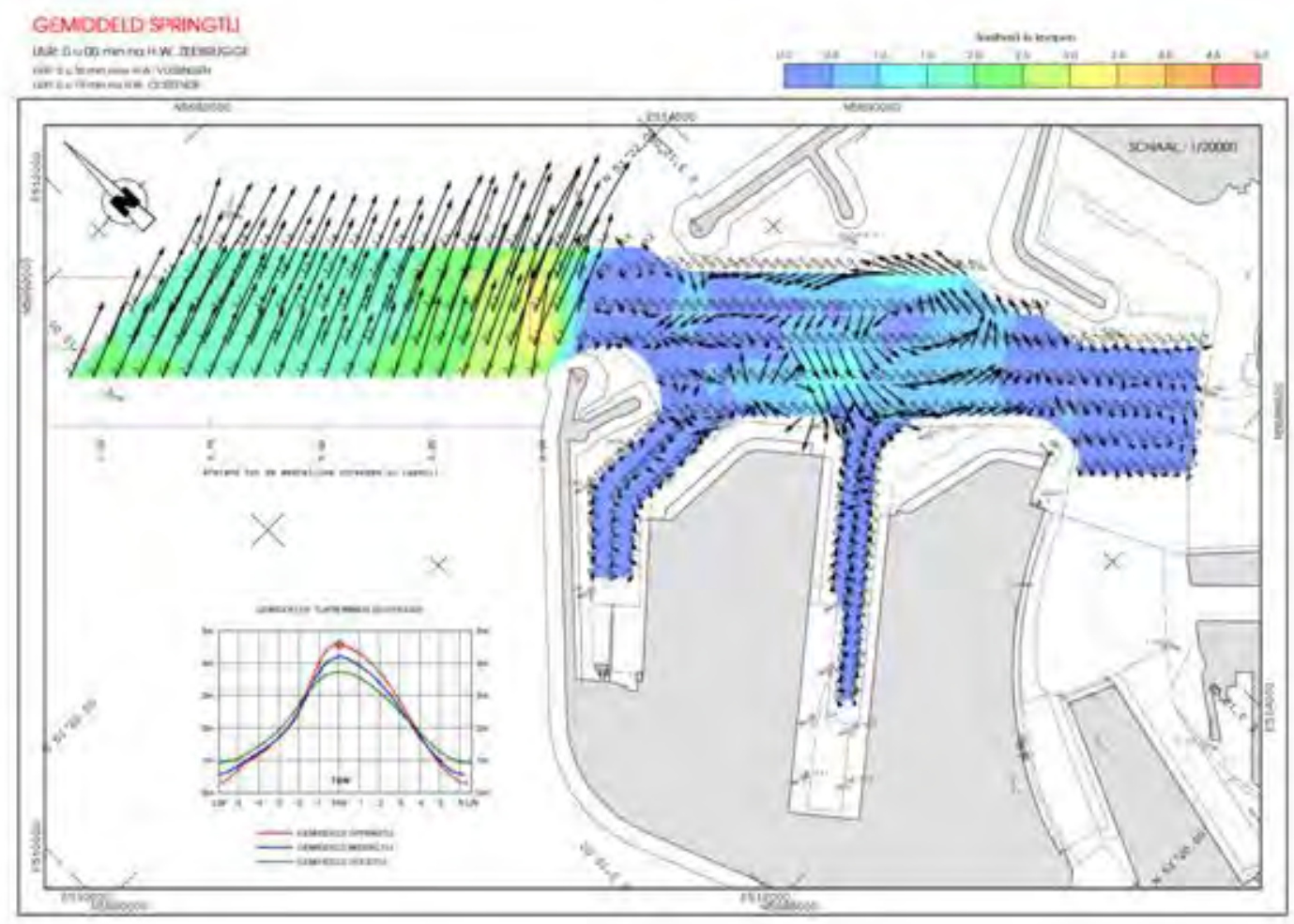

Figure 3: Current patterns during high spring tide. Adapted from Stroomatlas Haven van Zeebrugge [2011].

\section{6 | Hydrol2}


DAS (Aqua Vision BV), affording real-time synchronization between ADCP, GPS, gyro compass and motion sensor. Data quality control, presentation and current atlas generation was carried out using ViSea-DPS (Aqua Vision BV).

\section{RESULTS AND DISCUSSION}

A representation of the current patterns in the outer port of Zeebrugge during spring, neap and average tides was created to aid shipping and navigation in this busy port (Figure 3).

The series of current maps provide insight in the $3 \mathrm{D}$ current patterns in the outer port of Zeebrugge. The most striking current patterns were visible during the spring tide. In the initial phase of high tide the currents outside the port remain southbound. This reflects the inertia of the westwards flowing water mass. As such, water enters the port basin from the south side of the port entrance and current velocities at the entrance are relatively weak. Two hours before high tide, currents outside the port have turned and start filling both Zeebrugge port. This coincides with the onset of the steepest part of the water level curve, which cause steep spatial water level gradients between the sea and the port basin. This results in high current velocities throughout the port system. Water enters the port at the northeastern side of the entrance and flows to the tip of the Leopold II-dam. This creates a jet-like system with the highest current velocities directed inward on this line. To the east and west, a return flow is created, causing a double eddy system in the outer port basin.

At the peak of high tide, the basin is completely filled, while currents are still strongly flowing northward at sea. The double eddy system however con-

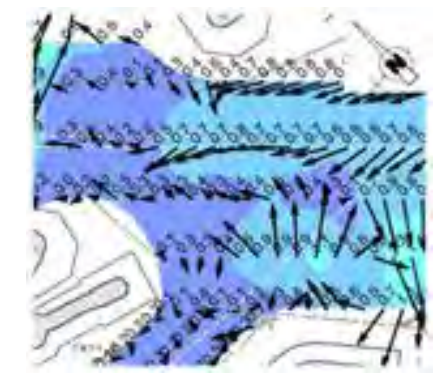

(a)

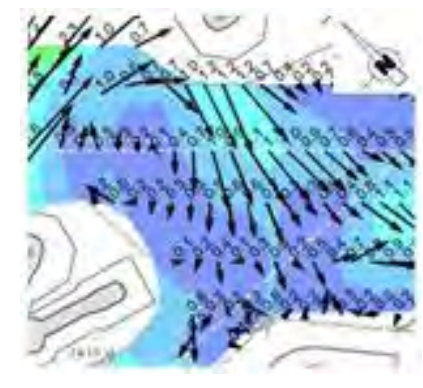

(b)
Figure 4. Current pattern at spring high tide just inside the port basin at (a) $2 \mathrm{~m}$ depth and (b) $16 \mathrm{~m}$ depth. tinues swirling inside the outer port basin. At this time, strong vertical shear also exists. An example can be found in the outer part of the port basin, just inside the port entrance, northeast of the Wielingendok (Figure 4). A seaward return flow is active near the water surface (Figure 4a) while water is flowing inward near the bottom (Figure 4a).

With the falling of the tide, the double eddy system is pushed seaward until it has vanished at 4 hours after high tide. From this time onward, water is steadily flowing out of the basin until low tide is reached. Current patterns at mean tide and neap tide are similar but with smaller current velocities.

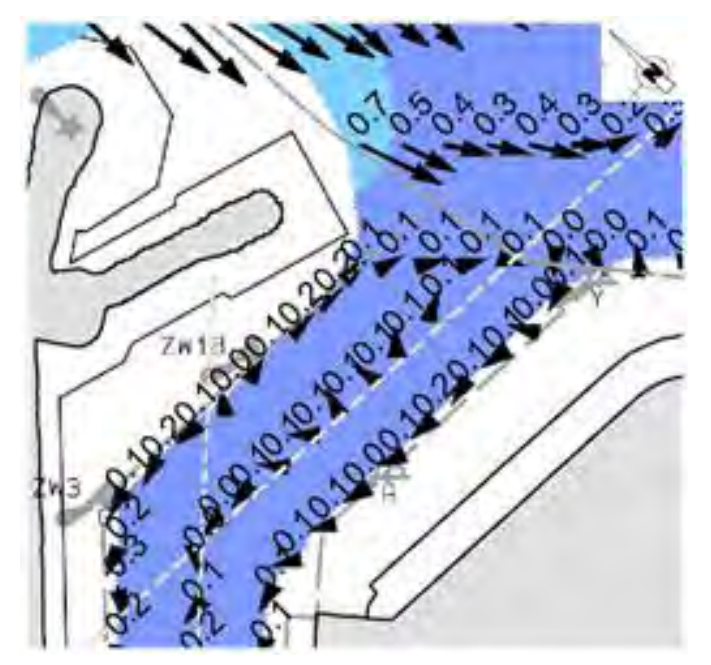

Figure 5: Current pattern at $4 \mathrm{hr} 40$ before spring high tide in the entrance of Wielingendok. Even though current velocities are small, a clearly visible eddy has accurately been mapped.

The high accuracy of the measurements becomes evident when viewing the current pattern in the entrance of Wielingendok at $4 \mathrm{hr} 40$ before high tide (Figure 5). Although the current velocities are extremely low ( 0.1 knots on average), an eddy is clearly visible, having developed due to water entering at the south side of the Zeebrugge port entrance.

\section{MOVING BED}

Low current speeds are inherent to port basin environments. Under such conditions the differential between current speed and vessel speed becomes a crucial factor in determining the precision of the data. During the data validation step the measured current speeds are corrected for vessel speed. In this 


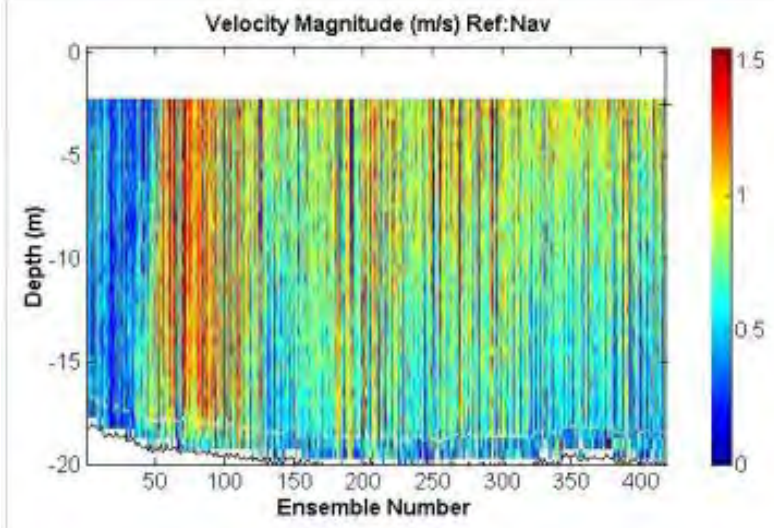

(a)

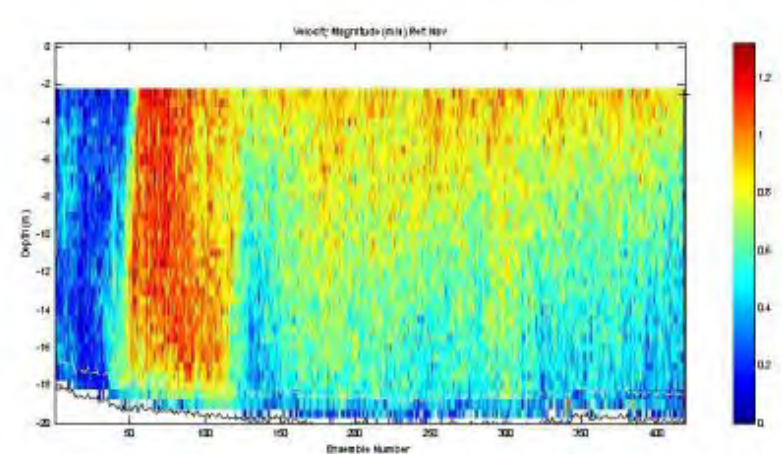

(b)

Figure 6: The application of a combined Bottom track/GPS correction for vessel speed, a) Velocity magnitude data before correction, b) Velocity magnitude data after correction. Adapted from Verwerkingsrapport Stroming meetcampagnes Zeebrugge [2011].

case bottom tracking is always the preferred method due to its direct synchronization with the ADCP. However, local sediment dynamics can sometimes disrupt bottom track detection, either due to a moving bed or no bottom detection.

This was case in the Port of Zeebrugge, where the muddy seabed at times became too diffuse to detect the bottom. When this occurs, bottom tracking is no longer available and GPS has to be used, with a resulting decrease in measurement precision associated with synchronisation issues. This results in sub-optimal current speed data. A new current speed correction method was developed based on a combination of bottom track and GPS data.

Vessel speed is measured dually by Bottom Track and by RTK. The speed variations are combined by making use of a low and high pass algorithm, speed variations with a period $<10 \mathrm{~s}$ are taken from the bottom track and variations with a period $>10$ s is taken from the RTK. This combination corrects for both moving bottom and ships movements. In the absence of a moving bottom the bottom track is used exclusively. In Figure 6a, the uncorrected current speed data is shown. After applying the highlow pass filter method, a clear improvement is seen in the data (Figure 6b).

\section{CENTRAL SURVEYOR STATION}

Any approaching shipping in this busy port not only requires a survey vessel to veer off track, but can also disturbs the acoustic signal from the ADCP. Ultimately, this results in poorer data, time delays and gaps in survey coverage. One innovative solution was found in the creation of a central surveyor station in the Eurosense office in Zeebrugge (Figure 7). Here, a surveyor oversaw the survey activities of all three boats via a remote desktop connection with each onboard survey PC. At the same time, the surveyor kept a close eye on shipping activity via www.marinetraffic.com. In this way the central surveyor could anticipate impending survey disturbances and relay a new survey strategy to the onboard surveyor and skipper - resulting in increased safety and an optimised survey strategy.

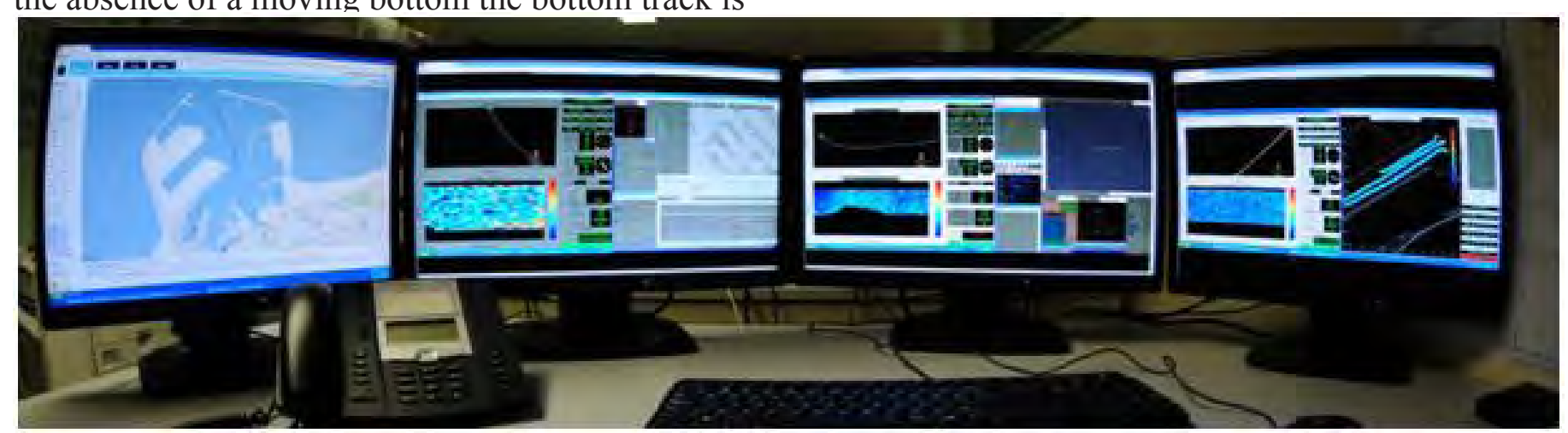

Figure 7: Central Surveyor Station in Eurosense office, Zeebrugge.

\section{8 | Hydrol2}


With the advent of high speed mobile internet it is now possible to remotely operate survey software. With a central surveyor station, like that used in Zeebrugge, are we seeing the precursor of remote surveying?

\section{CONCLUSION}

A current atlas has been created for the port of Zeebrugge during spring, neap and average tides to aid shipping navigating and safety on approach and within the outer port. This was achieved using 3 survey vessels measuring simultaneous over a 13 hour period, per tidal condition. Each survey vessel was mounted with an ADCP. Current patterns in the outer port show some interesting features, for example, a delayed response to rising tides, the creation of a double eddy system within the outer port and eddy systems even at very low current velocities. Due to local sedimentary conditions, a novel new method was used to correct the vessel speed data. To improve planning and anticipation during multi-vessel surveying a central surveyor station was set up using high speed mobile internet.

\section{BIOGRAPHIES}

Pim VAN SANTEN is now a researcher water systems at Waterschap Aa en Maas. He received his MSc in Physical Geography from Utrecht University, after which he spent several years as a researcher in sediment dynamics. At Aqua Vision BV he was involved in data analysis and processing.

Shauna NI FHLAITHEARTA, currently a data analyst at Aqua Vision BV, completed her BSc (Hons) in Earth Sciences at the National University of Ireland, Cork, and her MSc in Earth Systems Science at Wageningen University and Research Center. She then spend several years conducting research in marine biogeochemistry before joining Aqua Vision BV in 2010, where she is involved in data processing and communications.

Jeroen AARDOOM, a senior R\&D associate at Aqua Vision BV. He received his MSc in Physics from Utrecht University, specialisation computational science and physical oceanography. He worked at TNO Physics and Electronics Laboratory on the use of radar remote sensing data for underwater acoustics before he joined Aqua Vision. At Aqua Vision he develops hydrographic data acquisition software.

Frans CLAEYS, a senior project manager of Eurosense, received his Master of Science degree in electronics and control at the University of Louvain in 1982. After his military service he started with Eurosense in 1983 in the hydrographic department in Zeebrugge. He is experienced in accurate positioning, attitude determination, data acquisition and digital signal processing techniques.

Hans POPPE received his MSc in Physics at the University in Brussels in 1996 and his MSc in applied physics in 1999 at the University of Delft. From then on he started working for hydraulic and civil engineering consulting agencies, until the end of 2006 when he started to work as Project Engineer of Tide and Currents at the Coast Division of the Flemish government. In this job he is responsible for the various aspects involving tide and currents along the Flemish coast and on the Belgian continental shelf.

\section{CONTACT DETAILS}

\section{Jeroen AARDOOM}

Aqua Vision - THE NETHERLANDS

Email: j.aardoom@aquavision.nl

Web site: www.aquavision.nl

Frans CLAEYS

Eurosense - BELGIUM

Email: info@eurosense.com

Web site: www.eurosense.com 
10| Hydrol2 


\title{
Towards New Standards of Competence for Hydrographers and Nautical Cartographers
}

\author{
Andrew ARMSTRONG, United States of America \\ National Oceanic and Atmospheric Administration \\ University of New Hampshire Joint Hydrographic Center
}

Ron FURNESS, Australia

IIC Technologies Ltd

Gordon JOHNSTON, United Kingdom

Venture Geomatics Limited

Nicolas SEUBE, France

École Nationale Supérieure de Techniques Avancées Bretagne

Lysandros TSOULOS, Greece

National Technical University Athens

Topic: The Hydrographic Profession

\begin{abstract}
Expectations and demands for education and training and the achievement and maintenance of core and new competencies in the hydrographic community are changing apace. The accepted international minimum competency standards for hydrographic surveyors and nautical cartographers have served the profession well, but are presently under review against these changed expectations. Community participation will be critical as the standards deal with and address the changes, ever mindful of the need for effective delivery of education and training across the wider profession.
\end{abstract}

\section{INTRODUCTION}

The FIG/IHO/ICA International Board for Standards of Competence (IBSC) for Hydrographic Surveyors and Nautical Cartographers (hereafter referred as "the Board") have guided the delivery of education and training for Hydrographers and nautical cartographers since it was formed in 1977. The Standards, as promulgated in IHO Publications S-5 [IHO, 2011] and S-8 [IHO, 2010] (formerly M-5 and M-8), recognize two levels of hydrographic (or cartographic) competence-Category A and Category B. The current Editions of S-5 and S-8 can be downloaded from the IHO website.
Category A programmes offer a comprehensive and broad-based knowledge in all aspects of the theory and practice of hydrography or nautical cartography. Category B programmes provide the practical comprehension, along with the essential theoretical background, necessary for individuals to carry out the various hydrographic survey or nautical cartographic tasks.

The standards have been structured so that Category B programs provide technical education to support a set of fundamental and practical competencies. Category A educational programs must include all the Category B competencies plus additional detailed-level competencies. This means that Category B is a subset of Category A, and the S-5 S-8 standards are structured accordingly. Along with hydrographic and cartographic technology, the personnel and training needs of Hydrographic Offices and the hydrographic industry have evolved considerably since 1977.

\section{THE BOARD, THE STANDARDS AND THE RECOGNITION PROCESS}

The Board comprises ten Members representing the three constituent organizations: FIG, the International Federation of Surveyors (4); IHO, the International Hydrographic Organization (4); and ICA, the International Cartographic Association 
(2). The Board Secretariat is provided from the IHO. The present Board comprises a cross section of experts representing the broader hydrographic community and are from Australia, France, Germany, Greece, India, Malaysia, New Zealand, Trinidad and Tobago, United Kingdom and the United States. The Secretary brings his experience from Brazil. The Board meets annually and it is charged with maintaining S-5 and S-8 standards and considering course curricula submissions against these standards for recognition. Recognition of courses is granted only when those curricula meet the appropriate requirements. A list of those courses recognised is available online [IHO, 2010(2)].

The Board's operations are governed by its published Terms of Reference and Rules of Procedure [IHO, 2011(2)] as ratified by the constituent organizations. The decisions made by the Board are independent. A small submission fee and annual fee are levied on submitting organizations, which assists in funding the Board's activities although Members largely fund their own participation.

The Board has recognised various pressures for change that will be revisited below and is in the process of reviewing both standards in order to modernise them and better reflect modern requirements for achieving qualified hydrographic surveyors and nautical cartographers at various levels of competence.

Courses seeking recognition are submitted by competent educational and formal training bodies by 31 December each year. The Board meets subsequently after each member has reviewed submissions and in plenary the Board considers each submission. Once recognised, course recognition remains valid for six (6) years assuming its delivery continues. After six years a new submission is required.

The Board does not recognise individuals but has introduced minimum requirements by which it will recognise national or regional schemes, which in turn recognise or accredit individuals. Such schemes typically require qualified persons to remain current through access to continuing professional programs.
The Board will begin the process of changing the Standards with S-5. The S-5 Standards indicate the minimum degree of knowledge and experience considered necessary for hydrographic surveyors, and provide a set of programme outlines against which the Board may evaluate programmes submitted for recognition.

Early editions of M-5 were significantly changed with the publication of the fifth edition, which represented a fundamental change of approach in order to make the Standards more applicable to the different requirements for hydrographic surveyors in government and industry. The fifth edition Standards provided basic and essential subjects that are required for all hydrographic surveyors and a choice of three options for specialization in Nautical Charting Surveys, Surveys for Coastal Zone Management or Industrial Offshore Surveys.

The sixth edition incorporated a change in format, to facilitate easier cross-referencing between syllabus topics and programmes which were submitted for recognition and also included minor changes in content to eliminate duplication of subject matter and to reflect the evolution of technology. The seventh edition eliminated the distinction between Full/Academic recognition and increased the emphasis on developing techniques of GPS, multibeam sonar systems and ECDIS. The eighth edition eliminated the Specialisms and re-structured the Syllabus in two different parts: the "Minimum Standards", including Basic and Essential Subjects and the "Optional Units".

The ninth edition (2001) provided a better definition of the three levels of knowledge (Fundamental, Practical, Detailed) identified in the syllabus. Nautical Science was moved to the Basic Subjects, and was modified to reflect the minimum knowledge required by an hydrographic surveyor. This edition contained a more detailed description of each subject, which were divided into Category A / Category B and Category A-only learning objectives.

The tenth edition makes changes to Section 3 "Submission of Courses", introduces a new Appendix V "Annual Assessment Report" and also reflects the change of the Board's name which became "FIG/IHO/ICA International Board

\section{I2 | Hydrol2}


on Standards of Competence for Hydrographic Surveyors and Nautical Cartographers" as agreed during the 31 st Meeting.

In 2009 the IHO restructured its publications and the M-5 Standard was renamed S-5. The eleventh edition includes a new and expanded section relating to the recognition of Schemes that certify the competency of Individuals beyond their formal education and training.

The present Standard S-5 comprises:

- Educational and training programs at two levels:

$\begin{array}{ll}- & \text { Category A } \\ \text { - } & \text { Category B }\end{array}$

- 3 Knowledge Levels: Fundamental, Practical \& Detailed

- 2 Groups of Subjects: Basic \& Essential

- 7 options (Nautical charting, Hydrography to Support Port Management and Coastal Engineering, Offshore Seismic Surveys, Offshore Construction Hydrography, Remote sensing, Military Hydrography, Inland Waters Hydrography)

- Individual Recognition Schemes

Category B is currently defined as a programme that provides a practical comprehension of hydrographic surveying for individuals - along with the essential theoretical background - with the skill to carry out the various Hydrographic surveying tasks.

- Example competency: "Explain the principles of various types of water level gauges and poles. Describe characteristics of river, coastal and offshore water level gauges. Install and operate water level gauges and poles".

Category $\mathrm{A}$ is a programme which provides a comprehensive and broad-based knowledge in all aspects of the theory and practice of hydrography and allied disciplines for individuals who will practice analytical reasoning, decision making and development of solutions to non-routine problems.

- Example Competency: "Evaluate and select appropriate instruments and sites for water level monitoring. Calibrate analogue and digital recording water level gauges. Evaluate sources of error. Apply appropriate corrections".
Individual recognition schemes are regional or national bodies that evaluate, certify, and track the competence of individual hydrographers. S-5 sets out standards of organization and content for these schemes. Recognized schemes may certify individuals at levels other than Category $\mathrm{A}$, or $\mathrm{B}$, but only individuals who have completed a Category A or B course may be certified as Category A or B Hydrographers. At the May 2012, 35th meeting of the Board in Buenos Aires, Argentina, the Board recognized the Australasian Hydrographic Surveyors Certification Panel (AHSCP) as the first approved scheme of individual hydrographers competence.

\section{NEW CHALLENGES IN HYDROGRAPHY EDUCATION AND TRAINING}

It has become evident to the Board that there are a number of influencing factors that bring about imperatives for change in the way hydrographic surveyors and nautical cartographers are educated to meet modern hydrographic practice and products requirements.

New use of the seas has shifted the hydrographic products from those intended mainly for navigation safety to a wide variety of deliverables, motivated by emergent fields like energy production (wind farms, marine turbines, etc.), marine environment understanding and protection (habitat mapping, coastal erosion monitoring, coral reef mapping, etc.), remote sensing bathymetry (using bathymetric LiDAR, AUVs, ASVs, or satellite data). Field operations are and will be conducted in the near future at a wide variety of scales: from detailed port infrastructure inspection survey to regional satellite bathymetry.

To respond to these new challenges, equipment and software are becoming more and more sophisticated and automated. We are now dealing with hydrographic systems (being by essence kinematic mapping systems), composed of complex sensors incorporating a high level of technology and embedded software.

The increasing complexity of field operations with added requirements for skills such as project management, financial acuity and broader professional aptitude with greater cross discipline experience and exposure - in some cases without 
actual seamanship skills (LiDAR operations perhaps or port based operations) requires consideration and definition.

The increasing amount of data that are collected need to be processed (cleaned, controlled, generalised), and integrated in marine geospatial data management systems. Data processing and management systems incorporate advanced numerical methods enabling the hydrographer access to high-level models built from multi-sensors raw datasets. These stretch the knowledge required by hydrographers.

Technology in the field increasingly requires better qualified technicians and operators who may not be required to go further than a consolidated Category B programme. This apparent conflict is compounded by the increase in demand for competent hydrographers. More and more there is little time available as busy individuals attempt to balance their work and leisure life. The challenge in its broader sense is to be able to provide adequate technical foundations combined with appropriate practical exercises but without removing the individual from their work environment for too long a period or requiring the educational organisation to invest in complex and expensive equipment that may only be used a few weeks per year.

The influence of blended, direct and distance learning initiatives is beginning to have an impact. The growing perception now is that modular, short educational courses coupled with intensive time on practical and field work may offer a solution that combines the desires of individual and course providers through a flexible approach to the selection, completion and assessment of course elements making up. For the Board these must be of adequate time and rigour as well as accumulating into a comprehensive cover of any minimum Standards.

In the framework of these new challenges the Board has decided to strengthen the importance of programme review as a process for evaluating and continuously enhancing the quality and currency of programmes. The evaluation will be conducted through a combination of self-assessment, followed by peer on-site consultation by members of the Board, for the mutual benefit of all parties. In addition, a visit will serve to raise the profile of hydrography and nautical cartography nationally and regionally.

\section{TOWARDS NEW STANDARDS}

Early thoughts of the Board suggest the separation of the present Category B and Category A requirements and a future separate path of development for each. In view of the foreseen challenges in hydrography and nautical cartography, the Board believes that a fundamental change to the structure of the Standards is appropriate. The Board is in the process of developing a new structure for S-5 and S-8 that will separate the Standards for Category A and Category B programs. Standards for each category will be designed and developed independently.

Category B standards will be aimed at the basic educational and training requirements for hydrographic technicians and field hydrographers (S-5), and nautical cartographers (S-8). Category A standards will be aimed at the theoretical educational and foundational background necessary for Hydrographers/Nautical Cartographers-InCharge and hydrographic/cartographic managers who will develop specifications for surveys and charts, establish quality control and quality assurance systems, and respond to the specific requirements of a full range of hydrographic/ cartographic projects.

For both Category A and Category B standards, the ability to conduct or operate hydrographic surveys in the field or utilize hydrographic/cartographic databases to compile and produce charts, remains an essential competence, and thus an essential part of education and training through the necessity of practicals (field exercises/projects).

The Board expects to complete new S-5 standards by 2014 , and intends to communicate about this process before the final release of the new S-5 and S-8.

\section{THE DEVELOPMENT PATH}

The Board will need to grapple with various and varying impacts as it works through how best it can provide guidance for minimum standards into the future. Anecdotally, at least, it is clear to the Board that the demand for qualified hydrographic surveyors and nautical cartographers is increasing.

\section{4 | Hydrol2}


Simultaneously, as evidenced partly by the creation and introduction of professional bodies that review, certify and track the competences of practitioners within the industry, there is an increasing clamour for qualified competent hydrographic/cartographic personnel. Many hydrographic contracts, by way of example, now demand evidence of formal and appropriate hydrographic/cartographic qualification and competence as a consideration in the evaluation of tender responses. Naturally, this is accompanied by demand from the personnel themselves for opportunities to study and to continue their skill refreshment within accredited and recognised programs that provide evidenced continuation of individual, and thus consequently, corporate, professional competency.

Those personnel entering the profession do not find it easy in at least some parts of the world to find courses that suit their needs. Not everyone seeks a military career that was hitherto often the genesis of many a longer term successful hydrographic career. The Australasian region, for example, has struggled to sustain its civilian hydrographic training courses and even recognised courses have foundered for a number of reasons. A new attempt to provide such initial training opportunities is presently under way.

The reasons for the difficulty of maintaining courses are varied, but for those bodies offering them, it all boils down to the critical number of students applying for the course - or rather - a lack of sufficient numbers to sustain such specialist and high cost training and education. Factors affecting student numbers include costs, time, and changing expectations on the parts of both students and employers. These are high on the lists of influencing factors for those who make their difficulties known.

Industry-wide, and broadly speaking, the employment of hydrographic professionals is changing from life-time careers to project and contract employment which frequently requires skill-set refreshment and new technology-based competencies which sometimes are found to be lagging in established courses. Longer term practitioners require access to change learning paradigms. Students bring changed expectations therefore, given that they must work in such an industrial environment. Expectations are high among modern students: they are typically computer literate and modern survey equipment competent, but require rapid and often short term results for a specific instance of employment.

Employers, on the other hand, have complementary expectations that they will either find such students in the market place or will take on board their own training in order to meet the exigencies of the tenderer's expectations and project demands. Demand for immediately functional skill sets is high. Increasingly, the market place cannot immediately deliver.

The educational world itself is in turn influenced by changing technological and methodological imperatives. The older forms of institution of university or national agency are being challenged to deliver. Connectivity and the introduction of so-called e-learning methods, blended learning techniques, webinars, e-seminars, e-meetings and the like, have naturally attracted the attention of hydrographic agencies and companies and their staff and it is not surprising that, given the offshore nature of much of the industry, attempts are being made to harness the better technologies and methods to achieve the requirements outlined above. The potential of these forms of program delivery are beguiling and seemingly cost-effective in their promises however their successful delivery largely still needs to be proven.

All components of the hydrographic profession face challenges as to how best to ensure the continuance of the high standards and how best to ensure the continuation of best practices based on minimum standards of competence world-wide. A cooperative approach will best deliver future guidance to all.

\section{CONCLUSIONS}

Attitudes toward training and education are changing. The hydrographic profession is not immune from such broader pressures. There are, however, some unique aspects of hydrographic surveying that impact on how training and education can best be delivered. While the S-5 approach has stood the profession in good stead and is generally well recognised throughout the hydrographic world, there is sufficient evidence to suggest it needs a complete review and overhaul to 
bring it in line with current expectations of how to achieve community-wide best practice for minimum standards of competence. The Board, in facing the challenges outlined above, anticipates posting its draft revisions online for stake-holder feedback and contribution. This paper itself is to be considered a part of this process.

\section{REFERENCES}

IHO - International Hydrographic Organization. 2011. "Standards of Competence for Hydrographic Surveyors," Publication S-5, 11 th Edition, Version 11.0.1-May 2011, accessed 24 June 2012. http://www.iho.int/iho_pubs/standard/S-5 Ed_11.0.1_06May2011_Standards-Hydro.pdf

IHO - International Hydrographic Organization. 2010. "Standards of Competence for Nautical Cartographers," Publication S-8, 3rd Edition, 2010, accessed 24 June 2012.

http://www.iho.int/iho_pubs/standard/S_8_3rd Jan_2011.pdf

IHO - International Hydrographic Organization. 2010(2). "List of Recognized Courses Hydrography," May 2010, accessed 24 June 2012. http://www.iho.int/mtg_docs/com_wg/AB/AB33/ LISTMAY10.pdf

IHO - International Hydrographic Organization. 2011(2). FIG/IHO/ICA International Board (IB) on Standards of Competence, "Terms of Reference," Revision 1, 2011, accessed 24 June 2012. http://www.iho.int/mtg_docs/com_wg/TOR/IBSC_ TorsRops_2011-rev1.pdf

\section{BIOGRAPHIES}

The authors have a wide variety of hydrographic and cartographic experience in government, academia, and private industry. All are members of the FIG/IHO/ICA International Board on Standards of Competence for Hydrographic Surveyors and Nautical Cartographers. 


\title{
The CARIS Engineering Analysis Module - Assisting in the Management of Queensland's Waterways
}

\author{
Owen CANTRILL, Australia \\ Maritime Safety Queensland \\ Daniel KRUIMEL, Australia \\ CARIS Asia Pacific
}

Topic: Innovations in processing techniques

\section{INTRODUCTION}

Maritime Safety Queensland (MSQ) is a division of the Department of Transport and Main Roads within the Queensland State Government. MSQ's role is to protect Queensland's waterways and the people who use them - providing safer and cleaner seas. Within the corporate structure of MSQ, the Hydrographic Services section carries out hydrographic surveys on behalf of clients. Current clients include North Queensland Bulk Ports (Ports of Hay Point, Weipa, Abbot Point and Mackay), Ports North (Cape Flattery, Thursday Island), Gladstone Ports Corporation and Boating Infrastructure and Waterways Management (recreational boating facilities). These various sites are spread over $1700 \mathrm{Nm}$ of coastline.

\section{OVERVIEW OF OPERATIONS}

MSQ utilize a variety of survey equipment, such as a Kongsberg Simrad EM 3002D multi beam echo sounder, Klein 3000 Sidescan, Starfish 452f sidescan, SEA Swath plus $234 \mathrm{kHz}$ interferometry system, Echotrak MK III dual frequenciy single beam, Deso 300 single beam, Applanix POS MV 320, Applanix POS MV Wavemasters and Lecia RTK DGPS. Surveys range from boat ramps that integrate land survey and a small hydrographic component, through to high precision surveys for Under Keel Clearance systems.

A permanent installation of the EM3002D exists on the vessel QGNorfolk, with other mobile systems deployed on vessels of opportunity, such as the QG Bellara used during rapid response surveys in the 2011 Brisbane floods.

MSQ ensures a high quality of work through the use of experienced and competent personnel. There are six surveyors certified at Level 1 by the Australasian Hydrographic Surveyors Certification Panel (AHSCP) and five surveyors (including graduates) that work under direct supervision.

In an effort to improve acquisition to processing ratios, MSQ first incorporated CARIS Ping-to-Chart products into their workflow early in 2009, turning to HIPS and SIPS for processing their bathymetric data. Later that year, BASE Editor was also brought on board to assist in bathymetric data compilation and QC. Staff from MSQ have stayed well versed in the latest functionality for the software packages through participation in open training courses held in the region by the CARIS Asia Pacific office. After attending a training course on the new Engineering Analysis Module (compatible with BASE Editor) in August of 2011, MSQ sought to expand on their current functionality and utilize the new module to assist them in the management of their ports and waterways throughout Queensland.

\section{THE ENGINEERING ANALYSIS MODULE}

The Engineering Analysis Module features under the 'Analysis' pillar of the Ping-to-Chart workflow, as part of the Bathy DataBASE suite of products. Recognising the fact that different users have different requirements, Bathy DataBASE is a scalable solution.

In order to provide more functionality for users in the ports and waterways environment, the Engineering Analysis module was introduced to the Bathy DataBASE product suite. The module works with either BASE Editor or BASE Manager, and includes many functions migrated from an existing CARIS application (BEAMS - Bathymetry and Engineering Management System). These functions include volume computations, shoal management, 
conformance analysis and reference model creation and maintenance.

\section{VOLUME CALCULATION METHODS FOR HYDROGRAPHIC SURVEYING}

The calculation of volumes in hydrographic surveying is frequently used in dredging applications and reservoir analysis (for example, sedimentation). A number of different methods can be utilized in determining a volume. The 'best' method to use is determined by factors such as the technique of sounding for the data (single beam, multibeam, LiDAR etc.) and also the nature of the material (smooth, sandy bottom is quite different to an undulating, rocky terrain).

"Accurate volume estimates are important for the choice of dredging plant, production estimates and ultimately project costs. " (Sciortino J.A., 2011) In addition to the volume of material, the type of material is another important factor. The cost of dredging rock will be much higher compared to the same amount of material in sand.

\section{End Area Volumes}

End Area volumes have been derived from landbased methods used in railroad and roadway construction. They involve calculating the volume from cross sections of a channel, surveyed at regular intervals (see Figure 1). The key components in computing the volume are the cross sectional area (an average is taken of the two areas) and the length between the cross sections. This method assumes that the cross sectional area is relatively constant between two successive cross sections. If this assumption is not true, the volume produced will realistically just be an approximation.

\section{$\underline{\text { TIN Volumes }}$}

Triangulated Irregular Network (TIN) Volumes are based on the true positions of depths to calculate the volume of a surface. This calculation involves modelling the surface as a collection of small planes. TIN's can either be derived from a gridded bathymetry source (i.e. surface) or from a point cloud. One advantage in using the TIN method (particularly for point data) is that the true position of the source depths will be utilized in the volume calculation. This is the historically preferred method for most dredging type applications where volume is critical.

\section{Hyperbolic Volumes}

For this method, a hyperbolic cell is created from the centres of every four adjacent grid cells. The depths from the grid cells are used as the depths for the corners of the hyperbolic cell. For this calculation, the surface is modelled as a collection of hyperbolic paraboloid sections, with a hyperbolic paraboloid created to smoothly pass through the points of each hyperbolic cell (see Figure 2). This gives a smooth approximation of the surface and good volume results, but is processing intensive and can be time consuming.

\section{Rectangular Volumes}

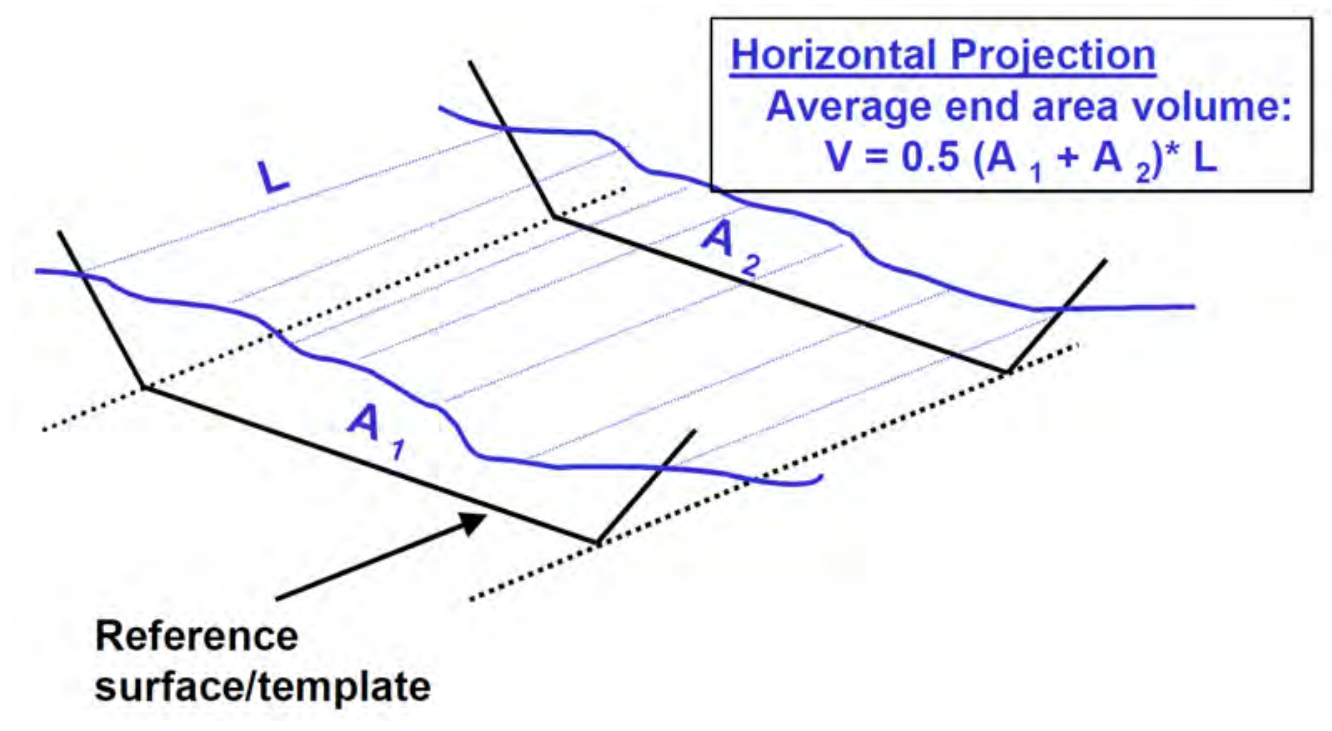

Figure 1: Calculation of End Area Volumes (USACE, 2001). 


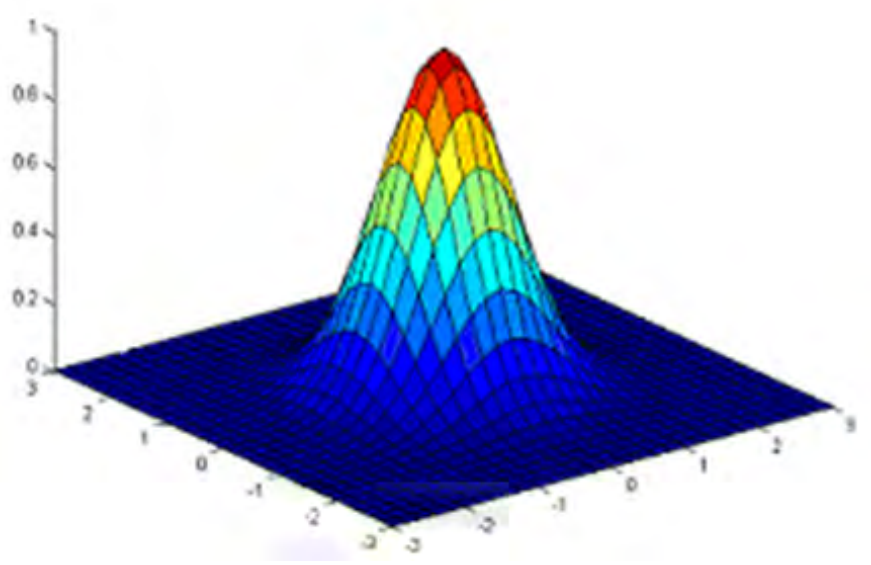

Figure 2: Representation of the hyperbolic paraboloid volume method.

In this method, a single depth value from each cell (or bin) in the surface is used to calculate the volume. The surface is modelled as a collection of disjointed rectangular prisms, with the depth for each grid cell becoming the depth of the prism (see Figure 3). In comparison to the previous hyperbolic method, this results in a much more 'simple' volume calculation which is processed much faster, however the accuracy of the computed volume may not be as reliable.

One limitation on the rectangular volume method is the inability to perform a volume calculation against a sloped or non-horizontal surface in a reference model (for example the bank of a channel). This is because by definition, a rectangular prism cannot have a sloped edge, so only horizontal reference surfaces are supported.

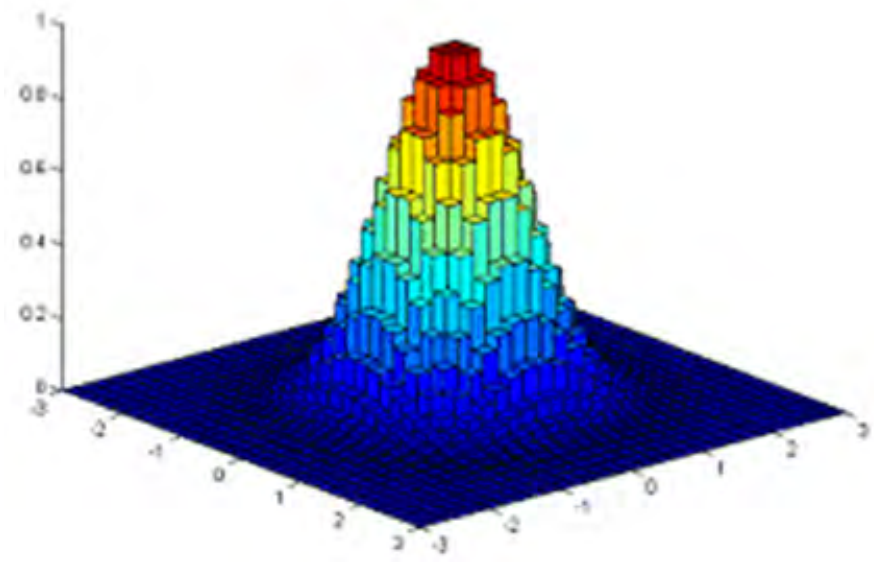

Figure 3: Representation of the rectangular volume method.

\section{VOLUME COMPARISONS}

As previously outlined, there are a number of different methods available to the hydrographer for volume determination. So this leads to the next question - which method should be used? This will largely be dependent on what technology is available to conduct the survey. If the user only has access to a single beam echo sounder, they will be limited to end area volumes and TIN volumes. For a full density multibeam survey, rectangular and hyperbolic volumes can also be taken into consideration.

The nature of the seafloor (or riverbed/reservoir) could be another factor in determining which is the most suitable volume method to be used. If the bottom topography is smooth (such as with sand), hyperbolic volumes, which produce a smooth estimate of the terrain using constructed hyperbolic paraboloids could yield the best results. For a harsher, rocky terrain, TIN volumes utilizing the true positions of each depth may be the most robust answer.

\section{Case Study in Weipa}

In order to test the results produced by the various methods of volume calculation, a case study was carried out using survey data collected by MSQ at the Port of Weipa in October, 2011. The data was provided as an ASCII XYZ file that had already been binned at $1 \mathrm{~m}$. A reference model for the Port of Weipa was also used in the calculations. The test area used is a section of channel located just to the east of beacons 7 and 8 in the south channel.

Volumes were calculated in the test area to determine the amount of material that would need to be removed to bring the channel down to a declared depth of $16 \mathrm{~m}$ (Note: this is just an arbitrary value chosen for testing purposes). The methods used for comparison were hyperbolic, rectangular and TIN volumes. Simulated end area volumes were also calculated by extracting profiles from the multibeam bathymetry at intervals of $25 \mathrm{~m}, 50 \mathrm{~m}$ and $100 \mathrm{~m}$. The results can be seen in Table 1. (Note: In this case, the hyperbolic volume has been used as the benchmark for determining volume difference and error for other methods. This does not mean that there is zero error in the hyperbolic volume result). 


\begin{tabular}{|c|c|c|c|}
\hline METHOD & VOLUME $\mathrm{m}^{3}$ & DIFFERENCE $\mathrm{m}^{3}$ & VOLUME ERROR \% \\
\hline Hyperbolic volume & $794,912.5$ & 0 & 1.280 \\
\hline Rectangular volume & $805,090.2$ & $10,177.7$ & 0.471 \\
\hline TIN volume & $798,654.2$ & $3,741.9$ & 1.020 \\
\hline End area 25m interval & $803,019.1$ & $8,106.5$ & 0.987 \\
\hline End area 50m interval & $802,755.3$ & $7,842.7$ & 0.894 \\
\hline End area 100m interval & $802,022.8$ & $7,110.2$ & \multirow{2}{*}{} \\
\hline
\end{tabular}

Table 1: Comparison of volume results for the test area in Weipa

The results displayed in Table 1 yield some interesting results. As could be expected, the two volumes closest to each other are the hyperbolic and TIN volumes. What is probably most surprising are the results achieved through the use of end area volumes. One would generally assume that profile spacing would be inversely proportional to the volume difference/error (i.e. the lesser distance between profiles, the greater the accuracy of the computed volume). This is not reflected in these results, where the error actually decreases as the interval increases. This may be due to the nature of the seabed. The data used was a pre dredge data set following the wet season. The channel is typically smooth and shaped in a reasonably consistent $\mathrm{V}$ shape due to the amount of siltation and the effect of significant shipping movements which assist in keeping the centreline clear of siltation.

\section{Validation of Case Study}

As the results produced in the Weipa case study did not reflect expected results, an additional independent case study was sought out. One was found by Dunbar J.A and Estep H of the Baylor University Department of Geology (BU) in Texas, USA. The project undertaken by BU was to study the hydrographic surveying methods utilized by the Texas Water Development Board (TWDB) in determining water and sediment volume in reservoirs throughout Texas. Whilst the project also investigated sub bottom profiling and sediment surveys, the volume comparison was carried out in Lake Lyndon Baines Johnson (LBJ), a Highland Lake on the Texas Colorado River.
As part of the project, Hydrographic Consultants Inc collected and processed a multi-beam survey in Lake LBJ. In order to evaluate the influence of survey profile spacing on volume accuracy, "BU extracted simulated profiles at spacing's ranging from 100 to $2000 \mathrm{ft}$ from a high-density multi-beam survey collected by an independent contractor. Volume calculations based on the extracted profile sets were compared to the volume based on the full multi-beam survey. " (Dunbar, J.A, Estep, H, 2009)

The results produced in the study by BU can be seen in Table 2. They are also shown graphically in Figure 4. When extracting the profile sets to produce simulated volumes, BU did this in two runs (Run 1 and Run 2). This meant that for each simulated profile spacing, two independent sets of profiles were extracted from the multibeam bathymetry.

By undertaking a statistical analysis of the BU Volume comparison results, values from Run 1 have a coefficient of correlation of 0.884 and 0.936 for Run 2. This indicates a strong positive correlation between profile spacing and volume error, which is what we would generally expect. However despite the strong correlation, there are inconsistencies in the data. Such as the very low value of $0.14 \%$ for $1000 \mathrm{ft}$ profile spacing in Run 1, and a difference of $0.696 \%$ in Run 1 and Run 2 error for $300 \mathrm{ft}$ profile spacing. This is because the Volume Error of $0.718 \%$ for $300 \mathrm{ft}$ profile spacing in Run 1 is higher than expected in contrast to other results. 
Table 2: Results of BU Volume Comparisons (Dunbar, J.A, Estep, H, 2009)

\begin{tabular}{|c|c|c|c|c|}
\hline $\begin{array}{c}\text { Simulated } \\
\text { Profile Spacing }\end{array}$ & $\begin{array}{c}\text { Run 1 } \\
\text { Volume } \\
\text { (acre-ft) } \\
\end{array}$ & $\begin{array}{c}\text { Run 1 } \\
\text { Volume } \\
\text { Error (\%) } \\
\end{array}$ & $\begin{array}{c}\text { Run 2 } \\
\text { Volume } \\
\text { (acre-ft) }\end{array}$ & $\begin{array}{c}\text { Run 2 } \\
\text { Volume } \\
\text { Error (\%) } \\
\end{array}$ \\
\hline Full Multi-Beam & $51,701.5$ & 0.0 & $51,701.5$ & 0.0 \\
\hline $100 \mathrm{ft}$ & $51,726.6$ & 0.048 & $52,020.9$ & 0.062 \\
\hline $200 \mathrm{ft}$ & $51,646.9$ & 0.106 & $51,746.4$ & 0.087 \\
\hline $300 \mathrm{ft}$ & $52,072.8$ & 0.718 & 51.712 .7 & 0.022 \\
\hline $500 \mathrm{ft}$ & $51,803.2$ & 0.196 & $51,703.9$ & 0.005 \\
\hline $700 \mathrm{ft}$ & $52,247.2$ & 1.06 & $51,076.0$ & 1.21 \\
\hline $1000 \mathrm{ft}$ & $51,775.6$ & 0.14 & $51,277.4$ & 0.82 \\
\hline $1500 \mathrm{ft}$ & $52,712.5$ & 2.00 & $49,581.3$ & 4.10 \\
\hline $2000 \mathrm{ft}$ & $53,141.1$ & 2.78 & $49,584.5$ & 4.10 \\
\hline
\end{tabular}

From these results, a conclusion can be drawn that when increasing the population size of our sample dataset, the error values do display a tendency for strong positive correlation. In the Weipa Case Study, the population size was only three $(25 \mathrm{~m}$, $50 \mathrm{~m}$ and $100 \mathrm{~m}$ spacing) so these results were not apparent. If further intervals were added and multiple runs (as in the BU example), perhaps we could expect to see similar results.

It could therefore be argued that while there is a trend for volume error to increase with profile spacing, for any given dataset based on one set of profiles (i.e. a single beam survey) the accuracy of the volume is essentially down to 'luck.' In their report, Dunbar J.A and Estep H state that "Reducing the profile spacing to less than $500 \mathrm{ft}$ does not guarantee improved volume accuracy. " (Dunbar, J.A, Estep, H, 2009)

\section{VOLUME COMPUTATIONS AT MSQ}

MSQ have traditionally used the TIN method when required to compute volumes for their

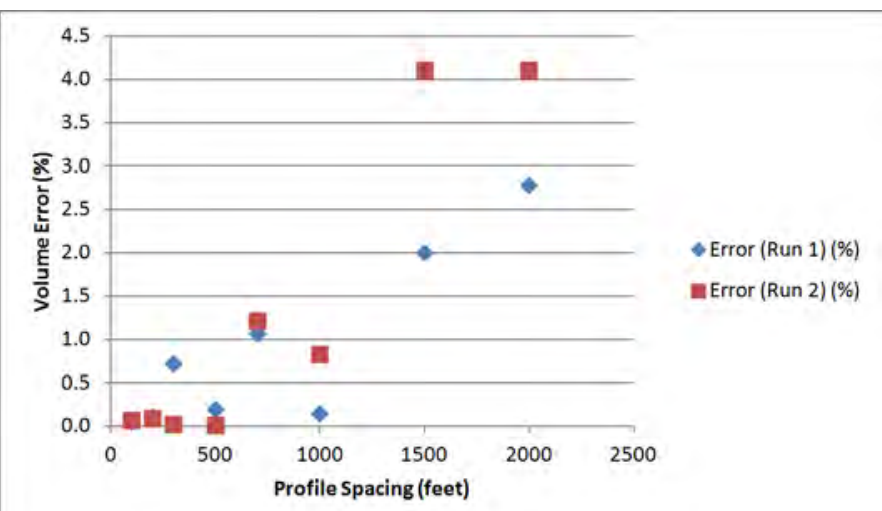

hydrographic surveys. As part an evaluation for the Engineering Analysis Module in 2011, MSQ ran a comparison of TIN volume computations using the module against their existing capability. Results from the comparison can be seen in Table 3. The Engineering Analysis Module produced the same TIN volume results, in less time across all cases, as well as having the ability to compute a volume for the entire channel (which the existing capability was not able to achieve).

\section{CONCLUSION}

The Engineering Analysis Module is able to greatly assist users in managing Ports and Waterways through the use of conformance analysis, sophisticated volume computations, shoal detection/management and the creation, editing and maintenance of reference models. When computing volumes, users should consider what type of volume will deliver the most accurate results. While End Area volumes have traditionally been quite widely used, this paper presents evidence that TIN volumes and hyperbolic volumes should be taken

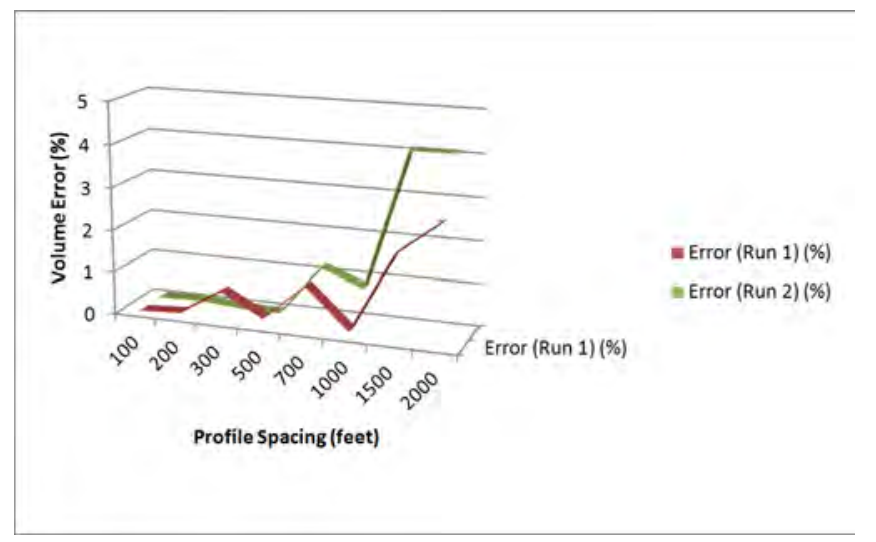

Figure 4: Scatter plot and 3D line graph of BU volume comparisons. 
Table 3: Volume results and processing times at MSQ

\begin{tabular}{|c|c|c|c|c|}
\hline & \multicolumn{2}{|c|}{ CARIS Engineering Analysis Module } & \multicolumn{2}{c|}{ Existing capability } \\
\hline Area & $\begin{array}{c}\text { Time to Process } \\
\text { (hh:mm:ss) }\end{array}$ & $\begin{array}{c}\text { Volume to Dredge } \\
\left(\mathrm{m}^{3}\right)\end{array}$ & $\begin{array}{c}\text { Time to Process } \\
\text { (hh:mm:ss) }\end{array}$ & $\begin{array}{c}\text { Volume to Dredge } \\
\left(\mathrm{m}^{3}\right)\end{array}$ \\
\hline Whole Channel & $0: 47: 00$ & 116,724 & $\begin{array}{c}\text { Not enough } \\
\text { memory to } \\
\text { compute }\end{array}$ & $\begin{array}{c}\text { Not enough } \\
\text { memory to } \\
\text { compute }\end{array}$ \\
\hline BN16 - BN18 & $0: 01: 57$ & 2,234 & $0: 03: 14$ & $2,233.8$ \\
\hline BN6 - BN 8 & $0: 05: 50$ & 31,015 & $0: 19: 34$ & $31,016.2$ \\
\hline BN 8 - CH15500 & $0: 02: 00$ & 19,049 & $0: 02: 45$ & $19,048.8$ \\
\hline BN2 - BN4 & $0: 05: 52$ & 10,492 & $>1 \mathrm{hr}$ & 9867 \\
\hline
\end{tabular}

into consideration as they are capable of producing volume results that are reliable and repeatable.

The Engineering Analysis Module has provided MSQ with the ability to compute volumes faster and on much larger data sets than their existing capability, along with new functionality for advanced visualization techniques. The ability to increase the data sets reduces the trade off historically required between precise volumes (e.g. $0.5 \mathrm{~m}$ spaced data) with practical processing limits. (Data generalised to $2.5 \mathrm{~m}$ )

\section{REFERENCES}

Cantrill, O, (2012) General Aspects of Port Surveying and Shallow Water Bathymetry, Proceedings of SWPHC Ports \& Shallow Water Bathymetry Technical Workshop, Brisbane, Australia, March 13-14

Dunbar, J.A, Estep, H, (2009) Hydrographic Survey Program Assessment Contract No 0704800734, Baylor University Department of Geology, Waco, TX

Kruimel, D, Fellinger, C, (2011) Bathymetric Data Management: The Ports and Waterways Environment, Proceedings of Hydro 2011 Conference, Fremantle, Australia. November 7-10

Sciortino, J.A, (2011) Fishing Harbour Planning, Construction And Management: Fao Fisheries And Aquaculture Technical Paper No. 539

USACE, (2001) Hydrographic Surveying, Engineering Manual 1110-2-1003, United States Army Corps of Engineers, Washington, DC.

\section{BIOGRAPHIES}

Owen Cantrill is a Level 1 Certified Hydrographic Surveyor having gained certification in 2000 . He gained a Bachelor of Surveying with honours from the University of Melbourne in 1989. He is currently employed as the manager of the Hydrographic Services section of Maritime Safety Queensland (MSQ).

Daniel Kruimel is an active member of the Spatial Industry and is currently a member on the SSSI Regional Committee of South Australia, as well as the Hydrography Commission National Committee. At the start of 2011, Daniel took up a role with CARIS Asia Pacific as a Technical Solutions Provider.

\section{CONTACT DETAILS}

Daniel Kruimel

CARIS Asia Pacific

Level 3, Shell House, 172 North Terrace

Adelaide SA 5000

AUSTRALIA

Tel.: +61 450802039

Email: daniel.kruimel@caris.com

Web site: www.caris.com

LinkedIn account: http://www.linkedin.com/pub/

daniel-kruimel/2b/295/67

Twitter account: @dkruimel 


\title{
Sediment vs Topographic Roughness:
}

\section{Antropogenic Effects on Acoustic Seabed Classification}

\author{
Ruggero Maria CAPPERUCCI, Germany and New Zealand \\ MARUM, Center for Marine Environmental Sciences, University of Bremen \\ Department of Earth and Ocean Sciences, University of Waikato \\ Marine Research Department, Senckenberg am Meer
}

Alexander BARTHOLOMÄ, Germany

Marine Research Department, Senckenberg am Meer

Topics: Careful marine planning; Geophysics of the marine environment

\section{INTRODUCTION}

In recent years, environmental case studies of highly developed marine areas have become more relevant [Winter and Bartholomä, 2006; van der Veen and Hulscher, 2008]: for monitoring both the short- and long-term human impact on bio- and geo-sphere; for modelling the effects of such increasing pressure on ecosystem; as a key tool for environmental and socio-economic policy and management.

Among the different marine domains, coastal areas are the most accessible ones and the most difficult to be studied in detail, due to the complexity of natural and anthropic processes in action [OSPAR, 2008]. As a consequence, there is an increased demand for reliable high-resolution mapping tools, less dependent on expertise interpretation, and therefore more objective [Cutter, 2003].

In this scenario, the combination of acoustic, sedimentological and biological data is becoming the main approach for seabed habitat mapping studies [Brown, 2011]. Nevertheless, some specific aspects need further investigations: firstly, the analysis of acoustic data is still largely dependent on human expertise [Cutter, 2003]; secondly, repeated sampling technique is a standard procedure for biological studies but not a common practice for sedimentary research; and lastly, the ground-truthing process by means of sediment samples assumes that the point-based information can be consistently extended to the near vicinity of the sampling station. Besides, the positioning error/uncertainty is often not even mentioned as a key factor for assessing the reliability of the final seabed classification.

The latter assumptions have to be proved for extremely heterogeneous environments, where anthropogenic impact increases significantly the disturbance (and, hence, the variability) of ecosystems.

In our study site of the Jade channel in the German Bight (southern North Sea) hydrodynamic conditions, topography, sediments and biocommunities are tremendously influenced by multiple human activities. Fishing and mussel farms are present [Herlyn and Millat, 2000]; the navigation channel is constantly monitored and dredged by the local harbour authority (Wasser- und Schiffahrtsamft Wilhelmshaven - WSA); moreover, a new container terminal (Jade-Weser Port, http:// www.jadeweserport.de/) is under construction since 2008, with massive land reclamation, dredging and dumping operations. The Jade channel area represents, then, a unique site where to test the reliability of acoustic ground discrimination systems (AGDS) in a cumulative disturbed area.

The present study aims to address the following research questions:

1. What is the variability of repeated sediment samples in a highly heterogeneous environment?

2. How do the positioning error/uncertainty of sediment samples affect the ground-truthing process?

3. What drives the seabed classification in the different acoustic systems?

\section{STUDY AREA AND METHODS}

The Jade channel connects the Jade Bay with the German Bight (southern North Sea), being part of a wide tidal flat system that includes the Weser estuary (Figure 1). 


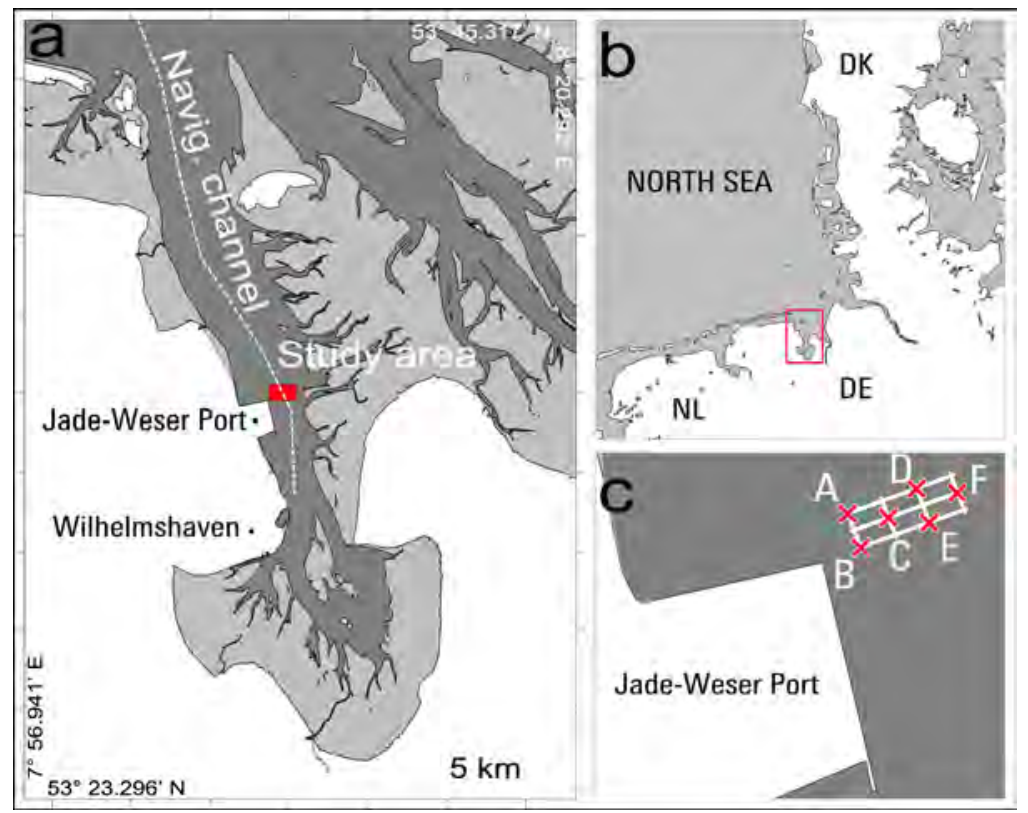

Figure 1 a) The Jade

region, with the Jade-

Weser Port and, in

red, the study area. b)

Location map of the

Jade system. c) close

up un the research

site; white lines: main

acoustic transects,

red crosses: sampling

stations

The northern end (Outer Jade) is a mesotidal environment (sensu Hayes, 1975), with semi-diurnal tides ranging between 2.3 and $2.8 \mathrm{~m}$, whereas the southern part (Inner Jade) is a macrotidal environment, with the tidal gauge reaching $3.9 \mathrm{~m}$ in Wilhelmshaven.

The sediment distribution shows a general decrease of the grain-size towards the high-tide line, with the finest sediments being located in the south-eastern part of the bay; the Inner Jade is characterized by the presence of fine sand; fine to medium sand occurs in the Outer Jade area [Kahlfeld and Schüttrumpf 2006]. Bedforms are commonly observed along the tidal inlet.

The research area covers approximately $0.8 \mathrm{~km} 2$ in the Jade Channel, north-east of the Jade-Weser Port, partially within the old navigation channel. The water depth ranges between 14 and $26 \mathrm{~m}$.

Acoustic data were collected aboard the R/V Senckenberg using a Reson Seabat $8125^{\mathrm{TM}}$ multibeam echosounder (MBES, $455 \mathrm{kHz}$ ), a dual-frequency Benthos $1624^{\mathrm{TM}}$ side-scan sonar (SSS, 110-390 kHz) and a QTC 5.5 ${ }^{\mathrm{TM}}$ system mounted on a Furuno FCV $1000^{\mathrm{TM}}$ single-beam echosounder (SBES, $200 \mathrm{kHz}$ ). All devices were deployed simultaneously along 7 main transects (3 approximately east-west and 4 approximately northsouth oriented). Additional lines were collected for a complete MBES coverage and a denser SBES grid. A DGPS system with LRK correction was used for positioning.
6 stations were sampled (4 replications each) using a Shipek grab.

\section{Data processing}

MBES bathymetric data were processed using QINSy $^{\mathrm{TM}}$ and a final $0.5 \times 0.5 \mathrm{~m}$ grid was computed. DTM generation and seabed features mapping was done under Global Mapper ${ }^{\mathrm{TM}}$ v13. A set of QTC ${ }^{\mathrm{TM}}$ software was used for acoustic seafloor classification: QTC IMPACT ${ }^{\mathrm{TM}}$ for SBES data, QTC SIDEVIEW ${ }^{\mathrm{TM}}$ for SSS data, QTC SWATHVIEW ${ }^{\mathrm{TM}}$ for MBES data, and QTC CLAMS $^{\mathrm{TM}}$ for visualizing and editing classified data.

QTC IMPACT ${ }^{\mathrm{TM}}$ is based on a statistical analysis of the echo-trace shape, whereas QTC SIDEVIEW ${ }^{\mathrm{TM}}$ and QTC SWATHVIEW ${ }^{\mathrm{TM}}$ use statistical properties of backscatter images. The Automatic Clustering Engine function [QTC IMPACT User Manual, 2004], was used for splitting acoustic signals into a final number of classes that fits with the optimal split level suggested by the statistical parameters.

Sediment samples were analyzed following the procedure described by Wienberg and Bartholomä (2005) and classified using the GRADISTAT statistics package [Blott and Pye 2001]. The PAST software (Hammer 2001) was used for statistical analysis (Non-metric MDS and Cluster analysis). All the data were finally loaded in ArcGIS v9.2 for interpretation. 


\section{RESULTS}

\section{$\underline{\text { Sedimentary data }}$}

Due to the strong tidal currents acting in the area, sampling positions were shifted with respect to the planned locations, the average distance between replications being $20 \mathrm{~m}$ (Table 1a). Station $\mathrm{C}$ shows the highest positioning error (average distance between replications: $32 \mathrm{~m}$ ).

Sediments grain sizes range from coarse silt to very fine gravel (Table $1 \mathrm{~b})$, the main part (75\%) falling into the sand fraction. Replications show significant difference in sediment composition: Station A presents the lowest variability, all the replications being dominated by sand. Station C, on the contrary, is characterized by the highest variability in composition, with the replication JSA04 muddybased (47.6\%), JSA09 totally sandy (91.8\%) and JSA019 and JSA022 gravelly dominated (55.4\% and $47.7 \%$, respectively). Replications JSA02 and JSA14 (Station D) are the closest ones of the survey $($ distance $=2 \mathrm{~m})$. Nevertheless, JSA02 presents a high content of mud (75.4\%) and JSA14 is dominated by sand (60.1\%). Similar results for Station E, where JSA10 is characterized by a $75.7 \%$ of mud, while JSA 15 composition is mainly given by the sand fraction (76.6\%), albeit they are only 7 $\mathrm{m}$ far.
The results of statistical analysis confirm that there is no significant correlation between sediment similarity and sampling closeness. In particular, only replications from Station A tend to group, while the already mentioned replications from Station D and E show low similarity values, in spite of their closeness (Figure 3a).

\section{$\underline{\text { Acoustic data }}$}

The whole area is characterized by distinctive topographic features, mainly related to dredging operations. From West to East, 6 main morphological domains can be mapped (Figure 2):

- W: a wide area dominated by dredging marks related to the Jade-Weser Port construction phase;

- H: western high (min. depth: $14.4 \mathrm{~m}$ ), without dredging scours;

- P: western pit ( max. depth: $26.4 \mathrm{~m}$ ), without dredging scours;

- $\quad \mathrm{N}$ : old navigation channel, marked by regularly spaced and shaped dredging scours, elongated and parallels to the navigation channel;

- B: large bedform fields, mainly aside the old navigation channel;

- E: a wide domain characterized by the absence of dredging marks and by the presence of diffuse short-wave bedforms. It is the less disturbed area.

The SBES final classification (optimal splitting

\begin{tabular}{|c|c|c|c|c|c|c|c|}
\hline \multicolumn{2}{|c|}{ Station A } & \multicolumn{2}{|c|}{ (av.dist $=15 \mathrm{~m}$ ) } & \multicolumn{2}{|c|}{ Station B } & \multicolumn{2}{|c|}{ (av. dist $=20 \mathrm{~m}$ ) } \\
\hline & JSA07 & JSA18 & JSA23 & & JSA08 & JSA17 & JSA25 \\
\hline JSA05 & 17 & 17 & 20 & JSA06 & 28 & 18 & 28 \\
\hline JSA07 & & 14 & 18 & JSA08 & & 16 & 18 \\
\hline JSA18 & & & 3 & JSA17 & & & 10 \\
\hline Statio & & (av. dist= & $32 m)$ & Station & D & (av. dist $=$ & $21 m)$ \\
\hline & JSA09 & JSA19 & JSA22 & & JSA12 & JSA14 & JSA21 \\
\hline JSA04 & 37 & 39 & 50 & JSA02 & 38 & 2 & 13 \\
\hline JSAO9 & & 19 & 20 & JSA12 & & 36 & 26 \\
\hline JSA19 & & & 25 & JSA14 & & & 11 \\
\hline Statio & & (av.dist= & 13m) & Statior & $\mathbf{F}$ & (av. dist $=$ & $16 \mathrm{~m})$ \\
\hline & JSA10 & JSA 15 & JSA24 & & JSA11 & JSA13 & JSA2O \\
\hline JSA03 & 4 & 11 & 23 & JSA01 & 14 & 13 & 13 \\
\hline JSA10 & & 7 & 19 & JSA11 & & 5 & 27 \\
\hline JSA15 & & & 13 & JSA13 & & & 25 \\
\hline
\end{tabular}

Table 1a (left) and 1b (right). 1a: average distance between replications. 1b: sediment grain size analysis, expressed as dry weight percent on total sediment.

\begin{tabular}{ccccc} 
Sample & Gravel \% Sand \% & Mud \% & \\
\hline JSA05 & 3.0 & 64.7 & 32.3 & \\
JSA07 & 3.9 & 69.6 & 26.5 & A \\
JSA18 & 0.0 & 71.6 & 28.4 & \\
JSA23 & 13.6 & 57.9 & 28.5 & \\
\hline JSA06 & 32.5 & 59.7 & 7.7 & \\
JSA08 & 58.7 & 30.0 & 11.2 & B \\
JSA17 & 17.5 & 67.2 & 15.3 & \\
JSA25 & 63.9 & 21.9 & 14.1 & \\
\hline JSA04 & 19.2 & 33.3 & 47.6 & \\
JSA09 & 0.0 & 91.8 & 8.2 & \\
JSA19 & 55.4 & 34.2 & 10.4 & C \\
JSA22 & 47.7 & 45.5 & 6.8 & \\
\hline JSA02 & 0.0 & 24.6 & 75.4 & \\
JSA12 & 4.2 & 89.0 & 6.8 & D \\
JSA14 & 1.6 & 60.1 & 38.4 & \\
JSA21 & 0.9 & 66.3 & 32.8 & \\
\hline JSA03 & 0.0 & 25.7 & 74.3 & \\
JSA10 & 0.0 & 24.3 & 75.7 & \\
JSA15 & 11.7 & 76.6 & 11.7 & E \\
JSA24 & 0.0 & 95.4 & 4.6 & \\
\hline JSA01 & 24.1 & 52.8 & 23.0 & \\
JSA11 & 16.9 & 64.3 & 18.8 & F \\
JSA13 & 2.1 & 62.3 & 35.6 & \\
JSA20 & 13.1 & 84.0 & 2.9 & \\
\hline
\end{tabular}




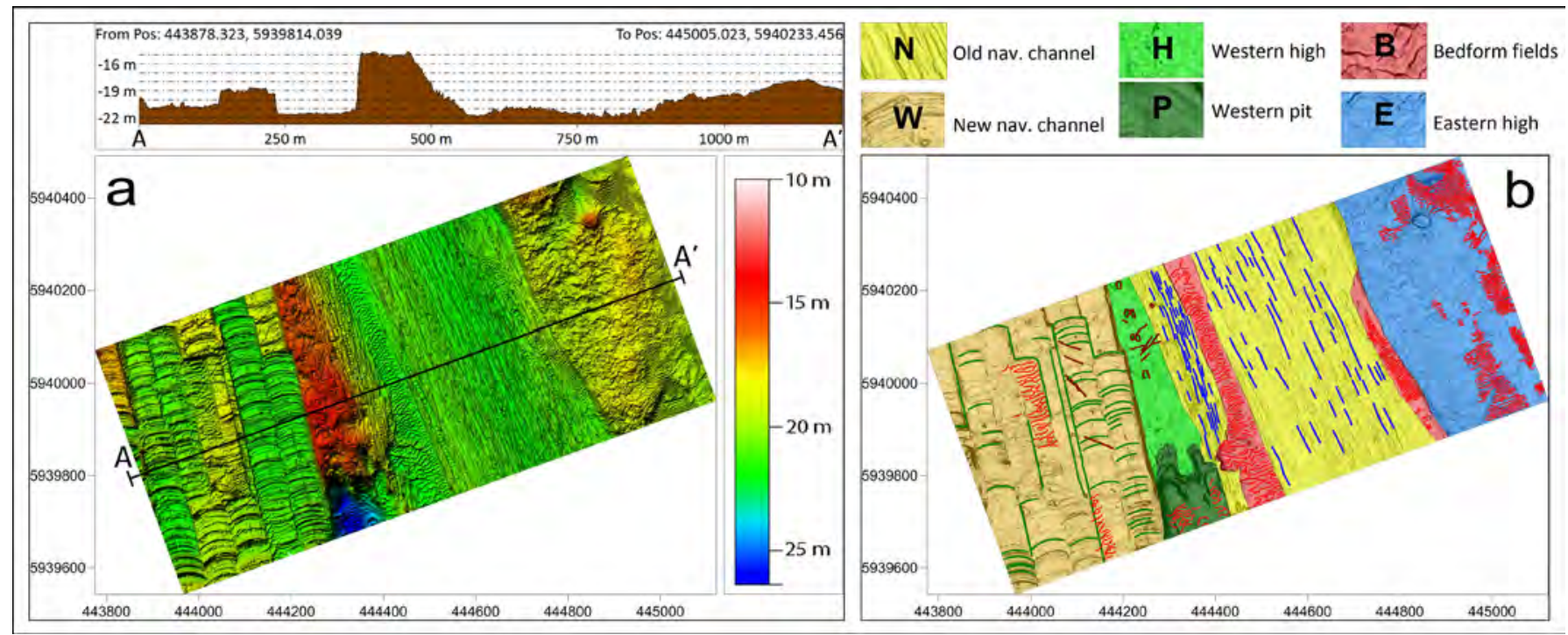

Figure 2: DTM of the research area (a) and main morphological domains (b).

level: 4) shows a patchy distribution of acoustic classes all over the area, with a dominance of the turquoise-colored class $(42.2 \%)$ and browncolored class $(32.0 \%)$, which do not correspond to any morphological domain (Figure $3 \mathrm{~b}$ ). The pink-colored class $(6.1 \%)$ is the only one focused around specific regions ( $\mathrm{H}$ and $\mathrm{P}$ domains), while the blue-colored one (19.7\%) is scattered all over the area, but scarcely represented in the same domains. All considering the extreme variability of sediment composition and distribution, the error in positioning and the patchiness of the acoustic classification, it is not possible to clearly correlate acoustic classes and sedimentary data.

The grey-colored class prevails $(69,2 \%)$ in the MBES acoustic classification (optimal split level:
5. Figure 4a), marking both the western (W) and eastern (E) regions, including the $\mathrm{B}$ areas and with the exception of the $\mathrm{H}$ and $\mathrm{P}$ domains. 2 specific classes (light and dark blue-colored ones, $14.2 \%$ and $8.1 \%$, respectively) cover the $\mathrm{N}$ morphological domain, where the green-colored class $(2.8 \%)$ is also present. Thus, a correlation between main seabed features and acoustic classification is clear. The turquoise-colored class $(5.7 \%)$ is spread all over the area. There is no correspondence between acoustic classes and sedimentary data: in fact, every acoustic class can be related to different sediment types and the same sedimentary group corresponds to more than one acoustic class.

The general pattern of the SSS classification (optimal split level: 4) follows the main

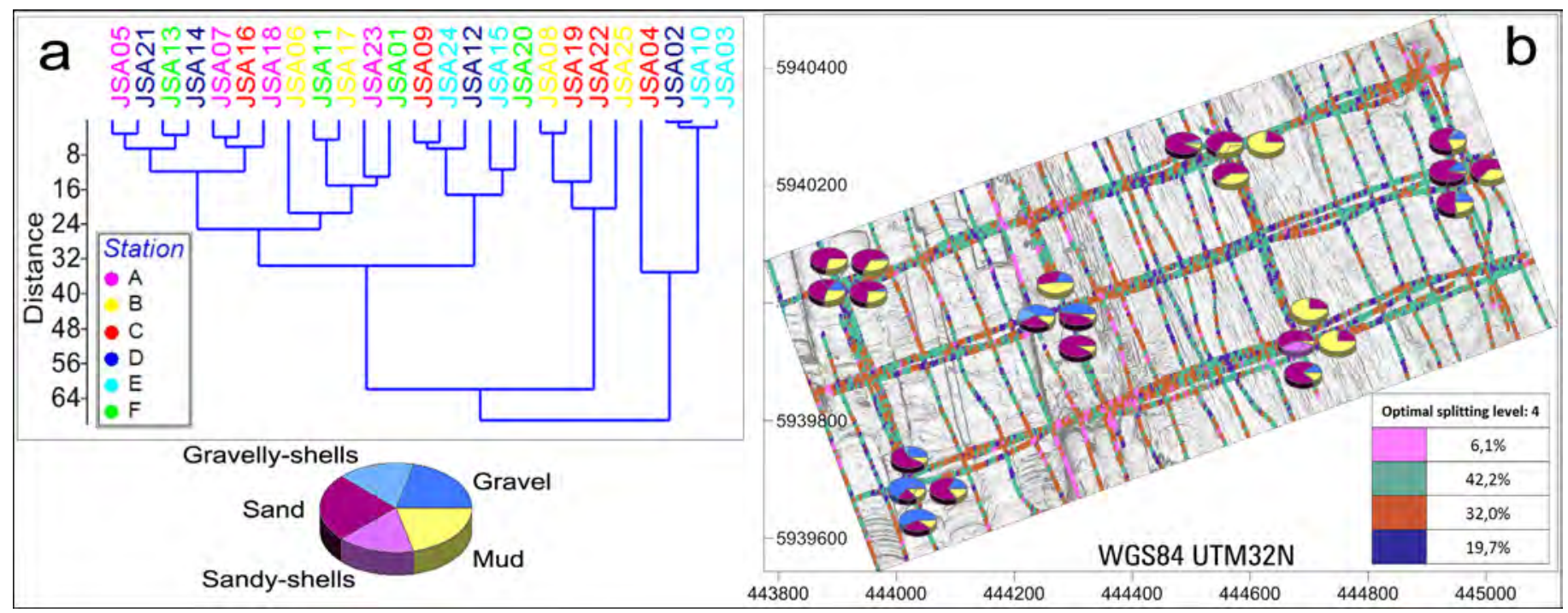

Figure 3: Clustering analysis, Euclidean similarity measure (a). SBES acoustic classification (b), overlaid by the sediment data. 


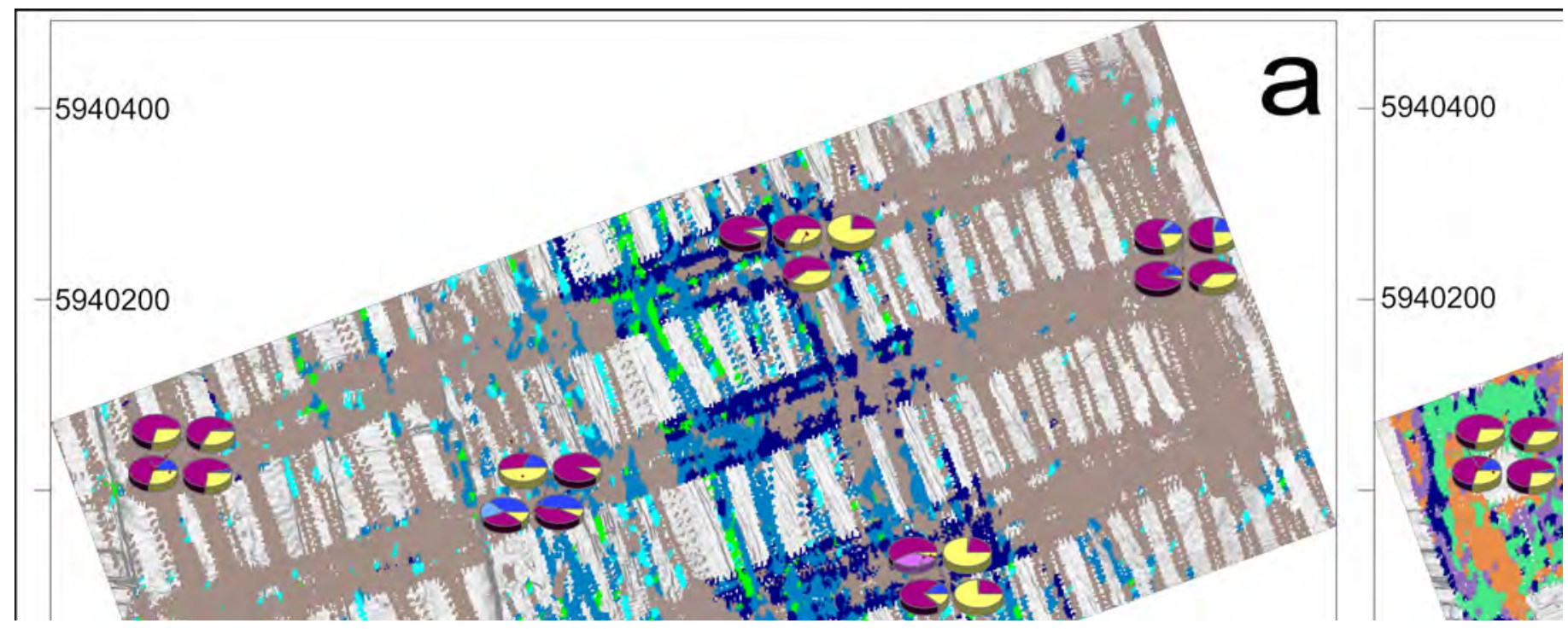

Figure 4: MBES acoustic classification (a) and SSS acoustic classification (b).

morphological divisions (Figure $4 b$ ), with the greencolored class $(36.3 \%)$ fitting the $\mathrm{N}$ area and the remaining classes distributed both in the western and eastern regions. The $\mathrm{W}$ domain seems to be equally represented by both the orange- $(30.7 \%)$ and the violet-colored $(24.0 \%)$ classes, while the $\mathrm{E}$ topographic area is mainly covered by the orangecolored class. The blue-colored class characterizes the slope between the $\mathrm{H}-\mathrm{P}$ and $\mathrm{N}$ regions.

The same catalogue of 4 classes was used for classifying separately the 4 north-south and the 3 east-west SSS lines, showing significant differences. In particular, the area corresponding to the old navigation channel presents a homogeneous dominance of the turquoise-colored class in the east-west transects, whereas the same region shows a distinctive multi-class pattern parallel to the dredging marks in the north-south classification. As for the MBES classification, the ground truthing process does not show any univocal correspondence between sediments and the SSS acoustic classes.

\section{DISCUSSION AND CONCLUSIONS}

Errors are always associated with sampling positioning. The mismatch between the planned and the sampled location can be negligible in homogeneous environment, giving a reliable classification. Punctual information can then be used for validating acoustic data even when the two sources does not perfectly overlap, assuming that the information inferred for a given position can be consistently extended to a certain neighborhood.
This is not true for highly heterogeneous environments; in fact, repeated sampling clearly demonstrates that:

- Replications show significant differences in sediment composition;

- There is not clear relationship between positioning and similarity;

- Less disturbed areas (e.g. station F) present the same variability of directed multi-impacted ones (e.g., Station A), therefore there is no link between anthropic disturbance and heterogeneity.

The results show that repeated sampling is a must in such complex environments.

SBES classification reveals a highly heterogeneous seabed texture with no clear dominant pattern, thus being likely controlled by the distinctive patchiness in sediment distribution ( $=$ sediment roughness). Nevertheless, the extreme variability of sediment composition does not allow any interpolation: only the samples located exactly along the acoustic line could be theoretically used for ground-truthing, resulting in a scarcely sufficient amount of information. In conclusion, SBES classification is ruled by sediment patchiness, but the final classification can hardly be translated into sedimentological information.

On the contrary, swath-based systems (MBES and SSS) seem to be largely dependent on seabed topography for their classification, with acoustic classes that match the general division in morphological domains (= topographic roughness). MBES does not allow the distinction between $\mathrm{W}$ 
and $\mathrm{E}$ regions, although they represent end members of highly disturbed and less disturbed environments. SSS classification not only stresses the different topographic domains, but also distinguishes between $\mathrm{W}$ and $\mathrm{E}$ regions. The angle between the acoustic lines and the seabed features is crucial for the final acoustic classification. In fact, regularly shaped and spaced features, like dredging marks, could lead to significantly different results.

In conclusion, mapping highly heterogeneous and disturbed environments is a crucial challenge for monitoring and protecting these extremely sensitive areas. Hydro-acoustic systems coupled with repeated sampling allow running this process in high resolution, but the resulting classification is mainly ruled by the sediment roughness for SBES systems and by topographic micro-roughness for swath-based devices. In any case, the resulting classes can only partially be linked to a proper sedimentological meaning.

\section{CONTACT DETAILS}

\section{Ruggero Maria CAPPERUCCI}

Marine Research Department, Senckenberg am Meer

Südstrand 40, 26382 Wilhelmshaven, Germany

Tel.: +49 (0)44219475212

Email: Ruggero.Capperucci@senckenberg.de

\section{REFERENCES}

Blott, S.J., and K. Pye 2001. "GRADISTAT: a grain size distribution and statistics package for the analysis of unconsolidated sediments." Earth Surface Processes and Landforms 26: 1237-1248. Brown, C.J., S.J. Smith, P. Lawton and J.T. Anderson 2011. "Benthic habitat mapping: A review of progress towards improved understanding of the spatial ecology of the seafloor using acoustic techniques." Estuarine, Coastal and Shelf Science 92: 502-520.

Cutter Jr., G.R., , Y. Rzhanov, and L.A. Mayer 2003. "Automated segmentation of seafloor bathymetry from multibeam echosounder data using local Fourier histogram texture features." Journal of Experimental Marine Biology and Ecology 285286: 355- 370.

Hammer, Ø., D.A.T. Harper, and P.D. Ryan 2001. "PAST: Paleontological Statistics Software Package for Education and Data Analysis." Palaeontologia Electronica 4: 9pp.

Hayes, M.O. 1975. "Morphology of sand accumulations in estuaries: an introduction to the symposium." In Estuarine Research, vol. 2, ed. L.E. Cronin, 3-22. New York: Academic Press. Herlyn, M., and G. Millat 2000. "Decline of the intertidal blue mussel (Mytilus edulis) stock at the coast of Lower Saxony (Wadden Sea) and influence of mussel fishery on the development of young mussel beds." Hydrobiologia 426: 203-210.

Kahlfeld, A., and H. Schüttrumpf 2006. "Untrim modelling for investigating environmental impacts caused by a new container terminal within the JadeWeser Estuary, German Bight." In: Proceedings of the 7th International Conference on HydroScience and Engineering, Philadelphia, USA, September 1013, 2006, 13pp..

OSPAR 2004. "Environmental Impacts to marine species and habitats of dredging for navigational purposes.” OSPAR Commission, Biodiversity Series : 22pp.

OSPAR 2008. "Assessment of the environmental impact of land reclamation", OSPAR Commission, Biodiversity Series, Publication number 368/2008 : 37pp.

QTC IMPACT User Manual, 2004. QTC IMPACT Acoustic Seabed Classification.User Manual, Version 3.40. Quester Tangent Corporation, Marine Technology Centre, Sidney, B.C., Canada, 153 p. van der Veen, H.H., and S.J.M.H. Hulscher 2008. "Effect of large scale human activities on the North Sea seabed." In Marine and River Dune Dynamics, ed. Parsons, D., Garlan, T. and Best, J., 307-314. Wienberg, C., and A. Bartholomä 2005. "Acoustic seabed classification of a coastal environment (outer Weser Estuary, German Bight) - a new approach to monitor dredging and dredge spoil disposal.", Journal of Continental Shelf Research 25: 11431156.

Winter, C., and A. Bartholomä 2006. "Coastal dynamics and human impact: south-eastern North Sea, an overview." Geo-Marine Letters 26: 121-124.

\section{8 | Hydrol 2}




\section{Fluid mud density determination in navigational channels}

Stijn CLAEYS, Belgium

Flanders Hydraulic Research

Ben DIERIKX and Simon PAUL, the Netherlands

Ministry of Infrastructure and the Environment, Rijkswaterstaat

Jeroen van REENEN, the Netherlands

Port of Rotterdam

Topic: Geophysics of the marine environmemt

\section{INTRODUCTION}

Cohesive sediment management in navigable channels and harbors needs to be tackled in a cost-effective and safe way. The sedimentation and consolidation of sediments is a natural driven continuous process which needs to be controlled. The forming of mud layers are driven by time dependent natural hydraulic conditions, ambient conditions and sediment input. Also harbor and dredging activities will alter the mud layer in thickness and its rheological behavior. Depending on the composition, time and ambient conditions the mud will build up strength and will become nonnavigable at a certain level.

Dredging the whole mud layer is not needed because part of the mud layer is fluid enough to sail through it. This requires the mapping of the mud layer properties. But, not only the total mud-body needs to be mapped, also a vertical picture of its strength is needed. The strength behavior of the mud is depending on the applied deformation force and time. In-situ measuring of the reaction against deformation of the mud is a very difficult task, therefore another site-related parameter, density, is measured instead. The whole monitoring scope is a difficult exercise between a correct measurement, reducing dredging cost and guarantying a safe vessel passage.

In the last few years, researchers of the Flanders Hydraulic Research (Flemish Government), the Port of Rotterdam, the Dutch Ministry of Infrastructure and Environment and third party manufactures have evaluated existing and new methods for the determination of the density of fluid mud. Different methods were analyzed on their physical principles, tested in a laboratory and tested in the field. This paper discusses the main results and conclusions. But first a brief description of the history of measuring the density of fluid mud is given.

\section{BRIEF DESCRIPTION OF THE HISTORY OF MEASURING THE DENSITY OF FLUID MUD}

In the 70ties and 80ties of the 20th century extensive research was carried out to map the nautical bottom ${ }^{1}$, with the aim to reduce dredging costs. Research was carried out to determine the non-navigable mud layer, which needs to be brought to the target level of the harbor. This was done in Belgium, the Netherlands, Germany and many other countries.

It was found that the mud density was the best (guiding) parameter. The nautical bottom density level was, however, different for every port. Guidelines and limits were documented in PIANC guidelines (PIANC, 1997).

In Belgium in the 80ties, physical scale modeling (at Flanders Hydraulics Research), mathematical modeling and real scale in-situ navigation tests were used to determine the nautical depth. Also large sampling campaigns together with rheology, density and other sediment related laboratory tests were executed. Comparable test programs were also carried out in the port of Rotterdam. Based on

\footnotetext{
${ }^{1}$ The nautical bottom is defined as the level where the physical characteristics reach a critical limit beyond which contact with a ship's keel causes either damage or unacceptable effects on controllability and maneuverability (PIANC, 1997).
} 
these tests, in Zeebrugge the nautical bottom was determined at $1.15 \mathrm{~kg} / 1$. Later, in 2001 , the density level has been revised to $1.20 \mathrm{~kg} / 1$ using more experimental research. At the Ports of Rotterdam and IJmuiden the density level was set at $1.20 \mathrm{~kg} / 1$. Initially an in-situ measuring device to map the resistance of the mud layer was looked for. However, at that time, it proved to be too difficult to measure and to interpret in-situ rheological properties. Density was chosen as guiding parameter.

This prompted the development of in-situ density measuring devices as the NaviTracker (developed by Belgium dredging companies) and later the D2ART (developed by TNO for the Dutch government). These instruments are still used by the Belgium port authorities and by the Dutch ministry of Infrastructure and the Environment.

The last 5 years also rheology based instruments have become available on the market. Still the in-situ measuring of rheology is a difficult task (Claeys, 2011). Therefore, the Flemish and Dutch Government and Port of Rotterdam still use density as a parameter to determine the nautical bottom. But research programs are being executed to find an answer on in-situ rheology measurement in Belgium (Flanders Hydraulic Research) and in the Netherlands (Rijkswaterstaat and Deltares).

\section{MEASURING PRINCIPLES}

Currently different types of instruments, based on different measuring principles, are commercially available. The different measuring principles can be classified on their measuring strategy. E.g. does the instrument measure the density directly or indirectly. The different measurement principles are shortly discussed below. The instruments used today, their measuring principles and their manufactures are shown in Table 1.

Sampling tubes and free fall probes (mass based) The density of a sample taken from the bottom of a navigable channel can be determined directly by weighing a given volume of that sample. This is very accurate and simple method with high repeatability. It can, however, be difficult to obtain a representative sample. Furthermore, the process is quite labor intensive.

Another way of getting the density via mass measurement is by sinking (free falling) a given weight into the mud layer, and measuring the acceleration (or deceleration) and pore pressures. The density calculations are then based on the measured pore pressure and difference between the mounted pressure sensors. The equilibrium of forces, e.g. gravity, drag etc.; compensated for the density difference between the sensor and surrounded mud layer (=buoyancy); can be used to measure the rheological parameters (viscosity and strain). This is a very straight forward and robust method, but difficult to calibrate. A lot of physical based algorithms are needed to fine-tune the results. Vertical profiles are easily applied and, in theory measurements, can be done with up to $5-8$ knots of sailing speed. Influences of other parameters (matrix effects) are sometimes difficult to discriminate (Vos et al, 2010 and Paul et al, 2011).

\section{$\underline{\text { Radioactive probes }}$}

The density can also be measured by deploying a device with in one leg a radioactive source, either $\gamma$-ray (source: Cs-137 or Ba-133) or X-ray (X-ray tube), and in the other leg a scintillation detector. The attenuation of the $\gamma$-rays or X-rays between the two legs, caused by the mud-medium, is a measure for the density of the sediment. The density calculation is based on the Lambert-Beer law (Vos et al, 2010 and Claeys et al, 2011).

These probes are very robust (e.g. wide measuring range and measuring conditions), give quick results concerning vertical profiles and have been used by the Belgium and Dutch government for many years now. It must be noted that working with radioactive sources is bound to strict regulation and safety issues need to be addressed carefully. This method provides only density measurements.

\section{Vibrating probes}

Tuning forks, tuning needles or tuning tubes can also be applied to measure density. For the tuning fork, one tooth is brought in vibration using a piëzo electrical element. Depending on the rheological characteristics of the mud between the two teeth the other tooth reacts with a response frequency. This is an indirect measure of the density.

These kinds of probes require complex and extensive calibration, which is location,

\section{$30 \mid$ Hydro 12}


hydrological and morphological state specific. The probe has difficulties with stronger non-Newtonian mud, gas bubbles and is sensible to the clogging of the sticky mud to the legs. But when calibrated, it is very easy to deploy and also gives rheologicalrelated properties (Vos et al., 2010, Claeys eta al., 2011 and Paul et al, 2011).

\section{$\underline{\text { Acoustic impedance probes }}$}

An acoustic impedance probe transmits an ultrasound signal through a known and unknown medium. It then uses the acoustic attenuation of a known medium (in the sensor) and of the measured medium to determine the acoustic impedance of the measured medium, which is an indirect measure of the density. The probe has a high resolution and high sample frequency, but is sensitive for gas bubbles, contaminants, changes in salinity and temperature (Vos et al., 2010, Claeys eta al., 2011 and Paul et al, 2011).

\section{$\underline{\text { Acoustic reflection }}$}

Echo sounders are used to map the in-situ mud layer. The following techniques can be distinguished: single beam, dual frequency single beam, multi beam and parametric echo sounders. Depending on the used acoustical frequency the beam penetrates or reflects at a certain impedance transition in the mud layer. Generally a dual frequency single beam echo sounder with a $210 \mathrm{kHz}$ frequency is used to detect the litocline transition level between water and the sediment layer (good reflector). The $33 \mathrm{kHz}$ beam tends to reflect on the hard bottom. Between these layers sudden and gradual impedances changes occur, which can be linked to different densities. This requires calibration from in-situ measurements and specific algorithms to link the acoustic reflections to the wanted density levels. Advantage of this tool is that line information can be obtained. This method is, however, needs calibration at every measurement campaign and is less sensitive to gradual impedance changes and higher sand concentrations.

All the above mentioned techniques are probes or echo sounders, except for the slib-sampler and the Silas system, which takes vertical samples.

\section{LABORATORY COMPARISON TESTS AT THE SEDIMENT TEST TANK (STT)}

All the techniques mentioned above, except for the Mudbug, the Silas system and the Slib-sampler, were tested at the Sediment Test Tank (STT) (see Figure 1) at the Flanders Hydraulics Research Institute in Antwerp. Here the specifications and performance of the different probes were tested in a laboratory environment. The mud column was sampled with the Beekersampler. All tests were validated with laboratory analyses. For the density

\begin{tabular}{|c|c|c|}
\hline Name of the Device & Measuring principle & Manufacturer \\
\hline $\mathrm{D}^{2} \mathrm{ART}$ & $\begin{array}{l}\text { Radioactive probe with CS-137 or Ba- } \\
133 \text { source; vertical profiler }\end{array}$ & Seabed B.V. (NL) \\
\hline Densitune & Tuning fork & Stema Systems (NL) \\
\hline GraviProbe* & $\begin{array}{l}\text { Free fall penetrometer with } \\
\text { accelerometers and pore pressures }\end{array}$ & dotOcean N.V. (B) \\
\hline $\begin{array}{l}\text { HRDP*; (before DRDP, Admodus } \\
\text { USP*) }\end{array}$ & Acoustic (impedance) probe & $\begin{array}{l}\text { Greiser und partner (EPA and US Army } \\
\text { ERDC); Synergetik GmbH (D) }\end{array}$ \\
\hline Mudbug* & Tuning needle & Hydramotion (UK) \\
\hline $\begin{array}{l}\text { Navitracker (will be superseded by } \\
\text { Navitracker 2011) }\end{array}$ & $\begin{array}{l}\text { Radioactive probe with CS-137 source; } \\
\text { vertical profiler }\end{array}$ & GEMS International N.V. (B) \\
\hline Navitracker 2011 & $\begin{array}{l}\text { Radioactive probe with X-ray tube; } \\
\text { vertical profiler }\end{array}$ & GEMS International N.V. (B) \\
\hline Rheotune* & Tuning fork & Stema Systems (NL) \\
\hline Slib-sampler (HbR design) & (Automated) modified Beekersampler & N-Seatec Subsea systems B.V. (NL) \\
\hline Silas system & Acoustic reflection & Stema Systems (NL) \\
\hline
\end{tabular}

Table 1. Commercial available instruments and techniques (Vos et al, 2010, Claeys et al, 2011) Specifications can be found on the internet sites of the manufactures. * These instruments are also suited to measure rheological parameters. 


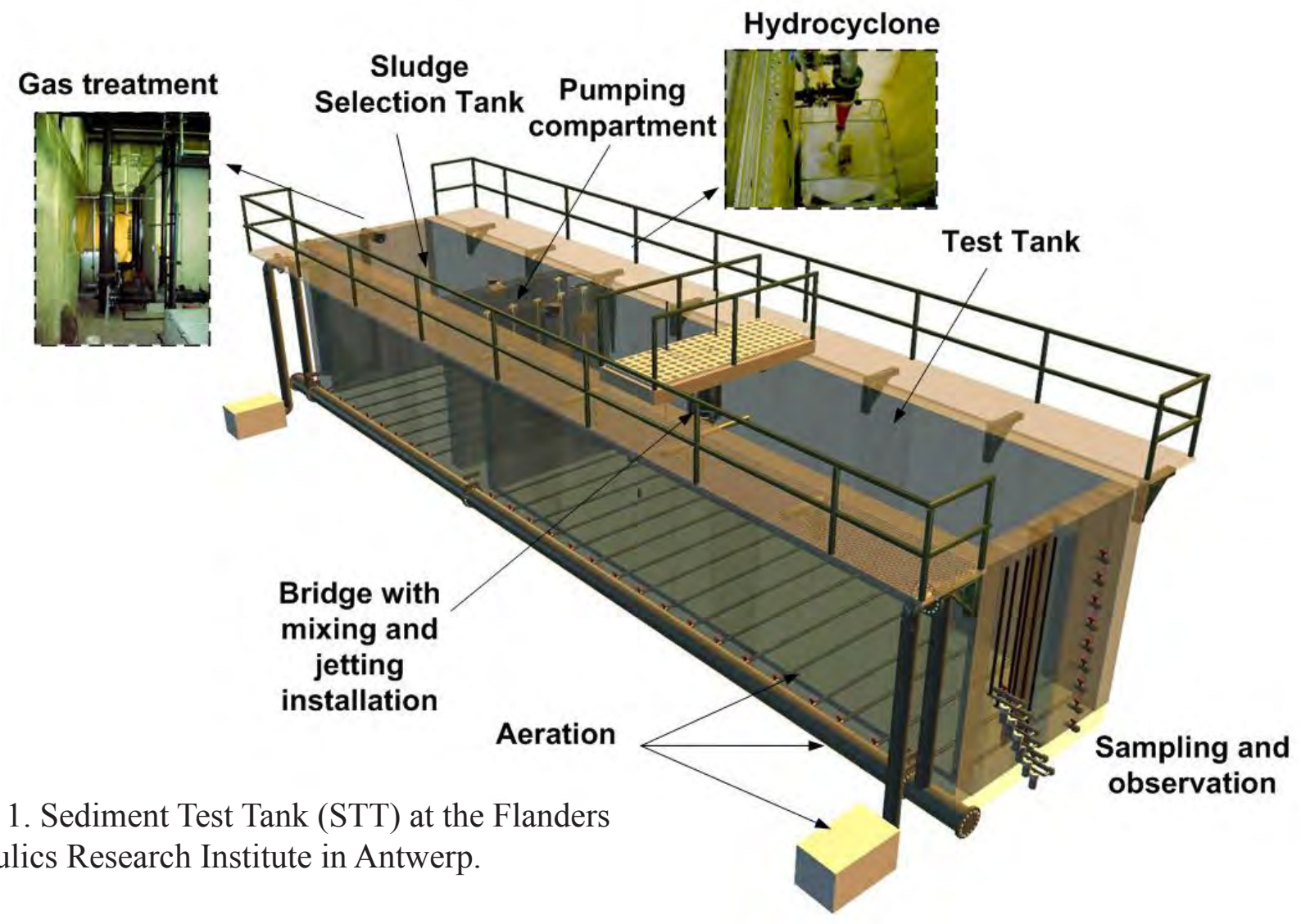

Figure 1. Sediment Test Tank (STT) at the Flanders Hydraulics Research Institute in Antwerp.

analyses the DMA (Anton Paar) was used. The accuracy on high density sticky mud samples is +/$0.02 \mathrm{~kg} / \mathrm{l}$. Even using a picnometer, does not give a better laboratory accuracy.

The STT is a concrete testing facility with 9.64 x $2.44 \times 3.11 \mathrm{~m}$ as inner dimensions. This sludge aeration and homogenization tank was built and equipped with the necessary tools: aeration, mixing plant and silt / sand separator. The STT is built to condition and maintain the in-situ sludge as natural as possible during a period of several years and the following operations can be executed:

- Simulating (representative) in-situ situations, sedimentation / suspension behavior

- Conditioning and storage of the sludge

- Reuse of the sludge for testing the repeatability of the measurement methods

- Platform for testing towed and vertically profiling devices

- Optional: Using sludge as the link between maneuverability of previous researches.

The STT is designed and equipped for the creation of a chosen sand-silt-clay (fraction) mixture and sediment layers. Most of the known compositions can be generated with the STT equipment.

The tests showed that all instruments were able to measure mud densities from 1.0 till $1.3 \mathrm{~kg} / 1$. However, earlier mentioned (dis)advantages must be taken into account. How these (dis)advantages are weighed depends on the situation and requirements. E.g. the available vessel and its equipment (davit, winch, a-frame...) will impose limits to sizes and weights can be used. Ease of manipulation and available (cheap) manpower will determine the ease to deploy. The size of the survey area determines the relative importance of time needed to calibrate the sensor.

Furthermore, the size and weight of the instrument determines the penetration depth. The type of instrument determines the density range. And the choice of the instrument will set its accuracy and its area's op application.

Finally, it must be stated that different hydraulic conditions will lead to different measuring conditions, were different instruments have different characteristics. 


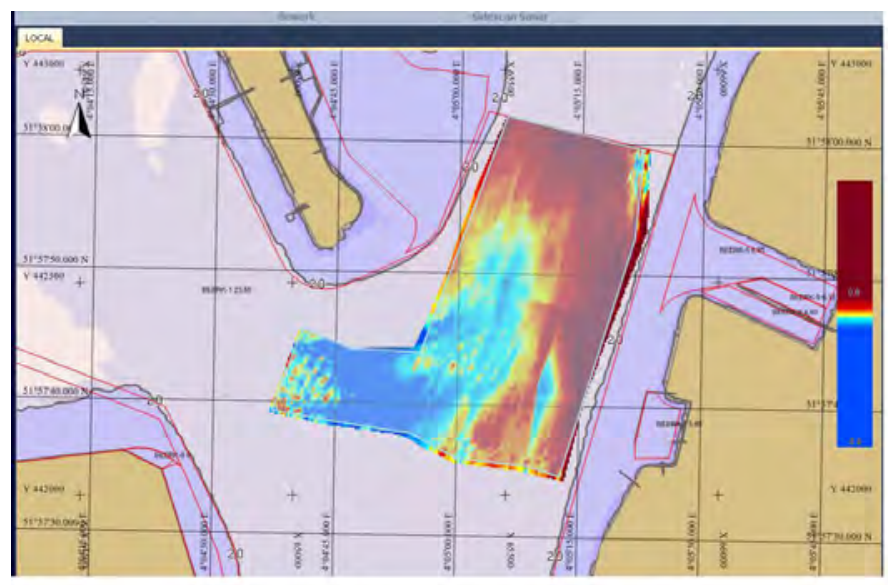

Figure $2 \mathrm{a} 1.2 \mathrm{~kg} / \mathrm{l}$ corrected survey using interpolated D2ART layer thicknesses (above maintenance level is colored red)

\section{FIELD TESTS}

Over the years a lot of instruments have been tested. In the last years parties focused on methods which are less labor intensive, are easy to deploy, need less operational and maintainability attention, shorten survey time and give a better spatial resolution.

For this reason recently the Silas system and the D2ART were tested at the Beerkanaal in Rotterdam by Port of Rotterdam and the Ministry of Infrastructure and the Environment

At February 23rd 2012 a comparison test was executed at the Beerkanaal. The goal of this test was to compare the measuring results of the Silas system with the D2ART system and to demonstrate the performance of the Graviprobe. The Silas system was calibrated by samples taken with a modified Beekersampler (Slib-sampler).

Figure 2 shows the comparison between $1.2 \mathrm{~kg} / 1$ corrected surveys with the two systems. The figure also shows that bottom roughness caused by dredging activities will be better covered by acoustic measurement systems instead of point

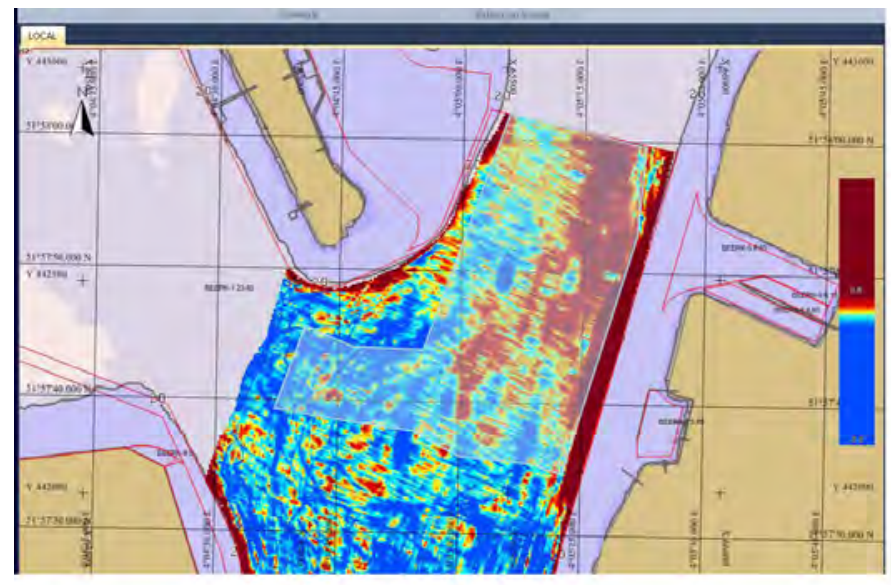

Figure $2 \mathrm{~b} 1.2 \mathrm{~kg} / \mathrm{l}$ corrected survey using interpolated Silas layer thicknesses (above maintenance level is colored red)

measurements.

The impact on the amount of mud that needs to be dredged is found in Table 2. It can be concluded that interpolated data of the D2ART system gives, on average, a slightly thicker layer above the local dredging maintenance level which results in a bigger dredging volume. The difference is partly explained by the fact that Silas measures lines and the D2ART system gives point information (Reenen, 2012).

\section{CONCLUSIONS AND FUTURE OUTLOUK}

Currently many types of instruments measuring fluid mud density, based on different measuring principles, are commercially available. A literature study and tests showed that all instruments are able to measure mud densities from 1.0 till $1.3 \mathrm{~kg} / \mathrm{l}$. But one needs to take the specific characteristics of an instrument or method into account. How the advantages and disadvantages are weighed depends on the situation and requirements by the operators and clients.

Field tests show that the amount of silt to be

\begin{tabular}{|c|c|c|c|}
\hline Survey & Volume above $\left[\mathrm{m}^{3}\right]$ & Volume below $\left[\mathrm{m}^{3}\right]$ & Layer thickness $[\mathrm{m}]$ \\
\hline \hline Multibeam & 222.335 & 1.137 & n.v.t. \\
\hline Silas & 44.911 & 55.531 & 0.12 \\
\hline D $^{2}$ ART & 68.373 & 51.780 & 0.19 \\
\hline
\end{tabular}

Table 2. Required dredging work based on measurements. 
dredged depends on which density measurement system is used. The absolute density measurement accuracy will have influence on the dredging amounts. Bottom roughness caused by dredging activities will be covered better by acoustic measurements systems instead of point measurements.

At the moment the Port of Rotterdam is using a Silas system, calibrated by mud samples. The Dutch governments employs nuclear probes, but is investigating new methods of determining the 1.2 $\mathrm{kg} / \mathrm{l}$ layer (in-situ and by acoustics) and is studying on new definitions of navigability. This is also the situation in Belgium.

\section{REFERENCES}

Claeys, S., De Schutter, J., Van Hoestenberghe, T., Van Eerdenbrugh, K., Mostaert, F., Sediment Test Tank. Beheersvraag no 1 \& 2. Martitieme Toegang, Not yet published

Claeys, S., Rheology as a survey tool, Hydro International, May-June 2011 Volume 15 number 3 (http://www.hydro-international.com/issues/articles/ id1264-Rheology_as_a_Survey_Tool.html)

PIANC, Approach Channels A Guide for Design, Final report of joint PIANC-IAOH working group II-30 in cooperation with IMPA and IALA, 1997

Paul, S., Hagendoorn, I., Addendum op rapport Advies Slibdichtheid, Ministerie van Infrastructuur en Milieu, Rijkswaterstaat, 2011

Reenen, J.J.J. van, 1.2 dichtheidmeting Beerkanaal - vergelijking Silas - D2ART - Graviprobe, Port of Rotterdam, June 2012

Vos, S., Krans, R., Dierikx, B., Advies slibdichtheidmeter, Ministerie van Infrastructuur en Milieu, Rijkswaterstaat, December 2010

\section{BIOGRAPHIES}

Styn Claeys has a Master in Geology. As project manager an researcher he has experience for already 15 years in sediment related research. From 2008 till the present day he executes and leads a project (client: the Flemish Government, detached from
Gems Group) called "Sediment related nautical bottom research" at Flanders Hydraulic Research.

Ben Dierikx has a Master in Geodesy and a BSc in Hydrography. He worked for 2 years at the Technical University Delft as a researcher. After which he started working for Rijkswaterstaat, first at the North Sea department and since 2004 at the Data-ICT Department as a specialist/advisor on Hydrography.

Simon Paul has a Master in Control System Engineering and a BSc in Environmental Science. Simon has 15 years of experience in both the Industrial and "natural" (the environment) world. He is employed at Deltares and has worked on several hydro projects for the Dutch Ministry of Infrastructure and the Environment.

Jeroen van Reenen has a BSc Hydrography from the in Nautical collage Amsterdam. He started as hydrographic surveyor for Boskalis and is currently employed as a project manager Hydrography for the Port of Rotterdam and has his own company, Van Reenen HydrographX.

\section{CONTACT DETAILS}

Ben Dierikx

Rijkswaterstaat Data-ICT-Dienst

Derde Werelddreef 1

2622 HA Delft

The Netherlands

Tel.: (+31)152757296

Fax: $(+31) 152757576$

Email: ben.dierikx@rws.nl

Web site: www.rijkswaterstaat.nl

\section{4 | Hydrol2}




\title{
The Progression of Multi-Dimensional Water Column Analysis in a Processing Environment
}

\author{
Corey M. COLLINS, P.Eng, Canada \\ CARIS
}

Topic: Innovations in processing techniques

\section{INTRODUCTION}

With the ever-increasing availability of CPU processing power and data storage, multibeam sonar systems used for shallow water surveys are now capable of collecting full water column imagery data. This imagery is being used by post processing software as a way to supplement bottom detection results, often for the purpose of detecting the shoalest parts of obstruction such as ship wrecks.

This paper will describe how water column imagery can be interrogated as part of an integrated bathymetric processing workflow. It will highlight tools and techniques that can be used in conjunction with standard swath analysis for the purposes of least depth detection. Perhaps more interestingly it will also describe how water column imagery can be represented in a 3D environment using the latest point cloud processing and visualization techniques. By representing water column imagery as a point cloud it becomes much easier to determine, shape, extent and volume of features in the water column.

Further to the reading and display of the water column data, the ability to interrogate water column data in an effort to add it as a supplement to existing bathymetric data will be described. The ability to incorporate post-processed data such as TrueHeave or SBET information from POSPac as well as the ability to compute total propagated uncertainty using real-time uncertainties allows the water column data to be fully and robustly integrated into existing bathymetric processing workflows.

\section{WATER COLUMN IMAGING}

Even though water column imaging was originally developed primarily for fisheries, today's technical and financial pressures to extract as much information as possible from hydrographic data makes water column data an obvious fit in the industry. Access to this data in post processing

software provides significant advantages for hydrographic data quality control [Hughes Clarke et. al., 2006].

With the release of HIPS 7.1.1, the reading and the displaying of water column Imagery was added. Initial support for WCI includes Kongsberg (.all, .wcd) sonars and Reson 7K (.s7k) sonars. The data can be read and displayed as a curtain image in Swath Editor, as well as read and displayed as a 3D point cloud in Subset Editor. The data as displayed can then be used to help aid the Processor in making decisions with regards to the bathymetric data. Whether it is the ability to verify valid or invalid data or the ability to identify areas of additional interest in regards to further investigation or even re-survey [Collins, 2012]. As development has progressed with the WCI implementation and with the release of HIPS 8.0, the user is now able to utilize the WCI as a supplement to traditional bathymetry.

\section{CARIS HIPS}

With a proven reputation of being a comprehensive bathymetric data cleaning and validation tool, it is only fitting that CARIS HIPS allow users to read, visualize, and utilize WCI data in a multidimensional environment. With proven automated data cleaning filters and algorithms, which assist in today's high data volume environments, WCI is a great addition to the work flows currently available in the application.

When first approaching this initiative, the goal was to implement Water Column Imaging within HIPS is such a way that it would be useful for a variety of applications. Examples include, quality control of bottom detections, least depth determination, $3 \mathrm{D}$ visualisation of water column data, volume calculations, environmental monitoring, detecting gas seeps, etc. Due to the size and complexity of the development effort, the initiative was broken down into five phases; 1) read WCI data, 2) display WCI data in Swath Editor, 3) display WCI data 
in Subset Editor, 4) ray-trace water column data, and 5) additional processing of WCI data [Collins, 2012]. With the release of version 7.1.1 in early 2012, users have seen the implementation of the first 3 phases. As the WCI initiative progresses, phase four will be released in version 8.0 late 2012 . Phases five will be tackled post version 8.0 and released to users as they become available.

\section{$\underline{\text { Swath Editor }}$}

Over the last five to ten years we have seen a decrease in the line by line editing techniques and a dramatic increase in the directed editing approach within post processing software. However, there is still value in having access to a line by line editor, such as the Swath Editor in an effort to $\mathrm{QC}$ and troubleshoot the data when issues arise. With that said the ability to view the WCI data in a 2D line by line editor is seen as beneficial and is a great addition for quality control and detailed investigation [Collins, 2012]. In order for the WCI data to be viewed in Swath Editor, the data as recorded in the raw data file has to be mapped into a two-dimensional near-vertical plane with respect to the transducer. This involves transforming the data from polar to Cartesian coordinates [Hughes Clarke, 2006].
With the ability to read the WCI and the transforming of the data to Cartesian coordinates, Swath Editor now has the ability to display individual polar plots (across track image) of WCI data associated with a specific profile as well along track image associated with the nadir beam. The user is able to step through these WCI images, in the Across Track, on a profile by profile basis. The view can also be stacked where all images are stacked one on top of the other with the highest intensity value showing through. This option provides a representation of all WCI data within the Plan view as opposed to one profile at a time. The Along Track view can be stacked as well, where all beams within a profile are stacked one on top of the other with the highest intensity value showing through.

These views can be utilized to validate what is being presented in the bathymetry. To add to these views, the bottom detections can be displayed, which allows for easy comparison of how the bathymetry relates to what is present in the water column imagery. This could potentially highlight what the sonar missed in the water column, as well as aid the decision of whether the bathymetry is valid or not. Should the need arise, where there is important information within the WCI data that is not present in the bathymetry, the user has the ability to select the desired WCI information and add it as additional bathymetry as seen in Figure 1.

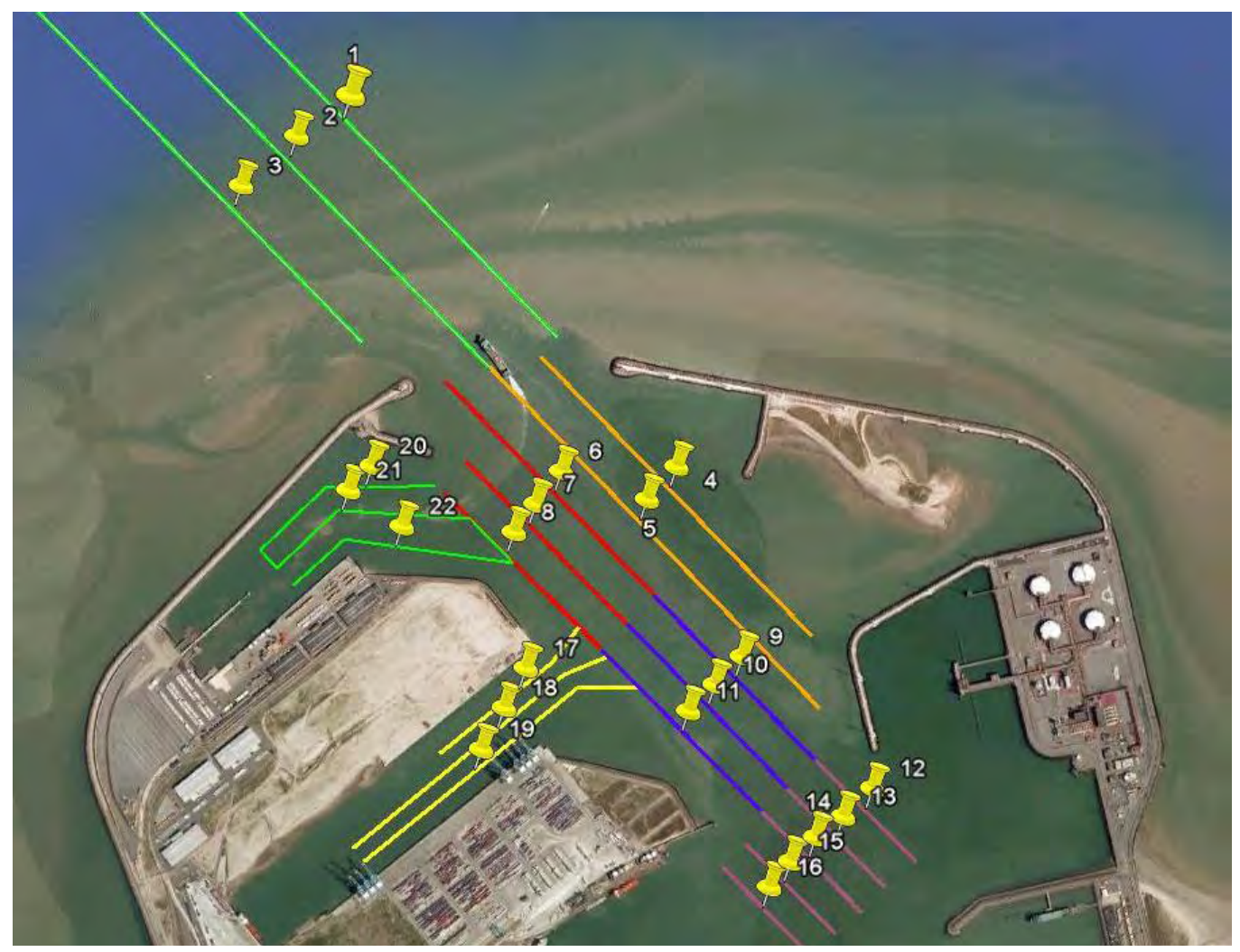

Figure 1: A selection of water column data in Swath Editor to be added as additional bathymetry.

\section{6 | Hydrol 2}


All existing options and functionality within the current Swath Editor, where relevant, have been connected with the WCI views to keep work flows consistent and familiar. Functionality such as colouring, selection of bottom detections, querying of bottom detections, editing of bottom detections as well as editing the additional bathymetry can be carried out in both the WCI views. Furthermore, all views update to indicate changes made in other views.

\section{$\underline{\text { Subset Editor }}$}

With the shift of data editing from a line by line approach to an area based directed editing approach; it was deemed critical that the WCI data could also be displayed in 3D space with the bathymetry. The Subset Editor, like the Swath Editor, also has the ability to load and display Water Column data, but in this case, as a geographically referenced 3D point cloud. Since CARIS has implemented a sophisticated 3D point cloud data structure that can store billions of multi-attributed 3D points, a perfect container for the WCI data in 3D space already existed. This technology has been leveraged to load and display the water column data seamlessly into this area based editor [Masry et. al., 2009].

The key to displaying the data in 3D space is to translate the water column data from a vessel referenced $2 \mathrm{D}$ plot to a $3 \mathrm{D}$ geographically referenced point cloud. This has been done by taking the WCI data and automatically pushing it through the standard processing workflow (vertical adjustment, svc and merge) to reference the data geographically with respect to the same coordinate system as the bathymetry. Like the swath Editor, should the need arise, if there is important information within the WCI data that is not present in the bathymetry, the user has the ability to select the desired WCI information and add it as additional bathymetry as seen in Figure 2.

All existing options and functionality within the current Subset Editor, where relevant, have been connected with the WCI display to keep workflows consistent and familiar. Functionality such as colouring, point size, etc. can be used to alter the display of the bathymetry as well as the WCI data coupled with the ability to edit the additional bathymetry.

\section{ADDITIONAL BATHYMETRY}

In order to allow the user to utilize the water column information as data with position and depth, it was decided to leverage again the CSAR point cloud. What the user can expect to see here is an additional data source contained within the HIPS project labeled as additionalBathymetry as seen in Figure 3. With the desired information within the water column isolated and added to the additional

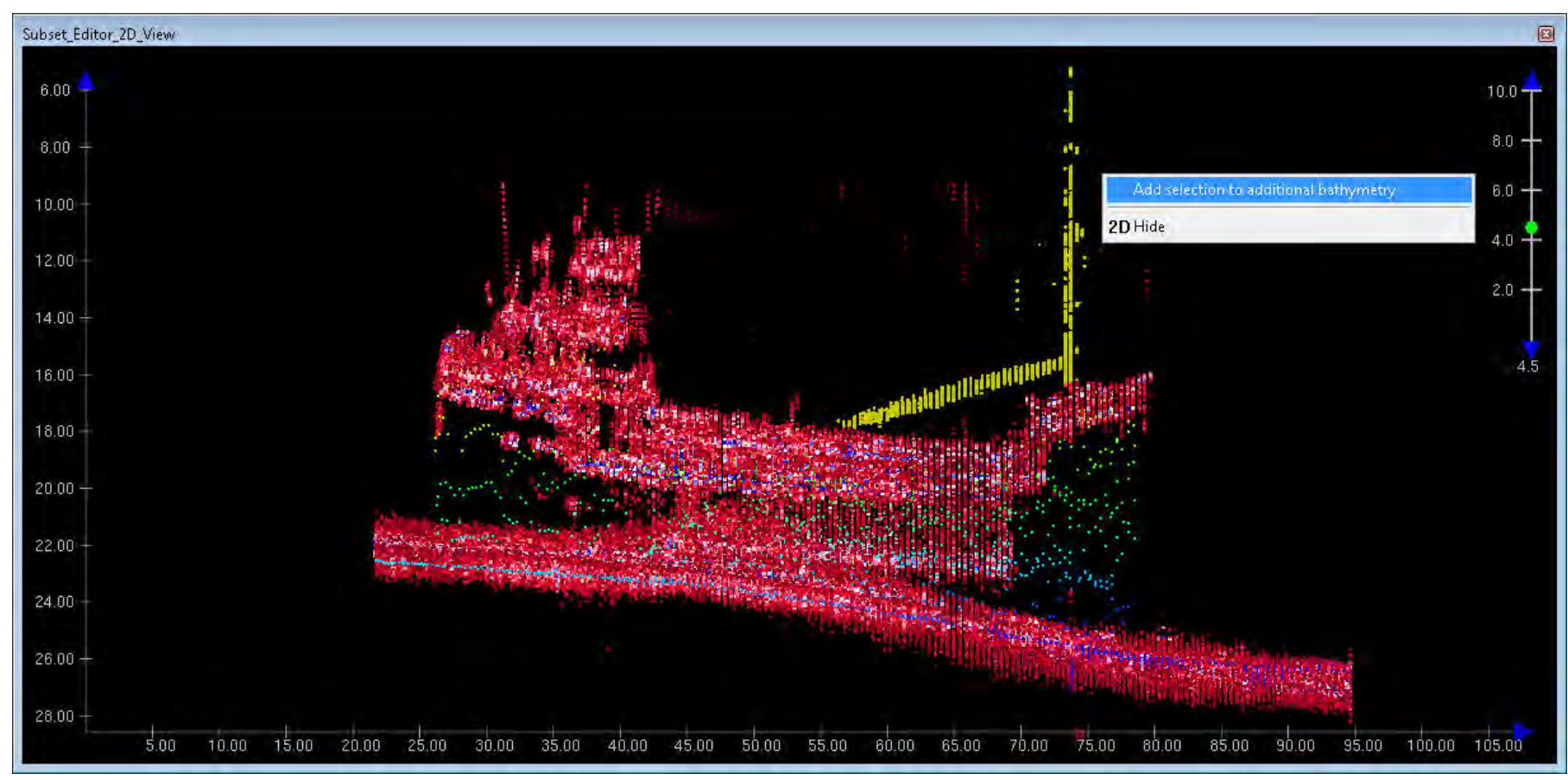

Figure 2: User can now interrogate water column data in Subset Editor and add it as additional bathymetry. 
bathymetry layer from either the Swath or Subset Editor, the user now has the ability to utilize this in the existing workflows. Once the user has decided that the information is of relevance and is required for a more complete representation of the submarine landscape, the data becomes available for things such as editing, uncertainty computation and surface creation.

As with the standard bathymetric workflow that currently exists in HIPS, the water column data that has been added to the additional bathymetry layer will be processed in the same way. Once the water column data has been selected and added to the additional bathymetry, the same processing options that have been applied to the bathymetry will be applied to ensure a properly geo-referenced point cloud of WCI data. These processes include proven ray tracing techniques (i.e. cone-cone intersection, Kongsberg supplied SVC dll) utilizing dynamic attitude data or post-processed attitude information such as a TrueHeave or SBET solution from POSPac. It also includes vertical adjustments such as traditional tide or GPS tide as well as positioning the data utilizing standard as well a post-processed gyro and navigation data.

Once the WCI information has been properly geo-referenced as a point cloud it then becomes available for further processing such as your standard editing (accept, reject, designate, etc.) in the bathymetric editors. Furthermore, if desired, uncertainty information can be computed for the additional bathymetry and in turn utilized in surface creation such as CUBE. With the progression of the implementation of water column processing in a multi dimensional environment it can now be seen how water column data can be fully and robustly integrated into existing bathymetric processing workflows.

\section{CONCLUSION}

With the use of WCI by post processing software such as CARIS HIPS, it is apparent that this data can be used in a way to supplement bottom detection results. As this paper describes, the incorporation of water column data with bathymetry also provides a more complete representation of the submarine landscape as a whole and as such has the potential to allow multibeam data to be used for many non-traditional applications.

This paper has also described how water column imagery can be interrogated as part of an integrated bathymetric processing workflow in CARIS HIPS. It also describes tools and techniques that can be used in conjunction with standard swath analysis for the purposes of visualization and quality control. It has also been shown how water column imagery

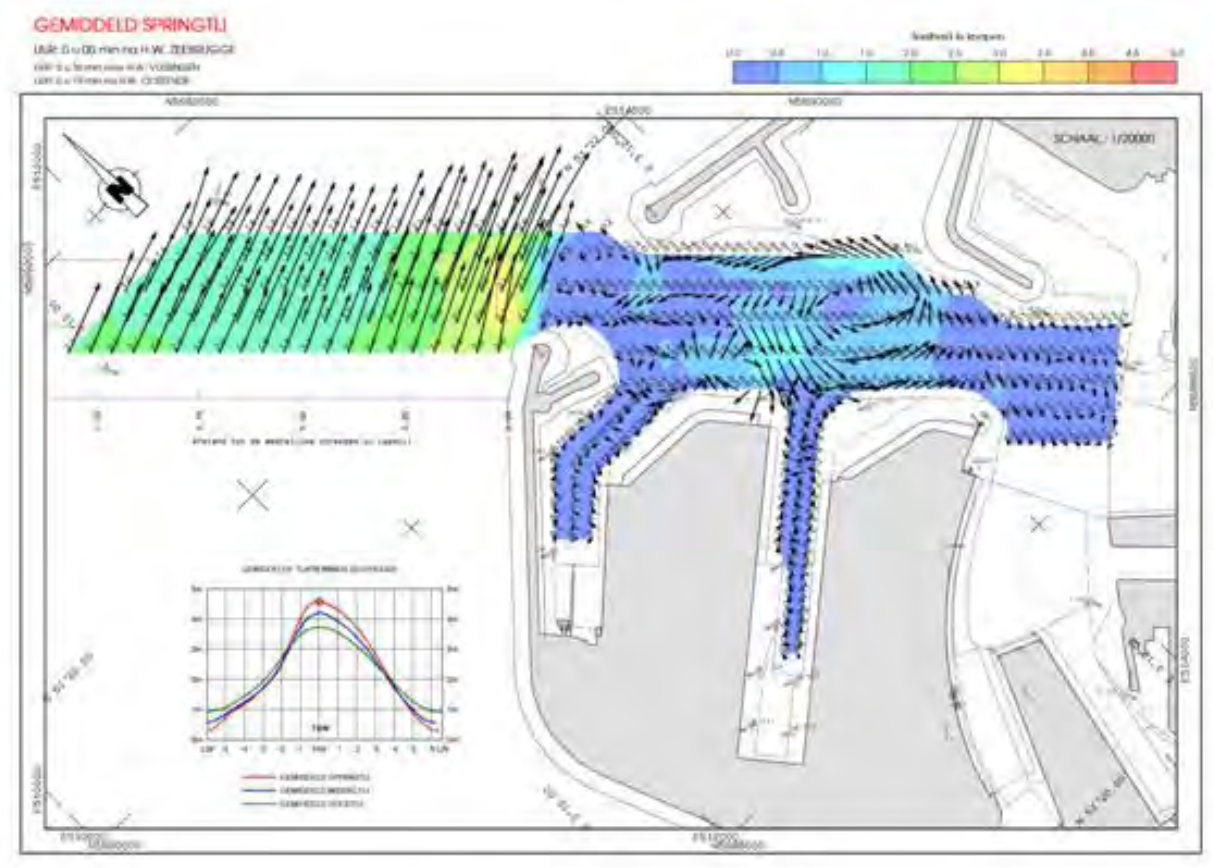

Figure 3: Additionally bathymetry layer leverages the CSAR point cloud technology to allow the WCI data to be utilized in standard processing workflows. 
can be represented in a $3 \mathrm{D}$ environment by using the latest point cloud processing and visualization techniques. Further to this it has been shown how the progression of this initiative in a multi dimensional environment has allowed the water column data to be fully integrated into existing bathymetric processing workflows utilizing the same processing options as applied to the standard bathymetry.

\section{REFERENCES}

Collins, C. (2012). "Multi-Dimensional Water Column Analysis as a Catalyst for Sustainable Hydrographic Survey." Presented at Shallow Survey Conference, 2012.

Hughes Clarke, J.E., Lamplugh, M., Czotter, K. (2006), "Multibeam Water Column Imaging: Improved Wreck Least-Depth Determination." Presented at Canadian hydrographic Conference 2006.

Hughes Clarke, J.E. (2006), “Applications of Multibeam Water Column Imaging for Hydrographic

Survey.” The Hydrographic Journal April, 2006.

Kongsberg, EM2040 Dataset (2011), Data provided courtesy of Canadian Hydrographic Service.

Kongsberg, EM3002 Dataset (2006), Data provided courtesy of John Hughes Clarke, OMG UNB, Canada.

Masry, M., Schwartzberg, P. (2009), "Marine High Density Data Management and Visualization." Presented at the seminar for Management of massive point cloud data: wet and dry. November 26, 2009.

Shallow Water Common Dataset (2012), Data collected for the 2012 Shallow Water Conference, February 2012.

\section{BIOGRAPHY}

Corey M. COLLINS, P.Eng. CARIS HIPS \SIPS $\backslash$

Notebook Product Manager. Received a Bachelor of Science in Engineering from the University of New Brunswick's Geodesy and Geomatics Program.
Before joining CARIS he worked in Hydrography as well as Marine Geophysical Surveying. Professional Engineer with the Association of Professional Engineers and Geoscientists of New Brunswick (APEGNB), Canada.

Corey M. COLLINS

CARIS

115 Waggoners Lane

Fredericton

CANADA

Tel.: +1-506-458-8533

Fax: +1-506-459-3849

Email: corey.collins@caris.com

Web site: www.caris.com

LinkedIn account: http://www.linkedin.com/ groups? mostPopular $=\&$ gid $=3217878$

Facebook account: http://www.facebook. com/pages/CARIS-The-Marine-GISExperts/123907500987669

Twitter account: twitter.com/CARIS_GIS 
$40 \mid$ Hydrol2 


\title{
Backscatter "From Ping to Database", a Canadian Hydrographic Service perspective
}

\author{
Roger CÔTÉ, Louis MALTAIS and Richard SANFAÇON, Canada \\ Canadian Hydrographic Service
}

Topics: Innovations in processing techniques, Smart data management, Easy customer access to data and products

\section{INTRODUCTION}

The Canadian Hydrographic Service (CHS) is planning to make a better use of the backscatter intensity data collected with their multibeam sounding systems. All the backscatter data collected during the last 2 decades were not systematically processed and maintained, so a lot of valuable information has not been used yet and is archived on tapes and disks. The intent of CHS is to make an inventory of this data and to process it to a minimum level so that it can be made accessible to its cartographers and to the scientific community.

A team of hydrographers from the Canadian Hydrographic Service, Quebec Region office, have produced a poster poster showing a potential dataflow which may serve as a guideline for future processes and tool development related to backscatter data.

\section{BATHYMETRIC PROCESSING and MULTI-RE- SOLUTION}

The implementation of CUBE (Combined Uncertainty and Bathymetry Estimator) in the Caris Software Suite had an important positive impact interms of processing time and data handling philosophy as we now see a dataset as a whole instead of a series of dots. In the past, the final extract of the dataset was mainly determined by the manageability of the data in the cartographic processes. With today's technologies, it is now possible to manage large volumes of data and bathymetric surfaces are now created at their optimal resolution (best extract of a dataset based on the sounder footprint and sounding density) independently from the cartographic process.

In order to obtain the most from CUBE, the number of soundings per cell is critical and must be perfectly balanced. With too many soundings,
CUBE may "forget" shoals and on the contrary, with not enough soundings, CUBE may "accept" outlier data. In large depth range areas, the use of a single resolution is not desirable as the sounding density varies with depth. Multiresolution is a key element in the future bathymetric data processing as it will help to get the most out of the data.

As they come from the same sounding system, the bathymetric and backscatter data are strongly linked. They should therefore be kept together in the final processing stage. Merging these 2 entities will greatly facilitate data management and data accessibility. A solution is to include the backscatter intensity layer in the bathymetric surface set of layers (.csar dataset).

CHS is in the process of loading its source and chart data in Caris BDB and HPD databases. At the end of this process, continuous maintenance will make the product generation faster and easier. All the new multibeam data sent to the bathymetric database will contain the final merged bathymetric and backscatter data surfaces.

\section{BACKSCATTER PROCESSING and BASIC SE- AFLOOR CLASSIFICATION}

It is widely recognized that producing one specific seafloor classification may not be suitable for all applications. The intent of CHS is to extract the best information from their sounding systems and make it accessible to its cartographers and to whoever may be interested in this valuable source of information. The bathymetric-backscatter data layers would be a starting point for enhanced seafloor classifications.

For many years, the processing of backscatter data signal has been in constant evolution and some concepts are promising. The implementation of these concepts in the processing tools is not yet 


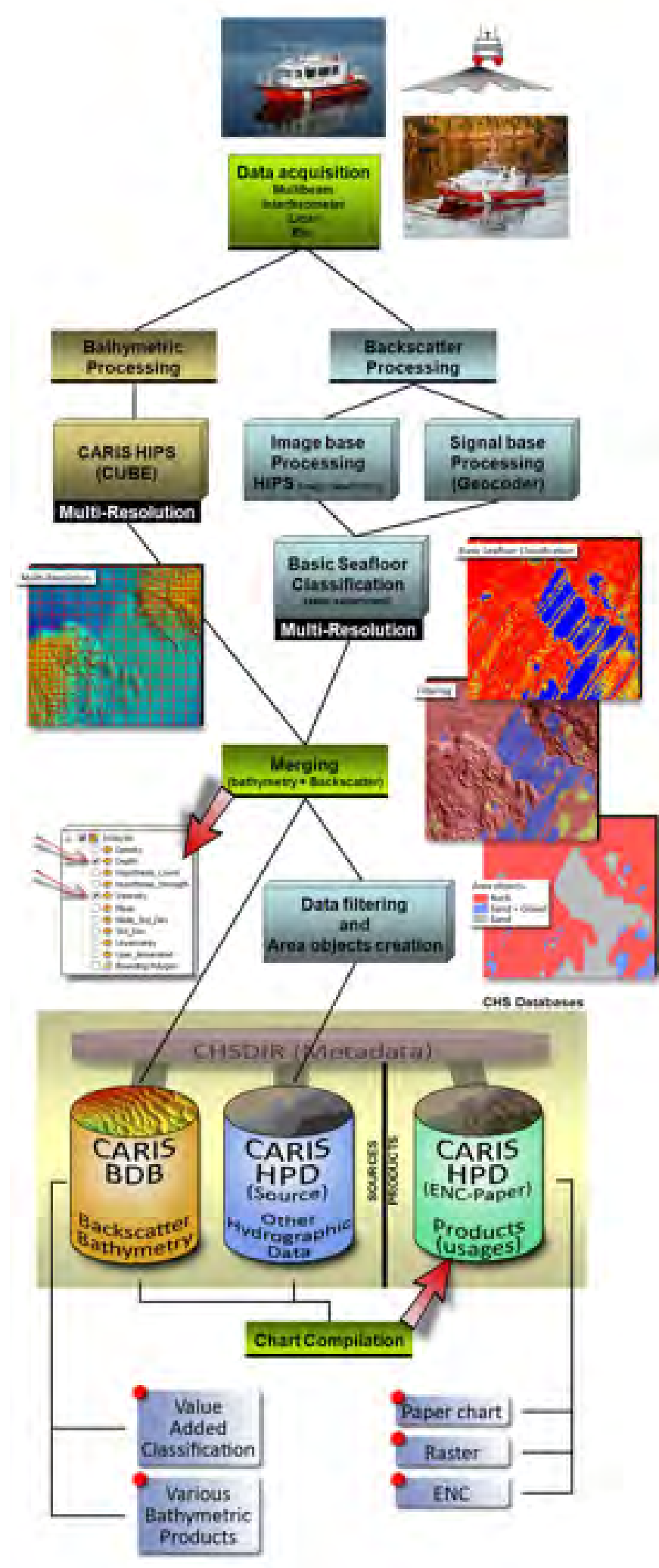

always reliable. Once again, CHS is willing to take the best out of the backscatter intensity data, including the resolution and the resulting backscatter values. The 2 processing paths available at this time are the signal base and the image base processing. CHS's intent is to experiment Caris HIPS Geocoder module to process the backscatter, and the implementation of the tool within the Caris software is in the process to be refined.

CHS's willingness to use the potential of the data collected while surveying, will result in producing, for its own use "Basic Seafloor Classification" (BSC) datasets. The idea of this BSC is to bring the data at the same level of processing. Data cleaning and adjustment will be based on a minimum bottom sampling and seafloor type classification (CHS Chart \#1, for ex. Rock gravel, sand, mud). The resulting surfaces will be loaded in the bathymetric source database.

One objective of the backscatter data processing and management is to find a way to bring the backscatter layer information on the official CHS products. Nature of Surface (NATSUR attribute) can be extrapolated from the Basic Seafloor Classification in the form of S57 area objects SBDARE (Seabed area). This area object creation process could be done manually at this time, but must be done automatically in a near future. The result of this process will be a series of seabed classification areas in the HPD source database available for the final products.

\section{CONCLUSION}

With the increase of backscatter data collected by a range of sounding systems, this process will help CHS to significantly improve its backscatter data management and accessibility. Backscatter will be systematically processed and used in the cartographic products as area objects instead of point features which is a giant leap in hydrographic seafloor characterization practices. In line with CHS's will, this process will remain valid when calibrated backscatter data will be available.

CHS has the intention to work toward this goal and make sure all those valuable returns from the pings are brought into its databases and products. It will then lead to a better and more complete delivery of 
seafloor information to the mariners and chart users. This is not only useful for navigation but also for sustainable development with respect to the environment, and therefore helping taking care of the sea.

\section{BIOGRAPHIES}

Roger CÔTÉ has been working for the Canadian Hydrographic Service for 27 years . He is Project manager with the Quebec Region's Hydrographic Operation Division, responsible for hydrographic survey projects and chart production projects.

Louis MALTAIS has been working for the Canadian Hydrographic Service for 15 years. He is a project ingeneer involved in numerous R\&D projects, implementing solutions to improve productivity, efficiencies and to better meet the clients' needs.

Richard SANFAÇON has been working for the Canadian Hydrographic Service for 33 years. He is manager of the Quebec Region's Hydrographic Operations, responsible for hydrographic surveys and marine charts production.

\section{CONTACT DETAILS}

\section{Richard SANFAÇON}

Canadian Hydrographic Service

Institut Maurice-Lamontagne

C.P 1000, 850 de la Mer

Mont-Joli

CANADA

Tel.: 418-775-0517

Fax: 418-775-0654

Email: richard.sanfacon@dfo-mpo.gc.ca

Web site: www.cartes.gc.ca 
44| Hydro 12 


\section{Hydrographic Training in Belgium}

Marc DAUWE, Micha LIBERT and Axel ANNAERT, Belgium

Antwerp Maritime Academy

Topics: Hydrography in the Benelux, The hydrographic profession

\section{INTRODUCTION}

Nautical charts for mariners, tidal predictions and information on changes in navigational areas are indispensable to the global merchant marine, and offshore, dredging and underwater projects. Collecting data on the world's oceans and seas is the responsibility of hydrographers. Their expertise is essential to modern society and economic systems, underlining the importance of quality education in this field.

Recent survey studies in the Netherlands ${ }^{1}$ and Belgium $^{2}$ however, have pointed to a weakness in hydrographic training in both countries, with a shortage of both suitable programmes and institutions offering such training. In Belgium, most hydrographers are engineers who are trained within a company. This implies a potentially unnecessarily long period of training before they are fully employable as hydrographers ${ }^{3}$.

A market study on hydrographic surveyors in Belgium revealed that over 300 hydrographic surveyors are active in Belgium, of whom a large portion are not certified. Moreover, the industry would need another 35 new hydrographic surveyors annually. With this in mind, the present system of companies using in-house training of existing engineers risks inefficiency, as well as missing the benefits of a healthy academy in support of the industry. Investigations on a global scale underline the shortage in hydrographic surveyors even further ${ }^{4}$.

Only few institutes in Europe offer programmes in hydrography, especially in English or the advanced category. In such a globalised set of industries as professional hydrographic expertise is required in, the lack of adequate training in English at the highest level represents a serious weakness. The Antwerp Maritime Academy (HZS) responded to the growing need with postgraduate programmes in hydrography. The institute established the postgraduate programmes Cat. B and Cat. A.

\section{METHODS}

History and the establishment of a programme

Some situations underlined the need for a proper programme in hydrography. The continuous interest in the introductory course in hydrography at the HZS, and the results of the market research, indicating a deficiency in top level professional qualification and certification, revealed a niche for setting up the first full programme of hydrography in Belgium.

The HZS organised a round table discussion concerning the absence of proper education for professional hydrographers. Several higher education institutes, Flanders Hydrographic Services, Flanders Hydraulics and the industry attended the discussion in March 2010. The conclusion of the meeting was clear: there is a need for hydrographic training in Belgium and the new programme should put a strong emphasis on international recognition and accessibility.

During several meetings over the course of two years, continuous deliberation led to the definition of the programmes. The entry requirements and duration of the courses were also discussed and

\footnotetext{
${ }^{1}$ Annelies Claeys, "Rapport hydrografieonderzoek" (Ma diss., Ghent University, 2009).

${ }^{2}$ Rodrigue Bijlsma, "Hydrografie" (Ba diss., Antwerp Maritime Academy, 2011); Rodrigue Bijlsma, "Hydrografie. Het in kaart brengen van de Belgische hydrografische sector, de Europese IHO gecertificeerde opleidingen en Het Institute For Hydrography" (Ma diss., Antwerp Maritime Academy, 2012).

${ }^{3}$ Bijlsma, "Hydrografie. Het in kaart brengen van ...", p. 83.

${ }^{4}$ Ibid.
} 
finalised, allowing lecturers to be identified and commissioned. Throughout proceedings, the flexibility of the course was held as the key criteria for the success of this new training programme.

As a result of careful management the postgraduate programmes were established by the HZS in close collaboration with Ghent University (UGent), Flanders Hydraulics, and partners from the maritime industry. The official launch of the 'Institute for Hydrography' within the HZS took place in March 2012.

\section{Programme}

The postgraduate programmes in hydrography were established in full accordance with the IHO Standards of Competence S-5: a category B programme for hydrographic surveyors and a category A programme for chief hydrographic surveyors. Both programmes consist of a two year training course, during which the HZS provides a solid theoretical framework complemented by practical and hands-on experience.

The timetables of the two, 2 year postgraduate programmes in hydrography run along similar lines. The first semester consists of 14 weeks of theory courses followed by examinations in January. This theory is then put into practice during a semester of practical projects, workshops, seminars and visits during which the students are rotated between different organizations, both industry practitioners and training establishments.

This approach provides the students with the opportunity to put their theoretical framework to good use in a practical environment. After successfully finishing this year of the programme, students are awarded a declaration.

The second year focuses on fieldwork at a company or institute, from amongst the partner organizations, to further develop the student's practical skills.

During this year students experience real work as a hydrographer and prepare themselves thoroughly for their future careers.

After completion the student receives a category $\mathrm{B}$ or category A certificate depending on the programme they have been following.

\section{Quality and certification}

The Antwerp Maritime Academy is certified ISO 9001:2008 . All activities of the Institute for Hydrography are incorporated into the Maritime Academy's quality system. As such, the school

\section{- Theory: lectures \\ 1 sem \\ - Sept. - Dec., examinations in Jan. \\ - Practice with partners Belgian industry 2 sem - Feb. - May, evaluation in June}

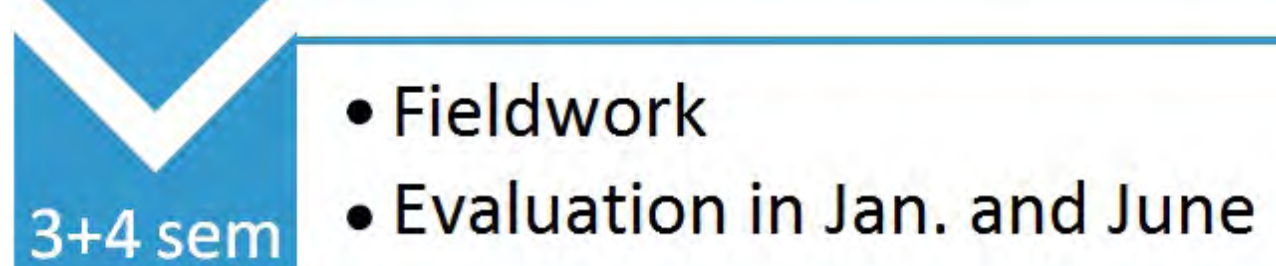


vouches for the high quality and excellence of its students, including hydrography postgraduates.

A crucial element that grants accreditation and lends validity to a programme and certification such as this one is its acknowledgement by an institution of note, respected in the field. The HZS is in the process of acquiring acknowledgement by the International Hydrographic Organization (IHO) in Monaco, the authority in the field of hydrographic survey. This vital recognition will allow the programme to fully develop its reputation through excellent training, and to be at the forefront of development in the industry.

To continuously monitor the quality of the programme, an interactive correspondence with students and industry has been made an integral part of the programme. This results in a constant upgrading of the course and practical training, keeping all aspects of the programme fully up to date and on the leading edge of industry methods and thinking. For this purpose a steering council has been established within the Institute to ensure quality and innovation. The steering council is responsible for decision-making, oversight, monitoring and follow-up of the programmes.

Furthermore all courses are delivered by lecturers expert in their fields. The cooperation between the different partners allows specific knowledge and skills to be taught by those individuals best qualified to do so; leaders in their fields. The collaboration between the HZS and UGent results in an immediate concentration of collective knowledge and experience, which enables it to become one of the leading institutes of hydrography globally.

\section{Compatibility and Flexibility}

Candidates for the postgraduate programme cat. $\mathrm{B}$ are required to present a Bachelor's degree. There is no field of study specified so any Bachelor can be admitted. Candidates have to prove their knowledge of Mathematics and Physics, as well as sufficient English proficiency. The knowledge of basic sciences is essential as science is the basis of most courses and this minimum of scientific accomplishment should be established at the beginning of the course.

Participants with relevant competences may be eligible for exemptions for certain modules. Based on documentary proof, the extensive application portfolio and personal interviews, a selection committee decides on exemptions for each candidate on an individual basis.

The programme structure allows the students great flexibility. Because of the modular system, the theoretical courses take place during the first semester of the first programme year. The second, third and fourth semester consists of fieldwork, during which the students engage in a specialized placement in the industry as trainees.

STCW educational decrees enable already active hydrographers to take up a flexible and individual curriculum. The candidate can choose to extend the programme courses over a period of maximum five years, thus allowing part-time work at one's own pace. This serves to ensure as seamless as possible an integration between existing in-house training arrangements and a more institution based approach.

\section{HYDROGRAPHY AT HZS}

The HZS as an educational institution focuses on the future with a scientific and innovative approach. Its aim is to provide outstanding programmes that answer to both the institute's standards and the international IHO standards of competence. Establishing a course in hydrography and meeting the demands of both the industry as well as the professional-to-be, was therefore a logical step. In addition to freeing up industry training resources and streamlining the process of becoming a hydrography professional, the benefits of centralised, concentrated yet easily accessible expertise are not to be underestimated.

Only a few institutes in Europe offer English language programmes in hydrography. With English as the course language, we are able to accommodate

\footnotetext{
${ }^{5}$ ISO 9001 are a set of standardized requirements for a system of quality control employed by a firm or institution. More info on www.iso.org.
} 
students from all over the world. With this, the Antwerp Maritime Academy underlines another element of its mission: international purveyance of education.

Continuous quality control and upholding high standards is a priority. The HZS pays extra attention to partnerships to safeguard the excellence of its training programmes. With a team of experts from academic and industry backgrounds, supported by specialized equipment, students receive a solid theoretical framework. The negotiated training opportunities enable students to practice their learnt skills in a professional environment, ensuring graduates are in the best possible position to thrive as hydrographers from the start of their careers.

Students can create an individual curriculum and study relevant subjects at a time most convenient and sensible for them in relation to their individual studies. Students may be eligible for exemptions from particular modules when they have previous knowledge or experience in a field. To ensure an open, international approach and increase accessibility, all courses are taught in English. This flexibility puts the programmes in an exceptional position to cater for students and active hydrographers alike.

\section{PROSPECTS}

The delivery of certified and capable hydrographers is the principle aim of these educational programmes. For a field that is in constant need of qualified people, in a country lacking any hydrographic training, the creation of the postgraduate programmes is a direct solution to the problems of this demand.

During the start-up of both programmes, its workings are closely monitored to evaluate and improve processes. The partnership with other educational facilities and interested parties within the maritime sector will ensure constant feedback and keep the training relevant at all times. At the same time the documentation needed for IHO accreditation will be finalized in order to validate the certificates issued by the HZS.

In the coming years the HZS envisions that the hydrography programmes will be promoted amongst students, interested people and people that are already active in the field. Academically, the postgraduate programmes would evolve towards a more standard academic structure to become more embedded and accepted as a field of study.

In the long run, the programmes aim to contribute to hydrographic institutions, the participating industry and the international nautical community as a whole. By employing high standards, the HZS aspires to deliver competent professionals, help build on the quality of education and make sea and subsea activities better and safer.

\section{CONCLUSION}

Hydrography is an important field that should not be neglected by academic institutions, which through close links with industry are uniquely placed to drive forward expertise in this field. The demand for certified hydrographers calls for a programme that can provide this highly qualified personnel trained for the specific and demanding task at hand.

In just two years Belgium has gone from an optional introductory master course to a fullfledged programme with the collaboration of higher education institutes, governmental bodies and the industry itself. The quality, flexibility and international allure of this course provides present and future candidates from any background with an attractive set of skills and prospects.

The aim of the HZS is to equip their students with the necessary knowledge and abilities to become competent and confident hydrographic surveyors. Extensive practice and fieldwork combined with an approved theoretical framework will enable graduates to successfully pursue their professional careers in the hydrographic field.

\section{REFERENCES}

Bijlsma, Rodrigue. "Hydrografie. Het in kaart brengen van de Belgische hydrografische sector, de Europese IHO gecertificeerde opleidingen en Het Institute For Hydrography." Ma diss., Antwerp Maritime Academy, 2012.

Bijlsma, Rodrigue. "Hydrografie.” Ba diss., Antwerp Maritime Academy, 2011.

\section{8 | Hydro 12}


Claeys, Annelies. "Rapport hydrografieonderzoek." Ma diss., Ghent University, 2009.

International Hydrographic Organization. Standards of competence for Hydrographic Surveyors S-5.

Monaco: The Hydrographic Bureau, 2011. Accessed May 30, 2012. http://www.iho.int/iho_pubs/ standard/S-5_Ed_11.0.1_06May2011_StandardsHydro.pdf.

International Organization for Standardization. ISO 9000 essentials. Accessed June 6, 2012. http://www. iso.org/iso/iso_9000_essentials.

\section{CONTACT DETAILS}

\section{Micha LIBERT}

Antwerp Maritime Academy

Noordkasteel Oost 6

B-2030 Antwerpen

\section{BELGIUM}

Tel.: +32 32056481

Fax.: +32 32250639

Email: micha.libert@hzs.be

Web site: www.hzs.be/hydrography

LinkedIn account: http://be.linkedin.com/pub/

micha-libert/46/b46/32 
$50 \mid$ Hydrol2 


\title{
Flexible Disposal Strategy: \\ monitoring as a key to understanding and steering environmental responses to dredging and disposal in the Scheldt Estuary.
}

\author{
Davy DEPREITER and Marc SAS, Belgium \\ International Marine \& Dredging Consultants
}

Kirsten BEIRINCKX, Belgium

Flemish Government, Department of Maritime Access

Gert-Jan LIEK, the Netherlands

Ministry of Infrastructure and the Environment, Rijkswaterstaat Zeeland

Topics: Careful marine planning, Geophysics of the marine environment, Hydrography in the Benelux

\section{INTRODUCTION}

The Scheldt Estuary is an intensely shipped area, holding the fairway to the ports of Flushing, Terneuzen (the Netherlands), Gent and Antwerp (Belgium). The Port of Antwerp is one of the 20 largest ports worldwide although it is located $80 \mathrm{~km}$ inland from the estuary's mouth. The shipping lanes are continuously dredged to maintain an appropriate navigable depth.

In 2005, the third deepening of the Scheldt river was decided in the treaty between the Flemish Government and the Kingdom of the Netherlands concerning the execution of the Development Plan 2010 for the Scheldt Estuary (Ontwikkelingsschets 2010 Schelde-estuarium, OS2010). The

Development Plan 2010 describes projects and measures needed to evolve from the current state of the Scheldt to a desired state as defined in the Long Term Vision Scheldt Estuary (LTV) in 2030, and directives for the monitoring.

In the treaty it is stated that seagoing ships up to a draught of $13.1 \mathrm{~m}$ should - tide-independently - be able to navigate to and from the port of Antwerp. Among other measures, the fairway had to be (further) deepened to fulfil this purpose. In 1970, the first deepening took place: shallow parts were dredged 3 to 4 meters deeper than before. In 1995, a second deepening was carried out, allowing a ship draught of $11.6 \mathrm{~m}$ for tide-independent navigation.

The dredging works related to the third deepening of the Scheldt estuary on Dutch territory, known as the Western Scheldt, were executed in 2010. In total, 7.7 million $\mathrm{m}^{3}$ of sediments were dredged. Since then, the shoals and sills along the main shipping channel are kept to a depth of $14.5 \mathrm{~m}$ below LAT (Lowest Astronomical Tide) through maintenance dredging. It is expected that the maintenance will initially involve 11.7 million $\mathrm{m}^{3}$ of sediments and that after a couple of years, it will have decreased to about $8 \mathrm{Mm} 3$ (Consortium Arcadis-Technum, 2007).

\section{THE FLEXIBLE DISPOSAL STRATEGY}

The aforementioned treaty includes a clause in which it is stated that a flexible disposal strategy has to be carried out, in order to preserve the physical system characteristics within its natural dynamics. This strategy has to include the close monitoring of the morphological evolution of the system to allow for adaptation of the disposal strategy. This is also reflected in the Dutch and Flemish (environmental) permits for the execution of the deepening and maintenance dredging.

The monitoring programme provided is the MONEOS-T Execution Plan 2008-2018 (Schrijver \& Plancke, 2008), expanded with bird- and sealcounts for the Western Scheldt. The MONEOS-T Execution Plan describes the measurements between 2008 and 2018 that are required to evaluate the effects related to accessibility.

The environmental impact assessment (EIA) (Consortium Arcadis-Technum, 2007) of the deepening project focusses on the investigation of 
the different disposal strategies. In the EIA, it was concluded that the approach of a flexible disposal strategy with disposal on the edges of specific intertidal flats, is the most environmentally friendly approach. A further consequence of disposal on the edges of the flats is that less sediments have to be disposed in the main channel, which must lead to less maintenance dredging activities. The EIA also set the condition that the intertidal flats, and their edges are to be monitored closely.

The evaluation of the estuarine system is based on a number of parameters, defined in the "Protocol conditions for flexible disposal Quality parameters", an annex to the permit for the disposal of dredged sediments. The testing of these parameters against pre-defined criteria are the base for adapting the disposal strategy - rendering it 'flexible' - and prevent or mitigate unwanted effects. Adaptation of the disposal strategy is related to the number and size of the disposal locations, volume of disposed sediment, disposal methods and time of disposal.

Firstly, the multichannel layout of the estuary is to be maintained. This is deemed important to support the main Long Term Vision functions safety, accessibility and naturalness. The loss of the multichannel system would lead to the disappearance of the intertidal flats and mudflats and thus lead to the loss of ecosystems. The main parameter and annex criterium used to evaluate this, is the volume of water in the secondary channel. The Western Scheldt is subdivided in 6 macrocells (morphological entities). For each of these, the water volume in the secondary channel should not drop below a certain level, as this would indicate undesired sedimentation which could ultimately lead to closing of the secondary channel.

Secondly, maximum ecological gain from disposal on the edges of the intertidal flats should be attained. This disposal location is one of three possible disposal sites. Disposal also takes place in the main and secondary channel of the estuary. In between these channels, intertidal flats with a high ecological value, exist. The ecological value is determined by the area of low-dynamical undeep water and intertidal areas (for settling, feeding, ...). The criterium here is that the surface of these areas, over the whole of the four disposal areas on the edges of the intertidal flats, should increase by 144 ha within five years after the start of the dredging and disposal. This means that the edges should neither become steeper (as this reduces the surface area), neither exaggeratively higher (leading to permanent dry-fall of the flats) or deeper. Within the second quality parameter, an ancillary criterium is that the stability of the disposed sediment (the net volume within the disposal area) should not decrease beyond a given limit. This parameter is

Table 1: Summary of the criteria as shown in the Protocol Conditions for Flexible Disposal

\begin{tabular}{|l|l|l|l|}
\hline Parameter & Multiple channel system & Edges of intertidal flats & Ecology (in genetal \\
\hline Desired situation & Preservation & $\begin{array}{l}\text { Additional ecological } \\
\text { valuable area at the edges } \\
\text { of the flats }\end{array}$ & $\begin{array}{l}\text { Preservation of the area of } \\
\text { ecological valuable area in } \\
\text { Western Scheldt }\end{array}$ \\
\hline Concrete goals & $\begin{array}{l}\text { No undesired shallowing of } \\
\text { secondary channels }\end{array}$ & $\begin{array}{l}\text { Increase in surface of } \\
\text { low-dynamic area near the } \\
\text { edges of the flats }\end{array}$ & $\begin{array}{l}\text { No decrease in the surface } \\
\text { of ecological valuable area } \\
\text { or sediment compression }\end{array}$ \\
\hline Monitoring instrument & $\begin{array}{l}\text { Determination of the water } \\
\text { volume in the secondary } \\
\text { channel }\end{array}$ & $\begin{array}{l}\text { Ecotope charts } \\
\text { Volume of the four specific } \\
\text { disposal areas }\end{array}$ & $\begin{array}{l}\text { Ecotope charts } \\
\text { Height surveying } \\
\text { Sediment composition }\end{array}$ \\
\hline $\begin{array}{l}\text { Criterium } \\
\text { undesired effect }\end{array}$ & $\begin{array}{l}\text { Lower water volume than } \\
\text { present than initial water } \\
\text { volume minus the disposal } \\
\text { criterium in each channel }\end{array}$ & $\begin{array}{l}\text { Ecological valuable area } \\
\text { not created } \\
\text { Dumped sediments are not } \\
\text { stable enough }\end{array}$ & $\begin{array}{l}\text { Significant deterioration } \\
\text { of the long-term trend per } \\
\text { ecotope area, taking into } \\
\text { account natural vatiation }\end{array}$ \\
\hline
\end{tabular}

\section{2 | Hydro 12}


used because it responds faster to sediment/erosion than the surface of ecologically valuable area because the latter needs time to develop through processes as the migration of dumped sediments towards the boundary of the intertidal flat.

Thirdly, the surface of environmentally valuable area in the Western Scheldt should be preserved. This parameter not only regards the edges of the intertidal flats but the entire Western Scheldt. Additionally, the height of the flat is monitored to prevent an undesirable buildup and dryfall of the flat, as well as the erosion of the salt marshes along the edge of the estuarium.

For the quality parameters summarized in Table 1 , warning thresholds have been defined. On exceeding a threshold, the administration is taking adequate actions by either starting up additional investigation, either altering the disposal strategy. This latter is then aimed to mitigate the undesired consequence of the natural evolution (the background signal) combined with the response to the disposal in a given area (the anthropogenic impact).

\section{FROM MONITORING TO DECISION MAKING}

The evaluation of the quality parameters listed above requires intense monitoring, involving many partners which The Department of Maritime Access (Flemish authority) and Rijkswaterstaat Zeeland (Dutch authority) rely on. Relevant surveys for the Flexible Disposal monitoring and analysis include multi- and single beam bathymetric surveys, RTK topographic surveys, ADCP measurements (see Plancke et al., 2012), sediment and biological sampling and surveying, LIDAR... Additionally, all dredging and disposal activities are meticulously recorded.

Reports are produced to allow the follow-up of the flexible disposal strategy. Yearly, formal checking of the quality parameters and reporting of their status, is performed. Bi-yearly, a broader analysis is made of MONEOS-T monitoring parameters, expanded with biological parameters (eg., bird and seal counts) in a progress report.

Bi-monthly, an assembly of the authorities and their partners meet to discuss the latest monitoring results and insights in dredging and disposal activities. Monthly reports of dredging and dumping activities and morphological changes on edges of the intertidal flats are produced for this assembly. Long-term studies of the effects of dumping in the main channel, quarterly reports of morphological and biological monitoring on the flats, etc... further support the analysis of the effects of the dredging and dumping on the estuarine system. With all information, a plan is made to steer the disposal strategy for the next two months. This assembly is crucial in the flexible nature of the disposal strategy. The bi-monthly assembly assures that potential undesired effects are detected in a very early stage. Additional monitoring and analysis are key elements in the decision making process.

\section{RESULTS}

In this section, results of the monitoring and the decision making procedure are illustrated.

Dredging and disposal volumes two years after start of the third deepening

The permit for the disposal of sediment between 2010 and 2015 includes maximum disposal volumes for the overall project, and per-year disposal limits. These quota are further subdivided in type of disposal area: intertidal flat edges, main and secondary channels and also subdivided in geographical parts within the Western Scheldt (the macrocells mentioned earlier). Table 2 shows that the largest part of the dredged sediment is to be dumped back into the main channel (24.5 million $\mathrm{m}^{3}$ ) whereas 22 million $\mathrm{m}^{3}$ of sediments are to be disposed in the secondary channels and nearly 20 million $\mathrm{m}^{3}$ on the edges of the intertidal flats.

The first year after the start of the deepening of the Western Scheldt, the main part of the volume (7.7 million $\mathrm{m}^{3}$ ) was related to the actual deepening, whereas in the second year, the volume is due to maintenance dredging. The EIA foresees in an intial maintenance dredging volume of 11.7 million $\mathrm{m}^{3}$ in the first years, to decrease after some years. In year two, the actual disposed volume is significantly lower than the expected volume.

On a yearly (or more frequent) basis, decisions are made to dispose in certain areas more or less than 
Table 2: Maximum permitted disposal capacity (in $\mathrm{m}^{3}$ ) for the first five years of the deepening project and the volumes disposed during the first two years after the start of the deepening.

\begin{tabular}{|l|c|c|c|c|}
\hline & Main channel & Secondary channel & Edges of flats & Total \\
\hline Maximum & 24500000 & 22000000 & 19700000 & 66200000 \\
\hline Year 1 & 113010 & 2688363 & 9877960 & 12679332 \\
\hline Year 2 & 5095563 & 2489796 & 2503472 & 10088830 \\
\hline
\end{tabular}

previously. The decisions are driven by the capacity of the disposal location, in combination with other factors described in the quality parameters.

Autonomous sedimentation on the edge of the Rug van Baarland intertidal flat

The 'Rug van Baarland' is an intertidal flat where an increase in valuable ecological area was to be created by disposal on the edge of the intertidal flat. During the first two years after the start of the deepening, it was observed that autonomous (natural) sedimentation was higher than the disposal volumes (Figure 1). So far, 1.3 million $\mathrm{m}^{3}$ of sediments were dumped in the disposal area, whereas the volume increase totalled 3.6 million $\mathrm{m}^{3}$.
A potential consequence of this was that not all disposal capacity could be used. Besides this, concerns existed over possible undesired sedimentation in the adjacent secondary channel 'Middelgat'. Although the shallowing of the edge of the flat, which would lead to an increase of the valuable ecological area, these concerns required an action or decision to be made. In order to mitigate the undesired sedimentation, and monitor the evolution of the autonomous sedimentation, it was decided in the bi-monthly assembly, not to dump sediments on the Rug van Baarland edge during the third year of the project.

\section{Disposal in the deep parts of the main channel}

Within the maintenance permit, disposal areas in the deep parts of the main channel are foreseen.
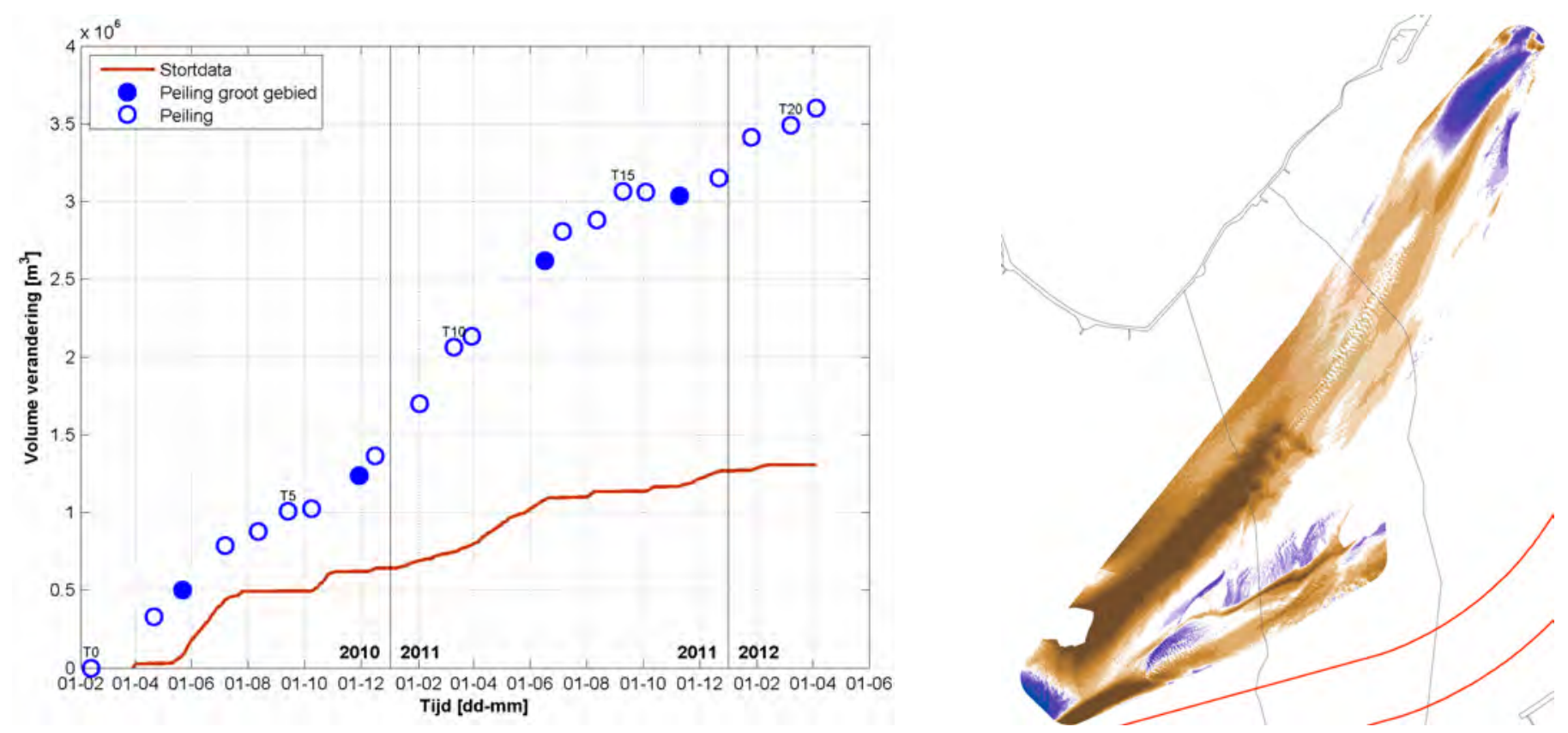

Figure 1: (left) Disposal volumes (red curve) on the Rug van Baarland intertidal flat edge, compared to the monitored volume increase (blue circles). Autonomous sedimentation leads to an undesired increase of the total sedimentation volume. Right: Difference map of the Rug van Baarland interitdal flat edge with sedimentation (brown) and erosion (blue) areas. The disposal area is indicated by the blue rectangles. The sedimentation is more widespread than the disposal area. Source: IMDC, 2012a.

\section{4 | Hydrol2}


The behaviour of the dumped sediments in these parts was analyzed for a period between October 2010 and October 2011 (IMDC, 2012b). Special attention was given to the stability of the dumped sediments and the (re)sedimentation at shallower locations in the main channel. This latter subject is of great concern because rapid resedimentation requires a high maintenance dreding intensity to guarantee a safe shipping activity. Three locations in the Western Scheldt and one location in the Lower Sea Scheldt were analyzed. For the study, dredging and disposal statistics where used together with volume calculations and morphological descriptions of detailed multibeam bathymetry. This analysis yielding general conclusions and recommendations for future disposal in the main channel.

The dumped dredging material erode from the deep parts of the main channel. Currently, it is expected that erosion half-lifes are about one half to one year. Increased sedimentation at the shallower parts could not be proved at this time but will be evident from possible changes in maintenance dredging intensity.

It was observed that the disposed sediment was most stable when it was dumped in a concentrated location as opposed to spread out over a larger area, and by dumping continuously in time. Near Walsoorden (Figure 2) a $600.000 \mathrm{~m}^{3}$ sediment body was built in multiple phases. On average, over a time span of 9.5 months, about $50 \%$ of the dumped sediment had eroded.

The stability appeared to be highest in the deepest part of the channel, except for locations where the depression was caused by a local turbulent feature caused by river infrastructure (Figure 3). Near the 'Nol van Ossenisse' groyne, 1.1 milion $\mathrm{m}^{3}$ was dumped. In the deepest part, $300.000 \mathrm{~m}^{3}$ of sediments were dumped in 5 months time; at the end of that period, only $24 \%$ of that volume was still present. In the immediate vicinity of the deeper parts, $940.000 \mathrm{~m}^{3}$ of sediments were dumped (within the same 5 months). Here, only $50 \%$ of the volume had eroded. In the greater surroundings, dumping also took place $\left(70.000 \mathrm{~m}^{3}\right.$ in total).

There, not erosion, but additional sedimentation had occurred.

In order to further refine the knowledge of erosion from the deep parts and resedimentation at the shallower parts, the study of the data continues on data produced until the end of 2012.

\section{CONCLUSION}

The Flexible Disposal Strategy is an approach to
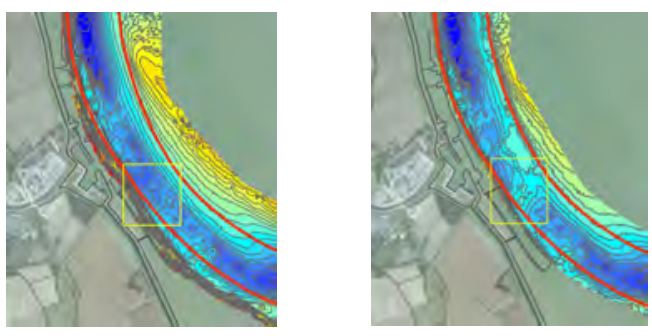

Figure 2: Creation of a concentrated sediment body in the main channel near Walsoorden. A concentrated body (nearly $600.000 \mathrm{~m}^{3}$ ) appeared more stable over time than spread-out disposal. Source: IMDC, 2012b.

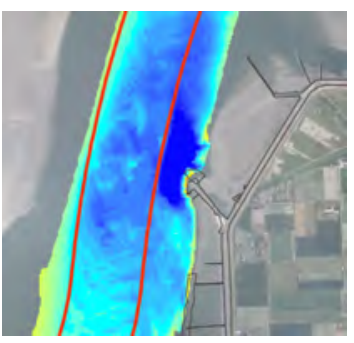

Figure 3: Disposal in the deepest part near the groyne 'Nol van Ossenisse' is unsuccessful due to the elevated turbulent energy of the deflected currents. Source: IMDC, $2012 b$.

sediment disposal in the framework of the third deepening of the Scheldt that sets strict goals for positive morphological and ecological effects of the disposal activities. To achieve these goals and obey predefined quality parameters, intense monitoring of hydrodynamic, morphological and ecological parameters is carried out to support a decision making procedure. Through careful analysis, reporting and discussion, an assembly is able to steer or adapt the disposal strategy both on long- and short-term basis to prevent or mitigate undesired effects and promote the positive effects.

\section{REFERENCES}

Consortium Arcadis - Technum, Rijkswaterstaat Zeeland and afdeling Maritieme Toegang. Milieueffectrapport Verruiming vaargeul BenedenZeeschelde en Westerschelde. Hoofdrapport. 2007. Accessed June 28, 2012. http://www.vnsc.eu/ uploads/2011/01/milieueffectrapport.pdf 
IMDC. Monitoringprogramma flexibel storten. Maandelijkse rapportage april-mei 2012. 2012a. Unpublished reportn number I/RA/11353/11.015.

IMDC. Monitoringprogramma flexibel storten. Analyse van stortingen in de diepe delen van de hoofdgeul. 2012b. Unpublished report number I/ RA/11353/11.076.

Plancke, Y., Vertommen, D., Beirinckx, K. \& Vos, G. High resolution topo-bathymetric and flow measurements and 2D-hydrodynamical modelling to evaluate the effects of the deepening of the navigation channel in the Western Scheldt. Hydro2012 - Taking care of the sea, Rotterdam, The Netherlands.

Schrijver, M. \& Plancke, Y. Uitvoeringsplan MONEOS-T 2008-2018. 2008. Middelburg: Rijkswaterstaat Zeeland; Antwerpen: Vlaamse Overheid. Accessed June 28, 2012. ww.vliz.be/ imisdocs/ publications/140364.pdf

\section{BIOGRAPHIES}

Dr. Davy DEPREITER has a background in marine geology, geophysics and geobiology of seabed fluid flow and a broad knowledge in marine and nearsurface terrestrial monitoring. This experience is now applied in the framework of studies regarding dredging activities and hydro- and morphodynamics of marine and estuarine systems. He is also responsible for the management of operational forecasting systems for hydrodynamic and hydrologic prediction and storm surge warnings.

Ir. Marc SAS is an expert in coastal and estuarine systems with over 30 years of experience in research and project management in the field of hydrodynamics, hydrology, sediment transport, mathematical modelling and survey campaigns in general, and related to the Scheldt Estuary specifically. He was responsible for the modelling teams working in the framework of the EIA Deepening Western Scheldt. He was involved in projects related to MONEOS-T, Moneos Safety \& Naturalness, Flexible Disposal, etc.

Kirsten BEIRINCKX is one of the environmental project-coordinators of the Flemish Government,
Department of Maritime Access. In particular, she is responsible for the environmental aspects of the dredging and relocation works in the estuary of the river Scheldt. Furthermore, she manages the assembly of the authorities and their partners that discuss the latest monitoring results and insights in dredging and disposal activities, together with het Dutch counterpart Gert-Jan LIEK.

Gert-Jan LIEK M.Sc. has a background in coastal engineering and has been working for Rijkswaterstaat as an advisor on morphology since 2001. In that period he's been involved in a large number of studies on the morphological an hydrodynamical devolopment of the Western Scheldt. Together with his Flemish counterpart, Kirsten Beirickx, he is responsible for the execution of the flexibel disposal strategy and manages the assembly of the authorities that discuss the latest monitoring results and insights in dredging and disposal activities.

\section{CONTACT DETAILS}

Davy Depreiter

International Marine \& Dredging Consultants

(IMDC)

Coveliersstraat 15

B-2600 Berchem

BELGIUM

Tel.: +3232709295

Fax: +32 32356711

Email:davy.depreiter@imdc.be

Web site: www.imdc.be

\section{$56 \mid$ Hydrol 2}




\section{Quantified sea-bed dynamics of the Netherlands Continental Shelf and the Wadden Sea: a morphological and sedimentological approach}

Thaiënne VAN DIJK, the Netherlands

Deltares, Department of Applied Geology and Geophysics

University of Twente, Department of Water Engineering and Management

Sytze VAN HETEREN, the Netherlands

TNO, Geological Survey of the Netherlands

Marco KLEUSKENS, the Netherlands

Alten PTS

Laura VONHÖGEN-PEETERS, Pieter DOORNENBAL, Ad VAN DER SPEK and Bob HOOGENDOORN, the Netherlands

Deltares, Department of Applied Geology and Geophysics

Leendert DORST, the Netherlands

Hydrographic Service, Royal Netherlands Navy

David RODRIGUEZ AGUILERA, the Netherlands

Deltares, Department of Soil and Groundwater Quality

Topics: Innovations in processing techniques, Careful marine planning,

Geophysics of the marine environment

\section{INTRODUCTION}

Sandy continental shelves and adjacent tidal basins are dynamic on different spatial and temporal scales. Sandy sea beds of shallow seas are characterized by marine bedforms of various size, such as sand banks, long bed waves, sand waves and megaripples. Tidal basins are dominated by migrating tidal channels and eroding and accreting tidal flats. Each of these bedforms and depositional environments evolves in response to extreme events and every-day processes of different energy and frequency. These dynamics may affect navigation safety, especially where drafts of vessels are similar to water depths. In areas with such critical depths for shipping, such as parts of the southern North Sea, nautical maps must be kept up-to-date, and the changing sea bed needs to be re-surveyed at an appropriate frequency. Other applications of up-to-date maps and bathymetric monitoring series are impact studies for planned offshore engineering projects such as wind farms, habitat mapping, evaluations of archaeological value and preservation, and assessments of system resilience to climate change. As of yet, no guidelines for the validation and optimization of re-survey policies exist. Guidelines on monitoring location and frequency must be a function of (a) relevance of bathymetric observations to various types of end use and (b) observed large-scale dynamics on different time scales.

Previous empirical studies of seabed morphodynamics have focused on the analysis of marine bedforms of small sites with specific local conditions [e.g. Duffy and Hughes-Clarke, 2005; Knaapen, 2005; Buijsman and Ridderinkhof, 2008; Van Dijk et al., 2008; Dorst et al., 2011]. Recently, a regional-scale study of morphodynamics was carried out for the German coastal zone [Winter, 2011]. Thus far, no such study exists for the Netherlands Continental Shelf (NCS). Such a study would provide an overview of the spatial variation in seabed dynamics, which would increase our insight and understanding of the processes of bed evolution.

Multiple datasets (time series) of digital bathymetric data, which are required for the study of seabed morphodynamics, have become sufficiently 
available for the NCS only recently. As monitoring techniques have improved, the horizontal precision of the resulting data has become increasingly suited to the detailed and quantitative analyses of bed changes and bedform mobility. In the analysis of the NCS, lessons can be learned from approaches used in quantifying bed dynamics and sediment transport in the Wadden Sea.

The aim of this paper is to present the vertical seabed dynamics of the Netherlands Continental Shelf and the Dutch part of the Wadden Sea, based on a quantitative analysis at a $25 \times 25 \mathrm{~m}$ (NCS) and $20 \mathrm{x}$ $20 \mathrm{~m}$ (Wadden Sea) resolution. Detailed analyses of selected locations serve to describe the local morphology and dynamics of individual bedforms.

\section{DATA AND METHODS}

\section{$\underline{\text { Bathymetric data }}$}

For the NCS, all data from the digital Bathymetric Archive System (BAS) of the Hydrographic Service of the Royal Netherlands Navy below the $10 \mathrm{~m}$ isobath were used. This database includes data collected by Rijkswaterstaat for the coastal zone. Digital data in BAS comprise both single-beam echo soundings (SBES) and multi-beam echo soundings (MBES). Digital data for the Wadden Sea include SBES of subtidal areas (older ones digitized from their original analog format) and laser altimetry for intertidal and supratidal areas.

It is not possible to generate a single time series for the entire study area. The overlap of surveys creates time series of various spatial extents and covering different periods. For the NCS, most time series comprise no more than two or three datasets; at few locations, time series of more than five datasets exist. For locations with only a single digital bathymetric record, time series were created by digitizing historical echo soundings from plotted or hand-written fair sheets. For the Wadden Sea, partial surveys have been conducted by Rijkswaterstaat in such a way that the entire tidal basin is surveyed every five to six years. The data density and precision (horizontal positioning and echo-sounding beams) differ per method and in time. The analyzed digital datasets for the NCS were acquired between the late 1980s and June 2010, those for the Wadden Sea between 1985 and 2006. Digitized fair sheets date from before those time periods, but are not available for the eastern Wadden Sea.

Digital Elevation Models (DEMs) were created from the NCS bathymetric data by interpolating to a 25 x $25 \mathrm{~m}$ grid, using the Inverse Distance Weighting algorithm with a search radius of $100 \mathrm{~m}$. This $25 \mathrm{~m}$ resolution was chosen to still represent sand waves (hundreds of meters in length) well and to minimize the introduction of interpolation artefacts of single beam echo soundings in track lines. The interpolation technique used to create grids from the Wadden Sea data is DIGIPOL, software that incorporates the orientation of (morphological) features in the original $x-y-z$ points as part of an iterative linear interpolation.

\section{Analysis of vertical dynamic trends}

In analyzing bathymetric datasets, we are confronted with overlap issues, different numbers of surveys, different periods of acquisition, and different methodologies and associated uncertainties. Therefore, it is insufficient to use average values of bed-elevation change or create simple erosionsedimentation grids.

For the quantitative analysis of vertical dynamic trends (m/yr) for each grid node on the NCS, we developed a fully automated linear regression of all bed elevations in the stacked time series per node. Visual inspection of the nodal bed elevations in time has shown that linear regression is justified within in the periods that are covered by the time series. Because the correction for tides and ship movements provided differences between surveys that are larger than the (natural) vertical dynamics, we corrected for this discrepancy by subtracting the averaged vertical dynamics for each specific stacked combination of surveys from the vertical dynamics at each node.

For the Wadden Sea, we used all values for each node to calculate the difference between the most recent grid (i.e. the 2006 bathymetry) and the minimum values for the period 1927-2006. The volume bounded by these grids provides a measure of the century-scale net sediment dynamics within the tidal basin.

\section{8 | Hydrol 2}




\section{Geometry and mobility of individual bedforms}

Detailed morphological and dynamic analyses of individual sand waves and long bed waves were conducted only for the NCS. As part of these analyses, the bathymetric signal was separated into bedform types of different spatial scales by truncating a Fourier approximation at certain frequencies [cf. Van Dijk et al., 2008]. From the smoothed bedform signal, locations of crest, trough and inflection points were then determined in a semi-automated way, from which the geometry and dynamics of individual bedforms were calculated.

\section{RESULTS}

\section{Vertical dynamic trends on the NCS}

The quantified vertical nodal dynamic trends for the NCS (Figure 1) provide an overview of regions of contrasting dynamics. In general, the coastal zone is more dynamic than the continental shelf. The highly dynamic coastal zone includes estuaries, tidal inlets with ebb-tidal deltas, tidal channels and breaker bars. Dynamic trends in these environments typically range between absolute values of 0.1 and 0.35 $\mathrm{m} / \mathrm{yr}$, with extremes up to $1.5 \mathrm{~m} / \mathrm{yr}$. In areas strongly

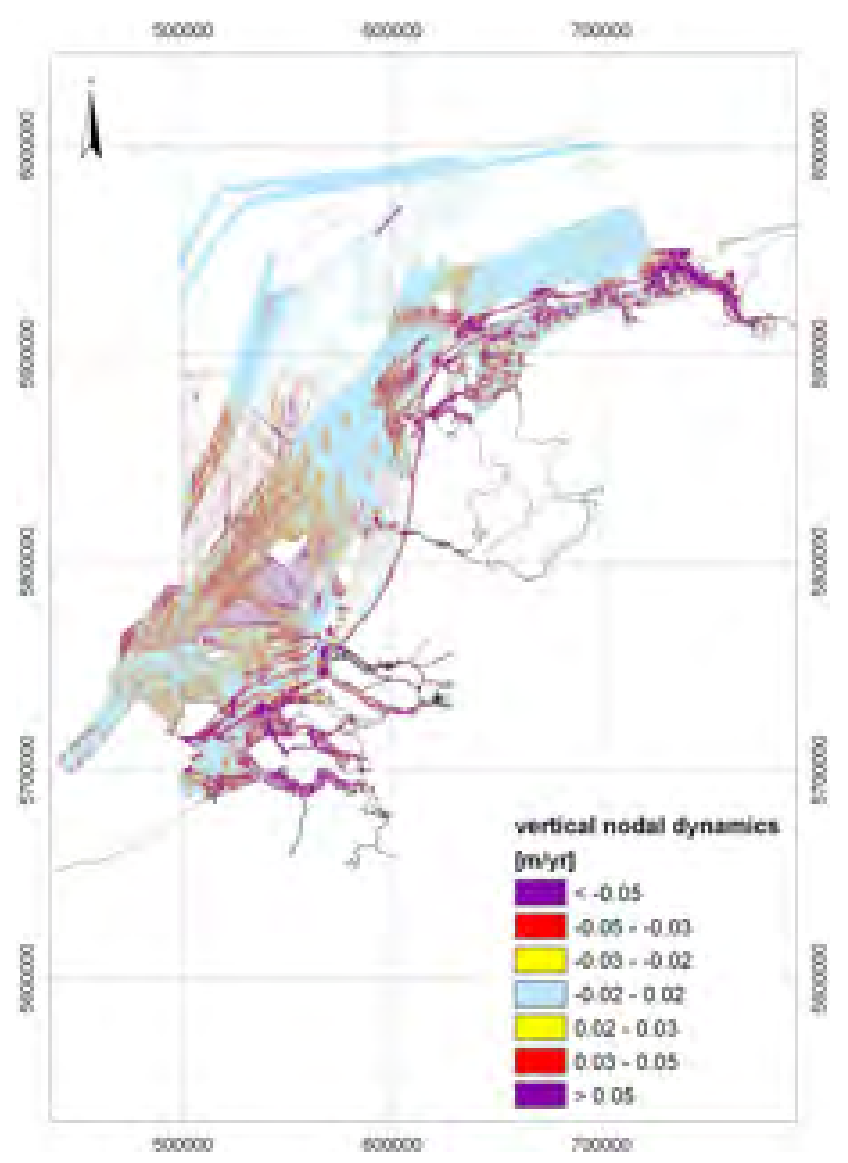

influenced by man, annual changes may even be greater.

Areas of moderate dynamics are prevalent farther offshore on mostly sandy parts of the NCS, where rhythmic bedforms are present. Here, values typically range between -0.1 to $0.1 \mathrm{~m} / \mathrm{yr}$, with extremes of $0.3 \mathrm{~m} / \mathrm{yr}$ in fields of rapidly migrating sand waves. The appearance of bedform patterns in the vertical dynamics map indicates that the measure of vertical dynamics is controlled by the migration and/or growth of individual bedforms. Examples are the sand-wave field west of Texel, a long-bedwave field north of Texel and Vlieland, and the tidal ridges $75 \mathrm{~km}$ offshore Texel.

Areas of very low sea-bed dynamics (around $0 \mathrm{~m} /$ yr; light blue in Figure 1) occur mostly in parts of the NCS where rhythmic bedforms are absent. The largest areas of low dynamics occur far offshore, in the deepest and parts of the NCS. Smaller stable areas are present north of the Wadden islands, where shoreface-connected ridges show little mobility, various patches offshore the coast and at the large ebb-tidal delta of the Western Scheldt.

\section{Vertical dynamic trends in the Wadden Sea}

The two surfaces formed by all minimum and 2006 values bracket the active layer, which has a volume of more than 1.7 x $109 \mathrm{~m} 3$ (Figure 2). For shorter periods within this time frame, subsets of the bathymetric database form the basis for various derivative grids that allow us to constrain the net sediment dynamics and its variability on a multi-decadal time scale. The value of annual net sediment dynamics is dependent on the time period considered. It is as high as $53 \times 106 \mathrm{~m} 3$ for 1999-2006 but less than 3

Figure 1: Vertical nodal dynamic trends of the NCS (absolute values). Vertical dynamic trends are simplified into classes of absolute values in order to amplify the dynamic contrasts. Thus, this map does not display the full range of dynamic trends, which apart from extremes may range between -0.35 and $0.35 \mathrm{~m} / \mathrm{yr}$ degradation and aggradation. 


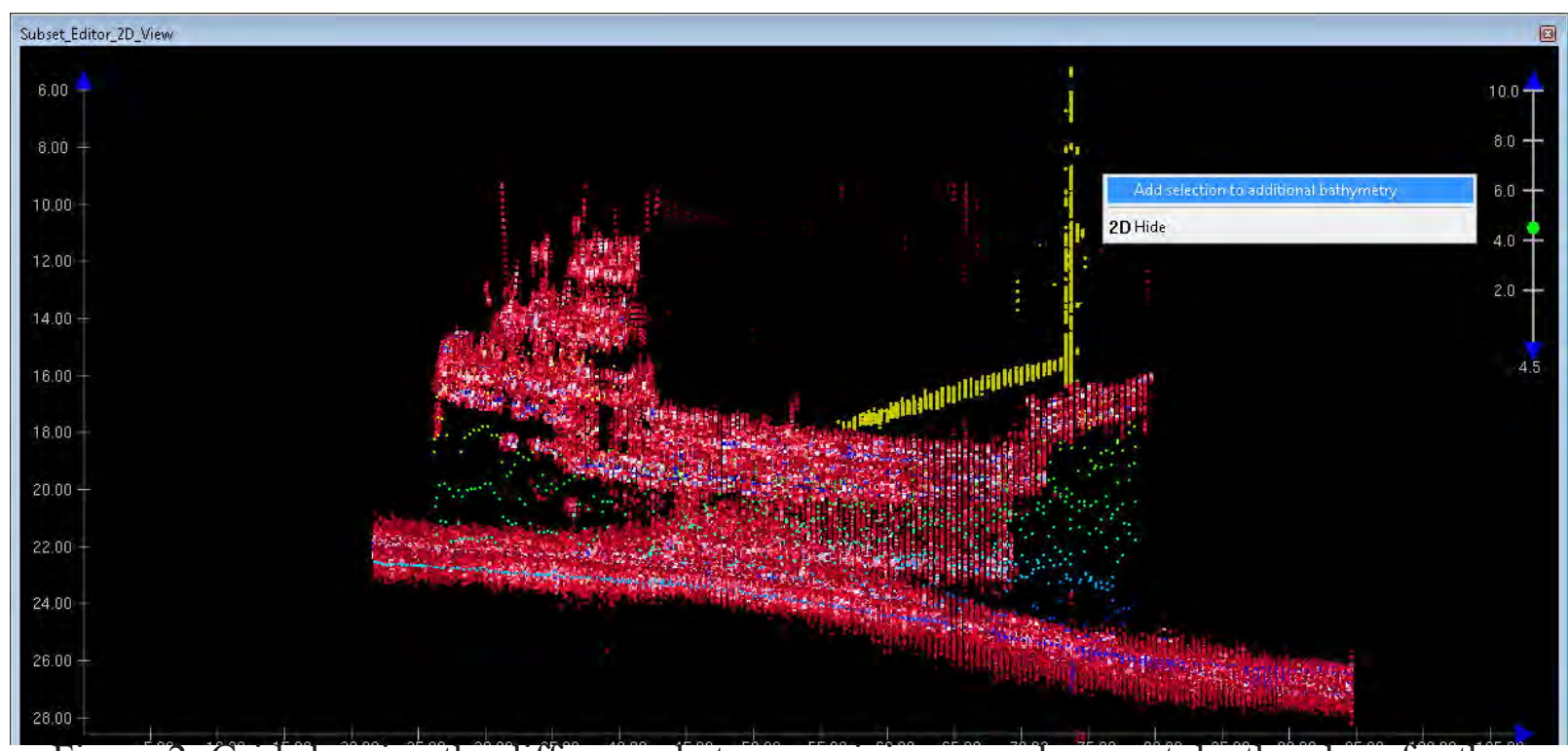

Figure 2: Grid showing the difference between minimum and present depth values for the period 1927-2006. Changes are the largest around the main channels, the main mechanism for the internal redistribution of sediments. The watersheds are clearly recognizable, as these areas have hardly been reworked.

x $106 \mathrm{~m} 3$ for the entire Holocene. In terms of net sedimentation rates, these two values translate to 1.9 and $0.1 \mathrm{~mm} / \mathrm{yr}$, respectively.

\section{Bedform size and mobility}

Detailed analyses of individual bedforms provide more information on the geometry, mobility and morphodynamics of bedforms. The sand wave field west of Texel comprises sand waves with an average wavelength of $345 \mathrm{~m}$ and an average wave height of $1.4 \mathrm{~m}$. With an average sand wave migration rate of 16 to $19 \mathrm{~m} / \mathrm{yr}$ to the northeast, this area is exceptionally dynamic compared to other sand wave fields on the NCS, where migration rates are mostly less than $5 \mathrm{~m} / \mathrm{yr}$ [Van Dijk et al., 2011].

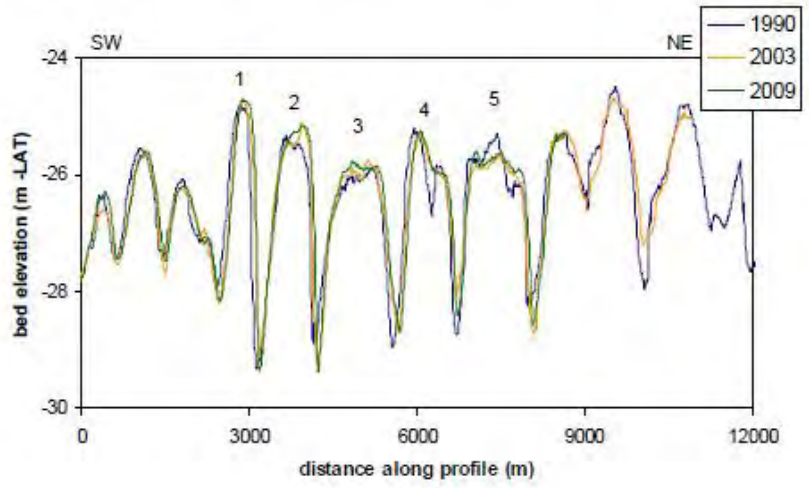

Figure 3: Profiles (SE to NW) of long bed waves north of Texel and Vlieland from the 1990, 2003 and 2009 datasets.
The long bed waves north of Texel have an average wavelength of $1125 \mathrm{~m}$ and an average wave height of $3.4 \mathrm{~m}$. Net migration rates, based on 3 surveys between 1990 and 2009 (Figure 3), range from 10.5 to $18.4 \mathrm{~m} / \mathrm{yr}$, with an average of $12.4 \mathrm{~m} / \mathrm{yr}$ to the northeast.

The average wavelength of the shoreface-connected ridges north of Wadden islands is $4614 \mathrm{~m}$ and the average height is $4.3 \mathrm{~m}$. Changes in dimensions are negligible and the average migration rate is $1.0 \mathrm{~m} / \mathrm{yr}$ to the southwest (Figure 4).

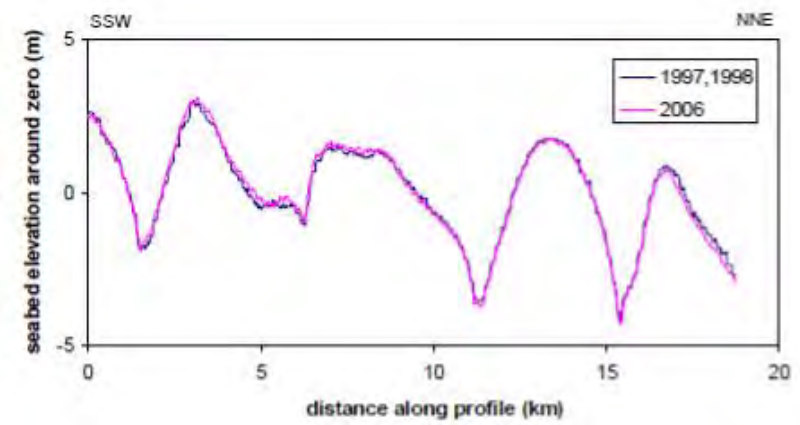

Figure 4: Profiles (SSW to NNE) of the shoreface-connected ridges north of the Wadden islands indicate that these bedforms are stable on a decadal scale. 


\section{DISCUSSION}

A study of vertical bed level changes of a wide coastal zone of the German Continental Shelf, recently completed by Winter [2011], shows an overall pattern of highly dynamic estuaries and tidal inlets and much less dynamic offshore areas that is in good agreement with our findings of the NCS and the Wadden Sea. When focusing on smaller-scale features, extreme differences can be observed. Shoreface-connected ridges offshore a German Wadden island, for example, are two orders of magnitude more dynamic than their counterparts offshore the Dutch Wadden islands [Antia, 1996].

Observed differences in the dynamics of similar bedforms may be related to grain-size effects (maps of median grain size and bed dynamics correspond well); current velocity (maps of sediment-transport potential agree with migration rates of sand waves and long bed waves), and bedform-size differences (the German shoreface-connected ridges are shorter and lower than the adjacent Dutch ones).

Vertical dynamic trends are sensitive to data-quality issues, such as data density and precision. Low-resolution data, especially from older measurements, may underestimate bedform amplitudes and even high-resolution state-of-the-art measurements are associated with vertical uncertainties of several centimeters to a decimeter. The shorter the time series under consideration, the more influential the errors of such data limitations. Therefore, comparisons of analog legacy data with modern digital bathymetries should only be attempted when the time period covered by these datasets is on the order of decades or longer. Aside from intercomparing individual survey results, extreme values derived from complete monitoring series may be used to assess and constrain sediment dynamics.

\section{APPLICATIONS}

Analyses of sea-bed dynamics can be used to validate and to optimize hydrographic survey policies. Grounding dangers for shipping can be determined from shipping intensity, predicted water depth and the probability of unknown objects at the bed. They also provide constraints on sea-bed stability, needed to budget offshore engineering projects, such as the construction and maintenance of offshore wind farms, cables and pipelines. The chance of exposed foundations and freespans must be minimized. Seabed dynamics are also relevant for habitat studies, with benthic species and assemblages being sensitive to temporal change. Finally, knowledge on the morphodynamics of tidal channels and sand banks is crucial in understanding the preservation potential and exposure risk of archaeological remnants such as wrecks and Mesolithic paleolandscapes.

Information on net sediment dynamics as derived from sea-bed monitoring is instrumental in assessing the reliance of sedimentary systems to effects of climate change, particularly relative sea-level rise. Bathymetric time series have demonstrated that the internal sediment dynamics of the Wadden Sea is perfectly capable of neutralizing both man-made and sea-level-driven increases in accommodation space.

\section{CONCLUSIONS}

Vertical nodal dynamic trends of the Netherlands Continental Shelf and Wadden Sea can be determined using different protocols, developed to maximize the usefulness of the underlying datasets and to minimize the effect of error.

Observed vertical trends in sea-bed dynamics are crucial in optimizing re-survey policies, marine spatial planning, assessments of archeological potential and studying the effects of climate change.

\section{ACKNOWLEDGEMENTS}

All data were provided by the Hydrographic Office, Royal Netherlands Navy, and Rijkswaterstaat, Ministry of Infra Structure and the Environment. Part of this work was financed by the Ministry of Defense.

\section{REFERENCES}

Antia, E.E. "Rates and patterns of migration of shoreface-connected ridges along the southern North Sea coast." Journal of Coastal Research 12 (1996): 38-46.

Buijsman, M.C. and H. Ridderinkhof. "Long-term evolution of sand waves in the Marsdiep inlet, II: relation to hydrodynamics." Continental Shelf Research 28 (2008): 1202-1215.

Dorst, L.L., P.C. Roos and S.J.M.H. Hulscher. 
"Spatial differences in sand wave dynamics between the Amsterdam and the Rotterdam region in the Southern North Sea." Continental Shelf Research 31 (2011): 1096-1105.

Duffy, G.P. and J.E. Hughes-Clarke. Application of spatial cross correlation to detection of migration of submarine sand dunes." J. of Geophysical Res 110 (2005): F04S12, doi:10.1029/2004JF000192.

Knaapen, M.A.F. "Sandwave migration predictor based on shape information." Journal of Geophysical Research, 110 (2005): F04S11, doi:10.1029/2004JF000195

Van Dijk, T.A.G.P., R.C. Lindenbergh and P.J.P. Egberts. "Separating bathymetric data representing multi-scale rhythmic bedforms: a geostatistical and spectral method compared." Journal of Geophysical Research 113 (2008): F04017, doi:10.1029/2007JF000950.

Van Dijk, T.A.G.P., C. Van der Tak, W.P. De Boer, M.H.P. Kleuskens, P.J. Doornenbal, R.P. Noorlandt, and V.C. Marges. "The scientific validation of the hydrographic survey policy of the Netherlands Hydrographic Office, Royal Netherlands Navy." Deltares report, 2011, 165 pp.

Winter, C. "Macro scale morphodynamics of the German North Sea coast." Journal of Coastal Research SI 64 (2011): 706 - 710.

\section{BIOGRAPHIES}

Thaiënne VAN DIJK studied Physical Geography at the University of Amsterdam, Netherlands, and obtained her Ph.D. at Keele University, UK, in 2001. She worked as a Marine Geologist at TNO - Geological Survey of the Netherlands on Quaternary mapping and habitat mapping projects in the North Sea. VAN DIJK now is a specialist in the morphodynamics and geology of sea beds. She leads applied research projects at Deltares and is a lecturer at the University of Twente in these themes.

Sytze VAN HETEREN is a coastal and marine geologist. He received his Ph.D. at Boston University. After completing a post-doc on sea-level change at the Vrije Universiteit Amsterdam, he joined the Geological Survey to coordinate and work on various national and international research projects on coastal behavior, sea-bed habitats and geological databases.

\section{CONTACT DETAILS}

Thaiënne VAN DIJK

Deltares

Dept. of Applied Geology and Geophysics

P.O. Box 85467

3508 AL Utrecht

NETHERLANDS

Tel.: +31 883357798

Fax.: +31 883357856

E-mail: thaienne.vandijk@deltares.nl

Website: www.deltares.nl

LinkedIn account: Thaienne A.G.P. van Dijk 


\section{Inland Electronic Navigation Chart production at the Flemish Hydro- graphy (Flanders - Belgium)}

Jasmine DUMOLLIN, Belgium

Flemish Ministry of Mobility and Public Works, Agency for Maritime and Coastal Services, Flemish Hydrography

Charles DE JONGH, the Netherlands

CARIS BV

Topics: Smart data management, Hydrography in the Benelux

\section{INTRODUCTION}

Safety of navigation on inland waterways is as important as in maritime waters. To guarantee the latter, Electronic Navigational Charts (ENCs) have been produced since several years.

As inland waterways have specific features and specific regulations different from the maritime area, the use of existing ENCs is not sufficient. Therefore international standards have been developed specifically for Inland ENCs. They contain all chart information required for safe navigation on inland waterways and in mixed traffic zones, where both maritime and inland vessels navigate.

The Flemish Hydrography is producing these Inland ENCs, on the authority of several commissioning bodies such as the Shipping Assistance Division of the Agency for Maritime and Coastal Services and the Ports of Ghent, Zeebrugge and Ostend.

These navigational charts are extremely important as they cover not only the maritime navigation zone, but also the adjacent inland waterways which haven't been mapped before on nautical charts.

This article is looking in more detail why and how the Inland ENCs are produced and used.

\section{LEGAL REGULATIONS OF EUROPEAN IN- LAND WATERWAYS}

As opposed to maritime navigation, which is governed by the worldwide regulations of the International Maritime Organisation (IMO), the navigation on inland waterways is regionally regulated. In Europe it is regulated by the European Code for Inland Waterways (CEVNI) of the United Nations.
In order to support inland waterway transport the European Directive 2005/44/EC of 7 September 2005, also known as the RIS Directive, establishes a framework for the development and use of harmonised River Information Services (RIS). This Directive provides a framework for the establishment and further development of technical requirements, specifications and conditions to ensure harmonised, interoperable, and open RIS on the Community inland waterways.

The same Directive obliges authorities to make official charts available for waterways of class Va (UNECE, 1998) and above, including the ports on such waterways. The commissioning bodies provide all the data that are to be charted by the Flemish Hydrography.

\section{DEFINITION AND CONTENT OF INLAND ENCS}

A detailed definition of Inland ENC has been elaborated by the Inland ENC Harmonization Group (IEHG, 2007):

'The database, standardized as to content, structure and format, for use with inland electronic chart display and / or information systems operated on board of vessels transiting inland waterways.

An IENC is issued by or on the authority of a competent government agency, and conforms to standards initially developed by the International Hydrographic Organization (IHO) and refined by the Inland ENC Harmonization Group.

An IENC contains all the chart information necessary for safe navigation on inland waterways and may contain supplementary information in addition to that contained in the paper chart (e.g. sailing directions, machine-readable operating schedules, etc.) which may be considered necessary for safe 
navigation and voyage planning. [IENC Encoding Guide, Edition 2.2, Feb 2010]'

Inland ENCs have to cover the specific features of the inland waterways. They are also produced for the so-called mixed traffic zones in which not only inland navigation but also maritime navigation happens. In Flanders the channel Ghent-Terneuzen and the Scheldt are defined as such mixed traffic zones. Inland ENCs contain a lot more details about bridges and locks for instance, than a maritime ENC. Buoys, traffic signs and other features that are specific to inland navigation are also charted.

Inland ENCs are based on an approach which is very similar to S-100 (IHO, 2010):

- The S-57 (IHO,2000) object classes, attributes and attribute values are used as far as possible;

- Introduction of new combinations of existing elements, if necessary;

- Introduction of new object classes, features or enumerations if necessary.

To ensure a common understanding and the same encoding in different areas, a very detailed Encoding Guide for Inland ENCS (IEHG, 2011(b)) has been established. This guide replaces the section "Use of the Object Catalogue" of S-57.

Inland ENCs are compiled for a variety of navigational purposes, the so-called usages. For maritime ENCs S-57 defines 6 usages: Overview, General, Coastal, Approach, Harbour and Berthing. On top of these 4 additional usages specifically related to Inland ENCs have been defined: River, River harbour, River berthing and Overlay.

Inland ENCs are displayed on board ships using an Inland ECDIS system. This is the version of the Electronic Chart and Display Information System that is used for inland navigation to read maritime ENCs.

\section{OVERVIEW OF COMPILED INLAND ENCS}

Since 2010 Flemish Hydrography produces Inland ENCs. As the already existing production of maritime ENCs with the CARIS HPD software met the requirements, it was obvious to choose the same software and database. After a succesfull test period an integrated system for all existing chart products within the Flanders Hydrography has been establis- hed. The Inland charts are produced on the authority of the Shipping Assistance Division of the Agency for Maritime and Coastal Services and on the authority of the Ports of Ghent, Zeebrugge and Ostend.

The Flemish Hydrography is using the Inland ECDIS Standard 2.3 (IEHG, 2011(a)). This Standard consists of:

- Edition 2.3.4. of the Encoding Guide (IEHG, 2011(b);

- Edition 2.3. of the Product Specification for Inland ENCs (IEHG, 2011(c));

- Edition 2.3 of the Inland ENC Feature Catalogue (IEHG, 2011(d))

The total area that has been charted is approximately $640 \mathrm{~km}^{2}$. This area is divided into 7 separate Inland ENCs to be able to comply with the maximum recommended size of each individual cell of $5 \mathrm{MB}$ (see Figure 1). These are:

- Inland ENC Channel Ghent - Terneuzen adjacent to the seaport of Ghent (1);

- Estuarian navigation (5-miles zone Belgian Continental Shelf) including seaport Zeebrugge (2);

- Channel Boudewijn: connecting outport Zeebrugge with the inner harbour Bruges (3);

- Antwerp N: western Scheldt from Dutch-Belgian border to Antwerp Rede (4);

- Antwerp S: Antwerp Rede to lock of Wintam (5);

- Estuarian navigation (5-miles zone Belgian Continental Shelf) including seaport Ostend(6);

- Channel Plassendale: locks outport Ostend till lock Plassendale (7).

All compiled Inland ENCs are on usage 7, meaning 'Navigating the inland waterways'.

The Flemish Hydrography uses a compilation scale of $1 / 10000$.

The working area of the Flemish Hydrography is shown in Figure 1.

The Flemish Hydrography is currently authorised to produce above mentioned Inland ENCs. The compilation of the Inland ENCs of the remaining Inland Waters in Flanders (approximately 1000 running $\mathrm{km}$ ) is done by the 2 main Waterway Authorities 'Waterwegen and Zeekanaal NV' and 'NV De Scheepvaart'.

\section{4 | Hydrol2}




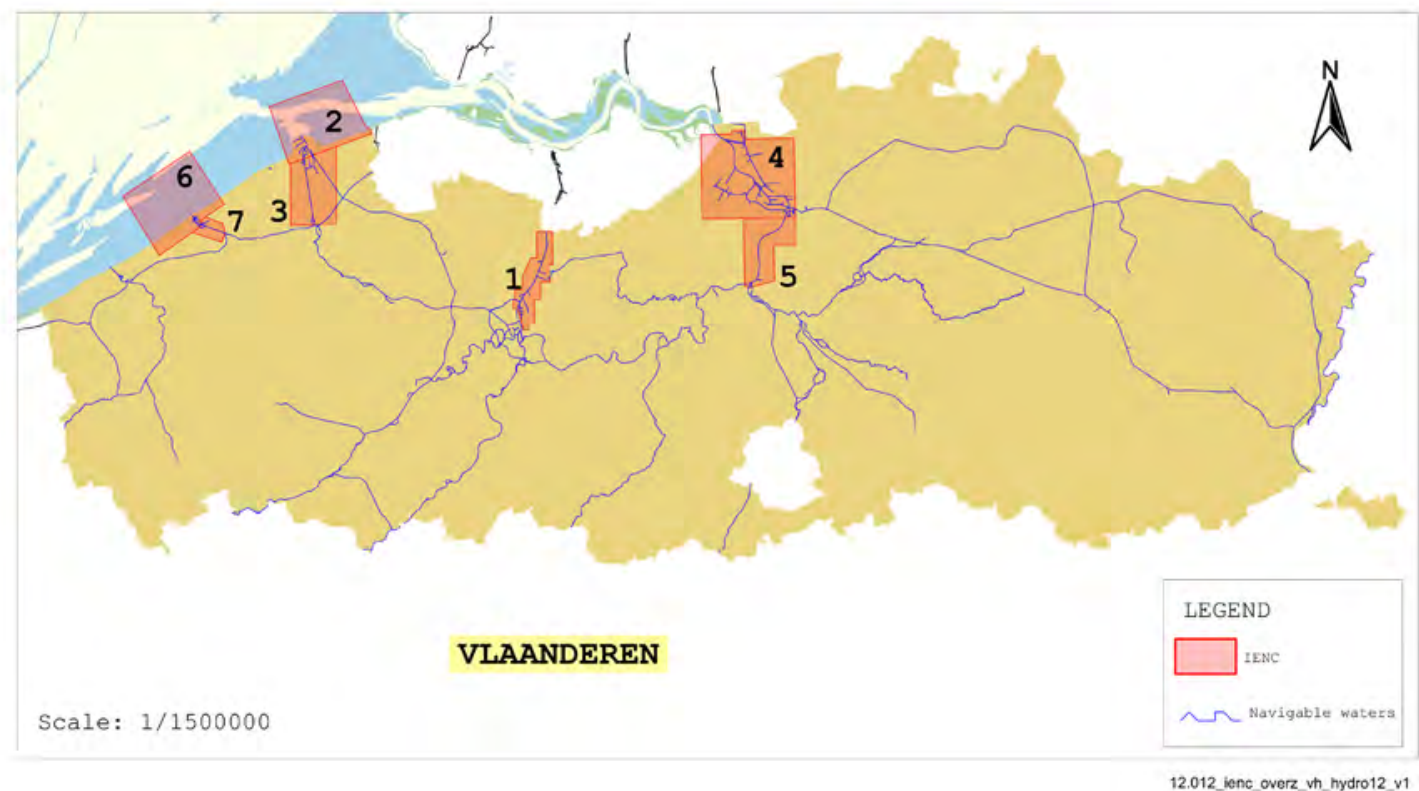

Figure 1: Inland ENCs produced by the Flemish Hydrography

As an example a detail of the Inland ENC Channel Ghent-Terneuzen is shown below in figure 2. The mapped area of the entire Inland ENC is approximately $56 \mathrm{~km}^{2}$. One of the most important objects to be mapped on this channel is the bridge at Zelzate. A lot of metadata is linked to this object. The detail below shows the information concerning the 'Communication Area' which is defined nearby this bridge. At the left bottom (inspector window) the additional information is shown.

\section{COMPILATION WORKFLOW}

At the Flemish Hydrography the data on Inland ENCs comes from different sources. The bathymetry is coming from surveys that are stored and managed in a gridded format in the CARIS Bathy Database

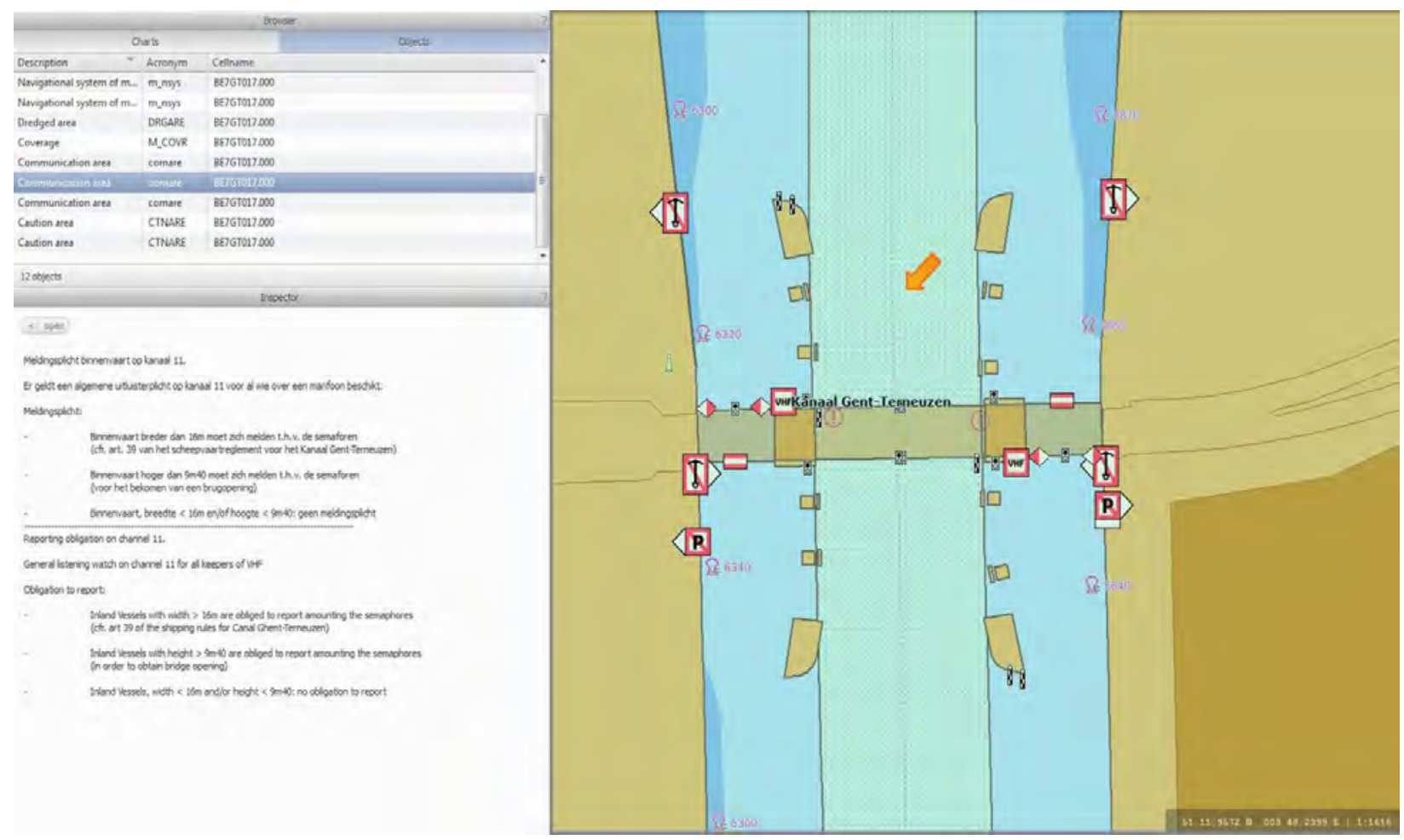

Figure 2: detail of the Inland ENC Channel Ghent-Terneuzen 
Suite. The bathymetry is exported from there in an S-57 vector format. The same bathymetry is used on ENCs, Inland ENCs and paper charts (depending on the scale of the data).

The (maritime) infrastructure that is shown on nautical products is coming from waterway authorities, shipping assistance, maritime access, harbours and others. Data is usually delivered in the form of ESRI Shape or AutoCAD vector formats and imported in the CARIS Hydrographic Production Database (HPD) where it's stored in an S-57 vector format and combined with the bathymetry.

HPD is a database driven solution, based upon Oracle, that consists of different components. In the HPD Source Editor all hydrographic vector information is stored, managed, validated and verified. The data is stored on different so called usages, corresponding to different generalization levels of the cartographic products.

Verified data is used in the HPD Product Editor, for the creation of ENCs and Inland ENCs. The Paper Chart Editor, which is another component of HPD, is used for the creation of INT1 nautical charts. All these products are produced from the same source database. This allows the use of one feature on multiple products, which increases efficiency.

Like ENCs, Inland ENCs are exported in S-57 format and put into a so called Exchange Set. After an external quality control using software of TRESCO, SevenCs and Periskal, the Inland ENCs are placed on the River Information Services Portal from which they can be downloaded to be used on board ships.

Figure 3 shows in detail the Inland ENC production workflow within the Flemish Hydrography.

\section{AVAILABILITY AND USE}

The Inland ENCs are intended for any inland vessels that travel in the areas shown in figure 1 and have an Inland ECDIS system on board. The Inland ENCs are free of charge and can be downloaded in a client friendly way through the Flemish RIS portal (RIS Flanders, 2008).

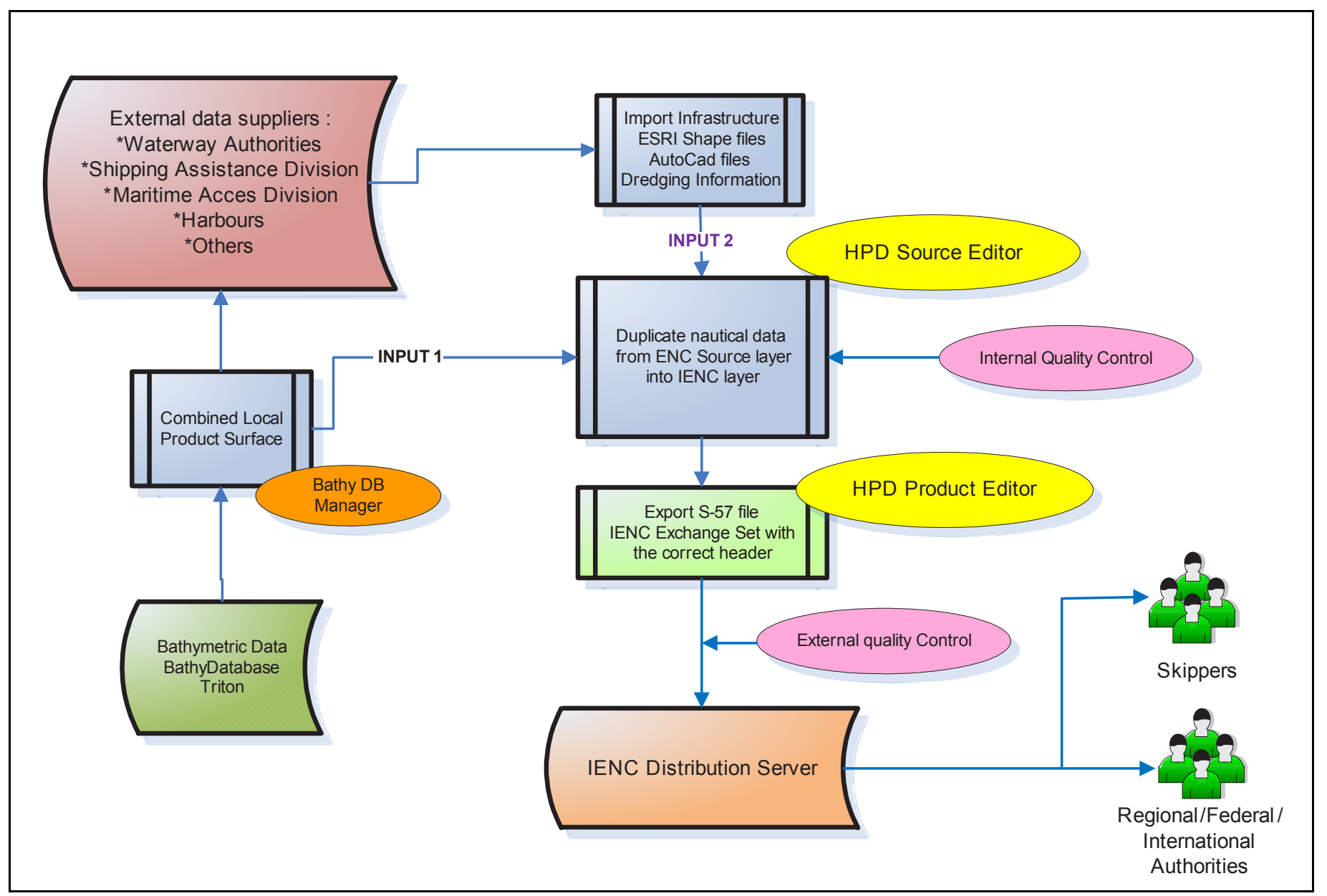

Figure 3: Inland ENC workflow production 
Additionally the charts made on the authority of the ports can be downloaded through their own websites.

\section{CONCLUSION}

The Flemish Hydrography has been able to set up an efficient Inland ENC Production unit in parallel to the other existing hydrographical production units within the team. The choice of the software CARIS HPD for the compilation of the Inland ENCs totally met the expectations.

\section{REFERENCES}

UNECE, 1998. Inventory of Main Standards and Parameters of the E Waterway Network. http://www. unece.org/fileadmin/DAM/trans/doc/finaldocs/sc3/ ECE-TRANS-SC3-144r1e.pdf.

IEHG, 2007. Inland ENC Harmonization Group. http://ienc.openecdis.org.

IHO, 2010. ” S-100 Universal Hydrographic Data Model." 1.0.0th edition, accessed January 2010. http://www.iho.int/iho_pubs/IHO_Download.htm.

IHO, 2000.” S-57 IHO Transfer Standard for Digital Hydrographic data." 3.1 th edition, accessed November 2000. http://www.iho.int/iho_pubs/standard/S57Ed3.1/31Main.pdf.

IEHG, 2011(a). Inland ECDIS Standard 2.3. Draft. http://ienc.openecdis.org/?q=node/34.

IEHG, 2011(b). "Encoding Guide for Inland ENCs." 2.3.4th edition, accessed June 2011. http://ienc. openecdis.org/files/Inland_ENC_Encoding_Guide_ Edition_2_3_4.pdf.

IEHG, 2011(c). Product Specification for Inland ENCs. " Product Specification for Inland ENCs." 2.3th edition, accessed January 2011. http://ienc. openecdis.org/files/ProdSpec_IENC_2_3.pdf.

IEHG, 2011(d). Inland Feature Catalogue. "IENC Feature Catalogue." 2.3th edition, accessed June 2011. http://ienc.openecdis.org/files/IENC_FC_23. pdf.
RIS Flanders, 2008. River Information Services Portal Flanders. http://ris.vlaanderen.be.

\section{CONTACT DETAILS}

\section{DUMOLLIN JASMINE}

Flemish Ministry of Mobility and Public Works, Agency for Maritime and Coastal Services, Flemish Hydrography

Vrijhavenstraat 3

8400 Ostend

BELGIUM

Tel.: +32 (0)59 554252

Fax: +32 (0)59 507037

Email:jasmine.dumollin@mow.vlaanderen.be www.vlaamsehydrografie.be 
$68 \mid$ Hydro 12 


\title{
Deepening of the Port of Santos - Brazil Dredging to Results; $5000 \mathrm{~km}$ surveyed
}

\author{
José Bartolomeu FERREIRA FONTES, Brazil \\ Consórcio Draga Brasil Ltda.
}

Mathias SCHLOESSER, Brazil

GEO TAG Engenharia Ltda.

Topics: Innovations in acquisition techniques, Careful marine planning, Geophysics of the marine environmemt

\section{SUMMARY}

Deepening of the Port of Santos is the major dredging project in the Growth Acceleration Program PAC (Plano de Aceleragao de Crescimento) of the Brazilian government. The dredged material had a volume of about 20 million cubic meters. The Port of Santos is located at the bay of Santos, coastal of Sao Paulo, in south-east of Brazil.

The first historical dredge work did happen between 1891 - 1909. The goal of the Deeping was to dredge the $22.5 \mathrm{~km}$ long harbor channel from 12 meters to a depth of 15 meters for the complete $22.5 \mathrm{~km}$ channel. Also the channel width was expanded from 150 meters to 220 meters. The new and wider channel allows vessel up to 9.000 TEUs to navigate simultaneously in the channel. Before the dredge work happened it was only permited that one vessel up to 5.500 TEUs could navigate in the channel at once.

In February 2010 the Deeping process and expansion of the channel started and finished in January 2012. The two years of work included main dredge work and also the removal of two big rocks lateral the channel, operated by another company. For now, there is only channel maintenance to do.

The dredging work in the Port of Santos was a significantly milestone in the national economy, due the increased capacity for large vessels and increased sharing of the channel by ships. The capacity of the Port of Santos will increase by $30 \%$ through the dredge works.

The dredging and result of dredging as provided in the contract are definite through bathymetric contours until the maximum depth of the project was achieved. The bathymetric systems of multi beam and single beam echo sounders are used for the control, monitoring and validation during the deepening process.

Each of the systems is implemented in a specific way but with controversy. These differences, advantages and disadvantages are discussed in this study. Two hopper dredges with a capacity of $5.000 \mathrm{~cm}^{3}$ and 13.500 $\mathrm{cm}^{3}$ were applied at the deepening project.

The dredge work was monitored weekly with a single beam echosounder system and the surveyed distance was $5.400 \mathrm{~km}$ from beginning to end of the dredge work. The single beam surveys were necessary to get valid information from bottom inside and sediment thickness.

Natural effects like storm surge and the continued harbor traffic and still operating port complicated the dredge work. The storm surges returned dumped material and refilled already dredged areas with new sediment. It causes that the refilled area had to be dredged again. Because of the vessel traffic in the harbor of Santos, the dredge and also bathymetric surveys were under high pressure to guarantee safety and efficient dredge work. 
The Brazilian environmental authority allocated a dumping area $6 \mathrm{~km}$ away from the coast. The dumping has a depth of 22 meters. The dredged sediments were examined in a laboratory, also they did biological analyzes and monitored dredge effects and influence along the beachside and maritime fauna.

Something interesting: a local fishing club reported that they had an increasing quantity and new fishes in their area of fishing, close to the dredged channel.

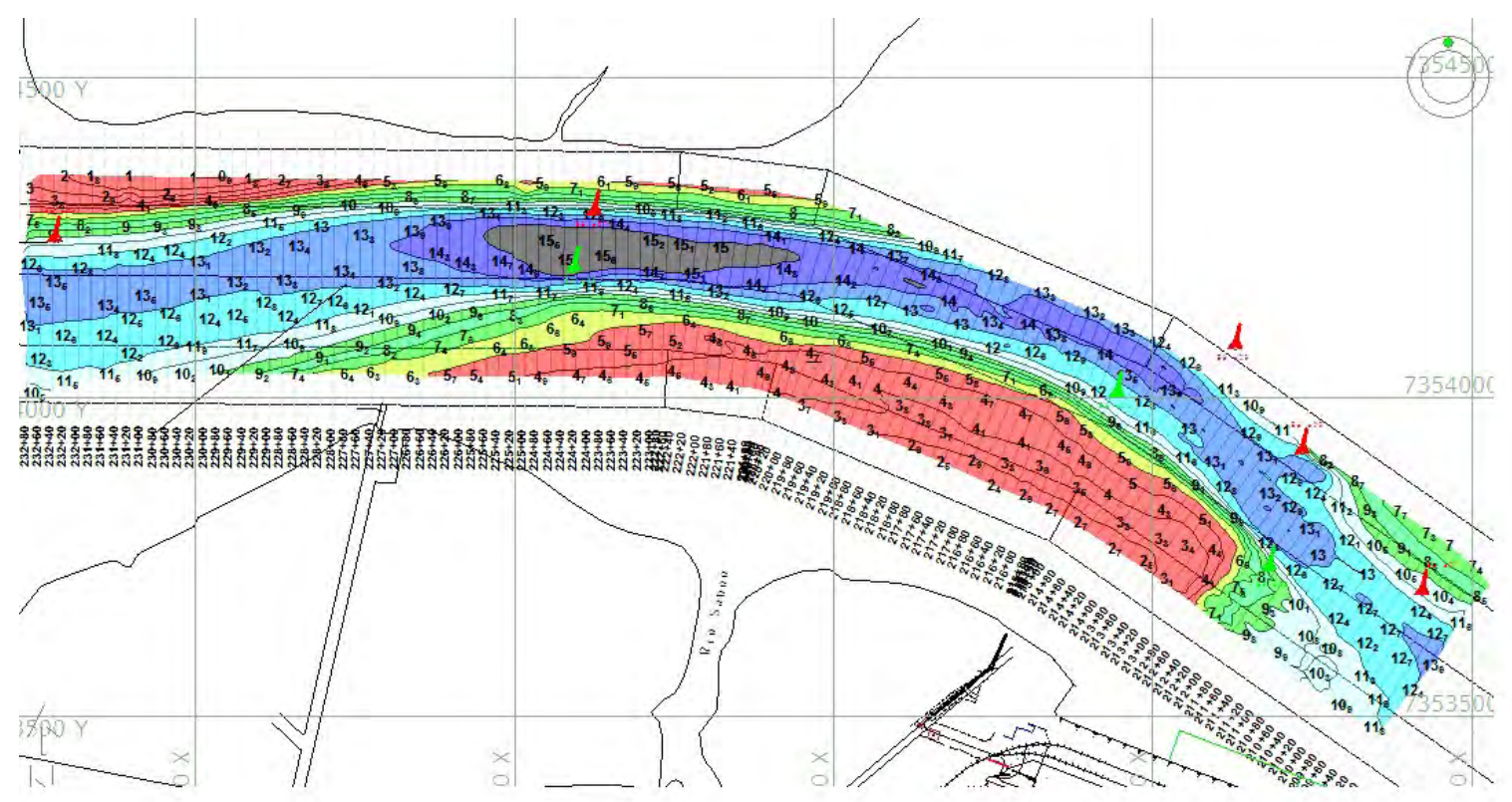

Figure 01: Difficult - Buoy

\section{INTRODUCTION}

The figures of this work are expressiv about the reality of the Brazilian dredge market, as well as its risks. The silting before achieve a project level, intense vessel traffic and bad sea conditions are risks assumed by the dredging company. For that reason I considered to do a "surgical dredging." The dredging operations have to be constantly monitored by bathymetric surveys with high accuracy, also the phenomena of silting has to be continuously monitored.

Principally unexpected difficulty are metallic objects cause damage to the teeth and dredge heads. Furthermore, interdiction areas due to archaeological searching and sea storms. The Port of Santos has historic wrecks, mainly ones who are inside the project area and impede the progress of work.

The first bathymetric survey, called "LHPRE" (Levantamento Hidrográfico Primitivo) was done to provides support for the project executive, including the calculation for the expected volume of material, which has to be dredged. The dredging company get the volume according to the agreement, if the contractual milestones are achieved. If on a given section the desired depth is 15 meters, the executor of the dredge work can only finalize the job and get the volume, when inside the complete section the depth of 15 meters is achieved (Table 01). Then the executor will be paid for his dredge work. But he only get the salary for the volume, which was (pre-) calculated after the LHPRE, and not what he really dredged throughout the project.

The advantage is that the first survey (LHPRE) was done with a multi beam echo sounder, which had a good data accuracy. The disadvantage is that the silting phenomena happens before the dredging started. The company will not easily receive the goal, so they have to dredge much more to achieve the same depth.

For bathymetric monitoring, or rather to provide the dredges with information and to monitor the progress of work, the surveys were almost done daily with a single beam echo sounder. To penetrate into the bottom layers, to check fluid mud and suspended material, an echo sounder with 200/24 $\mathrm{kHz}$ dual-frequency and simultaneously data registration was used.

\section{0 | Hydrol 2}




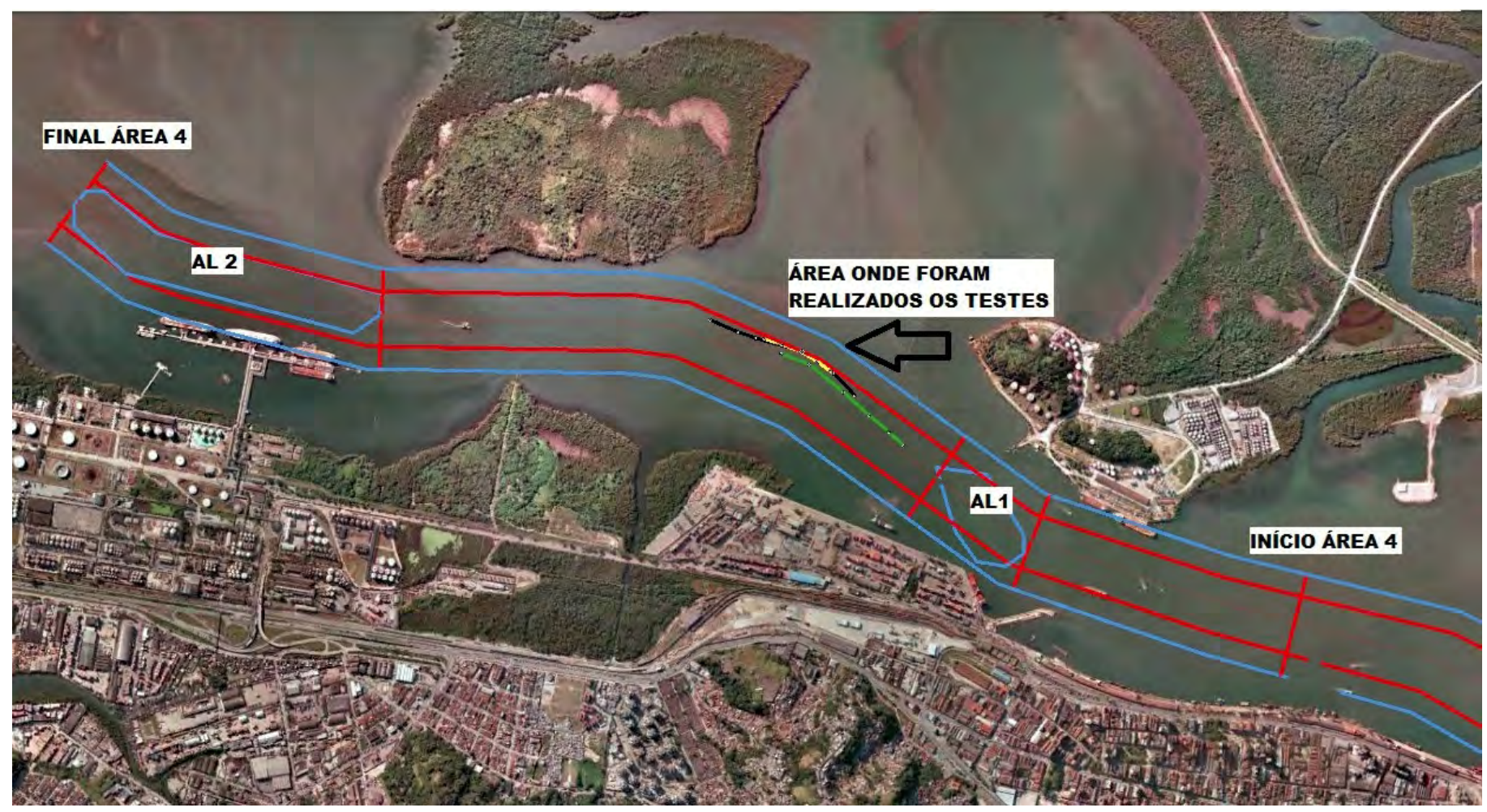

Figure 02: Last stage of deepening - Low quality material.

To complete the dredge work an ultimate bathymetric survey was done. The LHPOS (Levantamento Hidrográfico Pos dragagem) was surveyed with the same equipment and configuration as the LHPRE. Both data were analyzed and used for the official volume calculation for the deepening project of the Port of Santos.

The single beam survey data were used for dredge process monitoring and to support the dredge works with recent data.

The LHPRE and LHPOS were done with a multi beam echosounder because of its $100 \%$ bottom coverage which allows a precise and reliable volume calculation for the complete project area.

\section{METHOD}

\subsection{Multi beam}

The main advantage of multi beam sounders in seabed characterization is their potential for selecting the exact signal returning at particular angles (Lurton, 2002).

The multi beam system was selected by the awarding authority due to cover $100 \%$ of the area, which has to be dredged and to avoid interpolation of points between sections (Figure 03).

The calculated volumes, based on the multibeam survey with accurate and a substantial quantity of sounding. The equipment used for the LHPRE and LHPOS survey was the ODOM ES3 multi beam system, the ODOM Digibar Pro velocimeters, the motion sensor DMS-05 from TSS and HYPACK software (version 2010).

The first major difficulty was to find a qualified and experienced engineer to perform the survey within the required standards for data acquisition and fidelity. Many companies invest in new equipment, but do not invest in the training of technicians. This model of a multi beam system is widely used in the domestic market, because the major objective control activity at dredge works is to verify the dredged depths and the low costs of the device. But, the quantity of sections needed for a full coverage of the seabed are more than with a sophisticated (and more expensive) multi beam system.

\subsection{Single beam}

The single beam echo sounder is applied to monitor the dredge process, in principle for reasons of economics and secondly the practical assembly of the system. This application has been very effective to verify the dredged volumes. The dual frequency profiles are outstanding compared to the single frequency profiles (Figure 04). 


\begin{tabular}{|c|c|}
\hline \multicolumn{2}{|c|}{ DREDGING WORKS OF PORTO DE SANTOS } \\
\hline DEEPENING DREDGE TO LEVE & 13.8 Million $\mathrm{cm}$ \\
\hline LENGHT OF THE CHANNEL & $24.600 \mathrm{~m}$ \\
\hline NEW WIDTH OF THE CHANNEL & $220 \mathrm{~m}$ \\
\hline \multicolumn{2}{|c|}{ AREA 1 - EXTERNAL CHANNEL } \\
\hline LENGHT & $11.560 \mathrm{~m}$ \\
\hline FINAL DEPTH & $15 \mathrm{~m}$ \\
\hline MEDIUM DISTANCE TO DUMPING AREA & $6,65 \mathrm{~nm}$ \\
\hline VOLUME TO BE DREDGED & $4.025 .648 \mathrm{~cm}$ \\
\hline INTERMEDIATE MARK & $14,3 \mathrm{~m}$ \\
\hline FINAL DEPTH & $15,0 \mathrm{~m}$ \\
\hline MATERIAL TO BE DREDGED & SAND SILT AND CLAY \\
\hline \multicolumn{2}{|c|}{ AREA 2 - INTERNAL CHANNEL } \\
\hline LENGHT & $4.340 \mathrm{~m}$ \\
\hline FINAL DEPTH & $15 \mathrm{~m}$ \\
\hline MEDIUM DISTANCE TO DUMPING AREA & $11,4 \mathrm{~nm}$ \\
\hline VOLUME TO BE DREDGED & $2.508 .815 \mathrm{~cm}$ \\
\hline INTERMEDIATE MARK & $11-14,2 \mathrm{~m}$ \\
\hline FINAL DEPTH & $15,0 \mathrm{~m}$ \\
\hline MATERIAL TO BE DREDGED & SILT AND CLAY \\
\hline \multicolumn{2}{|c|}{ AREA 3 - INTERNAL CHANNEL } \\
\hline LENGHT & $3.340 \mathrm{~m}$ \\
\hline FINAL DEPTH & $15 \mathrm{~m}$ \\
\hline MEDIUM DISTANCE TO DUMPING AREA & $13,24 \mathrm{~nm}$ \\
\hline VOLUME TO BE DREDGED & $1.741 .999 \mathrm{~cm}$ \\
\hline INTERMEDIATE MARK & $11-14,0 \mathrm{~m}$ \\
\hline FINAL DEPTH & $15,0 \mathrm{~m}$ \\
\hline MATERIAL TO BE DREDGED & SILT AND CLAY \\
\hline \multicolumn{2}{|c|}{ AREA 4 - INTERNAL CHANNEL } \\
\hline LENGHT & $5.260 \mathrm{~m}$ \\
\hline FINAL DEPTH & $15 \mathrm{~m}$ \\
\hline MEDIUM DISTANCE TO DUMPING AREA & $15,5 \mathrm{~nm}$ \\
\hline VOLUME TO BE DREDGED & $5.252 .770 \mathrm{~cm}$ \\
\hline INTERMEDIATE MARK & $11-12,414,3 \mathrm{~m}$ \\
\hline FINAL DEPTH & $15,0 \mathrm{~m}$ \\
\hline MATERIAL TO BE DREDGED & SILT AND CLAY \\
\hline
\end{tabular}

Table 01: The deepening project of the Port of Santos in facts

The envelope delay of signals collected by a single beam echo sounder are different at any type of seabeds (Pouliquen and Lurton, 1994). This fact is very important because the dredge process can be differentiated in suspension materials or materials of different densities.

\section{Results}

The main result of this study is that there is the perfect application for each device and the sureness that one system does not replace the other one. The two systems complement each other. Various 


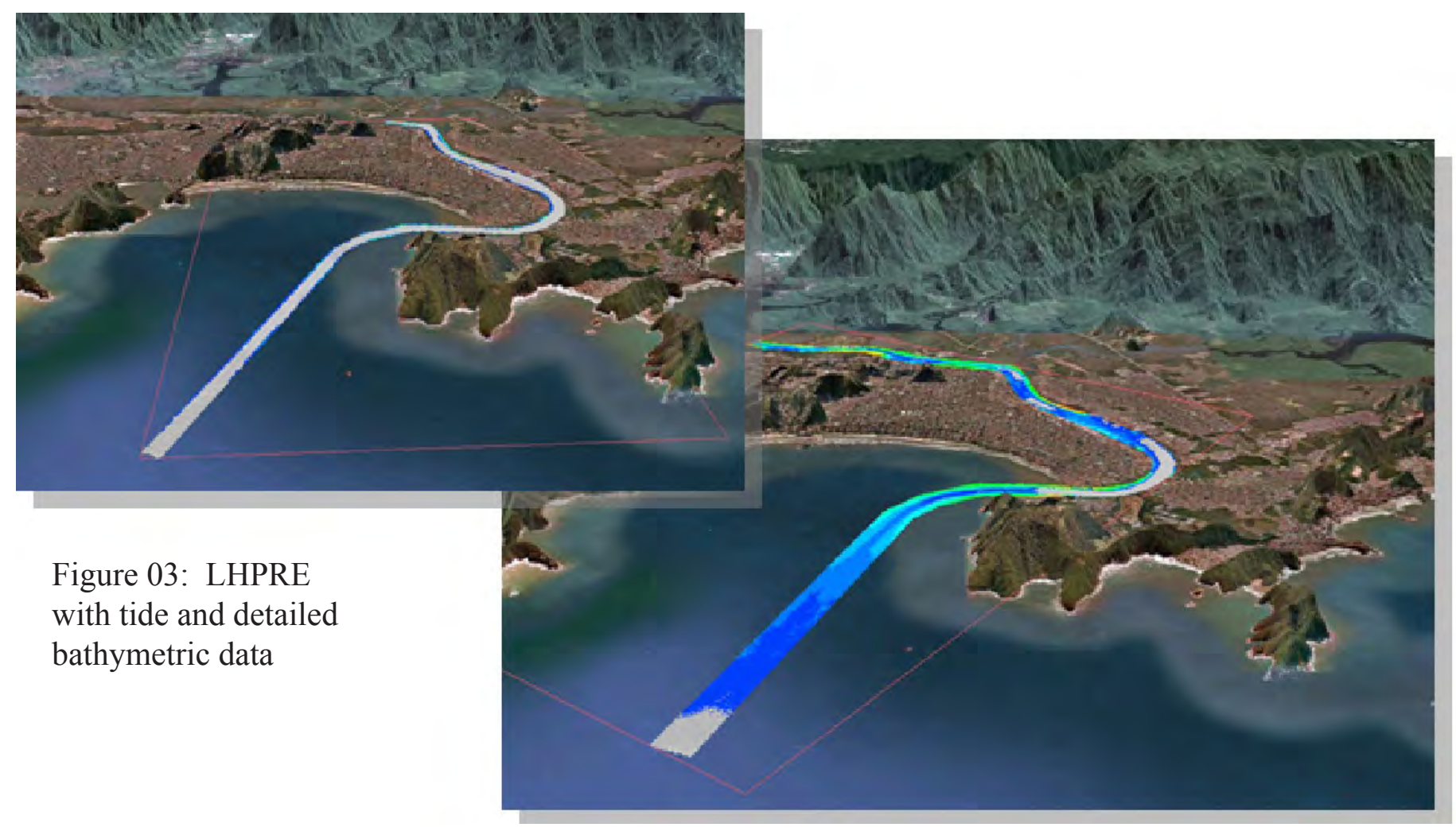

features, objects and intrinsic the calculation of volume were better defined by the application of the multi beam system.

The data generated by the single beam echo sounder system allowed to monitor the suspended material and a better understanding of natural phenomena. Finally, the surveys with single beam echo sounder were often operated by the dredgers.

Particularely to detect sediment layers and to have view inside the bottom, single beam echo sounder are still necessary. Even for not to overdregde and to adjust the dredge configuration for the area depending bottom condition.

\section{Final Consideration}

With about $5400 \mathrm{~km}$ surveyed bathymetry data and 20 million cubicmeters of dredged material, the dredge project Port of Santos was the biggest dredge work in the history of Brasil. The application
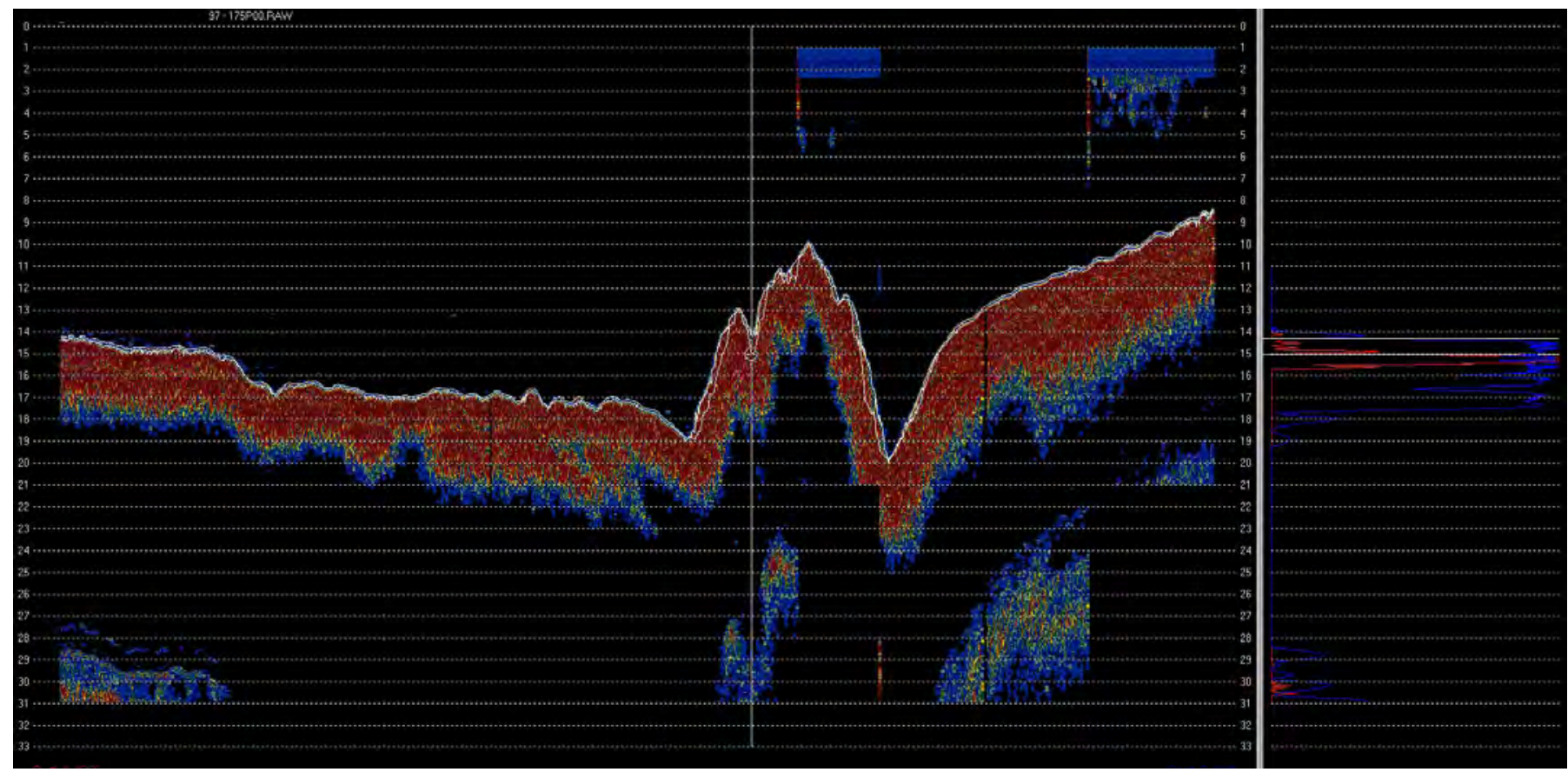

Figure 04: Profile with ODOM MKIII $(200 / 24 \mathrm{kHz})$ single beam echo sounder 
of both echo sounders systems contributed to a very satisfied result. For a project of this size, all technology resources of the equipment operate on a high performance within the given project.

\section{REFERENCES}

Books:

LURTON, XAVIER: An Introduction to Underwater Acoustics. Springer/ Praxis, 2002

Links:

http://www.portodesantos.com.br/down/APCODESP.pdf

http://www.transportabrasil.com.br/2010/01/portode-santos-tera-obras-de-dragagem-concluidasem-2011/

\section{CONTACTS}

José Bartolomeu Ferreira Fontes

Consórcio Draga Brasil

Rua Brigadeiro Galvão, 36 ap 46

Santos - SP

CEP 11030-370

BRASIL

Tel.: +55 (11) 8233-5050

Email: jbffontes@equipav.com.br 


\title{
Hydrodynamic Data from Radar Observations
}

\author{
Caroline GAUTIER, the Netherlands \\ Deltares
}

Herman PETERS, the Netherlands

Rijkswaterstaat DID (Ministry of Infrastructure and the Environment)

Jos van HEESEN, the Netherlands

Nortek BV

Topic: Innovations in acquisition techniques

\section{INTRODUCTION}

For a proper determination of hydraulic boundary conditions it is paramount that wave, current, water level and bathymetry measurements be available. On one hand, observations improve the understanding of flow and waves, the formulations and the models. On the other hand, observations are required in the statistical determination of extreme values. Besides, measurements are needed in the design of offshore and coastal structures and in operational forecasts used for instance in safe navigation, flood forecasting and ship routing.

Most commonly available measurements for such purposes are generally sparse, either in space (for instance point measurements of waves by buoys, or currents by ADCPs) or in time (for instance bathymetric survey campaigns).

However, ordinary marine radars, available at almost each port, have the potential to provide spatial wave, currents and bathymetric measurements in the regions they cover. Dedicated SeaDarQ software by Nortek processes the radar data and derives spatial information on waves, water depths and currents over a significant area. Their onshore position implies reliable operationality and limited maintenance costs. Existing radars and infrastructure are in general located in regions with complex geometries and complex wave, current and depth patterns (inlets, harbours); exactly the regions where data are most needed to validate and calibrate wave, flow and morphology models.

The lighthouse of Ameland - one of the Dutch islands in the Wadden Sea - is equipped with an X-band marine radar $(9.6 \mathrm{GHz})$. Since the beginning of 2010 this radar is connected to the dedicated SeaDarQ software. This paper describes the principle of X-band radar measurements and the application of the processed data.

\section{THE PRINCIPLE OF X-BAND RADAR FOR HYDRAULIC MEASUREMENTS}

$\mathrm{X}$-band radar refers to radar with electromagnetic energy ranging from approximately 8 to $12 \mathrm{GHz}$ in frequency. The wave length of the signal is a few centimetres. The method to derive hydrodynamical data from marine X-band radar is based on the reflection of the radar waves by small scale roughness features at the sea surface e.g. small capillary waves. In order to have enough capillary waves to produce a usable radar image, wind speeds are required in the range of about 2 to $20 \mathrm{~m} / \mathrm{s}$. This sea echo, known as sea clutter, is unwanted noise for navigational purpose. However, by virtue of an amplitude modulation mechanism, the sea clutter makes the wave crest patterns visible, with their associated wave lengths, velocities and orientations.

There are two reasons why the wave patterns are visible in the radar image. First of all, the roughness on a wave crest is higher than in a wave through due to hydrodynamic modulation. Second, the large gravity waves modulate the radar backscatter strength by tilting the sea surface and, for low grazing angles, the wave crests even create shadows at their back slopes. The latter mechanism only works for the range travelling waves (i.e. in the direction of the radar), while the former holds for both range travelling and azimuth travelling waves. This explains why the range travelling waves can be seen better in the radar image than the azimuth travelling waves. 
The radar antenna on top of the Amelander lighthouse rotates continuously around a vertical axis and transmits intermittently short pulses of electromagnetic energy, the reflections of which are received up to a distance of a few kilometres. After about $0.1 \mathrm{~ms}$, when all the echoes of the previous pulse have died away, the next pulse is transmitted in a slightly different azimuth direction. It takes 2.85 $\mathrm{s}$ (and thus a few thousand pulses) to cover the full azimuth sector of $360^{\circ}$.

From a series (film) of radar images the wave propagation direction and the associated phase velocity can be estimated unambiguously. Hereto, the radar images need to be transformed from (x, $y, t)$ space via $3 d$ FFT to $(k x, k y, \omega)$ space (with $\mathrm{kx}$, ky the orthogonal components of the wave number vector and $\omega$ the angular frequency). The ideal (simple) dispersion relation gives the relation between the wave length and the undisturbed phase velocity (no currents and deep water). However, in practice the phase velocity estimated from the sequence of radar images will often deviate from the undisturbed phase velocity. The measured difference makes it possible to compute the current velocity as well as the average water depth. To determine the water depth, mainly the low frequency part of the dispersion relation $(\mathrm{f}<0.15 \mathrm{~Hz})$ is used, while the high frequency part is mainly used to estimate the surface current vector. The measured current parameters represent the depth-averaged value of the vertical current profile in the upper few meters of the water column.

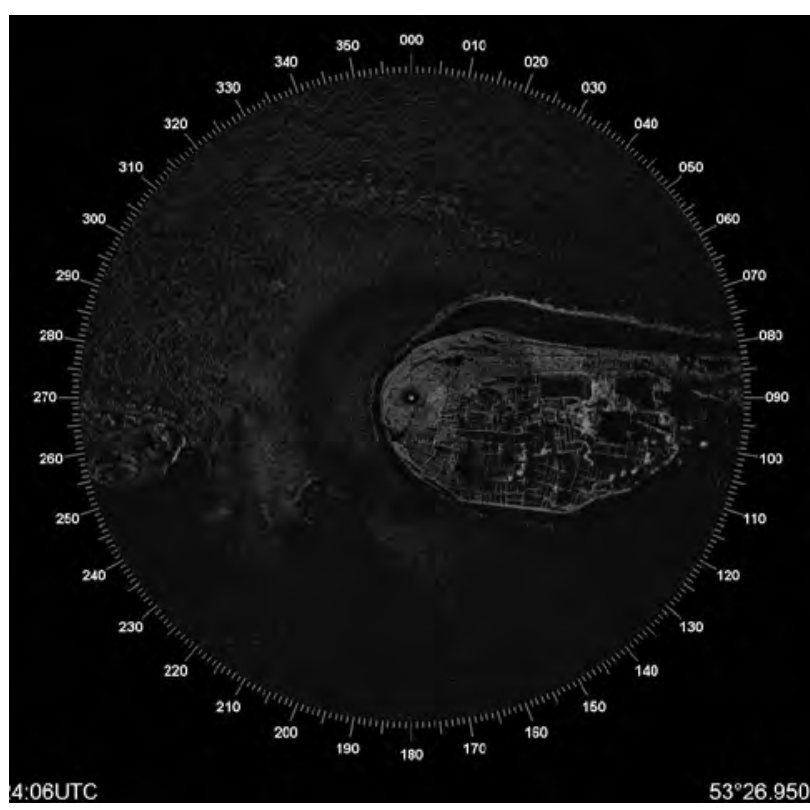

The radar spectra represent the radar intensity, and not the wave energy density. A Modulation Transfer Function (MTF) is required to assess the wave spectrum. This empirical function, linking the wave spectra with the radar spectra, depends on both the measuring system (video amplifier, antenna height, range compensation of the video signal) and environmental features (sea state, angle between waves and radar beam, distance to radar). In practice, it could be calibrated using buoy measurements.

Depending on the actual settings, the radar image may consist of rectangular pixels with ca. $7.5 \mathrm{~m}$ resolution, which form a calculation matrix of the underlying radar resolution cells. The radar range resolution $\Delta \mathrm{R}$ depends on the pulse length $\Delta \mathrm{T}$ $\left(\Delta \mathrm{R}=0.5^{*} \mathrm{c}^{*} \Delta \mathrm{T}\right.$, with $\mathrm{c}=3 * 108 \mathrm{~m} / \mathrm{s}$; speed of light $)$. The azimuthal resolution $\Delta \mathrm{L}$ depends on the radar beam width and thus on the horizontal length $\mathrm{D}$ of the antenna $(\Delta \mathrm{L}=\mathrm{R} * \lambda / \mathrm{D})$ with $\mathrm{R}$ the distance from the radar and $\lambda$ the wave length of the radar signal, being $0.03 \mathrm{~m}$. The radius of the radar image consists of 1000 pixels $(7.5 \mathrm{~km})$.

In case of the Amelander radar, the radar intensity spectra as well as wave and current parameters are computed for rectangular areas with size $959 \mathrm{~m}$ x $959 \mathrm{~m}$. The spatial resolution for the estimated spectra and the parameters derived thereof is ca 300 $\mathrm{m}$. Whereas spectra from buoys are based on time series (for instance 2048 values with $0.5 \mathrm{~s}$ interval) at one location, the radar spectra are based on a shorter period and more locations (for instance 128

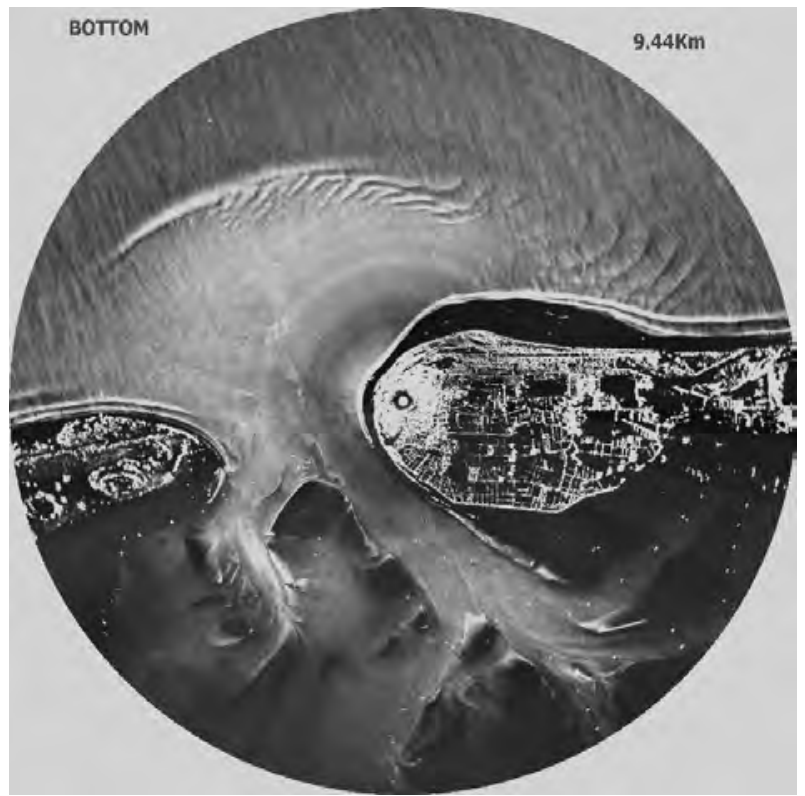

Figure 2.1: $\quad$ Unprocessed radar image (a) and processed snapshot (b), both at Ameland 
x 128 pixels x 32 images, equivalent to about 90 $\mathrm{s}$ of radar measurements). Since the FFT requires rectangular pixels, the original polar pixels are linearly interpolated to rectangles.

A 'snapshot' represents the moving average of a number (for instance 8, 16, 32, 64) of successive radar images. In this average view the waves are no longer visible, but bathymetric characteristics as channel positions and other fixed items as e.g. marking buoys emerge more clearly, see Fig. 2.1.

The following parameters can be derived from the radar measurements: Wave frequency, wave length, wave speed, wave direction, wave height (after calibration using a wave buoy), current velocity and water depth.

\section{APPLICATION OF RADAR DATA IN A WAVE HINDCAST}

\section{$\underline{3.1 \text { Introduction }}$}

The radar data of Ameland is part of the SBW measuring campaign by the Dutch Ministry of Infrastructure and the Environment. SBW stands for the "Strength and Loading of Water Defenses" Program, filling in the knowledge gaps in the periodic safety assessment of the primary flood defenses. One of the research topics within SBW is the penetration of North Sea waves into the tidal inlet systems of the Wadden Sea. Aim is to ultimately improve the numerical wave model SWAN (Booij et al., 1999) on this point. The radar data is not used as ground truth yet, but by using the data, experience is gained concerning its reliability and usability, see also Deltares, 2011.

\section{$\underline{3.2 \text { Data }}$}

The hindcast presented here concerns the northwestern storms of October 20 and 24, 2010, starting with a strong breeze (6-7 Bft). The significant wave height at the most northern buoys AZB11 and AZB12 was over $4 \mathrm{~m}$. We selected a strong ebb situation (9:10 (T2)). The next storm occurred a few days later on October 24th. This storm was more severe, both in terms of wind, waves and water levels. The wind ("gale", 8 Bft, wind speed above $20 \mathrm{~m} / \mathrm{s}$ ) turned from west to northnorthwest. The offshore buoys AZB11 and AZB12 observed significant wave heights of over $5 \mathrm{~m}$. We selected the maximum off shore wave height in combination with flood currents (6:00 (T6)).

Besides the radar data (covering about half a circle with $15 \mathrm{~km}$ diameter and a time window of about 13 minutes), twelve waverider buoys are present in the tidal inlet of Ameland, of which a subset of three within the range of the radar (see Figure 3.1). Offshore wave data is available at the wave buoys SON and ELD. Water levels have been measured at Terschelling Noordzee (TNZ) and Nes. Wind data is available from Huibertgat (Huib), Terschelling Noordzee en Wierumergronden (Wier). Use is made of bathymetry data measured in the period March September 2010, completed with bathymetry data from before 2008 .

\subsection{SWAN wave model}

Stationary SWAN simulations were carried out for several events, of which we only present the selected times T2 and T6. On a larger grid (G1) the eastern and western boundary conditions for the nested detail grid (G2) of the Amelander inlet are computed. Besides these, the nested grid receives observed wave conditions on its northern boundary. For simulations on the scale of the Amelander inlet, stationary simulations are appropriate.

The model input consists of bathymetric data, curvi linear computational grids, wave boundary conditions based on observations at ELD, SON, AZB11 and AZB12, uniform wind based on observations at Wierumergronden, uniform water levels observed at Nes (used on G1 only) and nonuniform water level and current fields computed by Delft3D (Deltares, 2012) used on G2. The computations were performed with SWAN version 40.81 in third generation mode. The physical settings are equal to the so called WTI-2011 settings, which were used to derive the Hydraulic Boundary Conditions 2011.

\section{$\underline{3.4 \text { Results }}$}

First, the SWAN results for the spectral significant wave height $\mathrm{Hm} 0$ are compared with the buoy measurements, to show that the agreement - in spite of a limited overestimation - is good, see Figure 3.2. 


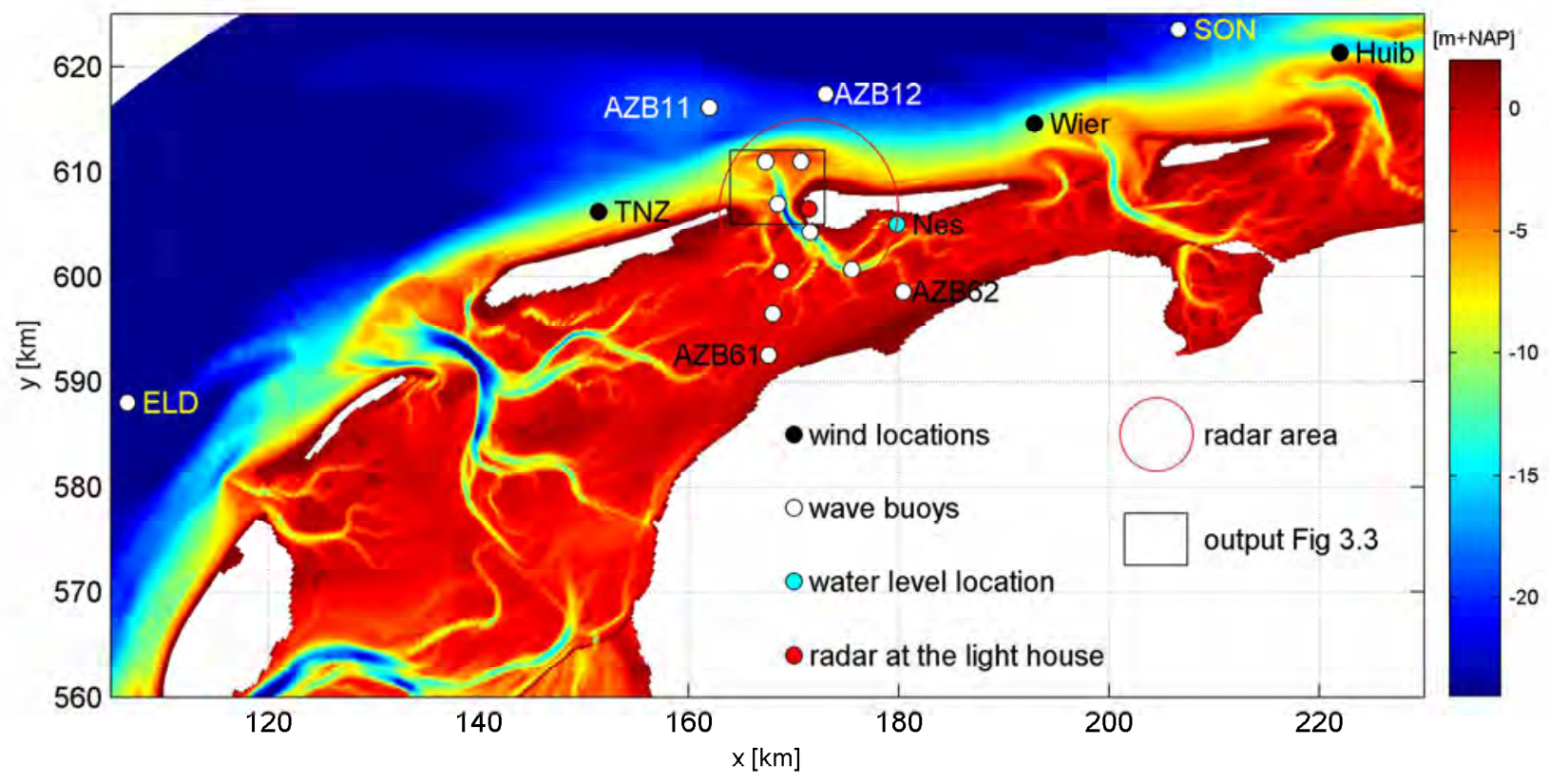

Figure 3.1: Measurement locations and bathymetry Amelander tidal inlet

Next, the radar data are compared to the SWAN results, to obtain an indication of their agreement. Note however that both the radar observations and the SWAN results have their uncertainties. Where differences between the two sources occur, it is unknown which of them is closer to reality. Where possible, the buoy data will also be included.

The radar data contain valuable information but should be used with care. In particular for areas with large bottom gradients, the results are less reliable.
This is primarily due to the spatial averaging over the relatively large resolution. The dominant wave direction is considered, this is the direction of the energy bin with maximum energy as function of direction and frequency. For SWAN, the dominant direction has been computed accordingly, from the absolute 2d-wave spectra.

In Figure 3.3 the wave direction from the radar observations and from SWAN on identical locations are compared for the selected times. The blue
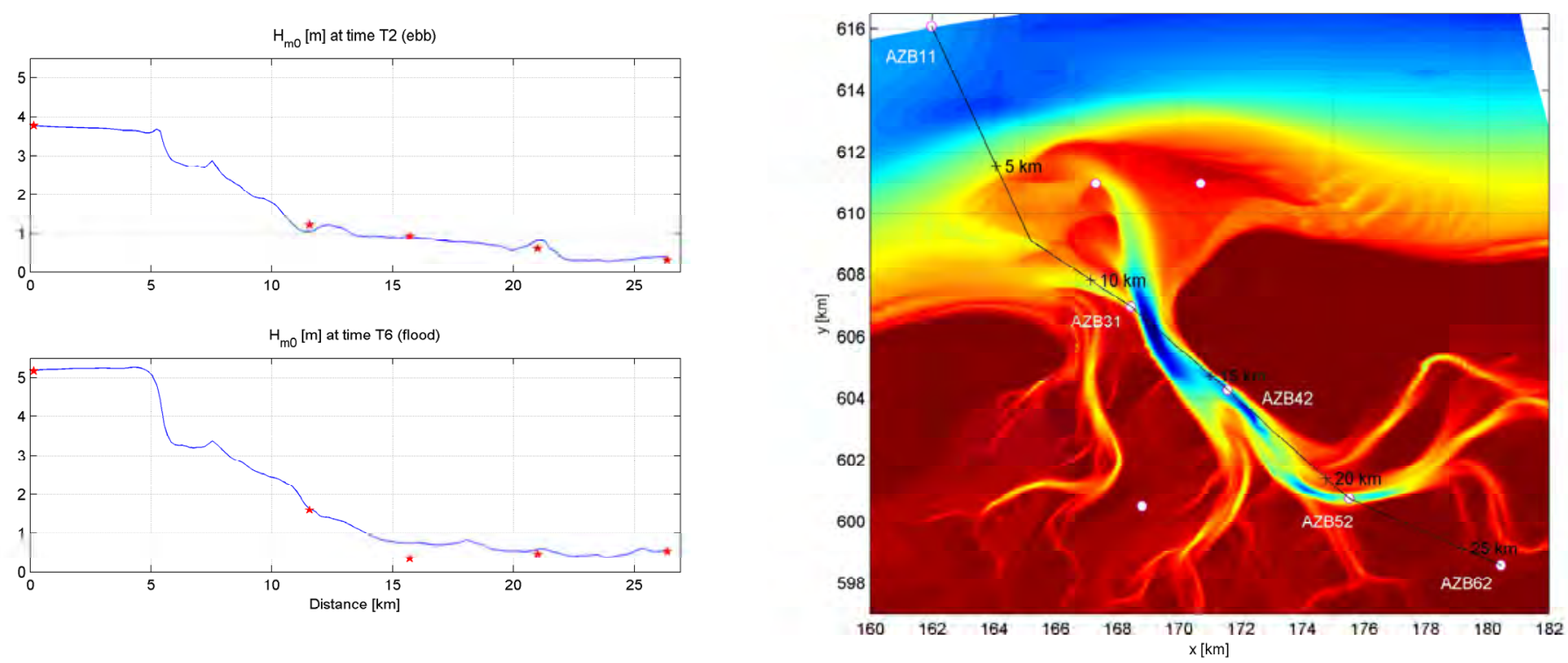

Figure 3.2: (left) SWAN model results wave height $\mathrm{Hm} 0$ for times T2, T6. red pentagons indicate measurements at buoys AZB11, AZB31, AZB42, AZB52, AZB62. (right) location transect. 

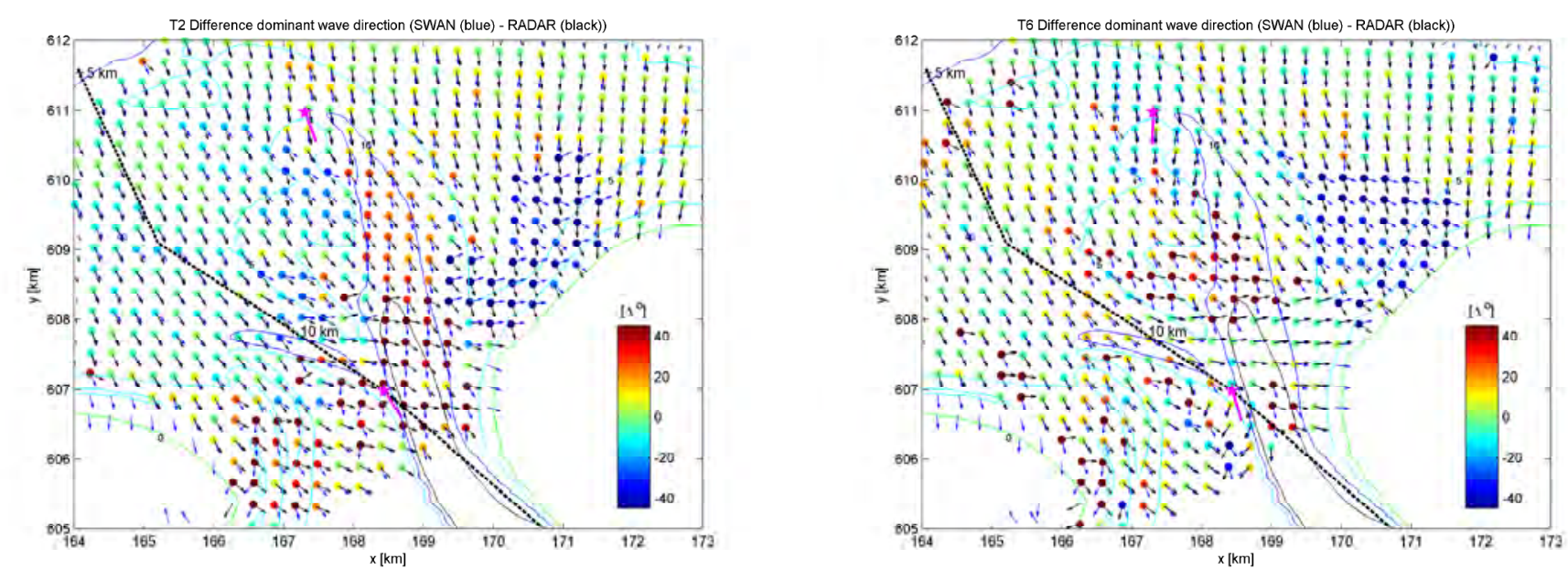

Figure 3.3: Difference dominant wave direction SWAN-RADAR for T2 (ebb) and T6 (flood)

arrows represent the wave direction as computed by SWAN, the black arrows refer to the radar data. The colors indicate the difference between the two sources (SWAN-radar). The majority of the area, especially outside of the inlet, turns out to be fairly green, which means that the directional differences between the radar and SWAN are small. However, moving into the inlet and to the north west shore of Ameland, some large differences are found. According to the SWAN simulations, the waves do not cross the tidal channel $(X=169 \mathrm{~km} ; \mathrm{Y}=607.5$ $\mathrm{km}$ ) in all situations. According to the dominant wave direction of the radar the waves do cross in all considered cases. Since both sources have their uncertainties, it is unknown whether SWAN or the radar performs better here.

In Figure 3.4 not only SWAN and radar data are present, but also peak directions according to waveriders AZB31 and AZB42 are included. On large stretches - from $\mathrm{km} 5$ to $\mathrm{km} 10$ - the agreement between SWAN and radar wave direction is good. In both cases, the wave direction changes over this stretch roughly from $340^{\circ} \mathrm{N}$ to $300^{\circ} \mathrm{N}$. The part of the transect past $\mathrm{km} 10$ shows a rather variable directional situation. This is due to larger spatial variation in bathymetry (and hence wave direction) and also due to the bimodality of the wave spectra here. The results at time T6 (flood) look good, with agreement between SWAN and radar and even with buoy AZB31. Just past the buoy at $\mathrm{km} 12$ the wave direction has its maximum $\left(360-380^{\circ} \mathrm{N}\right)$, as the waves refract out of the steep channel here. However, this does not occur on all times. Even with the buoy measurements included it is hard to judge the radar and SWAN results on the transect for such a locally varying parameter. The differences with the buoy observations are quite large, as is the spatial variation of SWAN and the radar.
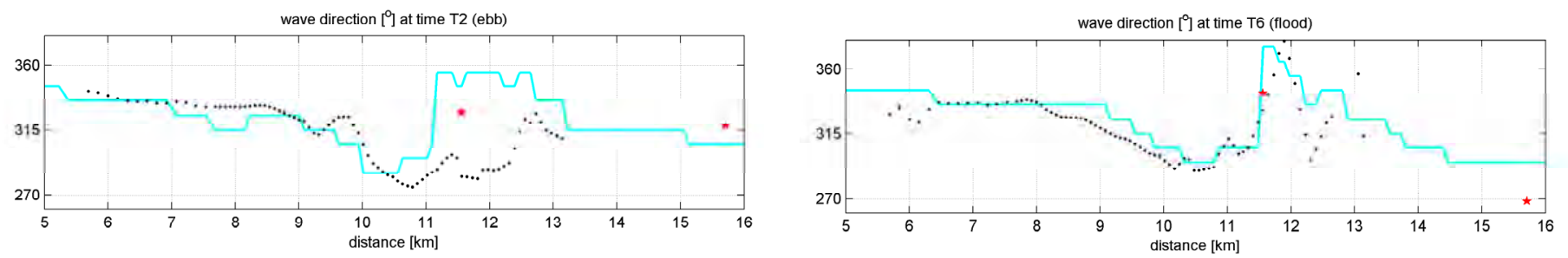

Figure 3.4: $\quad$ SWAN (blue line) and radar (black dots) dominant wave direction on transect (see Figure 3.3 for its position) for times T2, T6. Red pentagons are measured peak wave directions at buoys AZB31 and AZB42. 


\section{DISCUSSION}

The radar observations provide valuable measurements for waves, currents and bathymetry. The main advantage over point measurements is the spatial coverage. This paper focused on the wave analysis at Ameland. However, in the Netherlands there are also SeaDarQ systems available at Kijkduin and Hook of Holland. The latter has the task to monitor the currents for vessels entering the Port of Rotterdam. Since radar provides bathymetric data even during storms, when survey vessels can not sail out, both long term and short term morphologic changes can be derived.

It is important to know the definitions of the parameters in order to prevent inconsistent comparisons. The radar data is based on dominant wave parameters, referring to the maximum energy bin as function of direction and frequency. Dominant direction may shift abruptly if the variance in each directional lobe is about equal. For bimodal spectra it is difficult to catch the wave direction in one value. Small spectral differences could lead to large difference in the dominant parameters. Since the SWAN spectra show bimodality (not shown here), it is likely that this is the main reason for the rather large differences between SWAN and the radar here (see Fig 3.3).

\section{CONCLUSIONS}

Overall, the agreement between the wave direction of radar and SWAN is good. In areas with large spatial variation in wave direction the radar data seems to be less reliable. Some times, large differences exist between SWAN and the radar observations in the main channel. According to the radar, the waves always cross the channel, whereas in SWAN the dominant waves follow in these cases the direction of the channel, instead of crossing it. Since both sources have their uncertainties, it is unknown whether SWAN or the radar performs better here. Probably, the spectra are bimodal here, and the dominant wave direction can shift abruptly if the variance in each directional lobe is about equal.

The radar observations provide valuable measurements. However, this innovative technique is not yet up to such standards that it can replace other wave and current measurements. The data analysis shows that more experience must be gained in order to benefit from all its possibilities. Based on the first experiences with the radar data we hope that in the future the radar data will allow us to calibrate our hydrodynamic models for both water levels and currents, and provide proper insight in the wave models being applied in complex areas like the tidal inlet of Ameland.

\section{REFERENCES}

Booij, N., R.C. Ris and L.H. Holthuijsen. 1999. ”A third generation wave model for coastal regions, Part I, Model desciption and valdiation". J. Geophys. Res., 104, C4, 7649-7666.

Deltares. 2011. "Comparison SWAN, PHAROS and radar wave observations." Deltares report 1204199002-HYE-0009 dd 24 November 2011.

Deltares. 2012. "Water level modelling of storm events in the Wadden Sea." Deltares report 1204199003-HYE-0007 dd 10 January 2012.

\section{$80 \mid$ Hydrol 2}




\section{Is Multibeam Water Column Data Really Worth the Disk Space?}

Lindsay GEE and Maurice DOUCET, United States of America

Quality Positioning Services, Inc

David PARKER, United Kingdom

United Kingdom Hydrographic Office

Tom WEBER and Jonathan BEAUDOIN, United States of America

Center for Coastal and Ocean Mapping/Joint Hydrographic Center, University of New Hampshire

Topics: Innovations in Processing Techniques, Cost-effective solutions

\section{INTRODUCTION}

The very latest multibeam sonars have the capability to record the sonar time series for each beam; mapping the water column along with the seafloor. This capability opens up new uses for multibeam sonars, including the direct mapping of fish and marine mammals, the mapping of plumes and vents, the location of mid-water targets, and a wide range of physical oceanographic processes. To exploit these data, an efficient means of reading, processing and analyzing the data is required. This presentation describes the ongoing development of a commercial tool (FMMidwater) to make these data available for hydrographic surveyors, scientists, and engineers interested in visualization and analysis of water column data, in a multi-mode 4D environment.

\section{DEVELOPMENT CHALLENGES}

A number of challenges needed to be addressed during the development of commercial software tools to allow efficient exploitation of the water column data.

Each sonar manufacturer has a specific data logging file format that is used to capture water column data, and the lack of a standard sonar format provided a challenge for development. Each logged file or files contains data from a specific component within the system such as navigation, attitude, backscatter, multibeam and water column data. A single water column ping may be fragmented across multiple packets; this can be further complicated when navigation and attitude information are logged in separate packets, or in some cases logged to a completely separate file. This results in fragmentation of an instantaneous snapshot of the water column. In order to compute where each sample within a single ping exists in time and space, we need to integrate the information from these different packets/files.

Another significant challenge are the high data rates that exist in some of the shallow water multibeam sonars types, that results in an order of magnitude additional water column data above that from standard bottom detection. Historically there has been an increase in data rates for multibeam sonars as ping rates and number of beams increased, and these data rates can be expected to continue to rise. In order for data analysis and visualization to be efficient and interactive, data loading must be fast with a minimum amount of disk seek time and read delays. Noting the above challenges, it was necessary to avoid the loading of data from very large fragmented files.

The initial development of FMMidwater was built on a research prototype (GeoZui4D) developed at the University of New Hampshire to investigate methods for interactively visualizing time varying geospatial data [Arsenault et al, 2004; Ware et al, 2001] [1][2]. Water column data required a number of new visualization metaphors and export options beyond those used for bathymetry data, in order to address the geospatial and temporal aspects of the analysis, and to extract fully refracted and adjusted detections to fuse with seabed detections from the multibeam processing and visualization.

Finally, it was necessary to ensure that flexibility was incorporated in the tool to allow for both the simple addition of evolving data types as more multibeam sonars provided the water column data, and to facilitate the many emerging uses and users of the data. 
Addressing the primary challenges that exist in exploitation of water column data, an open generic water column format (GWC) was designed as a unified way of storing water column data in a compressed or sub-sampled, integrated manner to be used for efficient interactive visualization [3]. The GWC can be considered analogous to the GSF format [4] that is used for storing processed and raw bathymetry. The open format GWC also assists in meeting the challenge of the evolving multibeam data formats by providing a path for third party developers, such as sonar or survey companies, and researchers, to easily and quickly add format support to FMMidwater.

In the FMMidwater tool the water column packets, time-based navigation and attitude are re-integrated during source conversion, such that all the relevant data of any particular ping is available. The tool also allows the integration of separate navigation and attitude files that may have been processed separately such as with ROV and AUV operations. Files are indexed for fast non-linear extraction and every packet type is extracted for relevant information into the GWC format. Currently, the source conversion system supports a wide variety of hydrographic and fisheries sonars such as the Kongsberg EM series sonars, ME70, EK60, EK500, R2Sonic 2024 and Reson 7125.
The raw data rates of water column data collected from multibeam sonars are very high, however the information content is generally much smaller. An important aspect of any tool used to examine these data is the ability to rapidly review the data and extract features of interest. FMMidwater provides multiple ways to view and threshold the data for display and analysis; swath view, beam view, and stacked view, and a combination of these.

The various views allow easy and rapid identification of features for selection, threshold filtering and extraction. The various views also allow direct comparisons of the water column data with the online bottom detection, and easy identification of detection failures or errors in the hydrographic multibeam sonars. Filters can be applied to specifically focus on certain beams and to limit the range of data used. In addition, the threshold adjustment can be applied to the sonar signal itself. Each GWC file also generates a histogram of the data during the load process. A control is provided such that the user can eliminate low-level noise and either clamp or clip the data at either end of the threshold limits. The histogram can display raw amplitude, power, volume scattering or target strength depending on the capabilities of the sonar. Interactive digitizing can be used during the final selection to constrain the area of the data to be extracted.

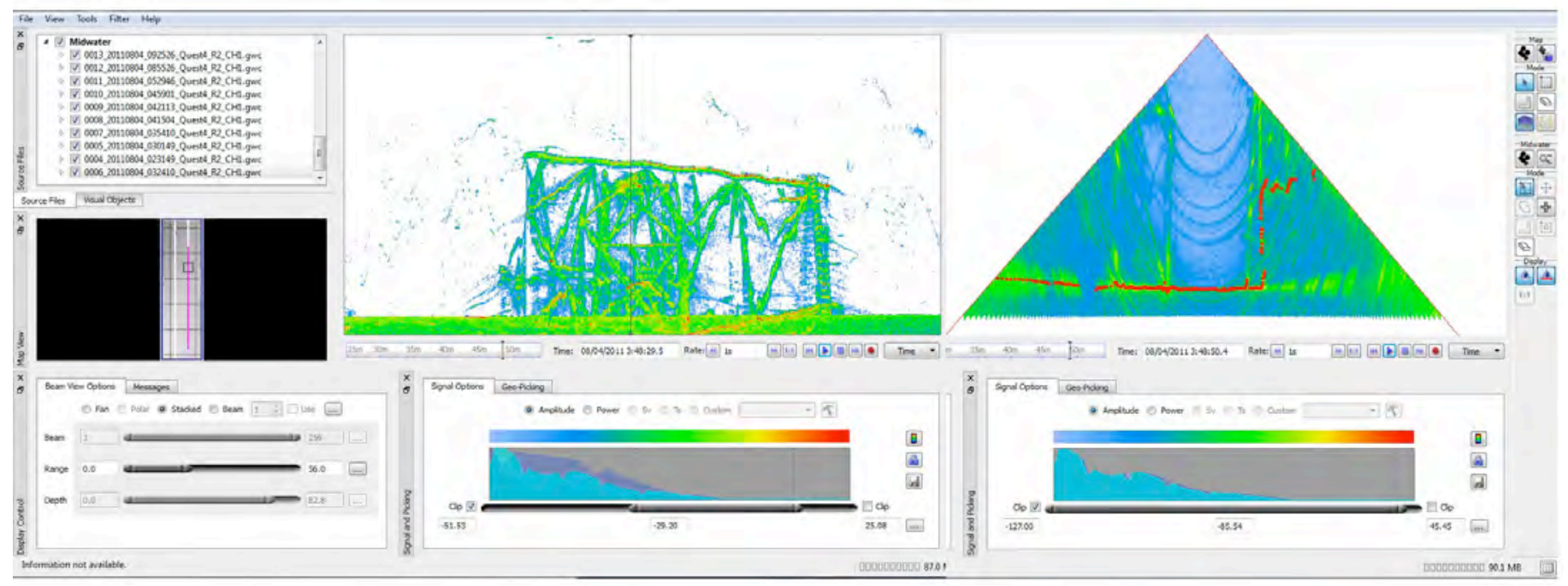

Figure 1. - FMMidwater Stacked and Fan Views - with red points from bottom online detection 
After focusing on the features in the water column in FMMidwater, the contacts can be exported for visualization and further analysis in the Fledermaus 4D environment. Four primary visualization metaphors were developed to provide the most effective means of reviewing water column features:

- Beam Fan Time Series object - a view of the swath that is temporally aware and rendered dynamically in the 4D environment from the GWC file

- Beam line object - a time-aware along-track curtain, or image fence, from an individual beam

- Point cloud object - a time aware object of extracted points with transformed location of the sample in the beam with attributes for line/beam and signal level.

- Volume object - a 3D grid of voxels at a specified cell size. In Fledermaus the voxel brick is used to generate ISO surfaces at user selected values.

The water column data can be used in hydrographic surveying for ensuring that hard targets, such as wrecks are fully detected, and to confirm the least depth in the water column versus the bottom detection. This is achieved in both FMMidwater and also in the Fledermaus PFM data object for integrated multibeam validation and analysis. In the following figures, data is from a Kongsberg EM2040 mounted on an ROV during a survey in the Gulf of Mexico.
The water column capability of modern multibeam sonars has widened the applications for water column data and has the potential to extend the capabilities of the multibeam sonars in various fields such as hydrographic survey, resource exploration, and marine habitat mapping. This presents a significant challenge in developing software applications that can address all of these potential user requirements. One option was to restrict the development of the mid-water tool to a particular area such as hydrographic surveying. Instead, FMMidwater has been structured to allow it to become a platform for processing water column data, with the flexibility to extend the baseline capabilities to meet specific user requirements by adding plugins. This model of extending software applications with new runtime capabilities is well used by the more traditional software market, however it is new in the market covered by maritime processing software. Plugins are a means of adding specific capabilities to a larger baseline application without the need of direct integration that would require a new build or release of that application. Just as important is that third party companies, universities, research institutions or singular individuals can offer the plugins they develop directly to other users. The plugins intellectual property can be maintained by the authoring organization and either given away or sold and supported just like traditional software. This approach addresses the significant problem of

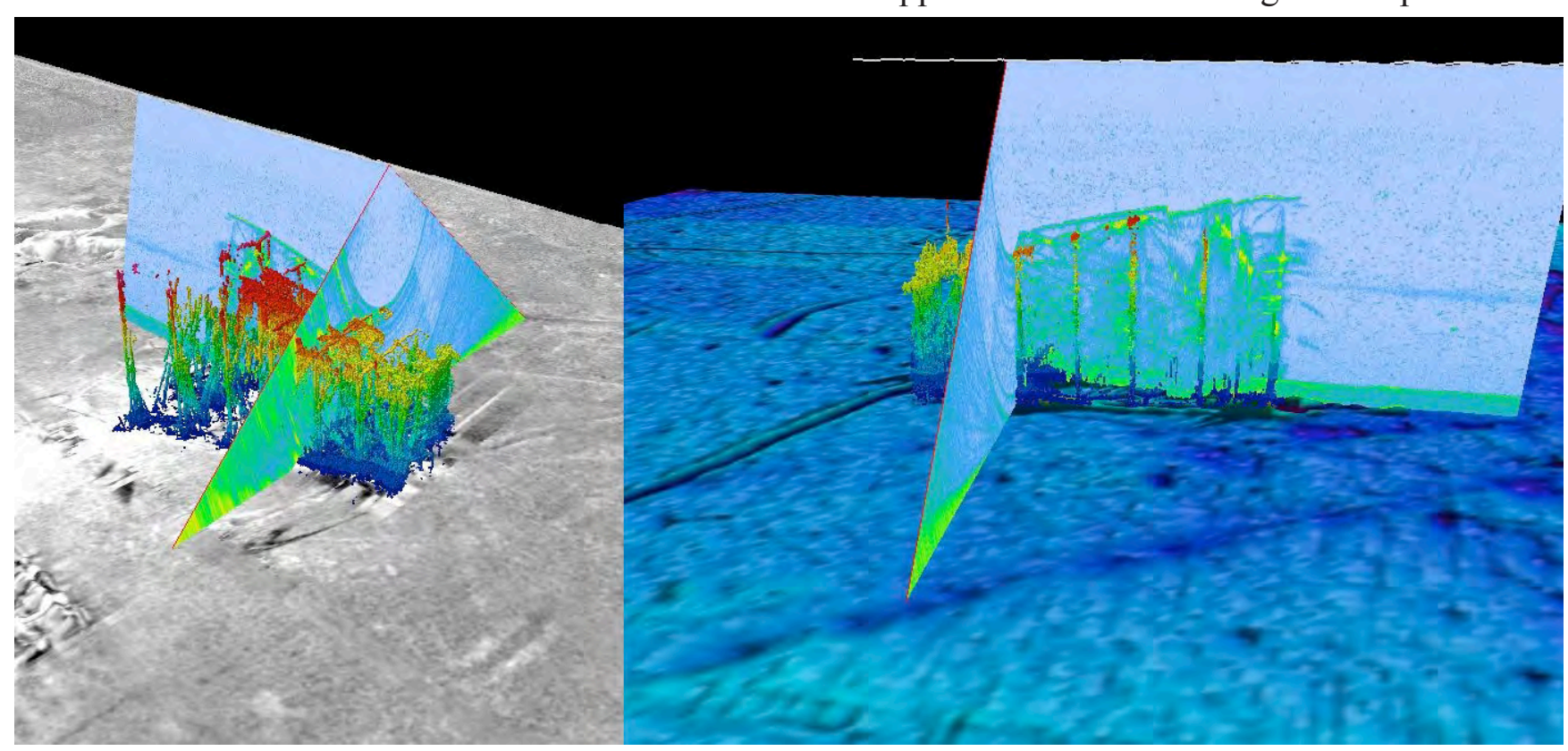

Figure 2. - Fledermaus fan and beam curtain objects with bottom detected points and seabed grid. Fan and beam show additional contacts in the water column data. 
bringing prototype developments from research to a broader community of users, without the researcher being required to develop and support an entire software application.

QPS began this approach with the Fledermaus Geocoder Toolbox (FMGT) for much the same reasons outlined for FMMidwater [5]. The original Geocoder research software was retooled, or refactored, into a robust, stable and modular software framework. A key in allowing external access was the retooling of the Geocoder processing pipelines into software modules; these modules honor the algorithms implemented in the original Geocoder framework but with clear boundaries being set between the various data flows and processing stages such that researchers can investigate and potentially improve upon a single module without the overhead of maintaining the overall software framework. Further architecture modifications allowed for swappable plugin functionality for the core routines such that researchers could focus on a specific stage of processing without having to rebuild and support the entire research application.

Plugins within the FMMidwater platform are broken down into a number of major types:

- Import - transform external data into formats for GWC files.

- SD Export - transform GWC data into other visualization objects.

- Data Export - transform GWC data into other custom formats, with or without additional processing. The first implementation of data refraction used this type of plugin. Another was jointly developed with the Royal Netherlands Institute for Sea Research (NIOZ) and CCOM $\mathrm{UNH}$; this plugin allows split-beam processing when exporting targets from the Simrad single beam series of fisheries sonars.

- Signal Processing - to transform the raw GWC time series data into some other domain such as volume scattering or target strength.

- Tools - any type of custom operation that can be added such as a datagram or navigation plotting viewer.

- Context Menu- perform specific operations on a selected file from the file tree view.
When a plugin is installed on the system, FMMidwater will interrogate it during startup for its specific type. Depending on the type, the plugin will be attached to a particular part of the FMMidwater user interface.

\section{HYDROGRAPHIC APPLICATION - WRECK INVESTIGATIONS}

For many years the UK Civil Hydrography Programme (CHP) specification has required survey contractors to undertake investigations of all wrecks in a given survey area using both side scan sonar and extra multibeam sonar survey lines. For critical wrecks, wire sweeping has also been required. For a number of years there has been concern as to whether multibeam sonars are able to safely determine least depth when fine features (e.g. masts) may protrude from a wreck. The capability of applications like FMMidwater now allows the processing of water column data and comparison against the bathymetry from conventional online bottom detection. This capability means that multiple features within each receive beam may be digitized, rather than one single solution, and also that very fine features within the water column finer than would ordinarily be seen in conventional bathymetry - should be detectable, especially in post-processing.

A field trial was undertaken with one of the CHP Contractors (Fugro OSAE) to compare the results obtained from these different methods; multibeam bathymetry, sidescan, wire sweeping and water column processing. It was hoped that the trial would confirm that logging and processing water column data alongside conventional bottom detection data could meet all wreck investigation requirements. The following three multibeam sonars were compared; Kongsberg EM3002, Kongsberg EM 710, and Reson SeaBat 7125.

Sixteen targets were investigated with each acoustic method, and five of these targets were also wire swept. On eight of the targets, the minimum least depth by acoustic methods was indicated by water column data; although only two of these were of real significance, being up to $2.6 \mathrm{~m}$ shoaler than the online bottom detection, as seen in Table 1. One target was a $3 \mathrm{~m}$ upright pole placed on the seabed. None of the multibeam sonar detected this feature in 


\begin{tabular}{|c|c|c|c|c|c|c|c|}
\hline No. & Wreck-Name & $\begin{array}{l}\text { General depth } \\
{[\mathrm{m}]}\end{array}$ & $\begin{array}{c}\text { MBES } \\
\text { least depth } \\
\text { [m] }\end{array}$ & $\begin{array}{c}\text { WCD } \\
\text { least depth } \\
\text { [m] }\end{array}$ & $\begin{array}{l}\text { SSS } \\
\text { least depth } \\
\text { [m] }\end{array}$ & $\begin{array}{l}\text { Wire sweep } \\
\text { cleared depth } \\
\text { [m] }\end{array}$ & \begin{tabular}{|c|} 
Difference from \\
Next Shoalest \\
{$[\mathrm{m}]$}
\end{tabular} \\
\hline 1 & Hellopes Boiler & 34.00 & 28.6 & 28.6 & 28.6 & - & 0.0 \\
\hline 2 & T-FG-009 & 37.30 & 36.0 & 35.9 & 36.0 & - & 0.1 \\
\hline 3 & T-FG-014 & 34.20 & 30.3 & 30.1 & 30.3 & - & 0.2 \\
\hline 4 & T-FG-016 & 37.00 & 29.6 & 29.6 & 29.6 & - & 0.0 \\
\hline 5 & T-HB-018 & 43.00 & 38.2 & 38.0 & 38.2 & - & 0.2 \\
\hline 6 & T-VH=003 & 41.00 & 35.6 & 35.6 & 35.3 & - & 0.3 \\
\hline 7 & W-16309 & 40.00 & 31.6 & 31.8 & 31.8 & - & 0.2 \\
\hline 10 & W- 16400 & 28.90 & 20.3 & 20.4 & 20.8 & - & 0.1 \\
\hline 11 & W-16445 & 40.00 & 34.3 & 32.6 & 34.3 & - & 4 \\
\hline 12 & W-16515 & 39.00 & 32.3 & 32.2 & 32,3 & - & 0.2 \\
\hline 14 & W-17789 & 33.00 & 27.4 & 24.8 & 27.3 & - & 21 \\
\hline 16 & W-16439 & 35.00 & 30.2 & 30.2 & 30.2 & - & 0.0 \\
\hline 17 & Hellopes N & 33.60 & 27.1 & 27.8 & 26.6 & 27.3 & 0.5 \\
\hline 18 & Hellopes S & 34.00 & 30.0 & 30.0 & 30.0 & 29.5 & 0.5 \\
\hline 19 & W-73522 & 42.40 & 35.4 & 35.7 & 35.9 & 34.9 & 0.5 \\
\hline 20 & W-73523 & 39.00 & 35.9 & 35.8 & 36.0 & 35.4 & 0.1 \\
\hline 21 & EM710-Frame & 18.80 & $18.8^{2}$ & 15.2 & 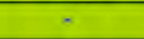 & 15.6 & 0.3 \\
\hline
\end{tabular}

Table 1. - Results from field trial (UK Hydrographic Office and Maritime and Coastguard Agency)

the conventional online bottom detection, but it was clearly visible in the water column data.

The conclusion from this initial trial was that in general, all systems gave similar results in most cases when the uncertainty of each method was considered. However, for some features the water column data did appear to detect features that were undetected in the other acoustic datasets. It was also found that even with excellent equipment, it was very hard to get good repeatability from wire sweeping. Following these conclusions, the CHP Specification now requires contractors to gather multibeam sonar water column data during all wreck investigation lines, then review this data against the online bottom detection. If shoaler wreck features are found in the water column data, then a new depth is to be selected by the hydrographer from the water column and incorporated into the dataset.

\section{CONCLUSION}

Mid-water capable sonars have been available for several years, but until recently there have been very few commercial tools to analyze and extract information from these data outside of the initial 2D view during acquisition. In 2009, FMMidwater, a commercial off-the-shelf module for post-processing and visualizing water column data was released. The software, developed in conjunction with researchers at the Center for Coastal \& Ocean Mapping, University of New Hampshire, provides a tool to make use of this new data type, allowing for the extraction of fully refracted and adjusted detections to fuse with seabed detections from the multibeam sonar, for further processing and visualization.

This capability has widened the applications for water column data and has the potential to extend the capabilities of the multibeam sonars in various fields such as hydrographic survey, resource exploration, and marine habitat mapping. The challenge of addressing all the new data from multibeam sonars with water column capability and the many emerging users is being addressed by developing a software platform that supports plugins. The plugin approach is a new paradigm for maritime processing software and provides significant advantage for third party users, developers and researchers by providing a flexible solution to add additional functionality to a robust software platform.

The trial by the UK Civil Hydrography Programme (CHP) using water column data and the modification of their specifications provides a good example of the emerging use of these data and developing 
applications. The use of an off-the-shelf module such as FMMidwater now allows extraction of fully corrected and refracted multiple returns from each beam, which can be used for the detection and definition of fine targets such as masts on wrecks.

\section{ACKNOWLEDGMENT}

The authors gratefully acknowledge the support of the initial development by a grant from the New Hampshire Innovation Research Center. Thanks also to Kongsberg Maritime for providing the EM2040 data of the oil rig water column sample survey.

\section{REFERENCES}

[1] Arsenault, R., Ware, C. , Plumlee, M., Martin, S. C., Whitcombe, L. L., Wiley, D. N., Gross, T., Bilgili, A., 2004, "A system for visualizing timevarying oceanographic 3D data", IEEE Oceans, Halifax, Nova Scotia, Canada, 1 - 5 October, 5 pages. Conference Proceeding.

[2] Ware, C. , Plumlee, M. , Arsenault, R. , Mayer, L. A., Smith, S. , House, D. H., 2001, "GeoZui3D: Data Fusion for Interpreting Oceanographic Data", IEEE Oceans, Honolulu, HI, USA, 5 - 8 November, pp. 2498 - 2502. Conference Proceeding.

[3] Doucet, M., Arsenault, R., Ware, C., Weber, T., Malik, M., Mayer, L., Gee, L., 2009 “Advanced Mid-Water Tools for 4D Marine Data Fusion and Analysis", IEEE Oceans, Biloxi, MS, USA, 26-29 October, 9 pages. Conference Proceeding. [4] SAIC, Generic Sensor Format, version 3.0, April 2009.

[5] Doucet, M., Paton, M., Calder, B., 2011 "From Research to Reality; Geocoder's Past, Present, and Future", USHydro2011, Tampa, FL, USA, 25-28

April. Conference Proceeding. 


\section{The Development of New Data Quality Visualisation Methods in Electronic Chart Information Systems and Investigation into Associated User Response}

Sam HARPER, United Kingdom

Seabed Data Centre, United Kingdom Hydrographic Office

David WELLS, Kandice GUNNING, United States of America

Hydrographic Science Research Centre, Department of Marine Science, The University of Southern Mississippi

Topics: Smart data management, Easy customer access to data and products, Cost-effective solutions

\section{INTRODUCTION}

The representation of geospatial data quality in a GIS environment is well researched with many different methods employed. The same level of research does not exist for the representation of data quality in ECDIS. There is a concern amongst the international hydrographic community that the current methods of representing data quality in navigational products are not meeting the needs of the mariner. Instead they rely heavily on the user's ability to understand the relevance of data quality indicators such as 'survey date' and 'acquisition method', or composite quality classifications like CATZOC.

The International Hydrographic Organisation (IHO) Data Quality Working Group (DQWG) was formed to address this problem by developing a new method of representing data quality in future S-101 ENCs. So far the work of the DQWG has been centred around the creation of the S-101 Data Quality model which provides the architecture on which new visualisation methods can be built. To support this work, a questionnaire on the mariners' current perception of data quality was produced by the DQWG, and distributed by the IHO to all member states and made available to the wider marine community. The analysis of the data has lead to the development of a specification, against which a new method of data quality representation can be designed.

This paper provides a review of this work to date, and an insight into future collaborative research between the DQWG and the University of Southern Mississippi (USM).

\section{IHO DATA QUALITY WORKING GROUP QUESTIONNAIRE RESULTS}

In 2011, the DQWG undertook a study into the Mariners' perception of data quality. The principle aim of this project was to produce a specification to be used in the development of any new means of representing data quality in future ENCs. This specification would take into account why mariners need data quality information, how mariners currently use data quality information, what mariners need from data quality information and the limitations of providing data quality information.

The analysis of the questionnaire results was based upon 574 responses, with 74\% (421 respondents) of the sample population having over 10 years navigational experience and 63\% (357 respondents) having in excess of 15 years navigational experience. In addition the results showed that a broad range of shipping sectors were represented.

The questionnaire itself was of mixed methods design, incorporating qualitative questions into a dominantly quantitative structure (QUANqual). The questionnaire was split into three sections; Demographics, Mariners' perception of current methods of representing the quality of data in nautical charts and Future developments.

The key results from the study are reflected in the following specification [Harper 2012]: 
- As a minimum the constituent elements of S-57 CATZOC (positional uncertainty, sounding uncertainty, features detected and seafloor coverage) must be encoded in S-101 ENCs for depth areas, as separate attributes

- All encoded data quality information must be discoverable

- Temporal degradation of data should be encoded

- New representation methods should be able to accommodate inputs such as dynamic tides, under keel allowance and vessel specific parameters. It is understood that international efforts on standardisation of display and mariner training address possible issues with user inputs.

- Where possible ENC attribute names should be more descriptive (eliminate 6 letter acronyms and make use of camelCase)

- Visualisation should take advantage of the mariner's preference for an on demand colour overlay

- Recommend to add ability for mariners to add notes to specific features, that again changes presentation of the feature (as an addition to the mariners' objects)

- Any representation method should be accompanied by an appropriate education strategy

\section{DRAFT S-101 DATA QUALITY UML MODEL}

The DQWG have been tasked by the IHO Transfer Standard Maintenance and Application Development working group (TSMAD), to develop a model for S-101 ENC data quality representation. Taking into account the results of the mariners' questionnaire, the DQWG have decided to focus on splitting the principle S-57 primary data quality indicator, CATZOC, into its constituent elements. The rational for this is that it will allow for a more flexible approach to capturing data quality, and reduce the likelihood that important data quality information is 'hidden' due to its inclusion in a composite indicator. In addition, it is an aspiration of the DQWG that the future S-101 portrayal of data quality can also include external inputs, as well as charted data.

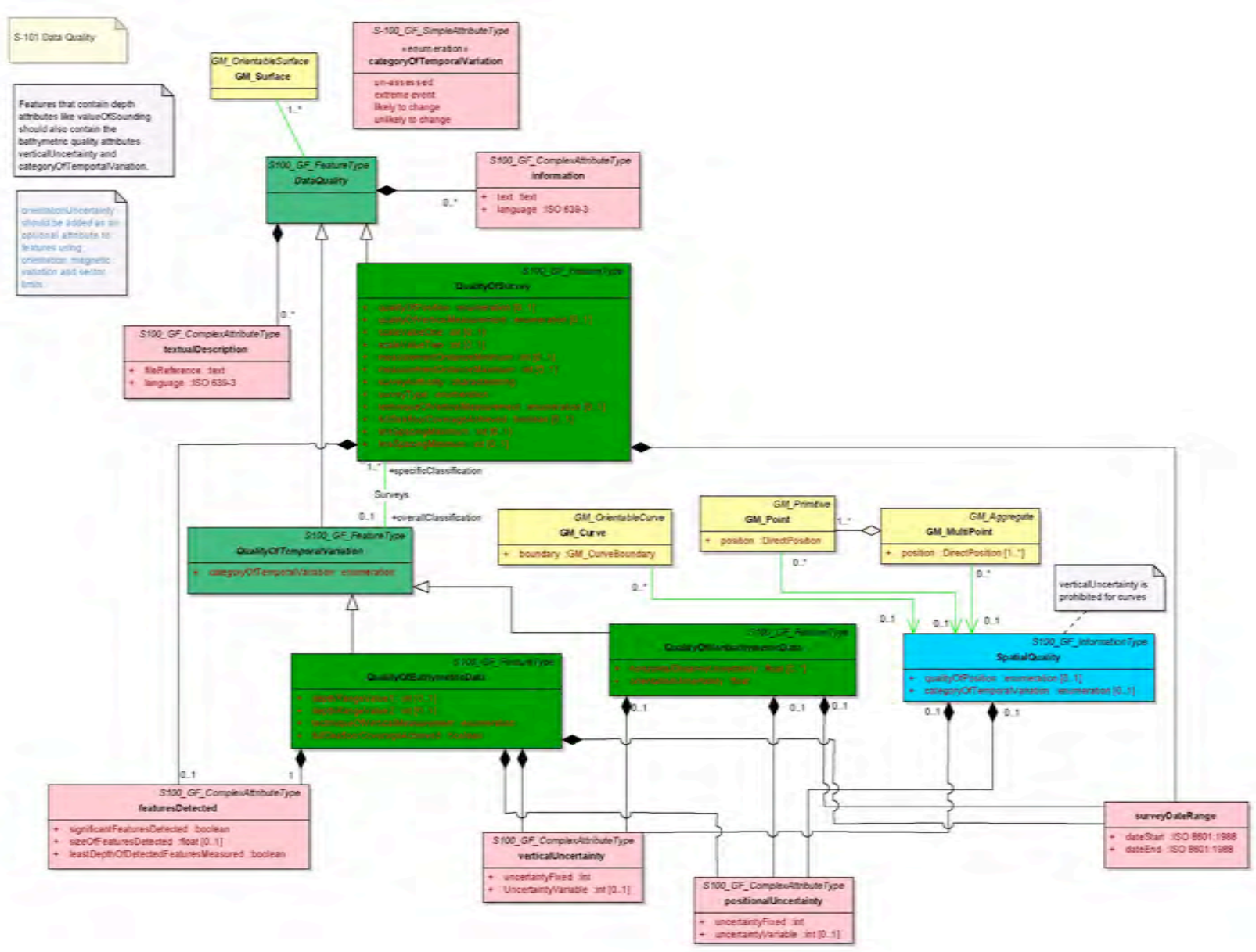

Figure 1. S-101 Data Quality UML model 


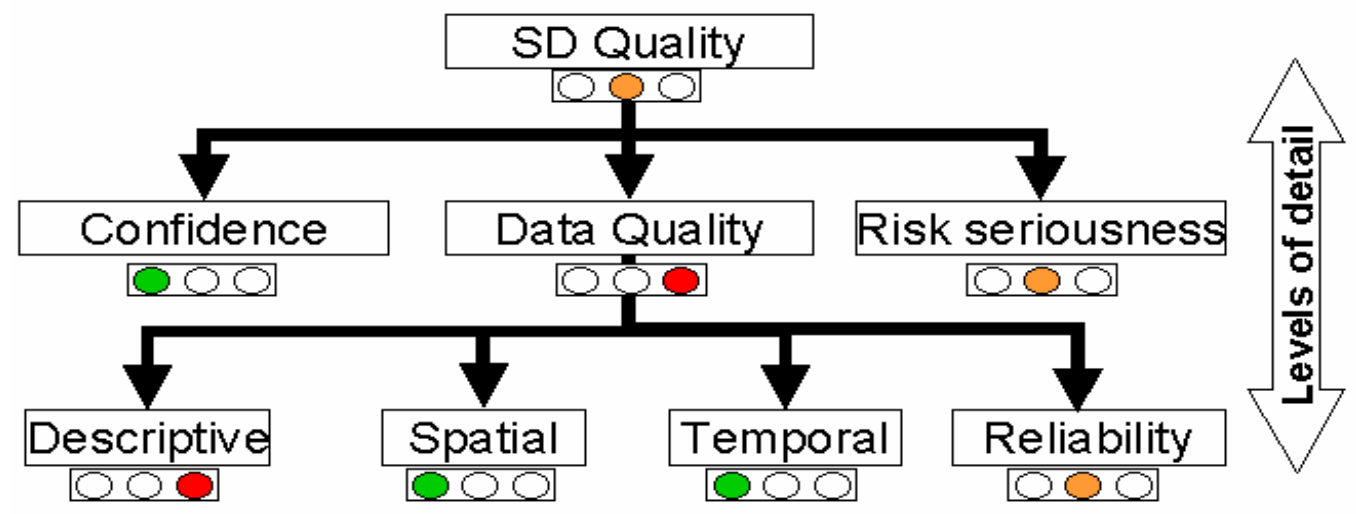

Figure 2. Example of Spatial Data Quality Indicators hierarchy [Devillers et al. 2002]

The Draft S-101 Data Quality UML model (Figure 1) includes three S-100 data quality meta-features; QualityOfBathymetricData, QualityOfSurvey and QualityOfNonbathymetricData. Out of the three, only QualityOfBathymetricData is mandatory, and it carries under it all of the constituent elements of CATZOC, plus the new attribute, QualityOfTemporalVariation. The inclusion of this new attribute was driven by the need to be able to represent the quality of charted data in terms of its currency. This is important as it is impossible to adequately represent in an S-57 ENC the uncertainty of data caused by regular geomorphological processes such as sandwave migration, or extreme events such as earthquakes.

\section{DRAFT ARCHITECTURE FOR S-101 DATA QUALITY REPRESENTATION}

One of the principle outcomes of the mariners' questionnaire was that a large number of chart users wanted to be able to utilise individual data quality indicators rather than rely upon a general indication of the quality of data in a particular area. However, this was not the case with all respondents. As a consequence the DQWG intend to develop a mechanism by which individually populated data quality indicators feed into an algorithm that intern drives a composite indication of general data quality. An example of such an approach is that suggested by Devillers et al. [2002], illustrated in figure 2 . This approach, termed the "Multidimensional User Manual", works on a hierarchical traffic light system, which allows the user to mine down through the layers to find out what indicators have influenced the composite indicator. The rules governing how each indicator is coloured are held as either user controllable or predetermined settings.

Figure 3 shows the DQWG's first draft of the high level architecture for S-101 ENC data quality portrayal. This approach builds upon the Multidimensional User Manual principles whilst allowing for the optional input of external models or parameters such as dynamic tides and vessel draught.

\section{USM STUDY INTO CHART QUALITY PORTRAYAL}

The DQWG have invited USM to use the results of the mariners' questionnaire and draft S-101 data quality UML model to research and develop the optimum method of representing data quality to chart users. Following initial meetings between DQWG members and USM staff and students, a two stage research project has been agreed.

Stage one will focus on developing a quality indicator visualisation test-bed that can be used to get feedback from mariners. This test bed will take the form of an S-57 Marine Information Object (MIO) that utilises the quality attributes that already exist in S-57 (POSACC, SOUACC and TECSOU), as well as a new quality attribute, CategoryOfTemporalVariation. 


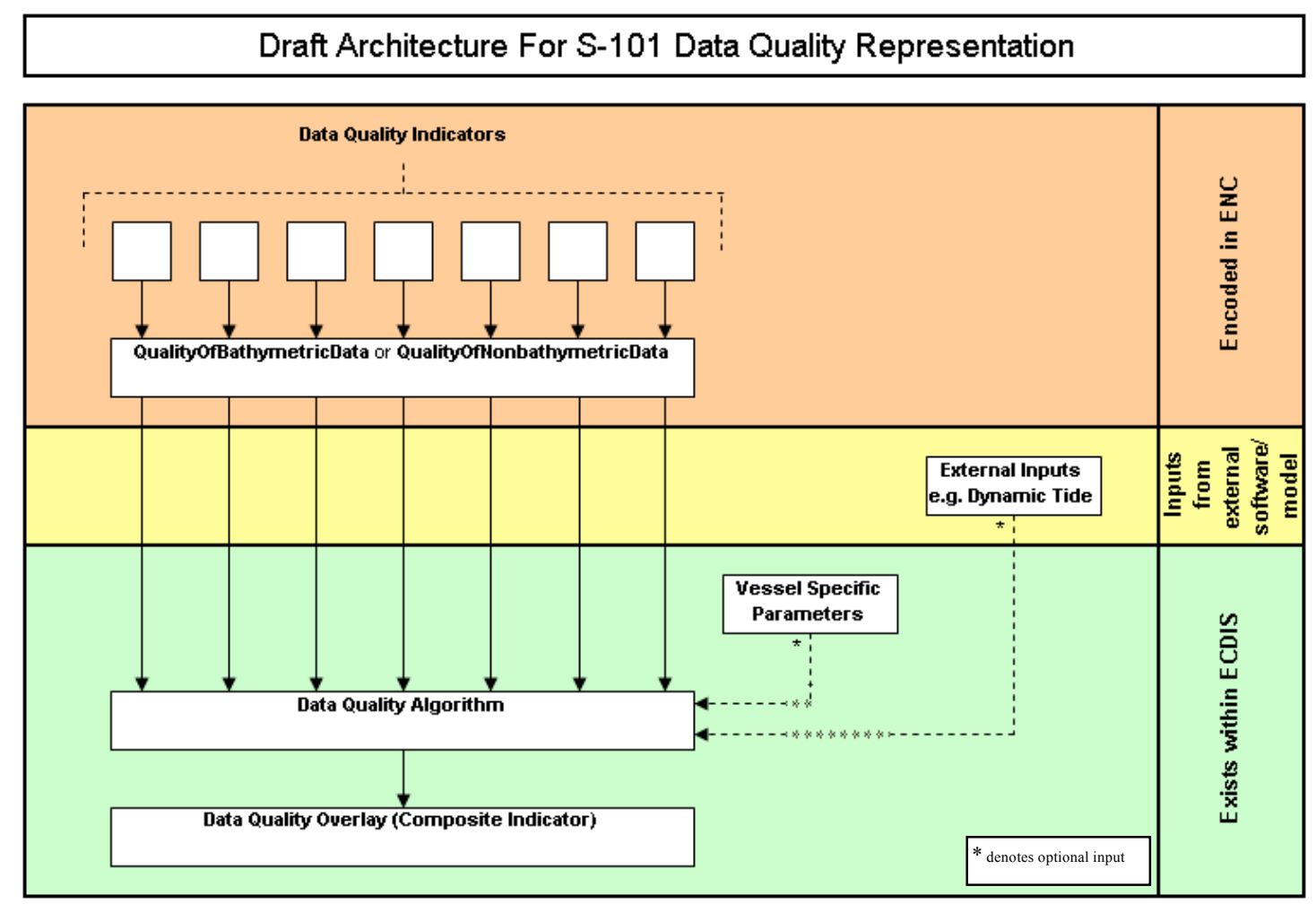

Figure 3. Draft Architecture for S-101 Data Quality Representation

Stage two will build upon this experience and focus on developing more sophisticated methods of representing data quality. This will include research into composite indicators that are potentially capable of interacting with external inputs from models such as dynamic draught or dynamic tides, as well as the option to tailor visualisation depending on vessel specific parameters.

\section{Perception of the Problem}

USM have made the following initial observations regarding the nature and scope of the research problem:

1. The purpose of nautical charts is to facilitate informed decision-making by mariners and other chart users.

2. Portrayal of chart quality indicators are most important during voyage planning, less important during voyage monitoring, but may also be important during emergencies. Emergency use may raise appropriate colour table encoding.

3. It is not the purpose of charts and ancillary information complementing charts, to replace the mariners and other end users as decision-makers. Information provided with charts should not extend into decision-making.
4. Component quality indicators, whose meaning is transparent to end-users, effectively facilitate informed decision-making.

5. The three quality components identified in Dorst \& Howlett [2012] (measurement uncertainty; completeness; currency) represent a good starting point in defining indicators that are useful, intuitive, 'mariner-friendly'.

6. The assumption built into the above statement must be tested by eliciting feedback from mariners on the use of these quality components, sooner rather than later.

7. Since elements of these three quality components are already captured in the S-57 attributes POSACC, SOUACC, TECSOU, and SUREND, there is an opportunity to continue a dialogue with mariners about quality components immediately, using S-57 compliant ENCs.

8. In general, composite indicators on their own, such as CATZOC, or a replacement for CATZOC, risk incorporating a priori decisionmaking, which is inappropriate, and has an opaque meaning to end users. It may be that mariners will find a composite indicator useful, when accompanied by its component indicators. But this should be tested.

9. Past efforts to represent chart quality, whether 
by source diagrams or CATZOC encodings, represent chart quality in ways that may be useful to a hydrographer, but as indicated by the DQWG survey results, do not address the needs of, nor are easily interpreted by, a mariner.

10. Efforts to develop a composite indicator to represent chart quality should proceed gradually, with mariner feedback at each step.

11. Regarding the visualisation of chart quality indicators, mariners have uniformly voiced approval and understanding of a scheme that encodes quality values into a green-yellow-red semi-transparent aerial overlay [Harper 2012]. We suggest a fourth colour, grey, for areas where quality indicator values are not available. We propose this as a starting point, while we develop and test more sophisticated ways of visualizing quality indicators.

These observations have been discussed with members of the DQWG and it has been agreed that they will form a strong basis on which to progress this research. The results from the first stage of the project will be presented to the DQWG at the next meeting in July 2013.

\section{CONCLUSION}

The DQWG study into the mariners' perception of data quality represents a significant change in the approach the international chart producing community are taking in deciding what information is presented on a chart. The DQWG is committed to developing data quality representation methods that are driven by the needs of the mariner. In order to fully realise this aim the DQWG is reaching out to academic institutions and industry experts in attempt to harness and strengthen the collective wisdom of the group. It is hoped that mariners will recognise their in put in the resulting solution.

\section{REFERENCES}

Devillers, Gervais, Bedard, Jeansoulin [2002] Spatial data quality: from metadata to quality indicators and contextual end-user manual, OEEPE/ ISPRS Joint Workshop on Spatial Data Quality Management, pp45-55, March 21-22, Istanbul

Dorst \& Howlett [2012] Safe Navigation with uncertain hydrographic data. Hydro International, June 2012, pp18-21.
Harper [2012] A Specification For Developing a New Method of Visualising Data Quality in Electronic Navigational Charts. Canadian Hydrographic Conference 2012, May 15-17, Niagara Falls

\section{BIOGRAPHIES}

Sam HARPER works as a Senior Bathymetric Appraisal Officer for the United Kingdom Hydrographic Office Seabed Data Centre and is a graduate of Plymouth University's MSc Hydrography programme. He is also the UKHO representative on the IHO Data Quality Working Group, a Director of the Hydrographic Society UK and the Hon. Secretary of the Hydrographic Society UK South West Region. Prior to specialising hydrography, Sam worked in GIS and marine science.

\section{CONTACT DETAILS}

\section{Sam HARPER}

Unted Kingdom Hydrographic Office

Admiralty Way

Taunton

United Kingdom

Tel.: +44 (0) 1823337900 Ext. 3843

Fax: +44 (0) 1823284077

Email: samuel.harper@ukho.gov.uk

Web site: www.ukho.gov.uk 
$92 \mid$ Hydrol 2 


\title{
From seafloor geomorphology to predictive habitat mapping: progress in applications of biophysical data to ocean management.
}

\author{
Peter T. HARRIS, Australia \\ Geoscience Australia
}

ABSTRACT

Hydrographic surveys are carried out mainly to ensure safe navigation, but there are other reasons for mapping the seafloor. These include: (1) to support government spatial marine planning, management, and decision making; (2) to support and underpin the design of marine-protected areas (MPAs) and fishing reserves; (3) to conduct scientific research programs aimed at generating knowledge of benthic ecosystems and seafloor geology; (4) to conduct living and nonliving seabed resource assessments for economic and management purposes; and (5) to support the construction of ports and offshore structures (oil and gas production facilities, wind farms, etc.). The geomorphology of the seafloor, interpreted from bathymetric data combined with geological knowledge, can provide a basic level of information to support goals such as these. By combining multiple spatial biophysical data layers (eg. depth, slope, rugosity, water temperature, primary production, etc.) using multivariate statistical techniques, scientists have produced integrated "seascape" maps to further assist ocean managers. Adding direct observations of marine life to seascapes provides the basis for generating predictive habitat maps, derived using statistical methods (maximum entropy or decision-tree techniques), which depict the potential distribution of species and benthic communities and that are useful for decision-making regarding conservation and management. These three broad categories of spatial seafloor classification (geomorphology, seascapes, and predictive habitats) also represent a progression for the utilization of environmental information, from data-poor to data-rich situations. Here we review some examples of seabed maps derived from the three categories and their applications and uses in the management of Australia's marine jurisdiction.

\section{INTRODUCTION - INFORMATION THAT MARINE MANAGERS NEED}

The governments of maritime nations commonly employ public servants (ocean managers) whose task it is to implement government polices that aim to limit the impact of human activities on the environment while simultaneously minimizing any added costs to maritime industries. The ocean manager's job is further complicated by the need to account for the cumulative impacts of industry activities (fishing, shipping, port construction, defense, laying of communication cables, oil and gas exploration and development, seabed mining, coastal development) intersecting with a range of legislation enacted to meet different conservation goals. The most common, overarching conservation goals covered by legislation relate to the preservation of biodiversity and the protection of ecosystems. Many books and articles have been published on this topic (for a recent review see Baker and Harris, 2012).

Perhaps less clear is the role of scientists employed by government in the area of marine management.
Their task is to provide a broad-scale context for understanding marine ecosystems and the spatial distribution of species and vulnerable communities having high conservation value. Ocean managers are usually under pressure to provide their governments with options quickly; there is no time for lengthy research programs that may take years to complete. Rather, ocean managers expect scientists to make use of existing data sets to provide succinct, easilycommunicated, timely advice.

To address this challenge, government marine scientists have adopted a number of strategies to be able to provide quick, scientifically defensible products to assist the decision-making process. Making use of existing data is a first priority and this requires the establishment and population of centralized databases of key biophysical parameters such as bathymetry, seafloor sediment properties, oceanographic data and satellite remotely-sensed variables (primary production, coastal habitats, etc.). The mantra for government-funded surveying is to "map once use many ways" (Harris and Baker, 2012); hence, bathymetric data collected 
by hydrographic surveyors for the production of nautical charts are used for creating other products like seabed geomorphic feature maps, seabed rugosity maps, bathymetric grids for hydrodynamic models, habitat maps and others.

In this paper we review three different ways that biophysical and biological data have been used by government marine scientists to support decisionmaking by ocean managers in Australia. First is the application of seafloor geomorphic feature maps for defining broad, provincial bioregions around the continent of Australia. Second is the derivation of a seascapes classification of the continental shelf based on biophysical data for predicting biodiversity hot-spots to guide in the design of a national representative system of marine protected areas. Finally, predicted coral reef habitat in the Great Barrier Reef (GBR), based on observations of live coral cover together with the distribution of geomorphic banks, illustrates the value of predictive habitat maps in designing and validating GBR marine reserves.

\section{GEOMORPHIC FEATURE MAPS UNDERPIN THE DEFINITION OF BIOREGIONS}

Broadly speaking, seafloor geomorphology is the scientific study of the formation, alteration, and configuration of seabed features and their relationship with the underlying geology. The geomorphologic classification of any area of seabed is a fundamental, first-order descriptor containing information about an area's relief, geology, geologic history, and formative processes. Geomorphic classification provides a synthesis of these attributes and information relevant for characterizing habitats. For example, geomorphic features and substrate type are interlinked in as much as some geomorphic features are inherently "rocky" in character (e.g., pinnacles, reefs, and ridges), whereas others are inherently "sediment covered" (e.g., basins, abyssal plains, and sandwaves). Habitat mapping based on geomorphic features has the added advantage that detailed ecological models already exist for many geomorphically defined habitats (Greene et al., 1999; Harris and Baker, 2012). As noted by Roff et al. (2003), marine ecology textbooks are commonly organized into chapters having broad, geomorphically defined habitat types as titles (the ecology of estuaries, coral reefs, temperate rocky reefs, etc.). A good example of the utility of geomorphic features for quantifying industrial use in relation to conservation value was provided by Harris et al. (2007) in relation to offshore oil and gas exploration leases in Australia. These workers demonstrated that oil and gas leases coincide with the occurrence of particular types of seafloor geomorphic features (especially shelf valleys, escarpments and submarine canyons) that also have high conservation value.

The ecological implications of geomorphology were fully exploited during the design of Australia's national representative system of marine protected areas (NRSMPA), that aims to protect endemic species found within each of 41 provincial bioregions located around the continent. The provincial bioregions are defined within the Integrated Marine and Coastal Regionalisation of Australia (IMCRA) based on the distribution of demersal fish species and seafloor geomorphology (Commonwealth of Australia, 2006). Specifically, whilst data on fish species endemism was used to define broad geographic bioregions, the actual boundaries between biogeographic provinces are defined based on seabed geomorphology (Heap et al., 2005). The geomorphic features map was also used to assess seafloor heterogeneity, a surrogate for benthic biodiversity, whereby hot-spots of heterogeneous geomorphology were identified as having potentially high biodiversity (and high conservation value; Harris, 2007).

\section{SEASCAPE MAPS SUGGEST HOT SPOTS FOR BIODIVERSITY CONSERVATION}

In many situations bathymetric data can be supplemented with other environmental data sets such as oceanographic data (spatial and temporal observations of temperature, salinity, dissolved oxygen, waves and tidal currents, etc.), remotely sensed imagery (showing spatial and temporal patterns of primary production, for example) and seabed substrate data (sediment chemistry and grain size, maps of rock outcrops, seismic data of sediment thickness, etc.). However, ocean managers will generally not be in a position to make use of numerous separate maps. In many cases they will not have the expertise needed to interpret all the different maps, and even if they could, it is simply not practical to try to grasp the ecological meaning

\section{4 | Hydrol2}


of multiple, intersecting data layers, without the use of computers and statistical methods (Roff et al., 2003).

One solution to this problem is to use multivariate statistics to integrate multiple spatial data layers into a single "seascapes" map. Marine scientists at Geoscience Australia have used ER-Mapper's unsupervised ISO class algorithm to simultaneously classify different variables, with equal weighting, to yield a range of statistically different classes (Harris et al., 2008; Heap et al., 2011). The seascapes approach is suggested by niche theory in ecology: every species has a certain range of abiotic (physical and chemical) variables within which it is able to survive and reproduce, a space known as the "fundamental niche" for that species. But most species are unable to fully exploit the entire volume of their fundamental niche because of competition with other species, diseases, and disturbances, all of which reduces their occurrence to a "realized niche." Seascapes are statistically significantly different environments defined from the input data layers, and as such they could individually (or in groups) represent the fundamental niche of particular species. Przeslawski et al. (2011) have discussed the relative strengths and weaknesses of the seascapes approach using existing biological data from the Australian continental shelf. They found that, while seascapes are not consistently useful as surrogates for all communities, they are an appropriate surrogate for broad-scale benthic invertebrate community patterns when biological data are limited.

Individual (or selected groups of) seascapes may have their own conservation value in some areas. For example if it is known that shallow, warm-water, high-energy sandy substrate habitat is rare within a bioregion and/or it is utilized by particular threatened species or communities, then that seascape may warrant special consideration in the design of spatial marine planning options. Another way in which seascapes may be useful is in regards to the assessment of seafloor heterogeneity, a surrogate for benthic biodiversity, whereby hotspots of heterogeneous seascapes may be identified as having potentially high biodiversity (and high conservation value; Harris et al., 2008; Harris and Whiteway, 2009).

\section{PREDICTIVE HABITAT MAPS DEFINE POTENTIAL NICHE OF SPECIES AND COMMUNITIES}

In some situations, biological observations are available to supplement and inform the biophysical data sets used to derive seascapes. However, because of the site-specific nature of most biological measurements (taken by towed-cameras or epibenthic sleds along a transect, or at single sites by drop-camera or grab sample) their interpolation to areas of surrounding seafloor was extremely limited prior to the advent of multibeam sonar seabed mapping systems. This new technology produces high-resolution ( $\sim 1-5 \mathrm{~m}$ grid resolution) bathymetric data that can be accurately cross-correlated to sample sites or survey track lines to directly link physical (acoustic) measurements with biological observations. Multibeam sonar technology has revolutionized benthic habitat mapping which is now regularly undertaken by many countries to support ocean management (Harris and Baker, 2012).

Niche theory suggests that by measuring the environmental parameters coinciding with the occurrence of a species and the relative strengths of the different relationships, one should be able to predict the species' fundamental niche. This is the principle behind predictive habitat modeling. Two statistical methods that are most commonly used in predictive habitat modeling among the many that are available (Gusian and Zimmermann, 2000) are decision-trees (De'ath and Fabricius, 2000) and Maxent (Phillips et al. 2004, 2006; Elith et al. 2011). Decision trees are constructed by repeatedly splitting the data, defined by a simple rule based on a single explanatory variable. At each split the data are partitioned into two mutually exclusive groups of optimum homogeneity. The splitting procedure is then applied to each group separately and so on until the desired number of branches is reached (De'ath and Fabricius, 2000). Maxent uses maximum entropy techniques to create models of the relative probability of species/community distribution across a study area. An important distinction between the two methods is that Maxent can use presence-only data, which is commonly the case in biological surveying (Elith et al., 2011).

As an example of predictive habitat modelling we here examine the distribution of coral communities 
in the Great Barrier Reef. Most near sea surface (NSS) coral reefs may be seen in remotely sensed imagery; other reefs are submerged below the surface and are invisible to satellites. Ocean managers need to know about the distribution of both types to ensure they are protected as required by government legislation. The problem is, we do not have a map of the submerged coral communities.

A solution is to use the geomorphology of the GBR to estimate the distribution of submerged coral communities (Harris et al., in prep.). Since coral reefs grow preferentially upon geomorphic banks, a map of banks was created using a new $100 \mathrm{~m}$ resolution bathymetric grid. Analysis of this map shows that only about $37 \%$ of available seabed on submerged banks is capped by NSS coral reefs $(16,110 \mathrm{~km} 2)$; the other $63 \%$ of bank area $(25,599$ $\mathrm{km} 2$ ) is submerged at a mean depth of around $27 \mathrm{~m}$ and represents potential deep reef habitat. In order to estimate potential coral cover of the submerged banks, a high-resolution multibeam sonar data set was used. Areas likely to support deep-water coral communities were identified using coral occurrence records derived from optical images taken by autonomous underwater vehicle, and geophysical data on depth, slope, aspect, rugosity, sidescan acoustic backscatter (a surrogate for substratum roughness and type), and geomorphic zone (slope, crest, flat or depression) gridded at $5 \times 5 \mathrm{~m}$ pixel resolution.

Out of 25,599 km2 of submerged bank area, predictive habitat modelling indicates that more than half (around 14,000 km2) is potentially occupied by coral communities. These results indicate that the total area of coral cover in the GBR is much greater (perhaps twice as large) as has been assumed based on maps of NSS reefs derived from satellite imagery alone (Harris et al., in prep.).

\section{DISCUSSION AND FINAL REMARKS}

The spatial representations of the environment discussed above (geomorphology, seascapes and predictive habitat models) may be thought of as illustrating a progression for the utilization of environmental information, from data-poor to data-rich situations. Such a data-poor to datarich gradient occurs as we move from local to global spatial scales and also from developing to industrialised countries. The scale dependence of data is obvious; high resolution data for almost all variables is lacking at a global scale. Initiatives such as the ETOPO-1 bathymetry, NOAA's Ocean Atlas and the Census of Marine Life, have provided global scale data sets but often the resolution is very low and broad extrapolations are needed to produce a map, with attendant errors.

Even so, it is interesting to note that many global data sets are available having a resolution of from 2 to $10 \mathrm{~km}$, which has allowed a seascapes type analysis to be carried out at a global scale (Harris and Whiteway, 2009). Such a resolution may be useful for management of national exclusive economic zones (i.e. 200 mile limits), and also for decision-making at the international level for the high seas and areas beyond national jurisdiction. An area of future research is to integrate the available global biophysical data with the 30 million biological observations collated by the Census of Marine Life for predictive habitat modeling at a global scale. Such a global model would have broad applications for decision-making at national and international levels.

\section{REFERENCES}

Baker, E. K., and Harris, P. T. 2012. Habitat Mapping and Marine Management. In Seafloor Geomorphology as Benthic Habitat: GeoHab Atlas of seafloor geomorphic features and benthic habitats. Ed. by P. T. Harris, and E. K. Baker. Elsevier, Amsterdam, p 23-38.

Commonwealth of Australia, 2006. A Guide to the Integrated Marine and Coastal Regionalisation of Australia Version 4.0. 16 pp. http://www. environment.gov.au/coasts/mbp/publications/imcra/ pubs/imcra4.pdf

De'ath, G., and Fabricius, K. E. 2000. Classification and regression trees; a powerful yet simple technique for the analysis of complex ecological data. Ecology, 8: 3178-3192.

Elith, J., Phillips, S.J., Hastie, T., Dudik, M., Chee, Y.E., Yates, C.J., 2011. A statistical explanation of MaxEnt for ecologists. Diversity and Distributions $17,43-57$.

\section{6 | Hydro 12}


Greene, H. G., Yoklavich, M. M., Starr, R. M., O’Connell, V. M., Wakefield, W. W., Sullivan, D. E., McRea, J. E., et al. 1999. A classification scheme for deep seafloor habitats. Ocenaologica Acta, 22: 663-678.

Harris, P. T. 2007. Applications of geophysical information to the design of a representative system of marine protected areas in southeastern Australia. In Mapping the Seafloor for Habitat Characterisation, pp. 449-468. Ed. by B. J. Todd, and G. Greene. Geological Association of Canada Special Paper 47, St Johns, Newfoundland, Canada.

Harris, P. T., and Baker, E. K. (Editors) 2012. Seafloor Geomorphology as Benthic Habitat: GeoHab Atlas of seafloor geomorphic features and benthic habitats. Elsevier, Amsterdam, 947 pp.

Harris, P. T., Bridge, T. C. L., Beaman, R., Webster, J., Nichol, S., and Brooke, B. (in prep.). Submerged banks in the Great Barrier Reef, Australia, greatly increase available coral reef habitat. ICES Journal of Marine Science.

Harris, P. T., Heap, A., Post, A. L., Whiteway, T., Potter, A., and Bradshaw, M. 2007. Marine zone management and the EPBC Act: How environmental marine geological information provides certainty for petroleum exploration. APPEA Journal, 46: 327-343.

Harris, P. T., Heap, A. D., Whiteway, T., and Post, A. L. 2008. Application of biophysical information to support Australia's representative marine protected area program. Ocean and Coastal Management, 51: 701-711.

Heap, A. D., Anderson, T. J., Falkner, I., Przeslawski, R., Whiteway, T., and Harris, P. T. 2011. Seascapes for the Australian margin and adjacent seabed. ICES Document 2011/06. 92 pp.

Heap, A. D., Harris, P. T., Hinde, A., and Woods, M. 2005. Draft Benthic Bioregionalisation of Australia's Exclusive Economic Zone - Geoscience Australia Report to the National Oceans Office. 140 pp.

Phillips, S.J., Dudik, M., Schapire, R.E., 2004. A maximum entropy approach to species distribution modeling. In: Proceedings of the 21 st International
Conference on Machine Learning, Banff, Canada, 8 pp.

Phillips, S.J., Anderson, R,P, Schapire, R.E., 2006. Maximum entropy modeling of species geographic distributions. Ecological Modelling 190: 231-259

Przeslawski, R., Currie, D. R., Sorokin, S. J., Ward, T. M., Althaus, F., and Williams, A. 2011. Utility of a spatial habitat classification system as a surrogate of marine benthic community structure for the Australian margin. ICES Journal of Marine Science: Journal du Conseil, 68: 1954-1962.

Roff, J. C., Taylor, M. E., and Laughren, J. 2003. Geophysical approaches to the classification, delineation and monitoring of marine habitats and their communities. Aquatic Conservation: Marine and Freshwater Ecosystems, 13: 77-90.

\section{CONTACT DETAILS}

Peter T. Harris

Senior Marine Science Advisor

Geoscience Australia

GPO Box 378 Canberra ACT 2601, Australia 
98| Hydrol 2 


\title{
Computer-aided quality assurance of high-resolution digitized historic tide-gauge records
}

\author{
Hartmut HEIN, Ulrich BARJENBRUCH, Christoph BLASI, Stephan MAI, Germany \\ German Federal Institute of Hydrology
}

Topics: Innovations in processing techniques, Accurate hydrodynamics

\section{INTRODUCTION}

In the recent era of strong discussion of climate change there is the growing need of historical data of observed sea level as the basis for different purposes from daily practical routines like navigation, operational modeling for storm-surge warnings, fundamental statistics and research on climate change itself. In a changing world long-term series of observations are essential to make decisions for the management of coastal waterways. Nevertheless, the data for all these purposes must undergo the restrict quality assurance to avoid incorrect planning or also for the sustainability of coastal managing. Future analysis of the data, allows to investigate in changes of astronomic tides and wind surges. High resolution data are one condition sine qua non for the basic understanding of both, the natural and man-made changes in coastal waterways.

During the recent meeting of the GLOSS Group of Experts (7-11 November, 2011, Paris) the rescue of tide gauge data which currently stored in noncomputer forms (sheets, tabulations, etc.) was addressed (Circular Letter, IHB File No S3/2705). Our study reports the difficulties connected with the digitalization of tide gauge data in paper form. The crucial challenge is situated in the quality control of the data. Generally, these data are so extensive that automatic methods, so called Computer-aided quality assurance (CAQ), must be used to identify failed digitization, data gaps or distortions of water levels.
Analogues sea-level records include many ambiguities and errors in the time series, which may disturb the automatic data processing. We analyze the suitability of methods to detect this uncertainties. Different statistical methods like spectral analysis or fuzzy-logic show good results in detecting outliers and also filling gaps. Gaps in time series are a serious problem, and every method that is used to fill them can give only estimations. For the time being, the fuzzy-logic methods investigated to find a suitable solution.

\section{DATA SETS}

In the archives of the German Federal Waterways and Shipping Administration about 10000 years of paper sheets from historic automatically but analogically recording tide gauges wait to be recovered and digitized. This is one of the biggest sea level archive worldwide, and much effort is necessary to make it available to science and management. With this dataset it is possible to reconstruct the whole tide curves of about 100 tide gauge stations - some of them started to work in the 19 th century.

For this study we use a test data set of $\mathrm{O}(100)$ years to detect general challenges of the digitalization; only to give two numbers: 100 years means more than 3000 paper sheets of more than 5 million data points. The four tide gauge stations, their location and the related years are given in table 1. For the given years equidistant points with a distance of ten minutes were digitized - if the paper sheets were

\begin{tabular}{|lcc|}
\hline Tide gauge & Location (DHDN Bessel 1841) & Digitalizited Years \\
\hline Borkum Südstrand & $5.938 .584,00 ; 2.543 .850,72$ & $1949-1985$ \\
\hline Emden Neue Seeschleuse & $5.912 .318,32 ; 2.579 .065,03$ & $1949-1982$ \\
Mellumplate & $5.960 .449,00 ; 3.440 .237,00$ & $1964-1990$ \\
\hline Bremerhaven Alter Leuchturm & $5.934 .916,00 ; 3.471 .446,00$ & $1965-1972$ \\
\hline
\end{tabular}

Table 1: Tide Gauges 

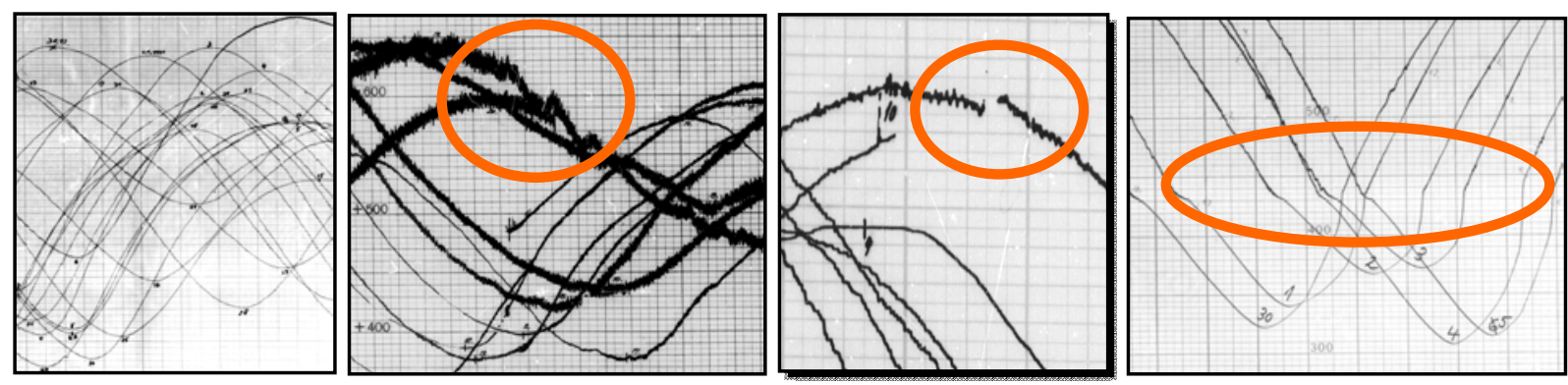

Figure 1: Example snippets from paper sheets to demonstrate the challenges of the digitalisation.

found in the archive.

Figure 1 shows some examples from paper sheets, which were digitized. Obviously, several challenges in the digitalization process can be seen. First, there is not only one tide-curve, but several overlaying lines, which must be assigned. Secondly, on historic paper sheets wind-waves are not every time damped mechanically in the writing process, so the line mutates into a thick doodle. Several cut-offs can be found. We detected also curios deformations of the drawn lines. For example, on the outer right side of Figure 1 pondage of water during low-water is shown, this is, however, not the water-level which is representative for the overall region near the tide gauge.

One critical point for the quality control is that the sea level in the German Bight is dominated by astronomical tides (mainly semidiurnal, M2). They are in general deterministic, but they also change with time (Müller, . The starting point therefore is that we must take into account both, the deterministic and the stochastic part of the tide gauge observations.

\section{OUTLIER TEST}

The first test which is applied is that for outliers, which are detected by the mean of a nearest neighbor running standard deviation test on the first deviation of the dataset. These new time-series of the running mean standard deviation is tested for outliers following the Thompson rule (Mueller et al., 1973). Because of the tidal signal in the data this stepwise procedure provides to assign tidal selfoscillations as outliers. We done this procedure for both, the time values and the water levels.

Figure 2 shows results of the estimations of outliers of the water level. Because of the inherent tidal signal in the data set the values change with a constant frequency. Nevertheless, some peaks can be seen visually. Such values, which are a kind of suspect by the means of the standard deviation must be flagged. We use a percentile based model to detect possible outliers (orange dots in figure 2). With these method $\mathrm{O}(500)$ outliers were found in the dataset. Two typical examples could be seen in Figure 2b, 2c. Figure $2 \mathrm{~b}$ shows a sudden jump in the time series, which may be related to the wrong assignment of a tide curve. Figure $2 \mathrm{c}$ shows an example which demonstrate the expose of the mechanics of the tide gauge. This yields the next challenge, the detection and the closure of gabs.

\section{GABS}

\section{$\underline{\text { Frequency based closure of gabs }}$}

Notwithstanding, the data have several gaps, almost for two reasons: 1. no sheet was found, or 2 . because of gabs in the observations on the sheet. Figure 3 shows two typical examples for gaps. In Figure 3 a a coastal hydrologist has manually inserted some curves for high and low waters. Figure $3 \mathrm{~b}$ shows some small gabs, which are related to short interruptions of the curve on the sheet.

To reconstruct the data inside the gabs we use the so called Lomb-Scargle Periodogram (LSP; (Lomb, 1976); Scargle, 1982), which was introduced to detect sinusoidal signals in noisy unevenly sampled time series, so it can be useful also for tide gauge time series with gabs. In practice, the first step of the method is to remove the mean value of original time series from each observation. Then the LombScargle periodogram is equivalent to a linear leastsquares fit of sine and cosine model functions to the time series. In detail: 


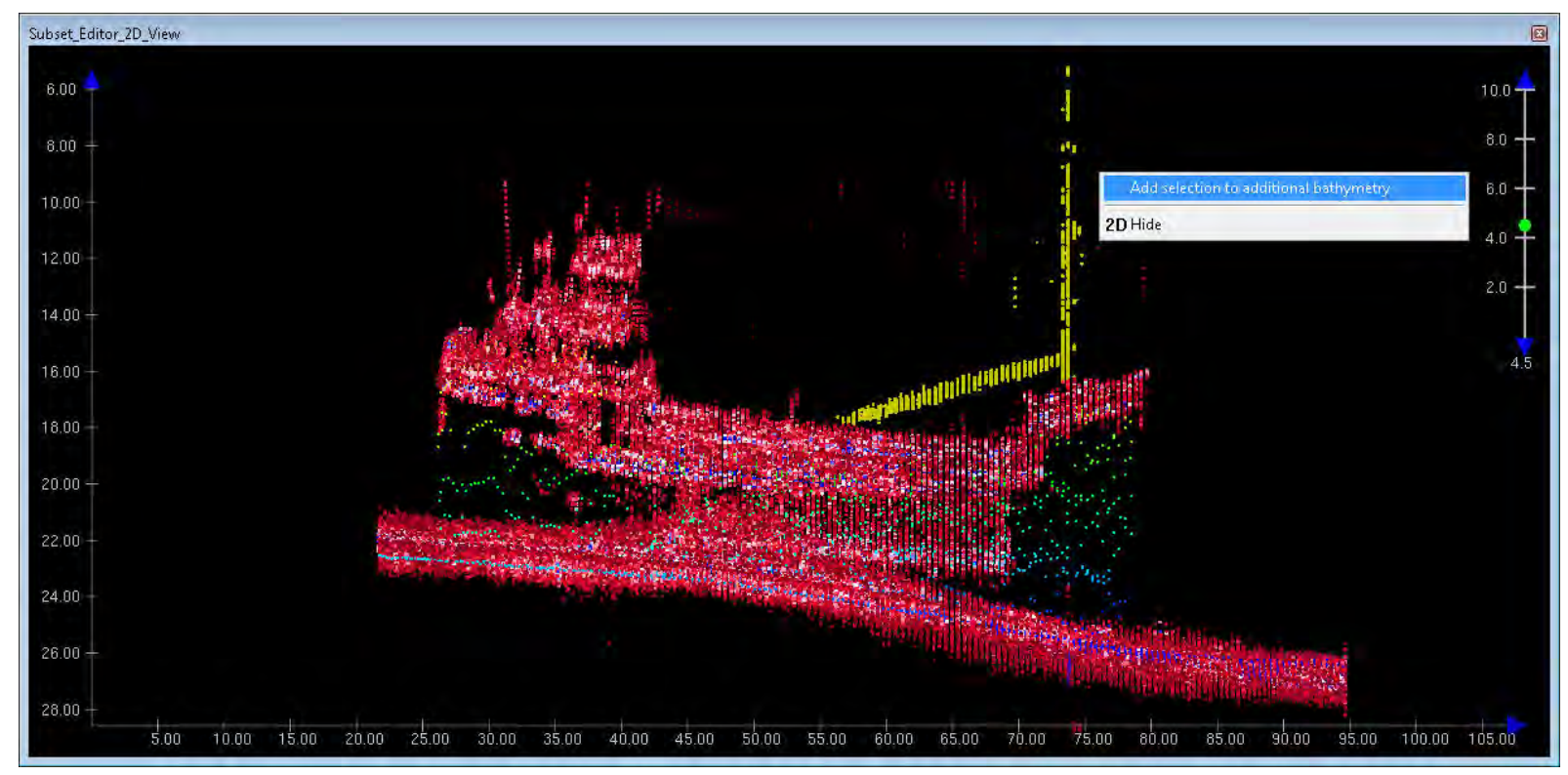

Figure 2: a) Marked automatic detected outliers. b), c) Examples for outliers. [Units are cm, except for the tide curve: $10 \mathrm{~cm}$ and Reference gauge-zero $-500 \mathrm{~cm}$ ]

$$
P(f)=\frac{1}{2 s^{2}}\left(\frac{\left[\sum_{i}\left(y_{i}-\bar{y}\right) \cos 2 \pi f\left(t_{i}-\tau\right)\right]^{2}}{\sum_{i} \cos ^{2} 2 \pi f\left(t_{i}-\tau\right)}+\frac{\left[\sum_{i}\left(y_{i}-\bar{y}\right) \sin 2 \pi f\left(t_{i}-\tau\right)\right]^{2}}{\sum_{i} \sin ^{2} 2 \pi f\left(t_{i}-\tau\right)}\right)
$$

Here the time constant of the frequency is defined with:

$$
\tan (4 \pi \tau)=\frac{\sum \sin \left(4 \pi f t_{i}\right)}{\sum \cos \left(4 \pi f t_{i}\right)}
$$

Hocke and Kämpfer (2009) used the LSP to compute the LSP of unevenly sampled time series and reconstructed the missing values in an astrophysical series from the amplitude and phase information of the dominant frequencies. Muller and MacDonald (2000) used the LSP to show the relation between ice-ages and astronomy. Figure 3 shows two example results of closed gabs. In the first example we use the hand-drawn lines on the sheet originated from a former hydrologist (which are part of the digitalization) as an additional non-observed information. Visually in both cases the reconstructed curves fit sufficient well. The handmade insertions of the former hydrologist fit quite well with the reconstructed curve.

\section{Fuzzy based closure of gabs}

Next, we use the fuzzy logic approach to fill gabs inside the time series, this methods is only possible if two comparable tide gauge data set are available. But if there are, fuzzy logic is a quite effective method to fill gabs of time series. Thereby, a fuzzy inference system simulates the behavior of the sea level system by means of "if-then" rules of correlations in the different gauge data. Fuzzy logic based on fuzzy sets and membership functions, which depict the tide gauge measurements to fuzzy sets and towards suitable logical operations on these quantities and their inference. In the sense of water levels Hein (2011) uses a fuzzy inference system for backward prediction of water levels and also for quality control and find quite well result. Thereby, fuzzy logic is also excellent with an additional quality control of time series data: with a comparison between trained and measured 


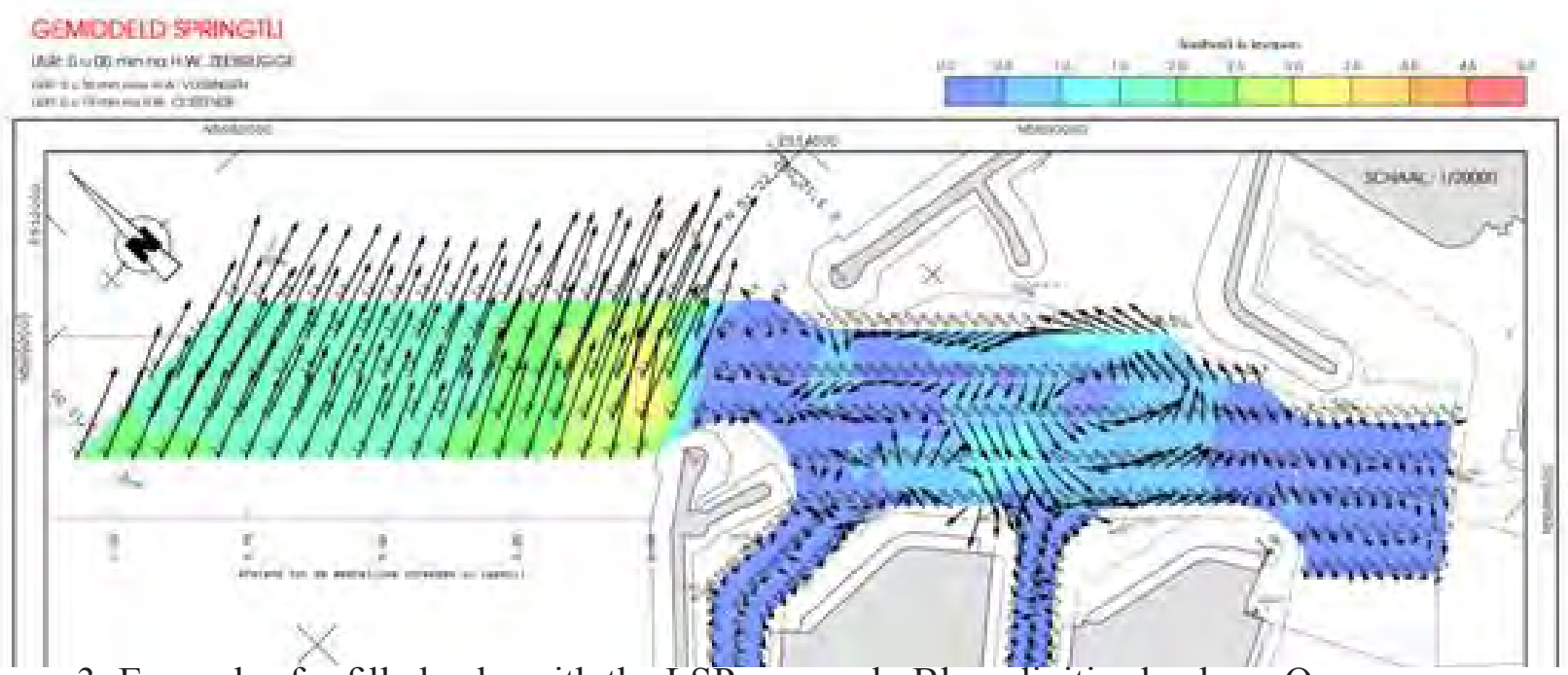

Figure 3: Examples for filled gabs with the LSP approach. Blue: digitised values. Orange:

Reconstruction.

time series we see rather good any discontinuities, outliers and systematic errors in single time series.

Figure 4 shows the performance of the fuzzy logic approach. In the middle of the figure not only a gab, but a complete non-sense cluster of digitized values can be seen. The fuzzy logic uses values from an other tide gauge for the reconstruction, because of this there is no influence on the reconstruction by this chuck of uncertain data. However, the reconstruction work fine if we use it against the propagation of the tide curve into an estuary, but not so well in the opposite direction. We explain that with the need of additional information from topographic induced self oscillating effects in the estuary, which take commonly a non-linear form.

\section{UNCERTAINTIES}

By uncertainties in long-term observations, there is a serious danger, that there are erroneous interpretations analysis of sea level data (Hein et al., 2010). Sometimes it is difficult to assess the data quality of long-term observations of the tide gauges,

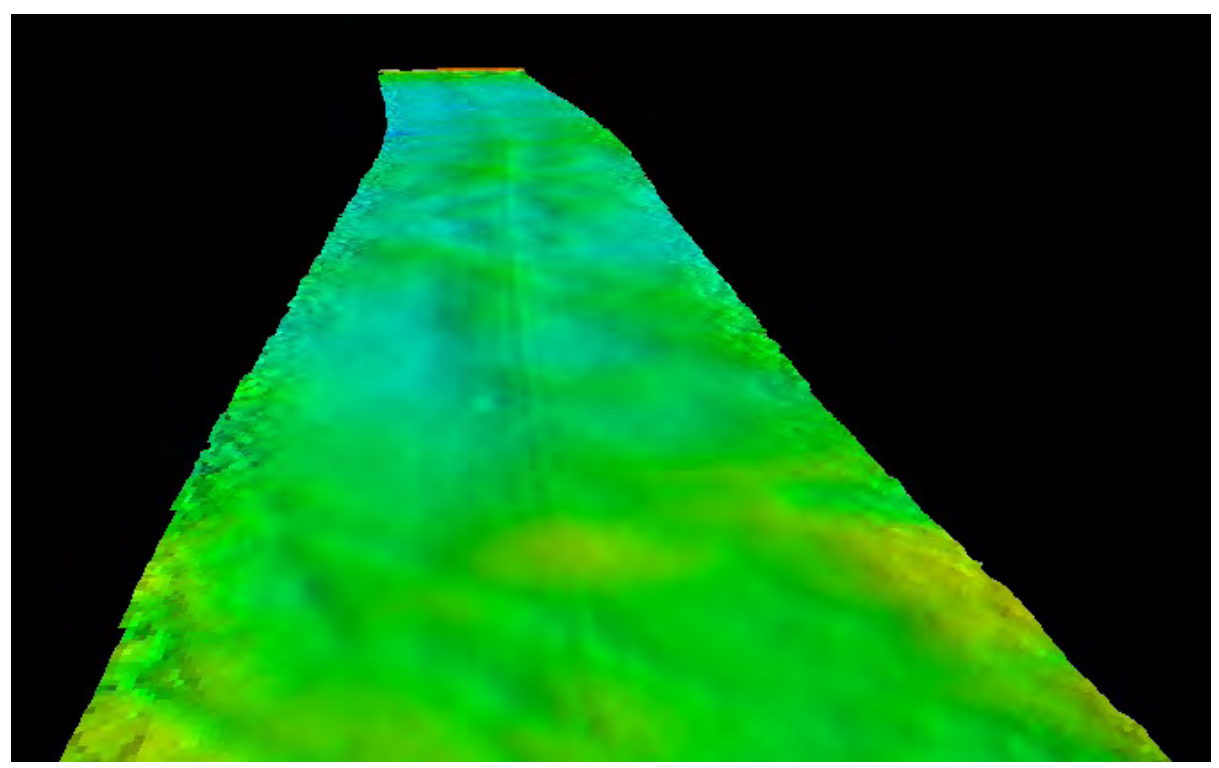

Figure 4: Example for a filled gab with the fuzzy logic approach. Blue: digitised values. Orange: Reconstruction. 
which provide a remarkable contribution to the current discussion to the possible acceleration of the sea level rise.

The one sigma mean standard deviation calculated in the procedure during the detection of outliers is $\mathrm{O}(2.5 \mathrm{~cm})$. However, we must understand this value as a subjective number, representing only the difference between the value from the digitalization and that from an idealized tidal curve. But, the value works well to conclude that the sheets in general are good basis for accurate digitalization. The one sigma standard deviation of the reconstruction by fuzzy logic is $\mathrm{O}(8 \mathrm{~cm})$ for one single digitized value. This uncertainty contains two parts, the uncertainty of the digitalization itself and the uncertainty of the reconstruction.

\section{CONCLUSION}

Our study reports the difficulties connected with the digitalization of tide gauge data in paper form. The crucial challenge is situated in the quality control of the data. Generally, these data are so extensive, that automatic methods must be used to identify failed digitization, data gaps or distortions of water levels. In this study we present several methods which are the base for a new degree of automations in the quality assurance. As well frequency based methods as stochastic methods - by the means of fuzzy logic - can be used to close gabs in the datasets. If more than one tide gauge was digitised we prefer the later method.

Both mentioned methods are reasonable useful to detect (subjective) uncertainties of the digitalisation. However, more robust methods are necessary for the final homogenisation of the data sets. We prefer to remove suspect observations generously from the dataset and use reconstructed instead of them. Moreover this should be done with the combination of the two methods we presented in this study, to take account for both, the deterministic and the stochastic part of the tide gauge observations. The next step must be the analysis of breakpoints to determinate long-term uncertainties in the data set. In a recent study we present some reasonable methods to do so (Jennings, 2012).

\section{REFERENCES}

Hein, H., Weiss, R., Barjenbruch, U., Mai, S. 2010. "Uncertainties of tide gauges \& the estimation of regional sea level rise". Extended abstract, Hydro 2010, Warnemünde.

Hein, H., Barjenbruch, U., Mai, S. 2011. "What tide gauges reveal about the future sea level”, Aqua Alta 2011, Hamburg, http://acqua-alta.de/fileadmin/ design/acqua- alta/pdf/abstracts/paper/13_10/Hein Harmut_full_papers.pdf.

Hocke, $\bar{K}$. and Kämpfer, N. 2009. “Gap filling and noise reduction of unevenly sampled data by means of the Lomb-Scargle periodogram", Atmos. Chem. Phys., 9, 4197-4206, doi:10.5194/acp-9-4197-2009. Jenning, S. Hein, H., Mai, S.; Schüttrumpf, H., 2012. "Breaks and long term trends of the tidal characteristics in the southern German Bight", International Conference of Coastal Engineering, Santander, 2012.

Muller, R.A., MacDonald, G.J. 2000: "Ice Ages And Astronomical Causes. Data, Spectral Analysis and Mechanisms", Chichester, UK: Praxis Publishing Ltd - ISBN 1-85233-634-X.

Mueller, P.H., Neumann, P. and Storm, R. 1973.

"Tafel der mathematischen Statistik", VEB

Fachbuchverlag, Leipzig.

Müller, M. 2011. "Rapid change in semi-diurnal tides in the North Atlantic since 1980". Geophysical Research Letters, 38, L11602, 6 PP., 2011

doi:10.1029/2011GL047312

Lomb, N.R. 1976. "Least-squares frequency analysis of unequally spaced data". Astrophys Space Sci 39: 447-462.

Scargle, J.D., 1982. "Studies in astronomical time series analysis. II. Statistical aspects of unevenly spaced data". Astrophys J 302: 757-763.

\section{CONTACT DETAILS}

Hartmut HEIN

German Federal Institute of Hydrology (BfG)

Am Mainzer Tor 1

56068 Koblenz

GERMANY

Phone: +49-261-1306-5226

Email: hein@bafg.de

WEB: http://www.bafg.de/nn_222644/M1/DE/06

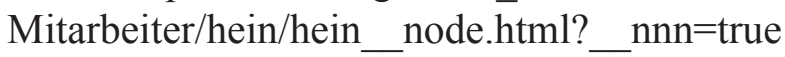


The results of this study are from the "KLIWAS" research program funded by the German Federal Ministry of Transport, Building and Urban Development. The authors thank the German Federal Waterways and Shipping Administration for the operation of the tide gauges, which is a more and more meaningful job in the era of climate change. 


\section{Measuring Bathymetric Uncertainty of the EdgeTech 4600 Sonar}

Thomas HILLER, United Kingdom

Thurne Hydrographic Ltd

Lisa Nicole BRISSON and Steve WRIGHT, United States of America

EdgeTech

Topic: Innovations in acquisition techniques

\section{INTRODUCTION}

High frequency $(100 \mathrm{kHz}$ to $600 \mathrm{kHz})$ sonar

'interferometers' (phase measuring bathymetric sonars or bathymetric side scans) have recently become a popular tool for shallow water swath surveys, and now form an integral part of the surveyors toolkit. The interferometric sonar can be considered as a multi-stave side scan, collecting a wide swath of bathymetry and sonar amplitude data, with the angle of arrival of the seabed returns determined by phase comparisons between the receive staves.

A-priori theoretical error models of interferometric systems are complex and have been difficult to reconcile with observed system performance. A reliable system error model is required in order to apply sophisticated postprocessing techniques, for example the CUBE algorithms developed at $\mathrm{UNH}$, and to determine the uncertainty indications to use on data sets and charts. Direct empirical measurements of system uncertainty can be used to refine and verify the sonar models and ensure that the Total Propagated Uncertainty (TPU) applied in the data processing is consistent with real data as collected.

Statistical techniques for analysing and optimising the performance of swath bathymetry systems have been used for several decades (for example de Moustier 2001), especially in the analysis of beamforming multibeam systems. A well-used technique is to compare a single line of test data against a reference surface to determine the sonar depth repeatability and consistency across the swath. While an independently surveyed reference surface with a higher accuracy than the system under test would be desirable, this is not often available and in practice is difficult to obtain when testing stateof-the-art survey systems (Whittaker et al., 2011). It has become accepted practice to test a system against itself, creating a reference surface using multiple passes in different directions, with tight data filtering, to create a very high data density which will average out errors. While this has limitations with regard to systematic offsets, the two effects of tight filtering to limit the reference surface data to the most accurate part of the swath, and the averaging of errors from multiple passes, will create a reference surface with a significantly higher accuracy and repeatability than obtainable from a single pass of the sonar.

Once a reference surface has been generated a separate survey line is recorded over the test area and the two data sets can be compared. Statistical analysis of the difference will give a good indication of the accuracy and repeatability of the sonar system in a single pass as a function of position across the swath. In early 2012 these techniques were applied to analyse the performance of a boat-mounted EdgeTech 4600 sonar system when used for shallow water surveys, with data collected off West Palm Beach FL, USA.

\section{METHODS}

The EdgeTech 4600 is a combined, fully integrated, swath bathymetry and side scan sonar system that produces real-time high resolution three dimensional (3D) maps of the sea floor while providing coregistered simultaneous side scan and bathymetric data. The 4600 uses eight receive element transducers and one discrete transmit element in a pair of transducer heads. The high number of channels enables enhanced rejection of multipath effects, reverberation and acoustic noise, and EdgeTech's Full Spectrum ${ }^{\circledR}$ processing techniques also provide a denser data set in the nadir region compared to other interferometric systems, meeting IHO SP-44, NOAA and USACE specifications for feature detection. 


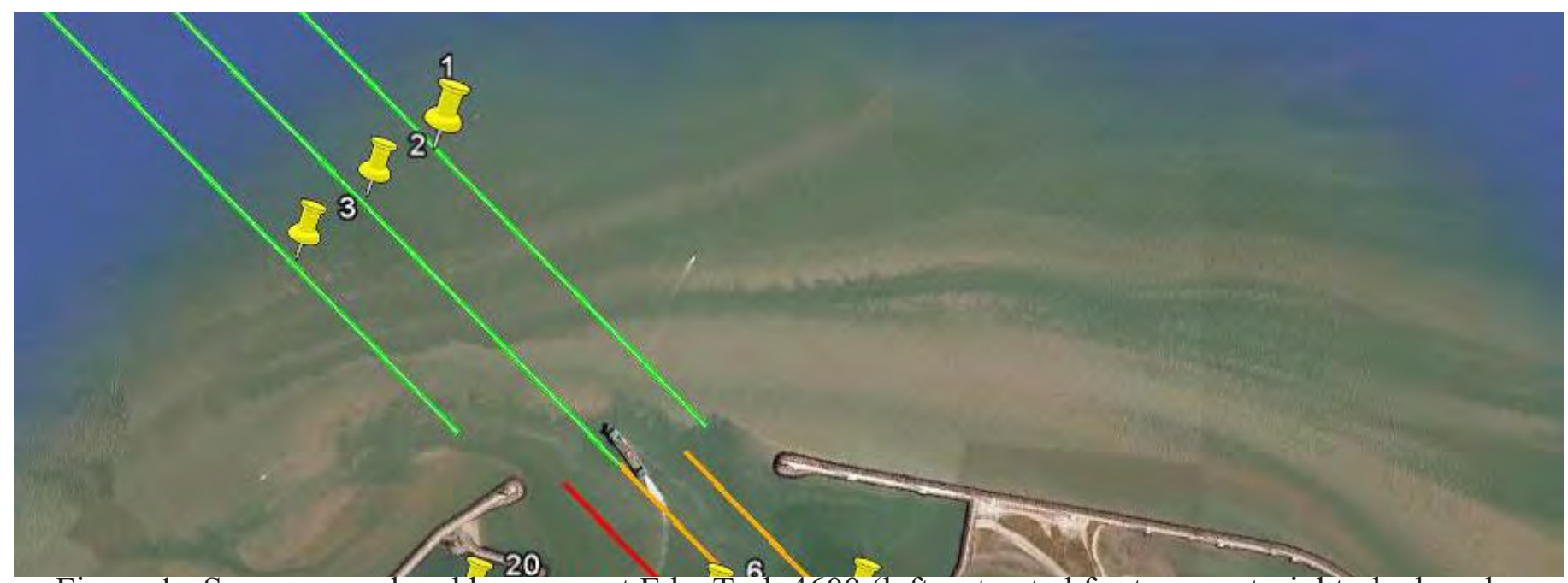

Figure 1: Survey vessel and bow mount EdgeTech 4600 (left: retracted for transport, right: deployed for survey).

On 17th-19th January 2012 a survey data set was collected using a $540 \mathrm{kHz}$ EdgeTech 4600 deployed on a retractable bow pole mount on the US Army Corps of Engineers trailerable Survey Boat SB-32.

Repeat surveys were run over a dredged navigation depth $(\sim 10 \mathrm{~m})$ area in the intercoastal waterway near Lake Worth Inlet, Palm Beach FL, with the aim of generating reference bathymetric surfaces and reference test lines. The area chosen was the nominally flat turning basin of Palm Beach Harbour in West Palm Beach, Florida, which was sheltered from swell and weather and was of sufficient size to allow orthogonal sets of 200 meter lines at $30 \mathrm{~m}$ spacing. A patch test area to the SW of the survey area was identified which had a flat area and a channel edge to enable roll, pitch, yaw and latency calibrations.
When setting up the data collection for the reference surface it is important to pay meticulous attention to detail, measuring accurate equipment offsets and system calibrations. Accurate and frequent sound velocity profiles are also important to minimise raybending errors in the final surface, and repeated patch tests were carried out to check the consistency of the system calibrations.

The sonar electronics and arrays for the 4600 were mounted onto a streamlined tow body that was deployed over the bow of the survey vessel via a pole. Alternatively, the sonar can be hull-mounted, mounted on a side pole, used as a towed system, or configured for ROV or AUV deployment. The standard configuration for the 4600 includes an integrated sound velocity sensor and there are interfaces for standard GPS, MRU, SVP, CTD, Altimeters and Gyros. Data is transferred from

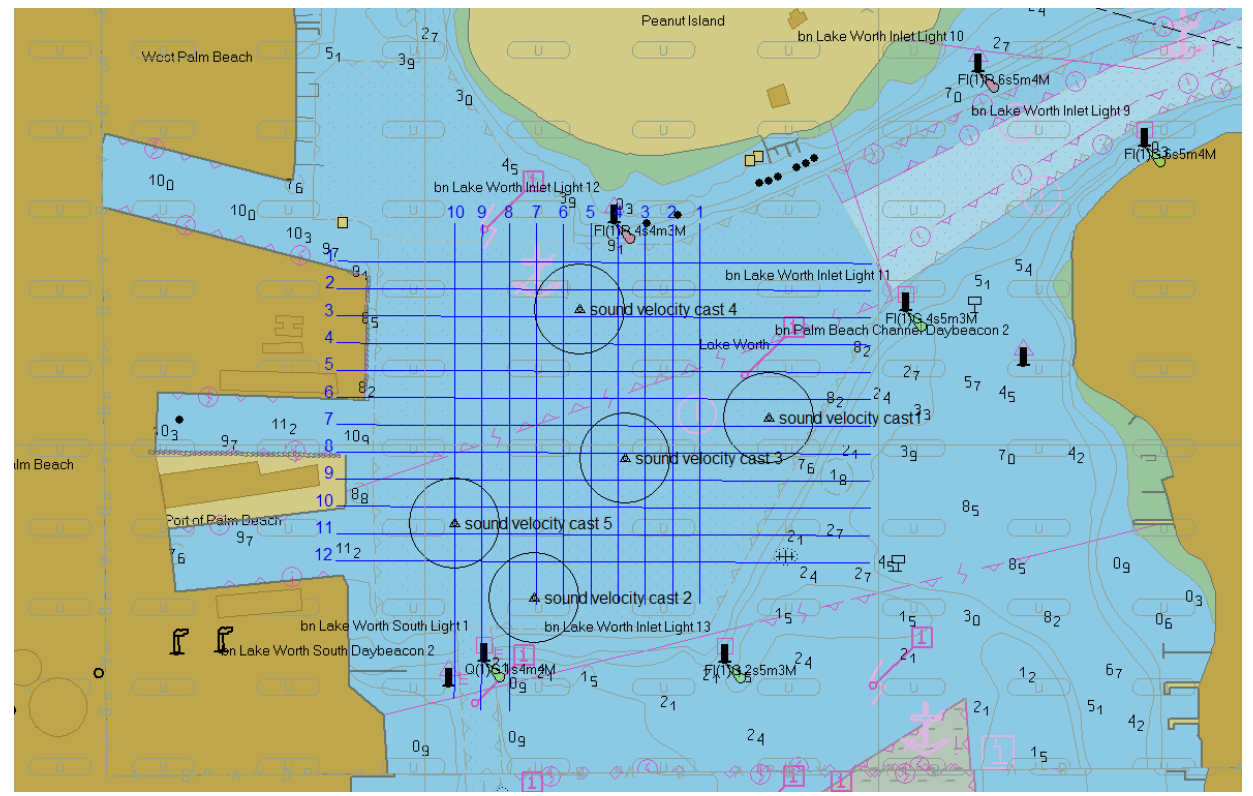

Figure 2: The survey area showing the reference surface lines (30m spacing) and SV dips. 
the transceiver at the sonar head to the processing unit in the survey cabin via Ethernet. In the Palm Beach tests a POS-MV from Applanix was used for position and attitude, with the POS applying lever- arm corrections from the GPS and IMU to the transducer head. While the real-time survey data was collected using predicted tides, the height control in final processing was achieved using POSPac PPK (postprocessed kinematic) GPS data (supplied by Kevin Smith of US Army Corps of Engineers).

The data was collected using EdgeTech's Discover 4600 software and Hypack Hysweep Multibeam, which has a real-time interface for collecting 4600 inteferometric data. Postprocessing was carried out in the office using Hypack Hysweep Editor (also known and MBMax). The 4600 also interfaces to many other 3rd party acquisition and processing software packages.

The data from each survey line was processed and filtered separately to remove outliers and water column hits (for example wakes and fish). Although the system is capable of collecting data from a swath of over 12 times water depth, the total swath width for the reference surface was limited to 6 times water depth in order to retain only the cleanest data. Care was taken to visually inspect the lines to check for outliers, blunders and bad data, and cross-check lines against each other to identify and eliminate calibration and offset errors. The full filtered data from all the reference lines were then combined to create a cleaned reference surface. This was binned by averaging to a cell size of $0.5 \mathrm{~m} \times 0.5 \mathrm{~m}$ for export as a final digital terrain model (DTM).

The same data collection and processing was carried out for the individual test lines and again these were binned to $0.5 \mathrm{~m} \times 0.5 \mathrm{~m}$ for comparison with the reference surface. A grid of the differences between the reference surface depths and the test line depths was created, and multiple cross profiles were taken orthogonal to the boat heading along this line. Cross profiles were spaced by $5 \mathrm{~m}$ and over 40 profiles were taken in order to generate the statistics for analysis.

\section{RESULTS}

The above process gave a set of profiles across the test swath which showed the difference between the test line depth and the reference surface. These profiles were analysed to find the mean and standard deviation of the differences between the test line and reference surface as a function of position across the swath. The mean difference shows the depth residual, or static offset, and the standard deviation is a measure of the bin-to-bin repeatability of depths

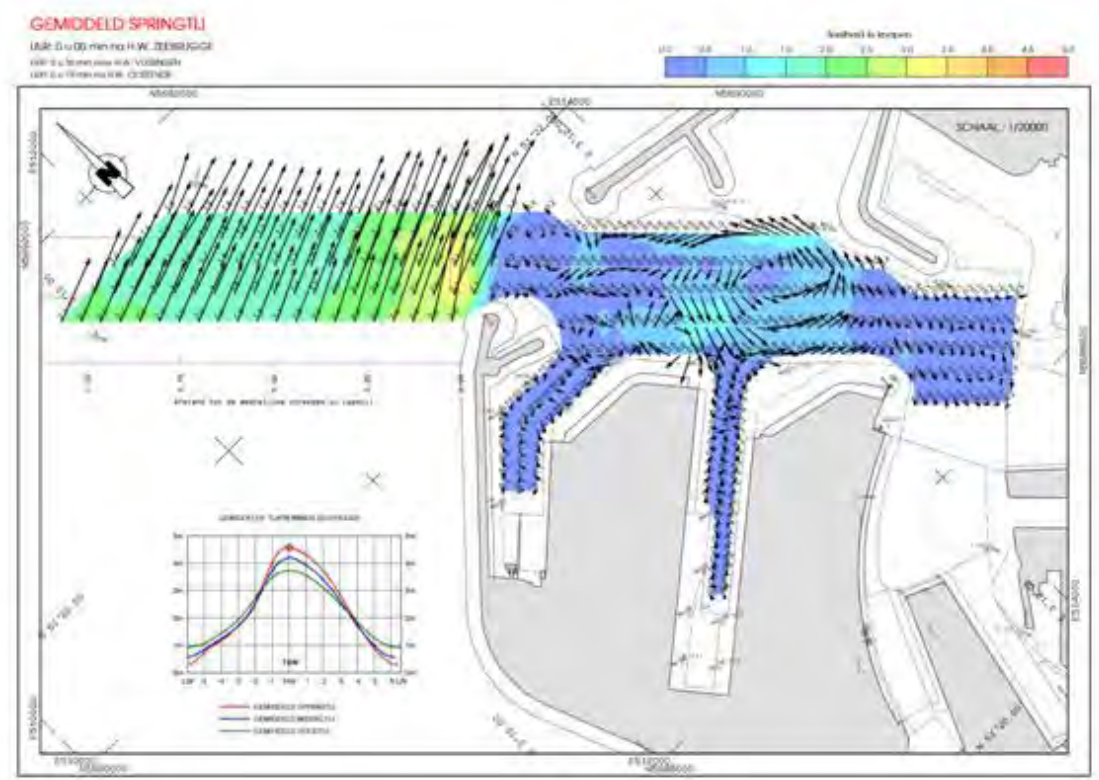

Figure 3: The reference surface $(250 \mathrm{~m} \times 250 \mathrm{~m}), 0.5 \mathrm{~m}$ bins ( $0.5 \mathrm{~m}$ contours shown). 


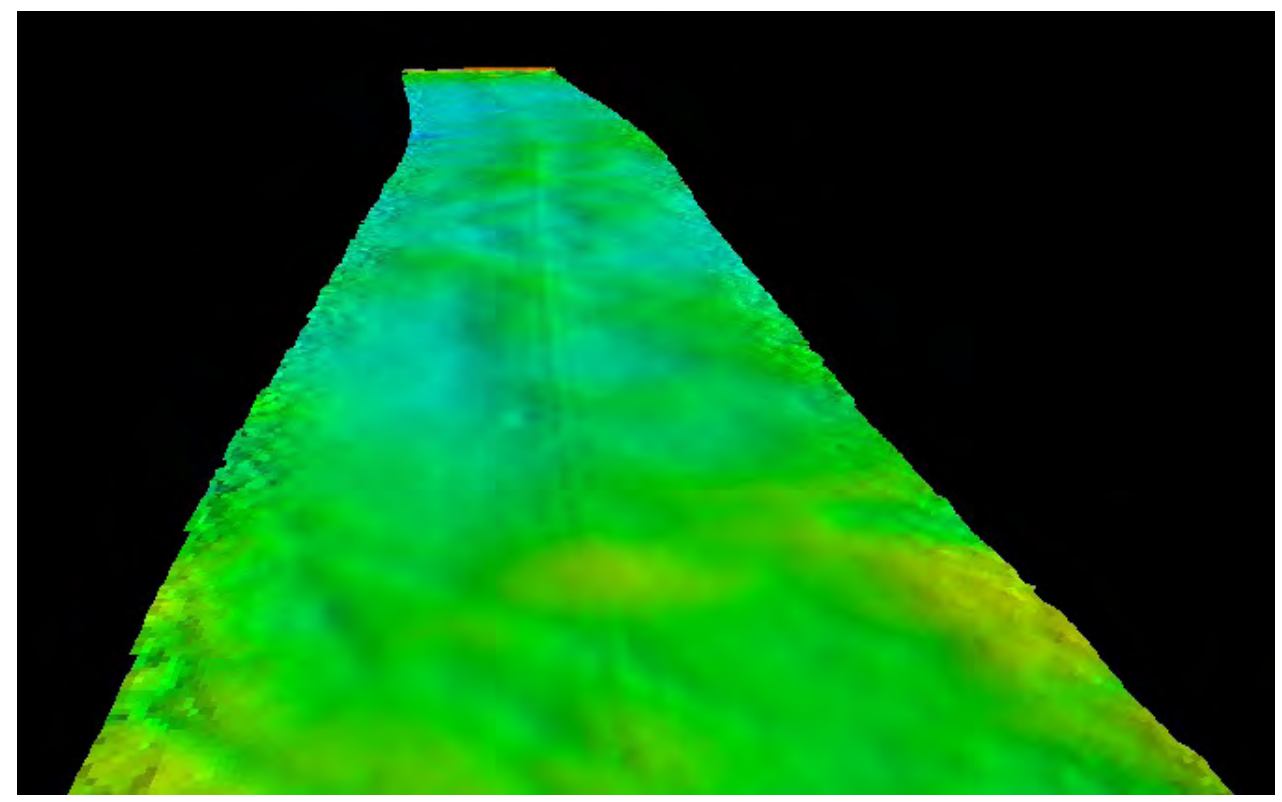

Figure 4: 3D sun-illuminated view of a $250 \mathrm{~m}$ test line (filtered to $60 \mathrm{~m}$ swath), colour scale as Fig. 3

at that swath position. The plots are shown in Figure 5 , for the centre portion of the swath limited to 6 $\mathrm{x}$ water depth (60m swath), and Figure 6, which shows a $150 \mathrm{~m}$ swath, roughly the limit beyond which the signal amplitude is too small to reliably provide a bathymetric solution in the depths and environmental conditions found here. Note that in

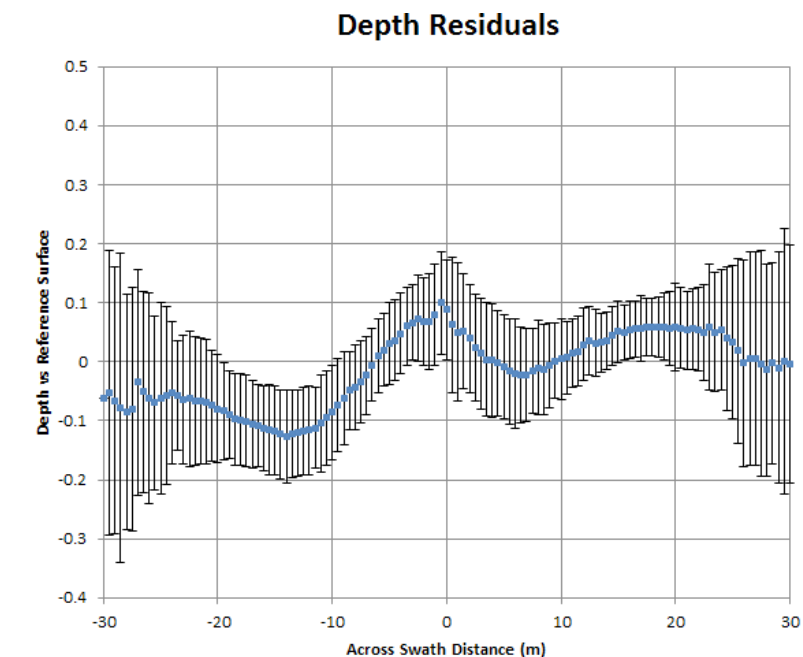

order to aid comparison with hydrographic standards the error bars show 2 standard deviations above and below the mean, which corresponds to the $95 \%$ confidence level.

Figure 5: Mean depth residuals across the swath (60m swath), error bars show $95 \%$ confidence level.

Figure 6: Mean depth residuals across a $150 \mathrm{~m}$ swath. Error bars show 95\% confidence level.

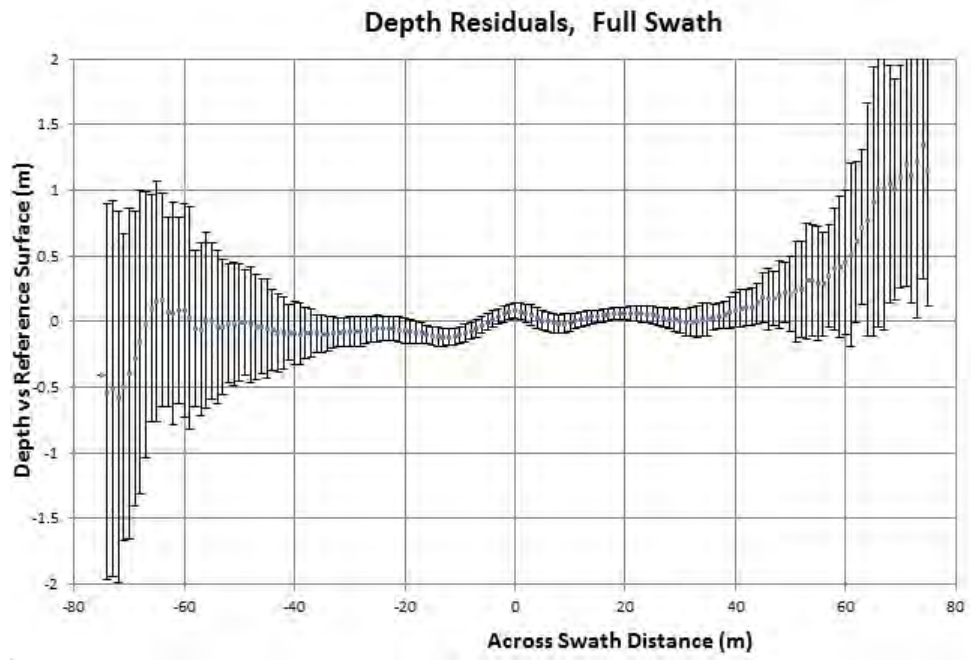




\section{DISCUSSION}

The mean depth residuals are considered to represent systematic errors or biases in the depth results. The standard deviations are caused by random error sources from the sonar combined with other dynamic error sources which change rapidly over the time taken to collect the test line ( 100s). Several features are apparent from the plots:

(1) The depth consistency of the test line is within IHO special order standards (Total Vertical Uncertainty of $25 \mathrm{~cm}$ at the $95 \%$ confidence level) out to a $50 \mathrm{~m}$ swath, and only just exceeds this on the port side out to a $60 \mathrm{~m}$ swath. It is within Order 1a $(0.5 \mathrm{~m})$ out to a $100 \mathrm{~m}$ swath $(10 \mathrm{x}$ water depth).

(2) The mean depth residual in Figure 5 is in places greater than the random errors, showing that there are consistent systematic variations in depth across the swath. The variation in the mean depth residual is smoothly varying over the swath. This error is likely to be from minor deviations of the stave spacings in the transducer head from the calibrated values used in the angle determination algorithms, and could be improved in future. It is worth noting here that the EdgeTech 4600 system used to acquire the data was an early prototype model. The asymmetrical results presented in Figures 5 and 6 led to an extensive study on both the port and starboard transducers. The results proved that the port transducer had one displaced element among the eight, which contributed to the increase in mean depth residuals across the swath.

(3) The centre of the swath shows a distinct ridge at nadir, which results in a 'track' in the survey (visible in Figure 4). This is suspected to be an effect of multipath as the sea was calm during the survey and the transducers were mounted near the surface.

(4) The outer edges of the swath (beyond about $60 \mathrm{~m}$, or a total of $12 \mathrm{x}$ water depth) show systematic deviation below (port) and above (starboard) the mean. This is probably caused by a combination of two factors: limits in the accuracy of the roll calibration and errors in the sound velocity raybending corrections at extreme shallow angles.

(5) Beyond about 70m from nadir the random error (at the $95 \%$ confidence level) rises to over $1 \mathrm{~m}$, showing the limits of swath width achievable using the 4600 technology in this environment.

The data used to generate the above plots will have many sources of error included, both from the sonar and the ancillary equipment, so can be considered as a reasonable proxy for the total propagated errors of the survey system. These plots will be expected to overestimate the TVU contribution from the sonar alone. However some static and slowly varying errors will be common to both the reference surface and the test line; these will be invisible to the above analysis. These will include errors in the static vertical offset from the GPS antenna to transducers and slowly varying GPS height and position errors. Comparison with reference surfaces collected using different equipment would be useful in estimating these errors.

\section{CONCLUSION}

The Edgetech 4600 sonar system was tested in $10 \mathrm{~m}$ water depth and the data consistency between a reference surface and a test line was within IHO Special Order specifications to a swath width of $5 \mathrm{x}$ water depth. The data was within IHO Order 1a specifications to $10 \mathrm{x}$ water depth, and useful $0.5 \mathrm{~m}$ binned survey data was available to $12 \mathrm{x}$ water depth. The shape of the mean depth residuals compared with the magnitude of the random errors indicates that more could be done to reduce systematic error sources, including a displaced element that was later found in one of the transducers, showing that this technology could achieve greater accuracy in future. The statistical analysis techniques applied here provided valuable information about sonar performance and helped measure the data quality that can be obtained from the sonar system. The total vertical uncertainty values obtained will help inform sonar use and aid in the use of advanced postprocessing algorithms with this data.

\section{REFERENCES}

de Moustier, C., (2001). 'Field Evaluation of Sounding Accuracy in Deep Water Multi-Beam Swath Bathymetry", MTS Oceans Conference 2001.

Wittaker, C., Sebastian, S., Fabre, D.H., (2011). "Multibeam Sonar Performance Analysis Value and Use of Statistical Techniques", International 


\section{AUTHOR BIOGRAPHIES}

Dr. Thomas Hiller obtained his $\mathrm{PhD}$ in experimental physics in the semiconductor sector, becoming involved with marine sonars in 1998 at Submetrix Ltd. He has managed interferometric sonar product lines at three different sonar manufacturers, including six years as Advanced Products Manager at GeoAcoustics Ltd. In 2011 Tom set up Thurne Hydrographic Limited to provide engineering consultancy, marketing representation, and survey support to the worldwide hydrographic industry.

Ms. Lisa N. Brisson is a Project Engineer at EdgeTech with experience in Underwater Acoustics and Hydrographic Surveying. Lisa graduated with a B.S. in Ocean Engineering in 2009 from Florida Atlantic University. After graduation, she continued her studies there and developed a detection and classification algorithm for forward look sonars, and later graduated with a M.S. in Ocean Engineering in 2010. Following that she joined EdgeTech and was involved in the design and development of an interferometric side scan sonar. Currently, she has been installing, testing, and providing training for hydrographic systems.

Wright, Steven - Director of Technology Development: Mr. Steven Wright holds a Bachelor of Science degree in Electronic Engineering with 30 years experience in sonar systems development. He has managed the development of Airborne SAR and Radarsat data processors while at MacDonald Detwiler and Associates in Canada. He has overseen new product R\&D and sonar technology development at Kongsberg Mesotech in Canada, and he has been working at EdgeTech for the last 12 years. He also has over 28 years of technical management experience in both small and large companies. Most recently, he has been involved in the development of compact sonar systems electronics, transducer arrays and swath bathymetry sonars. 


\section{Positioning Small AUVs for Deeper Water Surveys Using Inverted USBL}

Thomas HILLER, United Kingdom

Thurne Hydrographic Ltd

Arnar STEINGRIMSSON, Iceland

Teledyne Gavia ehf

Robert MELVIN, United States of America

Teledyne Benthos

Topics: Innovations in acquisition techniques, Subsea positioning

\section{INTRODUCTION}

The man-portable low-logistics survey AUV is now capable of rapid deployment and accurate navigation around a sub-sea inspection site, carrying a range of oceanographic and geophysical survey instruments. Over the past five years small survey AUVs have become increasingly accepted in the oil \& gas, engineering and marine environmental sectors, where they are seeing extensive use in pipeline surveys, rig scour, debris clearance and harbour engineering surveys.

A range of oceanographic and geophysical survey instruments can be mounted on the small AUV. Key equipment used in commercial survey work are depth mapping sonars, imaging side-scan sonars and optical cameras. In many areas the small AUV now offers a cost-effective alternative to a boat-mount, ROV-mount or towed sonar. The small vehicle size and low logistic requirements also confers specific advantages where low disruption, high asset safety, or access to hazardous areas are required. Small AUVs owned by commercial organisations are carrying out survey and inspection tasks on a weekly basis, delivering engineering-quality survey data with high productivity and low logistics costs, and it can be expected that the small AUV will become an increasingly important asset in many subsea survey and inspections roles (see for example McMurtrie 2010). Improvements in vehicle and payload reliability has helped drive system acceptance: experience in commercial deployments over the last 5 years shows that the small AUV is now capable of extended field operations with multiple deployments over multiple days with a variety of beach and boat launched missions to shallow, mid and deep waters.
A key factor in the commercial uptake of the small AUV has been improvements in the quality of the vehicle positioning. A survey platform must be accurately positioned in three dimensions for the sensor data to be useful for engineering purposes. In the small AUV this is achieved using an inertial navigation system aided by a doppler velocity $\log$ (INS/DVL) and high accuracy depth sensor. Advances in the integration of navigation-class INS/ DVL systems in the 1990s and early 2000s led to a reduction in footprint and power requirements, enabling their use in small diameter AUVs.

The INS/DVL/depth sensor combination can provide positioning suitable for engineering survey and inspection tasks over tens of minutes. Long term errors in the sensors result in a position drift that grows with time, reducing positioning accuracy during extended missions. The size of the positioning error depends on a number of factors, including water depth, water currents, and survey layout. After the AUV submerges a typical error figure would be about $0.05 \%$ of distance travelled (e.g. McEwen et al 2005). At AUV operational speeds this error will exceed typical engineering positioning requirements in less than an hour. The positioning accuracy is therefore sufficient for short submerged missions but this is significantly less than the AUV battery life under operational load. Operational practices have been developed to extend the accuracy, for example in shallow waters by surfacing to correct the position drift using a GPS fix, and this can enable the use of small AUVs in many engineering survey roles (Hiller et al, 2011).

The small AUV can be deployed in areas where other survey methods are very costly or difficult. As 
an example of this, small AUVs are now capable of acquiring higher resolution bathymetry, side scan and sub-bottom data from up to $1000 \mathrm{~m}$ water depths. In deep water surveys the AUV enables the surveyor to get a suite of high resolution sonar instrumentation close to the survey site using a low noise, stable platform, with none of the cable handling and logistics hazards of a large ROV or deep tow system. Surfacing for a GPS fix is not practical in deeper water missions, and there is also likely to be a time during the dive to the survey site when the DVL will not be in bottom lock, resulting in a large INS position drift. In order to increase the accuracy of these surveys and expand the AUV envelope of operations other methods of subsea position aiding are required. Typical options are a boat mounted USBL system or an LBL array. A novel modification to the USBL technique is the 'inverted' USBL (iUSBL), where the azimuthal and vertical angles to a boat-mounted transponder are estimated by a system mounted on the AUV (rather than the boat), which gives several advantages over traditional USBL techniques.

\section{iUSBL CONCEPTS AND ADVANTAGES}

In standard USBL a directional transceiver is mounted on the vessel and is used to determine the range an angle to a transponder on the AUV. A surface vessel is a high noise, dynamic environment, which reduces the achievable accuracy of the USBL solution. Once the range and angle has been calculated on the vessel, this will need to be communicated with the AUV via an acoustic message. Errors are also possible in the synchronisation of the time of the position update from the USBL system with the AUV's navigation sensor messages.

In the iUSBL technique the directional transceiver is mounted on the AUV and this determines the range and angle to a transponder mounted on the surface vessel. The position of the surface transponder is sent to the AUV as part of the response message, and the position of the AUV can be calculated in the AUV control computer. The iUSBL solution is able to achieve better range and angle solutions over longer ranges because the AUV-mounted directional transceiver is in a low noise, low dynamic environment. The tight integration of the iUSBL directional transponder with the AUV systems allows it to be closely coupled with the AUV INS, simplifying system calibration and time synchronisation, and allowing highly accurate depth sensor correction. Having the USBL transceiver permanently mounted on the AUV in the iUSBL configuration also offers operational advantages, reducing issues with installing a through-hull or over-the side USBL transceiver and eliminating errors from offset measurements.

\section{EQUIPMENT}

This paper presents results from an iUSBL solution implemented using the Teledyne Directional Acoustic Transponder (DAT-900, Teledyne-Benthos, North Falmouth, MA) system on the Gavia Surveyor AUV (Teledyne Gavia ehf., Reykjavik, Iceland).

The Gavia Surveyor AUV is a widely used lowlogistics $20 \mathrm{~cm}$ diameter commercial survey AUV. It is fully modular and can be rapidly assembled in the field in various mission-specific configurations. The Gavia Base Vehicle consists of a nose-cone, battery, control unit and propulsion unit. This configuration includes a GPS for surface positioning, wireless LAN for communications, and Iridium satellite link for over-the-horizon messages. In the base vehicle a three-axis magnetic compass and $360^{\circ}$ orientation sensor provides input for basic vehicle control and dead-reckoning capability, although the dead reckoning accuracy is usually not sufficient

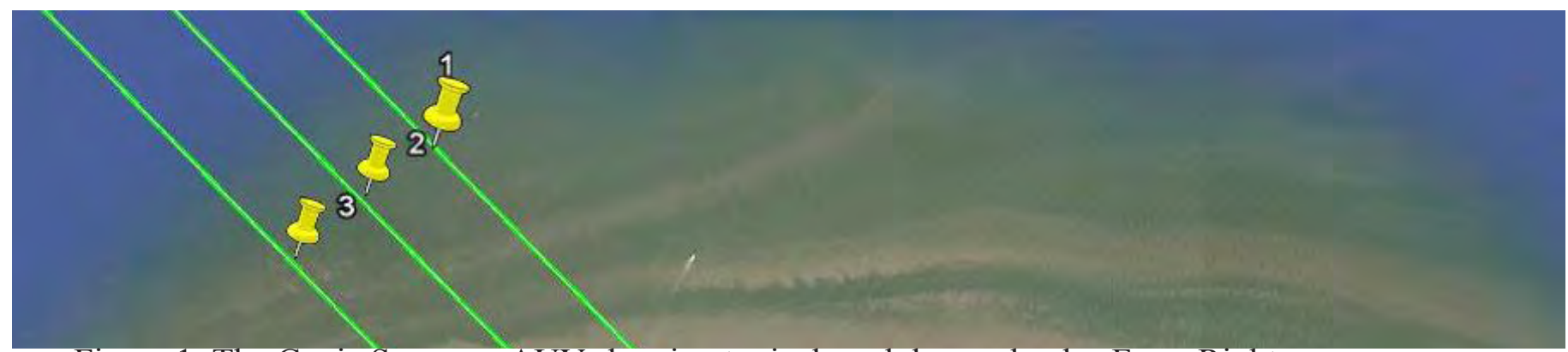

Figure 1: The Gavia Surveyor AUV showing typical modular payloads. From Right: nosecone, battery, DVL/INS (Kearfott T24), control with GPS and acoustic modem, GeoSwath, propulsion.

\section{2 Hydrol 2}


for commercial survey specifications. The Gavia Surveyor AUV, as used in commercial survey work, has additional positioning and payload modules (see figure 1 for an example of a Gavia configured for bathymetric survey). When configured for commercial survey work the Gavia includes: a differential-ready GPS receiver; a SeaNav T24 INS (Kearfott Corporation, Little Falls, NJ); a Teledyne WorkHorse 1200 DVL (Teledyne RDI, Poway, CA); and a Keller 33Xe depth sensor (Keller-Druck, Winterthur, Switzerland). For data acquisition the Gavia can be fitted with side scan sonar, wideswath bathymetric sonar and/or sub-bottom-profiler modules. The Gavia control module can be equipped with the DAT acoustic modem configured as a iUSBL system. In a typical survey configuration the vehicle is $2.7 \mathrm{~m}$ long and weighs less than $80 \mathrm{~kg}$. All data examples in this paper were collected using Gavia Surveyor AUVs in various configurations.

The DAT iUSBL system is an extension to the Teledyne Benthos Telesonar modem. The DAT operates as a modem combined with a high precision range and bearing estimation system in one integrated package. The system uses a broadband component of the modem message to form estimates of the azimuthal and vertical arrival angles of a message sent by a remote modem. The use of broadband signal technology gives improved noise immunity, increased dynamic range and greater accuracy. Appropriate processing of wide band signals provides far better combined range and arrival angle estimation, especially at low SNR, than tonal signals. The DAT-900 is able to operate on Low frequency (LF) $9-14 \mathrm{kHz}$, Mid frequency
(MF) $16-21 \mathrm{kHz}$ or Band C (C) $22-27 \mathrm{kHz}$. For the Gavia the Band $\mathrm{C}$ frequency range was chosen to reduce any interference with the sub-bottom profiler module.

Deployment of small AUV systems in commercial application requires a high level of reliability combined with ease of use. This requirement has driven developments in integration of the DAT system and the Gavia vehicle, along with improvements in the interface with the Gavia control software for the iUSBL set-up, mission planning and control.

The DAT transceiver can either be mounted on the Gavia control module just ahead of the GPS antenna tower (figure 2) or in a separate module capable of installation on existing vehicles. It broadcasts an acoustic request which triggers the transponder, which is usually pole mounted on the boat with a differential GPS. The responder replies with a message that includes all pertinent data required to calculate a subsea location. The DAT calculates the round trip travel time in order to measure range to the surface node and the hydrophone array determines the vertical and azimuthal angles to the transponder. This is combined with the AUV orientation data (from the INS) and the transponder position (in the transponder message) to obtain the position of the AUV. If the sound velocity between the pole-mounted transponder and the AUV is not constant then the range and angle data will need to be corrected for the path of the sound through the water. During the dive to survey depth the AUV can collect the sound speed profile, and this can be used to correct to the estimated range and angles.

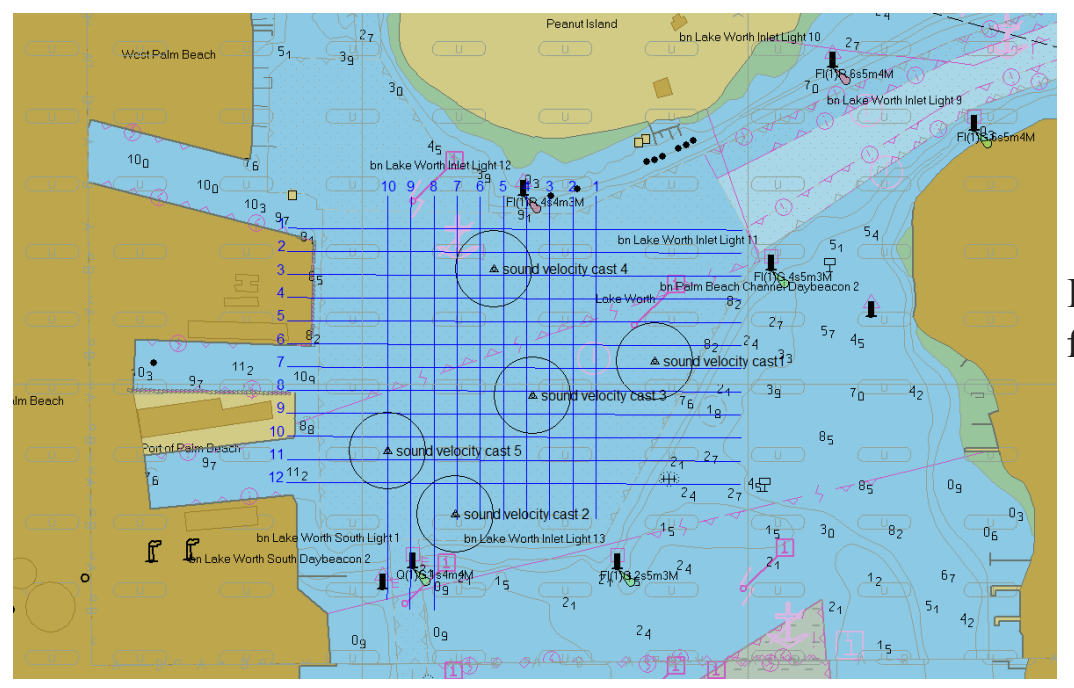

Figure 2: Gavia Control Module fitted with DAT iUSBL system 
Using the bearing, sound velocity profile, range, and location of the surface DAT node, and distance AUV has travelled during the USBL request, an accurate position can be calculated and used to aid the INS.

The estimation of the AUV position determined by the iUSBL technique will therefore have an error which depends on the acoustic environment and signal to noise level, and this needs to be taken into account when combining the iUSBL fixes with the other positioning data. In the INS the various sensor inputs (INS, DVL, GPS, depth and iUSBL) are combined in an extended Kalman filter. The objective is to provide the best estimate of the 3-D trajectory of the vehicle by combining all sensor information available, using appropriate weighting: the INS provides linear and angular accelerations; the DVL provides velocity; the GPS provides surface position; and the iUSBL system provides subsea position. In applying the iUSBL fix to the navigation care needs to be taken to use the correct weighting for the data, and to apply appropriate error models in the Kalman filters. The weighting of the fix will be variable based on the range and signal to noise levels. To help constrain the error the INS will perform filtering of the USBL fixes, and the system will not jump to a USBL fix unless commanded to do so.

\section{TRAILS RESULTS AND DISCUSSION}

Integration of the DAT with the Gavia AUV took place in the first half of 2012. During the summer of 2012 a series of trials were run near Reykjavik, Iceland, to test the performance of the DAT iUSBL solution. The trials tested the positioning performance in multiple shallow extended and deep missions in various typical survey environments, and compared these with expected performance and performance without the iUSBL navigation aiding. Selected targets on the seabed were used to provide confirmation of the integrated system positioning accuracy and repeatability. At the time of writing of this paper these results were not available for release, and will be presented at the conference where an updated version of this paper will be made available.

\section{CONCLUSION}

The use of iUSBL in small AUV deployments increases the accuracy of the navigation solution by providing direct position aiding to the INS in real time. This addresses two current problems in small-AUV navigation: during an extended mission the DVL-aided INS position will drift beyond operational requirements in a much sorter time than the vehicle endurance; and in deeper waters the lack of DVL bottom-lock during the descent results in significant unaided INS drift. This is particularly useful in small AUVs that are capable of deeper water missions, such as the $1000 \mathrm{~m}$ rated Gavia Surveyor AUV. The iUSBL solution has the potential to greatly increase the envelope of operations for the small AUV in commercial survey work, with a low impact in the operations logistics, deployed equipment, and system cost. Results from the trials of the DAT-900 modem on the Gavia Surveyor AUV illustrate the navigation improvements achievable with this technology.

\section{REFERENCES}

Hiller T., Reed T.B., Steingrimsson A. (2011). "Producing Chart Data from Interferometric Sonars on Small AUVs", International Hydrographic Review, no.6, pp43-50, Nov.2011.

McMurtrie, A. (2010). “The Efficiencies of Low Logistics Man-Portable AUVs for Shallow Water Surveying", presented at Oceanology International, March 2010.

McEwen R., Thomas H., Weber D., Psota F. (2005). "Performance of an AUV navigation system at Arctic latitudes", IEEE J. Oceanic Engineering, vol.30 no.2, pp 443 - 454, April 2005.

\section{AUTHOR BIOGRAPHIES}

Dr. Thomas Hiller obtained his $\mathrm{PhD}$ in experimental physics in the semiconductor sector, becoming involved with marine sonars in 1998 at Submetrix Ltd. He has managed interferometric sonar product lines at three different sonar manufacturers, including six years as Advanced Products Manager at GeoAcoustics Ltd., manufacturer of the GeoSwath sonars. He deployed the first interferometric sonar mounted on a man-portable

\section{4 | Hydrol 2}


AUV in Reykjavik Harbour in 2006. In 2011 Tom set up Thurne Hydrographic Limited to provide engineering consultancy, marketing representation, survey support, and data processing services to the worldwide hydrographic industry.

Arnar Steingrimsson heads up the sales and marketing department for Teledyne Gavia in Kopavogur, Iceland, and has since 2003 been involved in marketing, selling, and business development projects related to the Gavia AUV. Arnar has led the introduction and adaption of the Gavia AUV technology to international military, commercial and scientific users, with a recent emphasis on the commercial survey / hydrograhic use of the Gavia. Previous to joining Hafmynd / Teledyne Gavia, Arnar served in the US Navy on surface ships and amphibious construction battalions in various positions and has degrees in finance and international business from the University of North Carolina at Wilmington.

Robert Melvin is the Vice President of Engineering at Teledyne Benthos which includes Teledyne Gavia and Teledyne Webb Research. He has over 25 years of experience in both engineering and program management and is responsible for overseeing all of engineering including the GAVIA autonomous underwater vehicle and the Slocum glider. He has successfully managed numerous development programs for the U.S. Navy and commercial customers. Previous to Teledyne Benthos, he was engineering manager at Hydroid, Inc. While at Hydroid, Mr. Melvin spent over three years designing, developing, and operating autonomous underwater vehicles. During this period, he was the program manager working with the U.S. Navy EOD (Explosive Ordinance Disposal) team developing the Swordfish version of the REMUS-100. Previously he has held positions at Lockheed Sanders and the National Security Agency. He holds three U.S. Patents in the area of signal processing. 
II6 | Hydrol 2 


\title{
Accurate water levels using PREMO: Tool for reduction of hydrographic measurements
}

\author{
Micheline HOUNJET, Arnout BIJLSMA and Martin VERLAAN, theNetherlands \\ Deltares
}

\section{Leendert DORST}

Hydrographic Service of the Royal Netherlands Navy

Topics: Innovations in processing techniques, Vertical references, Accurate hydrodynamics, Hydrography in the Benelux

\section{INTRODUCTION}

The Hydrographic Service of the Royal Netherlands Navy (RNLN) publishes nautical charts for the Dutch sector of the North Sea. A major source of error in the charted depths based on echo soundings is the so-called "tidal reduction" of the measurements to their Chart Datum (the vertical reference surface). Tidal reduction is the correction for the local water level, depending on tides and meteorological conditions, relative to a specified reference surface. At sea, the accurate determination of vertical position, and thereby the reduction, with respect to Chart Datum from satellite positioning is still under development. Therefore, the water levels in the survey areas are obtained from temporary tide gauges placed on the seabed or by some form of spatial interpolation between permanent tidal stations. PREMO (PREdiction Module) version 2 estimated the water levels in the survey area using a database of tidal constants to predict the astronomical tide, and water level measurements in permanent tidal stations to determine the surge heights via a sophisticated interpolation method (Delft Hydraulics, 1998). The main reason to start the development of a new tidal reduction package was the seriously reduced working area of PREMO v2, since the water level measurement in some tidal stations was not continued, and new stations were difficult to include. The implication was that (pressure) tide gauges needed to be deployed at a much larger scale again.

The availability of hydrodynamic models predicting the daily movement of the North Sea sparked the redesign of the reduction tool PREMO. The new version uses data-assimilated model predictions of water levels, astronomical tides and surges stored in the databases of Rijkswaterstaat, Ministry of Infrastructure and the Environment (RWS). PREMO enables hydrographic vessels like the HNLMS Snellius and the HNLMS Luymes of the RNLN to retrieve the water levels along their route using an internet connection to access the databases. However, when preferred, reduction work by PREMO may well be performed by shore staff (RWS). Application by third parties is also anticipated.

The new development is a cooperation of the Netherlands Hydrographic Institute (NHI) partners, the Hydrographic Service of the RNLN and RWS,

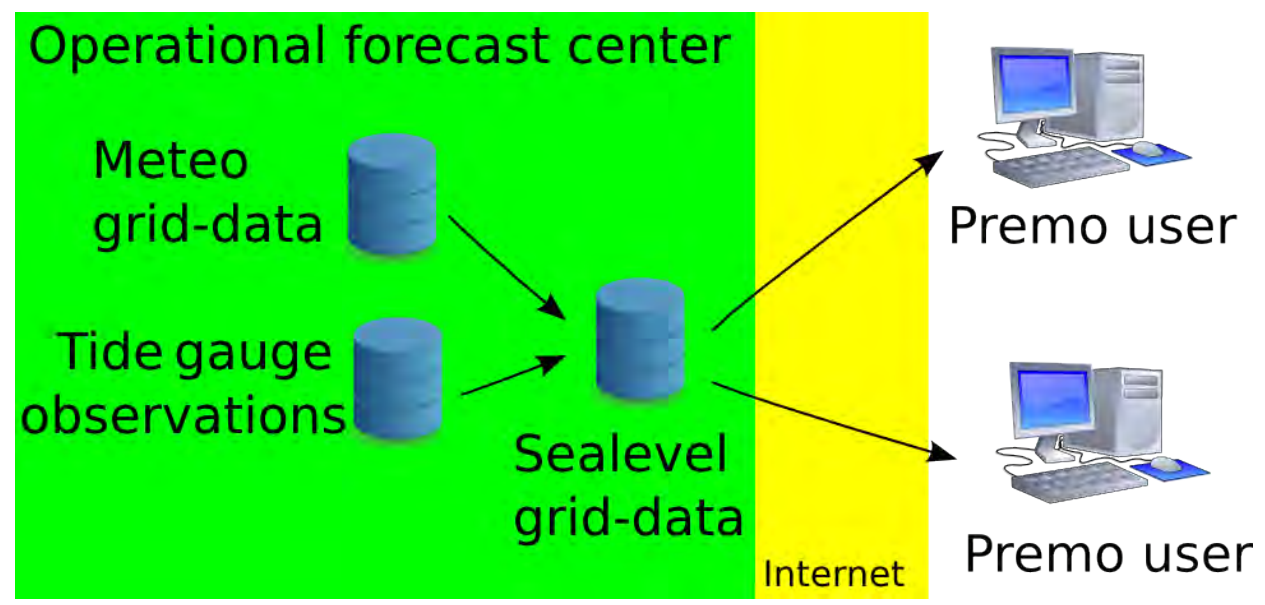

Figure 1: Data flow from operational forecast center via the internet to the PREMO users. 
with research institute Deltares. Deltares is the developer of the new tidal reduction package, the Hydrographic Service of the RNLN and the North Sea Department of RWS are the end users. The RWS Centre for Data and ICT (DID) and RWS Centre for Water Management (WD) provide support on operational measurements and modeling and database services.

\section{NEW METHOD OF TIDAL REDUCTION}

The new PREMO version 3 is based on the open source Delft-FEWS software, see Gijsbers et al. (2008) and http://oss.deltares.nl/. This software was originally developed for water level and discharge forecasts in rivers, but is now used for all kinds of operational systems. For the development of PREMO it means that much standard functionality of FEWS can be used. PREMO is designed as a standalone system, meaning that no external server is used to carry out tasks or model computations. An internet connection to the external MATROOS database of RWS is essential for PREMO, however. Data presented by the user or from MATROOS are imported in a local data store. The data in the local data store can be presented or manipulated in various ways by a graphical user interface.

The water levels required for the reduction are based on the computations four times per day of the Hydro Meteo Centre (HMC) of RWS North Sea. The HMC North Sea exports the computational results to the MATROOS database of RWS, where they become available for use by PREMO, see Figure 1. This means that the tidal reduction by PREMO can be repeated later, as long as the data is available in MATROOS.

In PREMO the user can choose between two hydrodynamic models from which results are available in MATROOS: the Dutch Continental Shelf Model (DCSM) version 5 (see e.g. Gerritsen et al. 1995) and a more refined model of the coastal zone. The DCSM covers the entire NW European

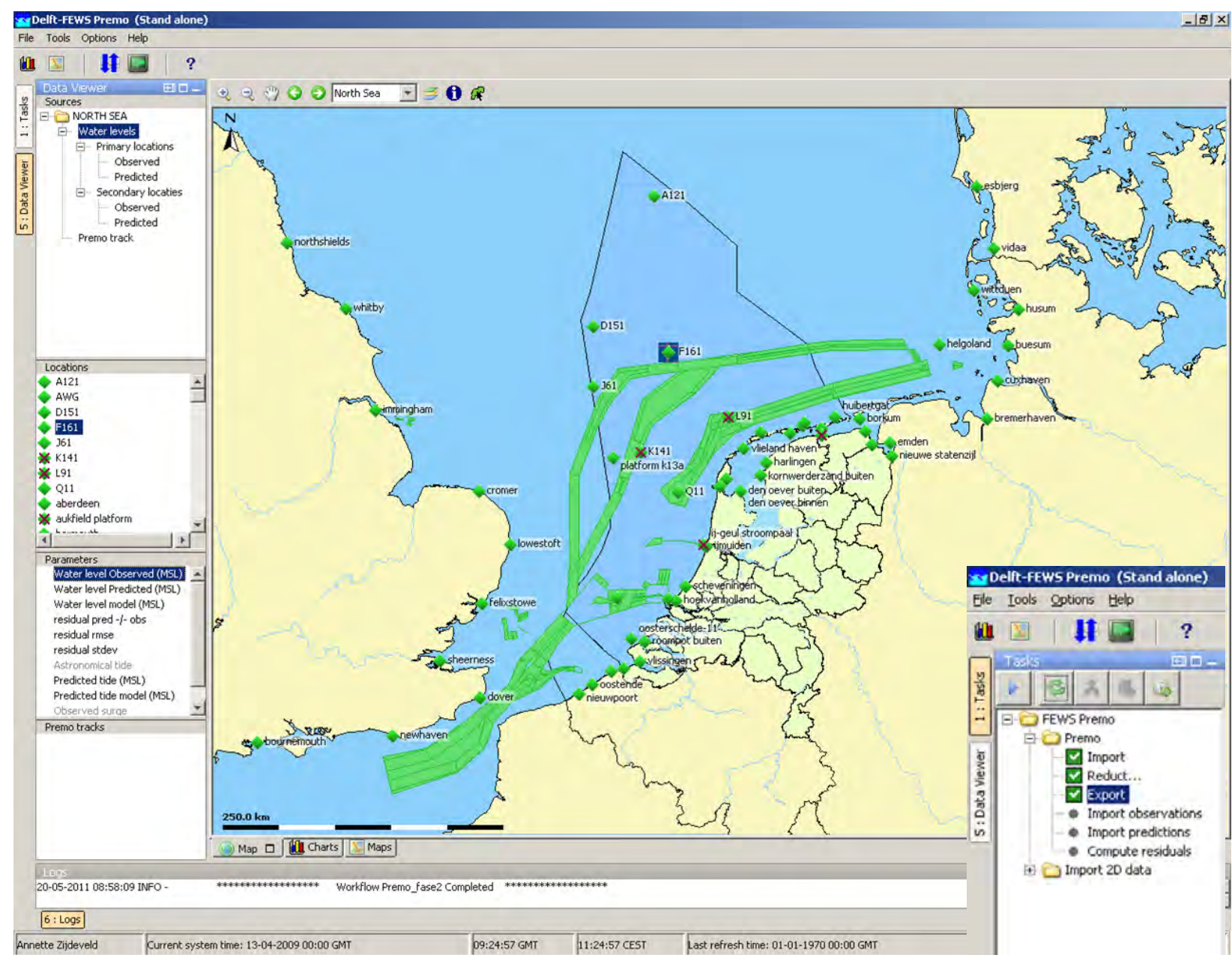

Figure 2: PREMO Explorer, showing Data Viewer filters (left) and Map with permanent tidal stations, with warning symbols for missing data and reduction errors, depending on the sources, locations and parameters selected. Inset: contents of PREMO Tasks tab (right). 
Continental Shelf with a resolution of about 8 $\mathrm{km}$ and is driven by tidal constants at the ocean boundary and wind and atmospheric pressure fields provided by Royal Netherlands Meteorological Institute KNMI. The water levels computed by DCSM v5 are not directly used for reduction. To improve the accuracy, a special tidal database was created, which is combined with surge heights computed in the operational cycle. Both tides and surges are improved further by data-assimilation. The model of the coastal zone, the Kuststrook-fijn Model v4 of RWS, covers the entire Dutch coast to about $60-70 \mathrm{~km}$ offshore. The boundary conditions are derived from DCSM via an intermediate model, and a Kalman Filter is used to further enhance the accuracy of the model results.

The operational models provide water levels relative to Mean Sea Level (MSL). For tidal reduction these levels need to be converted to Chart Datum, which is defined as Lowest Astronomical Tide (LAT), see Kwanten and Elema (2007). The definition of LAT with respect to MSL is available on a grid, and this information is included in the MATROOS database where, it can be approached by PREMO.

The graphical user interface of PREMO Explorer helps to perform the tidal reduction. The Explorer, see Figure 2, shows the various components, like the Tasks Tab, the Log window and the Data Viewer. The latter includes Maps, Charts and Filter options, which can be used to inspect and document the reduction results.

\section{RESULTS}

Both during the development and in the Acceptance Phase, the North Sea Department of RWS and the Hydrographic Service of the RNLN tested the performance of PREMO v3 by comparison with measurement series of pressure tide gauges. These reference measurements have been selected from surveys carried out in a period of several years (2009 -2011) and spread over the Dutch sector of the Continental Shelf. Figure 3 shows a representative result of such an accuracy analysis. For the tide gauge series GM3 at position $53^{\circ} 43^{\prime} 06.0^{\prime \prime} \mathrm{N}$ $3^{\circ} 06^{\prime} 06.0^{\prime \prime}$ E, about $140 \mathrm{~km}$ NW of Den Helder, the standard deviation of the difference between measured water levels and PREMO is $0.057 \mathrm{~m}$. This is well within the required accuracy.

The assessment of the measurements spread over the Dutch sector of the Continental Shelf generally showed good results. Based on the difference between PREMO and measurements, in most cases the $95 \%$ accuracy intervals were about $+/-0.1 \mathrm{~m}$. An exception was found at the Dutch coast near Petten, with a 95\% accuracy interval of $+/-0.24 \mathrm{~m}$. Due to the specific characteristics of the local tides, the numerical models may have some difficulty to accurately reproduce the water levels here. This needs to be investigated further.

The application of PREMO in an actual survey situation is illustrated by Figure 4. For the survey

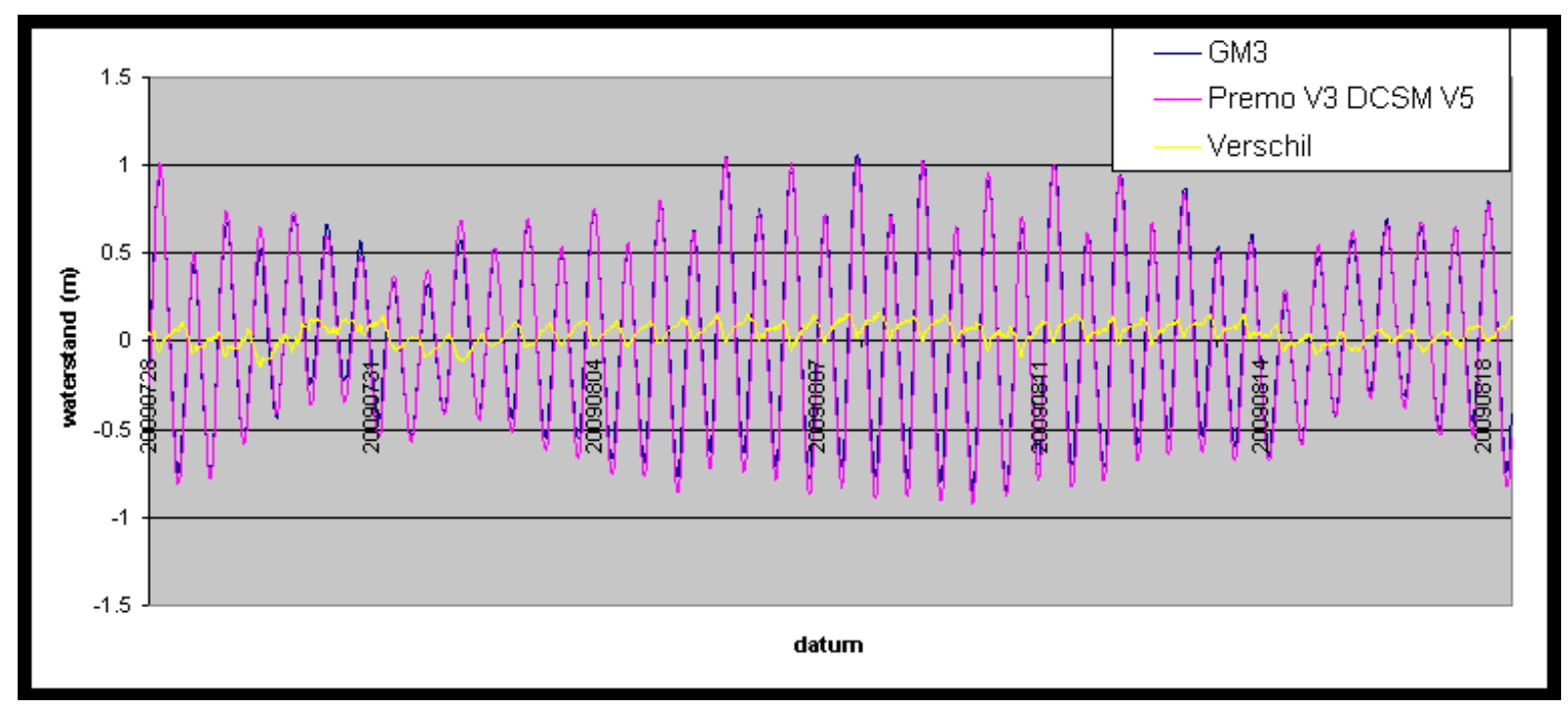

Figure 3: Accuracy analysis for bottom tide gauge at position $53^{\circ} 43^{\prime} 06.0^{\prime \prime} \mathrm{N} 3^{\circ} 06^{\prime} 06.0^{\prime \prime}$ E. PREMO v3 (pink line) against the water level measurement GM3 (blue line), and their difference (yellow line). 


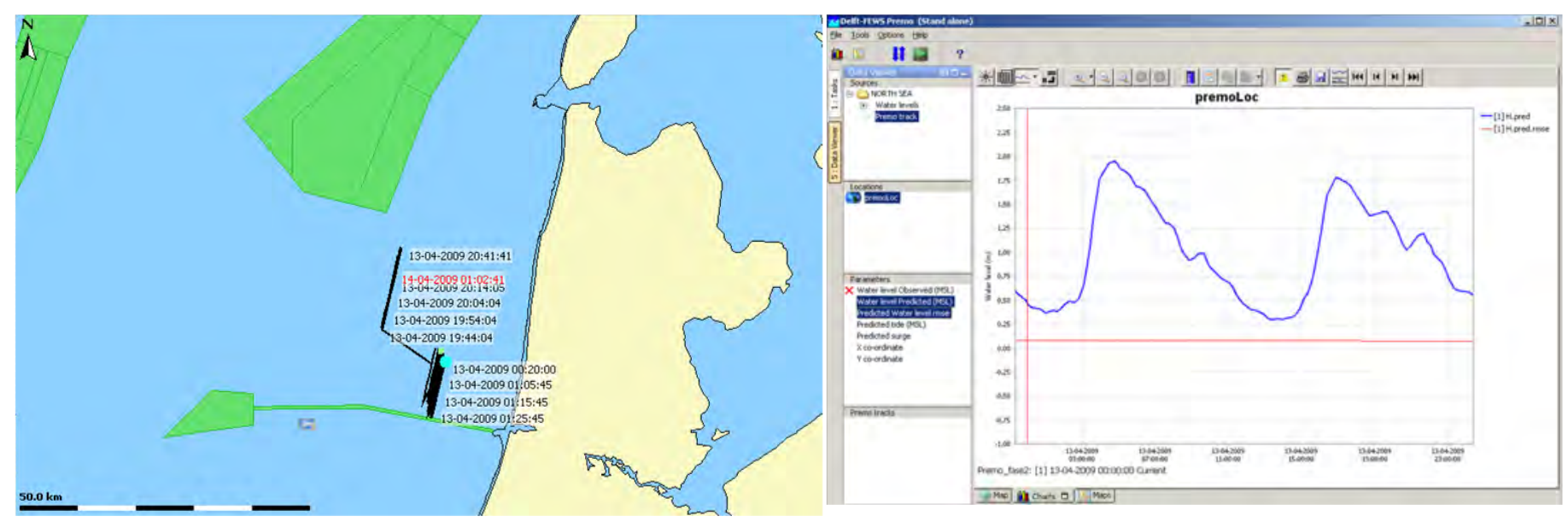

Figure 4: Survey track presented in PREMO v3 (left) and the computed tidal reduction along the track (right).

track imported in PREMO (Figure 4, left panel), the tidal reduction is computed, depending on the selected database and reference surface (LAT). The user can inspect the reduction result in various ways, e.g. in a time-plot along the survey track (Figure 4, right panel). Additionally, the user can verify and document the quality of the tidal reduction during the survey period in all stations of the tide gauge monitoring network.

\section{DISCUSSION}

During the tests, PREMO v3 demonstrated that the accuracy objectives for tidal reduction are met. Furthermore, it proved to work well on board of the hydrographic survey vessels of the RNLN. Other advantages compared to previous versions are the realization of a consistent reduction tool for all NHI partners, with greater operational flexibility, less dependent on the availability of individual measurement stations, and real-time reduction in survey track position. Compared to pressure tide gauges PREMO provides an unambiguous reference level for the water levels, and a more efficient and reliable reduction procedure. Time and risks related to instrument deployment and recovery are avoided, as are data and accuracy loss due to movement or settling of tide gauges on the seabed.

The main advantage of the model-based approach is that with every model update the user benefits directly from increased accuracy. By 2013, the inclusion of a new hydrodynamic model (Zijl et al., 2009) in the operational system of RWS will make the PREMO results even more accurate. The increased accuracy will allow the multibeam echo sounding tracks to be spaced further apart, saving time and money while still meeting the accuracy requirements.

The PREMO concept potentially has a much wider field of application, e.g. for other measurements requiring tidal reduction, or dredging operations and surveying in the North Sea. It can also be applied in other sea areas, if operational models and measurements are available. However, today, data on various hydrodynamic parameters are generally available over large sea areas, but these data are buried in databases. The techniques used in PREMO can make this information available for a large group of users for whom vertical positioning, currents, wave conditions, or meteorological parameters are important, for example for offshore and shipping activities. This approach can help to optimize cost and reduce risks.

\section{CONCLUSION}

The new FEWS based PREMO version 3 provides an easy to use tool for tidal reduction. Its strength is the generic open source software platform of Delft-FEWS, which makes efficient use of existing databases of operational water level measurements, model predictions and hindcasts of other organizations. An important advantage of this approach is that users directly benefit from increased accuracy for tidal reduction, introduced by updates of the operational models.

PREMO proved to function well both on board of the hydrographic survey vessels and ashore, providing an accurate tidal reduction in agreement 
with RNLN and RWS requirements. Besides tidal reduction of bathymetric surveys, the FEWSPREMO concept essentially has an even wider range of potential application: tidal reduction of other surveys in the North Sea, and elsewhere in the world, provided that operational models and measurements are available. The concept can also easily be extended to currents, waves, and meteorological parameters.

\section{REFERENCES}

Delft Hydraulics. 1998. Manual PREMO-offline version 2.0 - Offline generation of water levels for offshore tidal reduction.

Gerritsen, H., H. de Vries, and M. Philippart. 1995. "The Dutch Continental Shelf Model.” In Quantitative Skill Assessment for Coastal Ocean Models, Coastal Estuarine Stud., Vol. 47, edited by Lynch, D. R. and Davies, A. M., 425-467, AGU, Washington, D. C. doi:10.1029/CE047p0425. Gijsbers, P.J.A., M.G.F. Werner \& J. Schellekens. 2008. "Delft FEWS: A proven infrastructure to bring data, sensors and models together." International Congress on Environmental Modelling and Software. International Environmental Modelling and Software Society (iEMSs).

Kwanten, M.C. and Elema, I. 2007. "Converting NL Chart Datum: Consequences of Change from MLLWS to LAT." Hydro International, Volume 11, number 4, April.

Zijl, F., R. Plieger, D.K. Vatvani, M. Verlaan, H. Gerritsen, \& D. Twigt. 2009. DCSM v6 model setup and calibration of tidal propagation. Delft, Deltares report.

\section{BIOGRAPHIES}

Micheline HOUNJET is a Senior Advisor at Deltares' Hydrodynamics and Real-time Systems department in the Marine and Coastal Systems unit. She works on tool-development and serious gaming techniques for marine and coastal application.

Arnout BIJLSMA is a Senior Researcher and Advisor Hydrodynamics at Deltares. He is specialized in tide, wind and density driven flow phenomena in harbours, estuaries, coastal seas and shelf seas, and has a long-term experience with tidal analysis and prediction and tidal reduction.
Martin VERLAAN is Senior Researcher Oceanography/Mathematics at Deltares and Assistant Professor at the Mathematics department of the Delft University of Technology. He works in the field of data assimilation \& operational forecasting, and is actively involved in the development of OpenDA, a generic software package for data-assimilation.

Leendert DORST is head of the Department of Geodesy and Tides of the Hydrographic Service, Royal Netherlands Navy, where he works on technical aspects of the law of the sea, advice on maritime positioning, statistical aspects of bathymetric surveying, and transformations between coordinate systems. He is a member of the Subcommittee on Marine Geodesy of the Netherlands Geodetic Committee, and of the Working Groups on Standards for Hydrographic Surveys and on Data Quality of the International Hydrographic Organization.

\section{CONTACT DETAILS}

\section{Micheline HOUNJET}

Deltares

Rotterdamseweg 185

Delft

THE NETHERLANDS

Tel.: +31622546111

Fax: +31883358582

Email: micheline.hounjet@deltares.nl

Web site: www.deltares.nl 
I22 | Hydrol 2 


\title{
High Precision Hydrography in Canada, the ST. Lawrence River Channel, HD Bathymetry, Production, Distribution and Updating
}

\author{
Marc JOURNAULT, Louis MALTAIS and Richard SANFAÇON, Canada \\ Canadian Hydrographic Service
}

Topics: Innovations in processing techniques, Easy customer access to data and products

\section{INTRODUCTION}

The St. Lawrence River channel (Quebec, Canada) is a $320 \mathrm{~km}$ long navigation channel of which 210 $\mathrm{km}$ are maintained at minimum depth of $11.3 \mathrm{~m}$. Hydrographic surveys are conducted to exceed S-44 special orders requirements. Centimeter level precision is constantly achieved in depth measurements with the survey boats. They are calibrated and their measurement of depths over the same seafloor has to be within a couple centimeters, at two sigma, to receive a green light for survey. The data used to establish the available water column are processed, validated and delivered within 24 hours.

The trend in commercial navigation in general is towards bigger, wider and faster ships. Therefore safely manoeuvering in restricted waters with limited water depth and limited width brings interesting challenges. With all the potential environmental impacts, there is a limit to deepening (dredging) and widening the navigation channel. Ships' drafts and widths are increasing but not necessarily the available depth and width of navigation channels; precise and up-to-date information is the solution. Forecasted water level and constant bathymetry updates are now requested by clients.

This paper will briefly describe the intense survey operations taking place in the St. Lawrence River channel, every year from April to December. Based on recent work at the Canadian Hydrographic Service (CHS) -Quebec Region, the paper is also proposing a new way to produce, distribute and update rapidly, High Definition (HD) bathymetric files using the navigation surface and S-102 tiles concept. This leads to a positive influence on the content of the S-100 standard series being developed and offering a solution to a fast turnaround from surveys to bridge for areas facing dynamic changes with a limited water column. A fast turnaround from surveys to bridge is essential for safer navigation and therefore helping taking care of the sea.

\section{THE REGION and THE NAVIGATION}

The Great Lakes - St. Lawrence Waterway is a vital link between the heart of industrial North America (highly industrialised and urbanised, $50 \mathrm{M}$ inhabitants, 4 of the 6 largest port installations in Canada) and international markets. This waterway is about $3600 \mathrm{~km}$ long from the Atlantic Ocean to the head of Lake Superior, the western most of the five Great Lakes. The St. Lawrence River is the eastern part of it, approximately $1800 \mathrm{~km}$ long, starting from Lake Ontario (the eastern most lake of the five) to the Atlantic Ocean. The cruise industry is growing and this is also where we find more than 20,000 ship movements registered per year, $30 \%$ of the cargo handled in the country and several thousands recreationnal boats.

On this waterway, a portion located between Montréal and Le Massif (a winter ski resort near the shore, $80 \mathrm{~km}$ East of Québec City) is called The St. Lawrence River channel. This navigation channel is approximately $320 \mathrm{~km}$ long and silting is occuring in different areas all along the River channel. From downstream up, the width of the channel varies from $335 \mathrm{~m}$ to $310 \mathrm{~m}$ near Île d'Orléans and then 240m from Quebec City to Montreal. The size of the ships navigating the river is increasing and therefore ships' drafts and widths are increasing too, but not necessarily the available depth and width of navigation channels. Therefore constant monitoring of water depths and rapid updates of the information is getting more and more crucial.

THE STANDARDS for Hydrographic Surveys at CHS

In the St. Lawrence River channel, the hydrographic surveys are regularly and systematically conducted 
to exceed S-44 special order requirements. In fact, the surveys are meeting Exclusive Order. In canadian standards, Exclusive Order hydrographic surveys are based on the International Hydrographic Organization (IHO) Special Order with higher accuracy and their use is intended to be restricted to shallow water areas (harbors, berthing areas and critical channels) where there is an optimal use of the water column and where specific critical areas with minimum under-keel clearance and bottom characteristics are potentially hazardous to vessels. This order also applies to high precision engineering surveys. All error sources must be minimized. Exclusive Order requires very precise positioning systems, and a rigorous control on all aspects of the surveys.

The use of side-scan sonar or multi-transducer arrays or high-resolution multi-beam echo sounders is required to survey the feature size to be detected.
In required areas, appropriate sounding equipment and methodologies must be employed in order to ensure that all features greater than $0.5 \mathrm{~m}$ cubed are detected. The use of side-scan sonar in conjunction with multi-beam or multi-transducer echo sounders may be necessary in areas where pinnacles and dangerous obstacles may be encountered.

To accommodate different accuracy requirements for areas to be surveyed and to classify old surveys, six orders of survey are defined. These are described below and in Table 1 which summarize the overall accuracy requirements and constitute, in fact, the essence of the standards.

One other major difference with the IHO S44 is the way CHS classifies surveys. The classification is divided into four components: the horizontal accuracy, the vertical accuracy, the target detection capability and the type of coverage. For instance, a

\begin{tabular}{|c|c|c|c|c|c|c|}
\hline ORDER & Exclusive & Special & 1 & 2 & 3 & $\begin{array}{c}4 \\
\text { (Imprecise) }\end{array}$ \\
\hline $\begin{array}{l}\text { Examples of } \\
\text { Typical areas }\end{array}$ & $\begin{array}{l}\text { Shallow water } \\
\text { in harbours, } \\
\text { berthing areas, } \\
\text { and associated } \\
\text { critical channels } \\
\text { with minimum } \\
\text { under-keel } \\
\text { clearances or } \\
\text { engineering } \\
\text { surveys }\end{array}$ & $\begin{array}{l}\text { Harbours, } \\
\text { berthing } \\
\text { areas, and } \\
\text { associated } \\
\text { critical } \\
\text { channels } \\
\text { with } \\
\text { minimum } \\
\text { under-keel } \\
\text { clearances }\end{array}$ & $\begin{array}{l}\text { Harbours, } \\
\text { harbour } \\
\text { approach } \\
\text { channels, } \\
\text { recommended } \\
\text { tracks and some } \\
\text { coastal areas } \\
\text { with depths up to } \\
100 m\end{array}$ & $\begin{array}{l}\text { Areas } \\
\text { up to } \\
200 m \\
\text { water } \\
\text { depth }\end{array}$ & $\begin{array}{l}\text { Offshore } \\
\text { areas not } \\
\text { described } \\
\text { in the } \\
\text { previous } \\
\text { orders }\end{array}$ & $\begin{array}{l}\text { All areas where } \\
\text { the accuracies } \\
\text { do not meet } \\
\text { the } \\
\text { requirements of } \\
\text { the previous } \\
\text { orders }\end{array}$ \\
\hline$H \mid \begin{array}{l}\text { Horizontal } \\
\text { Accuracy } \\
(95 \% \\
\text { Confidence } \\
\text { Level) }\end{array}$ & $1 m$ & $2 m$ & $\begin{array}{l}5 m+5 \% \text { of } \\
\text { depth }\end{array}$ & $\begin{array}{l}20 m \\
+5 \% \\
\text { of } \\
\text { depth }\end{array}$ & $\begin{array}{l}150 m+ \\
5 \% \text { of } \\
\text { depth }\end{array}$ & $\begin{array}{l}>150 m+5 \% \\
\text { of depth }\end{array}$ \\
\hline$\checkmark \mid \begin{array}{l}\text { Depth } \\
\text { Accuracy for } \\
\text { Reduced } \\
\text { Depths } \\
\text { (95\% } \\
\text { Confidence }\end{array}$ & $\begin{array}{l}a=0.15 m \\
b=0.0075\end{array}$ & $\begin{array}{l}a=0.25 m \\
b=0.0075\end{array}$ & $\begin{array}{l}a=0.5 m \\
b=0.013\end{array}$ & $\begin{array}{l}a= \\
1.0 m \\
b= \\
0.023\end{array}$ & $\begin{array}{l}\text { Same as } \\
\text { Order } 2\end{array}$ & $\begin{array}{l}>\text { than values } \\
\text { of order } 2\end{array}$ \\
\hline ORDER & Exclusive & Special & 1 & 2 & 3 & $\begin{array}{c}4 \\
\text { (Imprecise) }\end{array}$ \\
\hline Level) (1) & & & & & & \\
\hline
\end{tabular}

Table 1

Standards for Hydrographic Surveys

\begin{tabular}{|c|c|c|c|c|c|c|c|}
\hline$D$ & $\begin{array}{l}\text { System } \\
\text { Detection } \\
\text { Capability }\end{array}$ & $\begin{array}{l}\text { Features > } \\
0.5 m \text { cubed }\end{array}$ & $\begin{array}{l}\text { Features > } \\
1 m \text { cubed }\end{array}$ & $\begin{array}{l}\text { Features }>2 m \text { cubed in depths up } \\
\text { to } 40 m ; 10 \% \text { of depth beyond } 40 m \\
(2)\end{array}$ & $N / A$ & $N / A$ & $N / A$ \\
\hline & \multicolumn{7}{|c|}{ Type of coverage (M270) } \\
\hline & \multicolumn{7}{|c|}{ 1. complete coverage (multi-beam, multi-transducer, acoustically swept); } \\
\hline$C$ & \multicolumn{7}{|c|}{$\begin{array}{l}\text { 2. systematic survey (single-beam echo sounder lines run parallel at pre-planned line spacing, } \\
\text { LiDAR); }\end{array}$} \\
\hline & \multicolumn{7}{|c|}{ 3. sparse coverage (lead-line surveys, reconnaissance, track soundings, spot soundings); } \\
\hline
\end{tabular}




\section{Table Notes:}

(1)To calculate the error limits for depth accuracy the corresponding values of $a$ and $b$ listed in Table 1 have to be introduced into the formula

$\pm \sqrt{\left[a^{2}+(b \times d)^{2}\right]}$

where

a: constant depth error, i.e. the sum of all constant errors in metres

$b \times d$ : depth dependent error, i.e. the sum of

all depth dependent errors

$b$ : factor of depth dependent error

$d$ : depth in metres

(2) The value of $40 m$ has been chosen considering the maximum expected draft of vessels.

The rows of Table 1 are explained as follows:

Row 1 "Examples of Typical Areas" gives examples of areas to which an order of survey might typically be applied.

Row 2 "Horizontal Accuracy" lists minimum positioning accuracy for each depth sounding to be achieved to meet each order of survey.

Row 3 "Depth Accuracy" specifies parameters to be used to calculate minimum accuracy of reduced depths to be achieved to meet each order of survey.

Row 4 "System Detection Capability" specifies the detection capabilities of systems used when 100\% bottom search is required. Row 5 "Coverage type" specifies the seabed coverage based on the system and the methodology used to achieve a survey. Row 6 "Maximum Line Spacing" is to be interpreted as:

- Spacing of sounding lines for single beam sounders and spot soundings surveys.

This table gives the different accuracy requirements for different areas to be surveyed according to a specific order of precision. The highest accuracy requirements are found in Exclusive Order while the least order of precision is given in Order 4. survey can attain an horizontal accuracy of Special Order, a vertical accuracy and a feature detection of Order 1 and the type of coverage could be 1 (complete coverage).

\section{THE FIELD OPERATIONS and SURVEYS RESULTS}

From the $320 \mathrm{~km}$ long St. Lawrence River Channel, approximately $210 \mathrm{~km}$ are maintained at a minimun depth of $12.5 \mathrm{~m}$ to $11.3 \mathrm{~m}$ (depending on the sectors) while proceeding more inland. The channel is divided in 5 sectors (C, D, E, F, G). In these sectors, three surveys boats operate during the icefree season, from mid-April to end of November. Two of those boats are catamaran equipped with sweep systems and the third one is an 8 meter long aluminum launch (Lifetimer) equipped with a R2-Sonic 2022 multibeam echosounder. We are also evaluating the Kongsberg EM2040 and the Reson 7025 during 2012 survey season. It's our intention, in the short term, to replace the traditonnal Navitronics sweep systems of the 2 catamarans by multibeam echosounder sytems.

Each day, the survey boats are assigned a sector to be surveyed. Two hydrographers are taking place in the boat controlling the acquisition of data and processing it in near real time. At the end of the day, a final check is done and minutes later the clean file is sent to the client, Waterways Management Division at the Canadian Coast Guard. The morning after an other sector is assigned to the boats and the process is repeated 4 or 5 days a week (depending on the boat) for the whole season.

Survey results give the most recent picture of the seafloor details. Using a full bottom coverage acoustic system like multibeam sonars, we generate high definition gridded bathymetry(HDGB). The HD simply refers to a much higher resolution than what is presented on the chart. For example, the resolution of the data coming from a MultiBeam Echosounder System (MBES) could be the insonified footprint on the seafloor. Using the CUBE processing method incorporated in CARIS HIPS, we deliver on a daily basis bathymetric surfaces to our internal clients. The gridded bathymetry can be described as a Navigation Surface (in marine environnement, a Digital Terrain Model ). These gridded bathymetric datasets are generally used for chart compilation, 
volume computation and visualisation but can also be a basic navigation product by itself.

\section{NEW PRODUCTS in LINE with S-100}

To develop a HDGB product for navigation, CHS adopted a collaborative approach where navigators and software manufacturers were informed and consulted for specifications of a future product. For consultation, prototype datasets were produced and made available in a simple format for experimentation and trials.

The work of the IHO Transfer Standard Maintenance and Application Development working group (TSMAD) on the new Geospatial Standard for Hydrographic Data (S-100) was promising and CHS decided to embark. The CHS and the United States NAVal Oceanographic office (NAVO) worked together to draft and propose a product specification for gridded bathymetry based on previous work done by the Open Navigation Surface group. The standard is named Bathymetric Surface Product Specification and identified as S-102.

The Hydrographic Services and Standards Committee (HSSC) approved the final draft of S-102 in November 2011. It also instructed the International Hydrographic Bureau (IHB) to submit it to Member States for their endorsement. Subsequently the IHO Circular letter 10/2012 requested the Member States to review and consider the draft edition of S-102 which is available on the IHO website.

To partition HDGB coverage, to allow unambiguous dataset exchange and to facilitate the updates, CHS intends to implement a systematic tiling scheme with three levels of resolution. Each tile is comprised of 1000 by 1000 grid cells, the level 1 (harbour) is $0.02^{\circ} \times 0.02^{\circ}$, the level 2 (coastal) is $0.1^{\circ} \times 0.1^{\circ}$, and the level 3 (overview or offshore) is $1^{\circ} \times 1^{\circ}$. For the below and mid latitudes, the orientation of the tiles fit the meridians and parallels with an origin based on a round number in latitude and longitude. Figure 1 shows an example of the tiling scheme.

\section{UPDATES of the PRODUCTS}

It will be easy, with S-102, for hydrographers to provide navigators with HDGB datasets very rapidly to enrich and complement the information of their ENCs. Partitioned into standardised regular geographic cells, the provision of updates becomes easy by just supplying an entire new cell dataset with the new bathymetry to the users who then just supersedes the tile. A possible way to use HDGB for navigation is to put the S-102 data in the background with an overlap of S-101 without the display of S-101 soundings, depth areas and contours. Figure 2 is showing an example.

Electronic chart systems manufacturers can do a lot more than just displaying it. The HDGB can

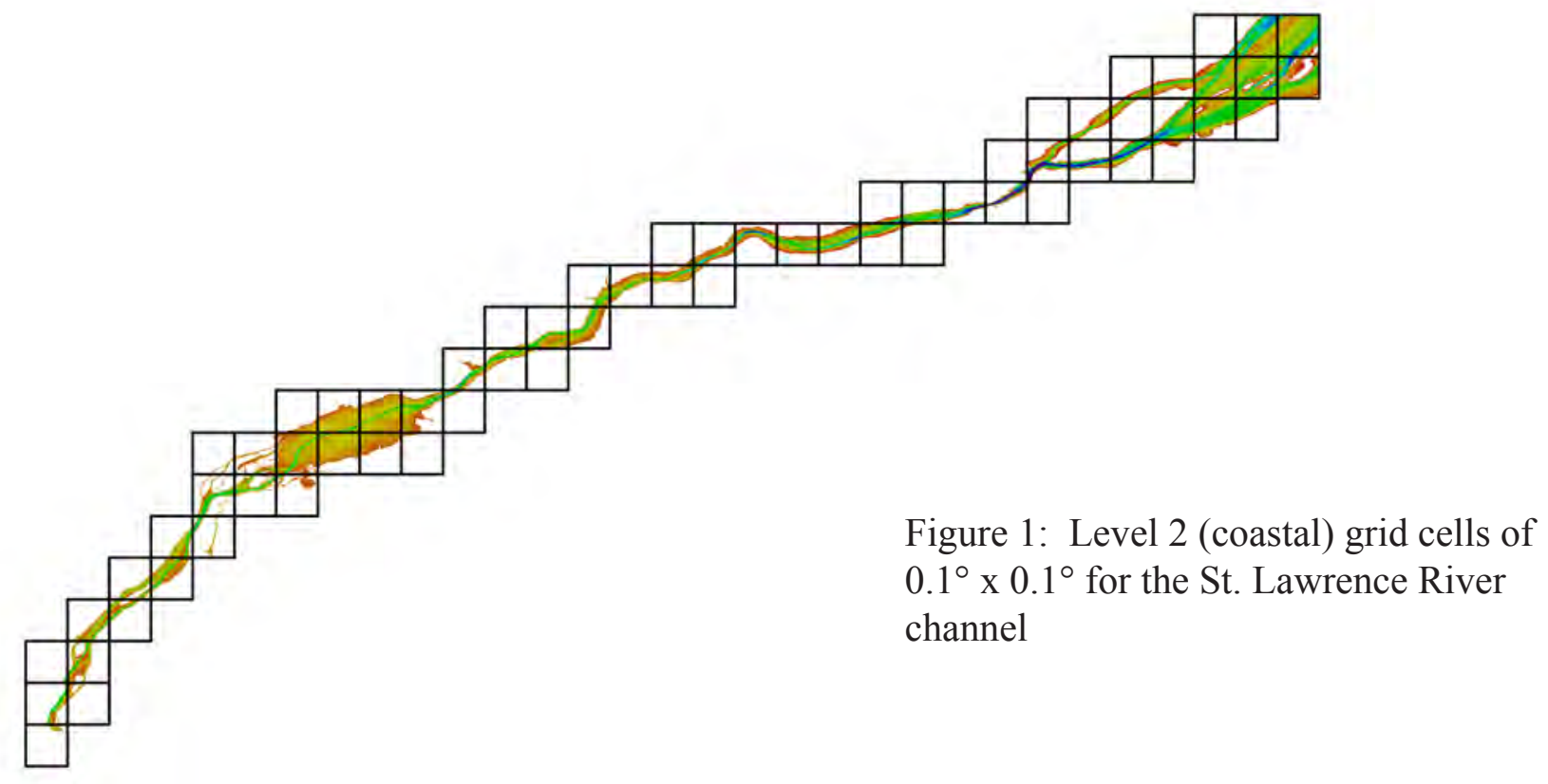




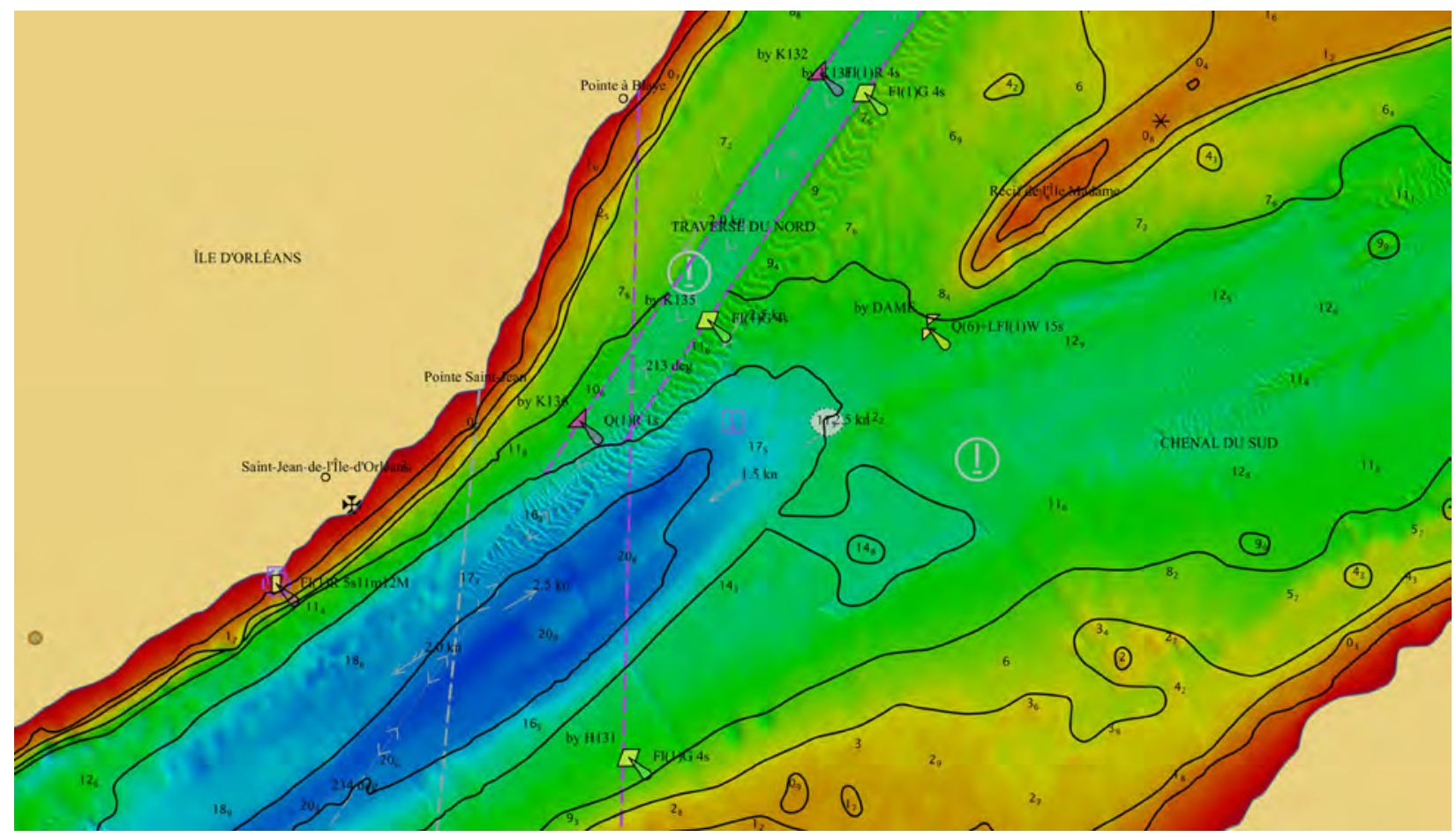

Figure 2: S-102 data in the background with an overlap of S-101, St. Lawrence River channel, South-East of Île d'Orléans

be used: to generate safety contour on the fly, to compute the available water column by the addition of water level (tidal data) on top of the bathymetry, to calculate a dynamic under keel clearance, etc. The exploitation of HDGB in an innovative way is left to the users and the software industry. The CHS wish to involve its partners at an early stage of design to consider feedback provided by the users communities and therefore make appropriate adjustements if needed.

\section{CONCLUSION}

High precision hydrography is present in St. Lawrence river Channel and in most areas in the world where intense commercial navigation occured in restricted waters with limited water depth and limited width. The data collected is powerful information to enhance efficiency and safety of navigation but unfortunately it does not make its way with its full potential to the mariners navigating these areas.

The advent of new hydrographic products in line with S-100 and the proposed S-102 product specification for High Definition Gridded Bathymetry is a solution to change this situation. The CHS development work and its intention to implement the systematic tiling scheme with three levels of resolution represent a good improvement and step ahead in trying to provide the mariners with better information. It will lead not only to a faster and more complete turnaround from surveys to bridge which is essential for safer navigation but it will also help taking care of the sea.

\section{BIOGRAPHIES}

Marc JOURNAULT has been working for the Canadian Hydrographic Service for 29 years . He is manager of the Quebec Region's Data \& Support Division, responsible for technological support and data mangement in the fields of hydrographic surveys, nautical puublications and marine services.

Louis MALTAIS has been working for the Canadian Hydrographic Service for 14 years. He is a project ingineer involved in numerous $\mathrm{R} \& \mathrm{D}$ projects, implementing solutions to improve productivity, efficiencies and to better meet the clients needs.

Richard SANFAÇON has been working for the Canadian Hydrographic Service for 33 years. He is manager of the Quebec Region's Hydrographic Operations, responsible for hydrographic surveys and marine charts production. 
CONTACT DETAILS

\section{Richard SANFAÇON}

Canadian Hydrographic Service

Institut Maurice-Lamontagne

C.P 1000,850 de la Mer

Mont-Joli

CANADA

Tel.: 418-775-0517

Fax: 418-775-0654

Email: richard.sanfacon@dfo-mpo.gc.ca

Web site: www.cartes.gc.ca 


\section{River bed classification using multi-beam echo-sounder backscatter data}

Niels KINNEGING, the Netherlands

Rijkswaterstaat Centre for Water Management

Mirjam SNELLEN, Dimitrios ELEFTHERAKIS and Dick SIMONS, the Netherlands

Delft University of Technology

Erik MOSSELMAN, the Netherlands

Deltares and Delft University of Technology

Arjan SIEBEN, the Netherlands

Rijkswaterstaat Centre for Water Management

Topics: Innovations in processing techniques, Cost-effective solutions, Hydrography in the Benelux

\section{INTRODUCTION}

The Netherlands form the delta for some of the major river systems of Europe, comprising the Rhine, the Meuse, the Scheldt and the Eems. These rivers are valuable parts of national and international ecological networks and are of high economic importance. A minimum depth should be guaranteed to keep the rivers navigable. This depth depends not only on water discharge but also on river bed topography that changes dynamically in response to discharge fluctuations.

Rijkswaterstaat is the Dutch governmental organization that is responsible to maintain the main river systems for both shipping, flood conveyance and ecological purposes. To keep the rivers navigable daily dredging activities are carried out. Furthermore the discharge capacity of the rivers is enlarged and the ecological quality is improved by widening the river and making secondary channels. The river topography and its dynamics are affected by spatial variations in bed sediment composition, thus making knowledge of the spatial sediment distribution highly important. It proved to be sufficient to detect a number of classes to produce classification maps of the bottom.

An attractive system to be used for obtaining information on both the river bed bathymetry and sediment composition is the multi-beam echosounder (MBES). This sonar emits short pulses of sound towards the river bed to determine the depth and the backscatter strength for a large number of closely-spaced beams. The MBES provides high spatial coverage of an area at moderate costs and within short time. The backscatter strengths are known to be indicative for the sediment types, and consequently have potential with regard to sediment classification. Consequently, the MBES system appears as a good alternative to the conventional, expensive and time-consuming, approach of mapping the river bed composition by taking a large number of physical sediment samples.

In the present paper, the results of a novel and fairly simple sediment classification method are presented. The method that developed in the Acoustic Remote Sensing Group of Delft University of technology is briefly described in the following section.

\section{BAYESIAN CLASSIFICATION METHOD (BCM)}

The BCM - developed in [1] for deep waters and extended in [2] for shallow waters ( $\sim 4 \mathrm{~m}$ depth) employs the backscatter strengths per angle, i.e., separately from other angles. The method is based on the assumption that the beam backscatter values are an average value of the sample amplitude values corresponding to all scatter pixels that fall within the beam footprint. Therefore, according to the central limit theorem, the averaged backscatter value for a single sediment type follows a Gaussian distribution for a sufficiently large number of scatter pixels.

The method fits a number of Gaussian Probability Density Functions (PDFs) to the histogram of the backscatter data at a given incident angle, i.e.,

$$
B S \sim f_{B S}(B S)=\sum_{i=1}^{r} c_{i} N\left(B S ; \mu_{i}, \sigma_{i}^{2}\right)
$$

where $\mathrm{m}$ and $\sigma_{i}^{2}$ are the mean and variance of the 
$i^{\text {th }} \mathrm{PDF}$, respectively, and $c_{i}$ is the contribution of the individual Gaussian functions to the total PDF. $f_{B S}$ is the fitted histogram. The optimum number of PDFs is found by consecutively increasing the number of PDFs until the chi-square distributed test-statistic of the residuals becomes close to one. The number of Gaussians then represents the maximum number of classes that can be discriminated based upon the backscatter values, and the borders of the classes are the intersections of each Gaussian with its neighbour.

The flowchart of the processing steps is presented in Figure 1. First the backscatter values are averaged over small surface patches, consisting of a small number of beams in the across-track direction and a few pings in the along-track direction. Then the backscatter data at a few outer angles are processed in order to estimate the mean backscatter strength, the variance and its coefficient per class. These parameters are used as guidance for the statistical processing of all other angles.

\section{RESULTS}

The method has been tested on different parts of the Dutch rivers with shallow water and river bed types that range from silt, clay and peat to sand, gravel and pebbles. Table I provides an overview of the specifics of the areas considered.

In addition to the MBES measurements also grabs were taken. Figure 2 illustrates the mean grain sizes as derived from the grabs for all areas.

The method was found to be able to discern between different sediments for all areas. Figure 3 shows two examples of applying the method to Dutch rivers. Figure 3 left presents a part of the river Waal close to Sint Andries. The data at outer angles was collected and three PDFs (thus 3 classes) fit their histogram (Figure 3 top-left). The sediment distribution map of Sint Andries is presented in Figure 3 bottom left. Mean grain size values were assigned to each class after comparing the classification results to a number of physical samples taken in the area (small frames). The fixed layer was identified when combining the backscatter with the depth residuals (see Ref. [3]). The results of another river (Dordtse Kil) that has a larger variation of sediments is shown in Figure 3 right. In this case, five PDFs were needed to sufficiently fit the histogram of the backscatter (Figure 3 top right) and the resulted sediment classification map is presented in Figure 3 bottom right.

The availability of bathymetric data in combination with the classification allows for a detailed assessment and interpretation of the sediments in an area. An example for Sint Andries river is presented in Figure 4, where the bathymetry is shown in 3D (Figure 4 left) and then the resulted classes are projected on top of the bathymetry map (Figure 4 right).

\section{CONCLUSIONS}

In this paper we presented a method for classication of the river sediments. Using the backscatter information of a multibeam echosounder system the method was found to be able to discern between

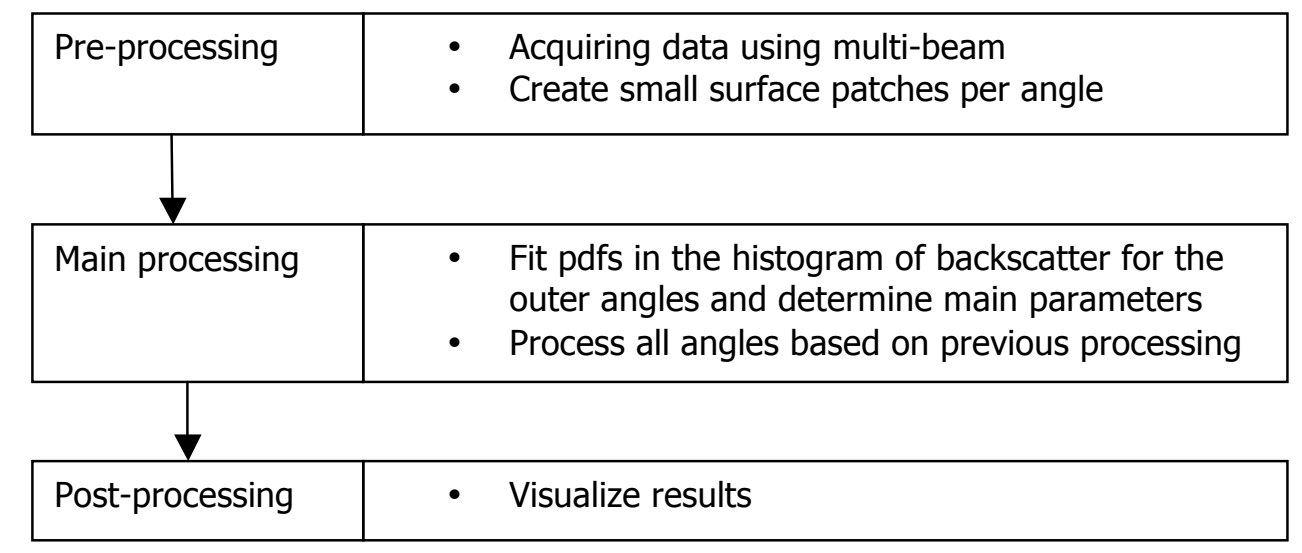

Figure 1: Flowchart of the BCM steps. 


\begin{tabular}{|l|l|l|}
\hline Area & Area specifics & Measurement specifics \\
\hline 1. Sint Andries & Fixed layer present; Water depth $\sim 5 \mathrm{~m}$ & $\begin{array}{l}\text { Surveyed in 2007. A small part of it } \\
\text { was surveyed again in 2008. }\end{array}$ \\
\hline $\begin{array}{l}{ }^{4} \text {. Waal-close } \\
\text { to Nijmegen }\end{array}$ & Fixed layer present; Water depth $\sim 6 \mathrm{~m}$ & Surveyed in 2008 \\
\hline 3. Upper Rhine & Water depths $\sim 4.5-\sim 2.5 \mathrm{~m}$ & Surveyed in 2008 \\
\hline 4. Dordtse Kil & $\begin{array}{l}\text { Part of the river has irregular surface } \\
\text { due to the presence of deep holes. } \\
\text { Water depth } \sim 11 \mathrm{~m}\end{array}$ & $\begin{array}{l}\text { Surveyed in 2009. Additional } \\
\text { measurements with device that is } \\
\text { measuring the radioactivity of } \\
\text { sediments. }\end{array}$ \\
\hline 5. Meuse & $\begin{array}{l}\text { Very coarse riverbed } \\
\text { Water depth } \sim 3 \mathrm{~m}\end{array}$ & Surveyed in 2010 \\
\hline
\end{tabular}

Table I

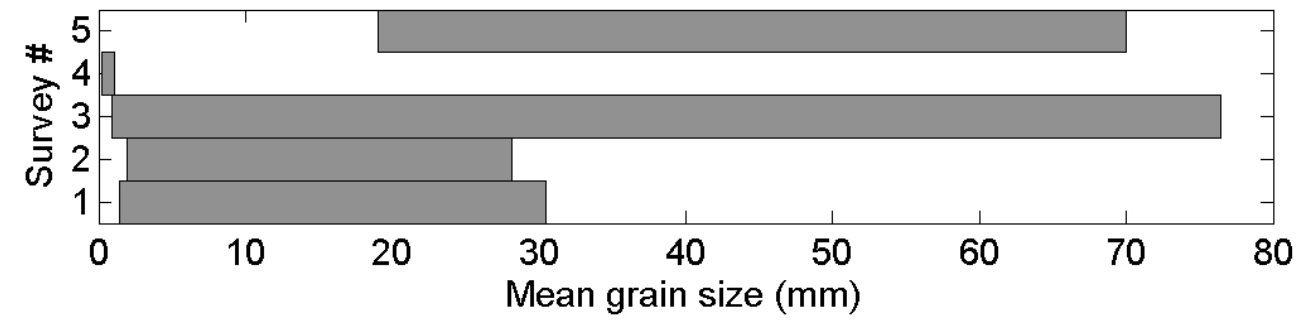

Figure 2: Mean grain size values encountered in the different areas.

different sediments for all areas over a large range of mean grain sizes. The main advantages of using the BCM for sediment classification include:

- Simple

- Highly Effective

- Low cost

- Extensively tested

- Very detailed sediment maps (almost 100\%)

- No need for calibrated sonars

At this moment the method has been applied using data of the EM3002 system However, since also other MBES systems (can) provide the backscatter strengths, the method can also be applied to the data acquired with these systems. For a routine implementation of the method in the work of Rijkswaterstaat it should be incorporated in the standard data acquisition and data processing packages.

Further improvement can be expected if the MBES systems would not only be calibrated for arrival times, but also for the transmitted and received amplitude information. If that information would be available the amount of ground truthing can be reduced considerably.

An alternative line of research and development is that the MBES systems are tested on known sediment beds in a laboratory flume. This is currently discussed within a co-operation between the faculties of Aerospace Engineering and Civil Engineering and Geosciences at Delft University of Technology.

\section{REFERENCES}

1. D.G. Simons, and M. Snellen. "A Bayesian approach to seafloor classification using multi-beam echo-sounder backscatter data", Appl. Acoust. 70, 1258-1268 (2009).

2. A.R. Amiri-Simkooei, M. Snellen, and D.G. Simons, "Riverbed sediment classification using multi-beam echo-sounder backscatter data", J. Acoust. Soc. Am. 126, 1724-1738 (2009).

3. D. Eleftherakis, A.R. Amiri-Simkooei, M. Snellen, and D.G. Simons, "Improving riverbed sediment classification using backscatter and depth residual features of multi-beam echo-sounder systems", J. 

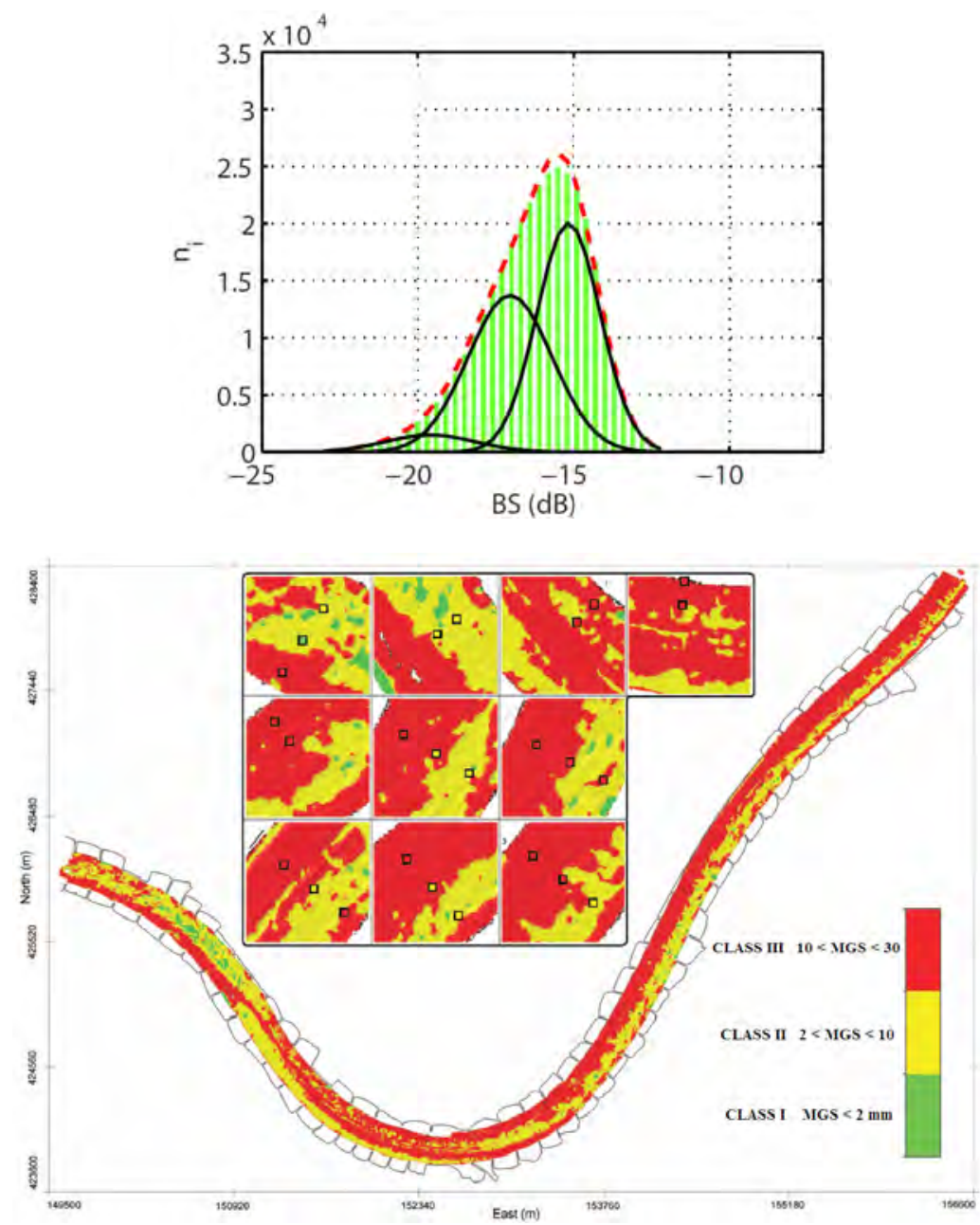

Figure 3: Pdfs fitted in the backscatter strength histogram of outer angles (top) and sediment classification maps (bottom) for Sint Andries (left) and Dordtse Kil (right).
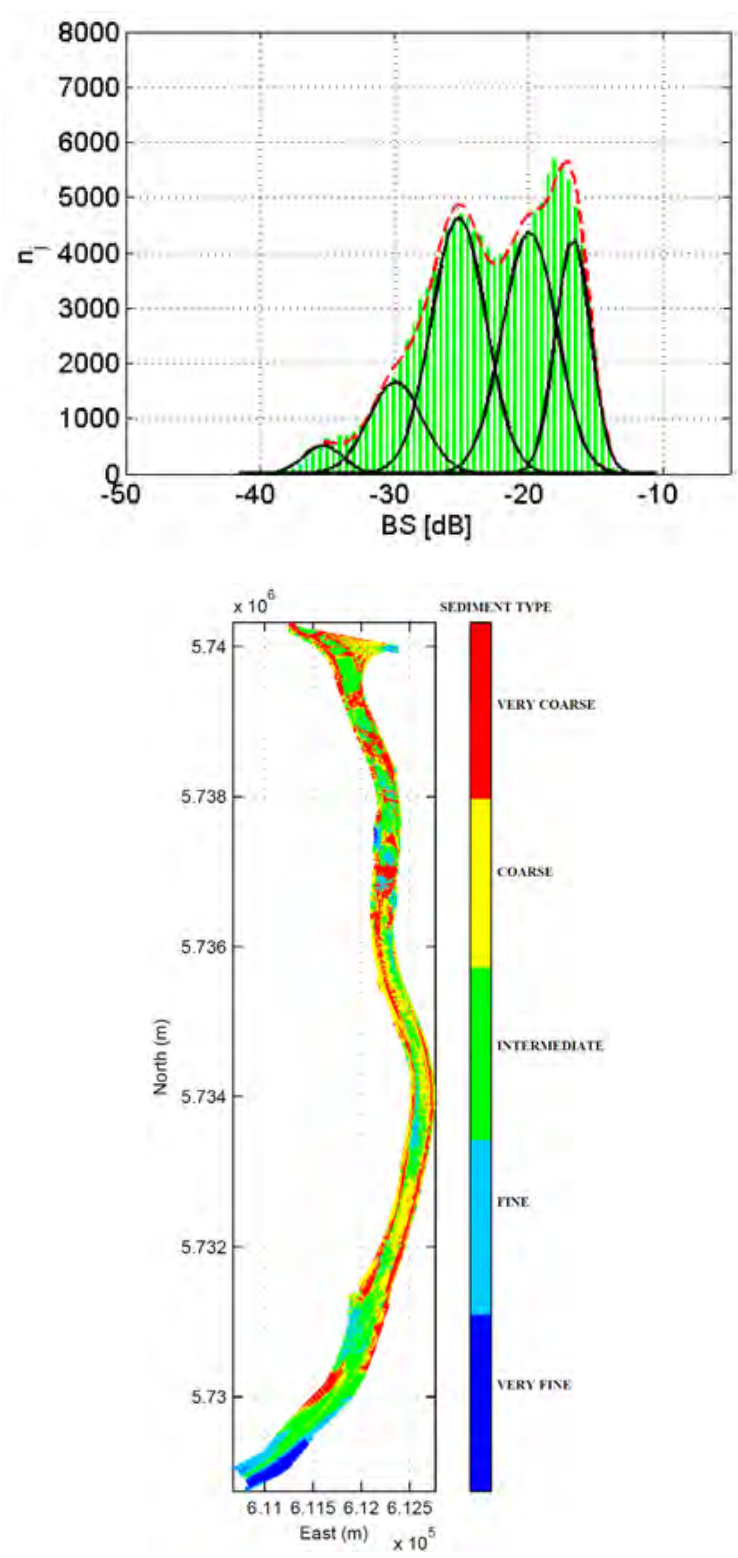
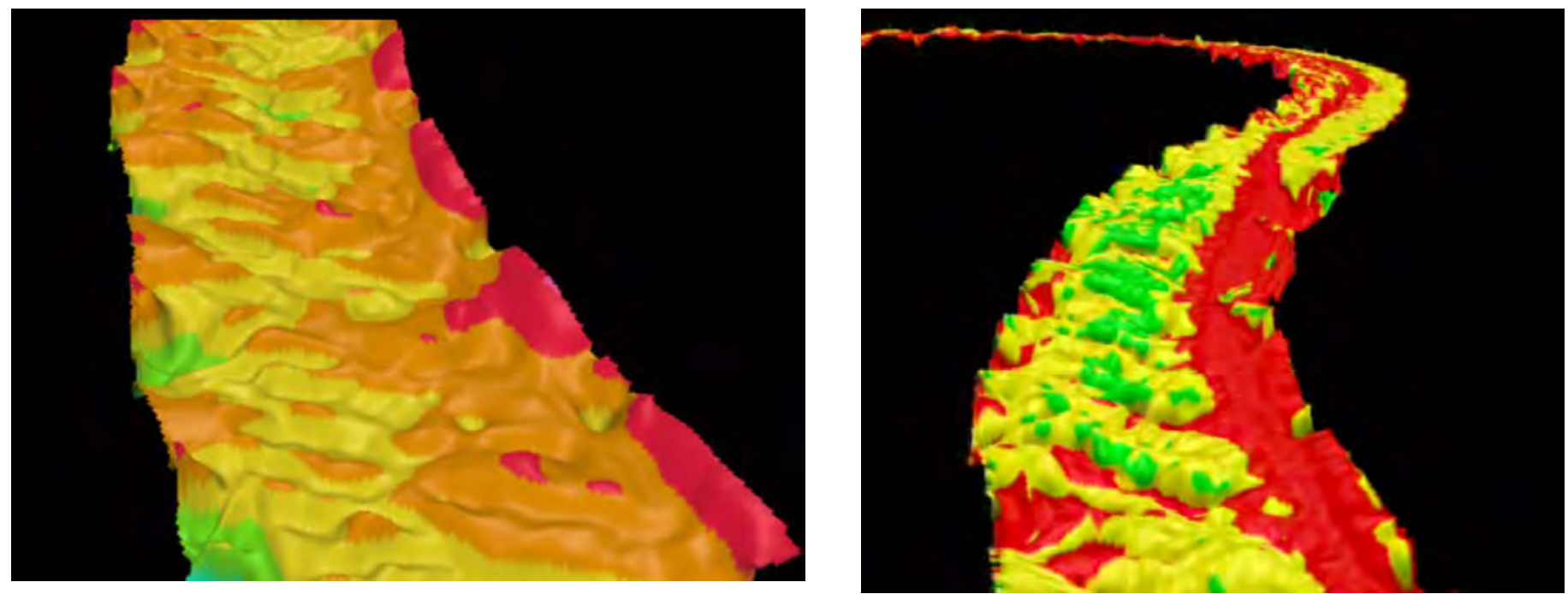

Figure 4: 3D bathymetry map (left) and sediment classes projected on top of the bathymetry map (right) for Sint Andries. 
Acoust. Soc. Am. 131(5), 3710-3725, (2012). 4. D. Eleftherakis, E. Mosselman, A.R. AmiriSimkooei, S. Giri, M. Snellen, and D.G. Simons. "Identifying changes in river bed morphology and bed sediment composition using multi-beam echo-sounder measurements", In: Proc. of the 10th European conference on Underwater Acoustics, Istanbul, Turkey, 1365-1373 (2010).

5. M. Snellen, D. Eleftherakis, A.R. AmiriSimkooei, R. Koomans, and D. Simons, "An intercomparison of sediment classification methods based on multi-beam echo-sounder backscatter data and sediment natural radio-activity", submitted to JASA (under review).

\section{BIOGRAPHIES}

Niels KINNEGING got his Ph.D. in Applied Physics from the Delft University of Technology. Presently is is responsible for the co-ordination of all hydrographic activities at Rijkswaterstaat, the Dutch governmental organisation for water management.

Mirjam SNELLEN SNELLEN got het Ph.D. from the University of Amsterdam. Presently she is assistant professor in the field of Acoustic Remote Sensing at the Delft University of Technolgy

Dimitrios ELEFTHERAKIS is currently a $\mathrm{PhD}$ student in underwater acoustic remote sensing at the Delft University of Technology (TU Delft). He is mechanical engineer with a Master degree in offshore and ocean technology.

Dick SIMONS is a physicist specialized in acoustics, signal processing and remote sensing. He received his $\mathrm{PhD}$ from the University of Leiden in 1988. In 2004 he was appointed professor in Acoustic Remote Sensing at the Delft University of Technology. Within his chair various sediment classification methods are being developed for imaging sonar systems, including the multibeam echosounder.

Erik MOSSELMAN is a river morphologist at Deltares and Delft University of Technology. He worked on numerous rivers in Europe, Asia and South America. One of his research interests regards the interaction between sand and gravel on the river bed.
Arjan SIEBEN is a river engineer at Rijkswaterstaat, engaged with river projects on flood level safety, fairway improvement and maintenance.

\section{CONTACT DETAILS}

Niels KINNEGING

Rijkswaterstaat Centre for Water Management

P.O. Box 17

NL - 8200 AA Lelystad

THE NETHERLANDS

Tel.: +31653215242

Email: niels.kinneging@rws.nl

Web site: www.rijkswaterstaat.nl

LinkedIn account: http://nl.linkedin.com/pub/nielskinneging/5/2aa/aab 
134 | Hydrol 2 


\section{A New Coastal Flood Forecasting System for the Netherlands}

Ir. Simone DE KLEERMAEKER, the Netherlands

Deltares

Dr. Ir. Martin VERLAAN, the Netherlands

Deltares, TU Delft

Ing. Jan KROOS, the Netherlands

Water Management Centre of Rijkswaterstaat

Ir. Firmijn ZIJL, the Netherlands

Deltares

Topics: Easy customer access to data and products, Accurate hydrodynamics, Hydrography in the Benelux

INTRODUCTION

The North Sea is one of the busiest seas in the world with dense ship traffic, fisheries, wind farming, recreation and many other activities. All these activities depend on the 'marine weather'. Accurate forecasts of waves, currents and sea level are crucial for operational management and for issuing warnings during extreme events.

The current operational forecasting system in the Netherlands has been operational since the 90 's. Over the last few years, a new generation forecasting system for the North Sea and the Dutch coastal waters has been developed. This involved both advanced model development as well as the set-up of an operational forecasting shell based on the FEWS (Flood Early Warning System) framework. From the start of the storm season on September $1^{\text {st }} 2012$, this new system will be used pre-operationally by Rijkswaterstaat (Dutch Ministry of Infrastructure and the Environment) and the Royal Netherlands Meteorological Institute, KNMI.

This paper gives an overview of the many developments that are needed for an accurate and reliable forecasting system. In addition to

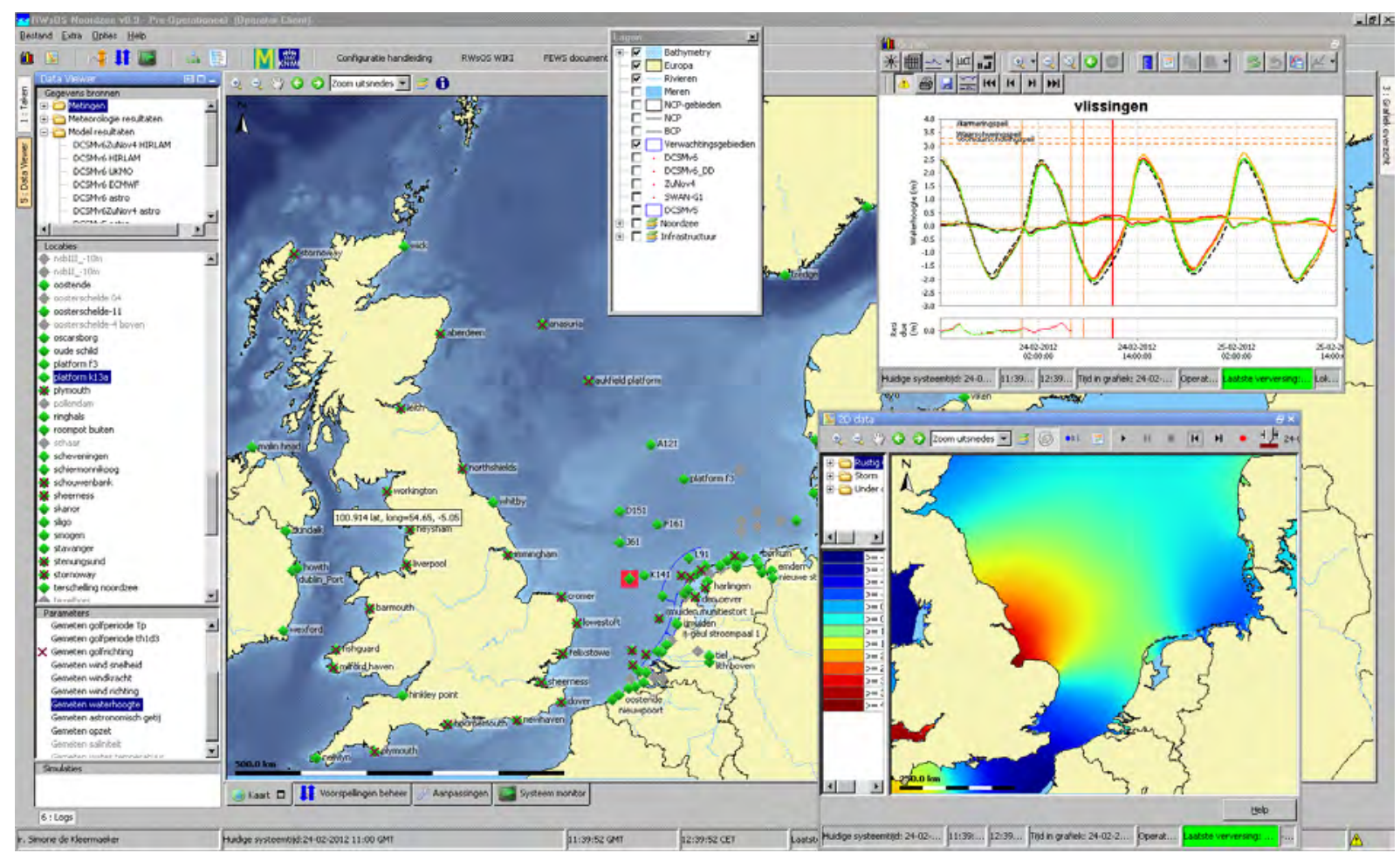

Figure 1: Screen shot of the operational system FEWS North Sea 
accurate and robust numerical models, one needs scheduling with backup options, quality control of observations, good interactive displays of many datasets, manual override for operators, and much more. The quality of the operational forecasts is as strong as the weakest link.

\section{OPERATIONAL SYSTEM}

In daily operations, the new FEWS North Sea system will be used for water management of Dutch coastal waters, e.g. to ensure maritime safety on busy shipping routes towards the large sea ports of Rotterdam, Antwerp and IJmuiden. The system also generates boundary conditions for fluvial models for the port of Rotterdam, the area of Dordrecht and the Scheldt estuary. During storm surges the forecasts will be used to issue warnings to coastal authorities, based on which measures can be taken.

The system is used to collect all necessary data and coordinate computations. Automated runs are scheduled 4 times a day, following the release of new meteorological forecasts from KNMI. Model output can be inspected and compared with observations, to assist forecasters to decide on appropriate warning levels. The distributed water level forecasts and warnings are based on model forecasts as well as on expert judgement of the forecasters. The system automatically synchronizes between multiple forecasters located in different offices or through mobile telecommunication. In case of a hardware failure, the forecast system automatically switches to a stand-by system.

The system is a major step forward both in accuracy of the model forecasts [Verlaan et. al, 2003] and in combining data from different sources into easily interpretable displays. It also assists the forecasters in cooperating between multiple offices of Rijkswaterstaat and KNMI.

\section{OBSERVATIONS AND METEOROLOGICAL FORCING CONDITIONS}

The operational system collects all data required to create the water level and wave forecasts. This includes observations of water level, wave data such as wave height, swell, period and direction, and also of air pressure, and wind speed and direction. Besides being used to monitor the current state of the North Sea and to identify possible deviations, observations are used for (real-time) dataassimilation.

$\underline{\text { Automatic validation of water level observations }}$

All models, including data-assimilation (see the corresponding Sections below), are scheduled to run automatically and mostly unattended at regular intervals. Therefore, it is essential to apply a good automated quality control to the observations. As a backup procedure, the operators can overrule the automated QC and visually inspect the observations and discard invalid data

The automatic quality control is based on the following rules:

- Absolute limits, which provide a crude test useful only to identify very large errors.

- Earlier or later (high frequency) observations at the same location, to detect spikes.

- Comparison with observations at a nearby locations.

- Comparison with the harmonic tide as a first estimate, and

- Comparison with a model first-guess, which can be expected to show much less deviation from the observation than the harmonic tide.

Rejection of all observations which exceed one of the limits usually leads to excessive loss of good data or acceptance of erroneous data, depending on whether the limits are narrow or not. Therefore a sensible combination of the qualifications is needed. We have chosen to make an arithmetical, rather than a logical, combination of the qualifications into a qualification score.

\section{$\underline{\text { Numerical Meteorological forecasts }}$}

Meteorological forecasts serve as one of the main forcings for the water level and wave models. The standard model suite uses forecasts from the HiRLAM Numerical Weather Prediction model provided operationally by KNMI, which has a forecast horizon of 48 hours.

\section{$\underline{\text { Additional numerical meteorological forecasts }}$}

For a reliable forecasting system, the possibility of a failure has to be considered. For this purpose 
additional computations are carried out with alternative meteorological forcing. These model results also gives the forecaster the possibility to assess sensitivities and expected magnitude of errors.

Alternative numerical meteorological forecasts are obtained from ECMWF and the UK Met Office (UKMO). UKMO is used for comparison and as a back-up of the HiRLAM model. This model has a horizon of 5 days. For the longer term forecast the ECMWF model is used, provided by the European Centre for Medium range Weather Forecasting. This model has a lower resolution but has a forecast horizon of 10 days. The lower resolution model DCSMv5 is run with the full range of the ECMWF EPS (Ensemble Prediction System) forecasts, to give an impression of the accuracy of the mid-range forecast.

\section{WATER LEVEL MODEL}

Part of the comprehensive upgrade of the operational forecasting system was the development of a new generation operational flood forecasting model for the Northwest European Shelf and North Sea. This Dutch Continental Shelf Model (DCSMv6) is a 2D (horizontal) application of SIMONA, the framework for hydrodynamic modelling of free-surface water systems used for Rijkswaterstaat modelling [SIMONA documentation].

Compared to the previous version (v5) internal tide generation has been included, while the cell sizes of the spherical grid have been decreased substantially to $1.5^{\prime}\left(1 / 40^{\circ}\right)$ in east-west direction and $1.0^{\prime}\left(1 / 60^{\circ}\right)$ in north-south direction, leading to more than 106 grid cells.

To reduce the computational time required to provide forecasts, parallel computing has been applied. With a computational time step of 2 minutes, a 1 day simulation takes approximately 5 minutes on a dual hexacore machine.

The spatial extent of the model has been increased, in order to ensure that the open boundaries are located in deeper water. This makes it possible to use harmonic boundary forcing derived from global tidal models. Furthermore, wind setup in deep water can safely be neglected, whereas the time- and space varying effect of local pressure (the so-called inverse barometer effect) is added to the water level variation along the open boundary. Tidal water levels at the open boundaries are specified in the frequency domain, i.e. the amplitudes and phases of a number of tidal constituents are specified. The tidal conditions of the eight main diurnal and semi-diurnal constituents have been derived from the GOT00.2 global ocean tide model. Sixteen smaller diurnal and semi-diurnal constituents have been derived by means of the admittance method. Additionally, the solar annual constituent $\mathrm{Sa}$ is specified, based on satellite altimeter data from the Topex-Poseidon and Jason missions.

Well distributed water level observations at more than 100 coastal tide gauge locations have been used for a thorough calibration and validation of the shelf areas. Automatic calibration methods available in the open source data assimilation toolbox OpenDA [OpenDA documentation] were applied to optimize over 200 control parameters for bathymetry and bed friction. Furthermore, a series of Goodness-of-Fit (GoF) measures (in frequency and time domain) was determined to quantify the quality of various aspects of the water level representation per sub-region and for the model as such. This structured approach has resulted in a significant reduction in errors at stations along the Dutch coast. The average RMSE as calculated for the year 2007 has reduced (compared to the previous operational model) from $13.1 \mathrm{~cm}$ to 7.8 cm, which implies a reduction in error of $40 \%$. Considering tide only, the reduction is an impressive $60 \%$ (from $9.5 \mathrm{~cm}$ to $3.7 \mathrm{~cm}$ ).

\section{Data-assimilation}

To further improve the accuracy of the forecasts for lead times up to around 15 hours, a steadystate Kalman filter has been developed. For this purpose the generic open source data assimilation toolbox OpenDA was integrated into the SIMONA modelling software. Observations of sea level (with a 10-minute interval) from over 30 tide gauge stations are assimilated every forecast cycle. In hindcast mode, in which historic observations are available for assimilation, the average RMSE along the Dutch coast for the year 2007 is $3.5 \mathrm{~cm}$. As this development is still ongoing, the improvement of the forecast accuracy for a range of lead-time intervals has yet to be quantified. 


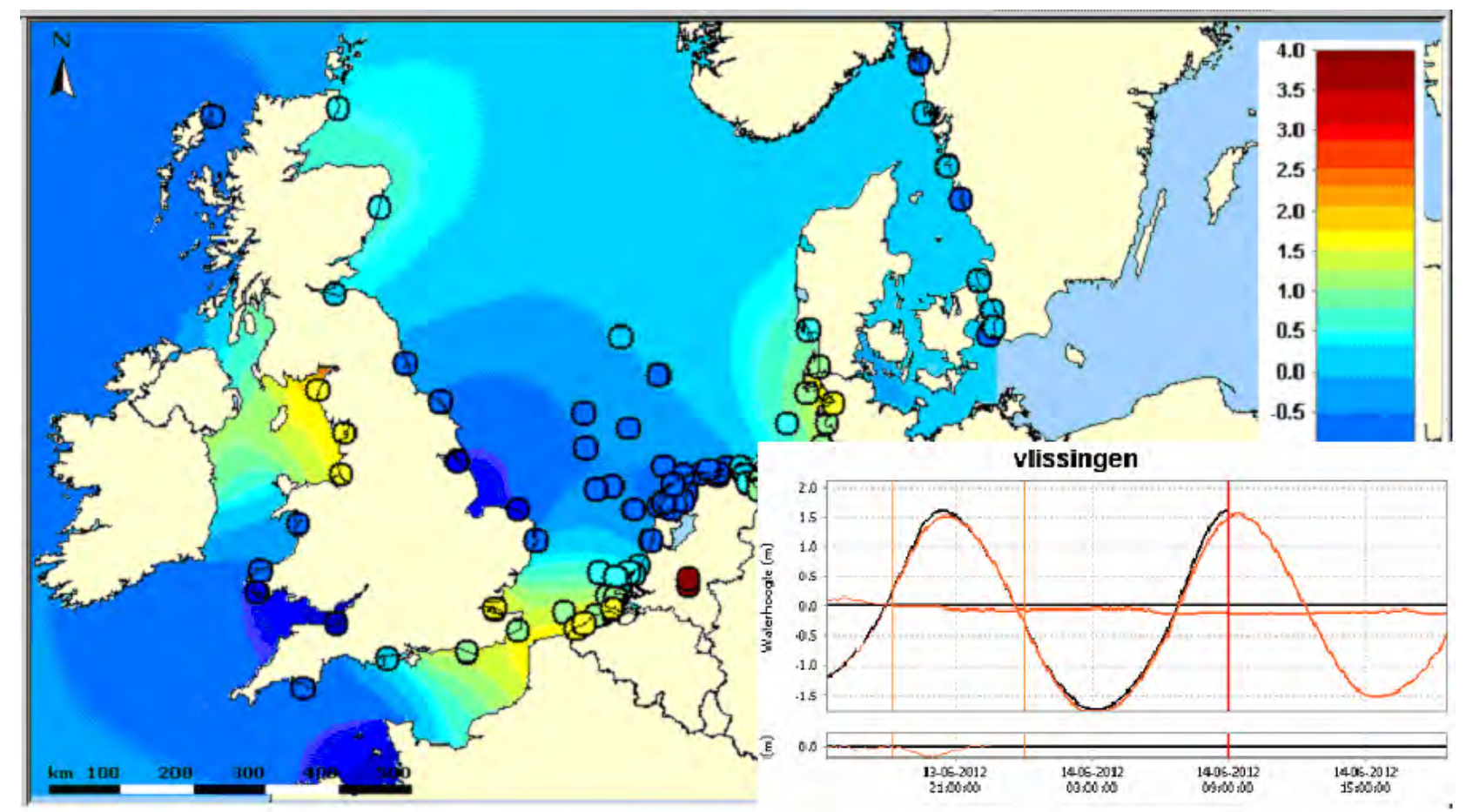

Figure 2: Spatial display of the Southern North Sea with water level [m] model results, combined with observations in circles. Overlay shows time series for one location with water level [m] model result and residue combined with the local observation (in black).

\section{WAVE MODEL}

The operational wave model NEDWAM from KNMI will be replaced by the newly developed SWAN-North Sea wave model [SWAN documentation]. This SWAN model covers a larger area and has a higher resolution than the NEDWAM model, both to increase the accuracy near shore. The model covers a large part of the northwest continental shelf and consists of two grids. The larger grid computes boundary conditions for the high resolution grid of the southern North Sea. The model is driven by HiRLAM wind fields, spectral wave conditions from ECMWF on the boundaries and water level and current fields from the DCSMv6 model.

A preliminary version gave $10 \%$ bias (18\% scatter) in wave height, and $0 \%$ (15\% scatter) in period. This results is already comparable to NEDWAM, and we see room for further improvement. The final calibration and validation is still ongoing. Dataassimilation for this model is being developed in the framework of the EU-project MyWave [MyWave].

\section{DISPLAY, INTERPRETATION, AND DISTRIBUTION OF DATA}

A crucial step in the operational process is to interpret and judge the available model results and observations (see Figure 3). Operational forecast often have to be made under time pressure, which combined with the large amount of different datasets can easily lead to a mistake, that can have serious consequences. Therefore the data should be presented in a way that is easy to interpret and consistent.

\section{Predefined plots}

In addition to the possibility to explore all the available data freely and manually create arbitrary combinations of data in a plot, a number of predefined plots were created. One set of predefined plots show the observed and forecasted sea level for a number of main locations. The difference between the model results and the observations, i.e. the residue, is calculated and shown as well. The forecaster can turn off part of the data, offering him some freedom combined with the consistency of how the data is displayed. 


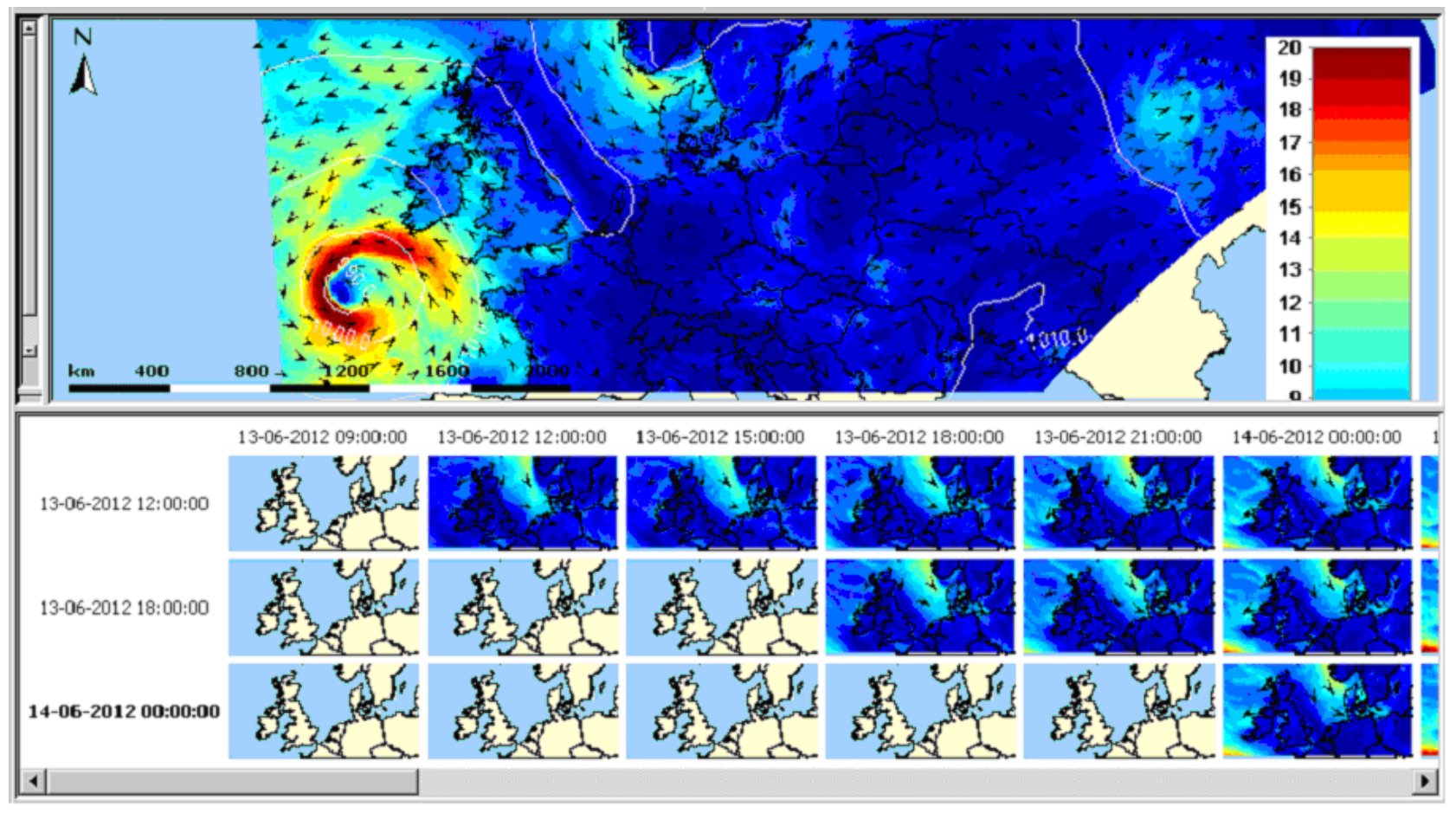

Figure 3: Three meteorological models run six hours apart. Thumbnails every three hours.

Combining different observations and results into one graph has more benefits than the obvious ease of overview. It can prevent mistakes made due to difference in presentation, such as scales or units, colour schemes and time zones. By organizing all data and pre- and post-processing in one system, the forecaster is assured of consistent information. The FEWS system is available to partners like KNMI, which means that both the hydrological and the meteorological forecasters use exactly the same displays. This makes discussions over the phone easier and less sensitive to communication errors.

\section{Comparison of multiple forecasts}

The models have a forecast horizon of minimum 2 days and are run every 6 hours. Therefore, the same window in time is forecasted several times. The variability between subsequent forecasts can give the forecaster information on changes and the stability of the model results and therefore the trustworthiness of the forecast. For this, we have developed a spatial display in which spatial data of several forecast for the same timeframe can be compared to each other. The thumbnails (see Figure 3 ) can be quickly inspected to locate differences. Each thumbnail can be selected to display the data in more detail in the main window.

\section{Generating the official forecast}

A composite water level forecast is generated automatically. For the forecast horizon of 0-12 hours the model with data-assimilation is used. This is extended to 48 hours using the model results with Hirlam forcing. The model results with ECMWF forcing are used to further extend the forecast horizon to 10 days. If any model is not functioning properly, the model next in hierarchy is automatically used as a fall back option.

The forecaster adjusts this composite forecast where necessary based on his expert judgement. He is assisted by the FEWS system allowing easy data analysis and discussions with the meteorological expert.

\section{Distribution of warnings}

The final step in the operational process is to distribute the official forecast and appropriate warnings. The official forecast is distributed using the FEWS North Sea system towards the National database and internet. By generating the warning messages within the same system, mistakes in data input can be prevented. 


\section{CONCLUSION}

Generating a forecast in the operational environment is based on more than a state of the art models alone. The entire work process from import and quality control of observations, via the running of the models and the interpretation of the results up to the distribution of the final warnings has to function properly. The weakest link in this chain of actions determines the strength of early warning system Therefore, the operational system should be judged as a whole, considering both accuracy and reliability.

\section{REFERENCES}

FEWS documentation, accessed June 3rd, 2012 http://publicwiki.deltares.nl/display/FEWSDOC/ MyWave, accessed June 15th, 2012. http://cordis. europa.eu/; search for mywave OpenDA documentation, accessed June 3rd, 2012. http://www.openda.org/joomla/index.php SIMONA documentation (in Dutch), accessed June 3rd, 2012.

http:/www.helpdeskwater.nl/onderwerpen/ applicaties-modellen/water_en_ruimte/simona/ SWAN manual. 2011. "User Manual", accessed June 3rd 2012. http://www.swan.tudelft.nl/ M. Verlaan, A. Zijderveld, H. De Vries, J. Kroos, Operational storm surge forecasting in the Netherlands: developments in the last decade, Phil. Trans. R. Soc. A (2005) 363, 1441-1453, doi:10.1098/rsta.2005.1578

\section{BIOGRAPHIES}

Simone DE KLEERMAEKER is senior advisor in the Marine and Coastal Systems Unit of Deltares. She has more than 10 years of experience with hydrodynamic modelling of both Marine and Coastal as well as Industrial systems, both as a project engineer and project leader. She applies these models in projects such as Serious Gaming, FEWS installations and calibration using tools such as OpenDA. She has a background in fluid dynamics, based upon her graduation in Technical Mechanics with specialisation on fluid dynamics.

Martin VERLAAN is a senior data-assimilation specialist at Deltares and assistant professor at Delft Technical University. He has almost 20 years of experience in data-assimilation and storm surge modelling. Current research topics include dataassimilation for wave models and quantification of the value of observations in data-assimilation. He is one of the lead developers of OpenDA and secretary of the OpenDA association. He is also a senior member of the Storm Surge Warning Service of the Netherlands (SVSD).

Jan KROOS is the teamleader of the Storm Surge Warning Service of the Netherlands (SVSD). The SVSD is a part of the WaterManagement Centre of the Netherlands (WMCN) of Rijkswaterstaat. He has over 30 years of experience in operational storm surge forecasting. He is also a member of the national flood coordination committee in the Netherlands, that gives advice to the appropriate national, regional and local authorities in the case that severe storms or extreme river flow that would threaten to flood parts of the Netherlands.

Firmijn ZIJL is senior reasearcher/advisor at the Marine and Coastal Systems Unit of Deltares, with a background in computational fluid mechanics. He has almost 10 years of experience with hydrodynamic modelling of free surface flows. He was responsible for the development of models in complex tidal systems (e.g. the Singapore region and the Northwest European Shelf) as well as 3D baroclinic models of weakly dynamic, stratified seas and deep lakes (e.g. the Sea of Marmara and various reservoirs in the Netherlands and Singapore).

\section{0 | Hydrol 2}




\section{Maritime Source Data Collection, Management and Integration}

John K KLIPPEN, Norway

Jeppesen Norway AS

Topics: Smart data management, Easy customer access to data and products, Cost-effective solutions

\section{INTRODUCTION}

A maritime navigational product today originates from a variety of different sources, data formats, data qualities and data providers. All this different data is used to compile, produce and maintain high quality navigational products as well as different nautical publications.

Data providers may be different governmental bodies/organizations, departments and private industry. Product compilations will also in many cases require compilation and processing of data with different qualities, from different data formats which must result in a complete and high quality product.

The requirement for source control, quality control of sources and traceability from products and their changes to original source is vital to ensure the quality value chain.

Jeppesen has a system allowing an (semi) automatic source registration, from local and remote locations, into a combined and complete Source data storage system. The system has a controlled registration process ensuring data conformity and quality allowing data recipient an assurance that received data is correct.

When a source is received it is processed by an expert and dispatched to a designated department and/or product/publication. The system may be set up to automatically dispatch received sources, depending upon predefined success criteria.

Dispatching may be directly to following products:

- Electronic charts

- Paper charts

- Other nautical/cartographic products (e.g. Leisure charts, Special task charts, etc)

- Notice to Mariners products here also including the different NtM Sections/paragraphs

- List of Lights

- Sailing directions
- Pilot books

- Other services/systems

The different production departments production system is then "picking up" the dispatched source message (with attached source files) and processing the source to the different affected products. Once the source is processed and quality control is accepted, the source is flagged completed and logged within the system. Logging is made to the different products, databases and to the source registry itself. This ensures full traceability from source to end product and vice versa.

The source message dispatched for publications is also collected within desired department and will form a draft notice for misc. chapters of e.g. the NtM booklet. The source message metadata and information is processed automatically to a NM (section) template, allowing the operator to focus on textual editing and presentation. A NM item may also require a product update before the booklet may be released, such as Tracing and/or Block.

The controlled processes and their different predefined quality control routines ensure the highest possible control of the data flow and the product change the source create. No products or publications are released before all defined QC steps are completed and accepted.

This system allows a data producer to release products and product updates directly, and the producer will not have to wait until the NtM booklet is released (or at least the specific NM is created).

The main difference between this system and a traditional NtM based updating regime is that the source is not only used to create the NM item, but is actually used for product creation and correction. In most cases the source will also have a much higher data quality and resolution than what one will find in the NM message. The NM message has been created mainly to handle updates and corrections to paper charts. 


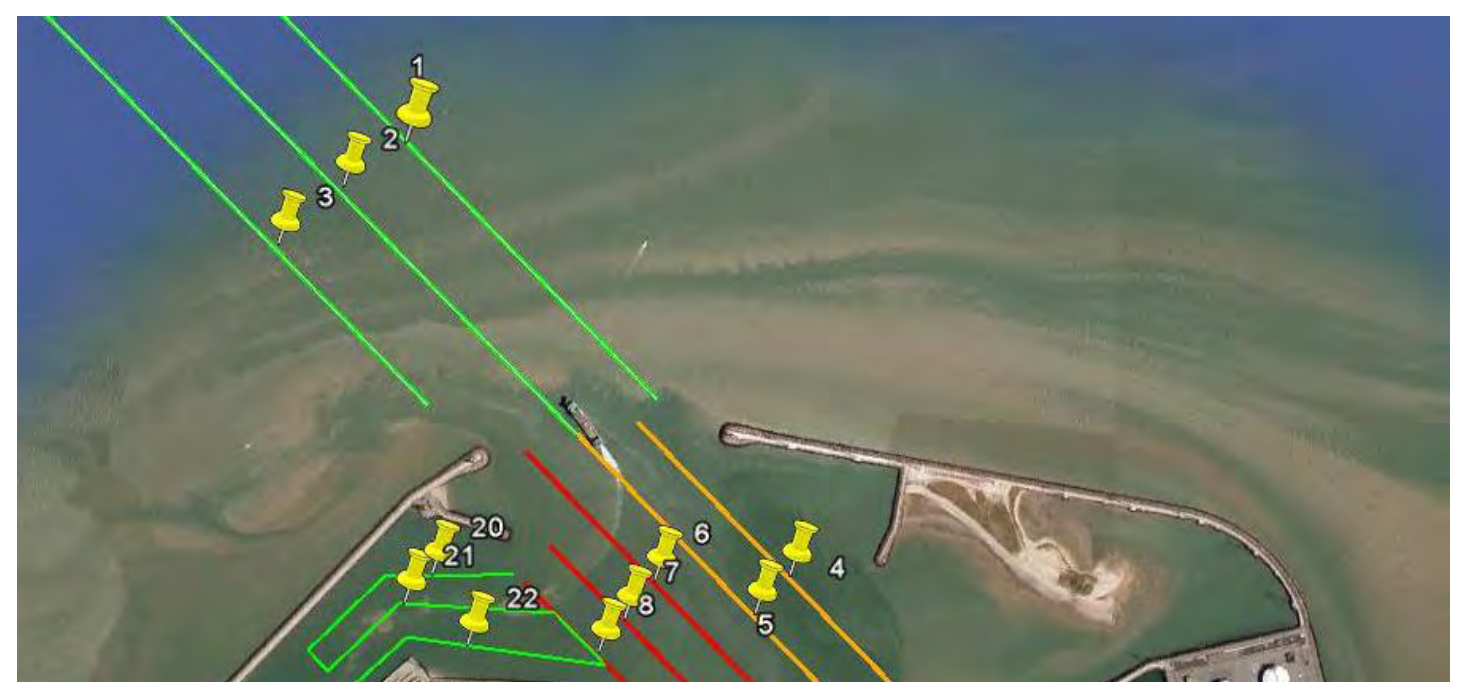

Figure 1 - Traditional NtM based updating

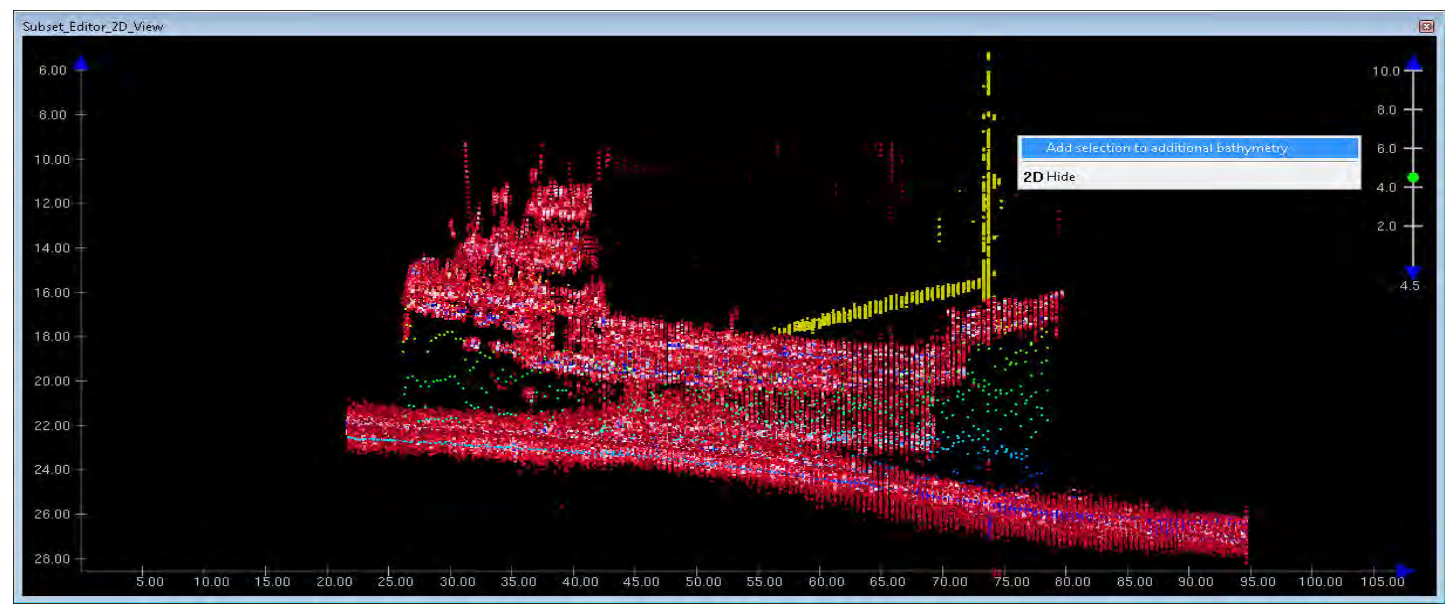

Figure 2 - Source based updating

The use of this system has proven to be an effective way to handle small to large product portfolios and to allow a quick and controlled update process without compromising on quality.

Print on Demand paper chart services and a very quick ENC update distribution have been proven possible using this system, together with an integrated and effective NtM booklet production and distribution.

\section{SOURCE DATA COLLECTION}

Source data is collected, constructed and registered into a Source Message. A Source Message comprise of (minimum) Mandatory Metadata, Additional Metadata defined by the pre-defined template, actual source data files and time/date and operator details.

The operator is guided through the Source registration by the pre-defined metadata templates.
These templates define mandatory attributes and data as well as defined available attributes for a Source message. The template also defined quality control criteria.

All templates used by a system is national customizable, ensuring a wide use of the system.

Once a source is registered, locally or remotely, it is checked against defined quality control measurements and if found accepted, the source message is flagged "Registration completed" and made available for "Dispatching"

Dispatching a source message is a system trigger operation. The Dispatch allow a Zero-to-Many dispatching, where Zero would be to Archive or to Delete if no further action is required and Many is dispatching to defined departments for further product processing. 


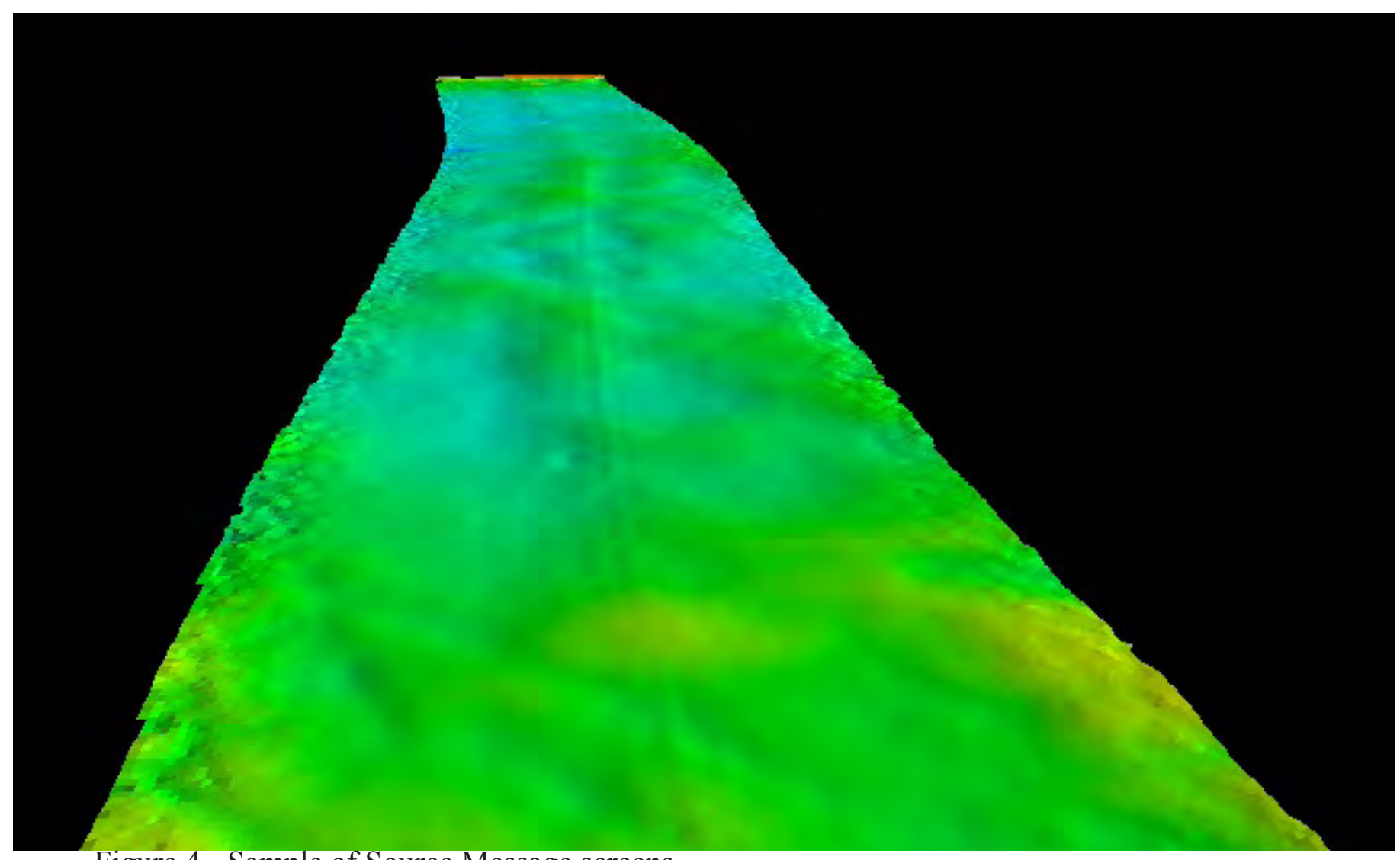

Figure 4 - Sample of Source Message screens

\section{SOURCE DATA PROCESSING}

Once a source is received by the production environment, which is a semi-automatic product dependent process, the different operators process the source for each product. The processing will, of course, be different depending upon product type, scale, format etc.
Processing Sources for Nautical Cartographic products

Within the production environment the operator checks the source message for any new updates for a series of products. All relevant sources are listed and the operator processes the corrections in a chronological order. Once the source message is processed and quality control is accepted, the SM is flagged Completed. This will then store process information to the specific product, database as well

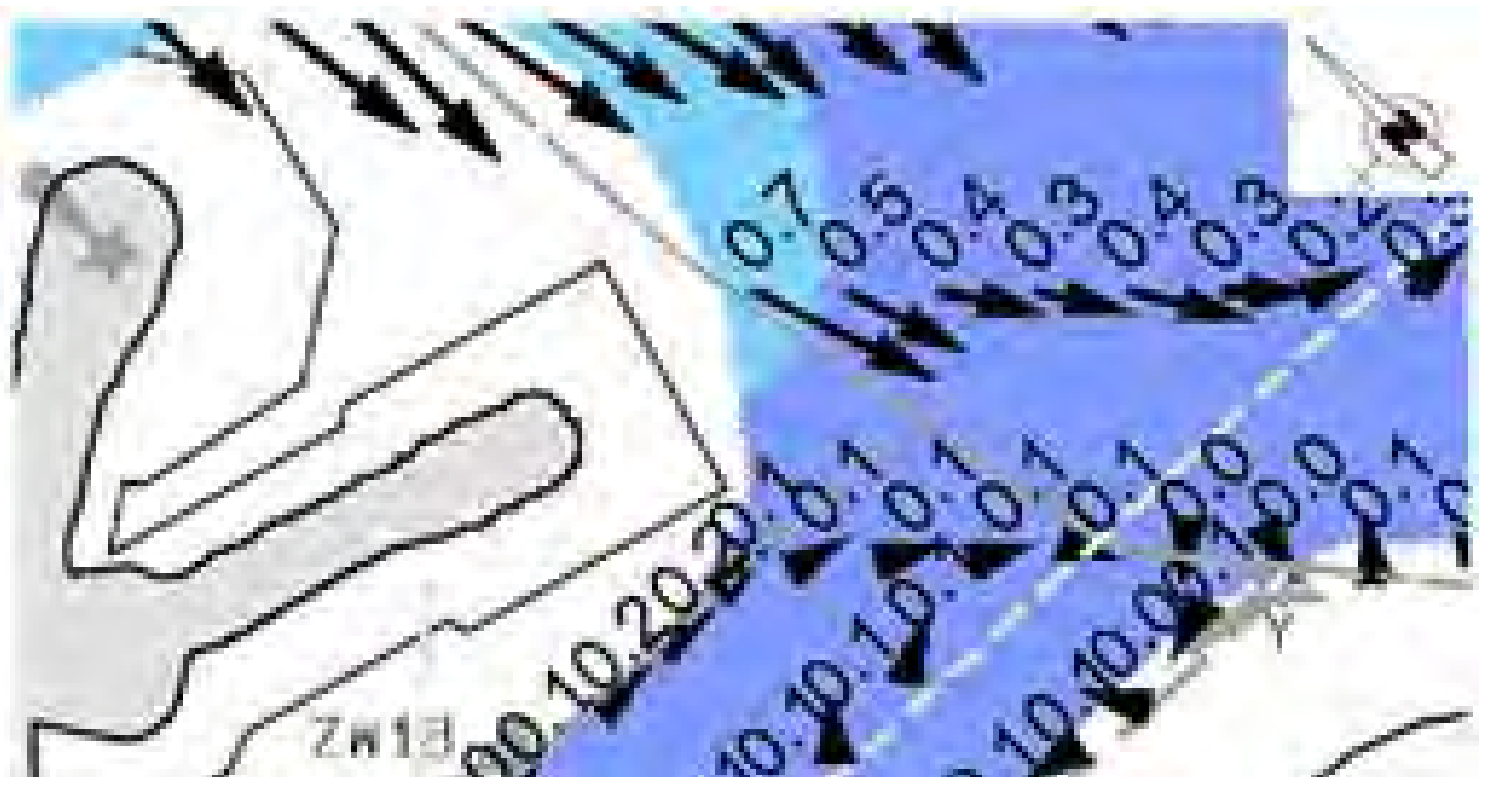

Figure 5

- Process description of Source handling 


\section{Depth Residuals, Full Swath}

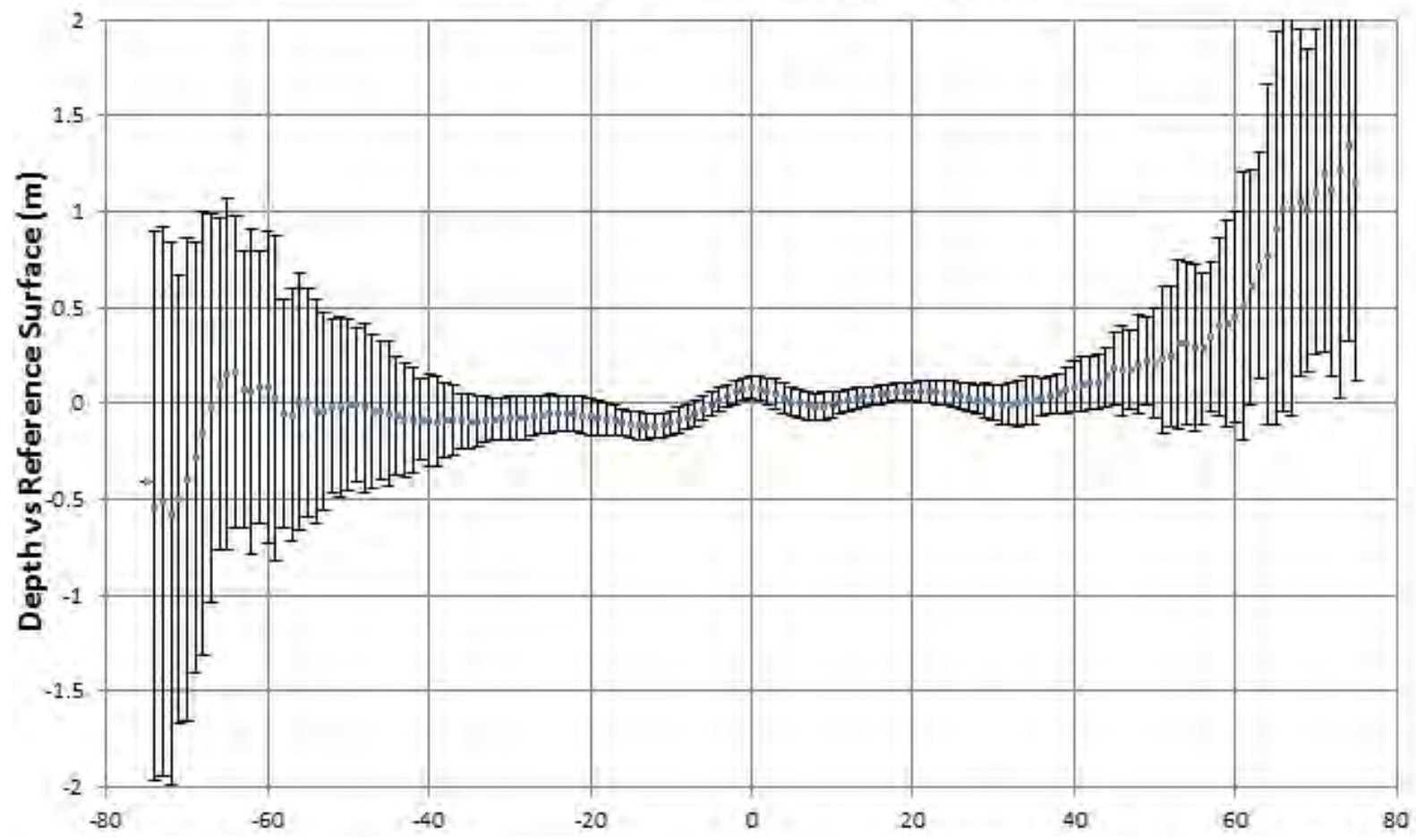

Figure 6 - Screen sample of source based ENC updating

as to the Source Message system ensuring a full traceability.

\section{Processing Sources for Publications}

As for the production environment, as soon as a Source Message is dispatched to a publication is made available for the Publication editor. For NtM Publication following process would be valid.
The source message has already been prefilled with most of the metadata needed to construct the Notice. So once the Source message is selected for a Notice, the system will convert the attribute based source message to a draft Notice textual message.

The operator will then perform textual editing ensuring that the content is formatted and presented as one would expect. The System will also

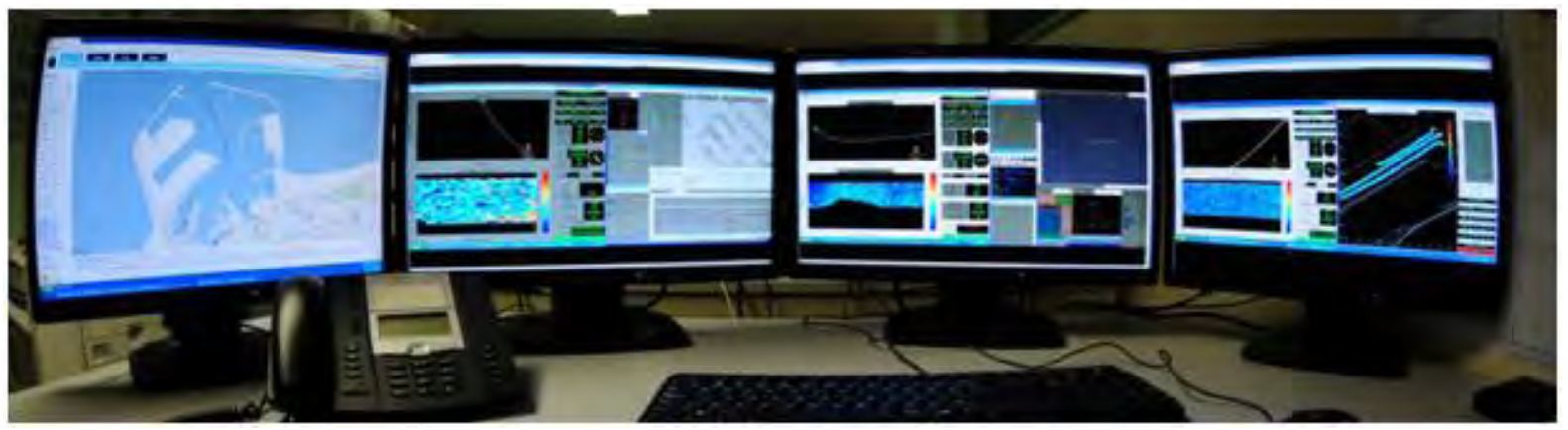

Figure 7 - Roles for Source processing to Publication 
automatically propose affected (paper) charts and allow the NtM editor to create cancelation messages etc. The Notice may be of Permanent, T/P or other categories.

If the Notice Editor defines that the notice must be accompanied with one or more Blocks and/or Tracings, this will be flagged here. The production of Tracings will be an integral part of the product maintenance for the specific paper charts, which the Block creation may be done either in production department (as part of the actual update) or the Notice editor may create the block him/herself when the source has been applied.

\section{CONCLUSION}

Jeppesen has successfully rolled out the Source Message system at several hydrographic offices. The system has proven to provide an effective storage handling, where several processes may be configured to proceed fully automatically. The system is modular and tunable so that it will serve the needs of a small as well as a large hydrographic office.

Jeppesen has implemented automatic integration with buoyage system monitoring, ensuring an efficient paper chart update process enabling Print on Demand to run a biweekly released schedule. Jeppesen has also implemented full featured Notice to Mariners system handling source to booklet in addition to ensuring the product maintenance.

\section{REFERENCES}

Jeppesen and dKart documentation.

\section{BIOGRAPHIES}

John K KLIPPEN has worked for Jeppesen Norway since 1994. He has been product manager for the dKart Office software products since 1998. John $\mathrm{K}$ Klippen has also been the project manager for several Hydrographic Office projects during this period. John K Klippen holds a degree in Computer Science from the NITH in Oslo.
John K KLIPPEN

Jeppesen Norway AS

Hovlandsveien 52,

Postbox 212, N-4379

Egersund

NORWAY

Tel.: +47 51464700

Fax: +4751464701

Email:john.klippen@jeppesen.com

Web site: www.jeppesen.com/marine

LinkedIn account: John K Klippen 
|46 | Hydrol 2 


\title{
Integrated Bathymetric Data Management - the platform for decision making in the Port of Hamburg
}

\author{
Frank KÖSTER, Germany \\ Hamburg Port Authority \\ Ottokarl BÜCHSENSCHÜTZ-NOTHDURFT, the Netherlands \\ CARIS BV
}

\author{
Verena BOSSELMANN-BORSOS, Germany \\ Hamburg Port Authority
}

Topics: Innovations in processing techniques, Smart data management, Easy customer access to data and products

\section{INTRODUCTION}

The Hamburg Port Authority (HPA) has used CARIS tools for bathymetric data management and analysis for more than 10 years. The inclusion of the Engineering Analysis Module (EAM) into the CARIS Bathy DataBASE (BDB) suite together with the professional Oracle based data management and the OGC webservice compliance through CARIS Spatial Fusion Enterprise opens new possibilities for the Hydrographic Survey Department and its customers, as a result of which HPA has now moved to this package.

The CARIS Bathy DataBASE forms the backbone of the bathymetric analysis performed at the HPA and is the platform for several product creation and decision making processes.

Using cleaned multibeam, multichannel and mobile laserscan data and different kinds of harbour maps like ENCs, AutoCAD files or 3D channel models, created within BDB, the Hydrographic Survey Department creates bathymetric models, bathymetric ENCs, all bathymetric objects for paper charts, difference models, profiles and volume computations for the Dredging Department, the Nautical Centre, the pilots, asset managers and other customers (see figure 1).

Additionally customers like the Hydrology Department can either directly access the Bathy DataBASE with the CARIS BASE Manager or can integrate OGC Web Services provided from the CARIS Spatial Fusion Enterprise into their own applications in order to carry out tailored analysis like sediment prediction.
This paper will show how a system like CARIS BDB is integrated into the different workflows within and between the different departments at HPA, showing how to share and jointly use one common data basis over a large and varied user base.

\section{DATA PREPARATION - LOADING DATA INTO THE BATHMETRIC DATABASE}

In order to reduce duplication of effort and chance for error HPA has adapted the standard configuration of the software to HPA specific needs and thus derived a customized workflow which transforms important metadata from the processed and cleaned bathymetric data coming from CARIS HIPS to BDB automatically. When loading the data from HIPS into BDB, metadata information like survey type, survey date or technique of sounding will be automatically mapped and stored as metadata in the surface object, based both on the naming convention of the data as well as existing metadata coming from the HIPS dataset. This is metadata information is then later giving HPA the possibility to query and export data based on customers' needs as well as to form decision rules when de-conflicting overlapping data.

\section{DATABASES IN USE}

In order to meet the various products' requirements for up to date survey by survey information on the one side, and seamlessness for the whole port area on the other side, two databases are in constant use as follows: 


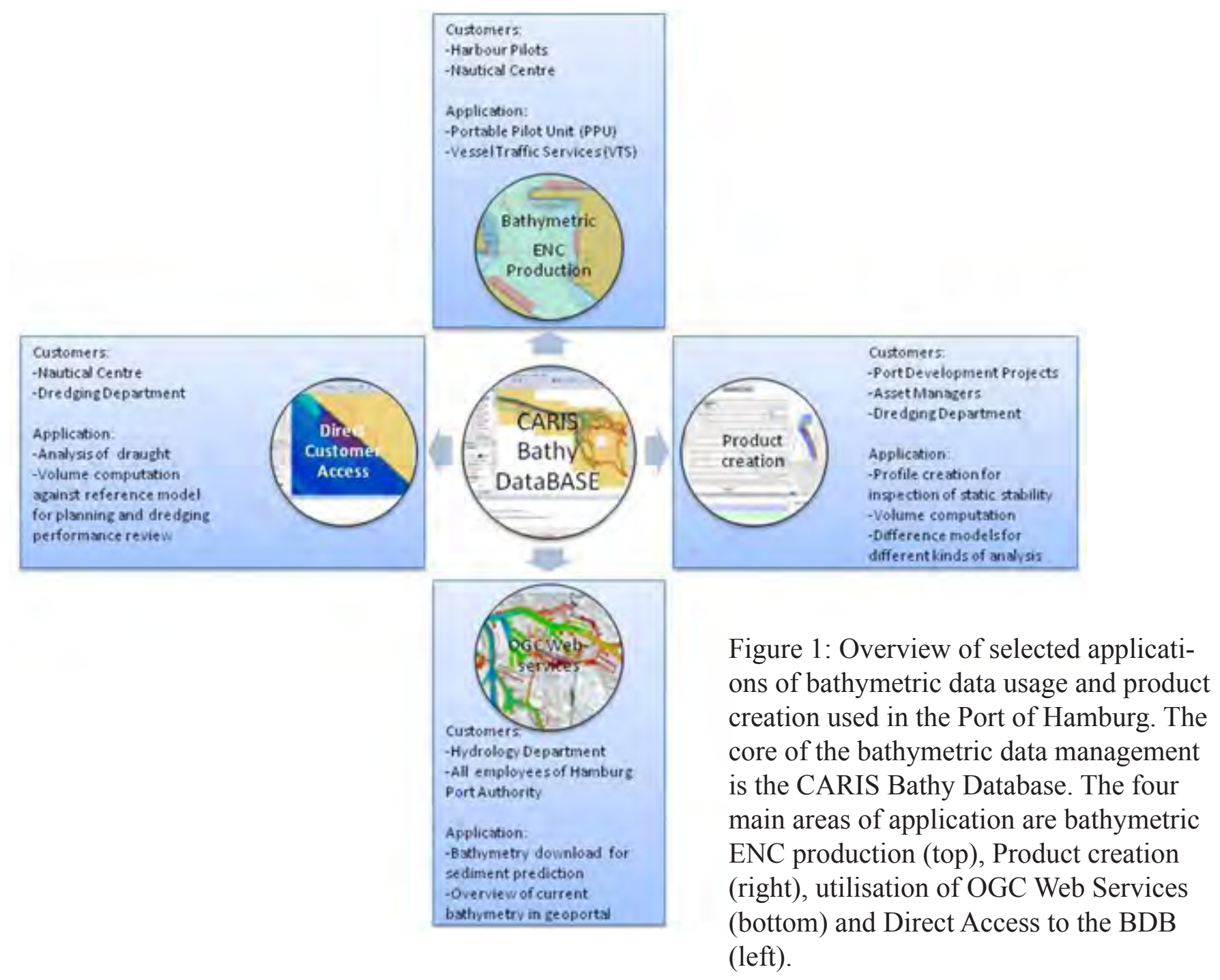

\section{The "daily" Database}

In highly frequented harbour areas berths are constantly blocked, other survey areas have large extents. For this reason many surveys in the Port of Hamburg are lasting for several days.

In CARIS HIPS a BASE surface is computed for each day and vessel respectively. It automatically contains all needed metadata and has a resolution from $0,5-1 \mathrm{~m}$. Those surfaces are loaded on a daily basis into the "daily" database containing the metadata and an automatically generated outline. The "Daily Database" is including the data from every survey. Based on the current survey activities and resources, this means that each year around 1500 surfaces will be added.

\section{The "full coverage" Database}

Beside the "daily database" HPA also has a "full coverage" database that is holding the most recent and shoalest data. Every week a surface containing the surveys from the last 7 days is created in the "daily database" which will be combined with the existing most recent data in the "full coverage" database. The result is one surface covering the whole area of the Port of Hamburg saved into the BDB. At each node the most recent and shoalest data is shown.

\section{CREATING PRODUCTS AND SERVICES}

The two bathymetric databases ("daily" and "full coverage") are holding all information in order to derive all services and products the customers of the Hamburg Port Authority demanded.

\section{$\underline{\mathrm{bENCs}}$}

The bathymetric ENC (bENC) is a product of the "full coverage" database. It is used as high quality data for enhanced port operations and is updated frequently. The bENC is based on the latest 
hydrographic survey and contains only high-density bathymetry like soundings, depth contours, depth areas and unsurveyed areas.

The team of the Nautical Center utilises the bENCs together with the Port ENCs in order to manage the traffic in the port area (see figure 2).

The Harbour Pilots will use the bENCs together with the Port ENCs of the Hamburg Port Authority in their Portable Pilot Units (PPUs) (see figure 2).

\section{Direct Customer Access}

Direct customer access is needed for high performance computation and analysis.

The Nautical Center carries out the analysis of draught for all berths through direct access to the "full coverage" and "daily" databases. The customized metadata workflow enables queries in the "daily" database for newest survey patches. Their outlines are overlaid with the "full coverage" database, where the analysis for the shallowest sounding is carried out (see figure 3 ).

The Dredging Department carries out volume computations and profile creation directly on the data in the two separate databases "full coverage" and "daily". Mostly volume computations against a reference model's depth are applied for planning or dredging performance review purposes.

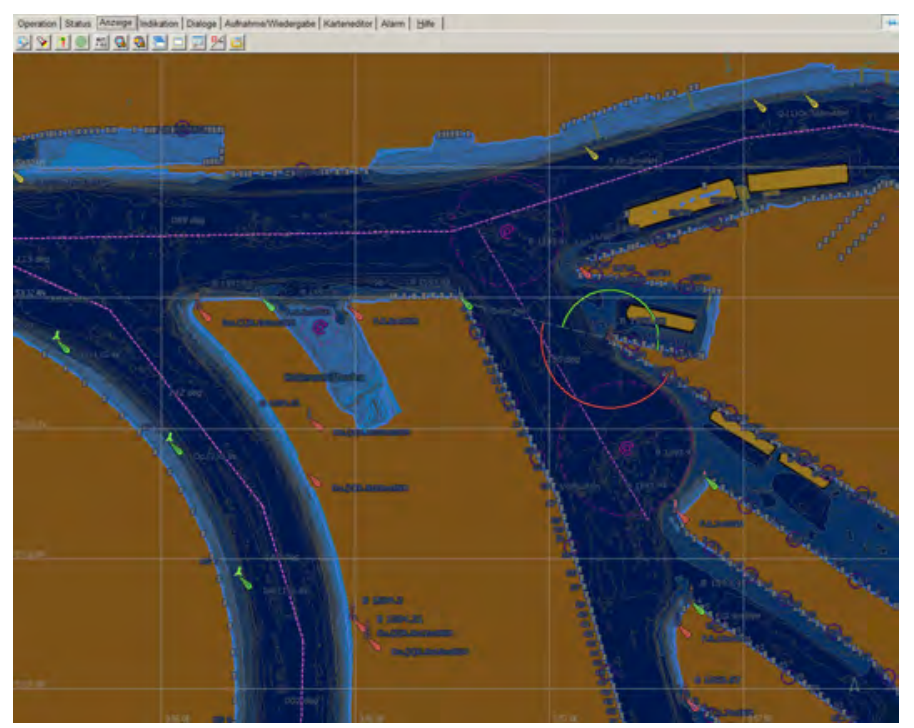

\section{$\underline{\text { OGC Web Services }}$}

The implementation of standardised OGC Web Services with CARIS Spatial Fusion Enterprise using a direct connection to the bathymetric database opens new possibilities for all customers.

\section{The Hydrology Department of the Hamburg}

Port Authority connects with the sedimentation prediction

software SeDiRa of Smile Consult to a combination of three OGC Web Services connected to the "daily" database. The Web Map Service (WMS) graphically shows the outlines of the surface, the Web Feature Service (WFS) delivers all the metadata contained in the bounding polygon of a surface and the Web Coverage Service (WCS) provides the relevant datasets in either Bathymetry Attributed Grid (BAG) format or ASCII XYZ files.

All employees of the Hamburg Port Authority can use the GeoPortal realised by AED-SICAD. The GeoPortal includes a WMS service accessing the "full coverage" database (see figure 3).

\section{Paper Product Creation}

Being able to create products from bathymetric data according to customers' needs is one core business of the Hydrographic Department of the Hamburg Port Authority.

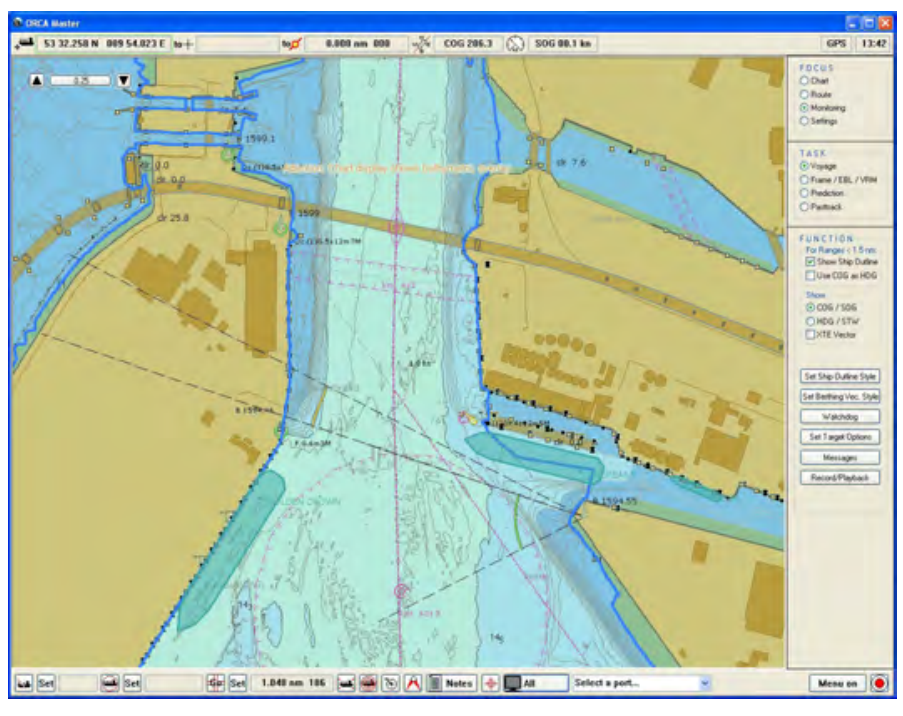

Figure 2: (left) The Vessel Traffic System from SIGNALIS in the Nautical Center of the Port of Hamburg showing the Port ENC superimposed by a bENC in custom colours. (right) The Orca Master/Pilot software of 7Cs is used by the Harbour Pilots in the Port of Hamburg displaying the bENCs and Port ENCs. 

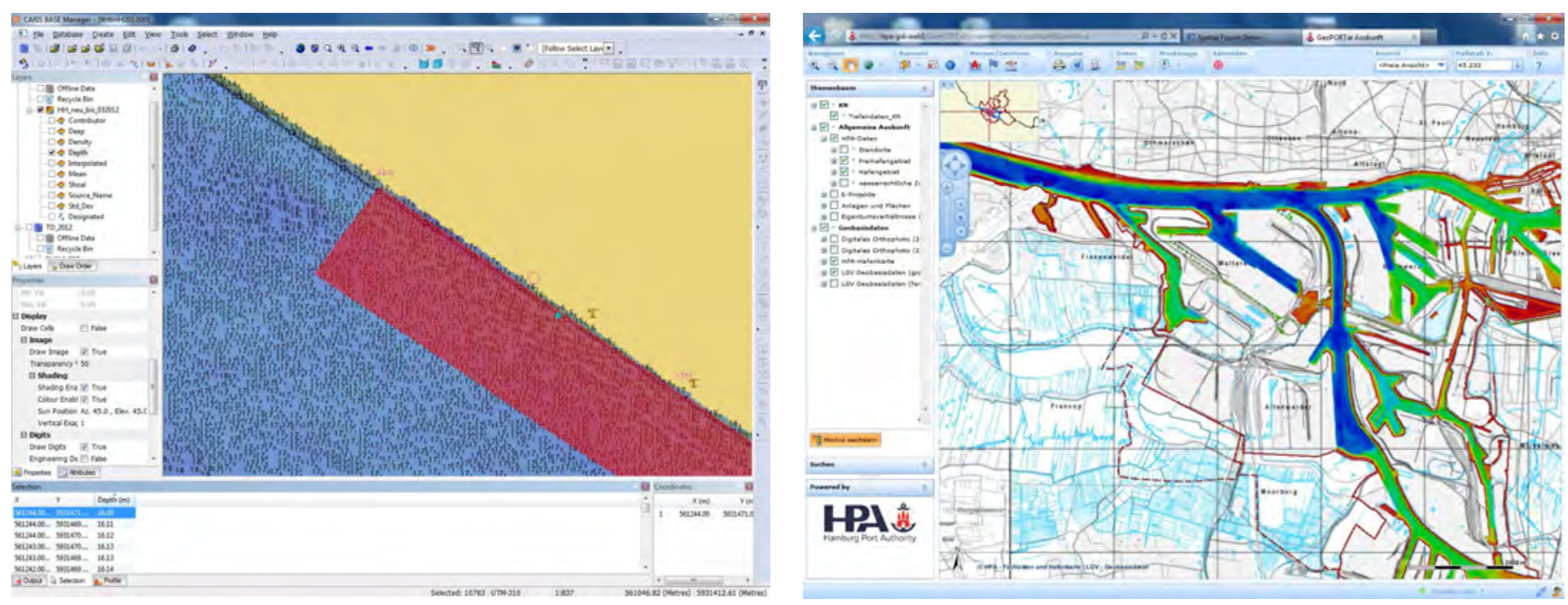

Figure 3: (left) In the CARIS Bathy Database Manager the analysis for the least depth at a berth is done by selecting the extent of the berth and searching for the shoalest sounding. (right) The GeoPortal includes a colour coded bathymetry layer covering the full extent of the Port of Hamburg and served from the SFE.

With the addition of the Engineering Analysis Module into the Bathy DataBASE it is now possible to not only compute difference surfaces between two surfaces (see figure 5) but also of surfaces against a reference model. The difference surface can be customized with different colour shadings and if needed soundings and contours can be created. Another frequently requested product is the profile. Profiles are computed for surfaces together with the reference depth in BDB, and are visualised in Golden Software Grapher (see figure 4).

\section{CONCLUSION}

The combination of the CARIS tools Bathy DataBASE and Spatial Fusion Enterprise provides an abundance of possibilities for HPA and their customers to maintain, access, produce and analyse bathymetric data in an efficient way. The application of open or standard formats like the OGC web standards or the bENC standard enable other users and software packages to utilise the bathymetric data for various different use cases. As a result these

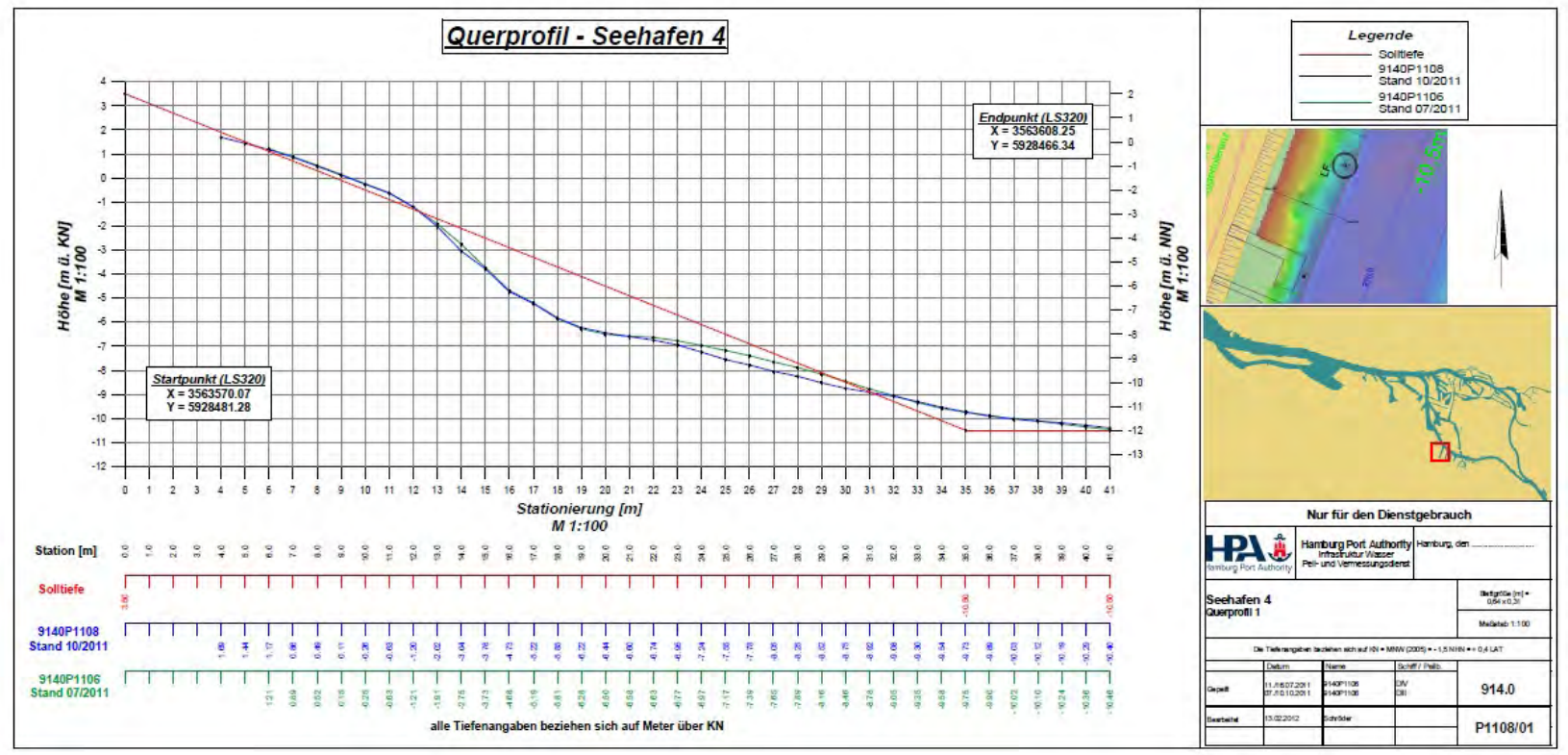

Figure 4: Profile at the "Seehafen 4" in Hamburg-Harburg. The red line depicts the reference model. The green and blue lines show survey data from two bathymetric surveys. 


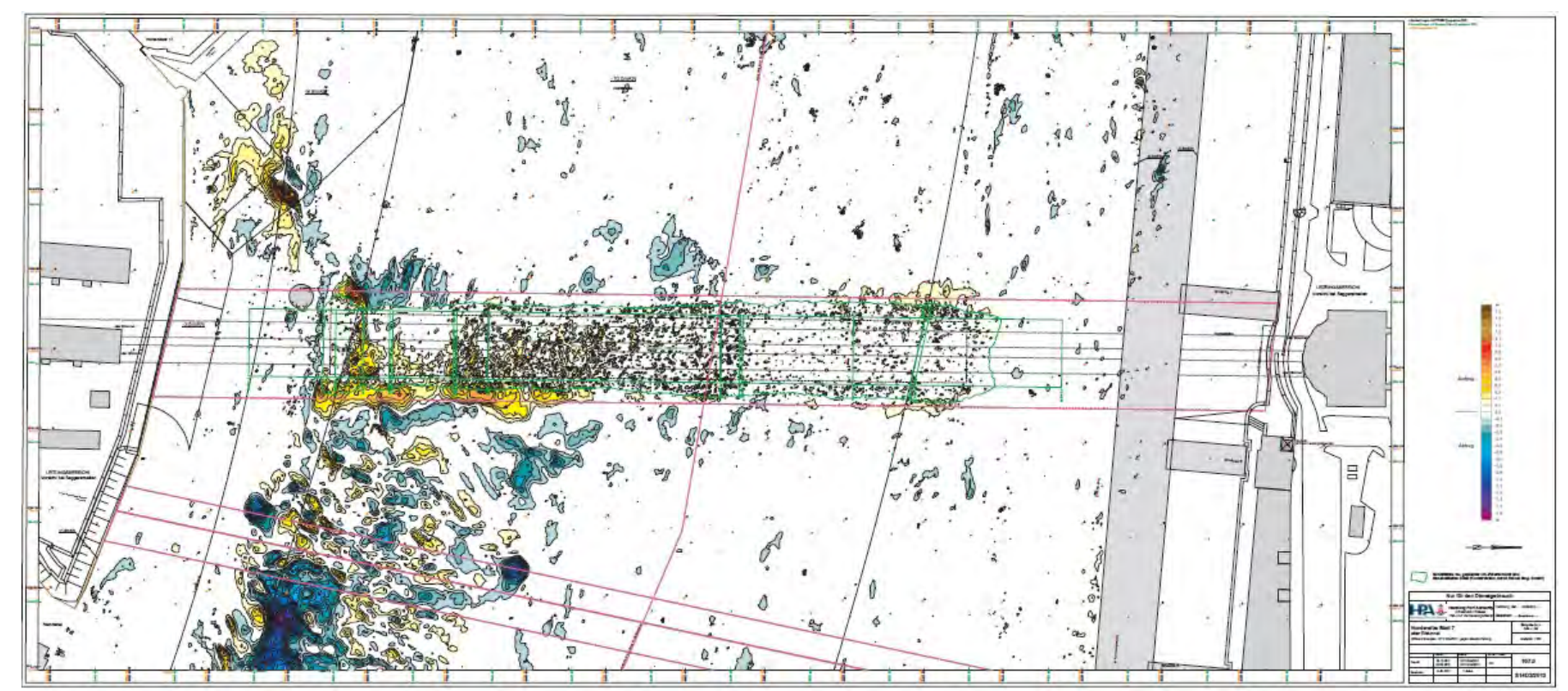

Figure 5: Difference model map compiled in CARIS HPD Paper Chart Editor. The depth contours and depth areas have been computed in CARIS BDB. This map shows a difference between two surveys with an interval of 6 months.

departments within HPA that require bathymetry for their planning and decision making can all draw on one common data source.

The addition of the Engineering Analysis Module to the Bathy DataBASE has expanded the creation of products to volume computation, profiles and difference models and reduced the need for the Hydrographic Department to keep another extra software for that specific purpose.

Further developments of the standard applications, which HPA will receive automatically as a result of a maintenance contract, will be reviewed when they become available, to see how they can help to both optimize the workflows further as well as in providing new products to HPA's customers.

\section{BIOGRAPHIES}

\section{Frank KÖSTER}

2003 Dipl.-Ing. (FH) Geomatics, Surveying and Hydrography (CAT A) at HAW Hamburg 2004-2010 Head of Hydrographic Data Processing at Hamburg Port Authority

2006 Master of Science in Hydrography at HafenCity Unversität Hamburg

Since 2010 Head of Hydrographic Department at Hamburg Port Authority
Verena BOSSELMANN-BORSOS

2002 Dipl.-Ing. (FH) Geomatics, Surveying at HAW Hamburg

2002 - 2004 Quality Assurance for ENC Production at SevenCs

2004 - 2007 Head of Quality Assurance for ENC

Production at SevenCs

2007 Data Analyst at HSA Systems Pty LTD,

Australia

2007 - 2008 Data Analyst at New Zealand

Hydrographic Office

2008 - 2010 Production Manager at New Zealand

Hydrographic Office

Since 2011 Head of Hydrographic Data Processing at Hamburg Port Authority

\section{Ottokarl BÜCHSENSCHÜTZ-NOTHDURFT,}

Support \& Training Manager at CARIS BV. With a degree of Geodesy and Survey Engineering from the University of Hannover and a CAT A (Academic) from the University of New Brunswick, he has joined CARIS BV in late 2002 as a Hydrographic Engineer in the Support \& Training Department. Since then he has moved on through the position of Support \& Training Coordinator to become the manager of this team in 2006. He is still actively providing training and consultancy in the products CARIS HIPS and SIPS and CARIS Bathy DataBASE amongst others. 


\section{CONTACT DETAILS}

\section{Frank KÖSTER}

Hamburg Port Authority

Neuer Wandrahm 4

20457 Hamburg

\section{GERMANY}

Tel.: +49 40 / 42847-2385

Fax: +49 40 / 42847-2048

Email: frank.koester@hpa.hamburg.de

Web site: www.hamburg-port-authority.de

mailto:submissions@hydro12.com 


\section{Determining rock quantities using swathe techniques on Maasvlakte 2}

Marnix KOL, the Netherlands

PUMA

Huibert-Jan LEKKERKERK, the Netherlands

Port of Rotterdam

Eric PEETERS and René ROELS, the Netherlands

PUMA

Tjebbe WESTERBEEK, the Netherlands

Port of Rotterdam

Topics: Innovations in acquisition techniques, Innovations in processing techniques, Hydrography in the Benelux

\section{INTRODUCTION}

For the Maasvlakte 2 extension of the Port of Rotterdam a large amount of rock has to be placed underwater under tight specifications in relatively thin layers. The rock is placed both under water as well as above water. In general measurements above water are performed using land survey equipment and are relatively simple and reliable provided a clear reference level is used. The standard method for surveying rock levels is described in CUR 154 [1991] and requires the use of a semi-spherical foot as a reference.

As the semi-spherical foot staff is unusable under water or in the surf zone, echo-sounders are commonly used here. Experience from various projects has shown that the application of modern systems for monitoring dumped rock, however, can be accompanied by problems. Above water the application of laser-based techniques is now starting to be used whilst crane measurement systems are used as an on-the-spot alternative for more advanced survey systems. Each of these systems has its own specific advantages and disadvantages.

\section{Errors in determining rock quantity}

One of the most important factors in the construction at Maasvlakte 2 was the determination of the layer thickness. Possible errors in the surveyed thickness are determined by the following factors:

- Definition of the level of the upper surface of the bed / dumped rock to be surveyed in relation to the (mean) level as measured by the surveying system.

- Influence of settling and compression of the ground and penetration of the dumped materials into the ground.

- Inaccuracies in the surveying system.

It is important when discussing results to define a reference level to which the results obtained can be compared. Two (potential) reference levels can be defined: the plane passing through the tops of the stones and the level as obtained by a semisphere survey complying to CUR 154 [1991]. CUR 154 specifies a semi-sphere diameter of 0.5 Dn50 (nominal average stone diameter) and measurements in 1x1 m raster. In general the semi-spherical foot is stated to give a reference level of about $10-15 \%$ below the tops of the stones.

\section{$\underline{\text { Available research }}$}

In an effort to find out more about the interaction between survey systems and the observed bottom, trials were held in 1999 in Dock VI of the Verolme company in the Botlek at Rotterdam. Initial conclusions pointed towards lower volumes being detected using multibeam surveys than with the semi-spherical foot [VBKO et al, 1999].

As the rock gradations tested in earlier studies were limited and survey techniques have advanced, it was deemed necessary for the Maasvlakte 2 project to extend these studies. Therefore a test-pit was constructed at the Maasvlakte 2 where various stone 

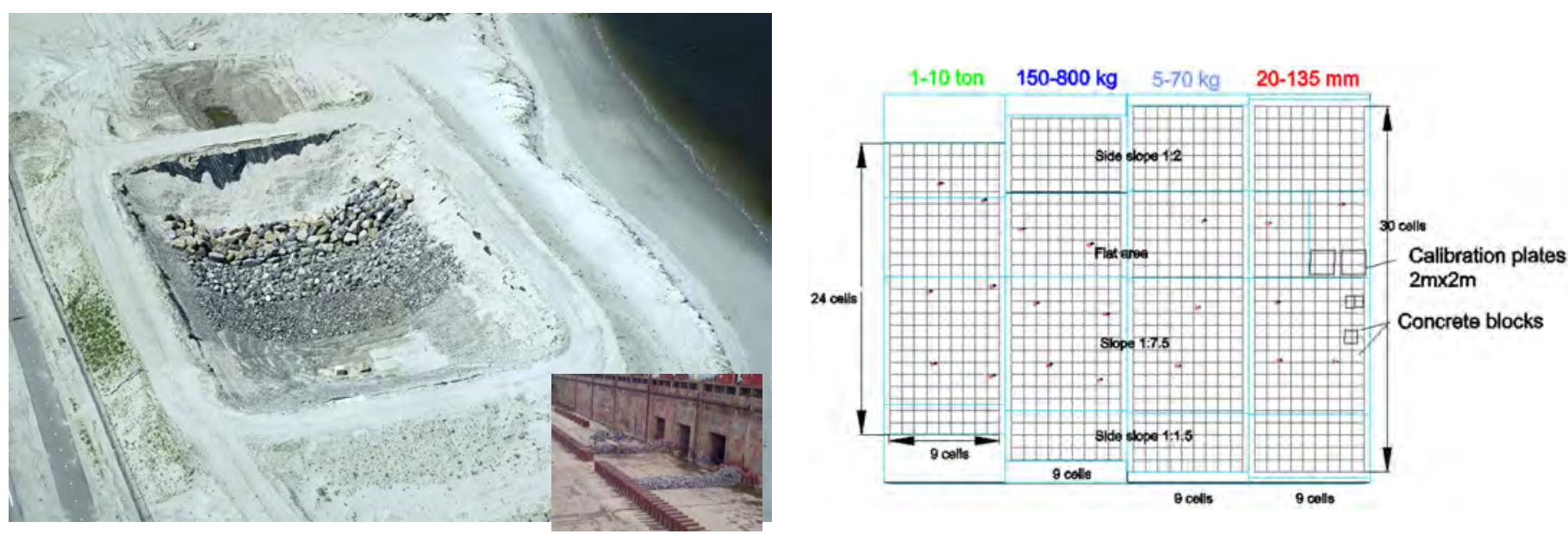

Figure 1: Trial set-up in the test-pit at the Maasvlakte port extension with $20-135 \mathrm{~mm}$ (including 4 objects), $5-70 \mathrm{~kg}, 150-800 \mathrm{~kg}$ and 1-10t gradations. Inset: Trial set-up in the Verolme dock (1999).

gradations were surveyed using a wide variety of survey methods [Lekkerkerk and Kol, 2011].

\section{SET-UP OF TEST PIT TRIALS}

The methodology used in the test-pit trials of 2010 was essentially the same as that of the dock trials from 1999. The main differences were the stone gradations, scale and survey systems used. The dumped rock in the dock trials consisted of a layer of $10-60 \mathrm{~kg}$ rock and a layer of $40-200 \mathrm{~kg}$ rock whereas in the test pit trials layers of 20-135 $\mathrm{mm}, 5-70 \mathrm{~kg}, 150-800 \mathrm{~kg}$ and $1-10 \mathrm{t}$ of rock were surveyed.

Layers were applied in the dry to a minimum thickness of about 2-2.5 times the nominal stone diameter of the gradation concerned. In the dock trials the layers were smoothed; in the test pit trials the roughness of the bed as expected from dumping (about 2 times the nominal stone diameter) was simulated using a crane. In both situations 'clean' rock (no foreign inclusions) was used. In the test-pit four different slopes were created $(1: 1.5 ; 1: 2 ; 1: 7.5$ and 'flat' - i.e. < 1:10).

\section{$\underline{\text { Survey systems used }}$}

After construction, the stone layers were surveyed using a variety of dry survey techniques. The following survey systems were used for the dry surveys:

- land survey point measurements with level pole

- semi-spherical foot staff. Diameter calculated from CUR 154 [CUR/CIRIA, 1991] based on nominal stone gradation.

- plate measurements with a minimum dimension of around $4 \times$ Dn 502 resulting in a $1 \times 1 \mathrm{~m}$ plate for all gradations except $1-10 \mathrm{t}$ and a $2 \times 2 \mathrm{~m}$ plate for $1-10 \mathrm{t}$.

- crane monitoring measurements using a variety of grabs and buckets fitted to the crane

- static laser measurements (single system) from a total of six positions around the test pit

- mobile laser measurements from both a crane using an inexpensive type of industrial laser as well as from a helicopter using the Fli-map system

Subsequently the test-pit was flooded and surveyed using 'wet' equipment mounted on a small survey vessel. The wet surveys were performed with the equipment at a height of around 4 and 6 meters above the test beds. The following systems were tested:

- single-beam system with different beam angles. Long- and cross line pattern with line spacing of 5 meters.

- multi-beam with most common shallow water systems. Swath reduced to $45^{\circ}$ either side of the normal $\left(90^{\circ}\right.$ in total). Lines sailed with $100 \%$ overlap [Lekkerkerk and Theijs, 2011].

- echoscope with $50^{\circ}$ x $50^{\circ}$ swath angles at both normal and high frequency 


\begin{tabular}{|c|c|c|c|c|c|c|c|c|c|c|}
\hline \multirow[t]{2}{*}{ Survey System } & \multicolumn{2}{|l|}{ Sand } & \multicolumn{2}{|c|}{$20-135 \mathrm{~mm}$} & \multicolumn{2}{|c|}{$5-70 \mathrm{~kg}$} & \multicolumn{2}{|c|}{$150-800 \mathrm{~kg}$} & \multicolumn{2}{|c|}{$1-10 t$} \\
\hline & 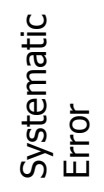 & 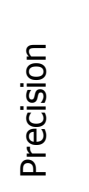 & 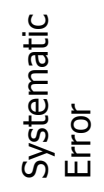 & $\begin{array}{l}\frac{\overline{0}}{\bar{n}} \\
\frac{0}{2} \\
\frac{d}{2}\end{array}$ & 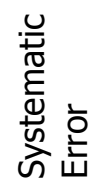 & 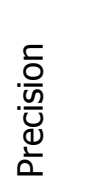 & 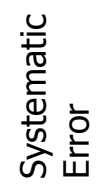 & $\begin{array}{l}\frac{.}{0} \\
\frac{0}{y} \\
\frac{d}{2}\end{array}$ & 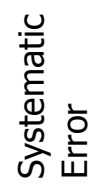 & $\begin{array}{l}\frac{}{0} \\
\frac{0}{2} \\
\frac{d}{2} \\
\frac{1}{2}\end{array}$ \\
\hline Total station - plate & n.a. & n.a. & 0.07 & 0.08 & 0.12 & 0.09 & 0.14 & 0.15 & 0.11 & 0.17 \\
\hline Total station - point & n.a. & n.a. & n.a. & n.a. & -0.07 & 0.07 & -0.13 & 0.19 & -0.27 & 0.51 \\
\hline Excavator - bucket $^{1}$ & n.a. & n.a. & 0.17 & 0.13 & 0.14 & 0.15 & 0.34 & 0.27 & 0.32 & 0.40 \\
\hline Excavator - orange peel $^{2}$ & n.a. & n.a. & 0.17 & n.a. & 0.08 & 0.11 & 0.18 & 0.21 & 0.20 & 0.36 \\
\hline Excavator - sorting & n.a. & n.a. & n.a. & n.a. & n.a. & n.a. & 0.14 & 0.22 & 0.18 & 0.32 \\
\hline Single-beam & 0.01 & 0.03 & 0.08 & 0.08 & 0.08 & 0.11 & 0.09 & 0.18 & 0.06 & 0.26 \\
\hline Multi-beam / Echo-scope & -0.01 & 0.02 & -0.03 & 0.06 & -0.11 & 0.09 & -0.19 & 0.15 & -0.38 & 0.26 \\
\hline Static laser & -0.01 & 0.05 & -0.01 & 0.06 & -0.04 & 0.10 & -0.05 & 0.15 & -0.18 & 0.23 \\
\hline Crane based laser & 0.02 & 0.05 & 0.04 & 0.07 & -0.01 & 0.10 & -0.08 & 0.15 & -0.25 & 0.24 \\
\hline Fli-map laser & 0.00 & 0.06 & -0.06 & 0.09 & -0.12 & 0.10 & -0.17 & 0.18 & -0.36 & 0.27 \\
\hline
\end{tabular}

Table 1: Results obtained in the test pit trials with the semi-sphere as reference (1x1 m grid)., All values in $[\mathrm{m}]$, a negative systematic error denotes that the measured value is below the reference level. Note 1: Values for $2 \times 1.2 \mathrm{~m}$ bucket with bucket closed and edge parallel to plane of slope. Note 2: grab Ø $2.5 \mathrm{~m}$ and grab closed.

\section{Processing}

The data from the swath systems (full coverage) was averaged in a regular $1 \times 1 \mathrm{~m}$ grid aligned with the test pit. The resulting average is then compared with the point survey result taken at the centre of that same grid cell. This results in a deviation between the two survey results which is then statistically processed.

\section{RESULTS}

The results from the test pit surveys can be described in a qualitative as well as a quantitative manner. In practice the qualitative results need to be translated into survey procedures where the quantitative results result in corrections to the surveyed levels.

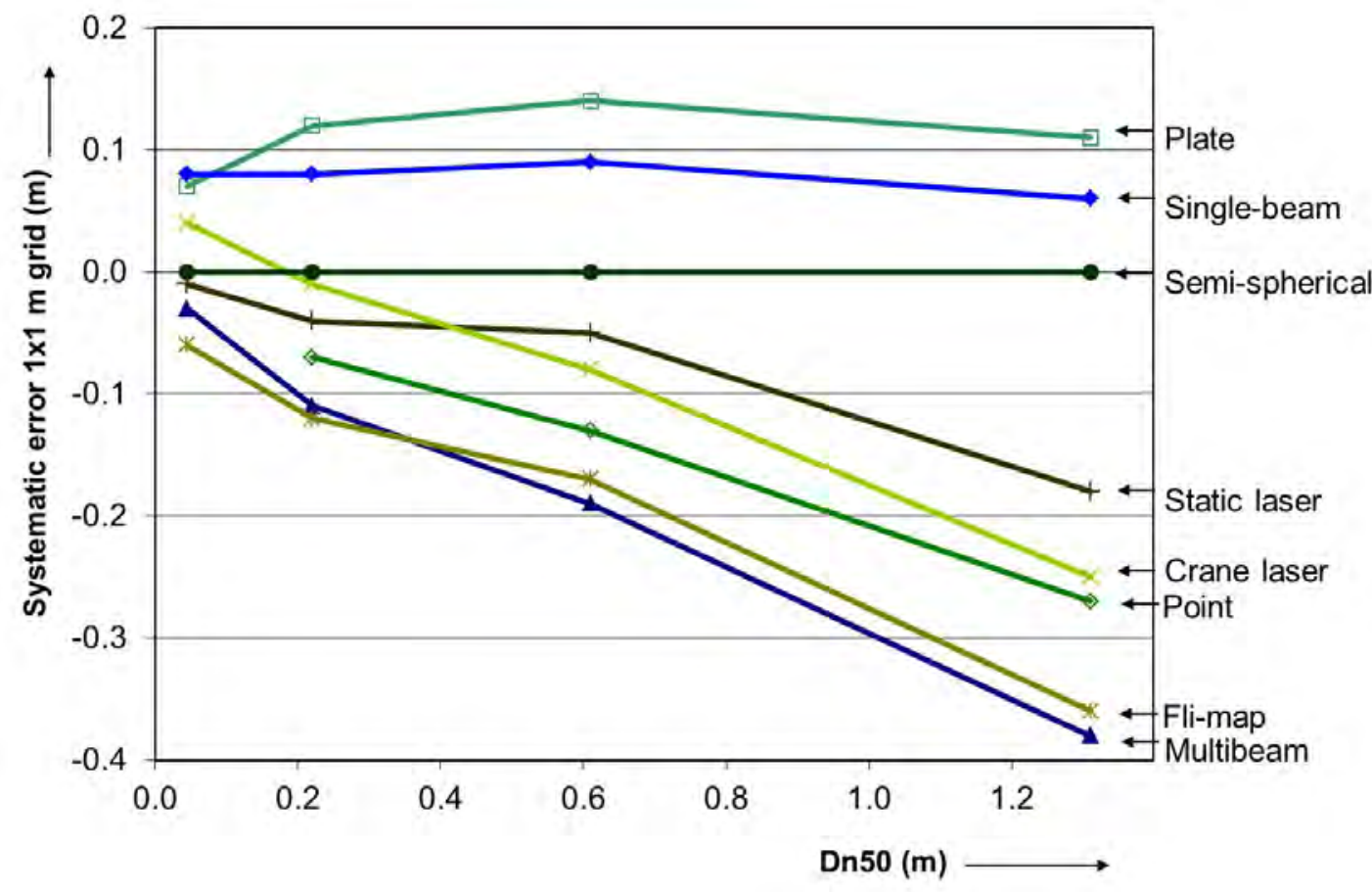

Figure 2: Systematic errors for the nonexcavator systems based on Table 1. 


\section{Quantitative results}

Table 1 shows the results of the test pit trials in relation to the semi-spherical foot as reference. The results were surveyed and computed in $1 \times 1 \mathrm{~m} 2$ grid cells to allow for direct comparisons between the systems. The results shown are the average for those obtained from the horizontal and 1:7.5 slope.

The measurements as presented in Table 1 were also computed with a $1 \mathrm{x} 1$ plate as reference. Figure 2 allows the determination of the systematic error for the plate as well as for the semi-spherical foot. Standard deviation when using the plate as reference was found to be smaller than with the semi-spherical foot.

\section{Qualitative results}

Besides the quantitative results from the table, the following qualitative results were also found and need to be taken into account when surveying stones:

- When using a crane monitoring system, special attention should be given to bucket size and shape as well as to a well-defined measurement protocol resulting in the bucket / grab always being placed in the same orientation (longest dimension transverse to average slope direction) and in the same condition (opened / closed)

- Surveys on the stones done using either multibeam or laser systems require a certain degree of (manual) editing and filtering as a high number of spikes may exist in the data when compared to surveys on sand / filter layers

- The precision of some multibeam systems degrades in very shallow water $(<2$ meter below the transducer); it is suggested that this is a result of the beam forming processes which requires a minimum water depth to take place fully. The effect becomes more pronounced with a greater stone diameter

- Surveys with the crane monitoring system produced each time the largest mean layer thickness as well as the largest values for the precision. The mean bed level surveyed by this system lies above both references when using a bucket as crane tool. Results vary with the size and type of bucket / grab used.

- Surveys with the multibeam and laser systems, on average, produced the lowest layer thicknesses.

\section{$\underline{\text { Multibeam reults in more detail }}$}

The results of both the dock and test pit trials for the multibeam system in a $1 \times 1$ meter cell size are displayed in Figure 3 and show a good comparison

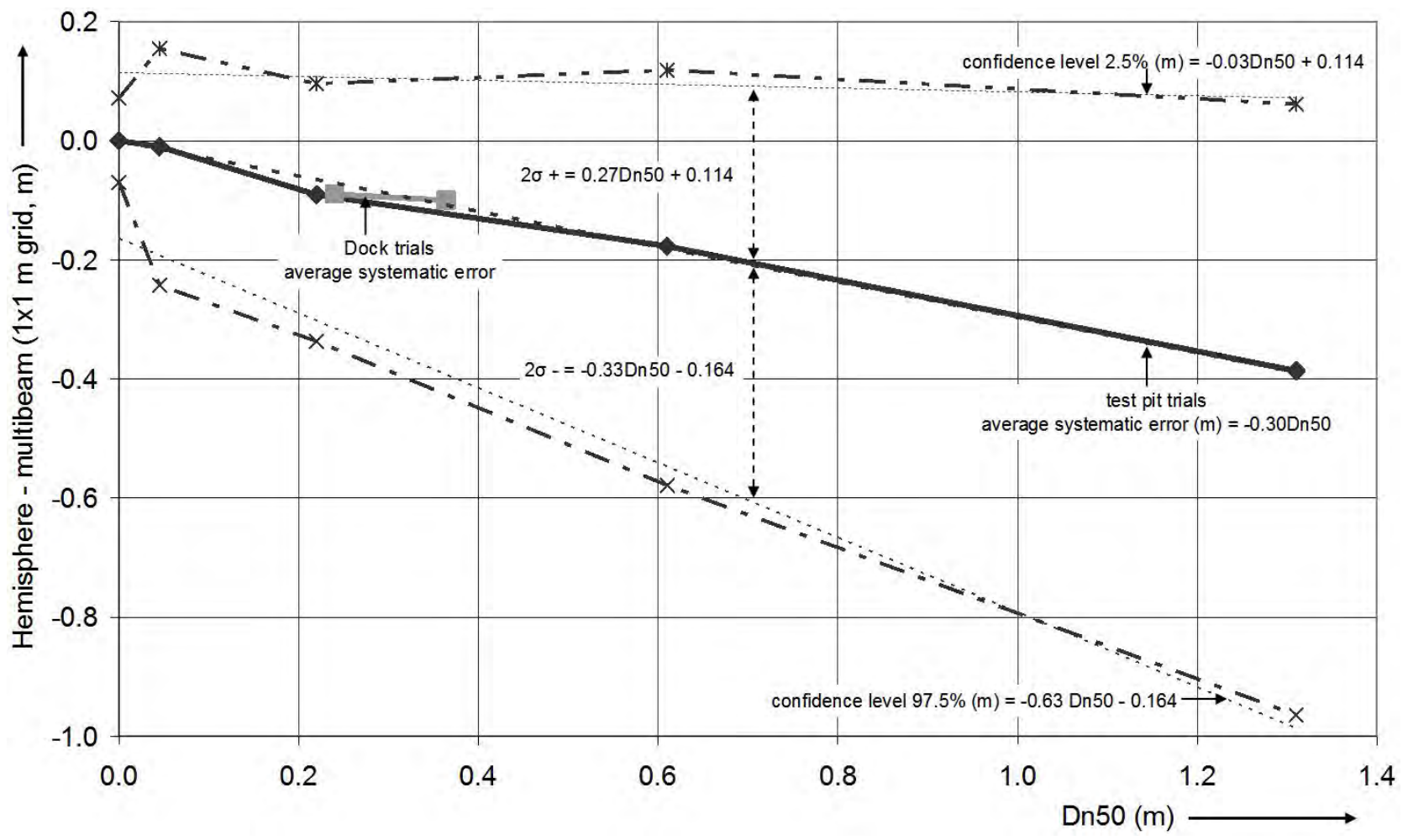

Figure 3: Results of systematic error and precision resulting from both dock and test pit trials in a 1x1 m grid 
between both trials. The graphs for the dock trials and test pit trials show a deviation from the trend line established at around a Dn50 of 0.25 meter.

\section{DISCUSSION OF RESULTS}

Based on the accumulated data both systematic error and precision for a multi-beam system seem to behave according to a common formula which depends on the stone diameter, slope and reference method. It should be specifically noted that the formula's given below are only valid for surveys with a high quality survey system (both good quality for the sounding system as well as good quality of operations) and are valid for clean stone (no foreign inclusions). In the situation where different conditions are found, additional tests are required to establish the correct values.

\section{Systematic error}

Based on the results from both the test-pit and the dock trials formula 1 is proposed for the computation of the systematic error of multi beam swathe systems.

Esyst $=-\mathrm{s} 1 * \mathrm{D}_{\mathrm{N} 50}-0.01 *(10-\mathrm{sg}) * \mathrm{D}_{\mathrm{N} 50}$

with:

Esyst Systematic error between average level as determined by reference survey and multi beam echo-sounder survey [m]

$\mathrm{D}_{\mathrm{N} 50} \quad$ Nominal stone diameter for the $50 \%$ mass fraction $[\mathrm{m}]$

s1 Error factor.

sg Slope gradient (e.g. 2 in a 1 vertical :2 horizontal slope) for slopes steeper than 1:10

The error factor depends on reference level and survey system used; as a rule of thumb, for multi beam systems this varies between 0.29 and 0.33 for the semi-sphere as reference and around 0.52 for a plate reference as derived from the tests. Based on these results the systematic error is relatively large in comparison to generally accepted construction accuracies for the placement rock under water.

Around a Dn50 of 0.25 meter $(10$ - $60 / 5$ - $70 \mathrm{~kg})$ an interaction between the multi beam and the stone layer seems to be occurring which has not yet been explained but could be the result of an interaction with the beam angle of the systems.

\section{$\underline{\text { Precision }}$}

The precision expressed as the standard deviation of the layer thicknesses measured with the various survey systems appears to show a linear relationship with the DN50 of the sounded crushed stone.

Formula 2 is proposed as a generic formula for computing the precision.

with:

$\sigma_{\mathrm{N}}$ precision at $68 \%$ confidence limits in a $\mathrm{N} \mathrm{m} 2$ gridcell [m]

$\mathrm{p} 1_{1}$ basic precision of the survey system in a $1 \mathrm{x} 1$ meter grid $[\mathrm{m}]$

$\mathrm{p} 2$ precision influence due to roughness of the bed in a $1 \times 1 \mathrm{~m}$ grid $[\mathrm{m}]$

$\mathrm{D}_{\mathrm{N} 50}$ Nominal stone diameter for the $50 \%$ mass fraction $[\mathrm{m}]$

$\mathrm{N}$ number of $1 \mathrm{x} 1 \mathrm{~m} 2$ cells in a $\mathrm{N} \mathrm{m} 2$ grid cell (i.e. 4 for a $2 \times 2 \mathrm{~m}$ grid cell)

For multibeam systems $\mathrm{p} 1$ can be determined during calibration measurements on a flat, smooth bottom such as a dock floor or flat sandy bottom. For various multibeam systems this constant was found to be around $0.03 \mathrm{~m}$. For laser systems the results can, in general, be expected to be better. The value p2 was derived in the tests and was found to be between 0.26 and 0.33 for multibeam systems when using the semi-sphere as a reference level.

The values of $\mathrm{p} 2$ are relatively large compared to generally accepted construction accuracies. During surveys with multibeam systems not only the systematic survey error, but also the random survey error can have a role of great significance upon the determination of rock levels.

\section{CONCLUSION}

It may be deduced from the results of both trials that the use of echo-sounding systems when surveying underwater dumped stone areas will be accompanied by relatively large systematic and random survey 
errors. This applies particularly to surveys with multi beam systems. The errors can be so large that actual construction inaccuracies on the micro level cannot be directly shown and that corrections need to be applied for showing construction inaccuracies on the macro level.

In general it can be said that the errors will increase with increasing nominal stone diameter. The systematic error when using the top of the stones (plate) is larger than when using the semi-sphere as a reference. The precision of plate measurements was however found to be better when using the plate as reference.

More background as well as the results presented in this article as well as more details on the surveying of rock quantities in general is to be published as a CUR / CIRIA report.

\section{REFERENCES}

CUR/CIRIA. 1991. Manual on Use of Rock in Coastal Engineering. Gouda: CUR / CIRIA.

Lekkerkerk, H-J., and M.J.Theijs. 2011. Handbook of Offshore Surveying volumes 1-3. Voorschoten: Skilltrade.

Lekkerkerk, H-J., and M. Kol. 2011. Onderzoeksrapport testgoot MV2. Rotterdam: Port of Rotterdam / PUMA.

VBKO et al. 1999. Een onderzoek naar hoogteligging breuksteen met multi- en singlebeam echo-sounders. Gemeentewerken Rotterdam / Baggermaatschappij Boskalis / Rijkswaterstaat / Vereniging van waterbouwers in bagger-, kust- en oeverwerken.

\section{BIOGRAPHIES}

Marnix Kol received his degree in Hydrography (A) from the Nautical College in Amsterdam. He has worked van Oord on various international projects as a hydrographic surveyor.

Huibert-Jan Lekkerkerk received his degrees in both Hydrography (A) and Maritime Electronics from Nautical College in Amsterdam. He has worked as client representative / consultant on various large projects, is author of a number of surveying books and teaches hydrography at Skilltrade.

Eric Peeters received his degree in Hydrography (A) from the Nautical College in Amsterdam. He has worked van Oord on various international projects as a hydrographic surveyor.

René Roels is employed by van Oord and has worked as civil engeineer specializing in rock placement on a number of projects including the Maasvlakte 2 extension and the rock layer St. Andries.

Tjebbe Westerbeek works as a hydrographic surveyor / client representative for the Port of Rotterdam. He received his degree in Hydrography (B) from Skilltrade.

\section{CONTACT DETAILS}

Huibert-Jan LEKKERKERK

Institution: Port of Rotterdam

Address: p/a Galjoen 01-34;

8243 MJ; Lelystad; the Netherlands

Tel.: +31653747717

Email: h.lekkerkerk@portofrotterdam.com

Web site: www.portofrotterdam.com

LinkedIn account: www.linkedin.com/in/hydrografie 


\title{
Assessing the Impact of INSPIRE on Related EU Marine Directives
}

\author{
Roger LONGHORN, Belgium
}

The Coastal \& Marine Union (EUCC)

Topics: Smart data management, Easy customer access to data and products, Careful marine planning

\section{INTRODUCTION}

The EU's INSPIRE Directive (EC 2007a) is to create a pan-European Spatial Data Infrastructure (SDI) focused on environmental data. INSPIRE's implementing EC Regulations and EU Decisions are intended to provide data harmonization and information services interoperability for spatial data required by many other EU Directives. In the marine community, INSPIRE has been proposed as the supporting SDI for the Water Framework Directive - WFD (EC 2000), the Marine Strategy Framework Directive - MSFD (EC 2008a), the Flood Risk Assessment Directive (EC 2007b), and other environmentally oriented Directives in many different areas, e.g. air quality, noise, health, etc. INSPIRE harmonized data is also expected to support the principles and data requirements of the Water Information System for Europe (WISE) (water.europa.eu) and its marine component (WISEMarine) (webgate.ec.europa.eu/maritimeforum/ category/554) as well as the Shared Environmental Information System (SEIS) (EC 2008b).

Oneo of the goals of these initiatives is to reduce the level of paper-based reporting required of EU Member States, to be replaced by online reporting using harmonized datasets. Another goal is to enhance the automated data sharing capabilities between Member States and EU institutions, such as different European Commission DirectoratesGeneral (DG Environment, DG Maritime Affairs and Fisheries) and the European Environment Agency (EEA).

The proposed reliance on INSPIRE to support the environmental monitoring and reporting requirements set out in these Directives raises two challenges. Firstly, much of the environmental geospatial information required for reporting, in order to be compliant with the other Directives, is not required to be harmonized under the INSPIRE Directive until between 2015 and 2020, long after that information is needed for both initial and later reporting for some of the Directives. Secondly, the data that is required to be harmonized according to INSPIRE and its Regulations is not always as comprehensive as that required for reporting by the environmental Directives themselves.

\section{INSPIRE AND THE MARINE COMMUNITY}

The INSPIRE Directive addresses 34 data themes that are considered to have a direct of indirect impact on the environment. The full list of themes is shown in Table 1, along with an indication of how relevant each theme may be to the broadly diverse marine/ coastal management and research communities. As you can see, 20 of the 34 data themes covered by INSPIRE are relevant to different marine/coastal management and research communities. Of these, ten are considered to be highly relevant, and deal with what could be considered to be primary marine/ coastal data.

Many of these themes cover data that are needed for monitoring and reporting on different marine, coastal or oceanic environmental themes as required by other EC Directives, as indicated in Table 2. Note that most of these Directives and their implementing EC Regulations pre-date the INSPIRE Directive itself. Their associated reporting monitoring and/or requirements certainly predate the date(s) by which the harmonized data is to be avaialble as a result of INSPIRE implementation, as indicated in the INSPIRE Road Map shown in Table 4.

During development of the data specifications for INSPIRE, the relevant Thematic Working Groups of experts were also to take into consideration the existing requirements of 'international law', as per Article 7 of the Directive: "Where organisations established under international law have adopted relevant standards to ensure interoperability or harmonisation of spatial data sets and services, these standards shall be integrated, and the existing technical means shall be referred to, if appropriate, in the implementing rules mentioned in this 
Scale: 1 = very relevant; 2 = relevant; 3 = less directly relevant

\begin{tabular}{|c|c|}
\hline INSPIRE Directive Data Themes & Relevance \\
\hline \multicolumn{2}{|l|}{ Annex I } \\
\hline $\begin{array}{l}\text { Hydrography - Hydrographic elements, including marine areas and all other water } \\
\text { bodies and items related to them, including river basins and sub-basins. }\end{array}$ & 1 \\
\hline $\begin{array}{l}\text { Protected sites - Area designated or managed within a framework of international, } \\
\text { Community and Member States' legislation to achieve specific conservation objectives. }\end{array}$ & 1 \\
\hline \multicolumn{2}{|l|}{ (marine protected areas?) } \\
\hline $\begin{array}{l}\text { Administrative units - Units of administration, dividing areas where Member States } \\
\text { have and/or exercise jurisdictional rights, for local, regional and national governance, } \\
\text { separated by administrative boundaries. (now proposed to model marine zones in this } \\
\text { theme as opposed to Sea Regions or Area Management) }\end{array}$ & $1 / 7$ \\
\hline $\begin{array}{l}\text { Geographical grid systems - Harmonised multi-resolution grid with a common point } \\
\text { of origin and standardised location and size of grid cells. (for reporting fisheries } \\
\text { statistics and MSFD indicators?) }\end{array}$ & 1 \\
\hline \multicolumn{2}{|l|}{ Annex II } \\
\hline $\begin{array}{l}\text { Elevation - Digital elevation models for land, ice and ocean surface. Includes terrestrial } \\
\text { elevation, bathymetry and shoreline. (shoreline excluded from Elevation - now modelled } \\
\text { in Sea Regions) }\end{array}$ & 1 \\
\hline $\begin{array}{l}\text { Geology - Geology characterised according to composition and structure. Includes } \\
\text { bedrock, aquifers and geomorphology. (seabed sediments modelling; coastal } \\
\text { geomorphology) }\end{array}$ & 1 \\
\hline $\begin{array}{l}\text { Land cover - Physical and biological cover of the earth's surface including artificial } \\
\text { surfaces, agricultural areas, forests, (semi-) natural areas, wetlands, water bodies. }\end{array}$ & 2 \\
\hline \multicolumn{2}{|l|}{ Annex III } \\
\hline $\begin{array}{l}\text { Area management/restriction/regulation zones and reporting units - Areas } \\
\text { managed, regulated or used for reporting at international, European, national, regional } \\
\text { and local levels. Includes dumping sites, restricted areas around drinking water sources, } \\
\text { nitrate-vulnerable zones, regulated fairways at sea or large inland waters, areas for the } \\
\text { dumping of waste, noise restriction zones, prospecting and mining permit areas, river } \\
\text { basin districts, relevant reporting units and coastal zone management areas. }\end{array}$ & 1 \\
\hline $\begin{array}{l}\text { Agricultural and aquaculture facilities - Farming equipment and production } \\
\text { facilities. }\end{array}$ & 1 \\
\hline $\begin{array}{l}\text { Environmental monitoring facilities - Location and operation of environmental } \\
\text { monitoring facilities includes observation and measurement of emissions, of the state of } \\
\text { environmental media and of other ecosystem parameters (biodiversity, ecological } \\
\text { conditions of vegetation, etc.) by or on behalf of public authorities. }\end{array}$ & 2 \\
\hline $\begin{array}{l}\text { Natural risk zones - Vulnerable areas characterised according to natural hazards (all } \\
\text { atmospheric, hydrologic, seismic, volcanic and wildfire phenomena that, because of } \\
\text { their location, severity, and frequency, have the potential to seriously affect society), } \\
\text { e.g. floods, landslides and subsidence, avalanches, forest fires, earthquakes, volcanic } \\
\text { eruptions. }\end{array}$ & 2 \\
\hline $\begin{array}{l}\text { Oceanographic geographical features - Physical conditions of oceans (currents, } \\
\text { salinity, wave heights, etc.). }\end{array}$ & 1 \\
\hline $\begin{array}{l}\text { Sea regions - Physical conditions of seas and saline water bodies divided into regions } \\
\text { and sub-regions with common characteristics. }\end{array}$ & 1 \\
\hline $\begin{array}{l}\text { Energy resources - Energy resources including hydrocarbons, hydropower, bio- } \\
\text { energy, solar, wind, etc., where relevant including depth/height information on the } \\
\text { extent of the resource. (offshore wind farms) }\end{array}$ & 2 \\
\hline $\begin{array}{l}\text { Mineral resources - Mineral resources including metal ores, industrial minerals, etc., } \\
\text { where relevant including depth/height information on the extent of the resource. (off } \\
\text { shore extraction) }\end{array}$ & 2 \\
\hline $\begin{array}{l}\text { Habitats and biotopes - Geographical areas characterised by specific ecological } \\
\text { conditions, processes, structure, and (life support) functions that physically support the } \\
\text { organisms that live there. Includes terrestrial and aquatic areas distinguished by } \\
\text { geographical, abiotic and biotic features, whether entirely natural or semi-natural. }\end{array}$ & 2 \\
\hline $\begin{array}{l}\text { Species distribution - Geographical distribution of occurrence of animal and plant } \\
\text { species aggregated by grid, region, administrative unit or other analytical unit. (relevant } \\
\text { to MSFD reporting) }\end{array}$ & 2 \\
\hline Bio-geographical regions - Areas of relatively homogeneous ecological conditions & 3 \\
\hline with common characteristics. & \\
\hline $\begin{array}{l}\text { Utility and governmental services - Includes utility facilities such as sewage, waste } \\
\text { management, energy supply and water supply, administrative and social governmental } \\
\text { services such as public administrations, civil protection sites, schools and hospitals. }\end{array}$ & 2 \\
\hline $\begin{array}{l}\text { Production and industrial facilities - Industrial production sites, including } \\
\text { installations covered by Council Directive } 96 / 61 / \text { EC of } 24 \text { September } 1996 \text { concerning } \\
\text { integrated pollution prevention and control and water abstraction facilities, mining, } \\
\text { staprage sites. }\end{array}$ & 2 \\
\hline
\end{tabular}


Table 2: EU Directives, Decisions and Communications impacting the marine/coastal environments and related environmental information initiatives (date order)

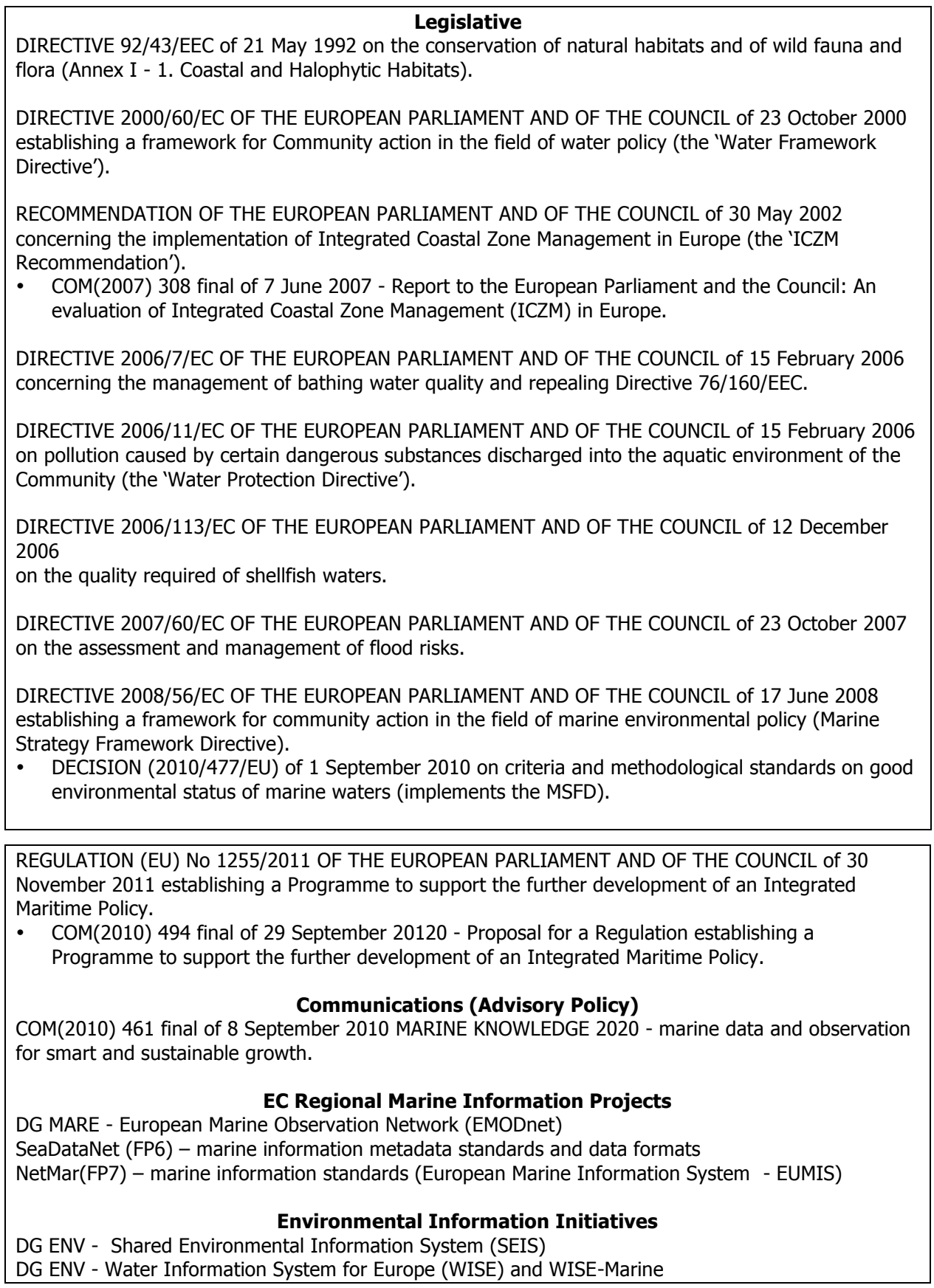

paragraph." (EC 2007a, 6). This has proven to be difficult, given the number of such conventions that exist in the marine arena, as indicated in Table 3.

\section{INSPIRE IMPLEMENTATION ROADMAP}

The INSPIRE Directive was the result of preliminary environmental SDI work that began in 2000. The Directive was published in 2007 and all EU Member States were required to implement the Directive in national legislation by May 2009. All have now done so, however, many Member States have yet to even completely update the metadata for the Annex I and II datasets, which was required by end of December 2010.

Table 4 shows the date by which the INSPIRE Implementing Rules (IR) for the 25 Annex II and III data themes will be promulgated in 2013 as an amendment to the existing EC Regulation (EC 2010), which entered into force on 28 December 2010. Note that data reporting requirements for 
Table 3: International Marine/Maritime Treaties and Conventions affected by data being harmonised in INSPIRE and other initiatives.

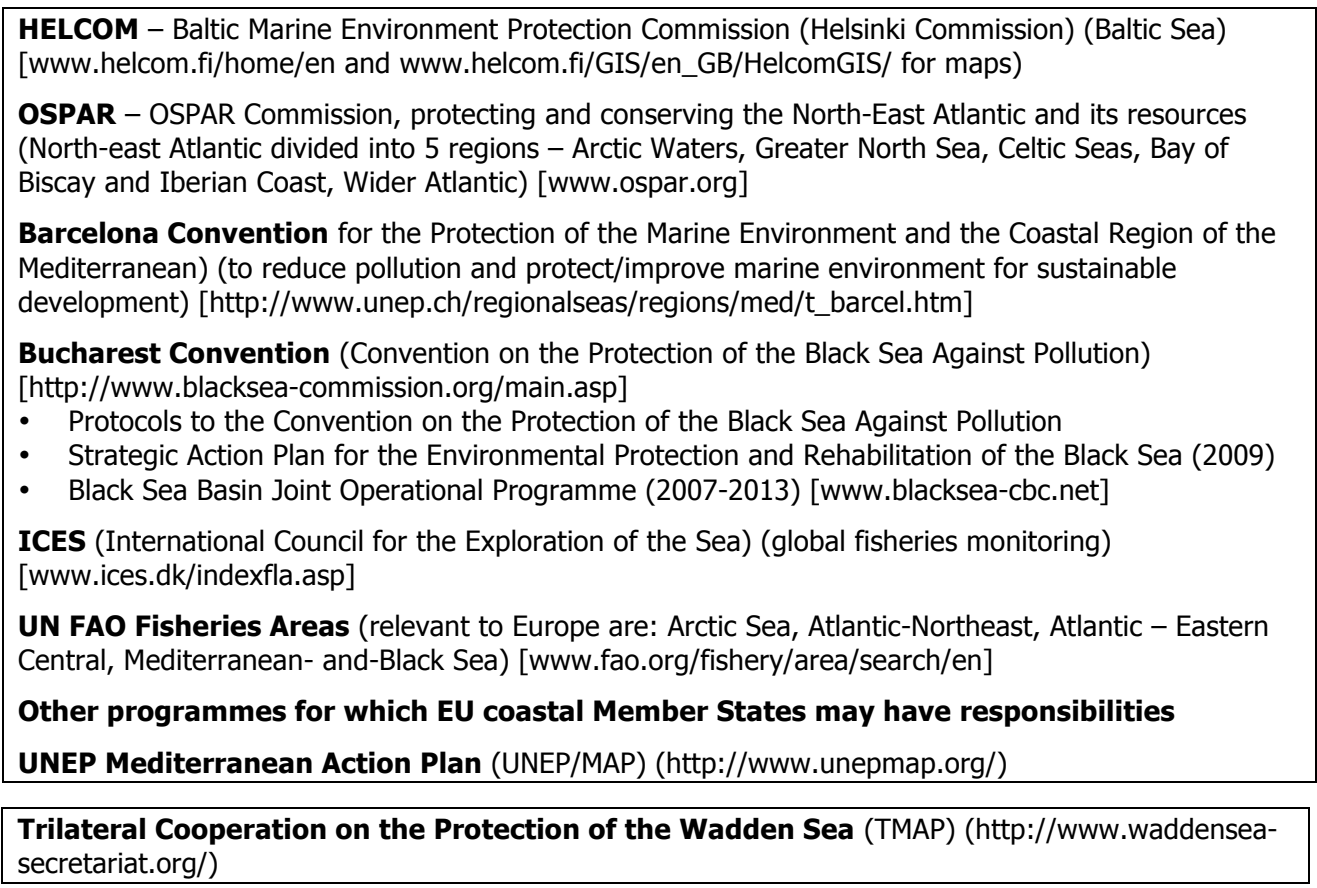

many of the Directives mentioned in the introduction occur prior to the INSPIRE harmonised data being available, under this roadmap.

The latest information on the INSPIRE implementation roadmap can be found at: http:// inspire.jrc.ec.europa.eu/index.cfm/pageid/44.

\section{RELATIONSHIPS BETWEEN INSPIRE AND OTHER DIRECTIVES}

Because the Water Framework Directive predated INSPIRE by many years, and also was the first EU Directive to include specific geographic information formats for reporting, its requirements were taken into consideration very well during development of the INSPIRE data specifications, especially for Hydrography and Area Management. Even so, there is talk that a future revision to the WFD will be needed and/or further extensions to INSPIRE in order to achieve the desired level of harmonised reporting envisioned when INSPIRE was proposed.

INSPIRE faces a similar challenge with regard to the Marine Strategy Framework Directive for which the initial assessment reports of Good Environmental Status are due by mid-October this year (2012), yet much of the data needed in harmonised format is not required by INSPIRE until October 2015 or even October 2020. An analysis carried out during development of the INSPIRE data specification for Area Management indicated that some of the attributes required for MSFD reporting are not in current (version 3.0 - final) INSPIRE data specifications for the relevant themes. Also, some of the INSPIRE themes required are in Annex I and others are in Annex II or III, while compliance deadlines for data harmonisation in Annex I, II and III are different.

The Flood Risk Assessment Directive of 2007 sets out the timetable for compliance in Chapters VI and VIII. Chapter VI states "Member States shall ensure that flood risk management plans are completed and published by 22 December 2015." (EC 2007b, 31) while Chapter VIII states (EC 2007b, 33):

- "preliminary flood risk assessment ... shall be reviewed by 22 December 2018 ..."

- "flood hazard maps and the flood risk maps shall be reviewed by 22 December 2019 ..."

- "flood risk management plan(s) shall be reviewed by 22 December 2021 ".

This is one case where it is possible that harmonised, INSPIRE compliant data may be available in a 


\begin{tabular}{|c|l|}
\hline Dates & \multicolumn{1}{|c|}{ Actions/Deliverables } \\
\hline & Adoption Roadmap \\
\hline 22 Sept 2012 & $\begin{array}{l}\text { Inter-service consultation of the draft Implementing Rules for INSPIRE Annex II and } \\
\text { III Data Specifications at the European Commission. }\end{array}$ \\
\hline 15 Oct 2012 & Draft IR/Regulation is sent to the INSPIRE Committee for review/approval. \\
\hline October 2013 & $\begin{array}{l}\text { Adoption of IRs for the interoperability of spatial data sets and services for Annex II } \\
\text { and III spatial data themes. }\end{array}$ \\
\hline & Implementation Roadmap \\
\hline 23-Nov-2012 & $\begin{array}{l}\text { Annex I spatial data sets to be available according to Commission Regulation (EU) } \\
\text { No 1089/2010 for existing data (9 data themes, including Hydrography) }\end{array}$ \\
\hline 28-Dec-2012 & Download \& Transformation services to be fully operational \\
\hline 04-Feb-2013 & $\begin{array}{l}\text { Annex I spatial data sets to be available according to Commission Regulation (EU) } \\
\text { No 1089/2010 for newly collected and extensively restructured Annex I spatial data } \\
\text { sets (9 themes) }\end{array}$ \\
\hline 03-Dec-2013 & Metadata available for spatial data sets and services corresponding to Annex III \\
\hline October 2015 & $\begin{array}{l}\text { Newly collected and extensively restructured Annex II and III spatial data sets to be } \\
\text { available (25 data themes) }\end{array}$ \\
\hline 23-Nov-2017 & $\begin{array}{l}\text { Annex I spatial data sets to be available according to Commission Regulation (EU) } \\
\text { No 1089/2010 and Commission Regulation (EU) No 102/2011 of 4 February 2011 for } \\
\text { spatial data sets still in use at the date of adoption (9 themes) }\end{array}$ \\
04-Feb-2018 & $\begin{array}{l}\text { Other Annex II and III spatial data sets available in accordance with Implementing } \\
\text { Rules for Annex II and III data sets (25 data themes) }\end{array}$ \\
\hline October 2020
\end{tabular}

timely manner, but determining whether all the data needed for such reporting is covered by INSPIRE is not as easily determined.

WISE-Marine is intended to be a "comprehensive and shared European data and information management system for the marine environment which supports implementation of the Marine Strategy Framework Directive. This will also include the use of the EMODnet and INSPIRE processes to establish the required infrastructure and data access." (EC DG Maritime Affairs 2012). As WISE-Marine is a 'work in progress', and tied in to other reporting requirements, we cannot at this time realistically judge the impact that INSPIRE will have on success of the initiative.

EMODnet has been developing in parallel with INSPIRE, but not always in full concurrence, as the developers of EMODnet see a need for many more data attributes in a range of marine areas than have been considered in developing the INSPIRE data specifications.

\section{CONCLUSION}

One of the key challenges faced in using INSPIRE data and interoperable services is the timing mismatch between the dates by which INSPIRE data is to be available in a harmonized format and the dates by which existing Directives or Regulations already require reporting to be completed. Also, because the individual data specifications resulted in attributes (or features) to satisfy, in some cases, a wide range of users or sectors, even within a single theme, the final INSPIRE specification may not be sufficiently inclusive to permit the degree of paperless, online reporting envisioned by the SEIS or WISE-Marine initiatives, such as EMODnet. Possible solutions to the data challenges posed by attempts at pan-European data harmonisation and services interoperability will continue to be a challenge for the marine community throughout the coming decade - and perhaps longer.

\section{REFERENCES}

EC DG Maritime Affairs. 2012a. EMODnet European Marine Observation and Data Network. https://webgate.ec.europa.eu/maritimeforum/ category/160.

EC DG Maritime Affairs. 2012b. WISE-Marine. https://webgate.ec.europa.eu/maritimeforum/ category $/ 554$. 
EC, European Commission. 2000. Directive 2000/60/EC of the European Parliament and of the Council establishing a framework for the Community action in the field of water policy. Official Journal of the European Union, OJ L 327, 22/12/2000.

http://eur-lex.europa.eu/LexUriServ/LexUriServ.do? uri=OJ:L:2000:327:0001:0072:EN:PDF.

EC, European Commission. 2007a. Directive 2007/2/EC of the European Parliament and of the Council of 14 March 2007 establishing an Infrastructure for Spatial Information in the European Community (INSPIRE). Official Journal of the European Union, OJ L 108, 25/04/2007. http://eur-lex.europa.eu/LexUriServ/LexUriServ.do? uri=OJ:L:2007:108:0001:0014:EN:PDF.

EC, European Commission 2007b. Directive 2007/60/EC of the European Parliament and of the Council of 23 October 2007 on the assessment and management of flood risks. Official Journal of the European Union, OJ L 288, 6/11/2007. http://eur-lex.europa.eu/LexUriServ/LexUriServ.do? uri=OJ:L:2007:288:0027:0034:en:pdf

EC, European Commission. 2008a.Directive 2008/56/EC of the European Parliament and of the Council of 17 June 2008 establishing a framework for community action in the field of marine environmental policy (Marine Strategy Framework Directive). Official Journal of the European Union, OJ L 164, 25/6/2008.

http://eur-lex.europa.eu/LexUriServ/LexUriServ.do? uri=OJ:L:2008:164:0019:0040:EN:PDF

EC, European Commission. 2008b. Communication from the Commission to the Council, the European Parliament, the European Economic and Social Committee and the Committee of the Regions Towards a Shared Environmental Information System (SEIS). COM (2008) 46 final, Brussels, $1 / 2 / 2008$.

http://eur-lex.europa.eu/LexUriServ/LexUriServ. do?uri=COM:2008:0046:FIN:EN:PDF

EC, European Commission. 2010. EC Regulation 1089/2010 of 23 November 2010 implementing Directive 2007/2/EC of the European Parliament and of the Council as regards interoperability of spatial data sets and services published on 8 December
2010. Official Journal of the European Union, OJ L $323,8 / 12 / 2010$.

http://eur-lex.europa.eu/LexUriServ/LexUriServ.do? uri=OJ:L:2010:323:0011:0102:EN:PDF

\section{BIOGRAPHIES}

Roger LONGHORN is Information Policy Advisor to the Coastal \& Marine Union (EUCC), lecturer on Marine SDI and communications at the UNESCO Intergovernmental Oceanographic Commission's Ocean Teacher Academ, and an expert in SDI development in the EU and globally since 1995. A graduate of the Massachusetts Institute of Technology in Ocean Engineering (BSc) and Shipping Management (MSc), Roger has long association with the marine transport and science communities since 1976 and represents EUCC on the INSPIRE Thematic Working Group 'Area Management' developing the data specifications for the INSPIRE Directive, including coastal zone management.

\section{CONTACT DETAILS}

\section{Roger LONGHORN}

The Coastal \& Marine Union (EUCC)

Fazantenlaan 24

Bredene

BELGIUM

Tel.: +32 59435396

Fax: +32 59795228

Email: ral@alum.mit.edu

Web site: www.eucc.net

\section{I64 | Hydrol 2}




\title{
Managing bathymetric data in a hydrographic survey company and making the data accessible to clients
}

\author{
Duncan MALLACE, United Kingdom \\ NetSurvey Limited \\ Tim KEARNS, United States of America \\ ESRI Inc.
}

Topics: Innovations in processing techniques, Smart data management, Easy customer access to data and products, Careful marine planning

\section{ABSTRACT \\ As data volumes increase, managing the large hydrographic datasets is not limited to the world's hydrographic offices. The hydrographic survey companies contracted to carry out the surveys need to be able to store their data in an easily accessible, spatial and quick manner. They also need to be able to serve their data to clients via The Cloud. This demand is being increasingly seen across all the survey sectors, from Oil and Gas through to Offshore Renewables, Hydrography through to Coastal Surveys.}

MMT Group (NetSurvey and MMT combined) have almost 1 Petabyte of survey data that was stored, like most survey companies, in a flat, file server-based setup. Trying to find one particular survey was particular challenging and trying to find consecutive surveys was almost impossible. NetSurvey and MMT have performed hydrographic surveys for the Maritime \& Coastguard Agency (MCA) in the UK, the Mareano Project for the Norwegian Hydrographic Service and also the Swedish and Finnish Maritime Administrations. The MCA surveys are both large in area and, for the Routine Re-Survey Contract, in time (over seven years). We wanted a system that would not only store bathymetry but also sediment types, digital video, survey reports and sub-bottom data. The Esri Bathymetric Information System (BIS) is a database specifically designed for this type of requirement and is accessed through the well-known and easily used Esri ArcGIS software. The Esri products also have the capability to serve the data either publicly or privately (to select clients and internally) via a simple web interface.

\section{INTRODUCTION}

For a spatially knowledgeable industry we have a very flat approach to storing our data.

MMT Group conducts high resolution surveys in the fields of Hydrography, Oil \& Gas Exploration, Offshore Renewable Energy and Cable industries. As the technology improves, so do the data quantities. Companies keep adding more storage capacity to their servers but this increase in the number and size of the servers creates a new problem. The data might be grouped by year or industry, but most likely it is collated into folders named after the project number, Hydrographic Instruction, Date or maybe all three. How do you go about finding the surveys you performed off East Anglia for instance in the last three years? If we bid for a survey tender it is very useful to be able to bring in the bounds of the survey area and see if it is adjacent or nearby to a previous survey. Metrics such as weather downtime and seabed sediment type can then be used to streamline the tender. Spatially viewing the datasets allows us to realise where datasets are. What we do not want to do though is duplicate our already huge datasets.

In nearly all of the survey sectors that we work in a GIS deliverable is becoming more common. In the vast majority of client's specifications, that GIS deliverable is an Esri ArcGIS geodatabase. Sometimes clients have their own geodatabase format to use (for example NordStream) but with ArcGIS 10.1 the use of data models as templates for deliverables is becoming more common. Examples of this are the Seabed Survey Data Model 
(developed by the OGP Geomatics Committee (formerly EPSG) and the ArcMarine datamodel for Habitat Surveys. Obviously it is much easier to produce an ArcGIS deliverable when you can access all your data from within ArcGIS products.

Another common factor between the different sectors is that the survey area size is becoming larger and the resolution of the final product is becoming higher. This stretches the limits of computing hardware to the maximum and one of the reasons for adopting the Esri Maritime Bathymetry solution is that it makes it possible to combine very large, very high resolution datasets and geospatial tools (like contouring and slope calculations) across the whole dataset and not just on individual elements. This saves time and complexity.

This extended abstract explains what the BIS is, how the BIS was built and setup at MMT Group and how we use it to produce products and future plans.

\section{BATHYMETRIC INFORMATION SYSTEM}

Bathymetric Information System (BIS) is a commercial enterprise GIS system for the management and deployment of bathymetric data, products and related information. It includes specialised schemas, metadata engine, functionality for ingestion of data and the ability to query, filter and compose continuous bathymetric surfaces based upon a user specified model. As well, the BIS supports workflows, integration with complementary applications, and the ability to generate image and map services within a service-oriented architecture and a commercially available web application for query and dissemination.

ArcGIS for Maritime: Bathymetry can be used for;

- Managing bathymetric data from a central geodatabase

- Storing and querying gridded bathymetric datasets and creating custom surfaces from them

- Creating and managing collections of bathymetric datasets

- Managing metadata for Bathymetric Attributed Grids (BAGs) from the Open Navigation Surface project for collections of datasets, or managing any custom metadata associated with the datasets

- Creating and storing custom bathymetric surfaces

- Extracting depth values from bathymetric surfaces

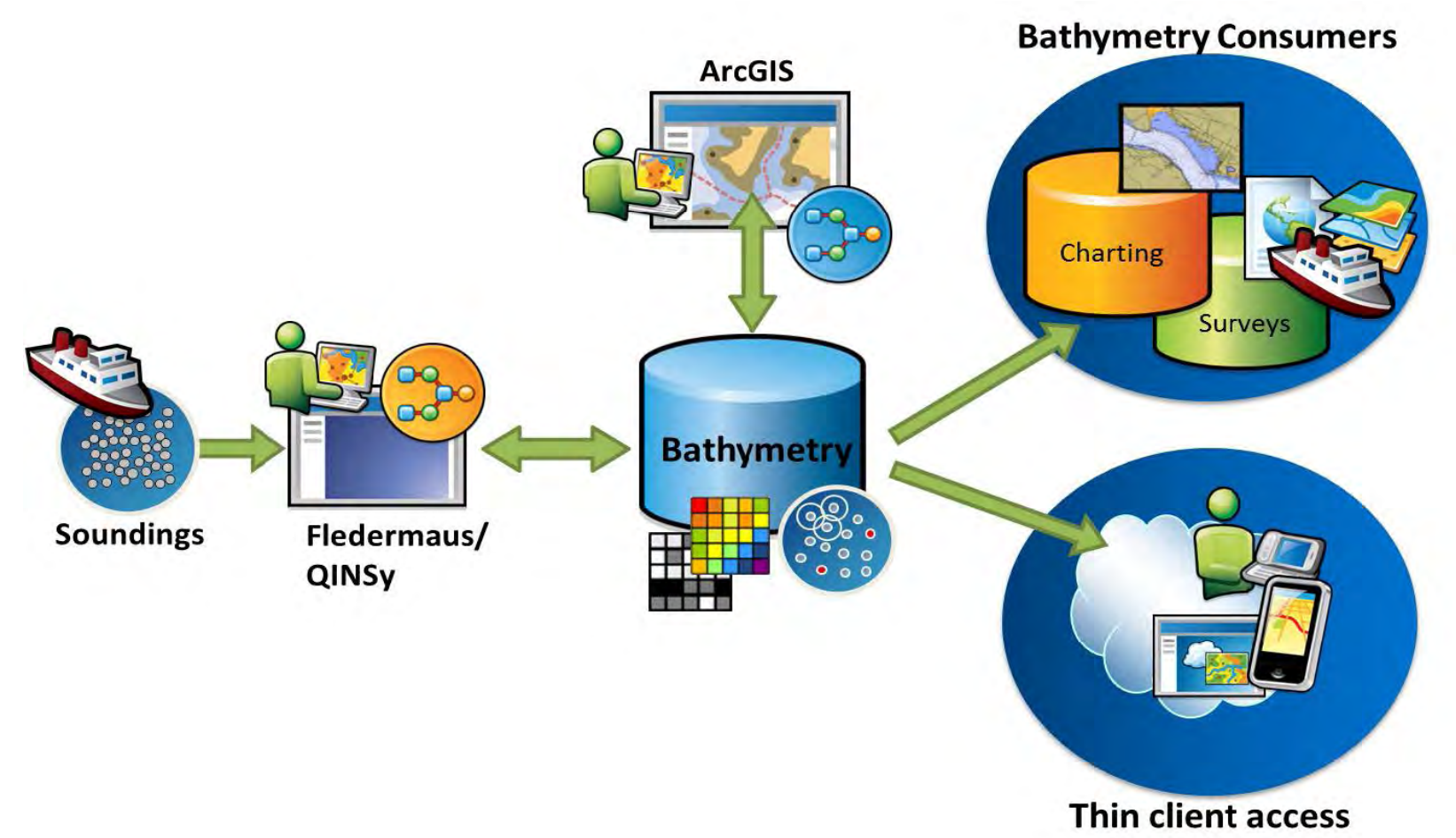

Figure 1: The Esri/QPS Bathymetric Information System is designed to handle large volumes of vector and gridded data that leverages an enterprise GIS platform. This includes integration with spatial and non-spatial databases, production environments and cloud computing. 
The primary objectives of such a system is to manage post-processed soundings and depths, ancillary information about the hydrographic survey (report, survey area, tidal adjustment reports, sound velocity cast reports, navigation lines, other supporting information), metadata about surveys, vector and gridded data and the storage and dissemination of bathymetric gridded data. An enterprise system must also be able to easily communicate in a service-oriented architecture via published feature and map services, integration with other geospatially enabled databases and consuming other data feeds through mash-ups and crowd sourcing.

The main architectural components of the BIS are common in the GIS industry. Complementary technology, QPS Fledermaus \& QINSy, serves as the primary ingest engine for survey related content in both vector and gridded data format. Reading and writing directly to the Esri geodatabase allows for a seamless flow of high density survey data through a quality control and visualisation application before it's appended to a central geodatabase. Once the bathymetric data is processed and cleaned it is managed from a central geodatabase by the Esri mosaic dataset data type. The mosaic dataset allows for bathymetric data to remain unaltered and unduplicated.

Using a bathymetric geodatabase brings many advantages to maritime GIS users. They can maintain a historical archive for comparing legacy survey data with modern data and updated charts.
They can also leverage bathymetric data by using it with other databases for a wide range of purposes, such as oceanography, coastal zone management, and meteorology that require seafloor information. In addition, users can easily edit their nautical products based on new and updated bathymetric information.

\section{BUILDING THE BIS}

Figure 2 below shows the fileserver setup in NetSurvey's office and will be common to most companies as to how they store their survey data. The storage keeps getting added to as the surveys come in and within each storage system the data is stored in folders named by project number. This is a good way of storing the data and absolutely essential for efficient file management. However, it is not a good way to view the data or to retrieve it.

One of the main reasons for MMT Group choosing the Esri Bathymetric Information System rather than some rival solutions is that it does not replicate the data by ingesting it into the geodatabase. Rather it maintains a link to the data within our existing file server network. Our completed surveys are archived in the Bathymetric Attributed Grid Format (BAG). The BAG is the highest resolution digital terrain model that can be obtained from the data and is normally the client's deliverable cell size as well. We create the BAG from within our QPS Fledermaus application (fig 3). It is a simple one button push and then a metadata field editor where additional information can be added. The fields are limited, as

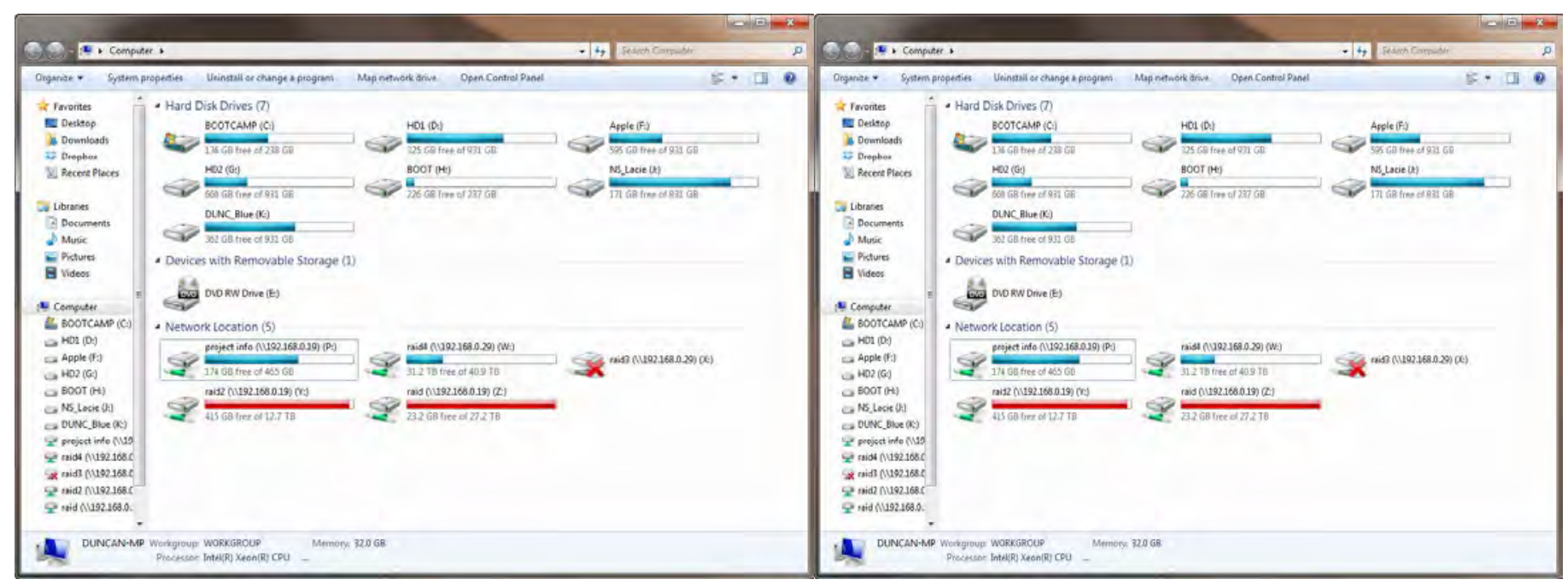

Figure 2: NetSurvey's folder example folder structure (left) and the RAID 4 structure (right). 


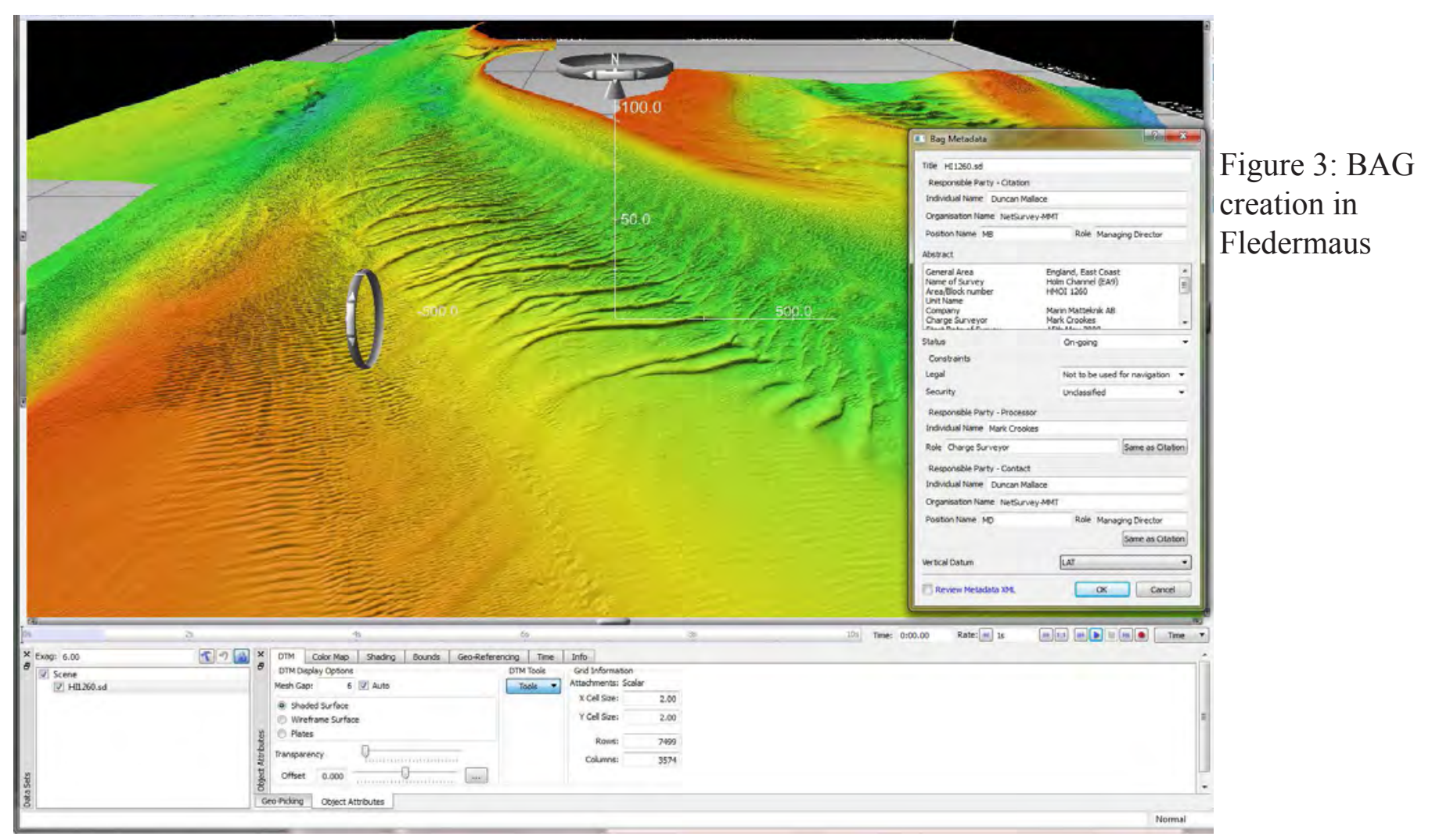

it is part of the BAG format, but more metadata can be added as External Metadata within ArcGIS later.

The BAG format is open source and compressed so it makes for efficient data storage and long term viability. It also contains information pertaining to the accuracy of the data as an Uncertainty layer.

MMT Group wanted to have a system that was easy to use, didn't require any special server structure and allowed for future expansion and progression. The BIS can be run as a standalone File Geodatabase or as an Enterprise ArcSDE Geodatabase. One of the benefits of ArcGIS is that it can run on any number of different types of database, so depending on your company's skill set you can choose to run it on Microsoft SQL, PostgreSQL, Oracle, etc.. or as a humble file. Esri's spatial toolset runs on top of all of these. The other packages that MMT Group looked at all had to run on a dedicated Oracle or PostgreSQL server which involved much more back office IT resources and skill set.

Creating the BIS was quite simple. It is all performed from the ArcMap interface, which is familiar to anyone who has used ArcGIS as this is

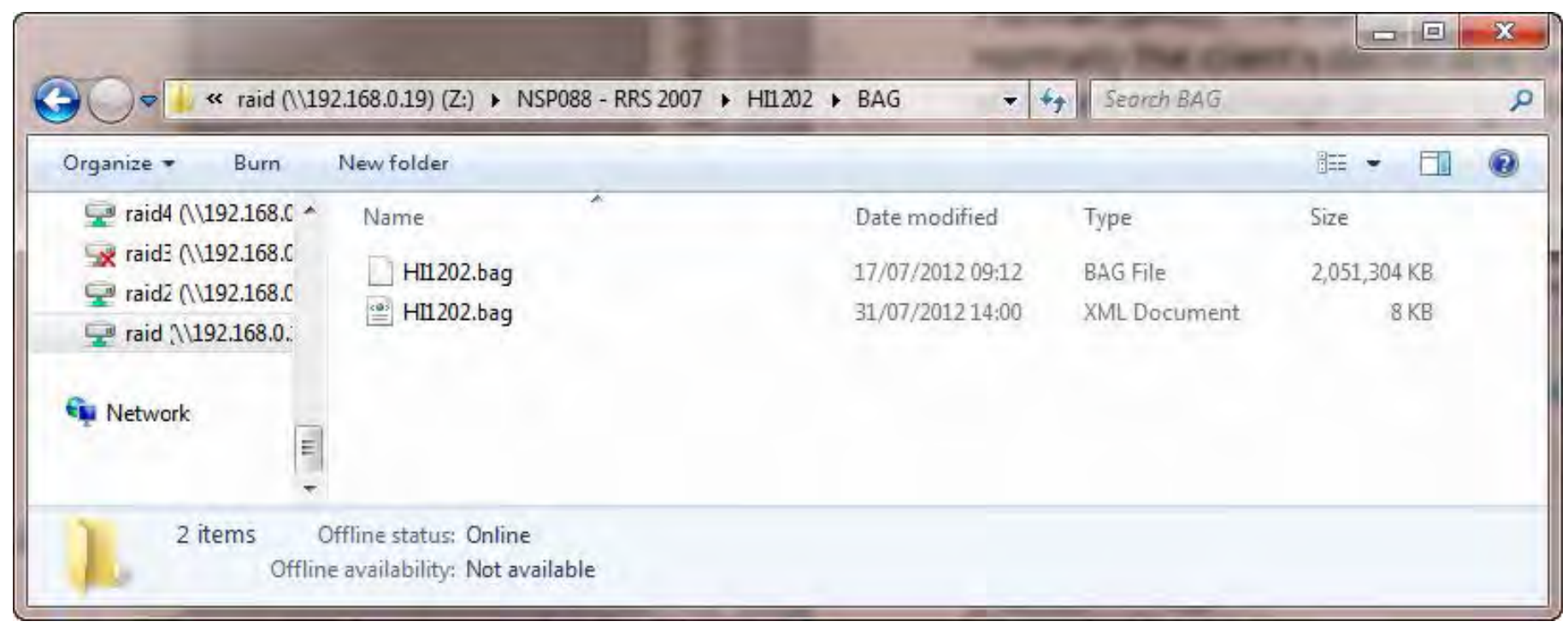

Figure 4: Image showing BAG example within file server 


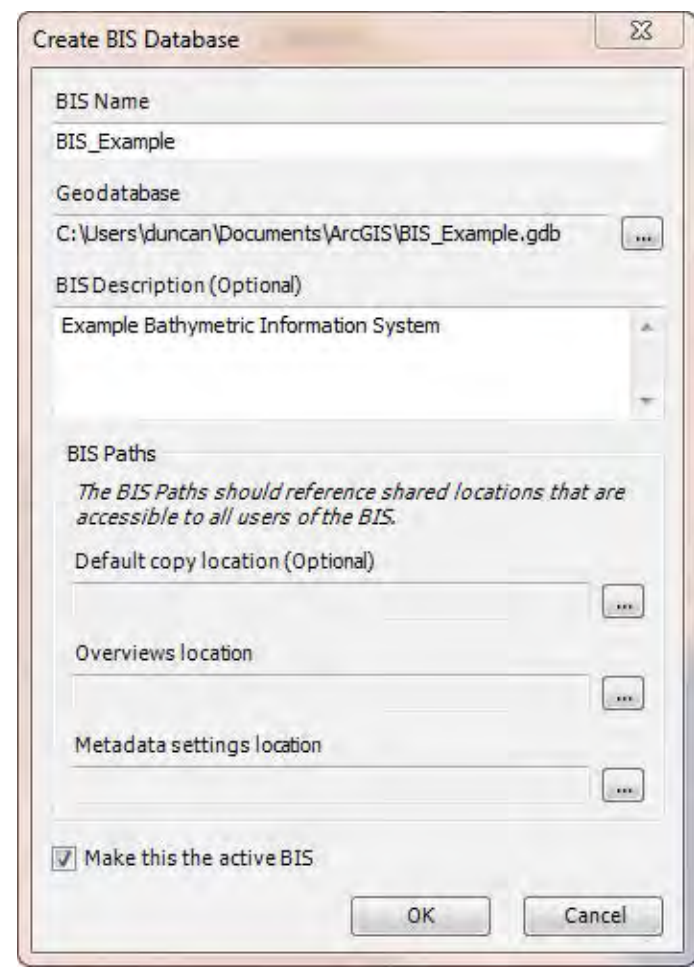

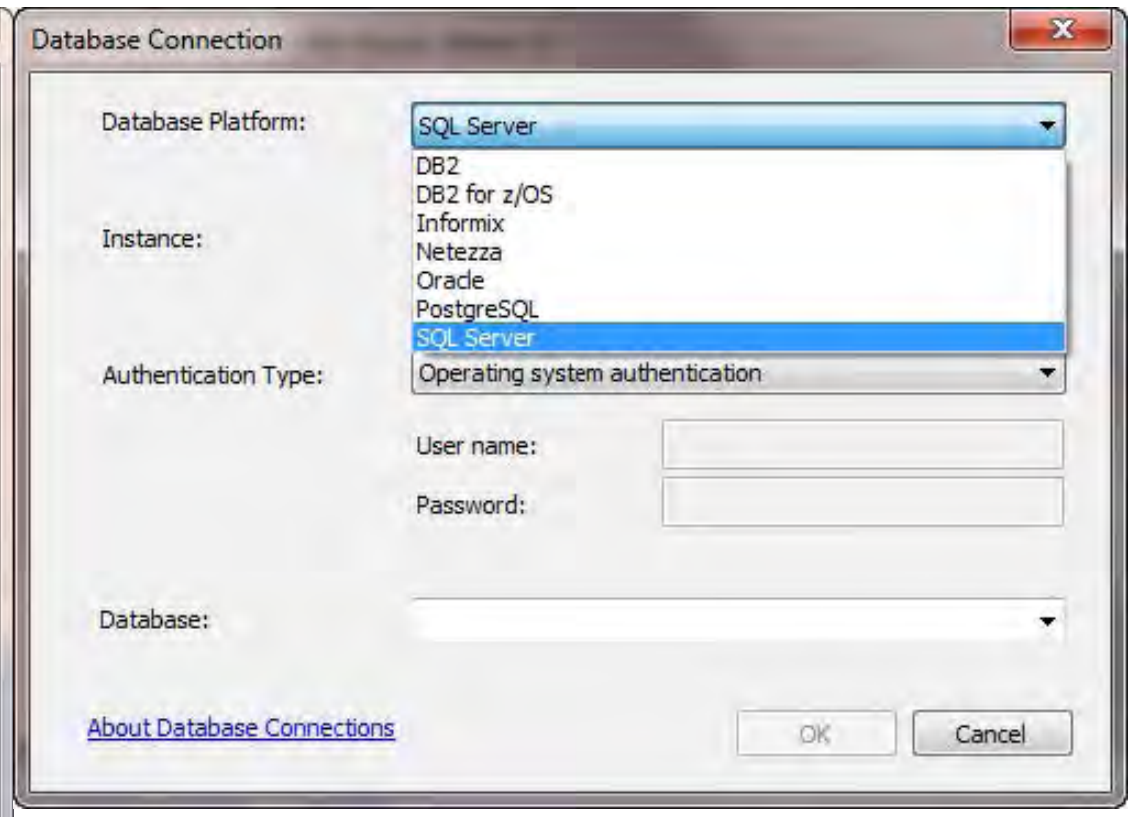

Figure 5: Images showing the dialogue boxes to create a BIS

the application where everything is built. All the tools available with the Bathymetry Solution are accessible from the Bathymetry toolbar. The Create $B I S$ button is selected and the dialogue box in Figure 5 appears, giving the user the option to name, add metadata and select the type of geodatabase to use for the BIS. This then creates an empty BIS to which bathymetric data can be added.

Once established we then created some collections within the database. A collection is a set of associated surveys. We created collections based on specific survey programmes, geographical areas and specific projects. This doesn't limit the functionality in any way but allows for quickly retrieving data sets and also for adding additional metadata to the collections. In Figure 6 you can see that we have a collection based on our surveys around the Orkney Islands. The metadata that includes overviews of the individual surveys can be viewed and the individual metadata for a particular survey can be seen.

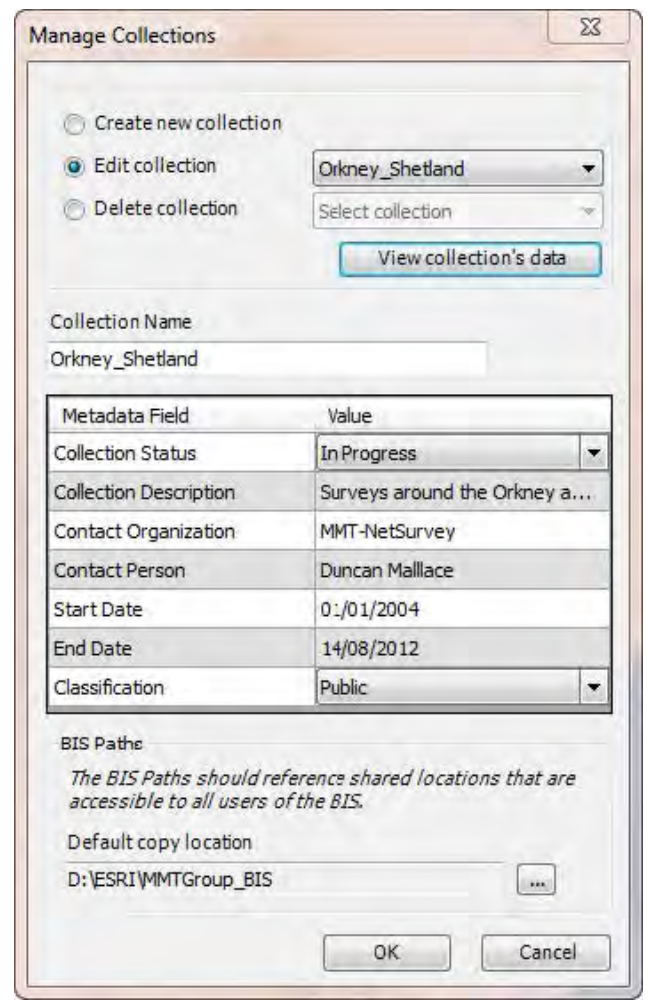

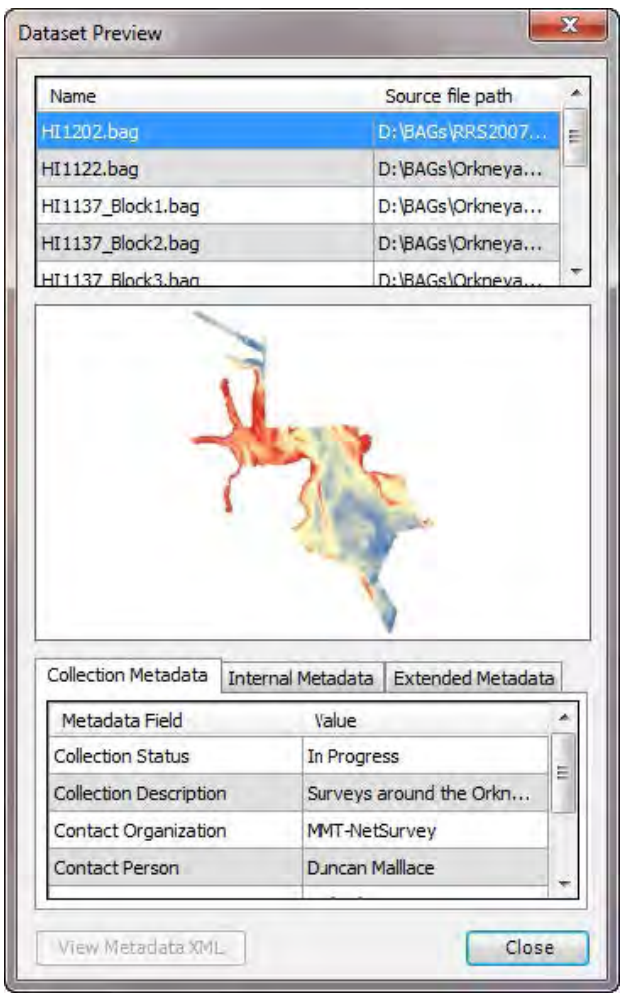

Figure 6: Images

showing BIS

Collections and a

Collection's dataset 


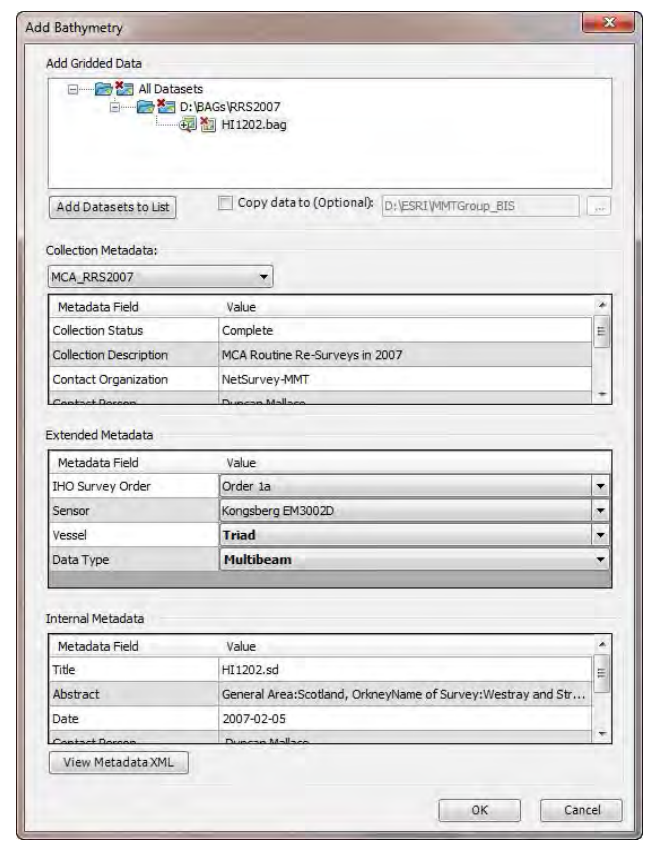

Figure 7: Adding a BAG to the BIS

Once the collections have been created the BAG that is stored on the storage server can be linked into the BIS. One of the main advantages of the BIS is that the geodatabase can leverage Esri's mosaic dataset data type, which links gridded data stored on-disk to its supporting tables in the BIS geodatabase. This data structure eliminates the need to duplicate data storage on-disk and in a database; with the Bathymetry extension, gridded surface data is stored only once on-disk and is accessed through the mosaic dataset through Bathymetry tools. When we import a BAG into the BIS it automatically contains the Internal Metadata that was input when we created the BAG. The Collection Metadata is associated with the BAG when we choose the collection to add it in to and we also add in additional metadata for the vessel name, type of equipment, IHO order and specific sensor. All of these various metadata fields can be used as a basis for rules when it comes to creating a continuous surface combing these BAGS (figure 7).

\section{USING THE BIS}

With the data in the BIS it is now possible to explore areas, create continuous surfaces, run analytical tools on the data and bring the data into 3D visualisation tools, such as QPS Fledermaus.

One of the main reasons for choosing the BIS was to view our surveys spatially. We have used the Esri Ocean Basemap to provide background information and for specific areas we have added in the S57 cells too. To view the surveys that we have performed in Morecambe Bay is as simple as zooming into the area on the Base Map and showing all surveys within the bounds of the screen (figure 8).

This can be further narrowed down to show a specific vessel's data or types of data. In figure 9 just

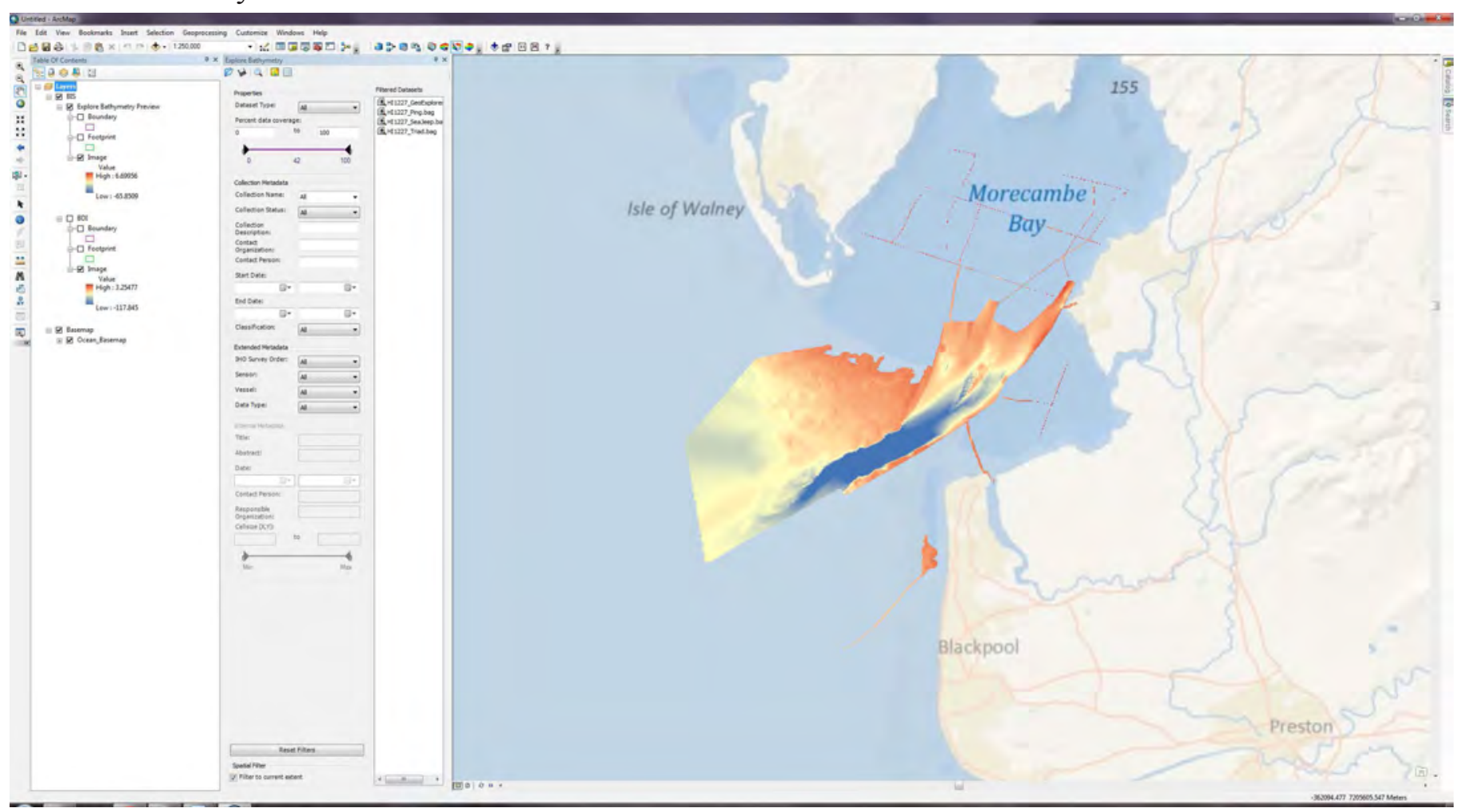

Figure 8: Viewing surveys within certain bounds. 


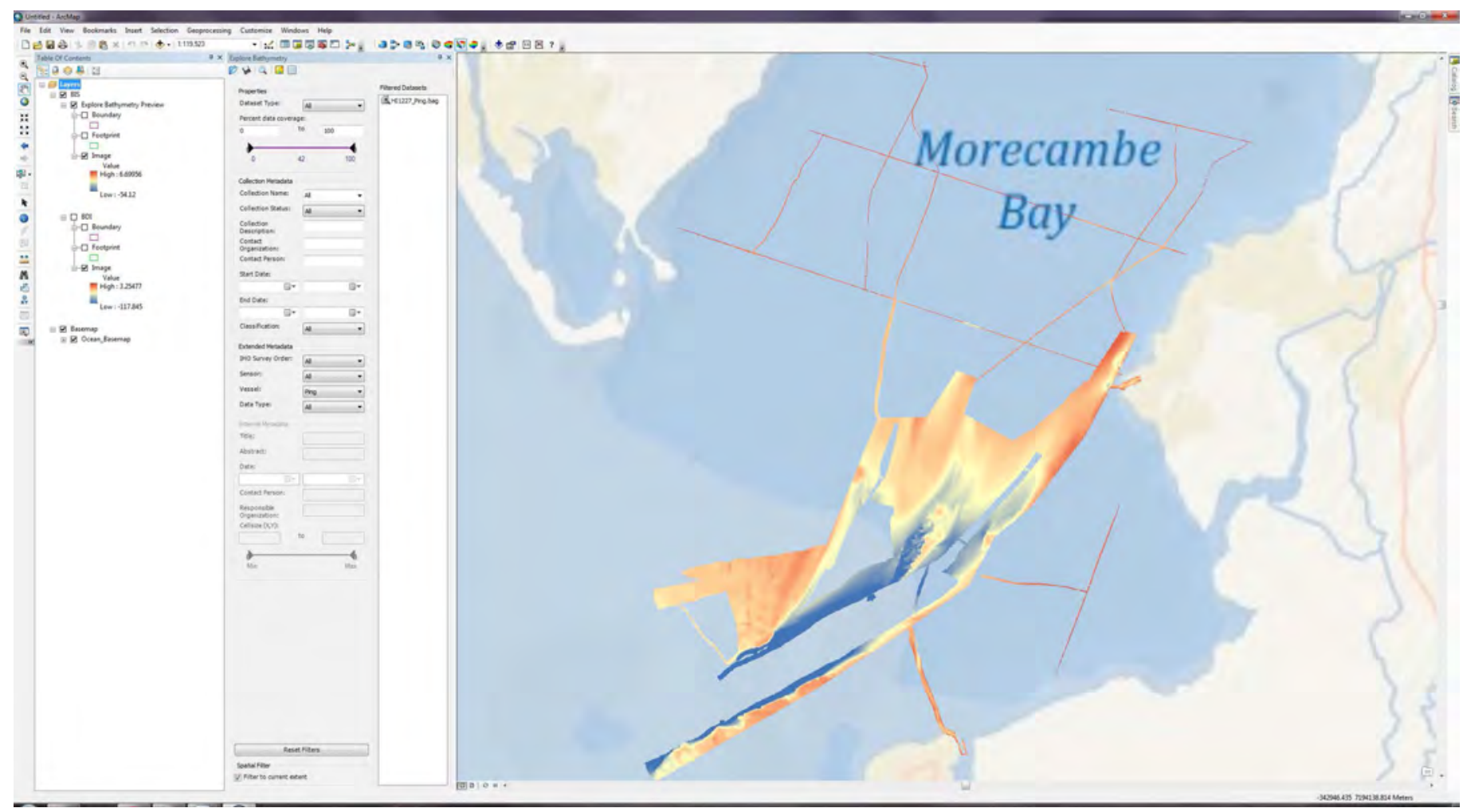

Figure 9: SV Ping's data shown

the surveyed area covered by our survey vessel Ping is shown. This performed just by simple drop down lists containing the different metadata headers.

Being able to view previous surveys is really useful for tendering purposes. Figure 10 shows the surveys in our BIS around the Orkneys. The images of the surveys are shown as mosaic datasets which have pyramid tiles, so as you zoom in the resolution increased. Within this dataset shown we have digital terrain models at $1 \mathrm{~m}, 2 \mathrm{~m}$ and $5 \mathrm{~m}$ resolution, there is no single cell size required and the cell sizes are determined by the original BAG's cell size.

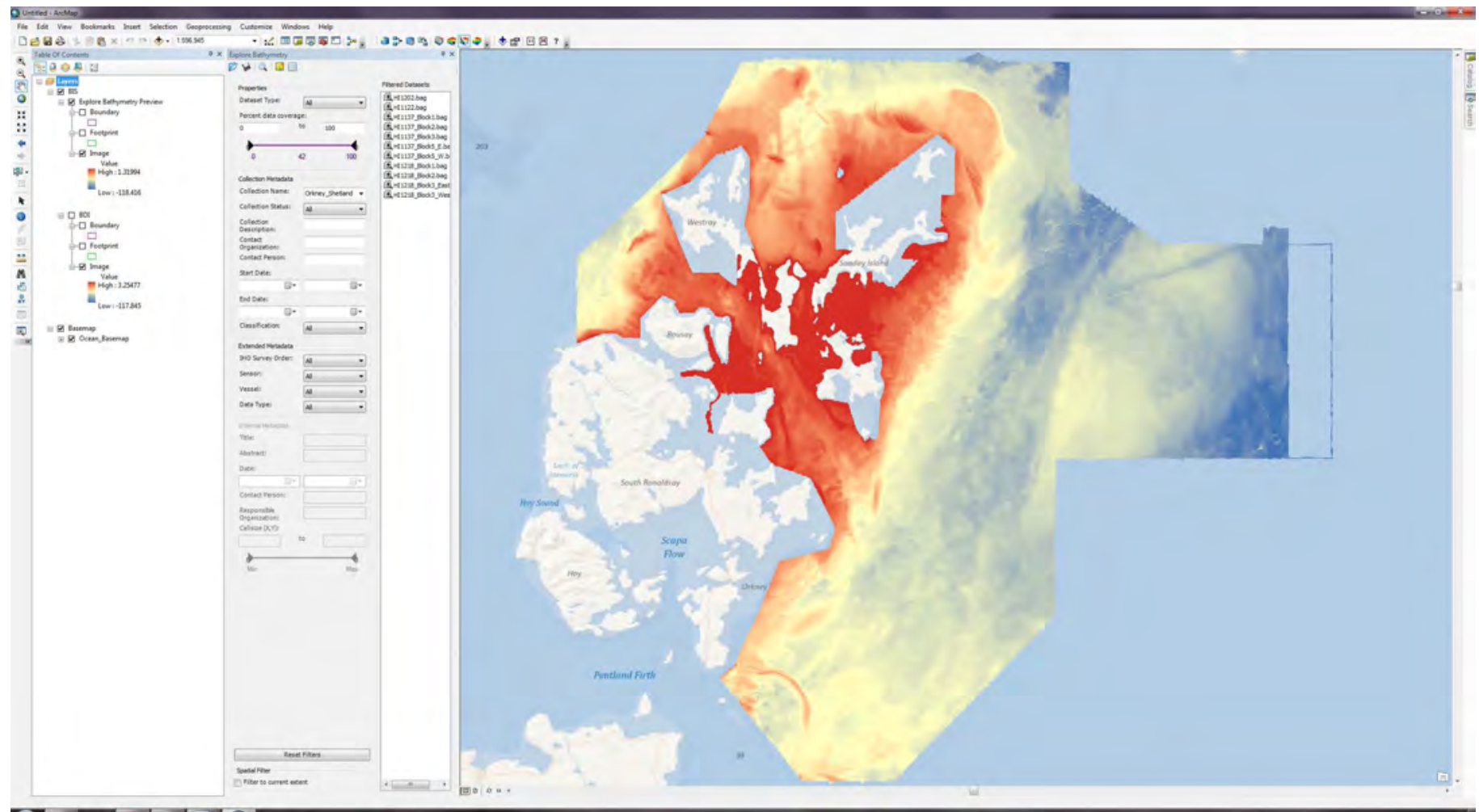

Figure 10: View of different survey BAGs around the Orkney Islands 


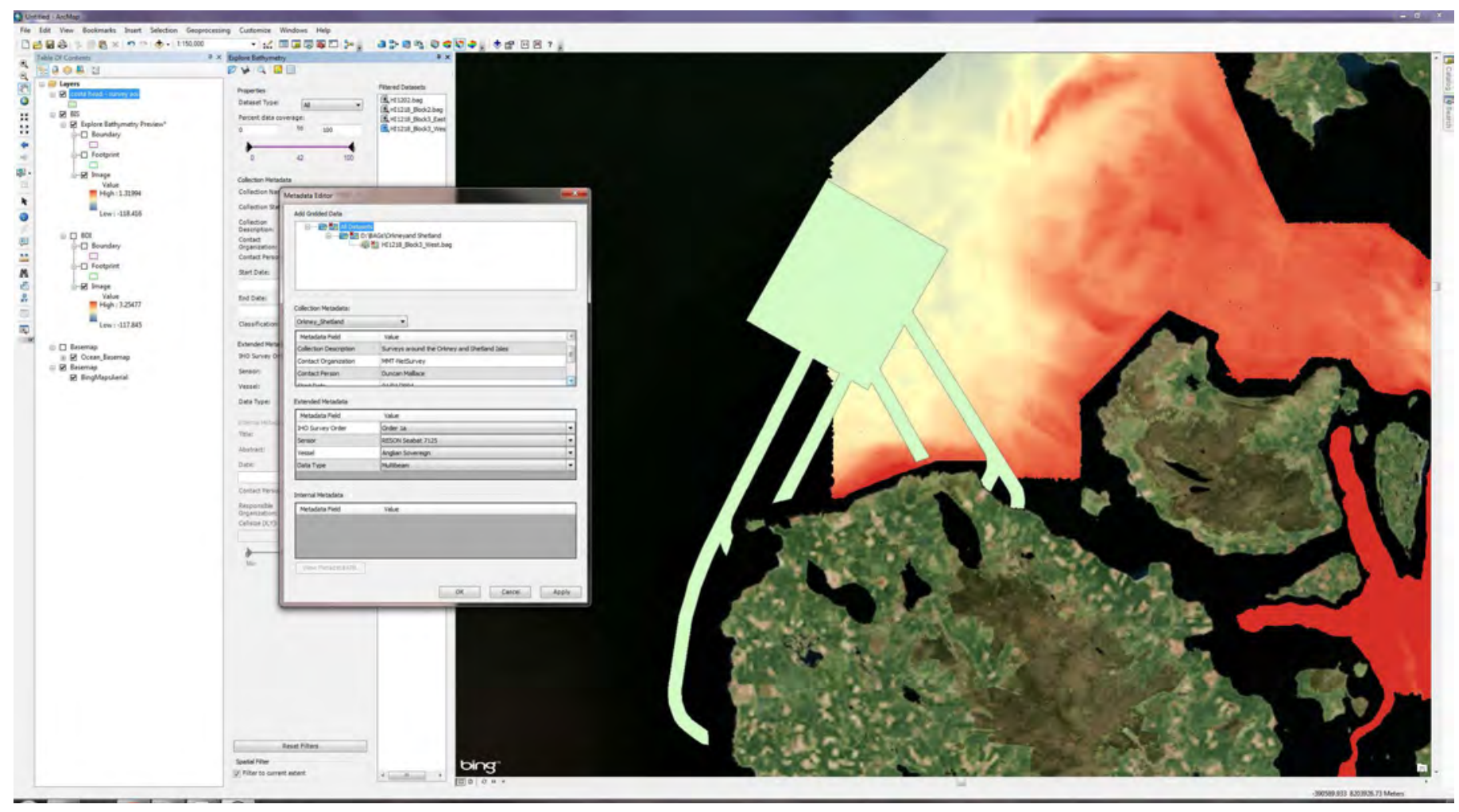

Figure 11: Proposed survey area overlain onto BIS

I took the Esri shapefile supplied with the tender and loaded it into ArcMap. When you zoom to the shapefile extents you see what survey data is adjacent or overlaps. By identifying the survey we could then drill down into the metadata to determine the time of year the survey took place from which we could analyse the potential weather downtime, from our own actual data for input into the tender calculations. The Bing Maps overlay is used in Figure 11 to provide additional information.

It would have course been possible to go into our fileserver, take an educated guess as to which survey it was and by a process of trial and error determine the survey, but this would have taken much longer. Provided we had a digital terrain model in a format that could be used easily with a shape file, we could then combine the datasets as above, however, if it was only the soundings that were available then a digital terrain model would have had to be created, potentially taking hours of time to produce.

\section{CREATING AND USING CUSTOM BATHYMETRIC SURFACES}

One of the very best features of the BIS is its ability to combine different digital terrain models together into one seamless surface, from which spatial tools such as contouring and sounding selection can be run. Even with modern computing hardware, the size of the individual surveys is huge and can stress even the very best computers. Using the Esri mosaic technology, a huge surface can be built that links together the BAGs rather than creating an actual file. A mosaic dataset is a collection of raster datasets stored as a catalogue and viewed or accessed as a single mosaicked image or individual images (rasters). These collections can be extremely large both in total file size and number of datasets. The raster datasets in a mosaic dataset can remain in their native format on disk or exist in the geodatabase. The metadata can be managed within the BAGs record as well as attributes in the attribute table. Storing metadata as attributes enables data to be managed easily as well as enabling fast queries to enable selections.

The data can even be completely or partially overlapping but be captured over different dates. The mosaic dataset is an ideal dataset for storing temporal data. You can query the mosaic dataset for the surveys you need based on time or dates, equipment or vessel or any other custom metadata field. 
Mosaic datasets are not limited to one particular type of raster data. You can add raster data in different projections, resolutions, pixel depths, and number of bands. Overviews (like pyramids) can be generated for the entire data collection. This allows for faster viewing of the data and allows you to easily serve these datasets. There are also many additional properties for viewing, including setting a mosaicking method, that make these datasets unique and functional in many situations. You can also query a mosaic dataset based on your spatial and non-spatial query constraints. The results of that query can be a set of images that you could process one by one, or it could be a dynamically generated mosaicked image.

At MMT Group we use these custom bathymetric surfaces to produce the deliverables required by Oil \& Gas and Renewable Energy companies. Typically and especially with pipeline and cable route surveys, traditional raster technology requires rectangular grids to be created which end up being very large files and sometimes too large for computer memory, so the data is subdivided into sections where the same actions have to be repeated for each block. This creates much longer data processing times than just performing the operation once and can lead to quality assurance issues with features being offset at joins and other cosmetic effects. A single contour file can, for instance, be referenced/linked into multiple alignment sheets. So rather than producing contours from blocks of survey data we combine all the areas together into one Custom Bathymetric Surface in ArcGIS using the Compose surface option. This allows us to specify a rule or just to combine all the datasets in one collection. Once they are combined into one "Surface" the contouring and other functions like long profiles and cross profiles can be generated from this combined surface. Figure 12 to 14 show the steps in combining surfaces, running contours and then viewing the result for the surveys in the Orkneys. First the continuous surface is setup by selecting a rule that says that if there is overlapping data, the survey that is most recent has priority.

Options are given to save the surface into the BIS geodatabase or create a separate geodatabase. The geodatabase just stores the image views seen in ArcMap and not the entire dataset.

Once the composite model has been formed the Arc Toolbox can be used on the model as if it were a normal ArcGIS raster product. In this case we are running the contour creation tool from the 3D Analyst toolbox over the entire dataset. To give you

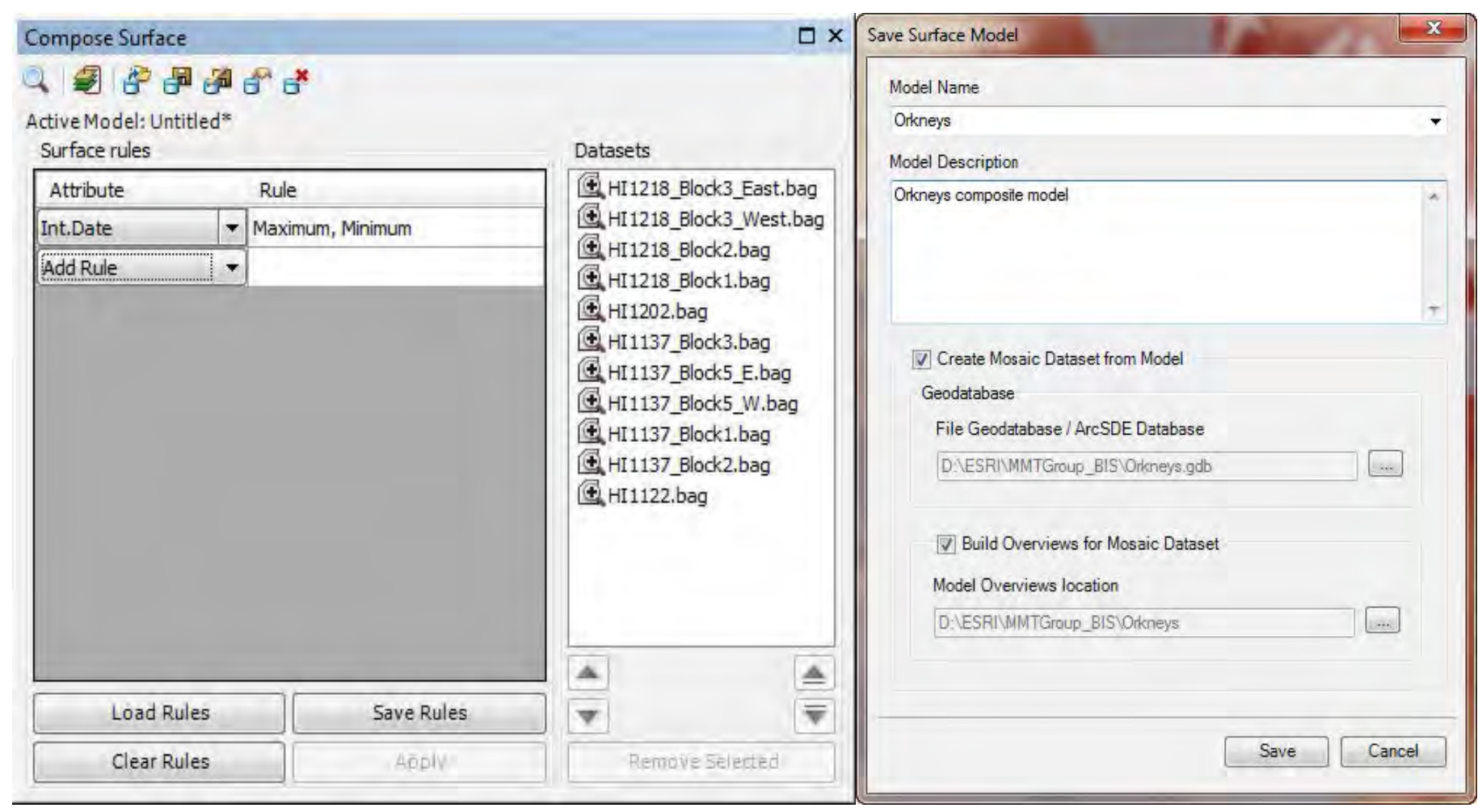

Figure 12: Creating a rule based on the most recent survey takes priority if they overlap and saving combined surface 


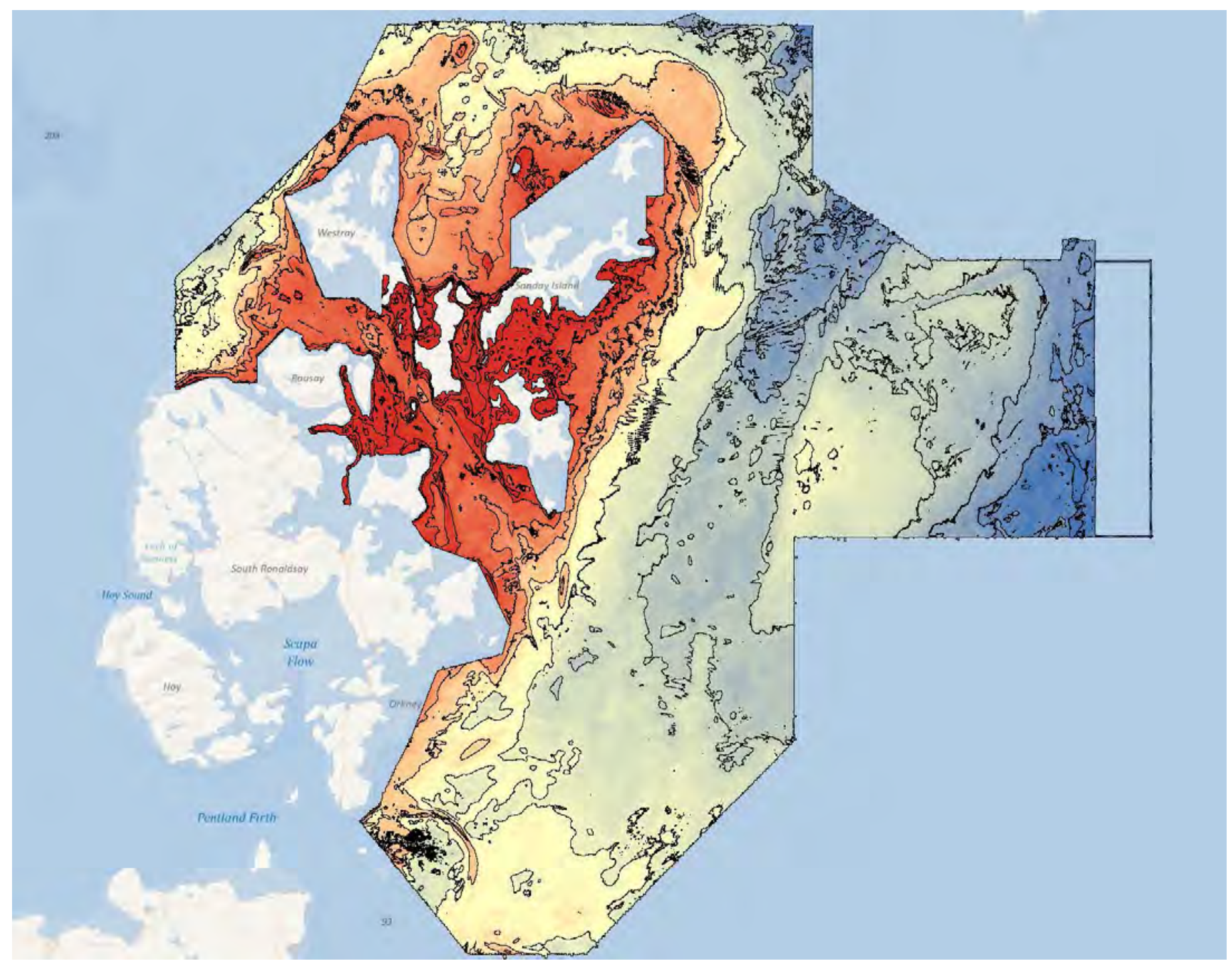

Figure 13: ArcMap showing the contours on top of the combined surface.

an indication of performance the Compose Surface took about 3 mins to run on 8.9 GBs of BAGs.

The contour option then took about the same time to produce, in this case, contours at $10 \mathrm{~m}$ intervals across the dataset.

We find that increasingly our clients are requiring ArcGIS based products. One of the most recent of these has been the Seabed Survey Data Model that has been created by the OGP Geomatics Committee (what was the EPSG). This is a blank Esri geodatabase template with specific fields that can be populated by the results of a geophysical survey. This provides a controlled deliverable format that can also be used between Oil \& Gas clients if they need to share data. The template also provides a very convenient way for the Oil \& Gas companies to ingest the data into their Esri GIS systems. As we are already in ArcGIS with our bathymetric data and products it is trivial to populate the Seabed Survey Data Model.

\section{FUTURE USES}

One of the main future uses we see is ArcGIS. com. This online web portal can be used both internally within the Group, to select clients and also some public access. The BIS includes a basic set of standards-based web services. These web services may be accessed directly or incorporated into composite services to deliver additional value to ourselves and our clients.

We can therefore host our clients data and provide them with an easy means of gaining access to their data and manipulating for their requirements. None of this requires the client to be GIS savvy and they can access the data from their desktops, tablet devices or smart phones. 
We see another great benefit in the Esri Pipeline Data Model as a new method of delivering pipe and cable route and inspection surveys. By combining the pipeline survey surfaces into one high resolution combined surface, products can be created that transfer easily into the Esri Pipeline Data Model.

\section{CONCLUSIONS}

The Esri ArcGIS for Maritime: Bathymetry solution is starting to revolutionise the way that MMT Group stores and accesses our bathymetric data. The quick, spatial access to our data coupled with the ability to combine survey datasets together is enabling us to speed up, not only our deliverable production but also our use of bathymetric data within the organisation, from initial tendering all the way through to final product.

With our use of ArcGIS.com it will enable our clients to use the full density products much more readily and without having to have a thorough GIS knowledge. This I think will change the way that clients perceive the data and will help in the shift from requiring deliverables based on older paper based products to new interactive digital products.

Most graduates from Geomatics based degrees come out with some ArcGIS knowledge. Very few come out with AutoCAD or other industry specific COTS products. By moving our deliverable production over to ArcGIS will reduce our training requirements and benefit new employees into understanding our work and the benefits to our clients.

Think spatial rather than flat!

\section{CONTACT DETAILS}

Duncan Mallace

NetSurvey Limited

2A Banbury Office Village, Noral Way

Banbury, OX16 2SB, UK

duncan@netsurvey.co.uk

Tim Kearns

Esri Inc., 380 New York St, Redlands, CA 92373-8100, USA

tkearns@esri.com 
176 | Hydrol 2 


\title{
Digital Mariner's Routeing Guide - An Exploration of the Standardization and Online Delivery of Marine Information
}

\author{
Raphael M MALYANKAR, United States of America \\ Jeppesen
}

Topics: Smart data management, Easy customer access to data and products

\section{INTRODUCTION}

Maritime data is produced in a variety of forms. This poster describes a prototype application intended to demonstrate the harmonisation of vector data with textual information, produced by different sources, and deliver it to end-users in an integrated and userfriendly form.

The chosen vehicle for this is a prototype online mariner's routeing guide using a data model based on the International Hydrographic Organisation (IHO) S-100 standard and developed using web services to make the information available to end users over the World-Wide Web. The producers of the content information are the Hydrographic Offices of three North Sea nations and the end users are mariners. Mariners' routeing guides are used for voyage planning. Current solutions are paper and PDF routeing guides, though a few digital versions have recently been developed. The IHO has produced a standards for (paper) routeing guides [International Hydrographic Organisation, 2010a].

The project uses the new IHO S-100 standard [International Hydrographic Organisation, 2010b] and product specifications based on it. Providing better information to mariners and making it easily accessible facilitates more efficient routeing of vessels, avoidance of dangers, avoidance of environmentally sensitive areas, and helps mariners become aware of rules pertaining to environmentally sensitive areas, reducing negative impacts of shipping on the envoronment.

\section{OVERVIEW}

Mariner's routeing guides are a mixture of textual, graphic, and geographic information about traffic separation, recommended routes, ship reporting systems, regulations for navigation and environmental protection, and other information.
They provide an overview of the information needed by navigation officers for planning voyages. Their presentation to end-users combines different types of information, including geographic features from nautical charts and text extracts from publications, in a largely graphical product.

The prototype Digital Mariner's Routing Guide (DMRG) described in this paper is a web-based system demonstration that will allow mariners to view information from different North Sea ports that has been converted to the new IHO S-100 data framework. DMRG features include:

- a user-controlled graphical display of land and sea areas, traffic separation, ship reporting, restricted areas, nature preserves, and similar information of use in voyage planning;

- auxiliary displays of specific information on navigation, rules and regulations, environmental protection, and other topics;

- different types of information access functionality, including geographic searches, intended to provide users with efficient access to information.

Data for the DMRG consists of geographic features from ENCs and extracts from text official nautical publications of hydrographic offices and other sources, converted to a format compatible with both S-100 and GML (Geography Markup Language). The current implementation is concerned with selected ports in Norway, Denmark, and Germany, and was executed with the participation of the Norwegian Hydrographic Service (NHS), Bundesamt für Seeschifffahrt und Hydrographie (BSH), and Kort \& Matrikelstyrelsen (KMS) in converting data from their publications to the new information model. 


\section{STANDARDS-BASED INFORMATION}

The IHO has recently developed a framework standard for nautical publications, based on the ISO 19100 family of standards. The S-100 standard [International Hydrographic Organisation, 2010b] is a framework from which standards for different data types and data products are derived. Examples of such derived standards are the S-101 and S-102 Product Specifications, both currently under development, which describe data models for ENC and high-density bathymetry data respectively. The IHO Standardisation of Nautical Publications Working Group (SNPWG) is working on a data model for nautical publications based on S-100. The scope of this model is far larger than digital mariners routing guides - it is a general model intended for making nautical publications information compatible with future Electronic Chart Display and Information System (ECDIS). At the core of the S-100 model are the concepts of geographic features (representations of real world phenomena) and information types (identifiable, discrete units of information which may be shared among features). The geographic objects in this model range from radio stations to port security areas. The information objects range from regulations to address/contact information, ship reports, hours of work, and specification of classes of vessels to which a rule applies. The SNPWG model is still evolving, but the DMRG work used the then-current version of the SNPWG model as its own data model.

The S-100 standard allows for different formats for data sets. The encoding for this product specification was defined using an XML application schema derived from GML 3.2.1. The encoding is capable of coding geographic features, information objects, simple and complex attributes, feature associations, information associations.

\section{INFORMATION CONTENT}

Mariners' Routeing Guides serve the purpose of bringing together several critical types of information needed for the task of creating a route plan for a voyage. Historically these have been produced in the form of a paper chart, but now there are examples of digital mariners' routeing guides. Today's examples, digital and paper, provide a basis for developing more intelligent presentations of data and facilitating trans-national harmonisation of nautical information.

\section{$\underline{\text { Source Material }}$}

The selection of source material was guided by the eventual application, namely the digital routeing guide. Source material consisted mainly of Sailing Directions or the equivalent, and electronic nautical charts (ENC) files. The ENC files were used mainly to determine the geographic locations with which information from the publications is associated.

The structure and volume of the source texts varied widely in their descriptions of the port areas and approaches. The Norwegian sailing directions for the Stavanger area (in Den Norske Los, Volume 3 ) are written as plain text in a narrative style, include several lists (of landmarks, pilot boarding places, etc.) and describe the approaches from seaward as well as providing details about berth sizes and port services. KMS has replaced printed sailing directions for port areas with web pages for individual ports, available on the KMS web site as Danske Havnelods. The structure is less of a flowed narrative compared to Den Norske Los, and is distinguished from the other two in using pictograms to convey some of its information about port services. BSH provides the equivalent information in Part C of the Nordsee Handbuch. This is structured as short sentences and sentence fragments which contain the essential information, and makes intensive use of visual style cues such as fonts and indentation to arrange associated information elements together and indicate the areas and vessels to which specific rules apply. Den Norske Los tends to provide area-specific regulations in full, compared to the other two; the Nordsee Handbuch presents them as text fragments prescribing or forbidding actions, under heads indicating the conditions under which a the specific prescription/prohibition applies. All three arrange the information under similar heads and subheads. All three hydrographic offices provide general information and the text of regulations in volumes or chapters different from the area-specific information - Volume 1 of Den Norske Los for Norway, a printed publication called Den Danske Lods for Denmark (not currently available on the Web), and Part A of the Nordsee Handbuch for Germany. The presentation of this information is more consistent across the three countries. 


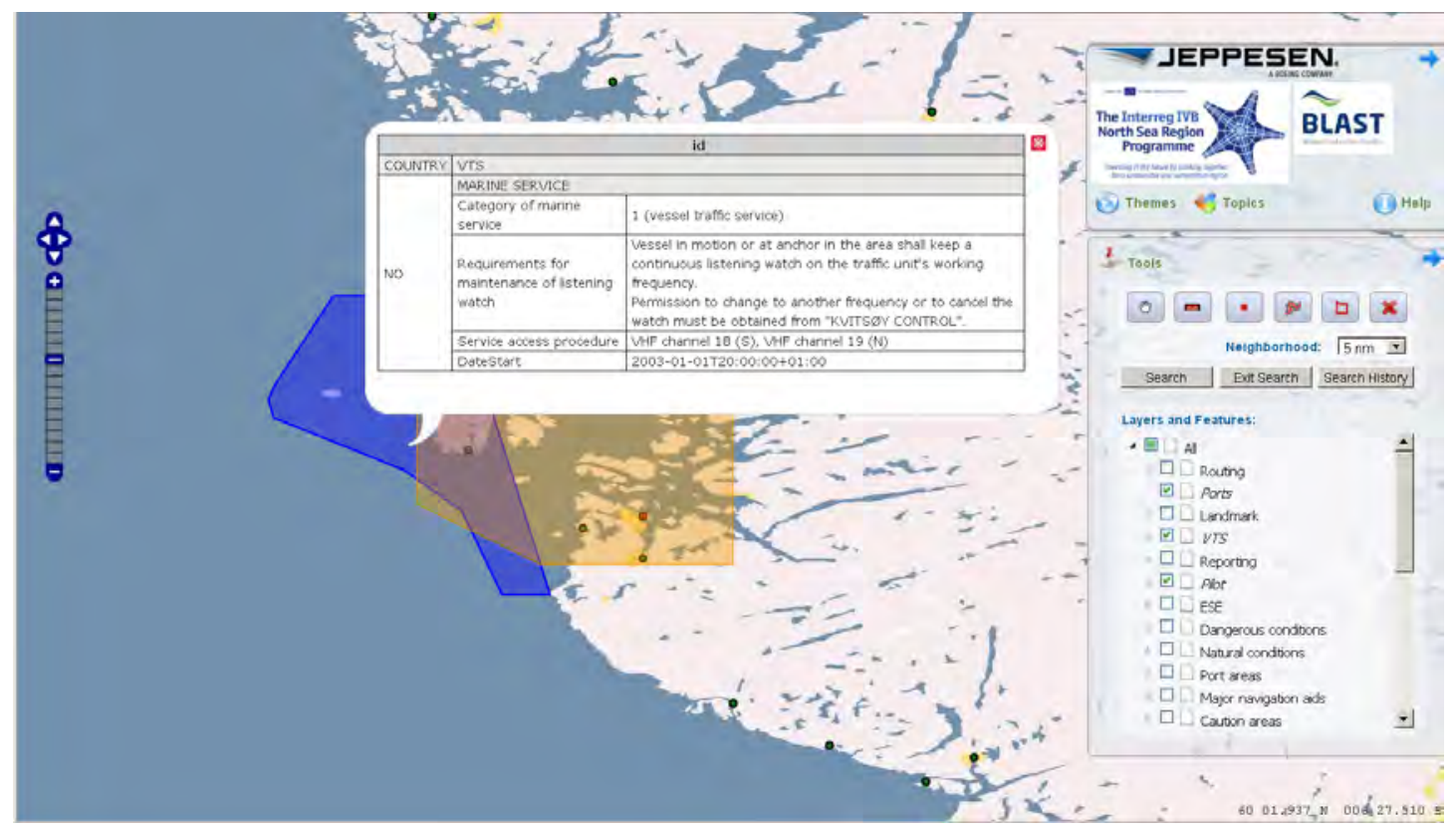

Figure 1: Users can browse for information on a single geographic feature using the graphical interface. Shown is the VTS area in the vicinity of Stavanger (blue highlight). The other feature represents the pilot service area for the region.

\section{$\underline{\text { Preparation of Information }}$}

As part of the project Jeppesen, BSH, KMS, and NHS converted unstructured textual information from nautical publications for one port each from Denmark, Germany, and Norway into structured data conforming to the IHO SNPWG data model and produced XML datasets for the three ports. The information mapping work for this project was performed by project participants at BSH, NHS, and KMS, and reviewed by Jeppesen. Coordinates for geographic features were determined from the text if available; if not, the coordinates were obtained from the appropriate ENC or created in an ENC editing tool.

Hydrographic office partners reported that information mapping took significant effort. A large fraction of the time was spent on linkages to geometry, in the form of geographic features or spatial objects. Also, preparing extracts of regulations and laws was reported as another point of concern, due to the difficulty of making some information in laws or regulation (usually about exceptions or applicability) conform to the object/ attribute data model. Further, sometimes the original text leaves room for interpretation. Regulations are often written to fit specific circumstances which were not considered general enough to warrant capture in the SNPWG model. Apart from this issue, the S-100 framework currently lacks convenient modeling elements for expressing procedural and rule-based knowledge. It is theoretically possible to capture such information in an object/attribute model, but the non-intuitive structures increase the difficulty of information mapping.

The mapped and cleaned data was converted into data sets conforming to the encoding specification developed for DMRG. The results were reviewed by the hydrographic office partners. The results can be viewed in an XML editor tool as well as a popular off-the-shelf free GML viewer.

\section{INTERFACE FUNCTIONALITY}

The characteristic feature of mariners' routeing guides is the balance between graphical, chartlike and text-heavy presentations. In this, they differ from both nautical charts (heavily graphical) and nautical publications (heavily textual). The DMRG attempts to balance geographic and textual information and provides both geographic browsing and textual presentations of information.

\section{Geographic Browsing}

The user can select feature classes (layers) for display and highlighting on the graphic display. Feature classes or layers correspond to vector objects as encoded in the spatial data available to the system, such as VTS service areas, major navigational aids, pilot services, etc. Activating a layer or feature in the Layers and Features panel displays and highlights the relevant feature(s). Clicking a feature in the graphic window brings up a popup with information about the feature. Figure 1 shows this functionality in action. 


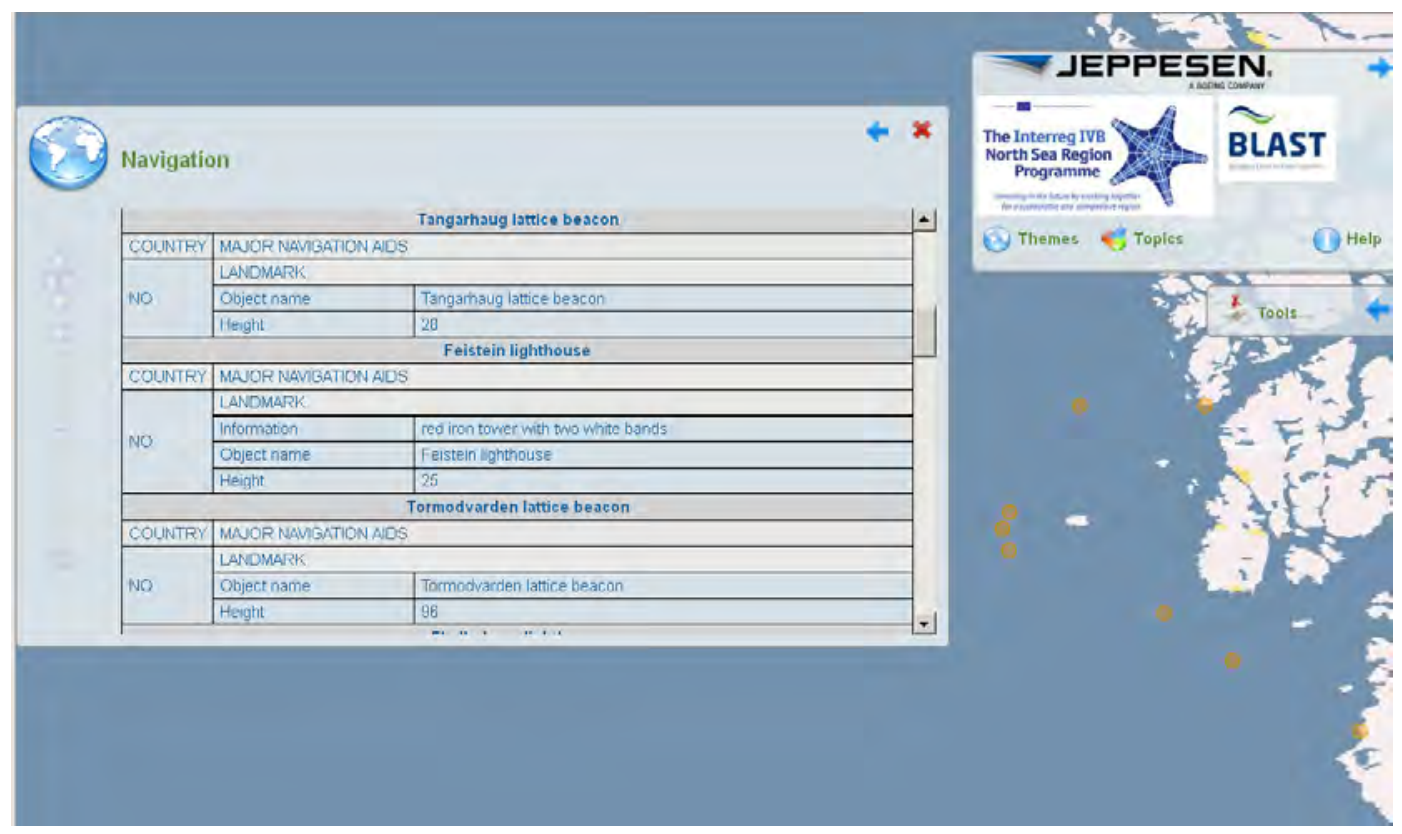

Figure 2: Organised text-based presentations about selected topics or broader subjects are available. The text box shows information about important navigation aids in the vicinity of Stavanger. The graphic display shows their locations.

\section{$\underline{\text { Structured Presentations of Text }}$}

The system provides a menu-based interface which allows the user to obtain results about a single feature class, a group of feature classes (topics), or a broad subject (themes menu). As shown in Figure 2, clicking a theme or topic item displays information in text or mixed text/graphic form, depending on what is available.

\section{$\underline{\text { Support for Voyage Planning }}$}

One of the most important activities of navigation officers on commercial vessels is voyage planning. The DMRG supports this function by providing geographic queries. A route query function allows the user to obtain all information intersecting, or in the neighbourhood of a route specified by the user (Figure 3). Area, region, or point-based queries can be used to find information pertaining to a specific area, region, or location.

\section{OTHER ROUTEING GUIDES}

The Admiralty routeing guide for the English Channel and Southern North Sea and the BSH routeing guide for the Baltic are a large format paper charts containing a mixture of text, diagrams, and specialised chart images. The contents include general information and guidelines for using the routeing guide, overviews of routeing schemes, an overview of international and local regulations and extracts from International Maritime Organisation (IMO) codes and the MARPOL conventions,

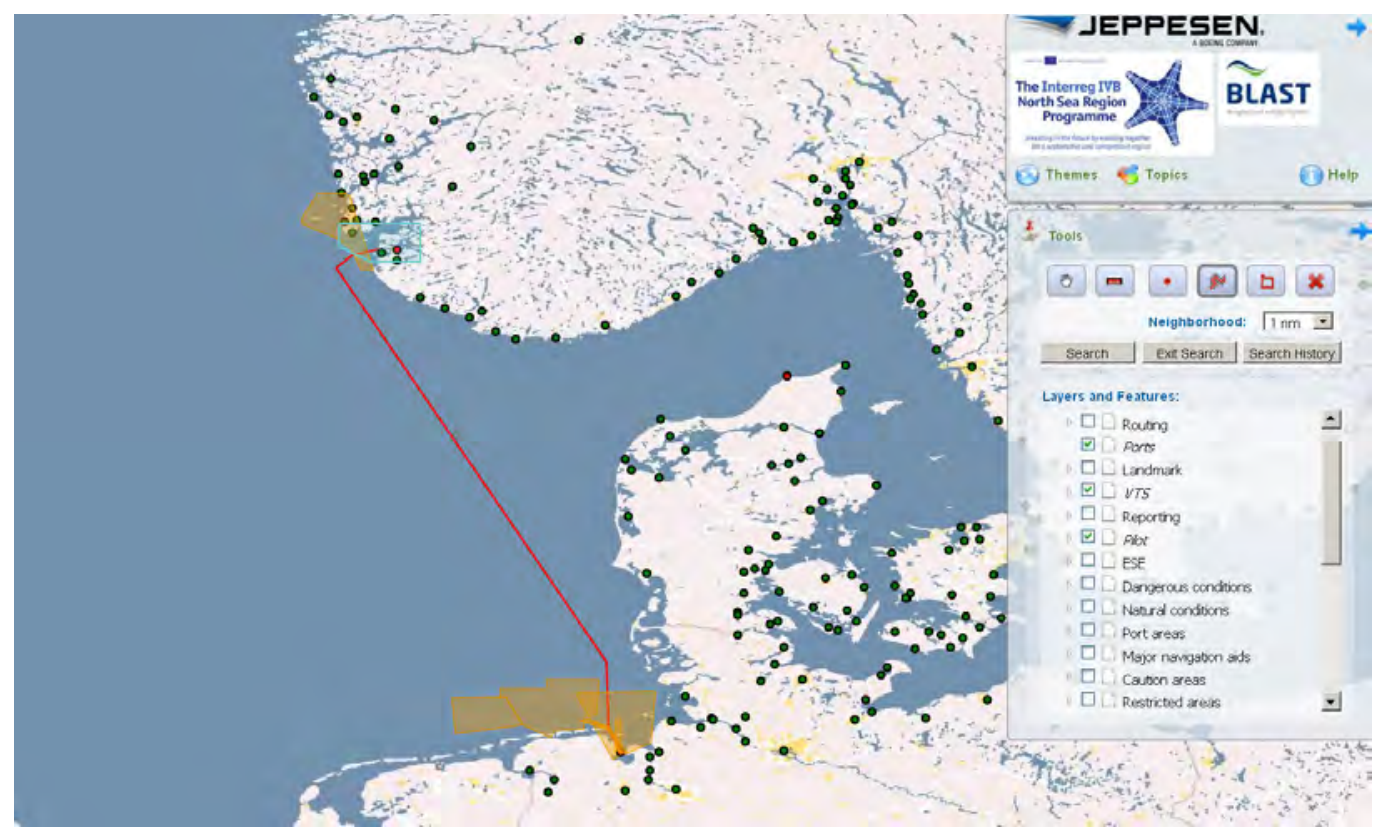

Figure 3: Users can retrieve information pertaining to specified locations, routes, areas, or regions. The figure shows an example route between Wilhelmshaven and Risavika, specified by the user. Executing searches displays information for locations within a user-configurable cross-track distance. 
considerations for tankers, and ships carrying hazardous cargo, outlines of reporting systems and requirements, radio services, information about VTS and pilot services.

There is also a Digital Mariners' Routeing Guide for the Baltic Sea, produced by collaborative efforts Denmark, Estonia, Finland, Germany, Latvia, Lithuania, Poland, Russia, and Sweden. The online version can be viewed at http://www. helcom.dk/map/index.htm. It provides information similar to that found in the other routeing guides described. The web-based version offers additional functionality of allowing users to select a view of routeing and planning information by subtopic, or filter the content by Country or topic. Drill-down access to topics such as Pilotage for a country triggers presentation of detailed text, chart images and diagrams in the form of PDF documents.

"DigiPilot", produced by the Hydrographer of the Royal Netherlands Navy as an official nautical publication, is interactive software with content from Dutch Sailing Directions, tidal information, the Netherlands Mariners Routing Guide for the Southern North Sea and Deep Draught Planning Guide. It provides interactive query functionality and multiple thematic layers.

\section{DISCUSSION}

As part of the BLAST (Bringing Land and Sea Together) project, Jeppesen collaborated with the hydrographic offices of the Federal Republic of Germany, Norway, and Denmark on a sequence of activities intended to advance the cause of harmonized and efficient information collection and demonstrate its delivery using the S-100 framework. The DMRG is the final phase and builds on activities in earlier phases on collecting and harmonising information.

The DMRG project demonstrates that standardized information models can be used for very different types of information, specifically text-based as well as vector data. It demonstrates the application of harmonised information modeling from different European nations, by making an information model and datasets derived from different countries, structured in different ways, and containing very different types of data (vector data and text-based information). It also demonstrates the integrated use of marine information, specifically vector data used in ENCs with text-based information form nautical publications, and its presentation to end-users in an integrated fashion - chart objects (ENC data) are presented seamlessly with text-based information from nautical publications.

Our experiences during the conversion of data to the common data model suggest that significant effort may be needed to map non-ENC data to S-100, and also to convert existing data. The mapping and conversion process helps discover gaps, ambiguities, and discrepancies in existing data, which results in improvements to the quality of the source data as well as the result. On the other hand, not everything in text sources can be mapped to an object-attribute model like S-100, due to the complexities of human language.

Finally, it is clear that a Digital Mariners' Routeing Guide can support more content and more varied content than the paper version because the digital medium makes it possible to dynamically maintain an organised, context-driven presentation of relevant information, and permits the dynamic selection of information for the end-user.

\section{ACKNOWLEDGMENTS}

The work described here was part of the Bringing Land and Sea Together (BLAST) project. Jeppesen's participation is funded in part by the INTERREG IVB North Sea Region Programme and in part by Jeppesen. We gratefully acknowledge the participation of personnel from Bundesamt für Seeschifffahrt und Hydrographie (BSH - Federal Republic of Germany), Norwegian Hydrographic Service/Statens Kartverk Sjø (NHS - Norway), and Kort \& Matrikelstyrelsen (KMS - Denmark), whose participation was funded in part by the INTERREG IVB programme and in part by their respective agencies.

\section{CONCLUSION}

A digital Mariners' Routeing Guide includes information about international and local regulations and practices, as well as a combination of chart and nautical publications information on a trans-national basis. It therefore provides a useful reference point 
and test bed for exploring the standards-based

preparation and distribution of information, and the integration of geographic data with other forms of information. The work described here demonstrates that new standards for marine information can be successfully employed in integrated presentations of spatial and non-spatial information.

\section{REFERENCES}

International Hydrographic Organisation. 2010a. "Standardization of Mariners' Routeing Guides". Edition 2.0. Publication S-49, International Hydrographic Bureau, Monaco. International Hydrographic Organisation. 2010b. "S100 - Universal Hydrographic Data Model". Edition 1.0.0. Publication S-100, International Hydrographic Bureau, Monaco.

\section{BIOGRAPHIES}

Raphael M MALYANKAR is a consulltant for Jeppesen working on marine standards and information models for marine data. His professional interests include information modeling and knowledge representation for geospatial information. His academic trainng is in computer science. His highest degree is a Ph.D. in computer science from Arizona State University.

\section{CONTACT DETAILS}

\section{Raphael M MALYANKAR}

c/o Cathrine Fierberg

Jeppesen

55 Inverness Drive East, Englewood, CO 80112

USA

Tel.: +1 4804913997

Email: Raphael.Malyankar@jeppesen.com

Web site: http://www.jeppesen.com 


\section{Beyond bathymetry - coastal marine mapping}

Travis MASON and Robert KINNEAR, United Kingdom

Channel Coastal Observatory, National Oceanography Centre

Andrew COLENUTT, United Kingdom

New Forest District Council

André COCUCCIO, United Kingdom

The Maritime and Coastguard Agency

David PARKER, United Kingdom

United Kingdom Hydrographic Office

Topics: Easy customer access to data and products, Careful marine planning, Cost-effective solutions

\section{INTRODUCTION}

Although IHO Order 1a is now the default standard for the UK's Civil Hydrography Programme surveys, there is a wealth of additional uses of the survey data, which is now being put to good use under the principle of "collect once, use many times". Recent involvement of maritime Local Authorities in England has encouraged extension of the survey into the inter-tidal area, where possible, and to make use of the bathymetry data and backscatter for a range of coastal engineering and management applications.

\section{BACKGROUND}

Coastal surveys have traditionally been difficult since they are usually, by definition, in very shallow water and are heavily tidally- and weather-restricted. In the UK, spring tidal range can vary from 1 to $12 \mathrm{~m}$; the higher ranges can aid the nearshore survey, although where these occur over relatively flat seabed, the speed of the tidal translation can still be a operational problem, whilst near the tidal nodes, the very small tidal range and nearshore bar systems can restrict how close to the shore even a small survey vessel can approach. Furthermore, breaking waves are also a potential hazard close inshore. Taken together, this means that bathymetry surveys of the nearshore require daylight hours, spring tides, good weather, calm seas and a shallow draught vessel; requirements which translate into "expensive" and since the nearshore region is typically of less interest for safety of navigation, the area within $0.5-1 \mathrm{~km}$ of the shoreline is justifiably known as the "White Ribbon", where little data exist.

Since 2008, however, thanks to collaboration with the Maritime Coastguard Agency (MCA)'s Civil Hydrography Programme, the DEFRAfunded, maritime Local Authority-led Southeast and Southwest Regional Coastal Monitoring Programmes have been able to upgrade their bathymetry survey programme from single-beam to swath bathymetry, with a resultant explosion in the usefulness of the data. The first collaborative project was between the MCA, New Forest District Council and Dorset Wildlife Trust and, together with a grant from Viridor Credits, resulted in the "DORIS" survey, covering some $800 \mathrm{~km} 2$ from the MLWS contour to $6 \mathrm{~nm}$ offshore, from Portland Bill to Swanage. Subsequently, further similar collaboration via the lead Local Authorities of the Southeast, Southwest and East Riding of Yorkshire Regional Coastal Monitoring Programmes means that $20 \%$ of the coastal strip of England has been surveyed to IHO Order 1a, with plans to cover a further $5 \%$ within the next 2 years.

Although not the responsibility of maritime Local Authorities, the recent introduction of the UK's Marine Bill, and subsequent requirement for the creation of Marine Conservation Zones and Maritime Protected Areas has resulted in a burst of interest in coastal surveys to provide data for mapping of marine habitats, based on the interpretation of the swath bathymetry and backscatter. 


\section{METHODS}

The swath bathymetry data commissioned by the Regional Coastal Monitoring Programmes is used for mapping habitats based on the JNCC version of the European-wide EUNIS classification system. Three broad parameters in varying combinations are used for EUNIS Levels I to III, in order of increasing complexity (Level I merely distinguishes between marine, freshwater and terrestrial habitats). Firstly, the nature of the seabed itself, which can be either rock or sediment or rock with a covering of thin sediment. The second banding is based on photic levels i.e. the depth to which light can penetrate, which depends essentially on the water clarity. The shallowest band is the inter-tidal region and hence the elevation of the Mean Low Water Springs contour can be used as the boundary between the shallowest (Littoral) and middle (Infralittoral) depth bands; in the English Channel, $5 \mathrm{~m} \mathrm{CD}$ is a typical depth boundary to the deepest category used for shelf seas (Circalittoral).

The third discrimination parameter is energy-based; this is not overly sophisticated being either High (e.g. Land's End, Cornwall), Medium (central English Channel coast) or Low (eastern Kent) wave energy. However, there may be areas within an overall Low wave energy category which are reclassified as Medium energy due to the presence of strong tidal currents, for example Hurst Narrows in the Solent. Combinations of these parameters produce 8 marine habitat classifications at EUNIS Level II and 26 categories at Level III. Finally, a revised substrate classification is then produced by reducing the Level III categories to rock, coarse or mixed sediment, sand or mud.

Amongst some of the habitat mapping community, there is an impression at large that all the mapping is, or can be, done directly from the backscatter, but accurate habitat mapping relies on a combination of bathymetry, backscatter and ground-truthing, with the relative importance of each facet varying with substrate. For example, on exposed, rock platforms, the habitat can be mapped almost entirely from the bathymetry alone (including derived information such as slope and rugosity) whilst, in contrast, rock substrate covered with a layer of thin sediment, or discrimination between sand and mud require careful interpretation of the backscatter and, ideally, ground-truth information such as grab sampling or video.

During the mapping procedures to produce EUNIS classification, GIS shape files are produced for anthropogenic feature such as pipelines, obstructions and wrecks, scour marks, trenches and cables. Slope, rugosity and, in some cases, geological information such as fault lines can also be mapped and stored as shape files for subsequent further investigation. From a coastal management point of view, the advantage of a Level III classification is the detailed mapping of the seabed substrate including classes of mud, sand, coarse or mixed sediment.

RESULTS AND DISCUSSION - Seabed mapping for coastal management

The seabed mapping results given here are from coastal bathymetric surveys conducted by maritime Local Authorities in conjunction with the MCA and UKHO. All data and mapping results are made freely available at www.channelcoast.org.

\section{Marine habitat mapping}

Until the relatively recent use of swath bathymetry and simultaneous backscatter, much of the habitat mapping in the UK was derived from modelling, validated in some cases by widely-spaced strips of multibeam data, but with grab sampling and biological sampling. As a result, the confidence in the results was high for the ground truthing assessment but low as regards to coverage and positioning. In contrast, habitat mapping from the IHO Order 1a surveys gives very high confidence estimates due to the $100 \%$ coverage of the seabed and accurate positioning, which usually result into a high overall confidence score despite the limited ground truthing. Biological sampling is still required to achieve the more detailed Levels IV and V but a Level III habitat map is still highly useful given the sparcity of measured data for defining draft Marine Conservation Zone areas. For example, seabed mapping of a recent swath bathymetry survey off Kent allowed the extent of the chalk reef (an EC Habitats Directive Annex I habitat) to be accurately mapped for the first time, along with the other marine habitats (Figure 1). 


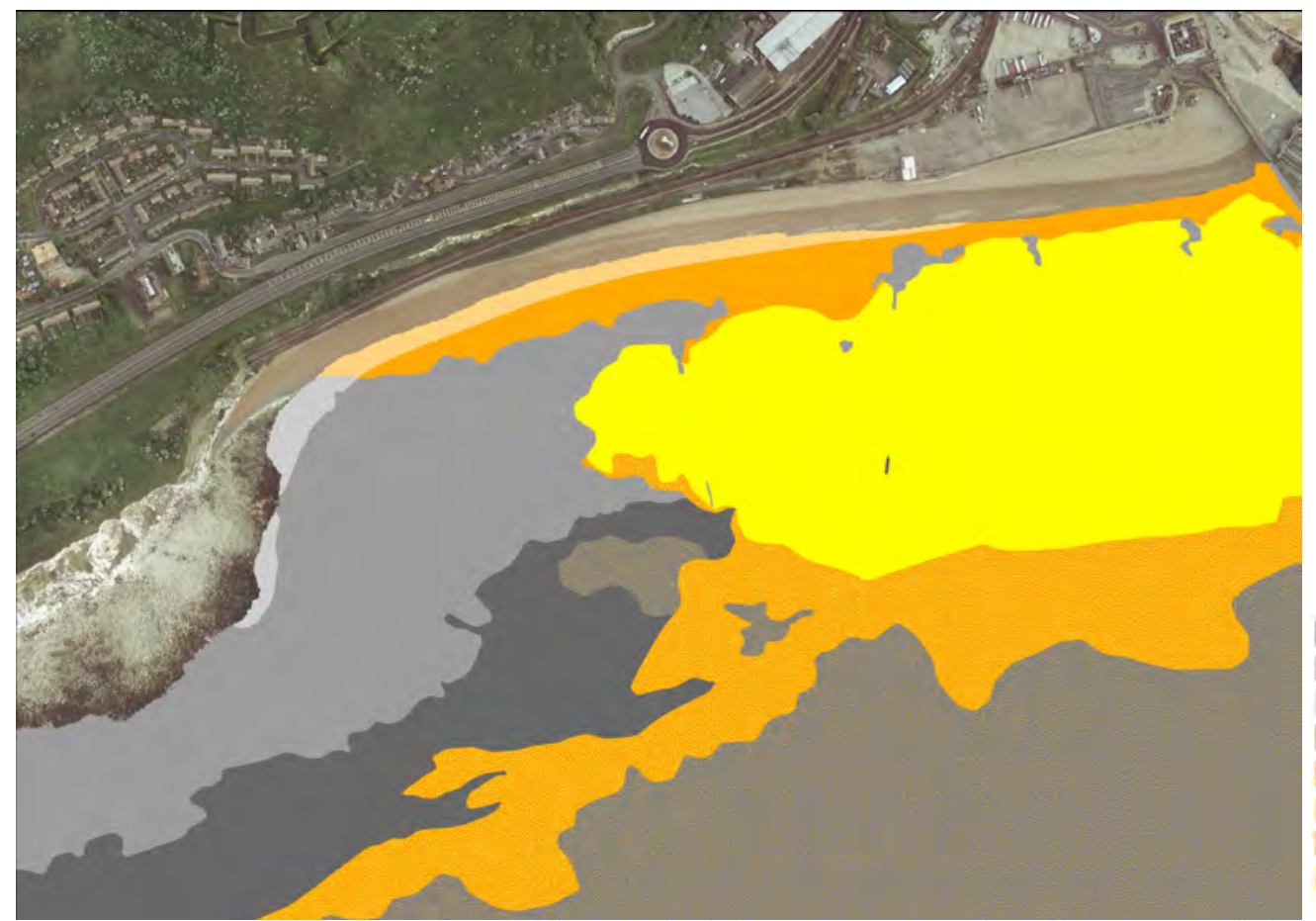

Figure 1: EUNIS

Level III habitat map, just south of Dover, Kent. The bathymetry overlaps the intertidal beach captured by ortho-rectified photography so that a seamless coastal habitat map can be achieved

Circalittoral Moderate Energy Rock Infralittoral Moderate Energy Rock Littoral Moderate Energy Rock

Circalittoral Moderate Energy Rock and thin Sediment Sublittoral Coarse Sediment Littoral Coarse Sediment Sublittoral Mixed Sediment Sublittoral Sand

\section{Coastal engineering}

In most cases, design of coastal structures or beach management operations are based on single-beam profiles $50-100 \mathrm{~m}$ apart at best. The additional information from the seabed mapping of swath bathymetry means that the seabed substrate, texture, variability, micro-scale slope and potential obstructions can now be taken fully into account. In Gurnard Bay, Isle of Wight, for example, the presence of long-term pipelines still visible in the bathymetry confirms the suspected lack of "spare" sediment in the system as well as the stability of the seabed (Figure 2). Operationally, the detailed nearshore bathymetry and resultant obstructions/ made-made features mapping have proved invaluable for planning operations to replenish beaches from dredgers.

\section{$\underline{\text { Implications for sediment transport }}$}

Predictions of sediment transport rates are notoriously inaccurate and despite decades of world-wide fieldwork and modelling, a daily sediment transport rate accurate to within 2 orders of magnitude is realistically the best that can be achieved; even predicting net transport direction over the timescales of months or years is fraught

Figure 2: Bathymetric survey of the northwest Isle of Wight, Hampshire, 2011

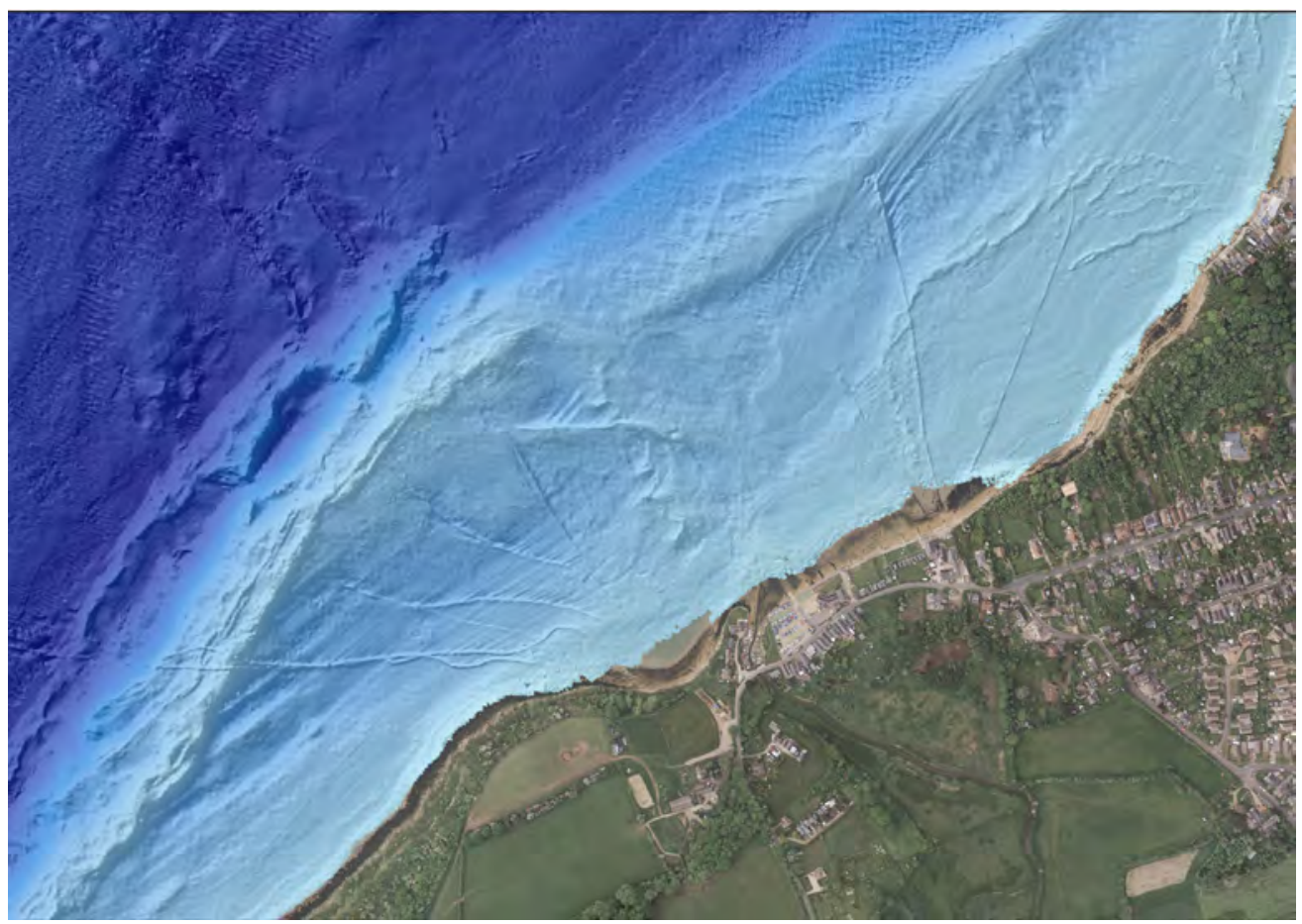


with difficulty, let alone for the decade timescales required for governmental planning. Part of the reason for this is that nearly all of the nearshore coastal monitoring takes place in the intertidal region. The Regional Coastal Monitoring Programmes of England undertake twice-yearly beach surveys using either RTK GPS topographic surveys or laser scanning and/or airborne lidar, which help to provide a good picture of the annual variability of the sediment. However, using landbased survey techniques means that surveys can extend seawards only to MLWS at best.

Typically, storms draw down beach material to the just sub-tidal area (say MLWS to -2m CD), but whether it is eventually returned to the beach (the classic summer/winter beach profile pattern) or becomes subject to tidal or wave-induced longshore currents resulting in transport out of the sediment system is rarely known or understood. This is a particular problem on steep shingle beaches, such as Slapton Sands, Devon, or Seaford, East Sussex, where the $\sim$ 1:8 beach slope and typically plunging waves prevent land-based surveyors from venturing into the water, and prevent boat surveys from approaching too close inshore. Yet without an assessment of the sub-tidal beach volume, few conclusions can be made regarding the sediment transport patterns implied by topographic difference models. Mapping of the substrate close inshore can help with this problem.
Swath bathymetry in the coastal zone has revealed hitherto unknown detail on sedimentary features such as sandwaves and other bedforms, giving an important source of new information for coastal management (Figure 3). Not only does the very presence of such features indicate a potential subtidal sediment supply, but new semi-automatic tools for calculating crest orientation, wavelength, height and asymmetry direction and ratios developed at the University of Southampton (Cazenave et al., 2012) can provide useful proxies for net direction of sediment transport and thus potentially the relative net effect of tidal and wave regimes. Research is onging to assess whether bedforms are active or relict which, again, will have significant implications for future marine planning.

Since marine sediment is an important source of material for beach recharge, the swath bathymetry provides the opportunity to identify potential new offshore banks in areas of the coastline where beaches are intensively managed, particularly if they can be shown to be non-mobile. Advantages include reduction in mobilisation and transport costs and the likelihood that sediment from within the same sediment circulation regime will be closer to the natural beach material both in terms of composition and sediment size, which is an important aspect in the performance of the recharged beach.

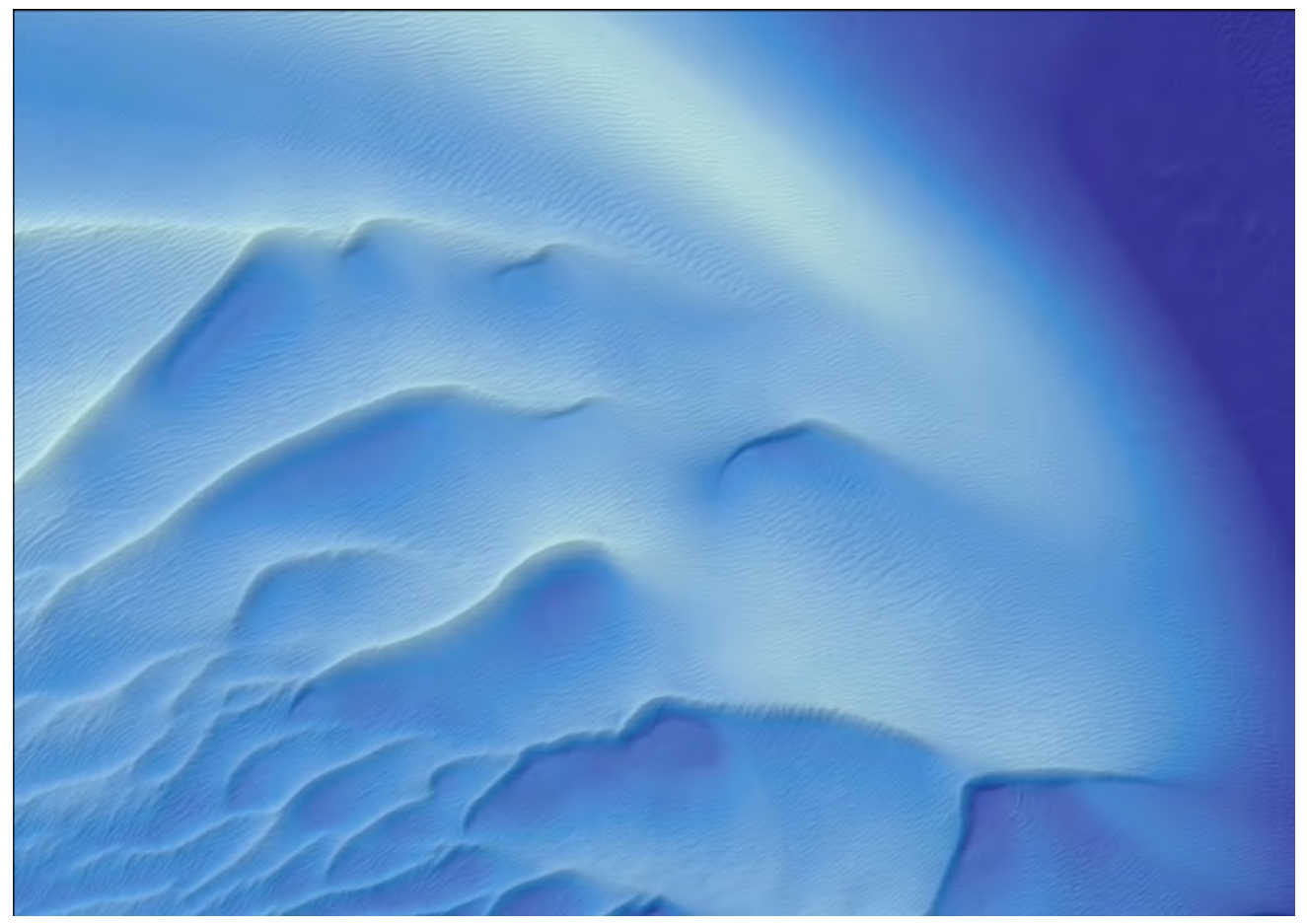

Figure 3: Mobile sand and gravel waves and parasitic bedforms (DORIS survey, 2010) 


\section{Design wave conditions}

Most coastal structures or beach management plans involve design wave conditions based on wave heights, periods and direction measured (or more likely, hindcast from wind fields) in $30-50 \mathrm{~m}$ water depth and numerically transformed to the nearshore location. Wave transformation models rely heavily on nearshore bathymetry, since most of the transformation occurs in water depths shallower than $20 \mathrm{~m}$ and, being a non-linear process, becomes progressively more influential inside $10 \mathrm{~m}$. The more sophisticated spectral wave models e.g. SWAN can resolve wave transformation over quite complex seabeds, taking into account refraction, diffraction and wave shoaling but the results are still dependant on a realistic representation of the seabed over which the transformation is modelled.

For example modelling of the wave climate at Preston Beach, Weymouth, is a particular challenge due to the peninsula of Portland Bill, and similarly the presence of ebb tide deltas off Hayling Island have a marked influence on the wave conditions at the shoreline; the DORIS survey and planned surveys in the eastern Solent are expected to improve the modelling of wave extremes at the coastline, for subsequent improvement of beach management practices.

\section{Implications for future monitoring}

Previous coastal monitoring of bathymetry, with single beam profiles at $100 \mathrm{~m}$ intervals, gave no indication of the nature of the seabed and surveys had been repeated several years apart, but were still unsuitable for difference modelling due to the sparse data. The results of the seabed mapping identifies areas of rock, for which there will be no need to re-survey in the foreseeable future, leading to considerable cost savings for coastal monitoring.

\section{CONCLUSIONS}

The more development of multibeam sensors within the last few years, the release by the MCA of a technical specification for IHO Order 1a swath bathymetry surveys, incorporation of backscatter processing and analysis into bathymetric survey software and a willingness by several public bodies in the UK to share resources and subsequent survey data have been major drivers in the uptake of swath bathymetry data for non-traditional uses. Surveys suitable for safety of navigation and charting have valuable secondary uses for coastal engineering and management as well as for habitat mapping and marine spatial planning. In turn, it encourages public bodies in the UK, when conducting bathymetry surveys for non-navigational purposes, to consider specifying Order 1a standard, where possible, so that the surveys are truly multi-purpose.

\section{REFERENCE}

Cazenave, P. W., Dix, J. K., Lambkin, D. O. and McNeill, L. C. (2012). A method for semi-automated objective quantification of linear bedforms from multi-scale digital elevation models. Earth Surface Processes and Landforms. doi: 10.1002/esp.3269

\section{ACKNOWLEDGEMENTS}

The seabed mapping was conducted under the auspices of the UK's MAREMAP project. The technical guidance of Dr Tim Le Bas (National Oceanography Centre) and Dr Justin Dix (University of Southampton) is acknowledged, with thanks, as is the assistance of Kent Wildlife Trust.

\section{BIOGRAPHIES}

Travis MASON is an oceanographer, specialising in coastal hydrodynamics and sediment transport. She is responsible for the SE and SW Regional Coastal Monitoring Programmes' extensive coastal wave and tide network in southern England, and also takes the lead for the introduction of Order 1a bathymetry to the new National Network of Coastal Monitoring Programmes of England.

Robert KINNEAR is a coastal process scientist undertaking marine habitat mapping of the Regional Coastal Monitoring Programmes' swath bathymetry data.

\section{Andrew COLENUTT is a Project Manager} specialising in flood and coastal erosion risk management. He is also responsible for technical oversight of the interpretation and production of marine habitat and substrate mapping of the swath bathymetry collected through the Regional Coastal Monitoring Programmes. 
André COCUCCIO is a marine geoscientist specialising in seabed survey and mapping to underpin safety of navigation in UK waters. He is the head of hydrography at the UK Maritime and Coastguard Agency, the principal hydrographer for the UK Civil Hydrography Programme and director of the European seabed mapping project "INIS Hydro".

David PARKER has worked in hydrography on every continent, including Antarctica, but within UK waters he is responsible for managing the UKHO's involvement in the Civil Hydrography Programme, in particular planning survey areas and defining technical requirements.

\section{CONTACT DETAILS}

\section{Travis MASON}

Channel Coastal Observatory

National Oceanography Centre

European Way

Southampton

UK

Tel.: +44 2380598467

Fax: +44 2380516320

Email:Travis.Mason@noc.soton.ac.uk

Web site: www.channelcoast.org 


\title{
A lithological and morphological map created from multibeam backscatter data in challenging circumstances: the Lower Sea Scheldt estuary
}

\author{
Mieke MATHYS and Marc SAS, Belgium \\ International Marine and Dredging Consultants (IMDC) \\ Frederik ROOSE, Belgium \\ Flemish Ministry of Mobility and Public Works, Maritime Access Division
}

Topic: Geophysics of the marine environment

\section{INTRODUCTION}

The Lower Sea Scheldt is regularly dredged to maintain the access to the harbour of Antwerp. The Maritime Access Division has the permission to relocate the dredged material within the Scheldt itself on the condition that a monitoring program is performed in order to detect any negative effects on the environment. The creation of a lithological and morphological map of the entire Lower Sea Scheldt is part of an extensive integrated monitoring program.

In the past, a lithological map was created based on the backscatter signal from singlebeam profiles and the morphological maps were created based on sidescan sonar data. The presented study investigated the feasibility and applied the most appropriate method to create a lithological and morphological map from full coverage multibeam backscatter data which are anyhow available from the regular depth soundings in the Lower Sea Scheldt.

\section{METHODS}

\section{Creation of a lithological map}

For the creation of the lithological map QTC MULTIVIEW ${ }^{\mathrm{TM}}$ is used. It is an integrated software package that classifies sediments using the amplitudes and statistical properties of backscatter images. Information is extracted from the amplitudes and variability of backscatter, and detailed bathymetry from the same survey is used for geometrical image compensation. Classification of the river bottom is done by an automated clustering method that adapts to the characteristics of the multibeam set. Each cluster or acoustic class represents a bottom type that can be identified based on ground truth.

If the bottom type is known before classification, data from the areas of diverse sediment types can be used to build a catalogue, which could then be used to classify subsequent or archived data. This is called supervised classification. The alternative, unsupervised classification, forms the data into logical clusters that can then be identified based on ground truth.

\section{Creation of a morphological map}

In the past, morphological maps were created based on side-scan sonar images. The disadvantage of this technique is that certain reflections due to sedimentological characteristics of the river bottom could not be distinguished from reflections due to the morphological character of the area.

A test was performed comparing the performance of both side-scan sonar and multibeam sonar over the same areas.

The following seven structural elements were recognized: large dunes $(\mathrm{H}=75 \mathrm{~cm}-5 \mathrm{~m}$; $\lambda=10 \mathrm{~m}-100 \mathrm{~m})$, small to middle-large dunes $(\mathrm{H}=7,5 \mathrm{~cm}-75 \mathrm{~cm} ; \lambda=60 \mathrm{~cm}-10 \mathrm{~m})$, slides, small scale cliffs, structureless bottom, dredging traces, irregular bottom structures.

\section{Multibeam campaigns}

Two different ships (Veremans and Parel2) were used to cover the Lower Sea Scheldt. One ship was used to sound the shallow tidal flat areas, the other 
ship recorded the deep channel areas. Multibeam sonars of type Simrad EM 3002 dual (frequency 300 $\mathrm{kHz}$, pulse rate $10 \mathrm{~Hz}$, pulse length $149 \mu \mathrm{s}$ ) were applied. Six section maps were created.

\section{$\underline{\text { Sampling campaigns and lab tests }}$}

Shortly after the multibeam recordings, for each section map, fifty control samples were taken with a Shipek bottom sampler. The samples were described and photographed on board and later analysed with a (laser diffraction) Malvern Mastersizer.

With the purpose of performing a supervised classification, at six reference locations, Shipek, Van Veen and box core samples were taken, during flood, ebb and slack time, followed by multibeam measurements in each area. The six reference locations represented areas with different lithology: sand, sandy mud, muddy sand, mud, hard soil due to clay, hard soil due to gravel. The backscatter data of the six reference zones were processed together to obtain a catalogue. Grain-size, carbon content and density profiles were determined of each calibration sample. To visualise the vertical structure of the subsurface also radiographs were taken.

In a final stage, validation samples were acquired to check the validity of the lithological map in areas which were not sampled before.

\section{CHALLENGING CIRCUMSTANCES}

The Lower Sea Scheldt estuary confronts us with challenging circumstances which are not present when mapping offshore areas with multibeam: during a tidal cycle, sediment concentration, salinity and water depth changes significantly. Moreover, due to the morphological character of the Lower Sea Scheldt two different ships were put into action to be able to cover both the deep channels and shallow tidal flats with multibeam.

$\underline{\text { Slack water and influence of sediment concentration }}$

Slack water is the moment when the ebb current changes into flood current (low water slack time) and reverse (high water slack time). Theoretically this coincides with the moment when the current velocity is zero. The moment of low and high water slack coincides, moreover, with the moment of minimum and maximum salinity respectively. During slack time, the current velocity is that low, that suspended sediment particles settle and form a high concentrated mud layer near the bottom. As a high-frequency $(300 \mathrm{kHz})$ multibeam is used, it is not unrealistic that during slack time, backscatter returns from the settled mud particles instead of the underlying bottom.

Two tests were performed to investigate the variations in acoustic backscatter during slack water. One test ran from high water to 2.5 hours after high water. The second test ran from 0.5 hours before low water to 1.75 hours after low water. During these periods, one track was repeatedly recorded and the created acoustic classification maps were compared. Only little variation was observed in the acoustic backscatter during slack water, mainly at the boundaries of the acoustic classes possibly due to differences in ship positioning between successive tracks.

\section{Absorption en refraction due to salt water and increasing water depth}

Absorption of noise by sea water is an important factor that can influence the results of highfrequency multibeam sonars (depending on temperature, water depth, salinity). This is especially the case in the Scheldt estuary where the salinity and water depth changes strongly over the tidal period and stratification occurs between fresh and salt water.

The QTC MULTIVIEW ${ }^{\mathrm{TM}}$ software is however developed in such a way that regular CTD measurements (Conductivity, Temperature, Depth) are not necessary. It concerns a classification method without knowing the absorption coefficient. An important part of the tool is a patented technique using compensation tables. The QTC compensation results in images consistent throughout the entire survey (normalized over the entire survey).

Backscatter is not expressed in physical units (e.g. backscatter amplitude in decibels), but in relative image amplitudes on a scale from 0 to 255 .

Nevertheless, the effect of salinity and the effectiveness of the software was tested using a simple set-up. The same survey line was analysed in case of two extreme salinity values (sound 
velocities). Few differences were observed between the positions of the footprints of the outermost beams, who would experience the strongest effect due to the longer distance these beams travel through the water column.

Changes in water depth also have an effect on swath width and resolution. In shallower areas, the swath width and foot print are smaller, but the same information is present, so more detail is captured. During the soundings one also has to ensure that the overlap between survey lines is sufficient. With changing water depth over the tide cyle, the spacing between survey lines has to be adapted.

\section{$\underline{\text { Recordings with two vessels }}$}

The effect of applying two different vessels with two multibeam transducers each, was tested qualitatively and quantitatively. In a first, qualitative test, the classification in acoustic classes was done on data from Parel2 and Veremans separately, and on a combination of the two integrated data sets, after which the resulting classification maps were compared. The integrated classification map differs clearly from the separate maps, mainly at the boundaries of the classes. The differences depend strongly on the percentage of the surface covered by the individual data sets.

In a second, quantitative test, the same two survey lines were recorded by both Parel 2 and Veremans (in the same direction) and the classification maps were subtracted to create difference maps. The differences between recordings of two vessels in an identical area were expressed in $\%$ of the total surface area. Also the reproducibility of a single transducer was tested, by covering a single line three times, over a time span of 8 minutes, in the same direction, with the same ship. Comparisons showed that differences between sequential measurements over a single line with the same transducer, were in the same order of magnitude as differences between transducers of two different ships, both in an acoustic homogeneous and heterogeneous area.

\section{Influence of oblique incidence}

From the previous test set-up, also the influence of the grazing and incidence angle (Figure 1) could be estimated, as a certain area was covered under two different angles with the same ship. A smaller incidence angle corresponds to a shorter distance between source and bottom, so less absorption in the water column. Results showed however that minor differences were due to navigation differences and not due a systematic error. It could be concluded that the QTC MULTIVIEW ${ }^{\mathrm{TM}}$ software compensates correctly for differences in travelled distance of the sound wave.

The grazing angle depends not only on the beam angle of the transmitted signal, but also on the local relief or morphology. That angle will determine how strong the signal is reflected and/or refracted. Also this effect is compensated by QTC MULTIVIEW ${ }^{\mathrm{TM}}$, and points with too sharp and too perpendicular grazing angles are removed from the data set.

\section{$\underline{\text { Time variations }}$}

As the section maps of the Lower Sea Scheldt were recorded over a period of more than one month, the effect of the time interval was investigated. Differences in maps created from data recorded with 1 week interval, apppeared to be mainly due to differences in positioning, than due to lithological changes. One exception, but only visible on the bathymetric maps, when sections were sounded just before and just after dredging works, adjacent sections show then a clear different morphology (cut-off dredging tracks next to smooth surface).

\section{CREATION OF A LITHOLOGICAL MAP}

\section{Processing and visualisation of data}

In a first step the ideal parameter settings were investigated to processes the raw data (threshold value for removal of spikes, masking of beams with certain grazing angle, removal of overlapping beams). And the best solution was sougth between data reduction (to reduce calculation time) and resolution of the maps.

In a second step, the best visualisation parameters were defined for the final classification maps (grid cell size, interpolation distance, number of data points within interpolation radius). The best settings showed no longer the sailing tracks, but still enough heterogenity in acoustic classes.

Afterwards, the influence of the software clustering 
settings on the resulting classification maps was tested. Using a different number of records, may result in a different number of acoustic classes. The minimal number of records and iterations needed for the clustering process were determined $(50 \%$ and 5 iteractions resp.).

The number of acoustic classes can be determined by the user (supervised classification) or the optimum number of classes can be determined statistically by the software (within a choosen range) (unsupervised classification).

\section{$\underline{\text { Supervised classification }}$}

Initially, a supervised classification was performed: the backscatter data of six lithological reference zones were processed together to obtain a 'catalogue' with a number of acoustic classes. Various catalogues with a different preset number of acoustic classes (6-7-9-15 classes) were tested by comparing the obtained classification maps in the reference areas with the calibration sediment samples. The best catalogue would then be applied to the entire Lower Sea Scheldt multibeam data set.

A catalogue of six acoustic classes was aimed for (corresponding to six lithologies: sand, sandy mud, muddy sand, mud, hard soil due to clay, hard soil due to gravel). But in fact, the catalogue which gave the best results (most samples with the same lithology belonging to the same acoustic class, least outliers within a certain class) had 15 acoustic classes. However, after applying this catalogue to the entire Lower Sea Scheldt data set, only 3 lithological facies could be discerned: mud, hard soil and a class covering 'sand-sandy mud-muddy sand'. After comparison with calibration and validation samples, it appeared that more than one acoustic class had the same lithology and that within one acoustic class different lithologies occurred.

\section{$\underline{\text { Unsupervised classification }}$}

As the supervised classification map did not give any surplus value over past maps, also unsupervised classification was considered. A catalogue was created now from the entire Lower Sea Scheldt multibeam data set, instead of using only a restricted reference area as was the case for the supervised classification. The optimum number of acoustic classes was statistically determined by the software iteration process, i.e. 14 acoustic classes. Afterwards the catalogue was applied to the same Lower Sea Scheldt data set to get a classification map. Based on the sediment samples, the acoustic classes could be lithologically interpreted.

The unsupervised classification map was considered the best lithological map, discerning 5 lithological classes: sand, hard soil, mud and two classes with different acoustic signature of 'sand-sandy mud-muddy sand'. Most likely the unsupervised map discerns more lithological classes than the supervised map because the complete backscatter dataset was used to set up the catalogue, which is important in a heterogeneous area as the Scheldt estuary.

\section{CREATION OF A MORPHOLOGICAL MAP}

Eight zones with a typical morphology were simultaneously surveyed with side-scan sonar (SSS) and multibeam. Comparison of the data showed that multibeam bathymetric data are more suited to distinguish morphological elements than SSS data. SSS data give a detailed photographic image of the seafloor, but contain no bathymetric information. Morphological structures, such as dune, cliffs and dredging tracks, are identified from differences in backscatter intensity. However, strong backscatter can on the one hand indicate that the seafloor is facing the transducer, but on the other hand, can also indicate a lithological facies like sand. In an area where on multibeam data clear bathymetric differences were recorded, on the SSS data, shade differences were wrongly interpreted as facies differences on a structureless bottom.

To be able to detect morphological units, hillshades were generated from the multibeam data. It is a shadow with a certain azimuth, altitude and exaggeration factor, placed on top of the bathymetric map to visually accentuate bathymetric differences. Seven structural elements were mapped by manually drawing polygons around areas with: large dunes $(\mathrm{H}=75 \mathrm{~cm}-5 \mathrm{~m} ; \lambda=10 \mathrm{~m}-100 \mathrm{~m})$, small to middle-large dunes $(\mathrm{H}=7,5 \mathrm{~cm}-75 \mathrm{~cm} ; \lambda=60 \mathrm{~cm}-$ $10 \mathrm{~m}$ ), slides, small scale cliffs, structureless bottom, dredging traces and irregular bottom structures.

\section{2 | Hydrol 2}




\section{RECOMMENDATIONS}

\section{Frequency multibeam}

The applied high-frequency multibeam $(300 \mathrm{kHz})$ gives a high resolution, but a very shallow penetration depth. The backscatter signal is therefore only determined by the characteristics of the water-bottom or water-top mud interface (roughness, grain size) and not by the characteristics of the underlying sediment volume. That is most likely the reason why 'mud' and 'hard soil' can belong to the same acoustic class. They most likely have similar interface characteristics (smoothness, specular surface).

A lower frequency multibeam (ca. $30 \mathrm{kHz}$ ) would have a larger penetration depth and capture the characteristics of the top sediment volume, and most likely be able to better distinguish between grainsizes, e.g. muddy sand and sandy mud.

\section{$\underline{\text { Sampling strategy }}$}

In case of supervised classification, a more intensive calibration sediment sampling campaign is suggested. By taken more samples statistically, the number of outlyers within a certain lithological classe will reduce. The sampling should also be performed over a more structured grid with samples at regular distances along transects crossing the boundaries of previously defined acoustic classes.

A detailed description of the samples on board is crucial. E.g. the presence of a fine mud layer at the top can strongly influence the acoustic backscatter signature, but will not appear from lab analyses. Also the presence of gravel, present as scattered boulders or as a continuous layer will give a very different acoustic reflection, although the percentage of boulders determined in the lab will be the same.

In contrast to the supervised classification, in which is started from a number of predefined lithological classes, the unsupervised classification allows to examine purposively why a certain area belongs to a specific acoustic class and the class next to it differs from it, taking into account not only grain size, but also structural elements and mixture of gravel, plant fragments, etc. It was observed during this project that 'hard soil' can belong to different acoustic classes and also 'mud' can have different acoustic signatures (e.g. consolidated crumbly mud versus sludgy mud).

It is recommended to take sediment samples along transects crossing different acoustic classes, in order to capture the lithological and structural evolution over the boundaries. Both the detailed description on board and the lab tests afterwards will show whether the acoustic change is due changing shell content, changing grain size, presence of gravel or plant material, presence of mud layer, etc. Without presuming that the acoustic classes are defined by grain size only (as was the case for the supervised classification).

\section{CONCLUSION}

As the study area is a tide-dominated estuary, water level, currents, salinity and sediment concentration in the water column vary strongly over a tidal cycle. Several tests showed, however, that the moment at which the multibeam data were recorded was not of importance. There were no meaningful differences observed between acoustic maps created from recordings at different moments in the tidal cycle. Variations in salinity, temperature and water depth are correctly compensated by the QTC MULTIVIEW $^{\mathrm{TM}}$ software.

Preference is given to unsupervised classification of the multibeam backscatter data. In a heterogeneous environment as the Lower Sea Scheldt it is important that the entire backscatter data set is used to created acoustic classification maps, instead of applying a catalogue from a restricted reference area to the entire investigation area (supervised classification). The unsupervised classification method should be combined with a structured and detailed sampling campaign which describes more than grain size alone. The obtained optimum number of acoustic classes should be ground-truthed in terms of characteristics of the water-bottom interface when applying a high-frequency multibeam sonar $(300 \mathrm{kHz})$. In case of applying a lower frequency multibeam sonar $(30 \mathrm{kHz})$, the characteristics (especially grain-size) of the underlying sediment volume will become more important. 


\section{ACKNOWLEDGEMENTS}

We want to thank the Flemish Hydrography for the high-quality multibeam recordings and for placing survey vessels and crew at our disposal during sampling campaigns.

We also want to acknowledge the Hydrology and Hydraulic Engineering department of VUB (Vrije Universiteit Brussel) and the Flanders Hydraulics Research centre for the analyses of sediment samples.

\section{CONTACT DETAILS}

Mieke Mathys

International Marine and Dredging Consultants

(IMDC)

Coveliersstraat 15

B-2600 Berchem, Belgium

Email: mim@imdc.be.

T: +32327092 21 .

www.imdc.be 


\section{INS aided subsurface positioning for ROV surveys}

Michiel VAN DE MUNT, Robert VAN DER VELDEN and Karel EPKE, the Netherlands Allseas Engineering B.V.

Topic: Subsea positioning

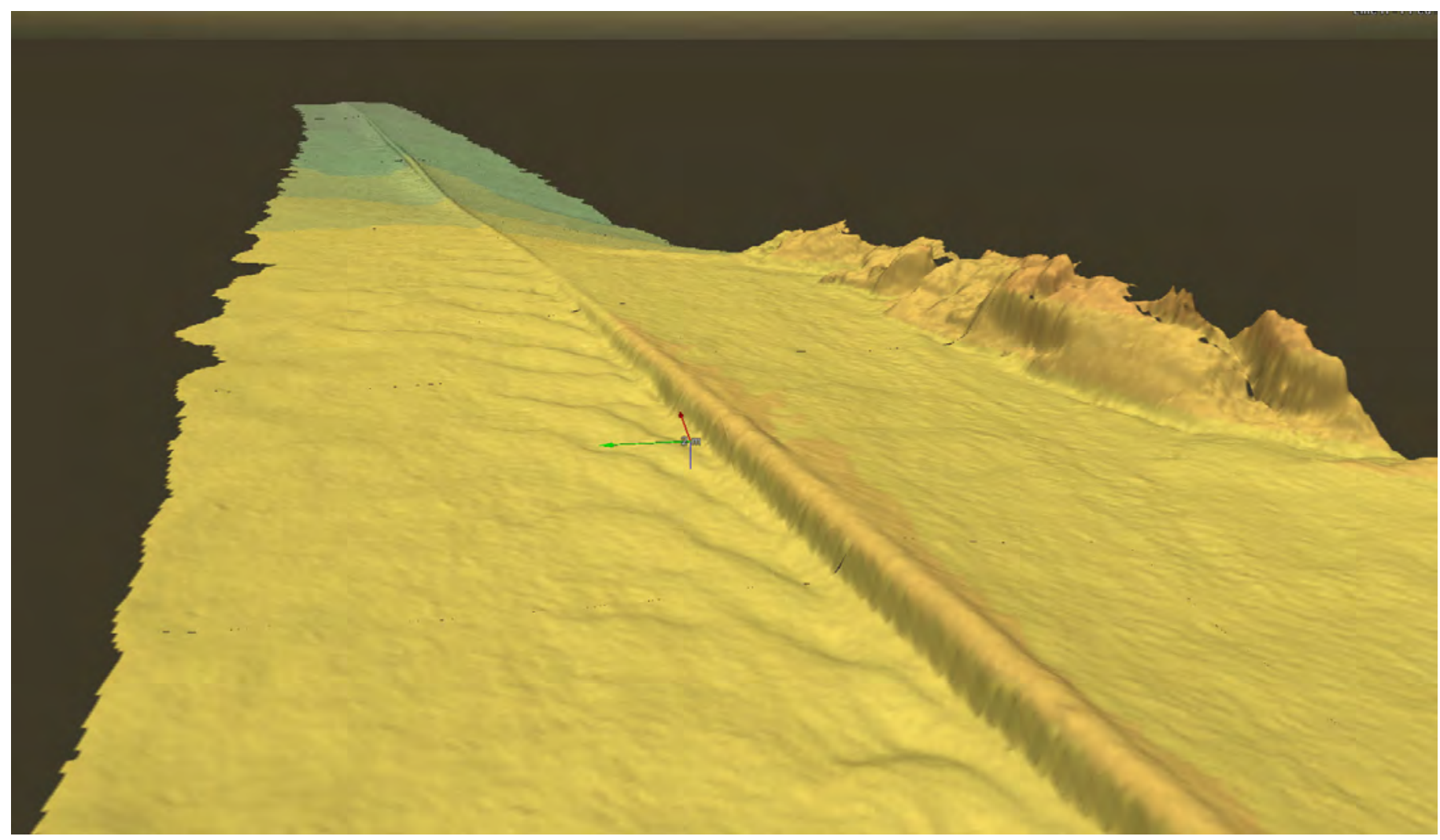

\section{INTRODUCTION}

ROV positions are established using a combination of surface and subsurface navigation systems aided by heading and motion sensors that provide global coordinates for the subsea sensor platform in near real-time. In past decades, the performance of these systems has gradually improved but not sufficiently to keep pace with the rapid move into (ultra) deep water and the related optimisation of pipeline design, especially for gas pipelines with hot mixtures. The current designs for 'hot' subsea pipelines require very tight measuring tolerances generally beyond the unaided capabilities of the acoustic (USBL) positioning systems.

A subsea pipeline which operates at temperatures and pressures above seabed ambient conditions will expand. If this expansion is restrained, for example by axial friction between the pipeline and the seabed, the axial force generated in the 'hot' pipeline could lead to localised and uncontrolled buckling. By controlling the pipeline's "relative" trajectory in three dimensions buckling can be avoided. Accurate positioning in $\mathrm{X}, \mathrm{Y}, \mathrm{Z}$, is crucial for the determination of any significant small pipeline deflections. These accurate ROV pipeline surveys are referred to as out-of-straightness (OOS) surveys.

Since the early 1990s, Doppler Velocity Logs (DVLs) are installed on ROVs to enhance the Ultra Short BaseLine (USBL) position by integrating the relative short-term accuracy of the DVL with the absolute long-term accuracy of the USBL systems. Integration was based on a variety of mathematical routines of which Kalman filtering is the most commonly used. In the past decade, with the launch of commercial AUVs, the combination of INS and DVL became a primary positioning solution for these platforms, acquiring high precision geophysical data in deeper water. Absolute positioning of these platforms is achieved 


\begin{tabular}{|l|l|}
\hline \multicolumn{2}{|c|}{ Standard survey equipment fitted on the ROV in addition to INS } \\
\hline \multicolumn{1}{|c|}{ Instrument } & \multicolumn{1}{c|}{ Type } \\
\hline Surface positioning & Veripos Ultra \\
\hline Vessel heading and motion sensor & IXSEA Octans \\
\hline Underwater positioning & Kongsberg Dual HiPAP500 \\
\hline Transponders & Sonardyne WSM \\
\hline ROV heading and motion sensor & IXSEA Octans \\
\hline Multibeam echosounder & Dual-head Reson Seabat 7125 \\
\hline Depth sensor & Paroscientific Digiquartz \\
\hline Altimeter & Kongsberg 1007 \\
\hline Doppler Velocity Log & RDI 1200kHz Workhorse Navigator \\
\hline Sound velocity sensor and CTD probe & Valeport SVX2 \\
\hline Obstacle avoidance sonar & Kongsberg MS1000 \\
\hline
\end{tabular}

\begin{tabular}{|l|l|}
\hline \multicolumn{2}{|c|}{ Survey software in addition to INS software } \\
\hline \multicolumn{1}{|c|}{ Package } & \multicolumn{1}{|c|}{ Type } \\
\hline Online DGNSS QC & Veripos VeriFy QC \\
\hline Online positioning & EIVA NaviPac \\
\hline ROV sensor data logging & EIVA NaviScan \\
\hline Survey data processing & EIVA NaviEdit \& NaviModel 3D \\
\hline
\end{tabular}

\begin{tabular}{|l|l|}
\hline \multicolumn{2}{|c|}{ ROV INS hardware \& software } \\
\hline \multicolumn{1}{|c|}{ Manufacturer } & Hardware - (processing) software \\
\hline IXSEA & PHINS - Delph-INS \\
\hline Kongsberg & ROV HAIN - NavLab \\
\hline Sonardyne & Lodestar SPRINT - Janus \\
\hline
\end{tabular}

Table 1.

through adding sparse DGNSS or acoustics during post processing. Migration of the same technology onto the ROV platform is a challenge and is not as straightforward as it may seem.

The presentation provides the results of various trials conducted by Allseas with INS aided ROV positioning along offshore pipelines. Included are comparisons between various combinations of ROV positioning survey sensor data. Although trials were performed in both 2009 and 2012, the presentation focusses on the most recent trials with the Sonardyne SPRINT system in April 2012. The experience gained during the 2009 trials provided the basis for the recent tests.

\section{METHODOLOGY}

To analyse the performance of a ROV mounted INS, a methodology was developed to survey the same section of a pipeline on the seabed multiple times and in opposite directions.

A pipeline provides a good bench mark for the positioning systems and their repeatability, which is easily checked by comparing the processed pipeline positions for each pass. A ROV mounted multibeam is required to generate the high density data necessary to accurately detect the top of the pipeline. This then allows for an accurate comparison between the pipeline positions derived from the various passes.

\begin{tabular}{l} 
Calibrations prior to ROV INS survey work \\
\multicolumn{1}{c|}{ Task } \\
\hline Local vessel and ROV offsets \\
\hline Calibration SV and CTD probe \\
\hline DGNSS health check \\
\hline Vessel gyro, pitch, roll calibration \\
\hline ROV gyro, pitch, roll calibration \\
\hline APOS (HiPAP) calibration \\
\hline ROV dual head multibeam calibration \\
\hline DVL alignment to INS \\
\hline Position confirmation checks \\
\hline
\end{tabular}

Table 2. 


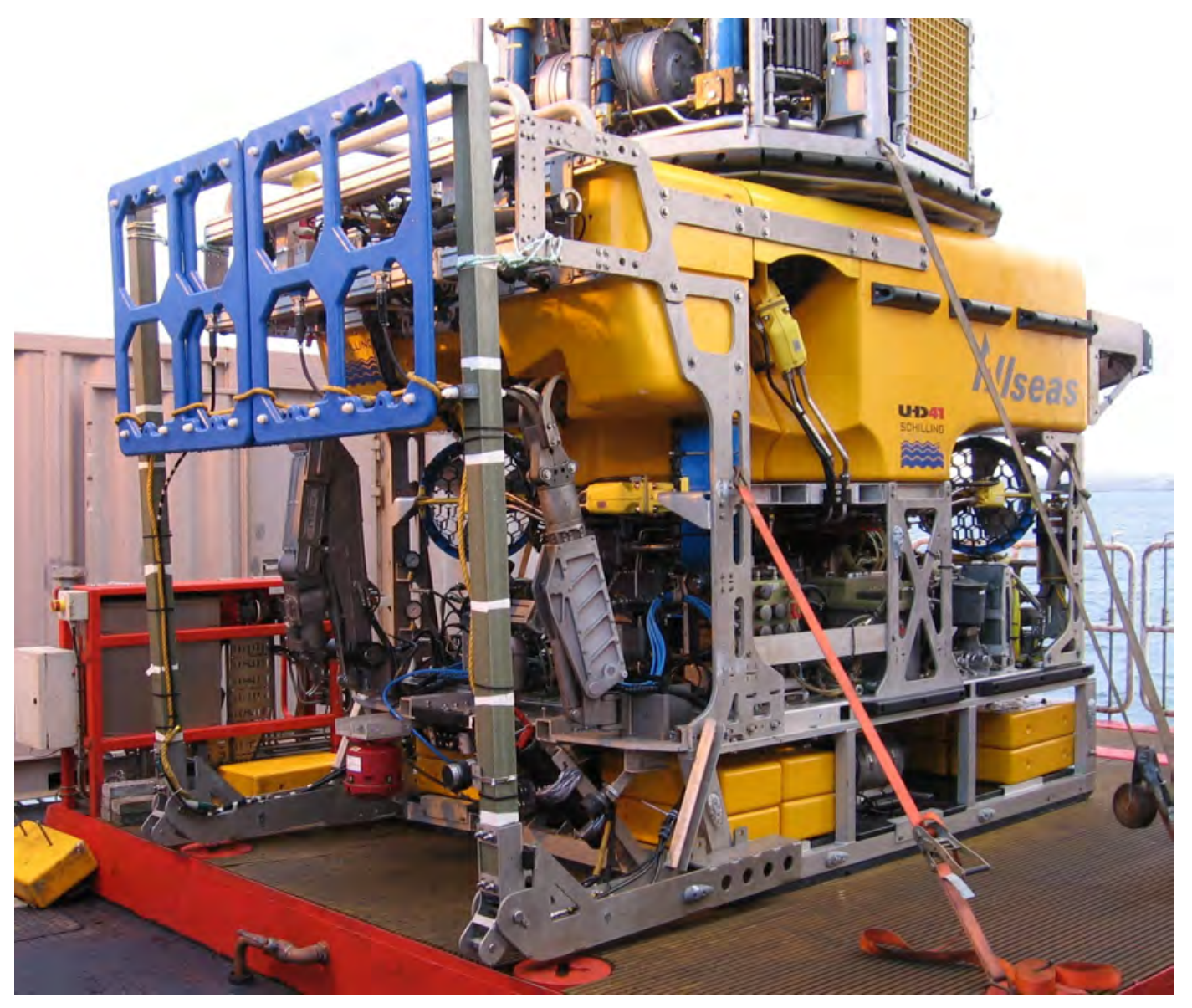

Figure 1: April 2012 ROV with INS mounted on survey skid

To check the impact of the range dependent USBL positioning accuracies in the equation, it is best to repeat the test for different water depths, covering both shallow and deep water.

The integration of USBL, DVL and INS was first adopted by Allseas for a project in Northwest of Australia. INS/DVL in combination with a conventional acoustic positioning system had to demonstrate the ability to detect a $20 \mathrm{~cm}$ deflection over a $50 \mathrm{~m}$ length of pipeline. Tests were performed with the Kongsberg HAIN system and IXSEA PHINS. Two years later, a similar set-up was tested with a Sonardyne SPRINT/Lodestar system offshore the Shetland Islands.

\section{HARDWARE AND SOFTWARE}

For both tests, offshore NW Australia and the Shetlands, an Allseas Schilling Robotics UHD ROV system was used as the instrument carrier. This system has a patented station keeping facility, allowing for steady and automatically controlled guidance along a predefined route section.

\section{INSTALLATION}

Two types of installation were trialled. In 2009 a bracket was made at the front of an UHD ROV to fit the integrated IMU and DVL. In 2012 the instruments were separated: the INS was mounted on the survey skid whereas the dedicated DVL and depth sensor were mounted at an offset.

The required calibrations were performed according to standard procedures. The dedicated DVL was calibrated to align with the heading sensor in the INS. For clarity the calibration sequence is listed in table 2 .

\section{RESULTS}

\section{Test}

In 2009 ROV INS tests were performed for a project in NW Australia. A detection criterion of $20 \mathrm{~cm}$ deflection over a $50 \mathrm{~m}$ length was defined. Both IXSEA and Kongsberg INS solutions were tested. Minimum four ROV passes along same pipeline segments were run in shallow and deep water depths of $85 \mathrm{~m}$ and $827 \mathrm{~m}$ respectively. A dual headed multibeam mounted on the ROV provided detailed 
digital terrain models along the pipeline. Calculated values for the top of the pipeline were extracted from digital terrain models. Results were compared to check compliance with the above described deflection criteria.

The IXSEA product provided a solution in real-time from a PHINS. However, the results at the time did not meet the criteria. After further detailed study in the office, post-processed results could be provided ultimately that passed the test.

The Kongsberg all integrated system provided on board post-processed results above expectations and within a short time frame.

Subsequently, the Kongsberg solution was selected for the out-of-straightness survey works.

\section{$\underline{2012 \text { Test }}$}

Based on the experience in 2009, a further test was scheduled to also investigate the performance of the new Sonardyne Lodestar SPRINT system and to compare different positioning solutions with and without INS, both in real-time and post-processed.
The test was performed in April 2012, with a similar type UHD ROV system equipped with the same standard survey instrumentation as in 2009.

The Sonardyne Lodestar INS, was configured to provide both an INS aided positioning solution and heading, pitch, roll and heave data.

$500 \mathrm{~m}$ segments of pipeline were surveyed four times in opposite directions. For the first segment, which is highlighted in this paper, lines A-D, lines A and $\mathrm{C}$ are surveyed in opposite direction to lines $\mathrm{B}$ and $\mathrm{D}$. The water depth at the survey location varied between $60 \mathrm{~m}$ and $80 \mathrm{~m}$.

The collected data was processed using four different positioning solutions:

1. Post-processed DVL enhanced USBL positioning, using EIVA NaviEdit software;

2. Post-processed DVL enhanced USBL positioning, without INS, further smoothed using in-house developed filter based on pipeline characteristics based on minimum bending radii;

3. Real-time INS aided by USBL/DVL positioning, using Sonardyne SPRINT Kalman filtered output;

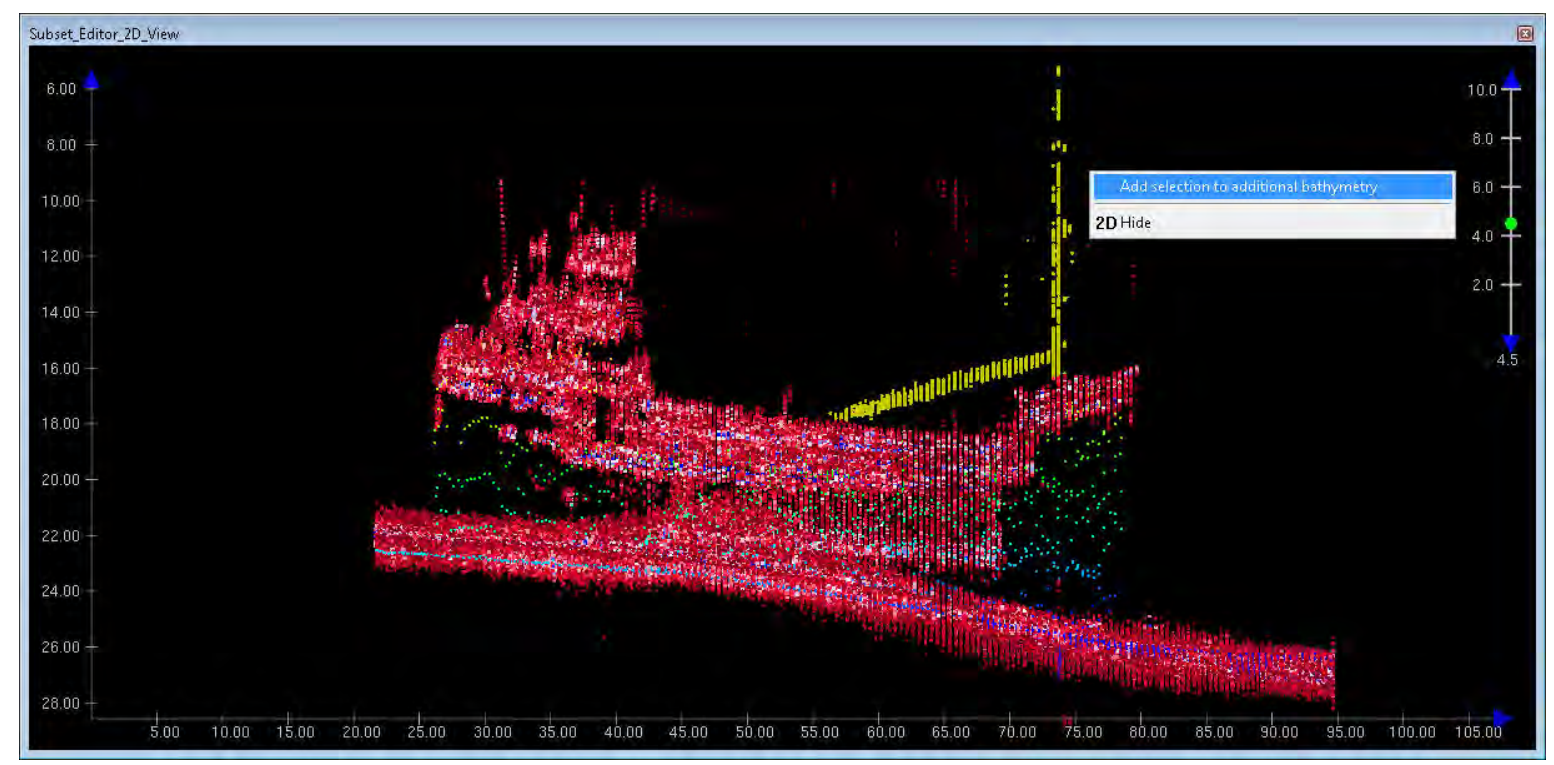

Figure 2: Resulting DTMs for the four positioning solutions - EIVA Navimodel 


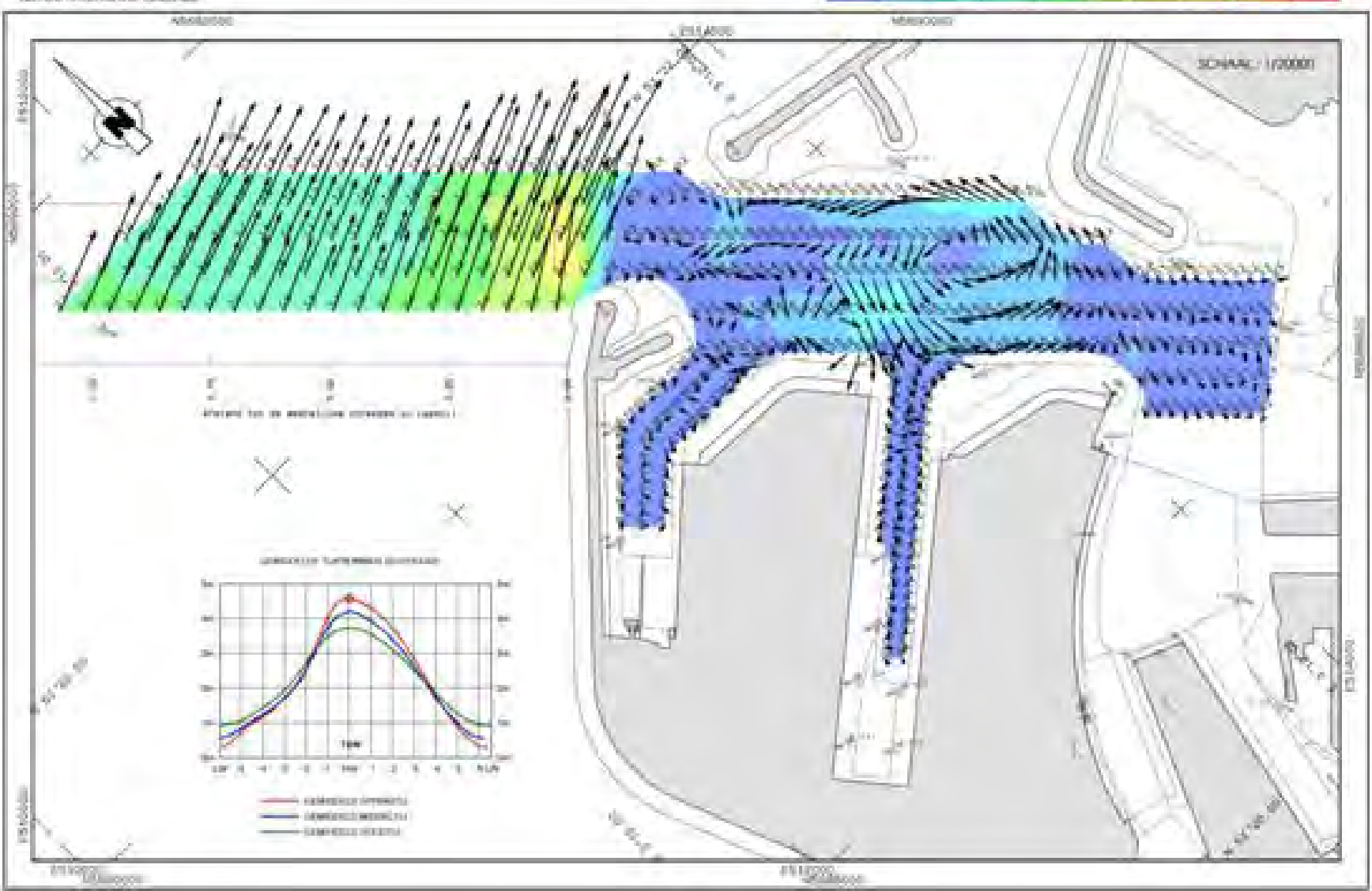

Figure 3: Relative comparison based on DOT values 


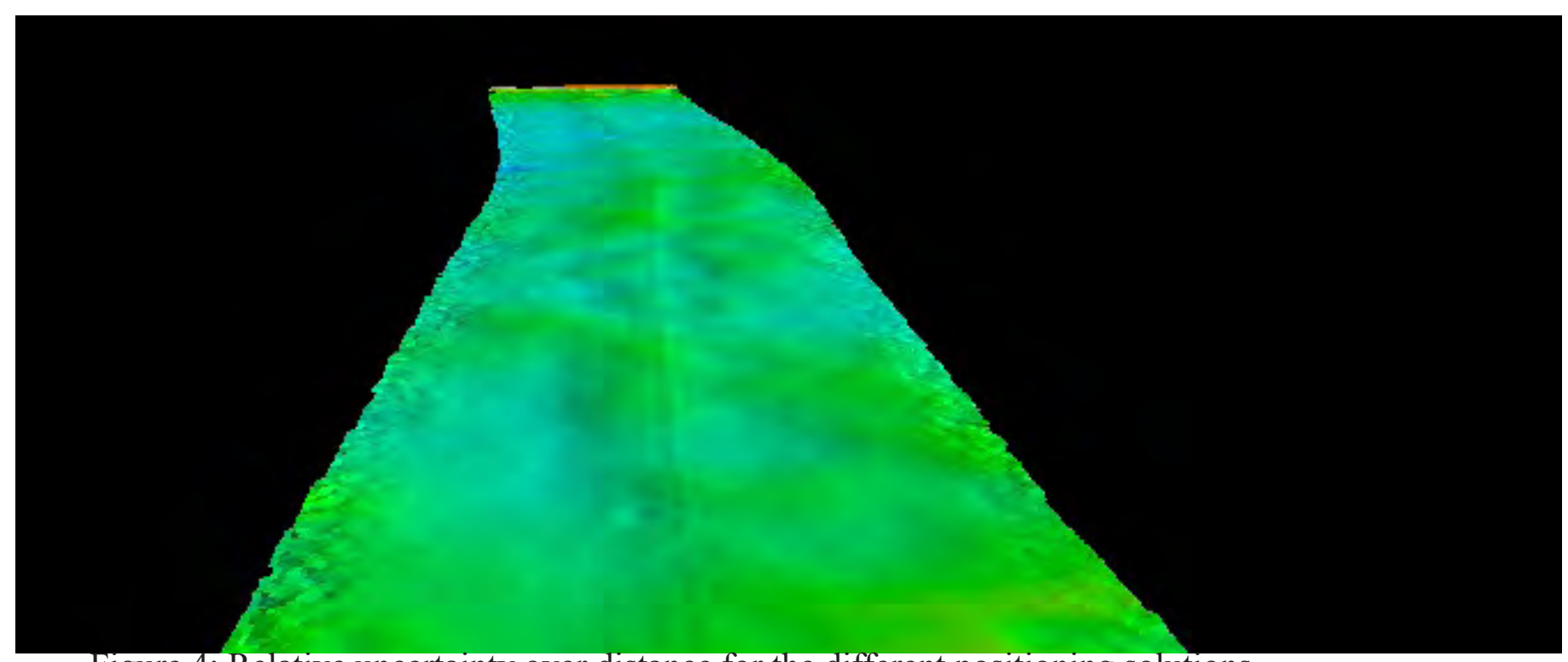

Figure 4: Relative uncertainty over distance for the different positioning solutions

4. Post-processed INS aided by USBL/DVL positioning, using Janus post-processing software.

Each positioning solution was used to generate detailed digital terrain models. Examples from the resulting DTMs using the USBL/DVL and the postprocessed INS solution are shown in Figure 2.

The USBL/DVL solution (1) showed artefacts in both the horizontal and vertical position of the pipeline. These are caused by USBL uncertainties and swell effects recorded by the depth sensor. Of all four positioning solutions, the post-processed INS (4) showed the best result.

The DTMs were used to determine the position of the pipeline. Using these pipeline positions, distance-of-track (DOT) offsets were computed relative to a reference line. The offsets allowed for a relative comparison in the $2 \mathrm{D}$ horizontal plane, as shown in figure 3.

Comparing the four graphs of figure 3, correlation between the four survey lines seemed to improve from positioning solution 1 to positioning solution 4 .

This is better shown in figure 4, which provides a better visualisation on the detection capability of lateral pipeline deflections for each positioning solution.
Results of figure 4 were computed using the following method:

- For each positioning solution, the initial DOT values were set to zero;

- The maximum difference between the DOT values for each line were calculated at a metre interval up to a distance of $100 \mathrm{~m}$;

- This process was repeated by moving the start point for the $100 \mathrm{~m}$ section one metre along the data set of $500 \mathrm{~m}$;

- Each point with a metre interval now included multiple values for the maximum DOT differences;

- By calculating the average and standard deviation for the DOT differences at a metre interval, the uncertainty for the measurements was determined within a $95 \%$ confidence level.

In figure 4, the maximum uncertainty in the measurements is shown for each metre distance over a length of $100 \mathrm{~m}$. Based on a $95 \%$ confidence level for solution 4, a lateral pipeline deflection of $20 \mathrm{~cm}$ can be determined over travelled distances of up to $100 \mathrm{~m}$.

\section{CONCLUSIONS}

\section{Test}

The test with the IXSEA system showed at the time that a real-time (PHINS) INS aided by USBL/ DVL positioning solution could not meet the specifications. 
The Kongsberg system clearly demonstrated that on board post-processed HAIN INS aided by HiPAP/DVL positioning in a water depth ranging from $85 \mathrm{~m}$ to $827 \mathrm{~m}$ was accurate with good correlation between subsequent survey runs along the same pipeline segment. In the detailed digital terrain models along the same pipeline segment, the positions of anodes, field joints, as well the curvature of the pipeline was checked. This test in NW Australia demonstrated that an integrated (HAIN) ROV INS is capable of detecting a $20 \mathrm{~cm}$ pipeline deflection over a $50 \mathrm{~m}$ pipeline length after on board post-processing.

\section{$\underline{2012 \text { Test }}$}

Analyses of the April 2012 results showed as expected that the post-processed INS provided the best positioning solution. Results exceeded the out-of-straightness survey specifications to detect a deflection of $20 \mathrm{~cm}$ over a $50 \mathrm{~m}$ pipeline length for water depths ranging from $60 \mathrm{~m}$ to $80 \mathrm{~m}$.

The fact that the IMU was not mounted above the DVL, was not observed to have a significant impact on the results.

Furthermore, the trials demonstrated that integration of different manufacturer type survey instrumentation, such as Kongsberg HiPAP, RDI DVL and Paroscientific Digiquartz, provided good results facilitating universal deployment of the methodology. 
202 | Hydrol 2 


\section{Recruiting and Training for the Future - Marine Geospatial Information Learning}

\author{
Shekhar MURTHY, India \\ IIC Technologies Academy
}

Duncan WARDLE, United Kingdom

IIC Technologies Group

Derrick PEYTON, Canada

IIC Technologies Group

Topic: The hydrographic profession

\section{INTRODUCTION}

Amongst its wide range of geospatial services, IIC has been producing ENCs and Charts on behalf of hydrographic offices for more than a decade. During this time we have trained several hundred people in various elements of nautical cartography. We have recognised for some time that the competences of our people will be the biggest single differentiator for survival and growth in the future. The development of our people therefore plays a crucial role in aligning our business performance to organisational goals. We have seen over the past couple of decades a degree of academic rigour introduced into hydrography through the Standards of Competence of FIG/IHO/ICA. S5 (hydrographic surveying) and S8 (nautical cartography) that comprehensively outline the subject matter to be taught. However, the effectiveness of training is not just about getting the content right; it is as much about the method of delivery and the means of instruction is largely left to the discretion of the teaching establishment. When designing a course, the mode of learning needs to receive as much attention as the syllabus if the overall effectiveness of the training is to be maximised.

The IIC Academy has recently designed a Marine Geospatial Information (MGI) learning programme - a Category B recognised course based on the S8 nautical cartography syllabus. We present it as a Case Study in the design of an effective mode of learning delivery. We start by looking at the needs of both organisation and individual, from which design principles can be derived for appropriate educational techniques. At the heart of the delivery is experiential learning, a "learn by doing" approach embed- ded within each element of the programme. This is supported by a blend of other teaching interventions and resources, including a "virtual faculty". The aim is to harness contemporary methods better to meet the demands of the modern generation of learners. Focusing more on the way we deliver course content is having a fundamental impact on the quality of the services we provide. This in turn is at the heart of all of our work in supporting the maritime infrastructure.

\section{IS THERE REALLY A PROBLEM IN THE CLASSROOM?}

Apparently there is a problem in the classroom. Research is showing that the new generation is not responding to traditional modes of instruction. We all face pressures to get value from the large investments made in educating our people. In 2010, through the IIC Academy, we set out to formalise our Marine Geospatial Information learning programme and bring it fully into line with the FIG/ IHO/ICA S8 Standards of Competence. The S8 syllabus is very well defined and with some enhancements we were able to construct course content that would cover the full range of our project work in support of national hydrographic organisations. More problematic was the way we would deliver the programme. We wanted to look beyond conventional course structures based on continuous classroom based instruction. Our motivation was simple: improve the delivery of the programme, so improve individual performance and thus improve organisational performance. To start we asked a series of questions. 
- What do we need from the course as an organisation?

- What do the students need (and want)?

- What are the strengths and the weaknesses of our existing training programmes?

- What can we learn from benchmarking other courses inside and outside our domain?

- How do we integrate the lessons learnt into the S8 MGI course design?

We will not dwell on the process that took us through answering these questions but present some of the findings that led to our design criteria for the MGI programme.

\section{ALIGNING ACADEMIC TRAINING TO ORGA- NISATIONAL STRATEGIES AND OBJECTIVES}

We have a Quality Management System in place whereby we strive to align our learning programmes to our organisational strategies and objectives. We review the effectiveness of training not just by tests and exams following training courses but later through performance metrics within our projects. As part of a continuous improvement programme we ask whether we can improve the effectiveness of our educational techniques and thus our performance and quality of output. The review we conducted as part of our MGI course design highlighted two interrelated elements that we felt could give our training more impact.

- Improved timing of the learning to optimise its impact.

- Ensuring the training is absolutely current and relevant to the work environment.

We read of debates as to whether training should be "just in time" or "just in case", often with it being presented as an "either - or" option. We analysed our own past training, looking at the knowledge we need, dividing it into three categories.

1. The tools of the trade: fast retreating are the days of pen and ink cartography. We are now in the digital world of MGI, and the new tools of the trade are software applications.

2. The underlying theory: it is essential to explain why something is done, i.e. what is going on in that black box - we need to prevent the unquestioning use of those software applications.
3. The practical application of both theory and tools of the trade; that is, understanding how something is done.

For the first category, the tools of the trade, we concluded it is neither just in time or just in case, it is a third category: "just has to be". Learning how to use a word processing package whilst you are writing a novel can only be demotivating and distracting. We find the same thing. Induction needs to ensure a degree of familiarity with the basic software tools of the trade. It yields rapid results. It motivates. It helps when teaching more of the "why and how". It needs to be out of the way before the more complex activities are undertaken.

For the second category, the underlying theory, we favour a "just in case" approach but with a caveat. Teaching the "how to do something" becomes more effective if some basic concepts are understood. Underlying this principle is the belief that to produce a quality chart or ENC, you need to know the full context of what you are doing - whether it be how a chart is used for navigation or how a border is constructed by the black box of modern software. The caveat comes in that the theoretical elements need to be refreshed and reinforced by seeing that theory in practice. Repetition and reinforcement of some of that theory is an additional overhead but necessary at the point the "just in time training" may be delivered.

Finally, for the third category of practical applications, then "just in time" wins hands down. Teach, and then consolidate as quickly as possible, is a well-trodden and proven path with which we have no reason to argue.

A statement of the blindingly obvious: to provide services effectively our knowledge has to be absolutely up-to-date. "Knowledge currency" is the basis of every aspect of our work. We need to know the latest standards and the latest techniques. This is a fundamental connection between the MGI learning programme and the organisational objectives. Without this we cannot gain a competitive advantage or undertake our work efficiently. We have to ensure that the teaching of the subject matter is continuously kept relevant. So we find course delivery needs to weave into the framework a blend, mixing "just have to" with "just in case" with "just in time". 
This means accepting repetition. There are some competences and knowledge that have to be laid as a foundation but then repeated and reinforced through consolidation at a later time through practical experiences.

\section{GIVING MORE REALISM AND RELEVANCE FOR THE NEW GENERATION OF MILLENNI- ALS}

Next, we turned our attention to the "target audience" - the new recruits and potential students and what they might need (and want). This new generation is different and will change our world of hydrography (Casey, 2009). They go by various names, such as the download generation or digital natives (in contrast to the digital immigrants who have not had the benefit of growing up immersed in the new technology) (Prensky 2001). We use the term "millennials". What are their characteristics? They are said to be a confident lot - they have been raised by parents who believed in their self-esteem. They question authority and are not afraid of debate. Some may see these as a challenge in the classroom but in the workplace they are strengths to be harnessed. It still seems that much teaching is: "rooted on how to tame youngsters to our way of living and working rather than to redesign our academic and workspaces to take advantage of their strengths" (Murthy 2011).

When it comes to learning, millennials exhibit several characteristics of which to take account.

- The Classroom. Research indicates that $65 \%$ of teaching is still conventional classroom based. Whilst we believe that the role of a teacher as a facilitator cannot be over-emphasized, the "sage on the stage" approach remains dominant decades after it was identified as needing reform.

- The Content. The immediacy of everything surrounding the millennial brings a desire for realism and relevance to the education rather than abstraction. An approach to learning through case-studies with a degree of real world realism has been in vogue for several years and is well suited to this generation.

- Assignments. We are told millennials are turned off with boring, structured, and bookish assignment submissions. They exhibit a "challenge me" attitude. The assignments have to be tailored accordingly - not an easy thing to achieve.
This may all be considered in line with current fads but should it be us the teachers that adapt and keep in tune with current fads, as it is this that draws their interest?

If it is the millennials that are going to form our future workforce, then we take the view our educational policies, methods, and processes must be millennial-centric, rather than historic.

"our digital immigrant instructors, who speak an outdated language (that of the pre-digital age), are struggling to teach a population that speaks an entirely new language" (Prensky 2001).

We were relieved to find more coincidence than clashes between the organisational needs and those of the individual. There was enough to convince us that we had to change the emphasis of tuition. It is also too simplistic to make the leap from the profile of millennial learners and assume that e-learning is the answer. Evidence points to the importance of interaction and collaborative activities. Also, it is too easy to dismiss altogether classroom teaching as being outmoded. We took the view that classroom teaching has a major part to play but as expressed by Shepherd (2011) that classroom courses "are at their best when collaborative and practical" and at their worst "when trainer centred as sage on the stage". Realism and relevance are two by-words we took to the design phase.

\section{THE IIC ACADEMY MGI LEARNING PRO- GRAMME DEFINED}

It is always difficult to avoid passing fads but the IIC Academy has studied the effectiveness of methods of teaching within academic circles (Murthy 2008, 2011) from which we were able to derive some core design principles that would meet our objectives for the MGI programme.

- Learn by doing (experiential learning techniques).

- Mix our teaching methods between traditional and unconventional (blended learning).

- Providing greater access to learning resources and the "virtual faculty". 


\section{Experiential Learning at a Macro and Micro Level}

The first of our design principles - experiential learning - is not new. As an academic doctrine it has its origins back in the seventies. Experiential learning is what it says: learning through experience. The key is however a cycle that moves from the experience, through to reflecting on that experience, then consolidation of the theoretical ideas behind that experience and moving into applying what has been learnt at the start of another cycle of learning (Murthy and Naraharisetty 2008). Experiential learning lends itself to hydrography. Our subject matter is highly practical. It attracts practical people. It fits the needs of millennial learners. How do we embed it more fully into our programmes? We have sought to do this at two levels - what might be termed the micro and the macro levels.

- At the micro level, that is, at every possible building block of the course, we look to base our learning around some form of experience. These move through the cycle of: do - reflection - teach theory - apply learning. Some doubters said, well surely this is what we already do in the classroom - you have just given it a fancy name? It is true most hydrographic and cartographic training has grown up around interspersing theory with practical exercises. The subtle but important difference is a move towards a more conscious adoption of that full cycle, whereby the theory is preceded by learning exercises and followed by group reflection before moving to consolidation. Combined with this, we base the exercises on real-life case studies and follow the real-world "stories" ideas of Schank (2007).

- At the macro level we have designed the course from the beginning (not as an afterthought) to be modular and to be taken over an extended period. There is a practical consideration here also, as it better fits with our organisational needs to balance training and project work. Again, we do not claim originality, merely that the choice of this design approach is to do with the effectiveness of the learning and not convenience. For this approach to work, the modules and the intervening periods have to be considered part of a full cycle of experiential learning. So where practicable, each module will be followed with project work, which will be supported by learning interventions to provide both the reflection and consolidation parts of the cycle.

\section{Blended Learning - Beyond E-Learning}

The second design principle is the implementation of a more "mixed economy" of methods. Few educators may admit to still being sage on the stage based in their training, but research findings say it is still dominant. It takes effort and resources to move towards the realism and variety that is demanded by the current generation of learners. Our experiential learning approach takes us further in that direction but we needed more imagination to give that much needed variety. So within the mix, we are developing e-learning components but importantly these are a supplement, not a substitute in the learning mix. We want to allow flexibility and to allow students access to additional teaching material away from the classroom, to allow them to self-pace their learning. But we also want our e-learning to look beyond the individual. We do not want to see students retreat into isolation. On the contrary, as a company we need to develop more collaborative working, not less. So our e-learning is being developed around shared experiences and workspaces wherever we can.

\section{Learning Resources and the Virtual Faculty}

Millennials have grown up with almost instantaneous access to infinite resources offered by the internet (to illustrate type "sage on the stage" into a search engine and you get 64 million plus results in .2 seconds). Do we make our students forego this and revert to the traditional research in a library? From a business perspective we are just as concerned as any higher educational establishment with diligent research that pays attention to the provenance of information. But we are also concerned with speed. A recent research study claimed that the average knowledge worked spends seven hours a week searching for information from within their company (Shepherd 2011). Shepherd states that not only is this a waste of time (and money) but that it was frustrating for the individuals (and those they interrupted). We concluded the need was to build more of an infrastructure of learning resources that blended the traditional and the modern.

There was a more important element of resource: 
access to experts. In addition to its tutors, the IIC Academy has access to deep domain expertise in the subjects we teach amongst the IIC practitioners spread across the globe. How do you harness this powerful resource to benefit the learning programme? We introduced the notion of Subject Matter Experts (SMEs). SMEs now play several key roles and are our "virtual faculty". All are passionate about their field and we had no difficulty in persuading people to be involved in our training programmes. For example, in terms of the teaching methods they provide an additional resource to keep us current, they provide new case studies based on recent projects and they provide a source of advice to students and tutors alike. Through the virtual faculty we supplement the abstraction of the web with professional role models.

\section{THE SUCCESS OF THE MGI PROGRAMME IN DELIVERING A CATEGORY B PROGRAMME}

The hydrographic community is fortunate to have well-thought through learning content (in S5 and S8). However good this content may be, it needs to be complemented by an effective mode of delivery. There are many trends and fads; it is fair to say educational theory has its fair share of buzzwords. Selection of the right methodology will benefit from a structured process that looks both at the organisational needs and those of the students. This needs to be followed by choosing appropriate teaching techniques. We do not suggest there is a silver bullet or any revolutionary concepts, more that carefully applied innovation can make significant improvements.

There has to be an acceptance that methods must change; one size has never fitted all and certainly does not with today's millennial learners. A beneficial move is the shift to a more blended delivery mechanism, mixing the way we engage with students and the way they engage with us. The nature of our field lends itself more than most subjects to the more formal adoption of experiential learning. This emphasises the practical side of learning but within a well-established educational framework. A delivery that is extended, flexible and modular, if designed correctly, should provide more effective way of delivering long term learning and repay the investment of time and effort in course construction. Outside traditional academia the concept of a "virtual faculty" of Subject Matter Experts provides a means of retaining strong human learning interventions.

Whether private or public sector, we should share the common goal of gaining better value from our training investment as it is this that in turn improves our performance through the quality and the calibre of our people. By adopting an approach that pays equal attention to delivery and content, we believe we can have learning programmes that meets both the exacting standards of S8, whilst at the same time delivering that content more effectively.

\section{REFERENCES}

Casey. M. 2009. "How The Download Generation Will Drive Electronic Charting In A New Direction". Paper presented at $3^{\text {rd }}$ International ECDIS Conference, Singapore, 19-21 Oct.

Murthy, S. \& Naraharisetty, P. 2008. "Enhancing Experiential Learning Through E-Pedagogy". Paper presented at TARC International Conference, Malaysia.

Murthy, S. 2011. Millennial-Centric Learning: Revisiting Education with Changed Mindset. Paper presented at NamCon11, ASBM, Bhubaneswar, India.

Prensky, M. 2001. "Digital Natives, Digital Immigrants". From On the Horizon MCB University Press, Vol. 9 No. 5, October 2001. Accessed June 2012 http://www.marcprensky.com/writing/prensky\%20-20digital\%20natives, $\% 20$ digital\%20immigrants $\% 20-\% 20$ part 1.pdf

Schank, R. 2007. "The Story Centred Curriculum". eLearn Magazine Accessed June 2012 http://elearnmag.acm.org/featured.cfm?aid=1266881

Shepherd, Clive. 2011. The Architect of Learning. Marston Gate: Onlignment

\section{BIOGRAPHIES}

\section{Shekhar MURTHY}

Shekhar Murthy is the President of IIC Academy at Visakhapatnam, India. In a career of nearly 30 years, he has held positions in learning and development in the Navy, engineering colleges and industry writing several papers on holistic lifelong learning, 
e-learning, just-in-time techniques adapted to learning, pedagogy and experiential learning. He is currently pursuing his doctoral studies in the area of "Building 21st Century Learning"

\section{Duncan WARDLE}

Course Director for the IIC Academy Marine Geospatial Information Cat B course, Duncan Wardle has a degree in Geography and an MBA. He has been involved for thirty five years in nautical cartography and the surrounding science. During a career largely in the public sector, but for the last five years with the IIC Technologies Group he has been involved in the training and development of hydrographic professionals.

\section{Derrick PEYTON}

Chief Executive and Chairman of the IIC Academy Governing Council, Derrick Peyton has been involved for over three decades in the world of hydrography. With an engineering degree, a Masters and MBA he is a qualified hydrographic surveyor to Cat A standard. He has actively been engaged in education throughout his career with teaching experience.

\section{CONTACT DETAILS}

\section{Derrick PEYTON}

IIC Technologies Group

Email: derrick.peyton@iictechnologies.com

Web site: www.iictechnologies.com 


\title{
Satellite remote sensing and coastal sediment monitoring approach with NigeriaSat-2
}

\author{
Henry Olatunbosun ODUNSI, Nigeria \\ Earth Info Services
}

Topic: Innovation in acquisition techniques

\section{INTRODUCTION}

Satellite remote sensing is a recent technology for the monitoring of the earth and its resources. The technique of mapping and monitoring coastal sediments with the satellite requires high-resolution current measurements (Romeiser, 2007). Satellite remote sensing of the coastal environment is important for environmental impact assessment because of its temporal and spatial characteristics. According to Chavez (1997) satellite images of coastal waters provides information about the quality of suspended sediment entering, residing and leaving a given system. The significance of satellite monitoring of coastal sediment is for flood and erosion control management as well as to ensure conservation of natural resources that abound in the coastal zone. Because of the challenges involved in monitoring river discharges in the coastal zone, it is imperative to carry out observations using optical sensors on board satellites for easy identification and analysis of sediment movement pattern along the coastline (Romeiser, 2007). The characteristic nature of the inter-tidal zone is a major factor for consistent monitoring of river discharges in the coastal environment. Caballero, et.al (2012) emphasized that satellite images is useful in areas with high ecological value, for determining the dynamics of sediments in the coastal areas. Sustainable management of the coastal zone is essential because of the dynamic nature in the area. Duffy, et.al (2004) also stated that erosion conditions of sediment transport can be estimated by the spatial gradient of the calculated bed load transport rate. However, in order to have a more detailed information of sediment dynamics along the coastal area, it is important to utilize the hyper spectral imaging technique which is a modern technology for effective acquisition of images. Satellite remote sensing is a cost effective method for coastal dynamics monitoring especially because of the vast area involved. NigeriaSat-2 is a very high-resolution satellite that is highly advanced for its acquisition capacity. This satellite uses the E2v imaging sensors that are inte-

grated into a focal plane array. According to Caballero, et.al. (2012) satellite-borne sensors are an ideal tool for characterizing nutrient loading and sediment dynamics. Therefore, satellite remote sensing and coastal sediment monitoring approach with NigeriaSat-2 is crucial especially for Nigeria in the area of sustainable management of the coastal environment due to the prevailing global climate change and the threat of sea level rise.

\section{METHODS}

The methodology and approach to coastal sediment monitoring with the satellite requires sensors on board satellite in space. These sensors are equipment that gathers and acquires information about the earth from space. Imageries are then generated from the information gathered remotely and are later refined after undergoing image processing and correction stages. Coastal sediment monitoring approach with NigeriaSat-2 entails the acquisition of data with the E2v imaging sensors on board the satellite. The hyper spectral imaging technique of satellite remote sensing gives an assessment of variation in coastal sediment network. This imaging technique acquires images simultaneously in many narrow, contiguous spectral bands and it reveals significant and comprehensive information about the environment. During monitoring and mapping, different wavelengths of light permeate through the water to differing degrees up to 30meters in depth. This help reveal information about the sediment materials, composition and sediment transport pattern.

\section{NigeriaSat-2}

NigeriaSat-2 is a very high-resolution satellite designed for natural resource management and environmental monitoring. NigeriaSat- 2 was launched into space in 2011 and is owned by Nigeria. It is very flexible due to its multi-mode imaging capability. NigeriaSat-2 is highly advanced for its size, acquiring $2.5 \mathrm{~m}$ pan-chromatic and $5 \mathrm{~m}$ multi-spectral data 


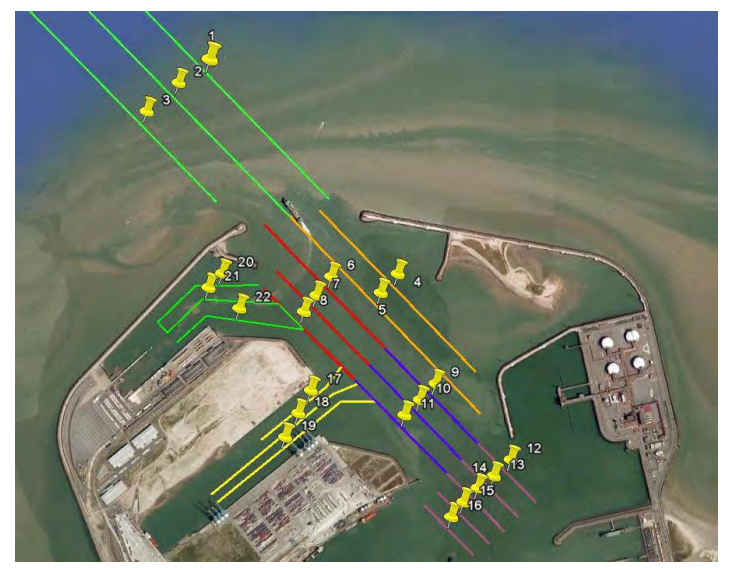

Figure 1: Image of NigeriaSat2

CNASRDA Source: www.sstl.co.uk

with special modes such as hyper spectral imagery. The e2v high-resolution focal plane is a CCD (charged-coupled device) imaging sensor. This sensor has five multispectral bands with ranges of $450 \mathrm{~nm}$ to $900 \mathrm{~nm}$. It is an $8192 \times 1$ pixel device with $12 \mathrm{pm}$ square pixels.

The sensors on board NigeriaSat-2 are

1. E-OP1 (Pan achromatic and 4 band colour imager)

2. E-OP2 (Wide area coverage imager)

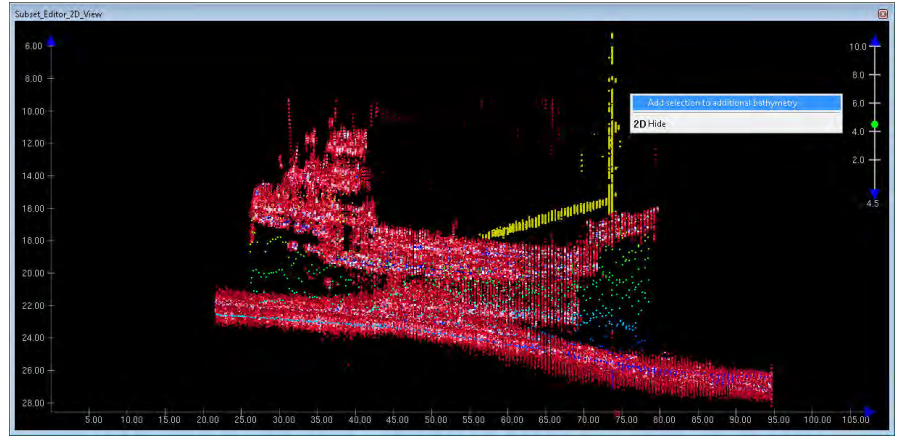

Figure 2: Sediment discharges in the Mississippi Delta (USA) (C) NASA/ORBIMAGE

\section{RESULTS}

Geology of a region is a major factor that determines the sediment materials transported by rivers and streams after weathering process. A typical example is shown in fig. 4 where the river discharge enters the estuary. Seafloor sediments in many coastal areas show great spatial and temporal variation but the surface sediments give information about the energy of the coastal waters as well as the movement of materials fig. 3 and fig. 5. Result from research indicates that complicated mixing processes occur at the turbidity front where the river discharge enters

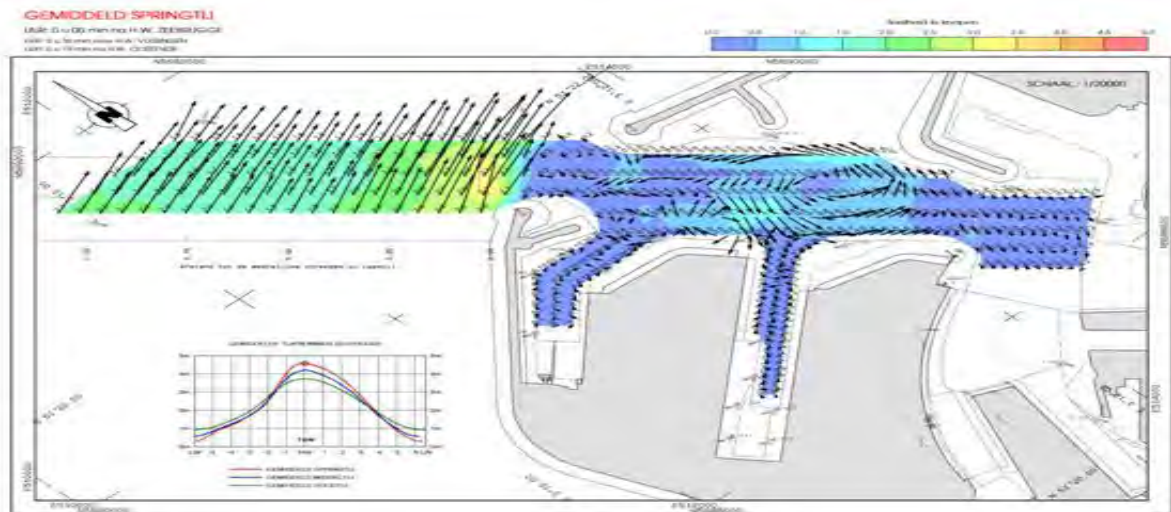

Figure 3: Coastal sediment discharges from Zambezi River Delta, 2000 Source: The World Delta Database 


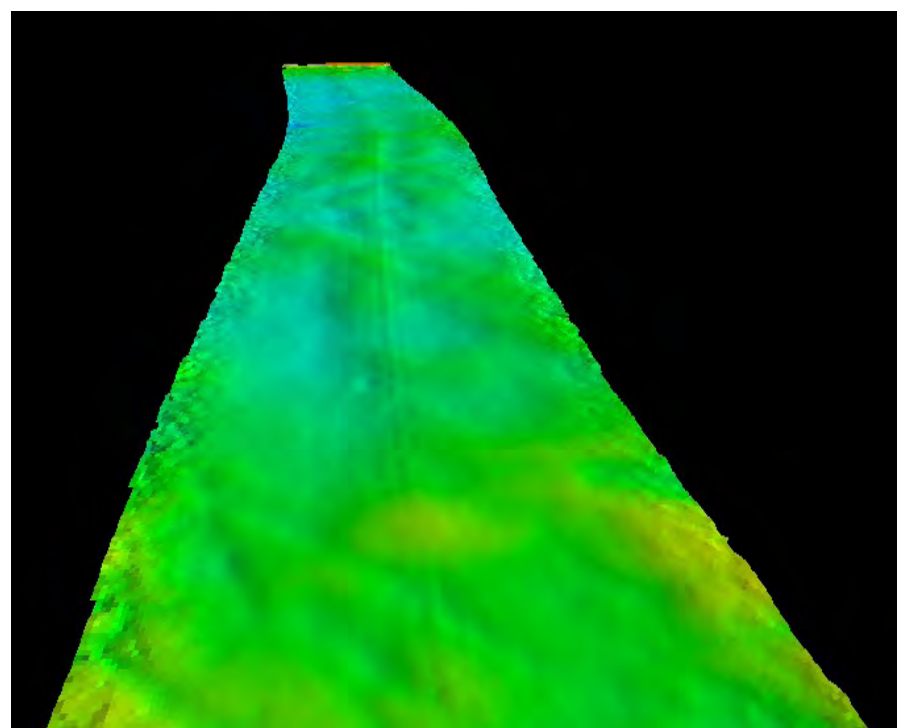

Figure 4: Sediment in the Rio de La Plata, Brazil CNASA Earth Observatory

Source: Flickr-Photo sharing

the ocean in form of sediment plumes fig. 3. Observations have also shown that river discharge during summer is generally at a minimum.

Variation in the sediment network along the coastal waters is basically due to the longshore drift which continually moves sediment material along the coast. This sedimentation problem can be easily identified with the satellite remote sensing method after detailed analysis of the imageries.

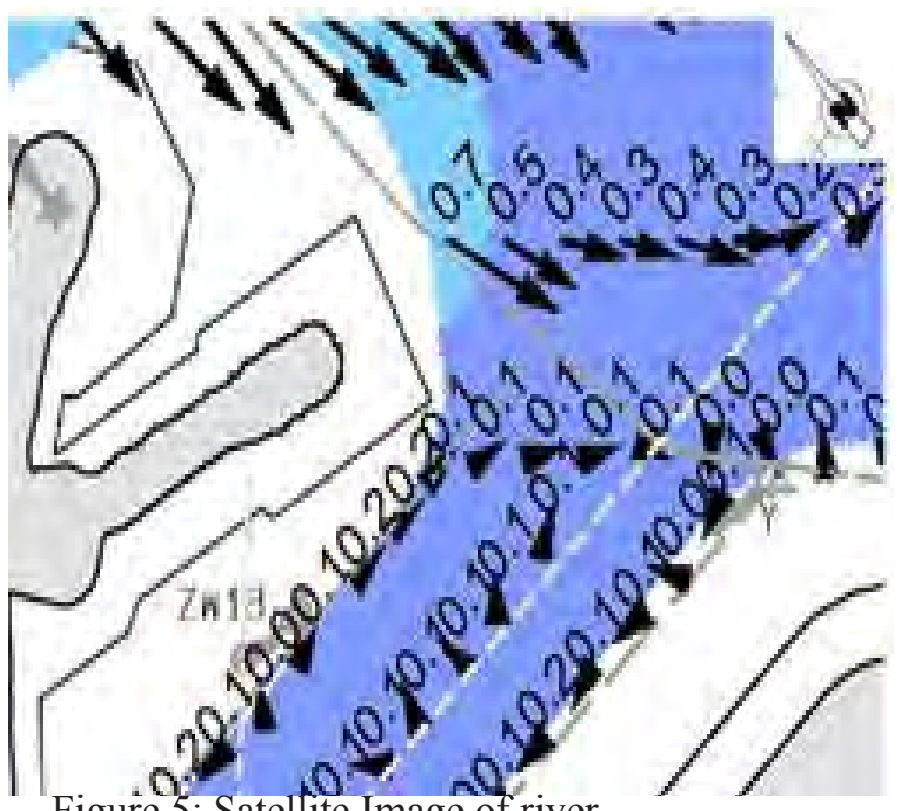

Figure 5: Satellite Image of river discharge in the Niger Delta of Nigeria CWildworld

\section{DISCUSSION}

Coastal sediment monitoring is important because of infrastructural development and anthropogenic activities in the coastal zone. It is essential due to the rapid and constantly changing nature of the coastal zones. Satellite remote sensing is an environmental monitoring system that is valuable during quantification of changes for coastal policy making. It is an important tool for understanding the interactions and processes in the coastal environment. Remote observation with the satellite provides information

Depth Residuals, Full Swath

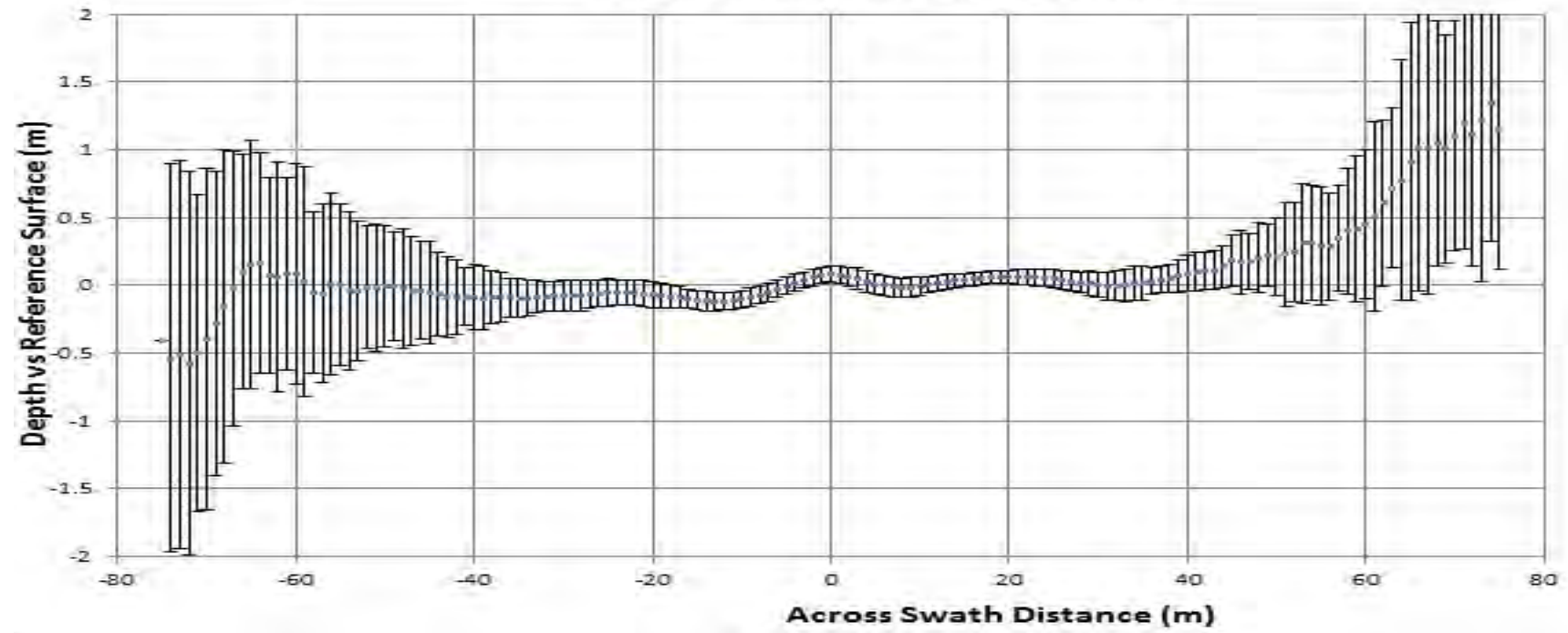

Figure 6: Parana River Floodplain, Brazil

(CNASA Earth Observatory Source: Flickr-Photo sharing 
on spatial variation than the traditional mode of monitoring.

With high-resolution imaging, significant and comprehensive information of the environment is revealed especially when it relates to sediment dynamics. This technology is effective for the identification of potential sedimentation problem and provides useful information for environmental impact assessment during coastal infrastructural developments. However, processing and interpreting the images requires skills and strategies for detection of environmental change. The technique also require gathering of in situ field data for validation of the interpretations from the imageries.

Nevertheless, coastal sediment monitoring approach with NigeriaSat-2 enables preparation and planning for baseline conditions prior to construction works. Establishment of ground controls for environmental monitoring of the changing coastline is critical to marine navigation especially for determination of bathymetry of the waterways. Satellite monitoring and mapping techniques allows different wavelengths of light permeate through the water to differing degrees up to 30 meters in depth. This help in revealing important information of the coastal sediment during dredging and reclamation of the coastal zone.

The threat of sea level rise which is as a result of the prevailing global warming and long-term erosion of sandy beaches is a major factor for considering coastal sediment monitoring. However, withdrawal or removal of sediment deposits from the shoreline and a change in wave transformation pattern is one of the factors that lead to sea level rise. This resultant effect of anthropogenic activities in the coastal zone is the basic reason why satellite monitoring of coastal sediment is important. Sustainable management of the coastal environment require critical measures such as construction of coastal defence structures is which a good way of stopping sediment from being washed away.

\section{CONCLUSION}

Monitoring the process at work in the coastal environment by satellite remote sensing approach is an important step in caring for the sea. Because of the impacts of flooding and coastal erosion on the global economy, agriculture and natural resources that abound in the coastal zone, it is important for governmental agencies and maritime organisations to consider this monitoring approach for the coastal waters in order to avert disaster from the threatening sea level rise.

Due to the importance of the coastal zone in a nation's territorial boundary and the productive level of the coastal zone in total global primary production, it is imperative to consider caring for the sea as a major step in achieving sustainable development. Therefore, the approach of monitoring coastal sediment with a very high-resolution capacity of NigeriaSat-2 cannot be overemphasized.

\section{REFERENCES}

Bruun, P. "Sea-level rise as a cause of shore erosion", Journal Waterways and Harbours Division, vol. 88(1-3), (1962):117-130.

Caballero Isabel, Edward Morris and Gabriel Navarro, "DEIMOS-1 Satellite Provides Imagery for Coastal management," Sea Technology volume 53, No.2 February 2012.

Chavez, Pat S. Jr. "Mapping Suspended Sediments Using remotely sensed satellite images": San Francisco Bay. Proceedings of the U.S. Geological Survey (USGS) sediment workshop, February 4-7, 1997.

ChevronTexaco CR Report, Case study: Environmental Monitoring with Hyper spectral Imaging, 2002

Demir, H., E.N.Otay, P.A. Work, O.S. Borekci, "Impacts of Dredging on Shoreline Change," Journal of waterways, Port, Coastal and Ocean Engineering. Vol. 130, No.4, July/August (2004):170-178.

Duffy Garret and John Hughes, "Detecting migration of Sand Dunes using spatial correlation," Sea Technology volume 45, No. 10 October 2004.

Evans, M.E, Hall, P.A, Samuels, L. A. et al. "Environmental Application of Hyper spectral Remote Sensing": Managing Liability in an Age of Transparency. Presented at the 17th World Petroleum Congress, Rio de Janeiro, Brazil. (2002)

\section{2 | Hydrol 2}


Felipe, I.P, Dohim J.M, Baker V.R. et al. "Flood detection and monitoring with the autonomous Sciencecraft experiment on board EO-1," Remote Sens. Environ. 101, (2006):463-481.

Larson Robert, Morang Andrew and Laurel Gorman, "Monitoring the Coastal Environment Part II": Sediment Sampling and Geotechnical Methods. Journal of Coastal Research, 13(2), (1997):308-330.

Manikiam, B., Honne Gowda, Manavalan, P. et.al "Study of Sediment dynamics using Satellite remote Sensing": Indian Space Research Organisation, Bangalore, India. 2002

National Space Research and Development Agency (NASRDA): "NigeriaSat1 - A Medium Resolution Satellite for Earth Observation," 2003.

Romeiser Roland, "High-Resolution Imaging of current fields from satellites," Sea Technology volume 48, No.9 September 2007.

Rong-Rong Li, et al. "Remote Sensing of Suspended Sediments and Shallow Coastal Waters," 2003

Sediment monitoring, 2009, http://www.grasdk.com

Smith Randal, "Introduction to Hyperspectral Imaging," 2012, http://www.microimages.com

Space blog, "Blogging the changing economics of Space," NigeriaSat-2 captures stunning high -resolution images March 19, 2012

www.digitalglobe.com

Www.mongabay.com (2004-2011)

Xiao, L. "NigeriaSat-2 Satellite Uses the E2v Imaging Sensors," Industry News 2011-8-30

\section{BIOGRAPHIES}

Henry Olatunbosun ODUNSI is the Director/CEO at Earth Info Services. He has more than 10years experience in dredging and reclamation survey, including 5 years work experience with Dredging International. He holds a B.Sc degree in Botany from the University of Lagos - Nigeria, a second B.Sc degree in Surveying from the University of Lagos and an
M.Sc degree in Surveying and Geoinformatics from the same University of Lagos. He was a $\mathrm{PhD}$ researcher at Cardiff University's School of Earth Sciences for a year. His research Interest includes airborne LIDAR bathymetry for coastal zone monitoring and management, satellite remote sensing, Geophysical acquisition survey, dredging and environmental management.

\section{CONTACT DETAILS}

Henry Olatunbosun ODUNSI

Earth Info Services

10, Ogundele Street, ewutuntun, Oshodi, Lagos

NIGERIA

Tel.:+234(0)8023202201

Fax: NA

Email: earth_info2002@yahoo.ca

Web site: http://www.earthinfoserv.com.ng LinkedIn account: earth_info2002@yahoo.ca Facebook account: henriodunsi@live.com Twitter account: odunsiHO@live.com 
2I4| Hydrol 2 


\title{
High resolution topo-bathymetric and flow measurements and 2D-hydrodynamic numerical modelling to evaluate the effects of the deepening of the navigation channel in the Western Scheldt
}

\author{
Yves PLANCKE, Belgium \\ Antwerp Maritime Academy \\ Flanders Hydraulics Research \\ Dries VERTOMMEN, Belgium \\ MDK - Flemish Hydrography \\ Kirsten BEIRINCKX, Belgium \\ MOW - Maritime Access \\ Gwendy VOS, Belgium \\ Flanders Hydraulics Research \\ ANTEA
}

Topics: Geophysics of the marine environment, Accurate hydrodynamics, Hydrography in the Benelux

\section{ABSTRACT}

To guarantee optimal port accessibility, one of the projects within the scope of the LongTermVision for the Scheldt estuary to be executed, is the deepening of the navigation channel. In 2001 the Port of Antwerp Expert Team proposed a new disposal strategy, using dredged material to reshape eroded sandbar. A pilot study near the Walsoorden sandbar resulted in the positive evaluation of the feasibility of this new idea. Within the project of deepening of the navigation channel, this new idea was formulated in one of the alternatives. The environmental impact assessment and an appropriate assessment concluded that a new disposal strategy should be applied: the dredged material had to be disposed near sandbars at 4 locations, to create new ecological valuable habitats.

To evaluate the success of this new disposal strategy an extensive monitoring programme was set up . Frequent (2-weekly up to two-monthly) topo-bathymetric surveys using multibeam echo sounding are performed in combination with seasonal sedimentation-erosion measurements using both RTK (intertidal) and singlebeam (subtidal). Also flow velocities on 10 transects, each consisting of 4 measurements points, in the shallow subtidal and the intertidal zone near the disposal locations are monitored using ADCP's (Nortek - AquaDopp). The ADCP devices on the intertidal zone are dug in the sandbar and look upward, allowing maximal vertical resolution when flooded during the tidal cycle.

Parallel with the monitoring, a validated 2D-numerical hydrodynamic model is used to evaluate the effects of the disposal of sediments. Every three months, a simulation is performed using the most recent topobathymetry. This allows an evaluation of the changes in flow velocities and flow patterns near the disposal areas.

A special "protocol" (see Depreiter et al., 2012) with several criteria was developed to evaluate the monitoring results and the success of the new disposal strategy. 


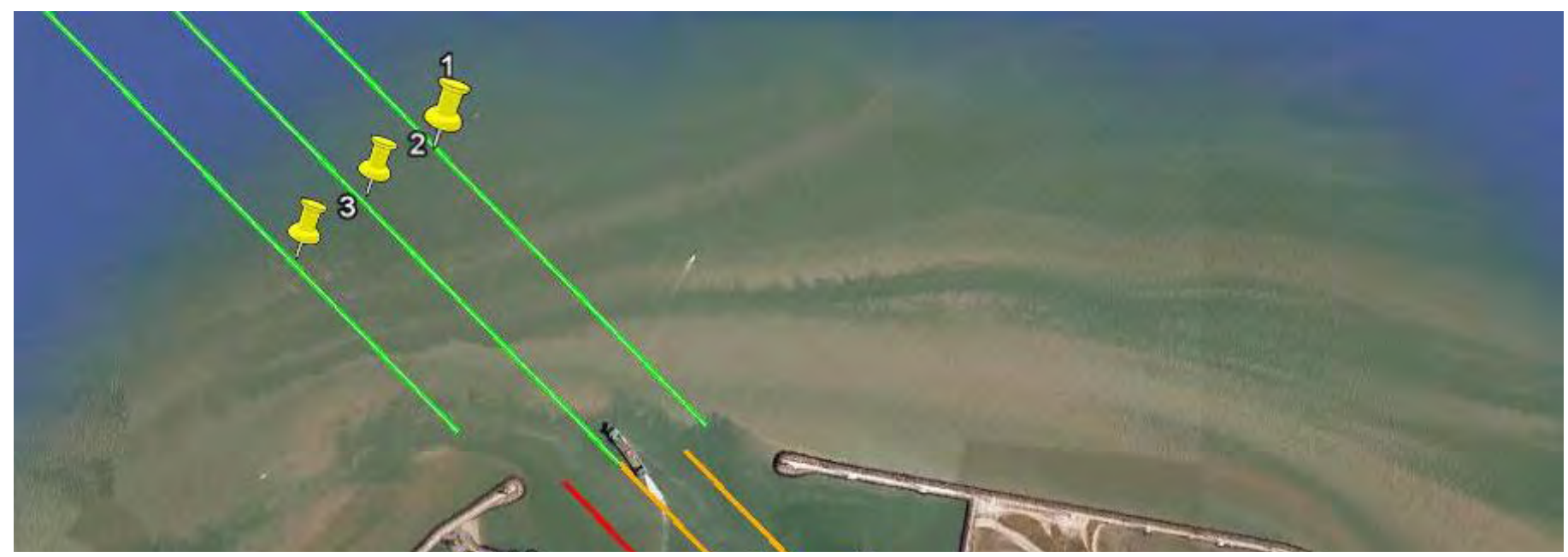

Figure 1: Western Scheldt with disposal locations near sandbars (green hatch) and in channels (white hatch) $\mid 1$ - Hooge Platen West | 2 - Hooge Platen North | 3 - Rug van Baarland | 4 - Walsoorden sandbar.

\section{A LONG TERM VISION FOR THE SCHELDT- ESTUARY}

In 1999, Flanders and the Netherlands agreed to set up a common strategy for managing the Scheldt estuary. In 2001, both parties signed a memorandum of understanding in which was defined a "Long Term Vision" (LTV) strategy and its objectives. The LTV focusses on the 3 main functions of the estuary: (1) safety against flooding, (2) port accessibility and (3) nature.

The preservation of physical characteristics of the Scheldt-estuary is a crucial aspect in the LTV goals. One of these characteristics of the Western Scheldt is a dynamic flood and ebb channel network, the socalled "multi-channel system" (figure 1). The present trend, a continuation of past natural morphological evolutions combined with human interference (land reclamation and polder building, dredging and other river works) may jeopardise this objective. With the further deepening of the navigation channel, the preservation of the multi-channel system was an important precondition.

\section{A NEW DISPOSAL STRATEGY IN THE SCHELDT-ESTUARY}

The sustainability of the traditional disposal strategy, where dredged material was disposed in secondary channels, was questioned. In 2001, an expert team appointed by the Antwerp Port Authority stated the need for morphological management, aiming at steering the estuarine morphology. In a first phase, sediment from dredging works could be used to reshape eroded sandbars where needed, in order for the flood and ebb flows to continue maintaining the multi-channel system.

A pilot study near the Walsoorden sandbar (figure 1 - location 4) was started in 2002, investigating the feasibility of the new disposal strategy [Plancke et al., 2010]. Extended research (2002-2003), execution (2004 + 2006) and monitoring (2004-2005 + 2006-2008) of two in situ disposal tests concluded that the new disposal strategy was feasible. The monitoring focussed both on morphology as on ecology. The ecological part consisted out of grain size and benthos analysis, using the "BACI"technique (Before-After-Control-Impact).

For monitoring the morphology, multibeam-echo soundings were performed on a regular basis. A special dual-head multibeam was used, to be able to monitor both the deeper parts of the zone of interest and the shallow water zones near the sandbars.

From the start of the experiment (November 2004) until March 2005, weekly surveys were executed in an area around the disposal location (area $\sim 900$ ha). From March until June 2005 the measurement frequency was reduced to one survey every 2 to 3 weeks, while from June 2005 until January 2006 one survey per month was executed. Beside this possible impact area, a larger zone was measured every 2 months, to capture possible larger scale influence of the in situ test. These surveys allowed volume computations for the control area. The evolution of the sediment volume is shown in Figure 2 . The amount of disposed sediment was measured

\section{6 | Hydrol 2}




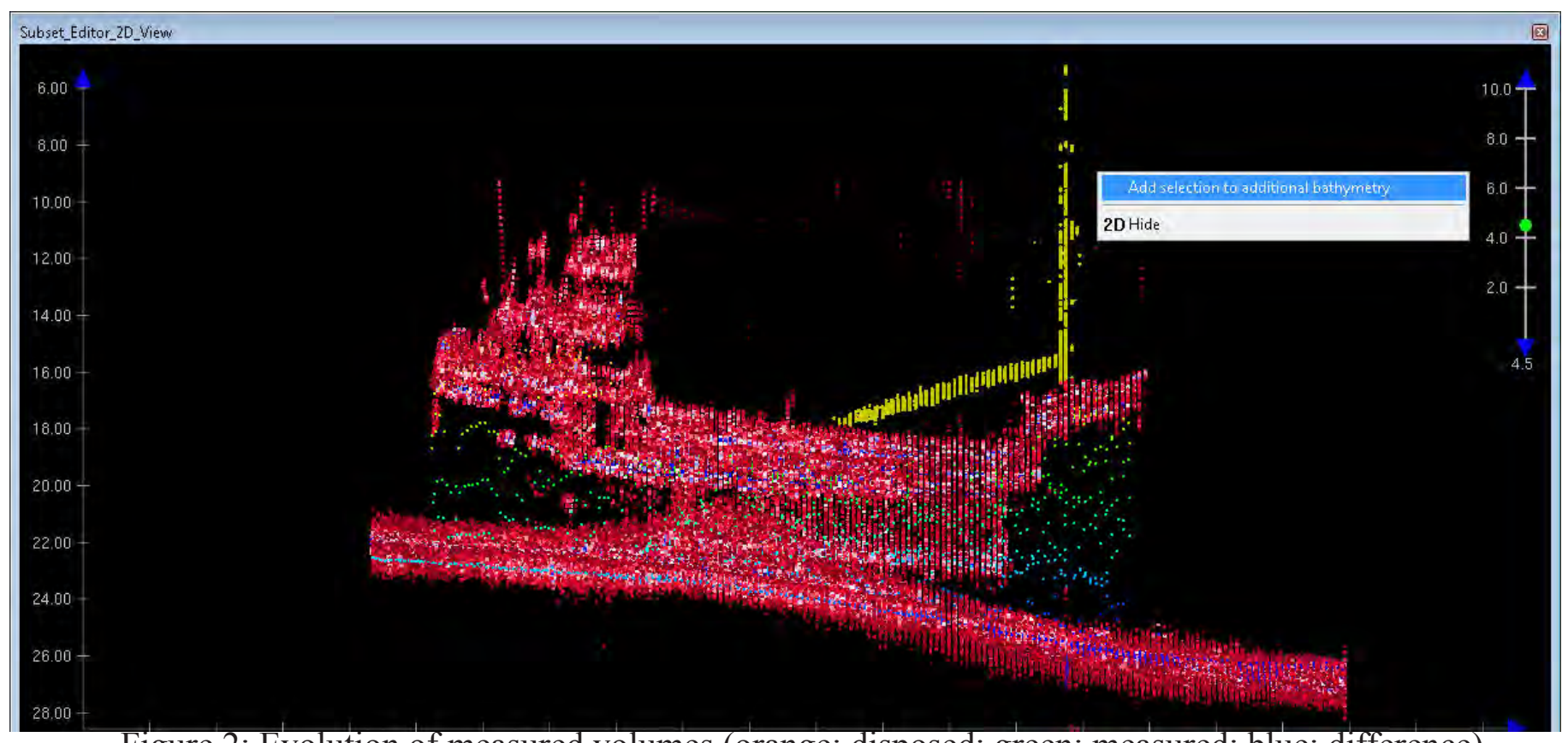

Figure 2: Evolution of measured volumes (orange: disposed; green: measured; blue: difference)

in the hopper. These amounts were then corrected taking into account the differences in density in the hopper and in situ. A correction factor equal to 0.9 was chosen based on experience.. During the first 2 months the volume within the control area was even higher than after execution of the test, probably due to natural processes. Afterwards a decrease of volume was measured, a loss of $\sim 10 \%$ after 6 months, almost $20 \%$ after one year. The main part of the eroded sand is transported during flood towards the Walsoorden sandbar (Figure 3). This evolution is in agreement with the predictions of the feasibility study. It was concluded that the disposed sediments stay well in place, and the imposed criterion was successfully fulfilled.

Due to the success of both in situ tests, the strategy of morphological relocation was proposed as

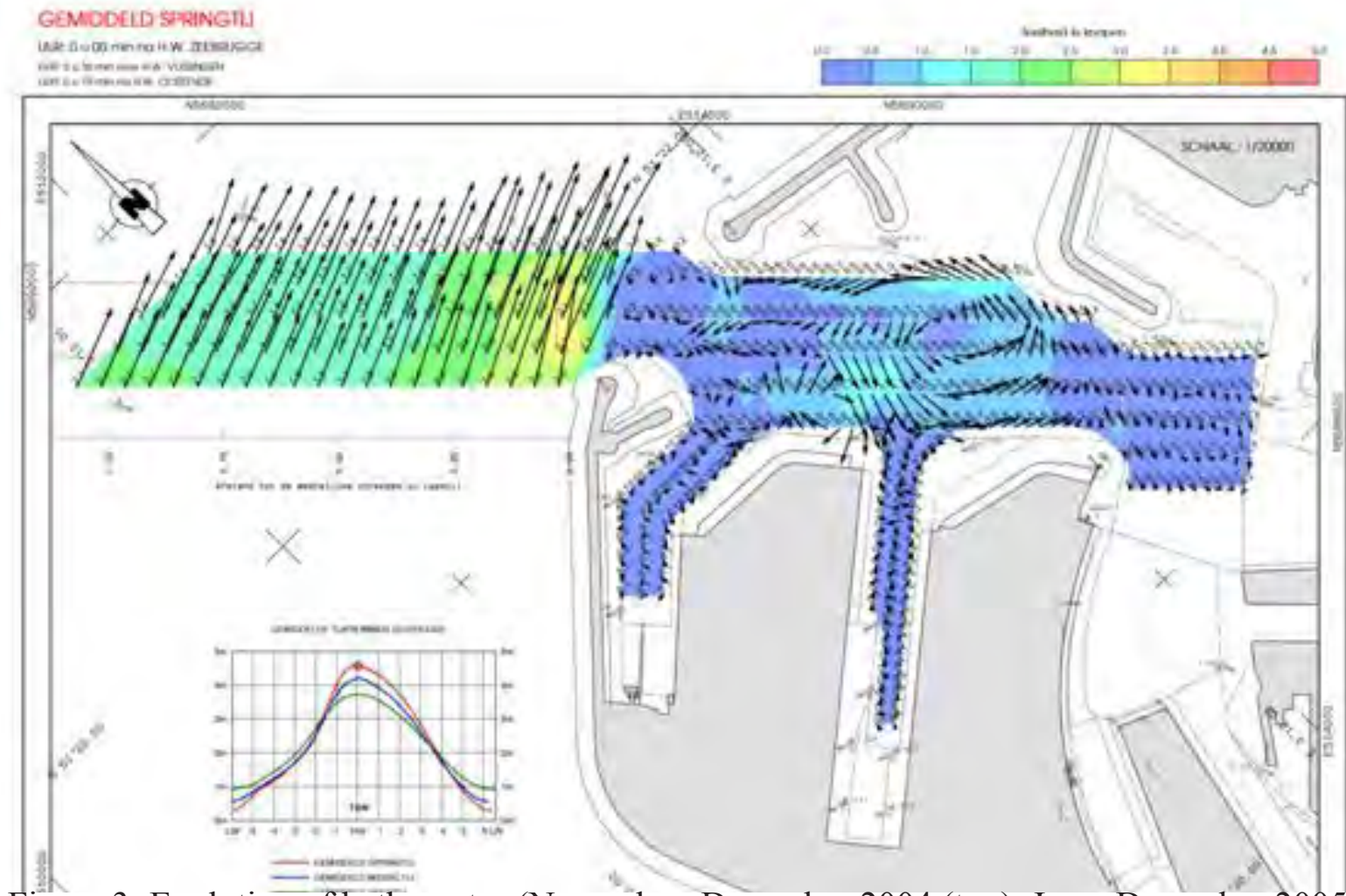

Figure 3: Evolution of bathymetry (November-December 2004 (top), June-December 2005 (down)) 
one of the alternatives investigated within the environmental impact assessment study for the deepening of the navigation channel. The assessment concluded that the continuation of the traditional disposal strategy could lead, on the long term, to a degeneration of the multi-channel system. On the other hand, the use of the new morphological disposal strategy could create new valuable areas for ecology without endangering the multichannel system. Within this new strategy, dredged material is seen as a means to create ecological benefits ("working for nature"), thereby mitigating uncertainties surrounding the effects of the channel deepening. The new disposal strategy will create ca. 100 ha of new ecological valuable habitat after 5 years. The final appropriate assessment concluded that no significant negative impact should be expected, due to this new strategy.

Further research was performed by Flanders Hydraulics Research to elaborate the disposal strategy at the 4 new locations. The goal for the new disposal strategy is to maximize the creation of ecological valuable ecotopes, i.e. subtidal and intertidal areas with low currents. The experience gained near the Walsoorden sandbar was used to investigate the optimal disposal strategy at these locations. Therefore an extensive research program was carried out, using field measurements (both GPS-floats and sediment transport) and hydrodynamic numerical models. An extra model validation was performed for the flow velocities on the intertidal area of the sandbars, to improve the correspondence of the patterns of ecological valuable habitats.

The study revealed that fundamental differences exist between the 4 proposed locations (figure 1). On one hand both the locations near the Walsoorden sandbar and the Hooge Platen West are located near the seaward tip of a sandbar, attacked by flood currents. It is expected that sediment disposed at these locations will gradually be transported towards the sandbar. On the other hand the locations near Rug van Baarland and Hooge Platen North are located along a sandbar, guiding the currents. It is expected that sediment disposed at these locations, will be transported along the sandbar.

For the Walsoorden sandbar and the Hooge Platen West (figure 4) the disposal strategy aims at creating a subtidal "megadune" which will migrate towards the sandbar under influence of the flood-dominated currents. This can be seen as an application of the "working with nature" principle. This so-called megadune aims for the creation of an underwater barrier which will reduce the currents between the barrier and the sandbar, creating a low dynamic shallow water area.

Near Rug van Baarland (figure 4) and Hooge Platen North the disposal strategy aims at constructing a "sand spit" near the tip of the sandbar. This new sand spit, in combination with the existing one, aims

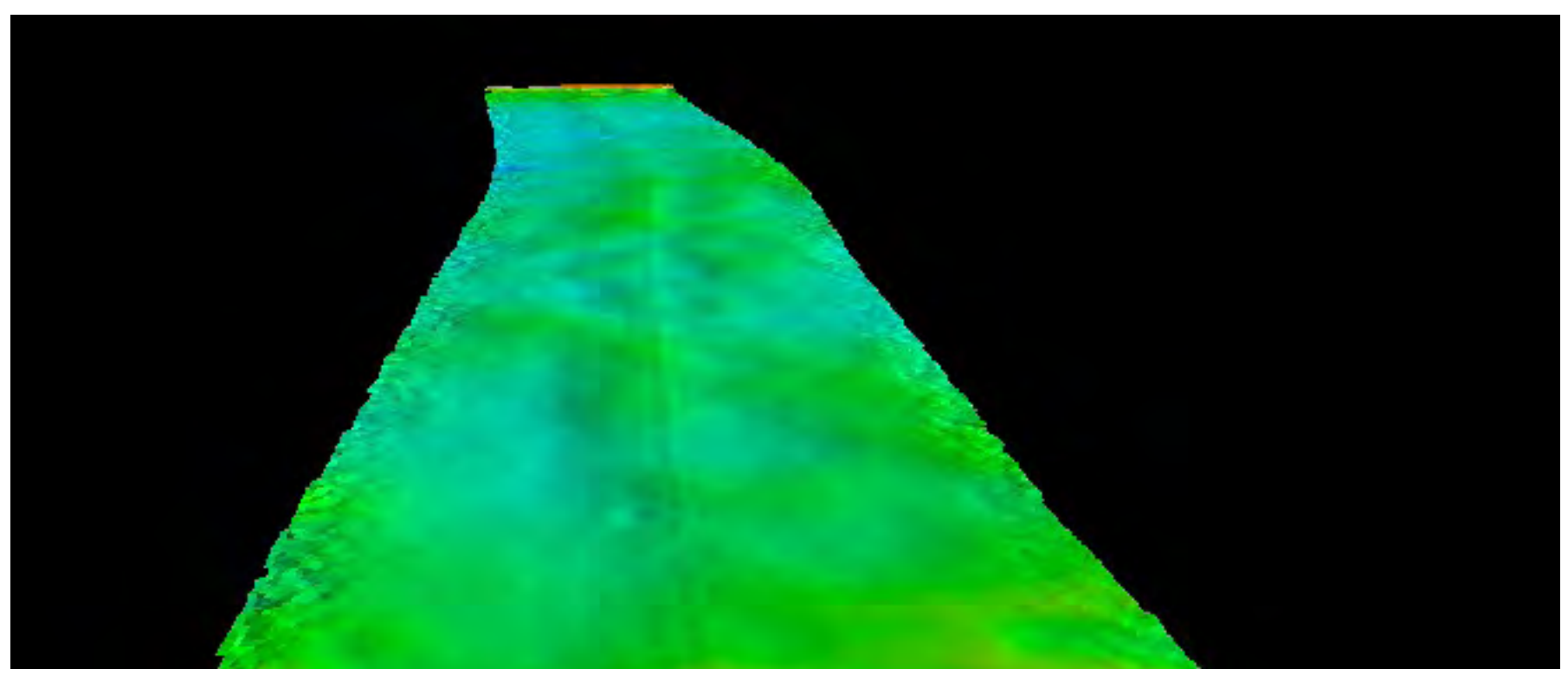

Figure 4: Megadune proposed at Hooge Platen West (left) and sand spit proposed at Baarland (right)

\section{8 | Hydrol 2}


for the creation of an underwater barrier reducing the currents between the barrier and the sandbar, creating a low dynamic shallow water area.

\section{EXECUTION AND EVALUATION OF THE NEW DISPOSAL STRATEGY}

On February 12th 2010 dredging works for the enlargement of the navigation channel in the Western Scheldt started. During a period of one year all necessary capital dredging works $\left(7,7 \mathrm{Mm}^{3}\right.$ of sandy material) were executed. The sediments were disposed near the 4 proposed locations along sandbars. In the deeper areas near the sandbars, the disposal was performed using the conventional "clapping" technique with hoppers. In the shallower areas, the trailing suction hopper dredgers connected to a floating line which was connected to a diffuser (figure 5). This technique allowed the disposal of sandy material in zones up to $2 \mathrm{~m}$ below low water. Simultaneously with the capital dredging works, maintenance dredging works had to take place. Part (20\%) of the dredged sediments from the maintenance works, are disposed near the sandbars, while the other part is disposed in the main or secondary channels. From February $12^{\text {th }} 2010$ until February $12^{\text {th }} 2012$ (the first 2 years) a total of 12.4 $\mathrm{Mm}^{3}$ of sediments have been disposed near all 4 sandbars, which is $63 \%$ of the amount foreseen to be disposed in 5 years (table 1). programme consists among others of high frequent multi-beam and single-beam echo soundings, current measurements and RTK height measurements.

Before the start of the deepening, the reference situation was monitored for all parameters. Since the start of the works, new measuring campaigns at all locations have been executed to evaluate the effects of the disposal activities. During the next years this monitoring will continue, allowing the evaluation of the new disposal strategy on the longer term.

To monitor the stability of the disposed sediment, high frequent multi-beam echo soundings (MBES) of the total disposal area were performed. In the period during the execution and 1 month after the last disposal, one sounding every 2 weeks was made. After this period, the intensity was reduced to one sounding per month and finally to one every 2 months. Additionally to these "disposal zone" soundings, a MBES of a larger area took place twice a year to monitor the morphological changes in case the sediment would be transported out of the disposal zone. Based on these echo sounding maps, the stability of the disposed material is calculated, showing that the stability is different at the four locations (Table 1). It should be mentioned that the location near the Rug van Baarland is characterised by an important natural sedimentation, additional to the deposited sediment.

The flow velocities are measured by Rijkswaterstaat on 10 transects over 2 full spring-neap-tide cycles. Each transect consists of 3 points in the intertidal

To evaluate the possible effects of the deepening of the navigation channel and the new disposal strategy, an extensive monitoring programme "MONEOS-T" [Schrijver et al., 2008] was set up. This monitoring Each transect consists of 3 points in the interidal

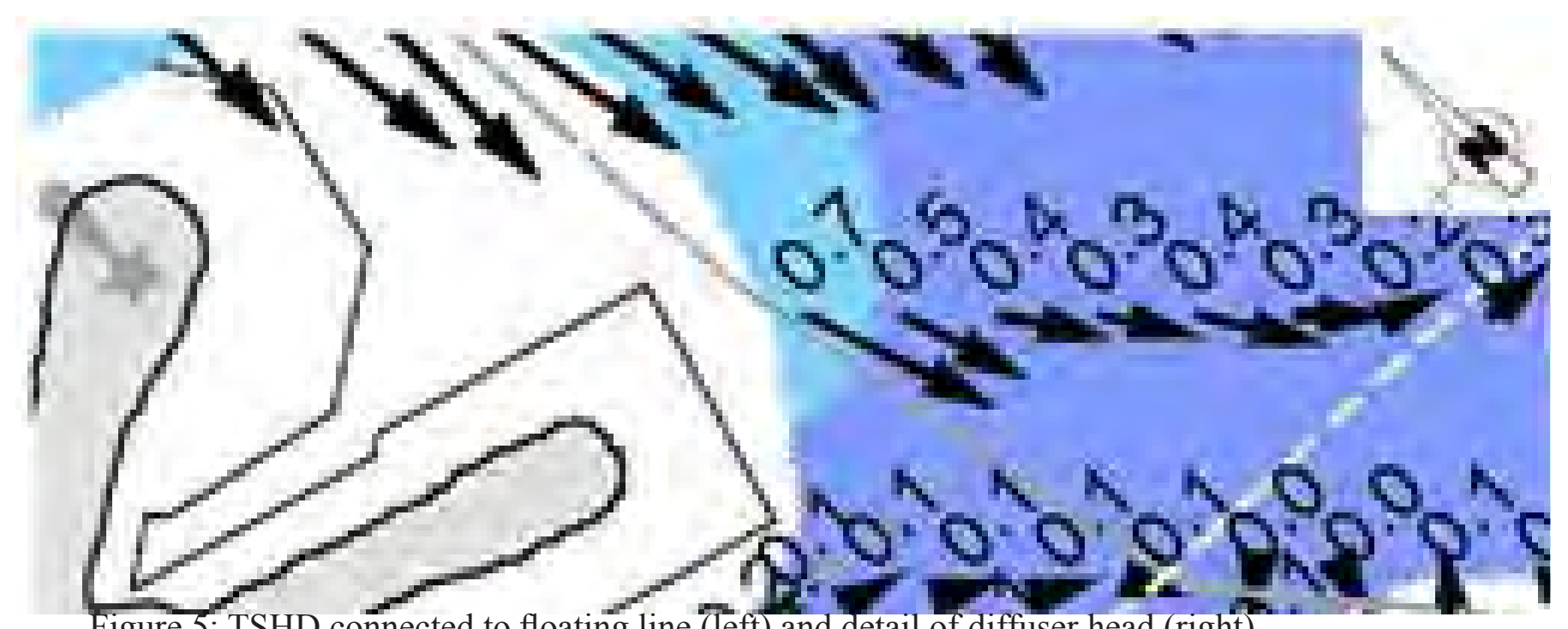

Figure 5: TSHD connected to floating line (left) and detail of diffuser head (right) 
Table 1: Overview of quantities to be disposed near sandbars and initial stability.

\begin{tabular}{|c|c|c|c|c|c|}
\hline Location & $\begin{array}{c}\text { Capacity } \\
\text { over 5 yr } \\
{\left[\mathrm{Mm}^{3}\right]}\end{array}$ & $\begin{array}{c}\text { Disposal } \\
\text { Year 1 } \\
{\left[\mathrm{Mm}^{3}\right]}\end{array}$ & $\begin{array}{c}\text { Disposal } \\
\text { Year 2 } \\
{\left[\mathrm{Mm}^{3}\right]}\end{array}$ & $\begin{array}{c}\text { Disposal } \\
\text { Year 1+2 } \\
{\left[\mathrm{Mm}^{3}\right]}\end{array}$ & $\begin{array}{c}\text { Stability } \\
{[\%]}\end{array}$ \\
\cline { 1 - 4 } Hooge Platen West & \multirow{2}{*}{8.20} & 1.95 & 0.58 & 2.53 & 70 \\
\cline { 1 - 3 } Hooge Platen North & 3.50 & 0.51 & 4.01 & 105 \\
\hline Rug van Baarland & 5.00 & 0.70 & 0.58 & 1.28 & 268 \\
\hline Walsoorden sandbar & 6.50 & 3.72 & 0.82 & 4.54 & 62 \\
\hline
\end{tabular}

area (measured with Nortek AquaDopp | $2 \mathrm{MHz}-$ figure 6) and 1 undeep subtidal point (RDI ADCP | $1200 \mathrm{kHz}$ ). The AquaDopps in the intertidal zone were dug in the sandbar and look upward, allowing maximal vertical resolution when flooded during the tidal cycle. To present measurement data, scatterplots are generated showing the maximum flow velocity (flood or ebb) versus the tidal range (rising or falling) (figure 6). The scatterplots show that at certain measuring points, located in the 'shadow' of the mega dunes, the flow velocities have decreased. Besides these measurements, a calibrated 2D-numerical model [Ides et al., 2010] is used to evaluate the developments of the flows near the sandbars. Simulations are performed on regular basis (every $3-6$ months), using the most actual topobathymetry near the sandbars. All 40 measurement points are defined in the model and similar analyses is performed. Additionally, spatial maximum flow maps are generated and changes in these maps are evaluated (figure 6).

A special "protocol" (see Depreiter et al., 2012), containing several morphological (stability of disposed material) and ecological (evolution of ecotopes) criteria was appended to the disposal license to, quasi continuously, evaluate the monitoring data. An independent group of experts ("Commission Monitoring Western Scheldt") supervises the evaluation of the monitoring and advices at least every 2 years on the disposal strategy.

\section{CONCLUSION}

Within the enlargement project of the navigation channel in the Scheldt-estuary, a new disposal strategy was chosen, aimed at creating new

\section{Depth Residuals, Full Swath}

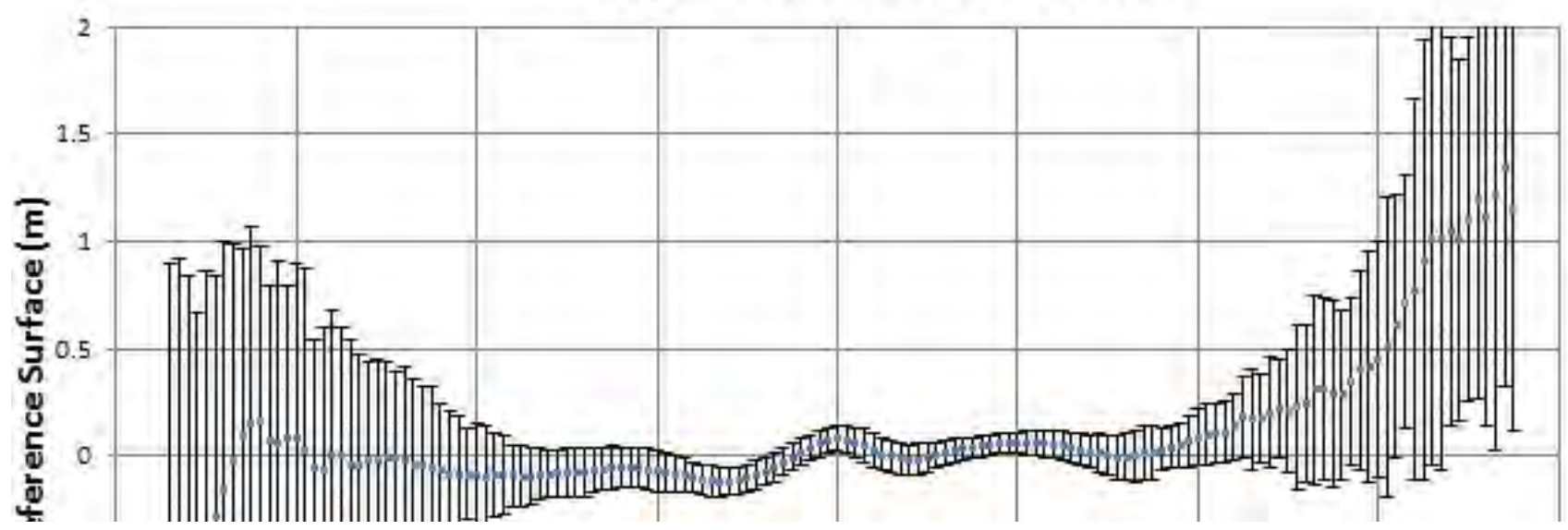

Figure 6: AquaDopp (left), scatterplot from ADP-measurement rising vs. maximum flood velocity (mid) and flood velocities and difference (T0+15 months $-\mathrm{T} 0)$ from numerical model (right) 
ecological valuable habitats. An extensive monitoring programme was set up to evaluate the success of this new strategy, focusing on topobathymetry (using MBES) and flow characteristics (using Acoustical Doppler techniques). Additionally, hydrodynamic numerical simulations were performed to investigate the changes in flow patterns near the disposal locations. The first results show different effects near different sandbars. The extensive monitoring programme makes it possible to understand the changes on a short term, and to adapt the relocation strategy based on analyses of the monitoring results if necessary. The continuation of the monitoring and the analysis of the data will allow a final evaluation 5 years after the start of enlargement project.

\section{REFERENCES}

Depreiter, D.; Sas, M.; Beirinckx, K.; Liek, G.J. (2012). Flexible Disposal Strategy: monitoring as a key to understanding and steering environmental responses to dredging and disposal in the Scheldt Estuary. Hydro2012 - Taking care of the sea, Rotterdam, Netherlands.

Ides, S.; Plancke, Y.; Vos, G. (2010). Validation of a 2D hydrodynamic model within a study to propose the optimal disposal strategy inthe Western Scheldt, in: SIMHYDRO 2010: modèles hydrauliques et incertitudes, Nice, France.

Plancke, Y.; Ides, S.; Vos, G.; Roose, F.; Peters, J.J. (2010). A new disposal strategy for the Western Scheldt, conciliating port accessibility and nature preservation, in:32nd PIANC Congress, 125th anniversary PIANC - setting the course, Liverpool, UK.

Schrijver, M.; Plancke, Y. (2008). Execution of the monitoringplan MONEOS-T (In Dutch: Uitvoeringsplan MONEOS-T 20082018). Rijkswaterstaat Zeeland, Middelburg, Waterbouwkundig Laboratorium, Antwerpen.

\section{CONTACT DETAILS}

\section{Yves PLANCKE}

Antwerp Maritime Academy

Noordkasteel Oost 6,

BE-2030 Antwerp, Belgium

TEL + 32.3.224.61.56

email: yves.plancke@mow.vlaanderen.be

Flanders Hydraulics Research

Berchemlei 115

BE-2140 Antwerp, Belgium

TEL + 32.3.224.61.56

email: yves.plancke@mow.vlaanderen.be 
222 | Hydrol 2 


\section{Key Elements of Remote Offshore Survey Operations}

Boudewijn POSSEL and Hannes SWIEGERS, the Netherlands

Fugro Survey B.V.

Topics: Smart data management, Easy customer access to data and products, Cost-effective solutions

\section{INTRODUCTION}

The advent of data communication between offshore systems and onshore facilities marks a major change that has occurred in the offshore (survey) industry. Up to the previous decade, many floating assets, like rigs, vessels and barges, did not have access to a continuous and global form of data communication. The lack of this capability requires offshore survey staff to perform all necessary tasks unsupported. Furthermore, the collected survey data can only be checked when it is returned to the office. In certain cases the absence of interaction with onshore facilities can contribute to inefficient work processes and errors, this can cause additional (post)processing, operational delays and lead to decreased revenues on projects.

With current technology and (remote control) software a highly reliable and secure data connection can be established to offshore systems. This interaction between offshore survey systems and onshore facilities allows for a number of survey related services to be performed remotely:

- Monitor operations (for example: Quality Control by clients, consultation with survey staff)

- Control operations (starting/stopping measurements, entering waypoints)

- File transfer and data dissemination

- Provide remote support (changing settings, perform calibrations, solving IT-issues)

- Remote meetings (get consensus and real-time feedback from multiple parties).

There are numerous advantages of these services that can be identified: improved project execution, better vessel management and risk mitigation. Support from experienced onshore personnel is available, this can be used to detect and resolve potential issues before they escalate and cause operational delays. Furthermore a reduction in the amount of personnel onsite can be foreseen, which will cut transportation and accommodation costs and limit Health,
Safety and Environment (HSE) risks. Disadvantages and risks that can be discerned are: investment costs, reliability issues, unauthorized intrusion into the system and the technology not being accepted.

Major oil companies like Shell, BP and service companies like Schlumberger, have established Real Time Operation Support Centers, allowing remote management of (drilling) operations from anywhere on the world $[1,2,3]$. These centers for remote monitoring and control are mostly used for inter-company purposes; experts provide support and the system can be used for educational purposes. The concept of remote offshore survey operations differs somewhat to that of the above mentioned Operation Support Centers, because it adds (paid) customer services. On the technical side there are also differences, mainly in the network setup. A number of offshore survey companies do already offer remote offshore survey services as a commercial product, like iSURVEY [4] and Fugro Survey B.V. [5].

To perform remote offshore survey operations a number of different fundamental elements are needed; satellite data communication, IT infrastructure, software and technology acceptance. A description of each of these key elements will be given together with the Fugro Survey B.V. implementation and solution.

\section{RELIABLE INTERNET CONNECTION}

Developments in satellite data communication in the last decade have made data connections, like the Internet, a common concept offshore. There are various satellite Internet systems available on the market, each with specific characteristics that make some systems more usable for certain tasks than others. Required characteristics for data connections used for remote offshore survey operations are: globally operational, high reliability, acceptable latency and cost effective operation. 
Many of the global Internet systems utilize Geostationary Earth Orbit (GEO) satellites. The distance between the earth and the geostationary satellite introduces a delay in the signal known as latency; for a two-way connection using GEO satellites this is in the order of $500 \mathrm{~ms}-1000 \mathrm{~ms}$ [6]. Especially for interactive applications, such as remote control of offshore systems, these delays can cause working with the systems to become time-consuming and tedious. Other global Internet systems use lower orbiting satellites which have lower latencies, however there are a number of drawbacks; dozens of satellites are required to provide coverage of the entire planet, a complex and costly ground segment is needed and often the data speed is lower if compared to GEO satellites.

Besides latency also the frequency of signals used for communication plays an important role in satellite communication. C-band and L-band systems have a high resiliency to signal attenuation caused by moisture and precipitation. However these systems have a lower bandwidth compared to higher frequency/higher bandwidth systems (like Ku-band and Ka-band), which can have significant interference due to absorption and scattering by moisture. For a reliable and redundant data connection a combination of satellite communications systems with different frequencies ranges would be the preferred solution.

For projects where survey networks are mobilized on client vessels there is often no independent/dedicated Internet connection available. This means that it is necessary to utilize a client supplied Internet connection. If this is not available or not possible then a solution is to mobilize a designated, portable satellite Internet system.

\section{IT INFRASTRUCTURE}

Offshore survey equipment is specifically designed, configured and interlinked with each other to create a network comparable to small-scale SCADA networks (Supervisory Control And Data Acquisition). Because the nature of many survey projects is ad-hoc and very varied, the total mobilization time of these networks ranges from a few days to several years. Connecting such a survey network over a client network to the Internet requires a flexible, but very basic, network setup. This is because the network architecture and IT-policies vary per client; sometimes lacking access to DNS-servers or prompting the use of proxy-servers. Another limitation is that the connection speed is often very low (even only a few kbps), this is because the Internet connection is shared with all the other users onboard. Access to the survey network by unauthorized individuals should be blocked by taking various precautionary measures [7], for example using very constrained firewalls at both ends of the connection.

Taking these IT-requirements into account, an overview of the current Fugro solution to remote offshore survey operations is presented in Figure 1. The system was developed based on market analysis, expected developments and field trials. The sensors connected to the survey network collect specific data and from there it is sent it over the Internet to a dedicated onshore server. This server is hosted on the Fugro Group Gateway, a server cluster which is scalable, redundant, backed-up and directly connected to the Amsterdam Internet Exchange (AMS-IX). The server also hosts a client website which gives an overview of the status of the ongoing project, effectively a Common Operational Picture (COP). The website can be custom configurable for each client, to track selected vessels on a map, show screenshots of specific offshore computer displays, but also other features like uploading (survey) data or reports.

\section{SOFTWARE}

The software needed for remote offshore survey operations has multiple requirements. First of all: to remotely take over control of offshore survey systems/computers, preferably having control of all features. Various processes are required to control drop-outs, low bandwidth and high latency situations. Besides that, a feature that could be incorporated in the software is to remotely switch equipment on and off.

The second objective for remote offshore survey software is to automatically gather specific data. Software installed on the computers onboard should automatically collect measurements of various parameters from the survey network, for example: location, speed, heading, time and vessel name. The collection of other vessel-status information, for example snapshots of the overview screen of the ongoing operations could also be supported.

\section{4 | Hydrol 2}




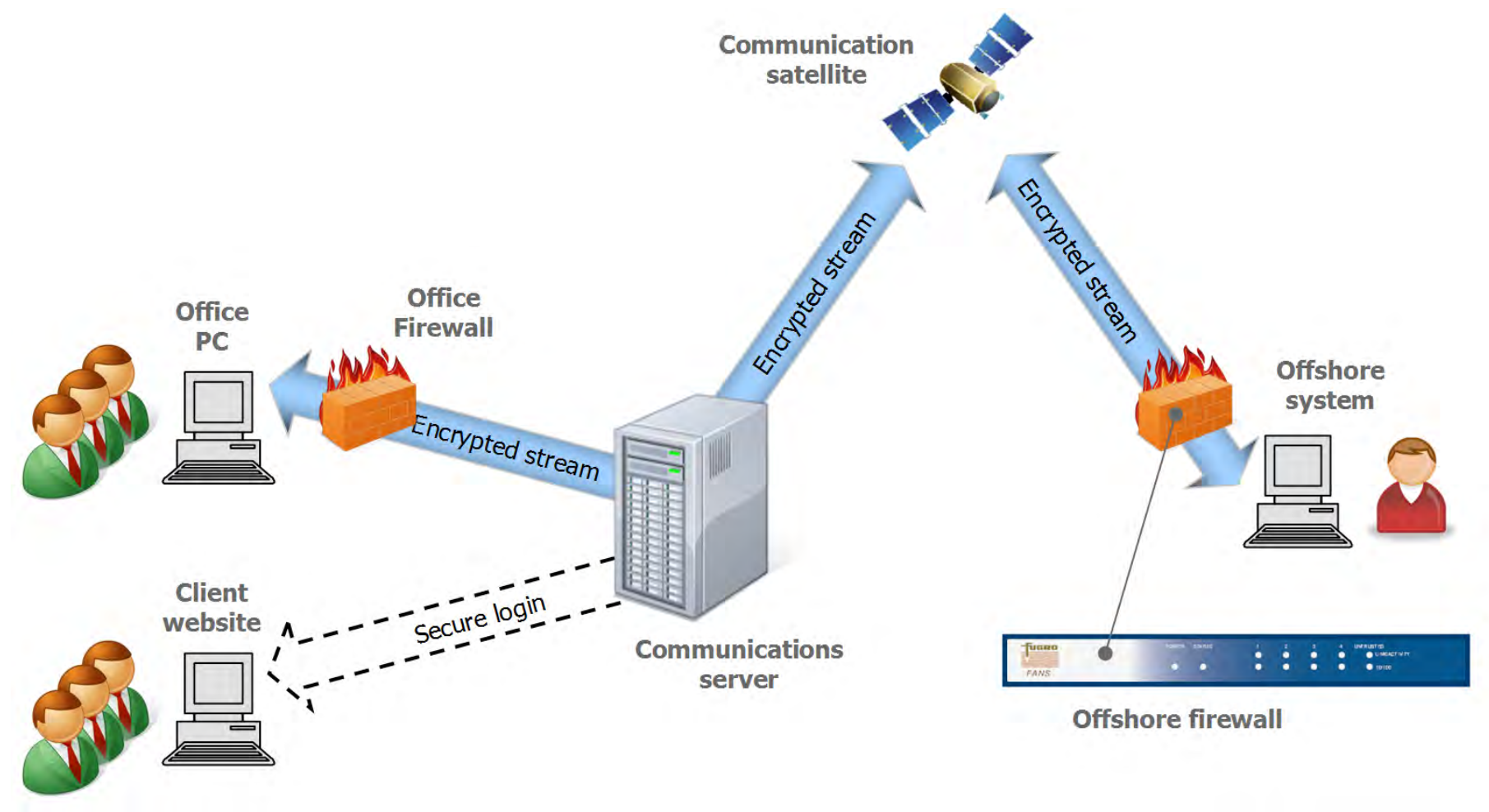

Figure 1: Schematic overview of the current Fugro Remote Services IT infrastructure.

A third objective is to supply an encrypted connection so data can be securely sent to onshore servers. If data passes through IP-based networks, including the Internet, this raises a number of security issues which can ultimately threaten the integrity of the survey network and security of data. Preventative measures have to be taken to ensure the survey network is not compromised and the collected data are not intercepted.

The software used for Fugro Remote Services supplies access to offshore survey computers using commercially available remote access software, and is protected by double password authentication. In addition, data is automatically collected from the survey network and sent over a HTTPS connection (128-bit AES encrypted) to the server where it is directly updated in the database. Website access is provided to customers using a separate log-in name and unique access code.

\section{TECHNOLOGY ACCEPTANCE}

In the offshore industry a minimum of risk and a high reliability is of utmost importance, this results in a conservative culture and a tendency to use proven/established technology. Subsequently it takes time and effort to introduce new technology, like the concept of remote offshore (survey) operations. However this new technology will only be successful if the user accepts and uses the technology. A model that theoretically described this effect is the Technology Acceptance Model (TAM) [8]; it presents a number of variables that influence the decision on how and when users will use new technology. The main variables described are:

- Perceived usefulness

- Perceived ease-of-use

To make remote offshore survey operations a more accepted technology, the main focus should thus be on communicating the advantages and possibilities of the system; this can be done by demonstrations, marketing and training. The focus of developments should be to increase the functionality of the system and at the same time to improve usability.

\section{FUTURE DEVELOPMENTS}

In the upcoming years various high speed and low latency global satellite communication systems will be launched, for example Global Xpress and O3B $[9,10]$. This will allow more bandwidth intensive services like live streaming video. Low latency communication systems will improve the quality and speed of remote controlling offshore systems. 
In addition to that an increase in satellite communication systems will introduce more competition that might force prices down for systems and data-plans, making these systems more affordable and feasible.

Specifically for Fugro Remote Services a number of future developments can be anticipated; the first is a continuously operational Remote Control Centre, which can assist with offshore operations and supply support. Another development is the visualization of related data sources on the customer website to give additional relevant information; this can be weather forecasting, AIS data (Automatic Identification System) or GIS layers on field layout. Also (live) data could be placed in a geo-spatial database and presented with $3 \mathrm{D}$ visualization techniques.

\section{CONCLUSION}

Satellite data communication has made interaction between offshore survey systems and onshore facilities possible, which allows a number of survey services to be performed remotely. These can be used as a tool to improve vessel management, control costs and mitigate risks. This paper presents a number of key elements for remote offshore survey operations; satellite data communication, IT infrastructure, software and technology acceptance.

To connect offshore systems to the Internet there are various satellite Internet systems available, each with specific characteristics. Connecting a survey network to the Internet requires a flexible and secure IT-infrastructure, especially when making use of a client network. This needs to be combined with software for remote control of offshore survey systems, automatic data collection and an encrypted connection. To make sure the technology is accepted and used, the advantages and possibilities of remote offshore survey operations should be communicated, together with further development of functionality and the improvement of usability.

\section{REFERENCES}

1) "Shell's Real Time Operation Center solves problems worldwide," Offshore (September 2007): 78.

2) M. Wahlen et al., "Improving Team Capability and Efficiency by Moving Traditional Rig-Site Services Onshore," BP magazine, issue 4, 2011, accessed May 28, 2012, http://www.onepetro.org/ $\mathrm{mslib} /$ servlet/onepetropreview?id=00078336.

3) "Remote Operations, Schlumberger", accessed June 23, 2012, http:/www.slb.com/services/drilling/ engineering_modeling/remote_operations.aspx.

4) "iCONTROL by iSURVEY", accessed June 1, 2012, http://www.isurvey-group.com/icontrol.aspx.

5) "Fugro Remote Services Client Website", accessed May 13, 2012, www.fugroremoteservices. com.

6) Mario Marchese, "Performance analysis of the TCP behavior in a geo satellite environment," Computer Communications, Volume 24, Issue 9 (2001): 877-888, http://dx.doi.org/10.1016/S01403664(00)00361-3.

7) Martin Gilje Jaatun, et al, "Secure Safety: Secure Remote Access to Critical Safety Systems in Offshore Installations" in Autonomic and Trusted Computing (Berlin/Heidelberg: Springer, 2008), 121-133, http://dx.doi.org/10.1007/978-3-540-69295-9_12.

8) Fred D. Davis, "Perceived usefulness, perceived ease of use, and user acceptance of information technology," MIS Quarterly, Volume 13, Number 3 (1989): 319-340.

9) “Inmarsat Global Xpress", accessed July 2, 2012, http://www.inmarsatgx.com.

10) “O3B Networks", accessed July 3, 2012, http:// www.o3bnetworks.com.

\section{BIOGRAPHIES}

Boudewijn POSSEL obtained his MSc. degree in Geomatics at Delft University of Technology in 2009. He is currently working at Fugro Survey B.V. as a Project Surveyor Remote Services, focusing on further development and implementation of remote offshore survey operations.

\section{6 | Hydrol 2}


Hannes SWIEGERS joined Fugro Survey B.V. in 2005, and has been a Construction Support Project Manager since 2007, particular for West African Oil \& Gas projects. Since November 2011 he is the business-line manager for Positioning \& Remote Services.

\section{CONTACT DETAILS}

Boudewijn Possel

Fugro Survey B.V.

Veurse Achterweg 12

P.O. Box 128

2260 AC Leidschendam

The Netherlands

Tel.: +31 70-311 1429

Fax.: +31 70-311 1838

Email: b.possel@fugro.com

Web site: http://www.fugro-africa.com/

LinkedIn account: http://www.linkedin.com/pub/

boudewijn-possel/9/a $7 \mathrm{a} / 707$ 
228 | Hydrol 2 


\section{High Resolution Multibeam Survey and Mobile Laser Scanning - Comprehensive Information for Coastal Infrastructure Management and Planning}

Jani PÖTRÖNEN, Finland

Meritaito Ltd

Topic: Innovations in acquisition techniques

\section{INTRODUCTION}

The use of professional divers is the most common method used in the inspection of underwater structures nowadays. However, comprehensive dive inspections are very time consuming and the results may consist of not much more than drawings, fuzzy photographs, and written text. In many locations poor visibility and certain environmental conditions can substantially lower the scope of such inspection or even make it impossible.

This paper presents how high resolution multibeam (MBES) survey, mobile laser scanning and scanning sonar technology can be used in an effective way to gather comprehensive information of your coastal infrastructure above and below the water surface. The benefits compared to other commonly used techniques to gather the information will also be outlined.

\section{MULTIBEAM SURVEY}

Multibeam survey is commonly used for hydrographic charting. Technical development with these sensors has been fast. Nowadays it is possible to collect a huge number of high resolution survey points of not only from the natural seabed but also from other kind of underwater objects. This way much smaller targets can be located and identified underwater.

Multibeam survey is the most economic and effective way to get an extensive underwater view of coastal structures. By tilting the multibeam sonar head sideways, underwater 3D data can be collected from the bottom up to the water surface level. This introduces new possibilities to inspect harbour structures and other underwater civil engineering targets more comprehensively.

High resolution multibeam data shows valuable information about possible slope failures, mass

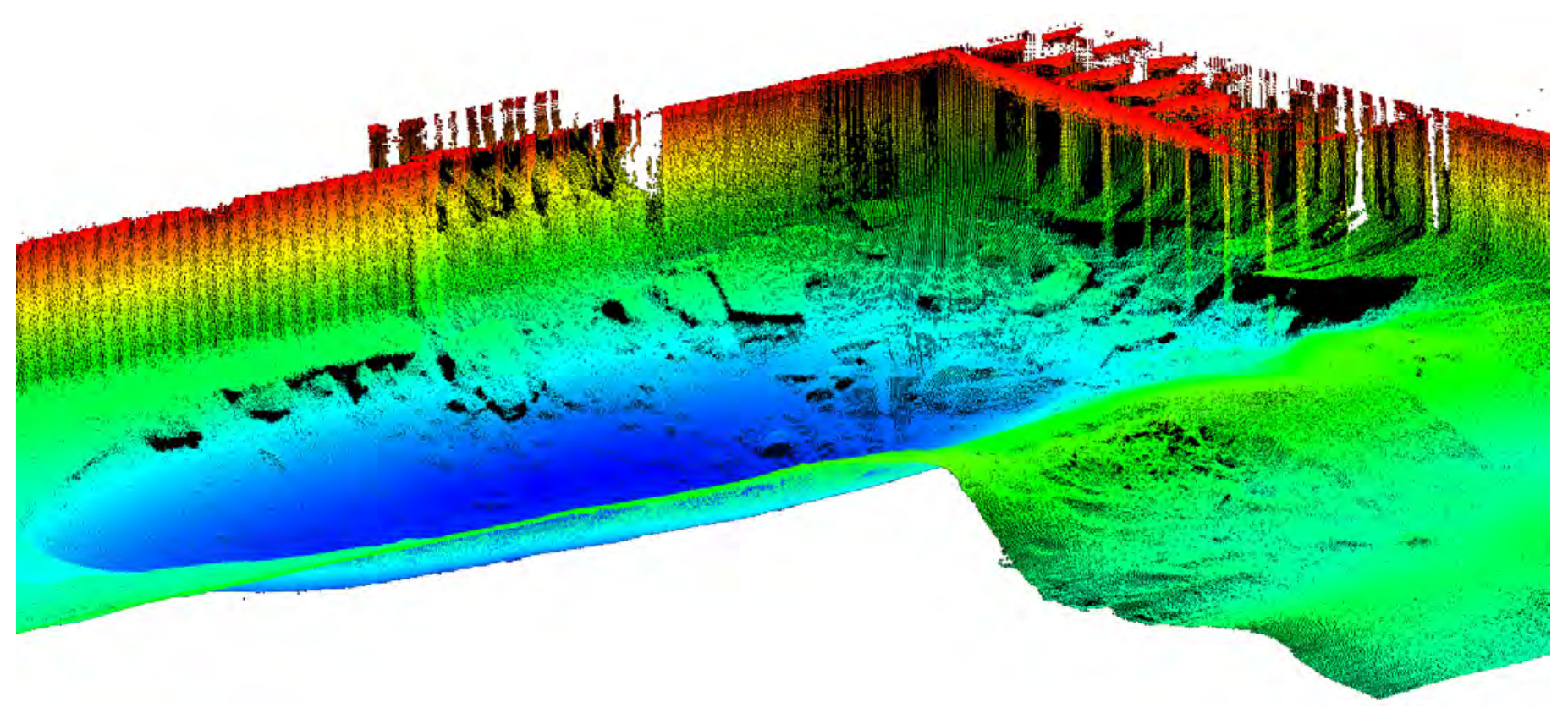

Figure 1: Multibeam survey dataset by tilted sonar head from Port of Helsinki. 


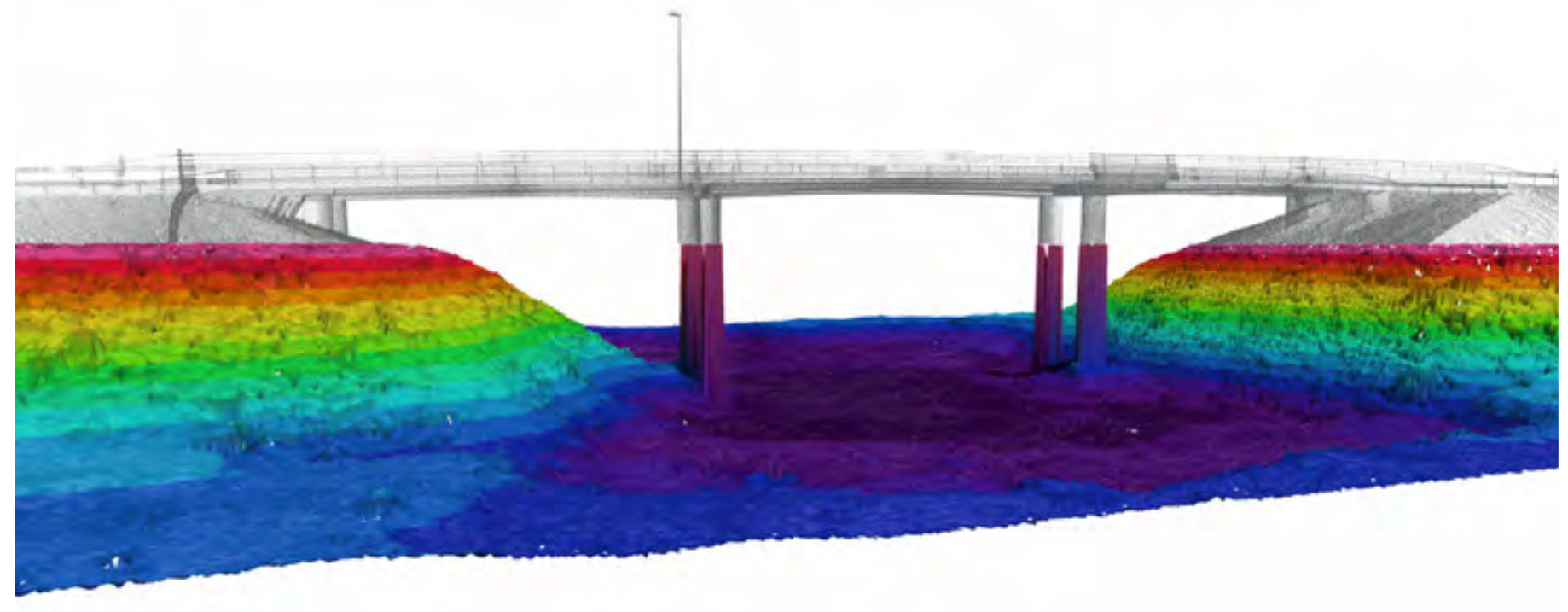

Figure 2: Combined multibeam and laser scanning dataset from Särkisalo bridge.

movements due to propeller race and condition of erosion protection in front of quay walls. Also missing objects like containers and quay wall fenders can be located from the data with high accuracy beside with possible hazards for save navigation in the harbour. The survey results as 3D point clouds are compatible with all modern software for designing, planning and engineering purposes.

\section{MOBILE LASER SCANNING}

Laser scanning is a state of the art method to collect a 3D point cloud of a certain area of interest in extremely high detail level. When mobile laser scanning is carried out simultaneously with the multibeam survey from a modern hydrographic survey vessel, this makes it a highly cost effective way of working.

Combining diver's observations and photographs in a paper report is not compatible to what you can achieve by combining mobile laser scanning of coastal infrastructure with multibeam point cloud of underwater structures. All the objects located in the dataset have exact coordinates and are easy to locate for further inspection through comprehensive view of the area of interest above and below the water surface. This kind of dataset also allows you to document your complete infrastructure for the future development needs.

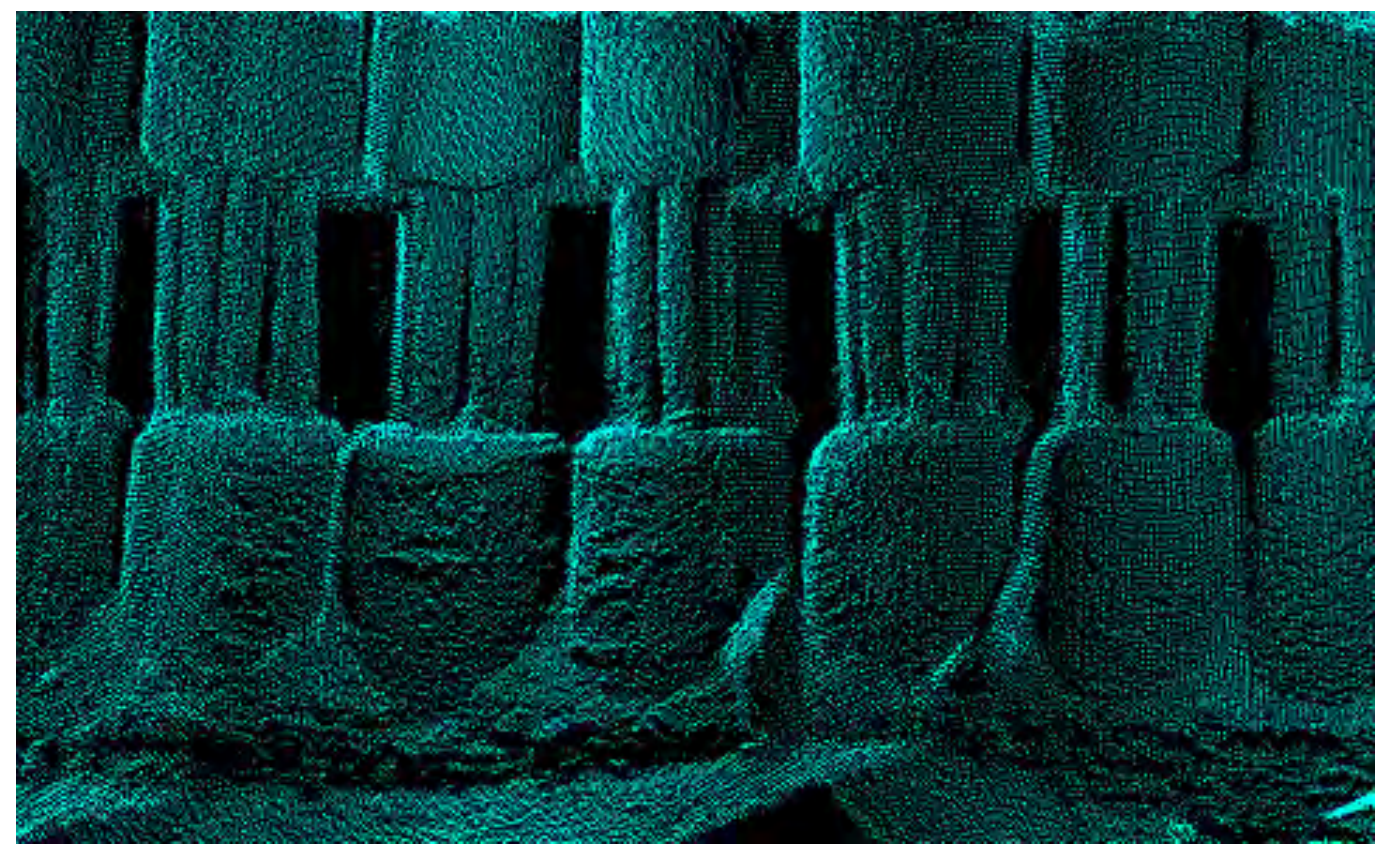

Figure 3: Scanning sonar dataset of the piles (VRT Finland Ltd). 


\section{SCANNING SONAR}

Scanning sonar is the most accurate method to make supplementary inspections for underwater structures in strong current or turbid waters where diving is not possible. Scanning sonar operates at high frequency typically from $600 \mathrm{kHz}$ which gives a good resolution.

Scanning sonar data can be accurate 2D images or $3 \mathrm{D}$ point clouds tied to a coordinate system. Any kind of damage or structural deviations as well as their location and extent can be defined in the inspection. Depending on the circumstances at the site, the inspections can be carried out from a barge, crane or even from frozen sections of water. Compared to multibeam data the resolution of the data is better when sonar mount is static and this way recognized potential targets can be inspected more carefully to do the repair planning.

\section{CONCLUSION}

Multibeam survey and mobile laser scanning provide us a tool to obtain a comprehensive view of a location on a larger scale, and to recognize potential targets for further inspection. These specific targets can then be inspected more closely for example by professional divers. Alternatively, scanning sonar technology offers the most accurate method to inspect underwater structures locally without the need to worry about visibility or strong current.

For a professional inspection of coastal infrastructure the most effective solution is a combination of simultaneous multibeam survey and mobile laser scanning combined with focused scanning sonar inspection. All information in 3D digital format is then usable in modern software for further maintenance planning and engineering purposes. This approach will help to safeguard maritime investments and improve maintenance planning in your harbours and other marine infrastructure.

\section{CONTACT DETAILS}

Jani PÖTRÖNEN

Meritaito Ltd

Porkkalankatu 5

FI-00180 Helsinki

FINLAND

Tel: +358 207030300

GSM: +358 405292748

Fax: +358 207030399

Email: jani.potronen@meritaito.fi

Web site: www.meritaito.fi/www/en 
232 | Hydrol 2 


\section{Sediment waves: geohazard or geofeature?}

Victoria PUTANS, Russia

P.P.Shirshov Institute of Oceanology, RAS

Topic: Geophysics of the marine environment

\section{INTRODUCTION}

The term "sediment waves" fully established in Special issue of Marine Geology [192, 2002] presents large-scale depositional bedforms in various parts of World Ocean. These undulating objects usually have is tens of meters to a few kilometers in wavelength and are several meters high and were generated beneath a near-bottom current or turbidite or both. The main question about the sedimentary wavy features was, and is, to distinguish them from soft sediment deformations. The criteria for such distinguishing is a) accurate processing of seismic sections to reveal whether the faults are real, b) top-wings granulometric distribution, c) regular morphology with obvious distribution law, d) form of crests in plan view. However, "current vs creep" argument is still common even for some well-known "wave fields" [e.g. Berndt et al., 2006].

Worldwide investigations of last decade revealed these controversial geomorphologic features in different geological and paleogeological environments, including ones connected with oil, gas, and gas hydrates fields [Riedel et al., 2010; Heinio \&Davies, 2009; Holbrook et al., 2002]. The revealed facts that sediment waves a) can be not only confused with but be complicated by creep processes [Mitchell\&Huthnance, 2007], b) are evidence for present or past active environment, e.g. turbid flows, trigging, gas eruption [Putans et al., 2010], c) due to lithologically sorted material can be small-scale reservoirs both for free gas and fluids [Wynn et al., 2007, Booth et al., 2003], lead to assumption that presence of these geofeatures may be direct indicator of "geological state that represents or has the potential to develop further into a situation leading to damage or uncontrolled risk" e.g. geohazard. However, the same facts could reveal sediment waves themselves as treacherous features.

Due to recently increased awareness of ecological consequences of offshore exploration, geohazard estimation has become the first thing to do especially in marine environment. Since any sea is very sensitive to any external impact, any information on risk criteria could be vital. Processing of seismoacoustic data and analysis of acoustic field anomalies are primary methods of geophysical survey. Re-interpretation and comparative analysis could be of much help in estimation of potential hazards and especially in distinguishing perilous setting and safe geofeatures. The paper represents such analysis made by P.P.Shirshov Institute of Oceanology RAS on examples from Caspian Sea.

\section{GEOLOGICAL SETTING}

Caspian Sea is a huge $(1200 \mathrm{~km} \times 300 \mathrm{~km})$ inland depression, isolated from World Ocean. Morphologically Caspiy can be divided into three regions: Northern (vast shelf plains), Central (depression, average depth $300 \mathrm{~m}$, maximum depth $-700 \mathrm{~m}$ ) and South (depression, average depth $500 \mathrm{~m}$, maximum $>1000 \mathrm{~m}$ ). Natural borders of these regions are Mangyshlak Threshold (sediment bow-shaped body) between North and Central parts and Apsheron Threshold (linear tectonic elevation) between Central and South parts (Figure 1). Significat regional processes are neotechtonic movements and great amount of deep-focus earthquakes (up to hundred each year). This trigging initiates mud vocano activity and mass movements on slopes of both deep basins. On the other hand, sedimentation processes in Caspian are controlled by bottom topography and sources of sedimentary material (rivers runoff first of all). The most famous Caspian pequliarity is its ever-lasting unpredictable level-change which is impossibble to correlate definitely neither with World Ocean nor with glaciation history.

Major hydrocarbon fields are situated on the Northern shelf and in deep Southern basin, and several prospective sructures occur in Central basin. There is a general distribution rule: main oil fiels are situated nothward from Apsheron threshold and main gas fields southward. Such situation is 

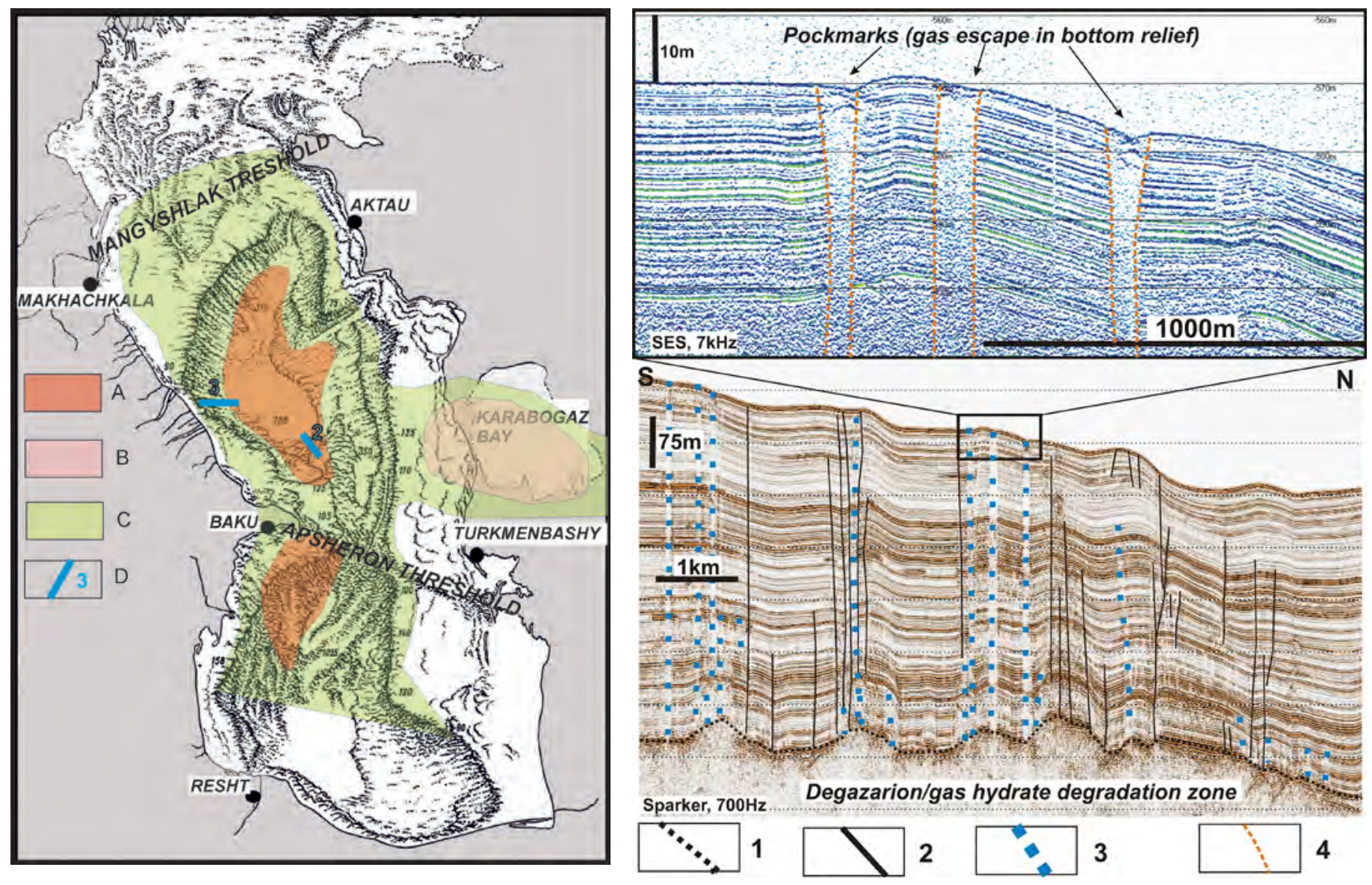

Figure 1 (left): Geomorphiligy scheme combined with scheme of heat flow from [Glumov, 2004]. Heat flow: A - most active, B - active, C - high; D - location of profiles on figures 2 and 3.

Figure 2 (right): Vertical degazation zones and pockmarks in bottom relief. 1 - top of gas hydrate degradation layer; 2 - falures; 3 - gas pipes; 4 - pokmarks. 1

due to sedimetation history and heat flow which is especially great near Apsheron threshold. Nevertheless, gas-saturated sediments in different forms occur nearly everythere in Caspian. Most usual acoustic anomaly for such sediments is "bright spot", but spectatular gas pipes exists as well (Fig.2).

Beside oil and gas fields, Caspian sea seems to have several fields of gas hydrates with different gas types. During intensive expropation in South Caspian gas hydrates were discovered offshore Azerbaijan both on the top of mud volcanoes [Ginsburg \& Soloviev, 1994] and in fairly undisturbed sedimentary section by clear seismic BSR [Diaconescu et al., 2001]. Zones A on heat flow map adopted from Glumov [2004] on Figure 1 correlate with "allowed existence" areas caluculated from parameters in Diaconesu [2001].

\section{STUDY METHODS}

During recent investigations of P.P.Shirshov Institute of Oceanology seismoacoustic data was aquired by several hardware sets (Table 1). A global positioning system (DGPS) provided vessel position with an accuracy 0.5-5.0 m. Polygons consist of orthogonally or obliquely crossing survey lines. The deposits have been sampled with gravity cores $15 \mathrm{~cm}$ in diameter and up to $4 \mathrm{~m}$ deep. Grain size analyses were made in MSU laboratories with standard methods. Volume density of unstrained and wet sediment was calculated by cutting ring method. Seismoacoucstics data was processed in RadExPro seismic processing program with standard algorithm (muting, filtration, sometimes deconvolution).

Plastic models, based on density and geometry, were calculated in FLAC $^{3 \mathrm{D}}$. 
Table 1: Hardware parameters

\begin{tabular}{|lllll|}
\hline Type & Function & $\begin{array}{l}\text { Frequency } \\
\text { range (kHz) }\end{array}$ & $\begin{array}{l}\text { Penetration } \\
\text { (depend on sediments) }\end{array}$ & $\begin{array}{l}\text { Vertical } \\
\text { resolution }\end{array}$ \\
\hline Sparker & Seismoacoustic & $0.2-0.7$ & $50 \mathrm{~m}-300 \mathrm{~m}$ & $2-3 \mathrm{~m}$ \\
\hline $\begin{array}{l}\text { SES - 2000 } \\
\text { standart }\end{array}$ & $\begin{array}{l}\text { Echo-sounder }+ \\
\text { seismoacoustical } \\
\text { profiler (tone signal) }\end{array}$ & $\begin{array}{l}100 \mathrm{kHz} \\
4-12 \mathrm{kHz}\end{array}$ & $10 \mathrm{~m}-50 \mathrm{~m}$ & $0.05-0.15 \mathrm{~m}$ \\
CHIRP-II & $\begin{array}{l}\text { Seismoacoustic profiler } \\
\text { with swip signal }\end{array}$ & $2-7 \mathrm{kHz}$ & $2 \mathrm{~m}-50 \mathrm{~m}$ & $0.2-0.5 \mathrm{~m}$ \\
\hline
\end{tabular}

\section{RESULTS}

Seismoacoustic data of high resolution shows distinct zonality of geomorphology and acoustic anomalies: bright spots and numerous filled paleovalleys in Northern Caspian; fans and paleodeltas on Mangyshlak theshold with creep zone and channel system down to Cenral basin; gas chimnes and unexpected mud volcano in basin itself; series of modern faults on Apsheron threshold; several fans and gas escaping zones in Southern Caspian.

The most significant event of recent years was discovery of several types of sediment waves on slopes of Central basin. The most vast $(\sim 150 \mathrm{~km}$ $\mathrm{x} 50 \mathrm{~km}$ ) field is situated on western slope of the Central Basin (Fig. 3). Previously, these forms were interpreted as creep, but reinterpretation of old and obtaining new data showed all distinctions of mixed sediment waves (see Introduction). There are several generations of waves, interbedded with conform parallel deposits. Geological samples show numerous sand/clay thin layers. The whole sequence age is $700 \mathrm{kyr}$ and it has form of a wedge between the shelf break and the steep step down to abyssal. The second area of sediment waves is on levees of channels/canyons on Mangyshlak Thresold. Compund fan of paleo Volga, paleo Terek and paleo Ural represents a highly complicated system with inflows and meanders, both recent and old (up to 600 kyr). Sediment waves on levees show different morphology, probably because of not precisely normal transsections. Samples show thin material (clay). The very recent studies (2012) reveal the third sediment waves field on northern slope of Apsheron threshold. However it is a matter of future research.

In close neighboughood with levee exists creep area. Folds have "classical" creep shape: flat tops, narrow valleys, irregular morphology and geometry. As well as on other "wavy" fields, there are several "generations" of creep folds, each slightly differs from others. Geological cores show water-saturated plastic clay.

Due to tectonic activity of the region, there are a lot of faults and failure of different scale. These features are inevitably connected to vertical zones without

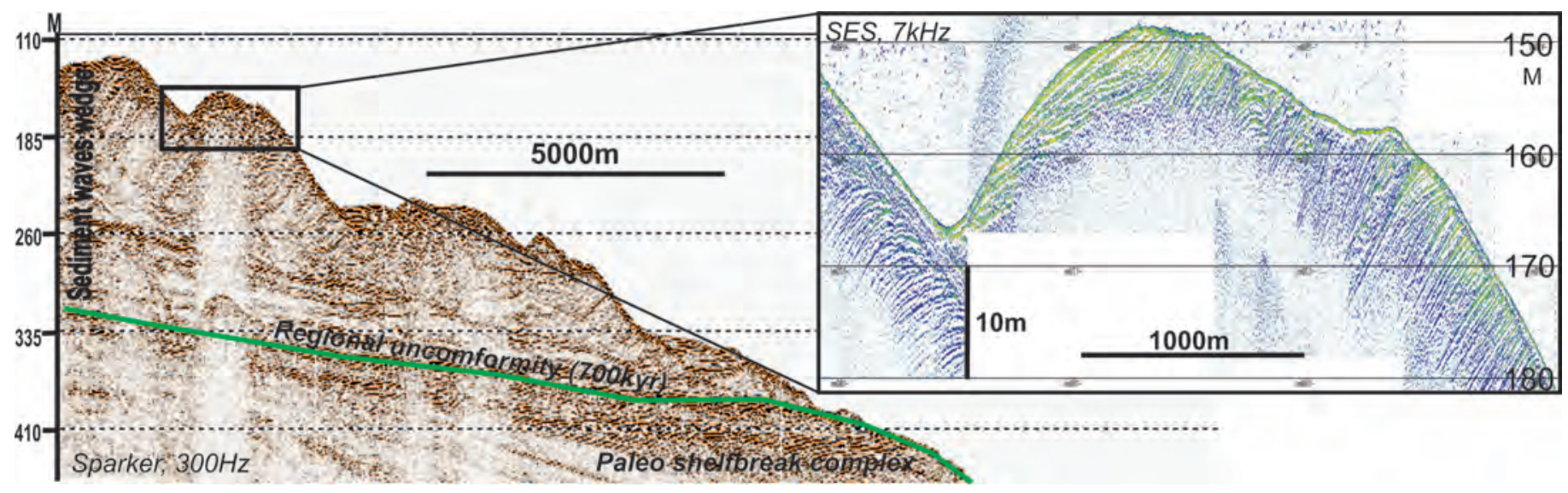

Figure 3: Sediment was on Derbent slope (Central Caspian). None zones of acouatic shadows on Sparker profile and reflections in water on SES data. 
correlation (pipes and chimneys). Most of these zones ends with pockmarks in bottom relif (Fig.2). The other end connects with vast zone of chaotic reflections, both in Central ans South Caspian. However, northward from Asheron Threshold there are three such zones on different levels and none of them comes up to bottom surface, whlie sothward the zone occure just below holocene sediments.

\section{DISCUSSION}

Due to recently increased interest to gas hydrates and awareness of ecological consequences of hydrocarbon exploration, author put special attention on correlation between sediment waves, gas escaping structures and gas hydrates with their principle evidence bottom-simulating reflectors (BSR). Indeed, all these features seem to show up together on perspective hydrocarbon fields. The most obvious explanation to this correlation could be unstable environment which works both ways: endogenous processes form rough relief, cause trigging, sedimentation results in wavy forms, which could a) be unstable or b) accumulate escaping gas due to well sorted material. The most noticeable is escaping of free gas below BSR or from dissociated gas hydrates layers. Such correlation is not absolute and requires further investigations. However, it is possible to classify two types of "gas-sediment waves" relation: a) direct escaping of gas through wavy features; b) geological association "sediment waves - BSR" on seismoacoustic transects.

Interpretation of high resolution profiles on Caspian Sea, taken in framework of this conception, provides good evidence for such distribution. For example, on Derbent slope there are several "bright spots" and escaping chimneys. Modeling of plastic deformation shows that wedge of sediment waves on Derbent slope is stable, while creep on the northern slope is in continuous flowing. Between them sets channel system which indicates active hydrodynamics in recent past or present. Several levels of this system also have "bright spot" anomalies and series of possible gas-escape unconformities. Thus it is possible to declare that in Central Caspian sediment waves are evidenses of geohazards [Putans et al., 2010]. But the flow and fluxes are not the only geohazard sediment waves could be conected with.
Just nearby last levee starts acoustic anomaly of great disturbance. This anomaly is connected to gas pipes and is believed to be weak layer of dissociated gas hydrates. Presence of free gas could be dangerous for drilling on nearby structures, and further southward. Data from Apsheron Threshold and Southern Caspian provides evidence of shallow BSRs. At the same time, Caspian data shows unusual acoustic pattern as mirrored reflection. Very acoustically sharp layer "mirrors" bottom relies so that at first glance it could be confused with BSRs and. Interesting fact is, that such effect occurs nearby gas escaping areas.

\section{CONCLUSION}

Are sediment waves geohazards or just geofeature? After one had found some "wavy" morphology and classified it as creep, we are talking of geohazard, on the other way it seems undisturbed accumulative object. Nevetheless, every sediment wave field is (or was) forming in active environment such as water flow or turbidite. Two latter are treacherous processes, escpecially for pipelines: erosion could cause stretching while intensive sediment input could bury pipe. Other exploitetion and exploration risks are solifluction under pressure of platform basement and gas explosion. Thus such geofetures as sediment waves should serve as a warning and to think in advance of anthropogenic impact and to take care of the sea.

The presented study was partially supported by RFBR, research project No.12-02-00543-a

\section{REFERENCES}

\section{Marine Geology, (2002), vol.192}

Berndt, C., Bünz, S., Clayton, T., Mienert, J., Saunders, M. (2004). Seismic character of bottom simulating reflectors: Examples from the midNorwegian margin // Marine and Petroleum Geology 21 (6), pp.723-733

Booth J.R., Dean M.C., DuVernay A.E. III, Styzen M.J. (2003). Paleo-bathymetric controls on the stratigraphic architecture and reservoir development of confined fans in the Auger Basin: central Gulf of Mexico slope // Marine and Petroleum Geology, v. 20, p. 563-586.

\section{6 | Hydrol 2}


Diaconescu C.C., Kieckhefer R.M., Knapp J.H. (2001). Geophysical evidence for gas hydrates in the deep water of the South Caspian Basin, Azerbaijan Marine and Petroleum Geology 18, pp.209 \pm 221

Ginsburg, G. D., \& Soloviev, V. A. (1994). Mud volcano gas hydrates in the Caspian Sea // Bulletin of the Geological Society of Denmark, 41, 95 \pm 100

Glumov I.F., Malovitskiy Ya.P., NovikovA.A., Senin B.V. (2004) Regional geology and oil and gas content of Caspian Sea. (In Russian) Moscow, Nedra

Heinio P., Davies R.J. (2009). Trails of depressions and sediment waves along submarine channels on the continental margin of Espirito Santo Basin, Brazil // Geological Society of America Bulletin, v.121, no.5-6, p.698-711

Holbrook W.S., Lizarralde D., Pecher I.A., Gorman A.R., Hackwith K.L., Hornbach M., Saffer D. (2002). Escape of methane gas through sediment waves in a large methane hydrate province // Geology, v.30, pp. 467-470

Mitchell N.C., Huthnance J. M. (2007). Comparing the smooth, parabolic shapes of interfluves in continental slopes to predictions of diffusion transport models // Marine Geology 236, 189-208

Putans V.A., Merklin L.R., Levchenko O.V. (2010). Sediment waves and other forms as evidence of geohazards (Caspian Sea) // International Journal of Offshore and Polar Engineering. Vol. 20, No. 4

Riedel, M., Collett, T.S., and Malone, M., (2010). Expedition 311 synthesis: scientific findings // In Riedel, M., Collett, T.S., Malone, M.J., and the Expedition 311 Scientists, Proc. IODP, 311: Washington, DC (Integrated Ocean Drilling Program

Wynn R.B., Cronin B.T., Peakall J. (2007). Sinuous deep-water channels: Genesis, geometry and architecture // Marine and Petroleum Geology 24, pp. 341-387

\section{BIOGRAPHY}

Victoria PUTANS, researcher in Seismostratigraphy lab in P.P.Shirshov Institute of Oceanology, RAS (IORAS). Since 2003 worked as part-time engineer in the IO RAS while being full-time student of Russian State Geological Prospecting Univ. (RSGPU), Geophysical Dept. Graduated RSGPU in 2007 as Mining engineer in geoghysical methods of prospecting and survey, Seismics. Continued in IO RAS as $\mathrm{PhD}$ student and recieved $\mathrm{PhD}$ in Oceanology in 2010. Participant of several international scientific projects, experience in exploration projects for Lukoil company. Current scientific interests: seismoacoustics, geohazards, sea-level change, marine exploration, all range of sedimentation processes.

\section{CONTACT DETAILS}

Victoria PUTANS

P.P.Shirshov Institute or Oceanology, RAS

36, Nokhimovskiy prospekt

Moscow

RUSSIA

Tel.: +79263193636

Fax: +499124

Email: vitapu@mail.ru; vitapu@ocean.ru

Web site: www.ocean.ru 
238 | Hydrol 2 


\title{
Innovative Positioning System Integration for Immersed Tunnel Construction
}

\author{
Bart-Jan RUESINK and Danielle DE GROOT, the Netherlands \\ Geocon BV (Strukton Immersion Projects)
}

Topic: Subsea positioning

\section{INTRODUCTION}

A road connection was constructed in the south eastern part of South Korea between Busan, the country's second largest city, and Geoje Island. The Busan-Geoje Fixed Link (BGFL) crosses the Jinhae Bay and reduces the travel time from 3 hours to 40 minutes. The BGFL has a total length of 8.2 $\mathrm{km}$, consisting of $3.2 \mathrm{~km}$ of immersed tunnel and two cable-stayed bridges of $2 \mathrm{~km}$ length. The $2 \times 2$ lane immersed road tunnel is one of the longest and deepest in the world, having a maximum depth of $48 \mathrm{~m}$. In total, 18 tunnel elements of $180 \mathrm{~m}$ (Figure 1) were immersed in a crossing directly connected to the Eastern China Sea and the Pacific. Significant wave heights of $8 \mathrm{~m}$, due to typhoons, are not an exception. Moreover, a current velocity of up to 2.0 $\mathrm{m} / \mathrm{s}$ make the marine circumstances challenging.

Performing the immersion of tunnel elements in these extreme conditions would appear impossible. Especially considering the maximum allowable deviation in the final position of no more than 0.050 $\mathrm{m}$ from the longitudinal tunnel axis. Both the length and depth of this immersed tunnel imposed great challenges and required 'out of the box' positioning solutions. Since the contract was awarded in March 2007 and the first immersion was scheduled for January 2008 the development and implementation time were very short. Main contractor Daewoo Engineering and Construction chose Strukton Immersion Projects for the immersion of the tunnel elements with its subsidiary Geocon taking care of the immersion survey.

\section{TUNNEL IMMERSION PROCESS}

In case it is not possible to build a tunnel at its final location an immersed tunnel can be the solution. Therefore the tunnel is divided in tunnel elements with a manageable length. These elements are built in a temporary precast yard. When ready the tunnel elements are floated and temporary stored at a mooring location. The tunnel elements are transported to their final location just before immersion. For the BGFL tunnel the conditions and phasing were as follows.

\section{Precast yard and mooring location}

The construction of the tunnel elements was carried out in a temporary precast yard (Figure 2 ) on the western side of the Jinhae Bay, about $40 \mathrm{~km}$ from the immersion area. The casting of the tunnel elements was carried out in two batches of four and two batches of five tunnel elements. The first 16 tunnel elements are $180 \mathrm{~m}$ long, $10 \mathrm{~m}$ high, $26 \mathrm{~m}$ wide and each weigh about 48,000 tons. The final two tunnel elements are equipped with a climbing lane and are $2 \mathrm{~m}$ wider. The tunnel elements were equipped on both ends with steel, reusable bulkhead panels.

After finishing each batch, the precast yard is flooded and the construction dock door is removed. The tunnel elements are floated up and trimmed one by one with the ballast water system inside the tunnel element. The transport inside the precast yard is carried out by a fixed winching system. Once

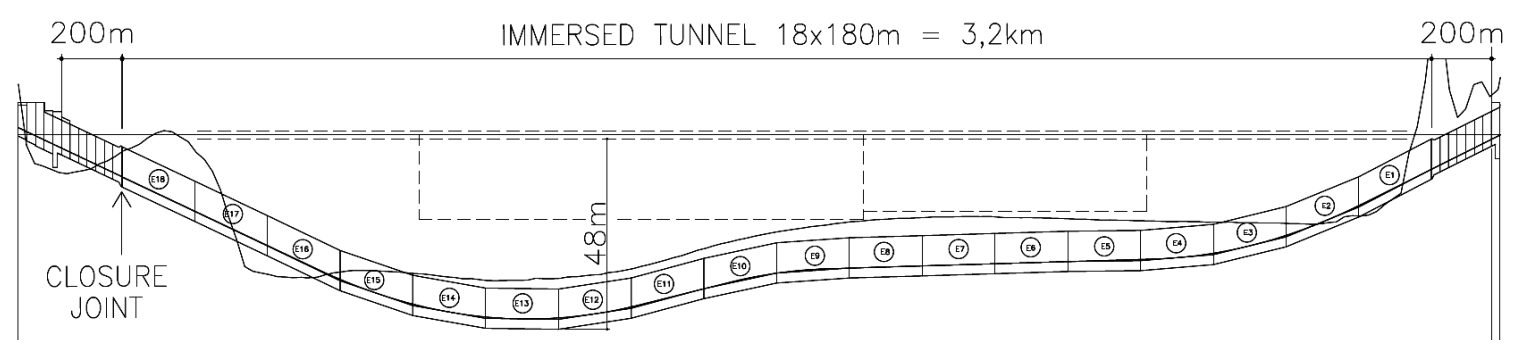

Figure 1. Immersed tunnel longitudinal section. 


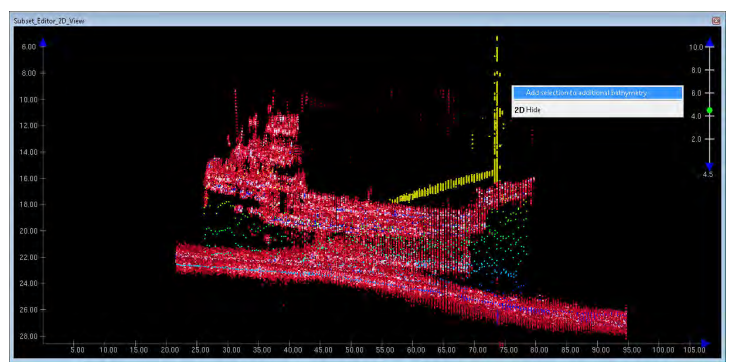

Figure 2. Temporary precast yard

the tunnel element has been moved through the dock gate, four tugs are used to transport the tunnel element to the nearby mooring location. A maximum of six tunnel elements at one time are stored at the mooring location. The tunnel elements are stored in floating conditions. Due to the sheltered area of the mooring location, the tunnel elements are not affected by swell waves and can be stored there throughout the year.

\section{$\underline{\text { Immersion preparation and transport }}$}

The tunnel elements are prepared for the immersion operation at the mooring location (Figure 3). Prior to the transport, two immersion pontoons are positioned over the tunnel element. The pontoons are of the catamaran type and consist of a main deck $(42.5 \mathrm{~m} \mathrm{x} 24 \mathrm{~m} \times 2.5 \mathrm{~m})$ and two floaters $(36 \mathrm{~m} \mathrm{x}$ $6 \mathrm{~m} \times 6 \mathrm{~m}$ ). The pontoons are each designed for at least 1000 ton pulling force.

On the tunnel deck, bollards, lifting lugs, sheaves and a landing tower are installed, as well as guide beams on the primary side (bow) and catches on

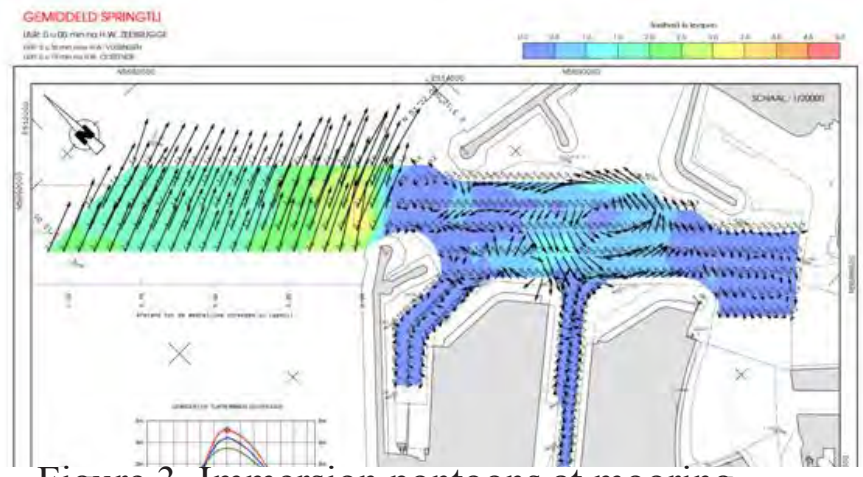

Figure 3. Immersion pontoons at mooring location

the secondary side (stern) of the tunnel element. The guide beams and catches are used to guide the tunnel element sideways during the immersion process. Equipment for the remote-controlled ballast water system and the immersion survey system are installed inside the tunnel element.

As soon as the predicted weather and wave conditions are within the limits and provide a weather window of 3 days, the final go decision was made. The combined system of tunnel element and pontoons is towed by four tugs to the immersion location.

\section{$\underline{\text { Immersion }}$}

A spread consisting of 18 winch wires is used in order to be able to carry out a controlled and secure immersion operation. Four mooring wires per pontoon for positioning the immersion pontoons above the target position of the tunnel element, three contraction wires per pontoon for positioning the tunnel element and two suspension wires per pontoon to carry the weight of the tunnel element.

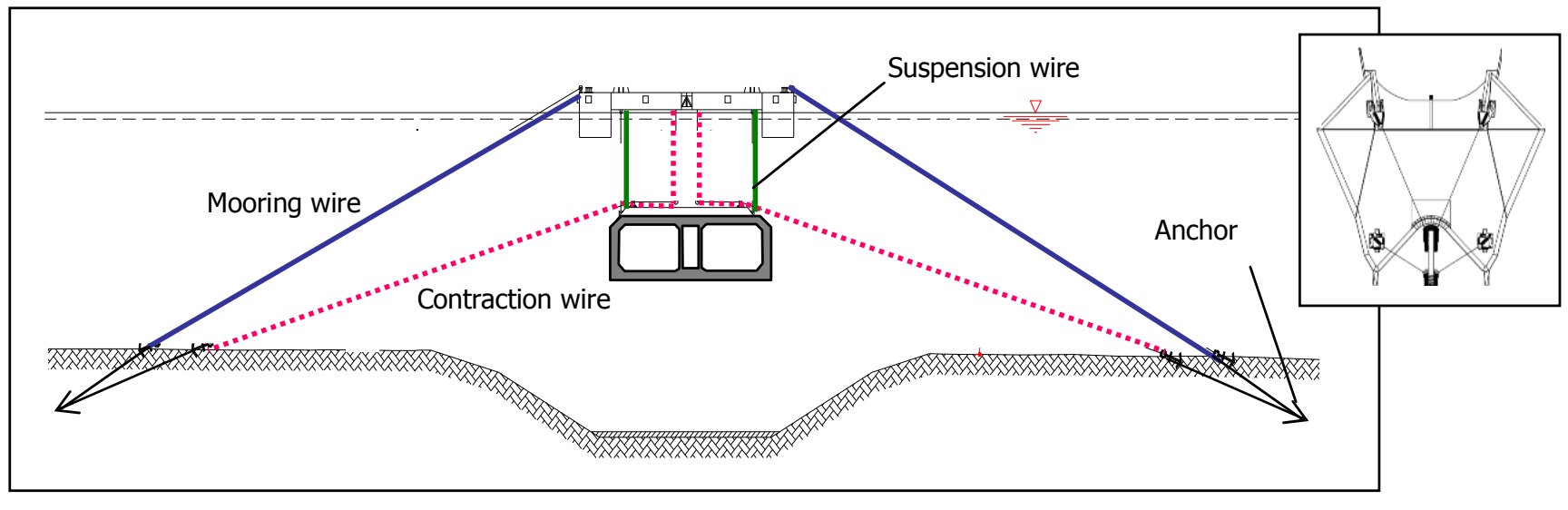

Figure 4. Immersion spread 
As soon as the tunnel element arrives at the immersion location, the winch wires are connected one by one to seabed anchors. The mooring and contraction wires are installed in a taut configuration in order to reduce the motions influenced by waves to a minimum (Figure 4).

After taking in the necessary water for the $2 \%$ overweight, the tunnel element is lowered to the gravel bed. The immersion pontoons fully bear the immersion loads during the immersion process. The connection with the previous tunnel element is carried out by the Gina gasket, a water tight seal between two tunnel elements. After connection of the tunnel element the immersion joint between the newly immersed tunnel element and the previously installed tunnel element is emptied. An Omega Gasket is mounted at a later stage for extra safety with regard to water tightness. Divers remove the deck layout from the tunnel deck. This equipment is returned to the mooring location where immersion preparations for the new tunnel element commence.

\section{TRADITIONAL IMMERSION SURVEY SYSTEM}

The survey of an immersion operation is usually carried out by a tacheometric system consisting of three total stations on shore, measuring four survey prisms mounted on an access shaft and an alignment tower (Figure 5). An inclinometer is used to measure the roll of the tunnel element. Before immersion the position of the prisms is measured and related to the tunnel geometry by known points on the deck of the tunnel.

This traditional system uses land survey techniques and functions appropriate up to a distance of $+/-$ $800 \mathrm{~m}$ offshore, at greater distances the accuracy

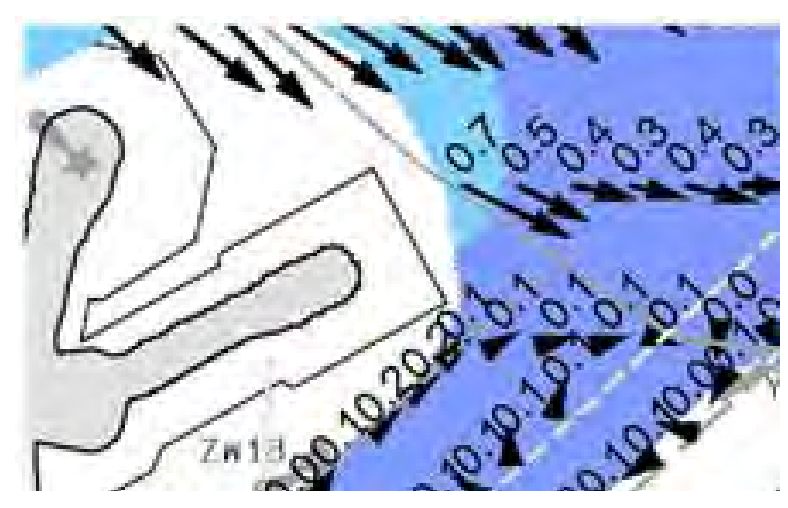

Figure 5. Traditional survey system

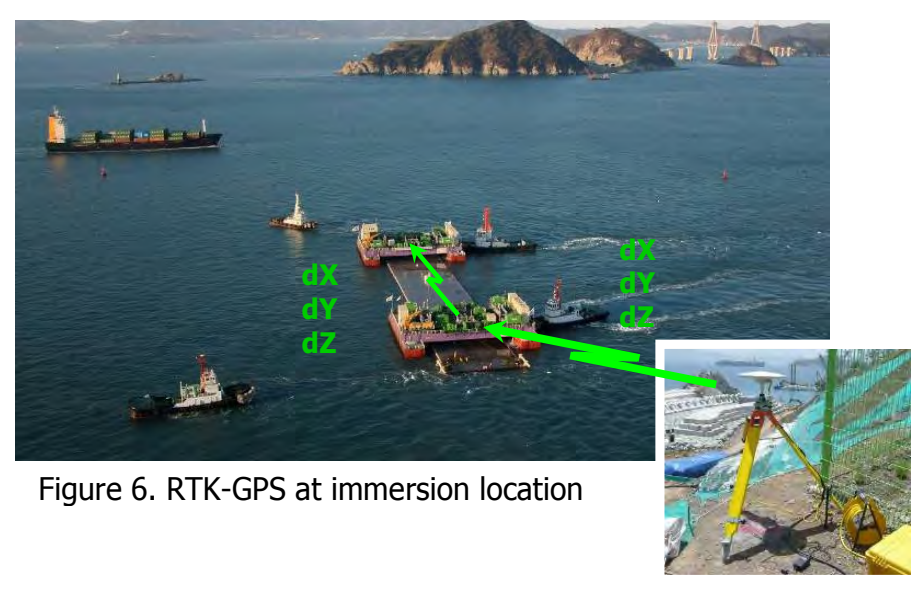

deteriorates. Also the greater depth of the tunnel restricts the use of the access shaft and alignment tower as result of the current forces. Therefore a new underwater survey system had to be developed.

\section{SURVEY SYSTEM USED FOR THE BGFL PROJECT}

The BGFL Survey System consist of a combination of new and existing techniques, with an increasing accuracy from the transport phase up to the joining of the tunnel elements. In total four new survey systems are used for the immersion. For the first tunnel elements the traditional survey was used as well for verifying the newly developed systems.

Transport and positioning above immersion trench

The first system, an RTK-GPS system on the immersion pontoons, was used for the transport phase and for the positioning of each tunnel element above the immersion trench. On both of the pontoons a GPS receiver was installed. Near the immersion location a GPS base station was placed which provided RTK-GPS accuracy for the positioning (Figure 6). The accuracy of the system is $+/-0.03 \mathrm{~m}$. in XY and $0.1 \mathrm{~m}$. in $\mathrm{Z}$.

\section{Immersion survey}

\section{Approach}

For immersing the tunnel element to a distance of $0.5 \mathrm{~m}$ towards the previous one a custom made 'light tautwire' system (Figure 7) was designed, the second survey system. The tautwire is an instrument running a tensioned steel wire up and down on a drum. The tautwire unit is attached to the primary bulkhead 


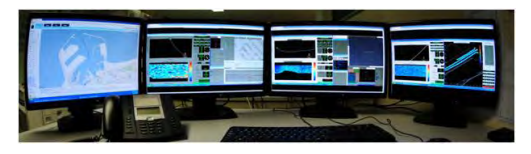

Figure 7. Taut-

wire system of the tunnel element; the wire is connected to the secondary side of the previously immersed tunnel element. The tautwire measures the length of the wire, as well as the angles of the arm guiding the wire. The accuracy of the tautwire increases the closer the tunnel element gets to its final position. Information about the secondary side, referenced to the primary side, was provided by a Fiber Optic Gyroscope (FOG). The accuracy of the tautwire system is $+/-0.03 \mathrm{~m}$ in $\mathrm{X}, \mathrm{Y}$ and $\mathrm{Z}$ in the final and most critical stage of immersion.

The third system, a USBL system, was used as a backup of the tautwire. This acoustic survey system consists of a transducer and several transponders. The transducer, mounted on the primary side of a tunnel element, transmits an acoustic signal. This signal is received by the transponders mounted at known positions on the previously immersed tunnel element. The transponders reply to the transmitted signal with their own acoustic tone which is subsequently received at the transducer. A sound velocity sensor is mounted near the transducer. The speed of sound is frequently updated in the USBL software. This software outputs forward, starboard and depth values for each transponder. The Geocon immersion software processes these values to an actual position of the tunnel element. The accuracy of this system is $+/-0.15 \mathrm{~m}$.

\section{Final immersion phase}

In the final phase of the immersion process, the Gina gasket is pulled against the steel end frame of the previous tunnel element to obtain the initial water tightness, necessary to empty the immersion joint. For this phase, distance sensors (Figure 8) were developed to provide accurate measurements. With their range of $0.4 \mathrm{~m}$, the four distance sensors are extended just before the moment the Gina gasket touches the previously immersed tunnel element. The submillimeter accurate readings of these sensors are used in several ways. The reading of the stroke is a direct indication of the distance. Using the four distance sensors on each corner of the primary side of the tunnel element, a conclusion can be drawn about the position of the secondary end from the differences in the readings of the sensors. The accuracy of this forth immersion survey system is $+/-0.005 \mathrm{~m}$ at the primary side, and $+/-0.02 \mathrm{~m}$ at the secondary side.

\section{As immersed survey}

To determine the final position of the tunnel element after immersion a final survey is performed. Traditionally this is done with laser-plummet measurements through the access shaft to confirm the final position of the tunnel element. For the BGFL-project most tunnel elements were not equipped with an access shaft and the end survey was done by tacheometric measurements through the bulkhead doors. The accuracy of this final

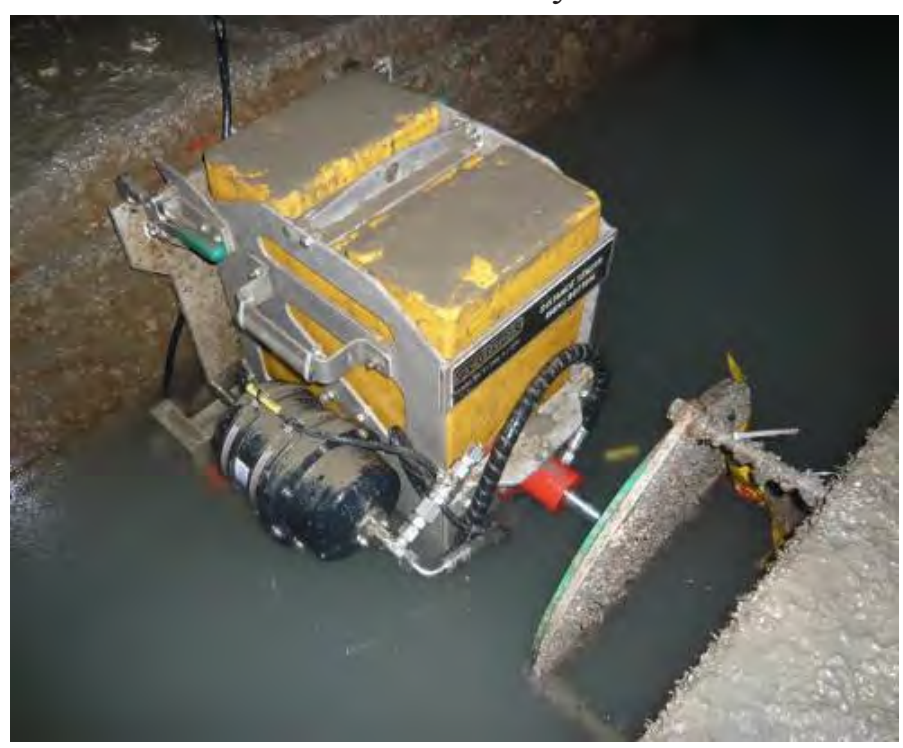

Figure 8. Distance sensor 
measurement is $+/-0.005 \mathrm{~m}$.

\section{IMMERSION SURVEY PREPARATIONS}

\section{Precast yard}

The immersion survey preparations start in the precast yard where the tunnel elements are built. The tunnel element geometry is verified by means of total station measurements. Survey points are created in and on the tunnel element. The steel end frame on which the Gina gasket is mounted needs to be flat within $+/-0.003 \mathrm{~m}$ and facing in the right direction. An as-built check on this plate is performed as deviations in its position may compromise the water tightness of the immersion joint.

Just before immersion, the tautwire and distance sensors are mounted on base plates. These base plates are mounted on the bulkhead and measured in the precast yard (Figure 9, marked) at the primary side of the tunnel element. During immersion the distance sensors are extended to reference plates that are mounted at the secondary side of the previously immersed tunnel element.

\section{Mooring location}

Before an immersion all survey equipment is transported to the mooring location where the tunnel elements are temporarily parked. The next element to be immersed is fitted with all necessary sensors required for the immersion.

\section{A GPS compass is used for the alignment of the}

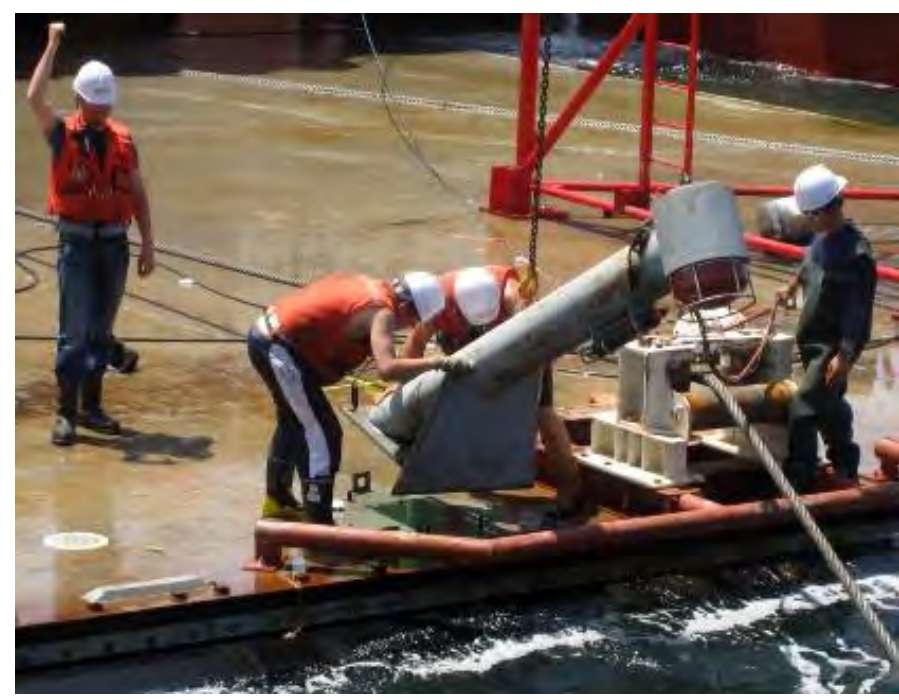

Figure 10. Mounting the USBL system

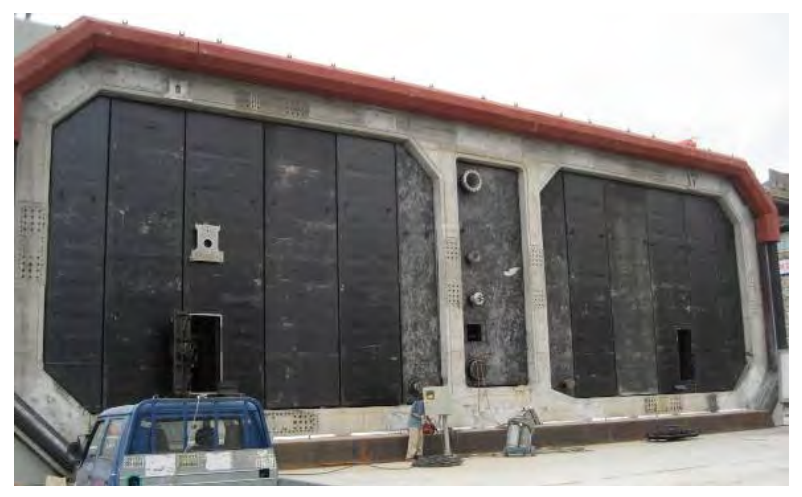

Figure 9. Baseplates on bulkhead

FOG inside the tunnel element as well as for the tunnel element position and heading during the transport phase. It is mounted on the two catamaran pontoons. After connecting these pontoons to the tunnel element the position of the GPS antennae is measured with a total station. With the known position of the antennae and the heading from the GPS compass, the heading of the tunnel element is calculated.

The FOG is used to measure the roll, pitch and heading of the tunnel element. The heading misalignment which is introduced due to the mounting of the sensor is dynamically determined by simultaneously measuring the heading of the tunnel element with the GPS compass and comparing it with the output of the FOG. After approximately 30 minutes of data collection the Geocon software calculates the best fit of the two data sets resulting in a $\mathrm{C}-\mathrm{O}$ value.

Since the elements are floating at the mooring location, the roll and pitch C-O's need to be determined in a dynamic environment. An automatic levelling instrument is set up above a known point on the tunnel element deck. A rod is placed above another known point and is observed through the levelling instrument. The rod is observed while it goes up and down behind the instruments crosshair as the levelling instrument compensates for the motion of the tunnel element. With the radio open the observer behind the instrument and the online surveyor take a reading of both the levelling rod and the inclinometer roll at the same time. After some 10 readings a reliable $\mathrm{C}-\mathrm{O}$ for the roll, and likewise for the pitch is determined.

At the mooring location the USBL transducer is mounted (Figure 10) and surveyed with land survey 


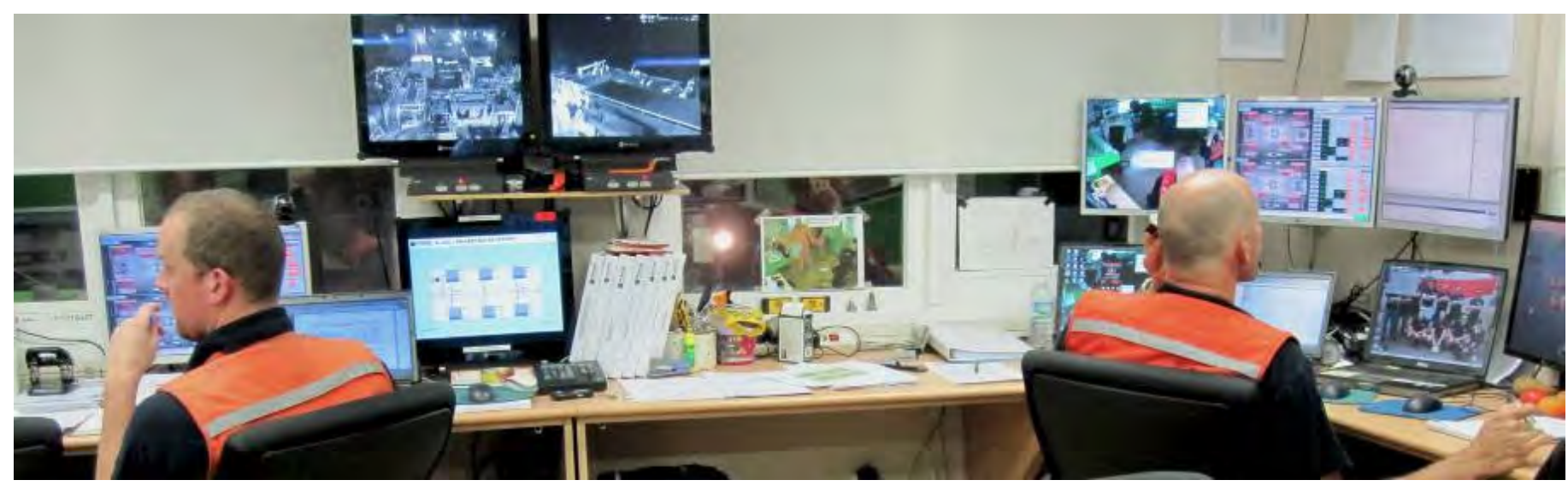

Figure 11. Immersion command center

equipment. Also an "as-mounted" check on the guidebeams and catches is performed. The Geocon immersion software is configured with all latest survey data and maps and the remaining checklist items are completed. The element is now ready to be immersed and awaits its final go decision.

\section{IMMERSION}

After leaving the mooring location the tunnel element starts a $36+$ hour journey to its final position. Crews of winch operators, hydraulic engineers, divers, surveyors, immersion commanders and other engineers work in 12 hour shifts until the immersion operation is successfully completed. The data coming from all sensors finds its way through the integrated systems to the immersion command unit from where the operation is lead. As no access shaft is used in this project all equipment inside the tunnel element such as valves of the ballast tanks, the dome cameras, the tautwire and distance sensors are remotely controlled. All the data from these systems is transmitted through an umbilical, running from the secondary bulkhead to the umbilical winch on the secondary immersion pontoon. The Geocon software displays and also logs all received data. After each immersion all logged data is reviewed, analyzed and reported.

\section{$\underline{\text { Visualisation }}$}

All immersion survey data is presented in a sober yet adequate data screen providing the immersion commander with no more information than necessary. Simultaneously, all immersion survey data is uploaded to a computer server. This data is directly available for the web application www. geocon3d.com which displays the immersion process in real time in a virtual environment. Management, client, engineers, relatives and all those interested can log on to this website and follow the immersion process through webcams and the virtual 3D model.

\section{Geodetic alignment control}

After immersion the position of the tunnel element is verified with a total station measurement through the tunnel gallery. As the tunnel is getting longer, the accumulated total station data results in a declining accuracy as a result of poor geometry and poor survey conditions. Large variations in humidity, temperature and line of sight due to construction works inside the tunnel influence the survey conditions considerably. The angular reliability of the geodetic network inside the tunnel decreases with the tunnel length. Therefore the geodetic network inside the tunnel is strengthened using land survey gyroscope observations. This instrument measures the true heading at several chords throughout the tunnel with an angular accuracy of $0.001^{\circ}$, equal to $0.015 \mathrm{~m} / \mathrm{km}$. The headings measured with the total station are dependent of the accuracy of the preceding survey points that are used in the tunnel. The gyroscope headings on the other hand are independent. The total stations measurements are corrected with the gyroscope observations. With this corrected data the as built tunnel alignment is determined.

\section{CONCLUSIONS}

The existing Geocon Immersion Software Package required to be re-written in order to cope with the

\section{4 | Hydrol 2}


input of data from sensors like remote controled winches, CCTV, ballast water systems and the new survey systems. Struktons in-house software engineers managed to successfully deliver this new software prior to the first immersion in January 2008. The integrated survey system approach by Geocon proved to be successful for the Busan Geoje Fixed Link immersed tunnel project. During the first immersion, all new positioning systems were mirrored against the traditional total station system. The accuracy and the reliability of the new systems proved to meet the requirements to position 3.2 $\mathrm{km}$ of immersed tunnel within just $0.05 \mathrm{~m}$ from its intended position. The 18th and final tunnel element was immersed in June 2010. The south Korean president proudly opened the tunnel for public in December 2010.

\section{CONTACT DETAILS}

Bart-Jan Ruesink

Geocon BV

Postbus 1025, 3600 BA MAARSSEN

Westkanaaldijk 2, 3542 DA UTRECHT

The Netherlands tel.: +31 652458262

bart-jan.ruesink@strukton.com www.geocon.eu; www.geocon3d.com LinkedIn account:

http://www.linkedin.com/in/bartjanruesink

Project related media: http://natgeotv.com/nl/ megastructures/videos/korean-superlink-teaser; http://www.struktonciviel.com/sites/mergor/ SiteCollectionDocuments/ Strukton_afzinktunnel_Zuid-Korea_1000.wmv 
246 | Hydrol 2 


\section{Results of operational sea-wave monitoring with radar gauges}

Sebastian RÜTTEN, Stephan MAI, Jens WILHELMI, Theodor ZENZ, Hartmut HEIN, Ulrich BARJENBRUCH, Germany

German Federal Institute of Hydrology (BfG)

Topic: Innovations in acquisition techniques, Accurate hydrodynamics

\section{INTRODUCTION}

New developments off the German coasts, like offshore wind farms, require operational monitoring of waves nearby such offshore structures.

Accordingly, several authors (for example [Mai 2008]) emphasized the need for reliable, continuous wave measurements. Therefore, the German Federal Institute of Hydrology - $B f G$ (in cooperation with the German Federal Waterways Administration WSV) developed a low-cost, non-contact monitoring system based on a single radar sensor. Such a system, for example, has been in operation since 2006 at the gauge "Lighthouse Alte Weser" in the estuary of the rivers Jade and Weser (see Figure 1).

The purpose of this study is to analyse possible future changes in wave heights at the "Lighthouse Alte Weser". Therefore, a transfer function of wind

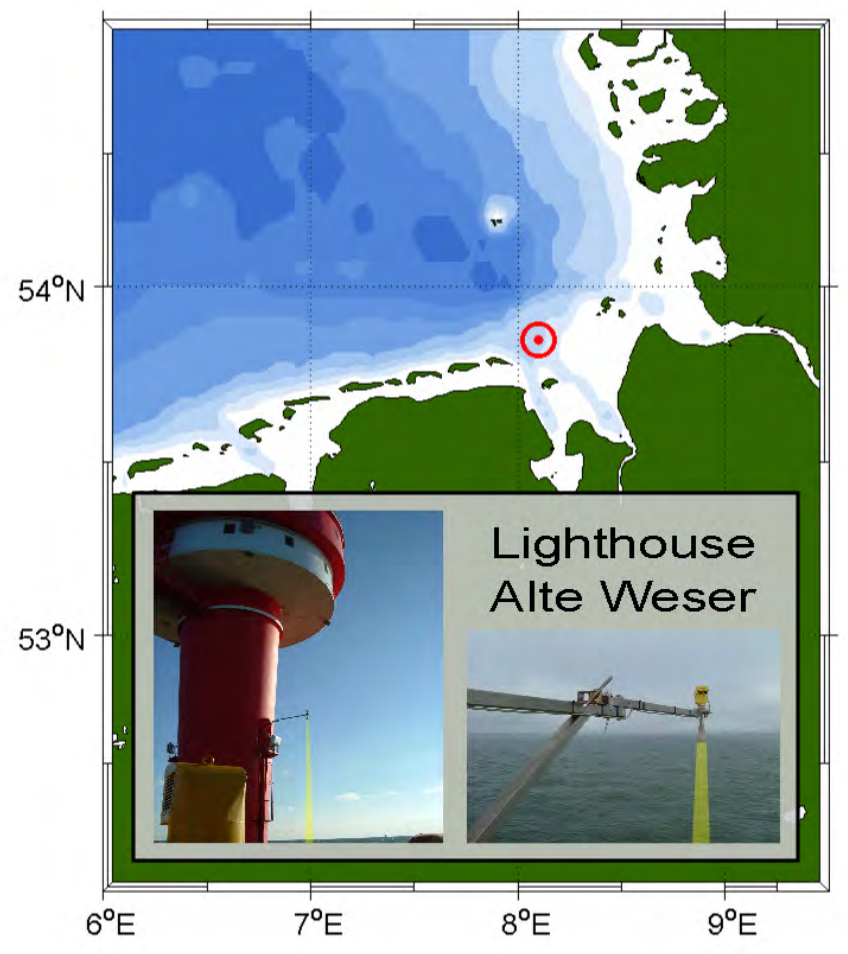

Figure 1: The operational wave monitoring system at the gauge "Lighthouse Alte Weser". speed to wave height was determined, also taking account of the wind direction. This function is used to derive predictions of changing wave heights due to expected future changes in wind statistics, as calculated by a global climate model.

First of all, data acquisition and -processing are described in brief.

\section{DATA AND METHODS}

The data basis of this study consists of wave and wind measurements recorded in the period from May 2006 until August 2011. Furthermore, wind data that were generated by the climate model "ECHAM5" are assessed for the years 1970-2090.

\section{WAVE MEASUREMENTS}

Many of the sensors that are commonly used to monitor the water-surface elevation (for example waverider buoys or pressure gauges) have to be installed directly in the water. This requires a lot of maintenance as those systems are permanently exposed to harsh environmental influences of the sea, such as wave attack or corrosion. For long-term measuring campaigns, sensors that are not directly in contact with the water are much more easily to operate and maintain. The described monitoring system, developed by the German Federal Institute of Hydrology (BfG) in cooperation with the Federal Waterways and Shipping Administration (WSV) and the German Federal Maritime and Hydrographic Agency (BSH) meets this criterion.

The measuring setup consists of a commercial radar liquid-level sensor, which is fixed to the end of a joist that is attached to a coastal or offshore structure (as illustrated for the "Lighthouse Alte Weser" in Figure 1). The radar sensor emits electromagnetic pulses at a frequency of $26 \mathrm{GHz}$ twice a second and, in turn, detects these pulses when they are backscattered at the water surface. The water surface elevation can be easily calculated since the 
distance between the radar and the water surface is proportional to the travelling time of each pulse. This allows to derive wave parameters such as the significant wave height (for further information see [Mai and Zimmermann 2000]).

In order to optimise the results, a very important first step is to detect outliers and replace them by interpolated values. This is particularly important because the commercial radar sensors used were originally designed for level measuring in processing industries.

Then, the significant wave height calculated adopting the "WAFO" Matlab-libary, developed by the University Lund/Sweden. An example of longterm recording of the significant wave height is illustrated in Figure 2 (c).

The precision of this system was tested under laboratory conditions as well as in the field [Wilhelm and Barjenbruch 2008]. The results of the waveflume experiments reveal an accuracy better than $0.5 \mathrm{~cm}$ for $95 \%(\sigma=0.017 \mathrm{~cm})$ of the recorded significant wave heights. Amongst others, field tests were run on the offshore platform "Finol" in the North Sea. There, the radar gauge is mounted close to the pillars of the platform. For reference, a waverider buoy is anchored at a distance of 100 meters. The comparison of the calculated significant wave heights shows only slight deviations without an significant trend. Thus, interactions of the sea with the structure that might affect the waveheight measurements seem to be unlikely. Further investigations of possible interactions will be made in another field experiment starting in July, 2012.

\section{WIND MEASUREMENTS}

Moreover, monitoring at the "Lighthouse Alte Weser" also includes wind parameters. A meteorological station of the Deutscher Wetter Dienst ( $D W D$ - German national meteorological service) records wind speed (Figure $2 \mathrm{~b}$ ) and direction (Figure 2 a) every minute at a height of 30 meters above the water surface. For preprocessing, the data are converted to local Cartesian coordinates ( $\mathrm{U}=$ zonal wind component, $\mathrm{V}=$ meridional wind component) with respect to a reference level of 10 meters above the mean sea level (following Kleemann und Meliss [1993]).

\section{Climate data}

To predict future changes in significant wave heights, additional wind-data of the Global Climate Model "Echam5" is used. This comprehensive general circulation model of the atmosphere was developed by the Max Planck Institute for
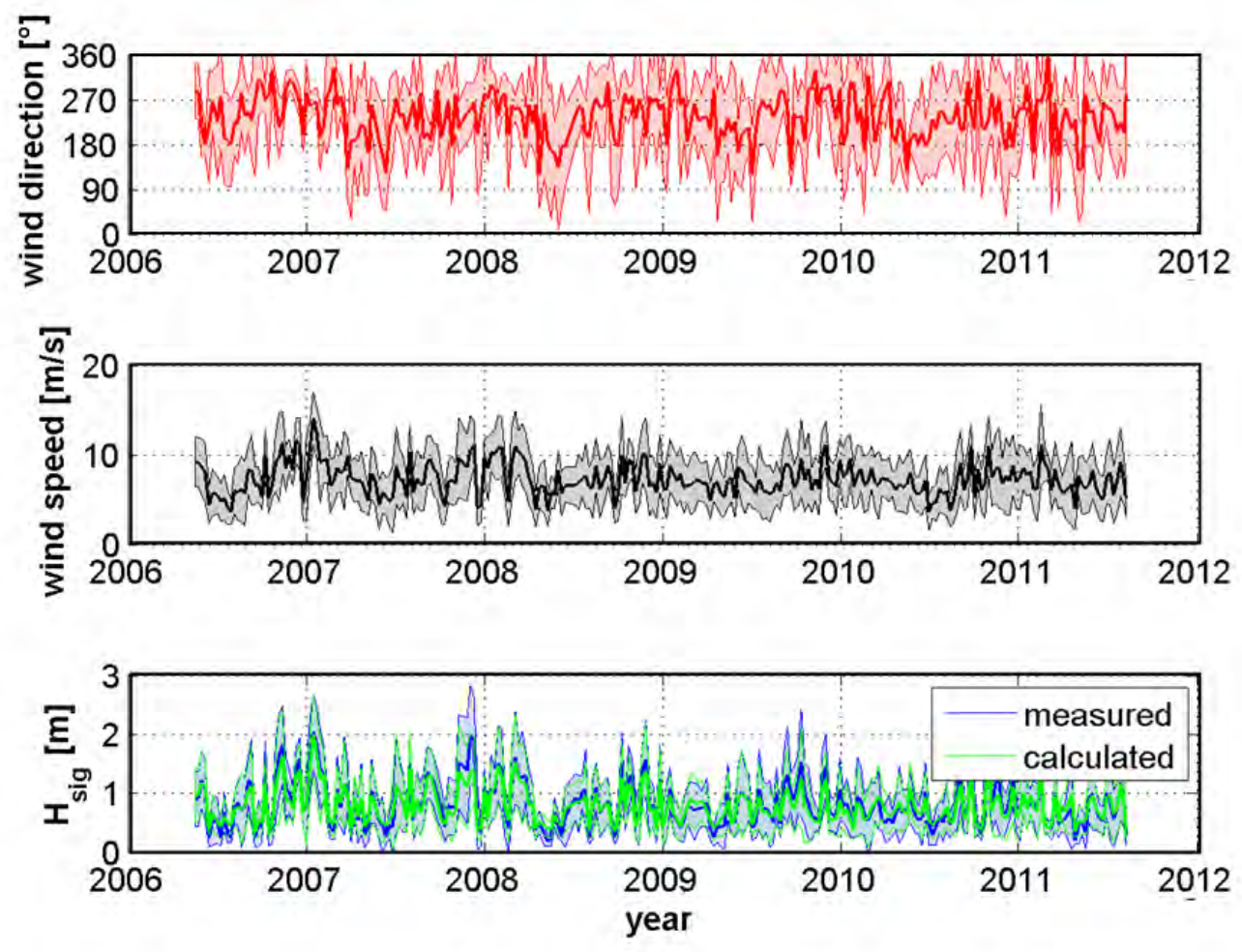

Figure 2: Illustration of the mean (bin size 1 week) wind direction (a) wind speed (b) and significant wave height (c) during the considered period. The shaded patches indicate the standard deviation. 
Meteorology. The data are given on a rotated pole grid with hourly resolution. As the "Lighthouse Alte Weser" is not located directly on a grid point of the model, the data need to be interpolated linearly to the exact position at first. Analyses of the interpolation methods indicate only slight differences (average deviation of $0,1 \mathrm{~m} / \mathrm{s}$ for $\mathrm{U}$ and $\mathrm{V})$ when choosing the nearest-neighbour method instead of linear interpolation.

The average variation of the wind speed is calculated with regard to its directionality to include directional changes. This is of particular importance, as the wave height at the "Leuchtturm Alte Weser" strongly depends on wind direction.

\section{RESULTS}

First, a transfer function of wind speed to wave height is presented. Based thereupon, an analysis of possible changes of wave heights due to possible future changes in wind statistics is given.

\section{$\underline{\text { Transfer function }}$}

Obviously, various factors influence the wave generation at the "Lighthouse Alte Weser": wind speed, fetch, wind duration and water depth are commonly assumed to be the dominant parameters. At this particular observation site, some additional aspects may also play an important role. As it is located within the estuary of the River Weser, windcurrent interaction could be relevant. Moreover, the water depth at the site (about 11 meter) is strongly tide-dependent. Due to the complexity of the processes involved, a deterministic calculation of the significant wave heights is almost impossible.

Assuming that all time-dependent differences will average out, due to the long time period of the recorded parameters, this study presents a simple transfer function for the location at "Lighthouse Alte Weser".

$$
H_{s i g}[\mathrm{~cm}]=f(U, V)=34,1+4,51 U-1,18 V+0,62 U^{2}+0,63 V^{2}
$$

It depends only on the zonal (U) and meridional (V) wind components. One possible interpretation of this function is that the wind stress, which is proportional to the square of the wind speed, is the fundamental impulse, whereas the linear correction terms include directional dependencies. The constant offset is partly determined by a lower measuring threshold of the radar gauge.

A comparison of the calculated and measured significant wave heights is shown in Figure 4, resulting in a correlation coefficient $\mathrm{c}=0.84$ with a $\mathrm{R}^{2}$ goodness of fit of 0.71 . Besides the expected scatter, there are only few larger deviations.

A comparison of the times series (Figure $2 \mathrm{c}$ ) shows an overall good agreement as well.

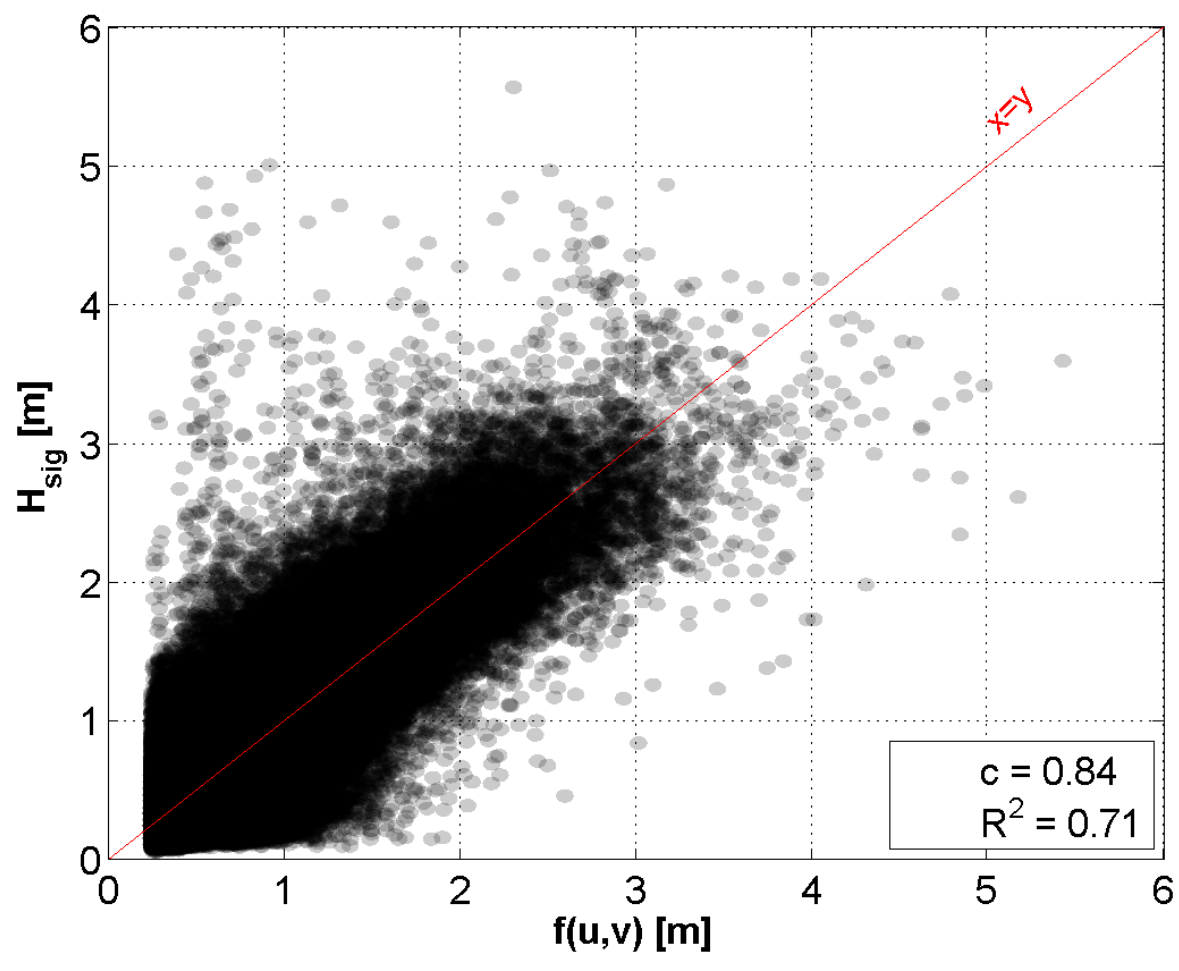

Figure 3: Scatter plot of the comparison of significant wave heights. 
For a wind speed of $16 \mathrm{~m} / \mathrm{s}$ at $240^{\circ}$ a significant wave height of $\mathrm{H}_{\text {sig }}=2,06$ meter is estimated by the transfer function (1). This is in good agreement with the results given by Mai [2008], who derived a significant wave height of $\mathrm{H}_{\text {sig }}=1.80-2.20$ meters by applying the phase-averaged wave model SWAN.

Assuming that the transfer function will continue to hold under the possible future climate as projected by the model, the variability of the exceedance probability of the significant wave height and the wind speed can be analysed.

\section{Prediction of wave-height changes}

A general increase of the wind speed along with an increase of the significant wave height within the next years is suggested by the model (see Figure 5). An average increase of the $99 \%$ quantile of the significant wave height of $0.33 \mathrm{~cm} /$ year is indicated until 2060. In the next 30 years, the model predicts an average increase that is slightly lower $(0.17 \mathrm{~cm} /$ year). One has to keep in mind that the uncertainty of predicted wind speed distribution can lead to large discrepancies in the results (up to 88\%). Mai and Zimmermann [2004] examined a climate scenario for the year 2050 near Solthörn. They determined an increase of the $99 \%$ quantile of the significant wave height of $0.4 \mathrm{~cm} /$ year, which is close to the results estimated in this study. However, they pointed out that a rise of the water level might be the dominating factor influencing the wave height in shallow regions, a circumstance which is not considered in this study.
The trend of $1.2 \mathrm{~cm} /$ year increase for the years 1958-2001 as determined by wind wave hindcasts [Weisse et al. 2003] seems to reduce slightly.

\section{CONCLUSION}

Although far away from being perfect, the presented transfer function yields results that are in good agreements with other methods. The derived change of the significant wave height at the "Lighthouse Alte Weser" suggests an average increase of the $99 \%$ quantile of $0.26 \mathrm{~cm} /$ year until the year 2090 . To detect long-term trends more accurately, continuous monitoring of sea-state parameters is indispensable. As demonstrated in this study, radar gauges have proven their suitability for long-term measurements.

\section{OUTLOOK}

So far, the wave-gauging station at "Alte Weser" is capable of monitoring wave heights and wave periods, while especially information about directionality is missing. Precisely these recordings would improve, on the one hand, numerical modelling of sea states [Haver and Nyhus 1986] and, on the other hand, the design of coastal and offshore structures. Bowers et al. [2000] underline that the maximum hawser tension at some structures may occur when the wind and waves are at $60-90^{\circ}$. They point out that the simple assumption of an aligned wind and wave direction is often invalid. They monitored a difference of $60^{\circ}$ before the storm is fully developed. Even at the peak of a storm, differences of $10-30^{\circ}$ are common.
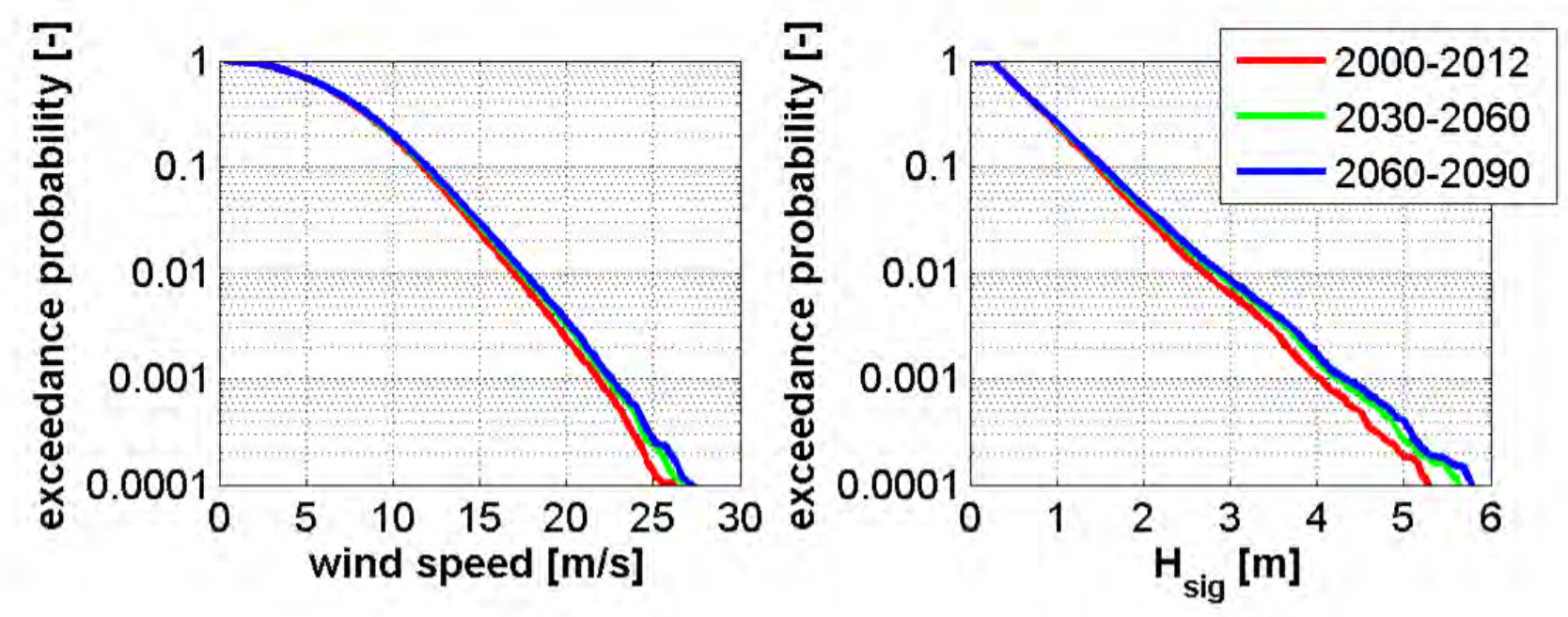

Figure 4: Exceedance probability of wind speed and significant wave height at the "Lighthouse Alte Weser"of several periods. 
To enlarge the capability towards monitoring of wave direction, the German Federal Institute of Hydrology - BfG (in cooperation with the German Federal Maritime and Hydrographic Agency - $B S H$ ) is developing an extension of the existing system based on an array of four radar sensors. Moreover, the upgraded system aims to offer the capability of analysing possible disturbances of wave measurements by the offshore structure itself. A first test construction will be mounted at "Borkum Südstrand" in July, 2012.

\section{$\underline{\text { Acknowledgement }}$}

The results of this study are partly from the "KLIWAS" research program and partly from the $B f G$ project "RiseARaF". Both funded by the Federal Ministry of Transport, Building and Urban Development ( $B M V B S$ ). The authors thank Anette Ganske for support. The authors would also like to thank the water and shipping agency (WSA) Bremerhaven for the installation and maintenance of the radar gauge.

\section{CONTACT DETAILS}

Sebastian Rütten

Federal Institute of Hydrology

Department of Hydrometry and Hydrological Survey

Am Mainzer Tor 1

56068 Koblenz

Germany

Tel.: +4926113065336

Email: ruetten@bafg.de

\section{LITERATURE}

Bowers, J.A., Morton, I.D. and Mould, G.I. 2000.

"Directional statistics of the wind and waves".

Applied Ocean Research 22. 13-22

Haver,S. and Nyhus, K.A. 1986. "A Wave climate Cescription for long term response calculations". Proceedings of the fifth international offshore mechanics and arctic engeneering symposium, Vol 4, 27-34

Kleemann, M. and Meliss, M. 1993. Regenerative Energiequellen. Springer Verlag.
Mai, S. and Zimmermann, C. 2000. "Applicability of Radar Level Gauges in Wave Monitoring”. Proc. Of the 2nd Int. Conf. Port Development \& Coastal Environment. Varne, Bulgaria

Mai, S. and Zimmermann, C. 2004. "Veränderung der Seegangsbedingungen an den Küsten von Jade und Weser als Folge der Klimaänderung". Coastline Reports $1.93-100$

Mai, S. 2008. "Statistics of Waves in the Estuaries of the Rivers Ems and Weser-Measurement vs. Numerical Wave Model". COPEDEC VII, Dubai

Wang, X. L., Zwiers, F. W. and Swail, V. R. 2003. "North Atlantic Ocean Wave Climate Change Scenarios for the Twenty-First Century". Journal of climate, Vol 17

Weisse, R., Feser, F. and Günther, H. 2003, "WindUnd Seegangsklimatologie 1958-2001 für die südliche Nordsee basierend auf Modellrechnungen", GKSS Report.

Wilhelmi, J. and U. Barjenbruch. 2008. "Application of Radar Gauges to measure the water level and the state of the sea". Proceedings of 31 st International Conference on Coastal Engineering, Hamburg, Germany 
252 | Hydrol 2 


\section{How deep will the water be?}

Simon Salter, United Kingdom

CherSoft Ltd

Topics: Innovations in processing techniques, Smart data management, Easy customer access to data and products, Careful marine planning, Cost-effective solutions, Vertical references, Accurate hydrodynamics

\section{INTRODUCTION}

To date ENCs have done very little to help answer this question. Contours and spot depths indicate how far the seabed is below chart datum; tables allow the prediction of tidal height at some specific locations. The uncertainties involved in manually estimating water depth at a certain position and time are essentially unchanged from paper navigation. This may be considered an omission given the crucial significance of the question.

Chart data and tide tables between them are intended to represent a genuine physical environment. In principle this can be modelled and interpolations made by using the same sort of assumptions that a mariner would use. Computer based calculations and interpolations are enormously faster than manual techniques and this opens the door to new methods of displaying and using the information. The resulting accuracy of the predictions can be tested against real world measurements.
We present some initial results from a study into techniques that support computer based 3D interpolation of charted depths and the integration of time varying tidal heights from commercially available data. The aim of this study is to make better use of readily available information by presenting it in ways that can directly assist the mariner's decision making process. In effect, this is extracting more useful information from the ENCs.

A better mechanism for predicting water depth allows safety margins to be defined with more confidence. Reducing the uncertainty in shallow water operations can contribute greatly to reducing the risk of grounding while at the same time potentially extending operational parameters.

\section{DATA SOURCES}

A key theme of this project is to use standard, commercially available data. We require bathymetric information and tidal height predictions.

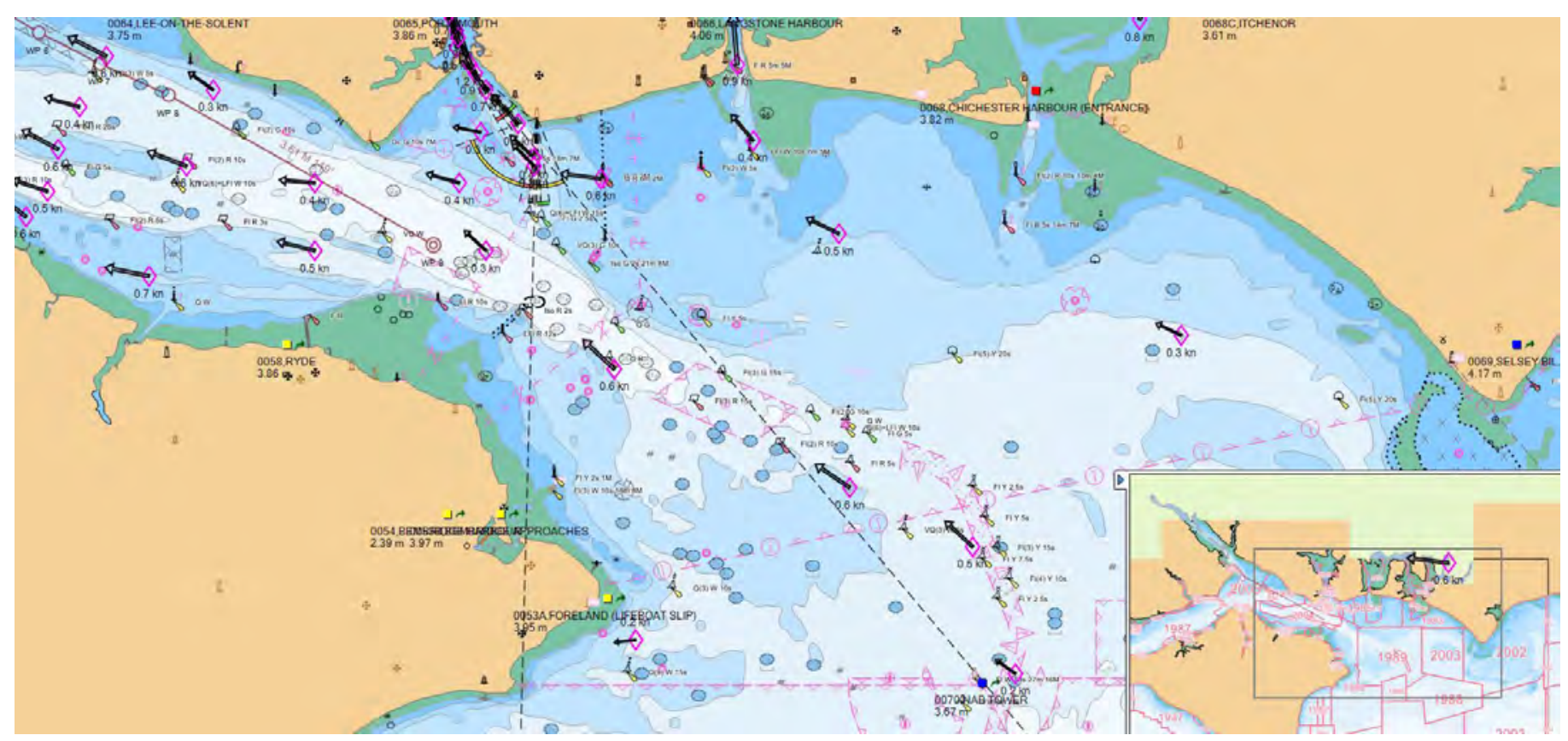

Figure 1 Standard chart data: ENC, Tides, Streams 
There are currently many projects using high density precision bathymetry. These include S-102, bENC and others. Coverage of this sort of data is sparse, availability is limited and updating can be uncertain. We have attempted to develop techniques which give useful results from ordinary ENC cells. Data that is possibly already in use on a vessel. This does not preclude the use of higher quality data and where available this would probably give more accurate results.

Tidal predictions come from Admiralty TotalTide. This provides good coverage, uses full harmonic predictions and supports programmatic access to the predictions. Other tidal prediction sources could be equally useful. In general the closer tidal stations are then the more accurately it is possible to interpolate between them. Use of SHM systems can be nearly as good as full harmonics in places with a simple tidal regime.

So our starting point is pretty much the same information as a navigator would use.

\section{PREDICTING WATER DEPTH}

Water depth is the charted depth plus the predicted tidal height.

Make sure both these values are to the same vertical datum.

To determine the water depth at an arbitrary location you need to estimate the charted depth from nearby soundings and you need to estimate the height of tide from one or more nearby tidal height stations.

When you actually arrive the measured water depth will likely be a little different from the prediction for several reasons including:

- Accuracy of the echo sounder

- Effects of air pressure, wind and other climatic factors

- Nature of the seabed and variations in the water column

At the moment we can't help in managing the residuals (although we have some ideas) but we can attempt to make a better prediction.

\section{INTERPOLATING CHARTED DEPTH}

To determine the charted depth at an arbitrary location we need to first build a 3D model of the seabed from the ENC data. Depth data is available from contours, soundings and the coastline. A Triangulated Irregular Network (TIN) is constructed from this information. Use of a TIN is a fairly standard technique for creating 3D models in GIS applications. Creating one from ENC data presents a few challenges. These mostly come about because the data is not intended to represent a genuine physical surface but only to create a 2D chart image. So, for example, contour lines join each other in a few places and occasionally just stop.

Another issue is that the density of available depth information can vary significantly across the charted area. Ideally (for our purposes) we would have a

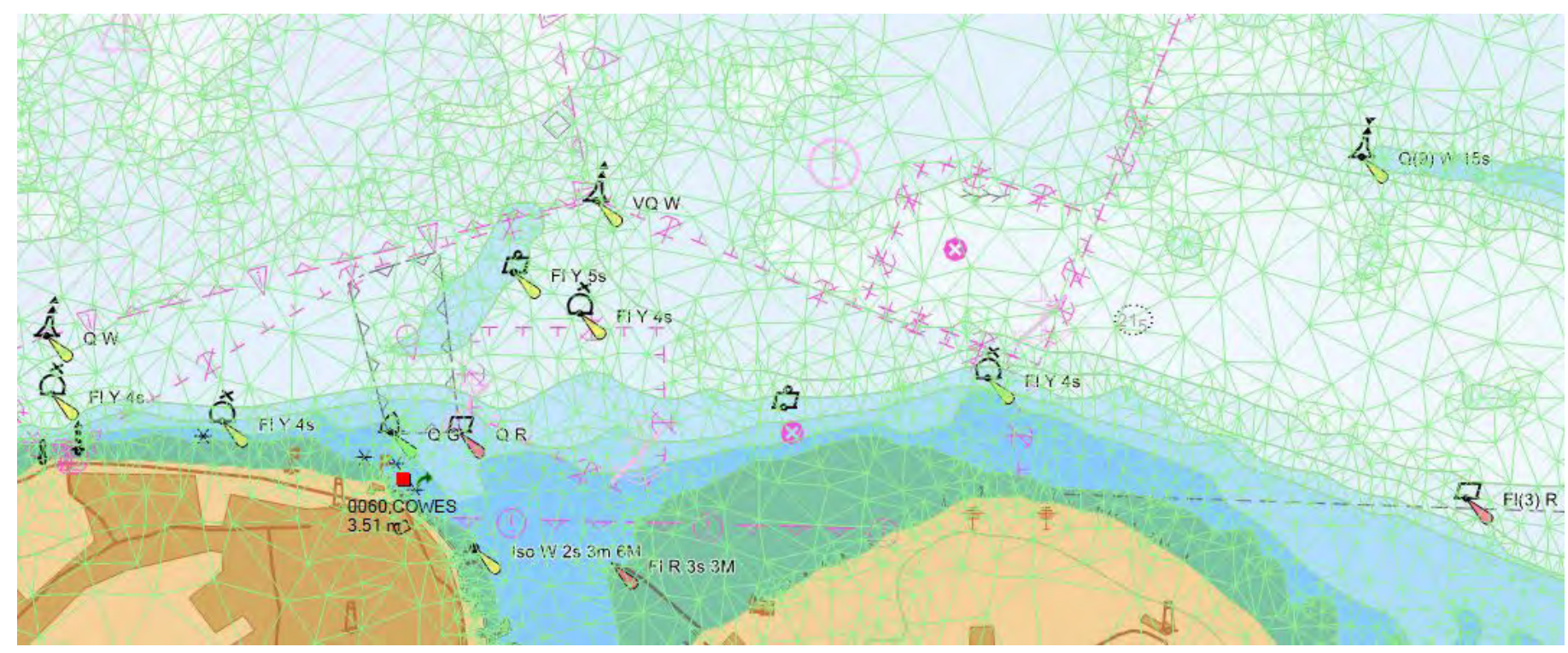

Figure 2 Creating a Triangulated Irregular Network (TIN) from ENC data. 
Figure $3 \mathrm{~A} 3 \mathrm{D}$ view of the TIN representing a river estuary

fairly even spread of data with maybe some more detail in locations where there were rapid changes in the seabed. In practise we see two broad categories of ENC:

- Many appear to use soundings off the paper chart. These often follow tracks and can be very sparse in some areas.

- Others contain evenly spaced soundings which seem a lot more like they have come from a model, possibly from a modern multi-beam survey.

\section{INTERPOLATING TIDAL HEIGHT}

A different type of TIN is used to create a mesh that links all the tidal stations. However the periodic nature of tides means that there is no single parameter which can map directly to the height value of the TIN. One approach would be to map each harmonic separately however the linear summation of harmonics works least well where there are shallow water effects. These tend to be the places that water depth is most important. We have tried several techniques for creating a time invariant description of the relationship between tidal stations and currently use two surfaces; one representing amplitude and the other a phase delay. In many ways these values are like the surfaces implied by the contours on a co-tidal chart.

From the tidal TIN we can intermediate virtual tidal stations at each of the nodes of the bathymetric TIN which are then close enough that a simple linear interpolation is sufficient.

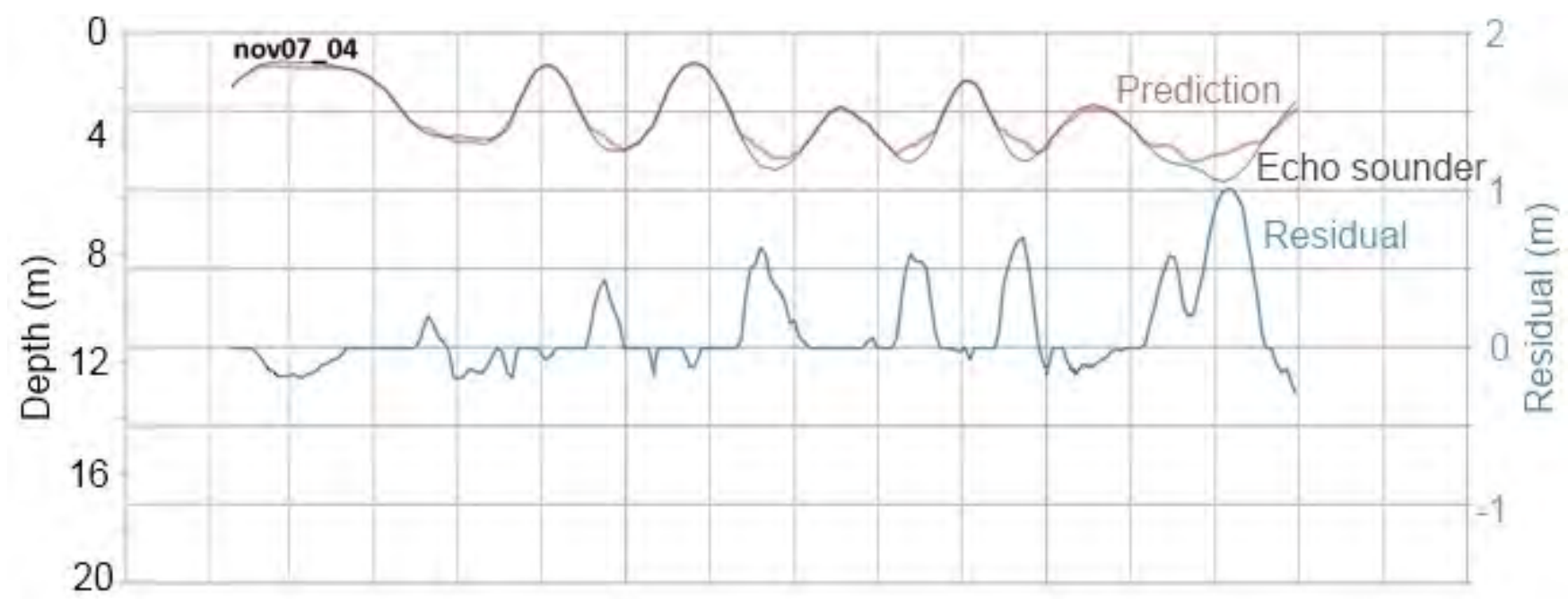

Figure 4 A twenty minute except from one of the trials. This data is typical rather than specially selected 


\section{ACCURACY}

A useful technique for assessing accuracy in interpolation is to remove the known data for a point in the model and then compare the interpolated values with the actual ones. We found this technique particularly effective in helping us develop the tidal models.

We've done some sea trials. We focussed on shallow water areas with rapidly changing depth. Results so far look quite promising.

We noticed that charts tend towards safety. They often indicate shallower water than we measured and this accounts for some of the residual.

Overall the accuracy of the system depends on the accuracy of the charts, the tidal data and the suitability of the algorithms used to predict water depth. We think the techniques developed here will prove to be useful in many circumstances but as with all aids to navigation judgment and experience will need to be applied.

Concern about over reliability on technology should never be understated. Consistency, speed and repeatability in the calculations are all very positive factors but really all we are doing here is providing another view, an interpretation, of the existing standard information. Good seamanship is still required.

\section{PRESENTING THE INFORMATION USEFULLY}

Our preliminary results suggest that the use of computer models is perfectly workable. The techniques we have developed appear to be at least as capable as a mariner might manage and in many cases much better.

By using computing power to do many predictions in a reliable, repeatable way we can present the information in ways which are more useful than the standard chart + tide tables. For example:

\section{CONCLUDING REMARKS}

We have attempted to emulate the types of water depth calculations and estimations that a good mariner would use. Using standard commercially available data it appears that this is not only possible but also useful. By taking advantage of contemporary computing and display capabilities we can present this information in a useful way that may give the navigator a better feel as to what the underlying data really means.

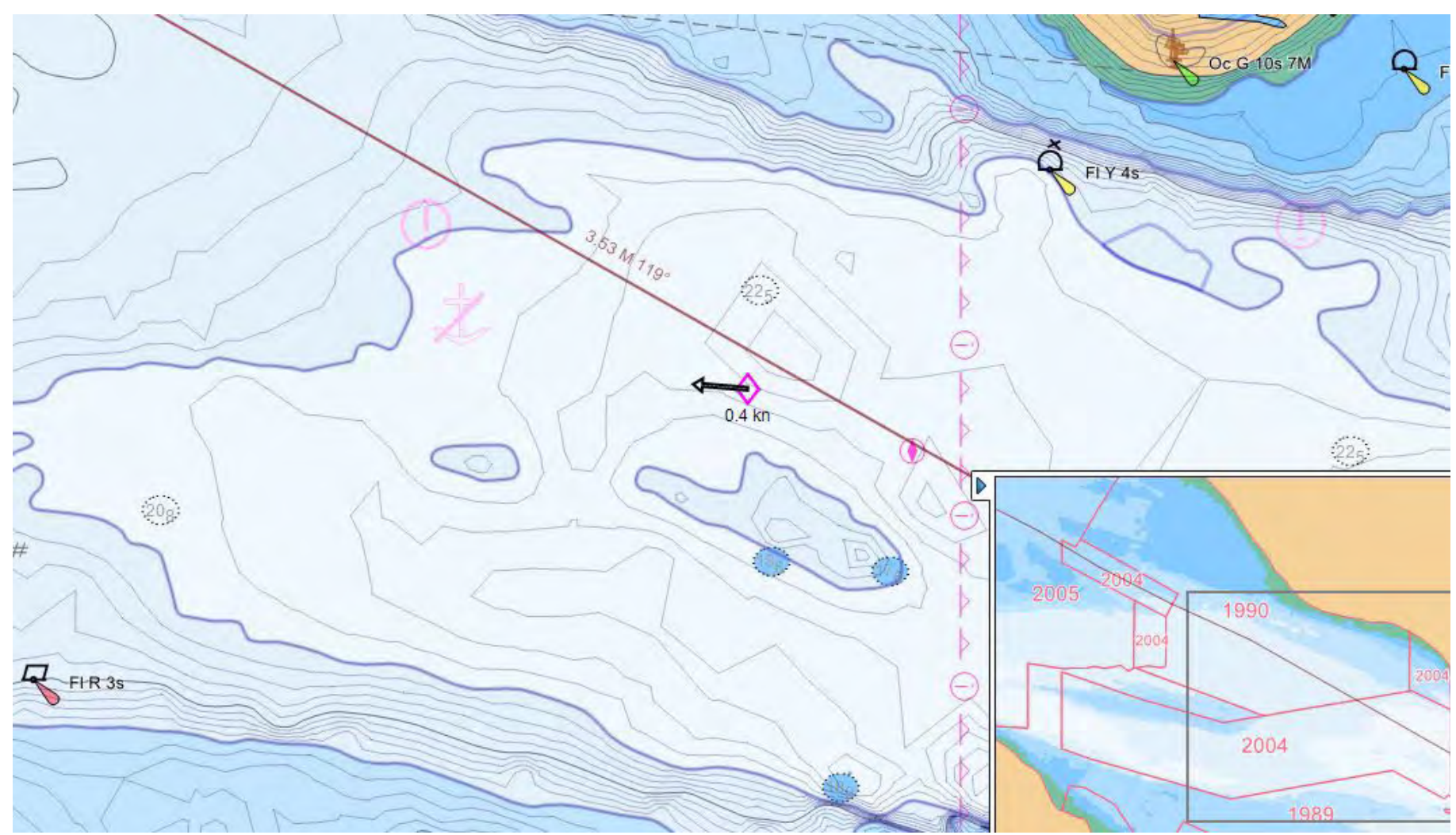

Figure 5 Interpolated $1 \mathrm{~m}$ contours 


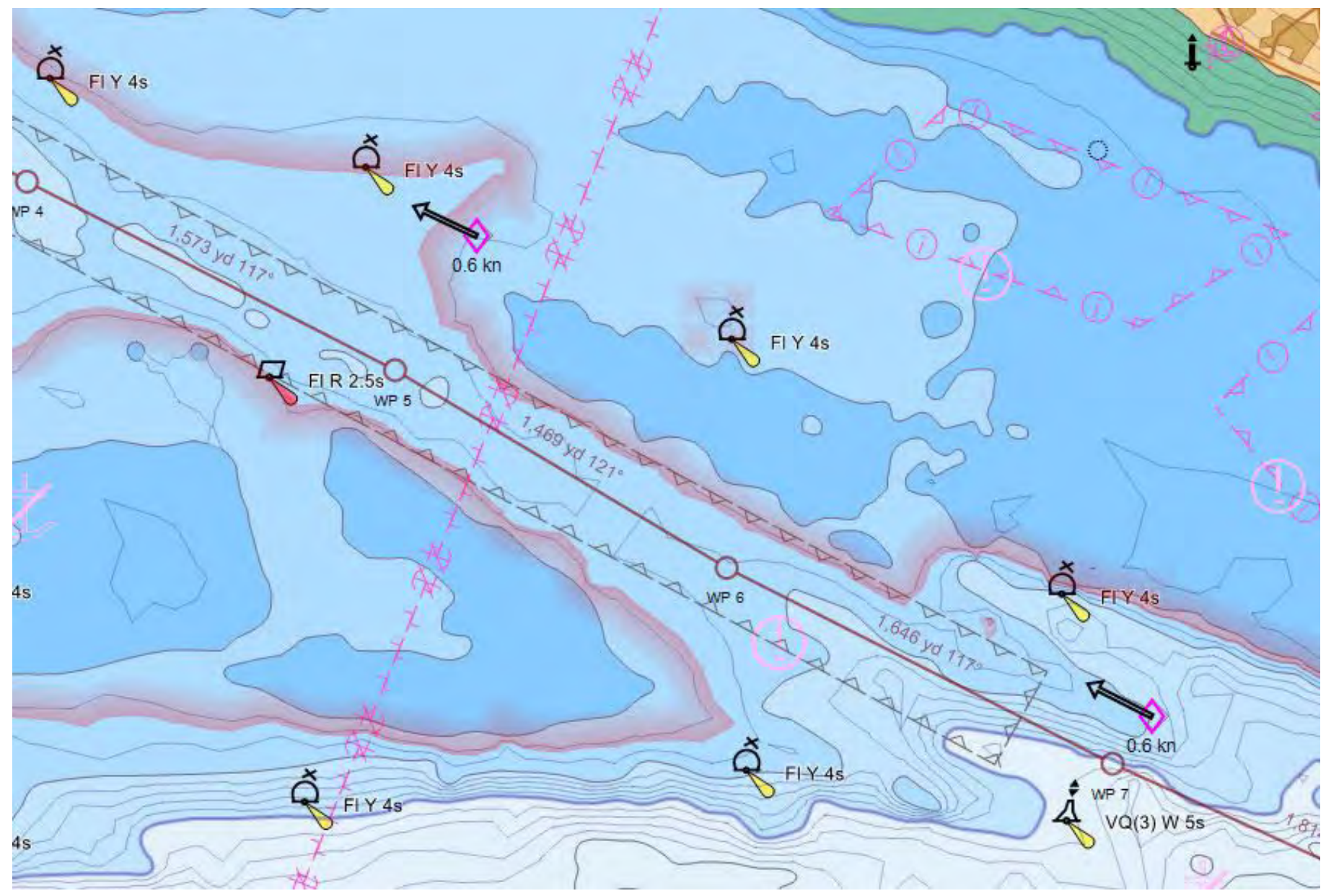

Figure 6 The red line indicates predicted $7 \mathrm{~m}$ water depth at the arrival time of the vessel. A better safety contour?

These techniques would work even better with higher resolution bathymetric data.

This is a practical solution to an apparent omission in the development of digital navigation systems.

We would like to recommend that chart producers start to consider their data as a model of real surfaces rather simply a chart image. 
258 | Hydrol 2 


\title{
A Comprehensive Definition and Systematic Subdivision of Hydrography
}

\author{
Lars SCHILLER and Volker BÖDER, Germany \\ HafenCity University
}

Hans Werner SCHENKE, Germany

Alfred Wegener Institute

Topic: The hydrographic profession

\section{INTRODUCTION}

The concept of hydrography is subject to constant change. The science continues to develop, its methods develop further, the view on the object of investigation changes, the objective is formulated differently. Someone who uses the term 'hydrography' today means most likely something different than he did 20 years ago when he used this term too. Perhaps he is even aware of it.

But actually, is there a guarantee that speakers and listeners have the same concept of hydrography? That the two parties share the same idea of hydrography? Unfortunately, no.

Why is that? Why could technical communication fail?

The main reason is that the concept of hydrography is indeed defined - for example, in general language encyclopaedias, technical dictionaries and standards -, but that these definitions do not always express the same thing, they are focused on different aspects, and sometimes they are even contradictory. Normally, in a conversation about hydrography it is not mentioned to which definition one refers.

Another reason is that the definitions - especially if they have been written by experts in hydrography - do not meet the requirements that lexicographers have on a definition. To make matters worse, very few definitions are clear and vivid.

Finally, it plays a role that the term 'hydrography' does not only denote the scientific discipline, but the term can take at least ten more different common meanings.

Therefore there is the need to present an up-to-date definition.

This newly presented definition is comprehensive and meets the lexicographic requirements. It is intelligible to everybody, clear and vivid, and it is completed by a systematic subdivision according to the object of investigation.

\section{ONE TERM WITH ELEVEN MEANINGS}

The term 'hydrography' seems to be very specific, but it is used in several meanings. After an extensive consultation of German and English encyclopaedias and general language dictionaries as well as after a wide-ranging literature review - also of nonhydrographic literature - eleven now common concepts were identified, all denominated with the (homonymous) term 'hydrography'.

In addition, some obsolete meanings were found, and concepts that are falsely denominated by the term. A total of 19 different concepts were identified.

In a technical language dictionary eleven current meanings could be included.

hy•drog•ra•phy -ies, | hî̀'drägrəfē | noun, 1 no pl., science of surveying of bodies of water and waters-related information;

2 no pl., a) depth measurement of waters (esp. of oceans), bathymetry;

b) surveying of bodies of water; 3 no pl., a) descriptive hydrology; b) characteristic features of bodies of water, descriptive set of watersrelated data and information;

4 no pl., (register of the) totality of the waters in an area, waters index;

5 no pl., a) map element; b) cartographic depiction 
of waters;

6 shape of the bottom of a water, topography covered by water, morphology;

7 a) no pl., art technique; b) artwork.

The fact that the term has so many different meanings makes technical communication more complicated and can lead to misunderstandings. Even hydrographers use the term in different meanings. But there is another problem: The concept of hydrography as a science is not clearly defined.

\section{THE CONCEPT OF HYDROGRAPHY}

The concept of hydrography as a science is hardly defined in common language dictionaries. But there are several attempts by experts to define the concept of hydrography. For example, the United Nations presented a definition in 1978 that is still quoted today (UN 1978, p. 67). Also the definition in the Hydrographic Dictionary published in 1994 by the International Hydrographic Organization (IHO) is popular (IHO 1994, p. 108). Finally, the IHO has introduced a revised definition in 2009. This definition has been adopted after an extensive consultation process of the member countries of the IHO; it can therefore be considered as the official definition based on a consensus (IHO 2009, p. 38).

An evaluation of the above mentioned definitions - and of other definitions - shows that experts do not necessarily share the same view. All definitions present a different picture of hydrography.

\section{The definition by the IHO}

"Hydrography is the branch of applied sciences which deals with the measurement and description of the physical features of oceans, seas, coastal areas, lakes and rivers, as well as with the prediction of their change over time, for the primary purpose of safety of navigation and in support of all other marine activities, including economic development, security and defence, scientific research, and environmental protection" (IHO 2009, p. 38).

\section{$\underline{\text { Significant points of criticism }}$}

Compared to the definition of 1994 this definition shows a more modern understanding of hydrography. This is also reflected in the length of the sentence. The sentence consists of 64 words. Linguists say that the limit should be 25 words, otherwise a sentence is not immediately evident.

There are two main points of criticism:

This definition provides only an incomplete understanding of the concept. And this definition does not meet the requirements set by lexicographers.

Why does the definition not describe the full concept? And why does it show formal mistakes?

According to this definition, hydrography is an "applied science". This statement should make it possible to classify hydrography. Unfortunately, the classification is much too vague. There are so many applied sciences. Therefore, it is necessary to name the hypernym. And it should be mentioned that there are also theoretical shares.

Then it says that hydrography deals with the "measurement and description". The question is: Why only 'description'? Why not also ‘depiction'? It is not only about a spoken or written representation, it is also about a visualisation. It is important to mention the cartographic aspect.

Furthermore it says that only the "physical features" of waters are described. It is hard to imagine what physical features are. This is certainly not wrong, but unfortunately it is unclear and abstract. Neither the chemical properties are mentioned nor the geographical relationship.

For the first time the IHO does not only focus on the sea: "oceans, seas, coastal areas, lakes and rivers" are listed in the definition. The intention is to express that hydrography examines all waters. But this is not said. And it is not explained what is studied in detail, what qualitative and quantitative investigations are carried out. And why are only the coastal areas mentioned, but not the shorelines? It is not correct to make a list, but not to list all items.

Although the definition refers to all waters, it then says "marine activities". This restriction to the marine sphere is not logical. The statements are not consistent.

\section{$260 \mid$ Hydrol 2}


It is a real improvement that the "changes over time" are mentioned in this definition for the first time. However, it is only about the "prediction". But hydrographers are also interested in the comparison between two states.

The last point is the exemplary reference to the reasons for hydrography ("for the primary purpose ... and ... including"). It is good to explain the motivation to get an idea of what the activities are. But the way this is done is too random and just exemplary. The definition does not explain, but it raises new questions.

Therefore, it is necessary to write a new definition.

\section{HOW TO DO BETTER?}

There is a lot to criticise. But the question is, after all, how to do it better. How is it possible to define the concept of hydrography in accordance with lexicographic requirements?

There are a few criteria to write a formally correct definition. In other words: There are several ways to write a definition (cf. Schaeder 2007). In a content definition the hypernym has to be mentioned, and the specific distinctive features have to be named. In a scope definition and in an inventory definition hyponyms are listed. The list "seas, lakes and rivers" would be good for a scope definition. When the coastal zones and shorelines are added, it is an inventory definition.

But there are also wrong definitions. Thus, for example, a definition can be too wide or too narrow. If it says hydrography examines only the oceans the definition is too narrow, because the inland waters are forgotten. A definition is too wide, if it says that hydrography examines all waters, because that includes the groundwater. But to examine the groundwater is not the job of hydrographers, it is the job of hydrologists.

Before starting to write a definition, one should acquire some basic knowledge of lexicography.

The task is not only to present a formally correct definition. The goal is also to define the concept comprehensively and vividly.
Therefore, it is necessary

- to name the hypernym in order to classify hydrography;

- to specify the distinctive features;

- to list all specific hyponyms, so that nothing is forgotten;

- to list the activities on the object of investigation.

This is best achieved by a systematic subdivision. Only then it is possible to create a clear and vivid definition. Besides, common language should be used in short sentences, and unknown words should be avoided.

\section{A NEW DEFINITION}

Hydrography is a branch of the science of surveying and geoinformation. It investigates the surface waters of the earth and collects the related data and information. Its goal is to expand the knowledge of waters in order to use them responsibly and safely and to protect the habitat. The practical engineering and geoscientific work is divided into three main fields of activity:

1. Surveying of waters, and recording of aquatic data;

2. Processing of the data, administering the data in information systems, and analysing the total set of data;

3. Visualising the waters on charts and in information systems, and informing about the waters.

After the examination of a surface water hydrography provides information about its current state and about past and future changes.

It makes statements about:

- the water depths in relation to a reference horizon,

- the positions of shoals,

- the positions of magnetic anomalies,

- the shape and structure of the bottom,

- the material composition of the bottom,

- the structure of the deeper soil layers,

- the location of deposits,

- the uniform change of the water level (tides),

- the short-term and long-term change of the water level (storm surge, sea level rise),

- the height profile of the water surface (orthometric height),

- the characteristics of waves, 


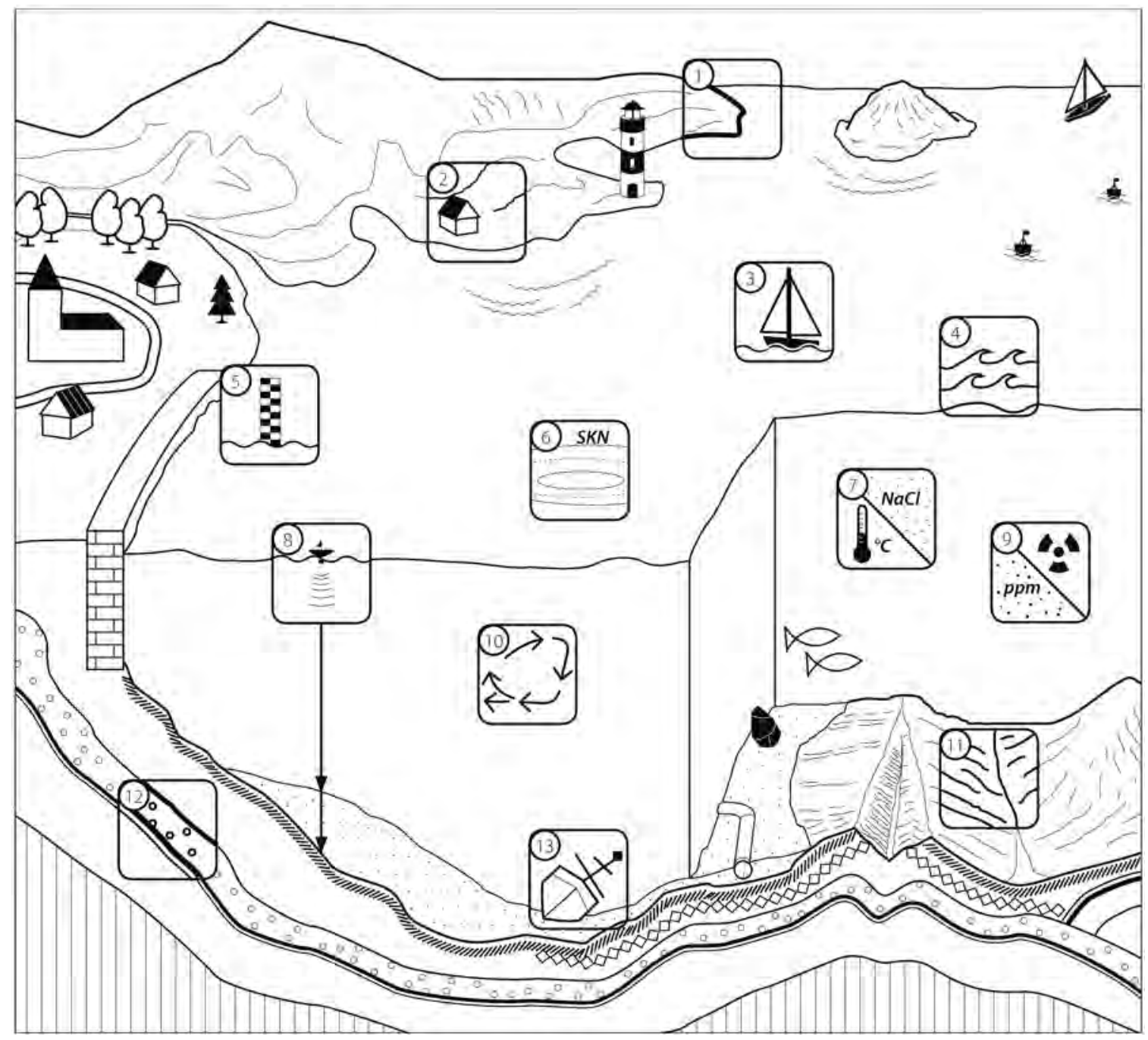

Object of investigation of hydrography

1. Course of the water's limit

2. Nature of the adjacent land strip (coastal zone resp. shoreline)

3. Traffic situation on waters

4. Characteristics of waves

5. Water level

6. Height profile of the water's surface (orthometric height)

7. Individual parameters of the water column (temperature, salinity)

8. Water depths

9. Water quality (particle concentration, radioactivity)

10. Characteristics of currents

11. Nature of the bottom

12. Structure of the deeper soil layers

13. Natural and artificial objects in and on the waters

- the characteristics of currents,

- individual parameters of the water column (temperature, salinity),

- the structure of the water body,

- the water quality (particle concentration, radioactivity),

- the natural and artificial objects in and on the waters,

- the traffic situation on the waters,

- the course of the water's limit,

- the course of boundaries within the waters,

- the nature of the adjacent land strip (coastal zone resp. shoreline).

\section{2 | Hydrol 2}


This comprehensive definition of hydrography provides a complete understanding of the concept, and it meets the formal lexicographic requirements. The definition allows a clear technical communication. A scientist who delineates his conception in another way is able to specify in what sense he uses the term. For this he simply needs to work out the difference between the definition and his own understanding of the concept.

Also the intercultural aspect is important, for example, when hydrography shall be exported to other countries in the context of development assistance and capacity building. In these countries hydrography is still unknown and there are therefore no terms in national languages for it. This definition makes it possible to evoke a clear idea - and to create a new term in another language in a further step. Even to make it clear to a layman what hydrography is in his own language, this definition is very helpful.

\section{REFERENCES}

IHO (1994): S-32 - Hydrographic Dictionary. Special Publication No. 32, Part 1, Vol. 1, English, Fifth edition; Monaco, IHB - International Hydrographic Bureau

IHO (2009): Proposal to Approve New Definition of Hydrography; in: IHO: 4th Extraordinary International Hydrographic Conference, June 2-4, 2009, Monaco, Report of Proceedings; pp. 38-40, Monaco, IHB - International Hydrographic Bureau

Schaeder, Bernhard (2007): Terminologie und Fachlexikographie; Materialienarchiv mit Skripten, online: http://www.uni-siegen.de/fb3/lissie/ materialien/mschaeder.html?lang=de, last access: August 15, 2010

UN - United Nations (1978): Report of the Group of Experts on Hydrographic Surveying and Nautical Charting; in: UN (1981): Second United Nations Regional Cartographic Conference for the Americas - Report of the Conference. Vol. I; Mexico City, September 3-14, 1979; E/CONF.71/3, pp. 63-96
Lars SCHILLER graduated in Surveying Engineering from the University of Applied Sciences Hamburg in 2002. Since 2008 he has been working as a technical writer at a full service company for technical documentation where he is responsible for terminology management. In March 2012 he finished his second study in hydrography at the HafenCity Unversity in Hamburg, and presented his master thesis about the position of hydrography in a system of sciences.

Volker BÖDER graduated in Geodesy from the University of Hannover in 1994. His doctoral thesis from 2002 was about precise positioning and attitude determination in marine applications. He received his Assessor Degree from the Government of the Federal State of Lower Saxonia in 2005. Since 2005 he has been professor for practical geodesy and hydrography at the HafenCity University, Hamburg.

Hans Werner SCHENKE graduated in Geodesy from the University of Hannover in 1977. Since 1983 he has been Head of the Geodetic and Bathymetric Lab at the Alfred Wegener Institute in Bremerhaven and responsible for scientific bathymetry and geodetic programmes in polar regions. He is member of several international Committees for ocean mapping and undersea feature naming. Since 1999 he has been lecturer for GIS Hydrography at the Leibniz University Hannover and received an honorary professorship there in 2011.

\section{CONTACT DETAILS}

Lars Schiller

HafenCity University Hamburg

Schulteßdamm 35

22391 Hamburg

GERMANY

Tel.: +49 4074397323

E-mail: lars.schiller@hcu-hamburg.de

\section{BIOGRAPHIES}


264 | Hydrol 2 


\title{
Calibration of Vessel Mounted LiDAR
}

\author{
Nicolas Seube, Alan Picard, Thomas Touzé, France \\ Ecole Nationale Supérieure de Techniques Avancées Bretagne \\ Jean-Guy Nistad, Mathieu Rondeau, Canada \\ Centre Interdisciplinaire de Développement en Cartographie des Océans
}

Topic $\mathrm{C}$ : innovations in processing techniques

\begin{abstract}
This paper investigates the problem of latency estimation between an IMU (Inertial Motion Unit) and a LiDAR (Light Detection And Ranging). The latency is due to the IMU itself, but also to the acquisition software and hardware configuration, which is generally set-up by survey systems users. We propose a method for latency estimation, and we show that this method meets the accuracy requirements of most LiDAR survey applications. We present test results of our method on various acquisition systems and hardware configuration which demonstrate that it is able to identify very accurately the total latency through a simple procedure. Our method does not require any positioning device, therefore it is independent of non modeled errors which may corrupt geolocalized data. Our method enable the user to estimate any LiDAR-IMU latency, in order to to optimize the configuration of a kinematic survey system and to enhance its robustness features with respect to high motion dynamics.

We also propose a new boresight angle calibration method between LiDAR and IMU, and we estimate its accuracy and precision. As these two methods do not need any positioning data, they avoid the propagation of GPS errors into the calibration procedure.
\end{abstract}

Key words: LiDAR, Boresight calibration, Latency calibration, Patch test, Marine Infrastructure surveys.

\section{INTRODUCTION AND BACKGROUND}

Kinematic LiDAR (Light Detection And Ranging) is now commonly used in the surveying community. In order to geolocalize detection points, a LiDAR is generally coupled with an Inertial Motion Unit (IMU) which gives attitude angles, and with a GPS system for both positioning and time stamping.

In order to get coherent and accurate survey datasets, all sources of systematic errors have to be minimized. These errors due may be to the LiDAR itself (range bias, deflection angle bias), to the presence of boresight angles between the LiDAR and the [Kumari et al., 2011, Skaloud and Litchi, 2006, Morin, K., Naser El-Sheimy, N., 2002] and to time-stamping errors. Timing errors may come from the IMU latency (time difference between physical measurements and the IMU output) and also from the acquisition device configuration, which is generally left to the survey system user. 
Most tactical grade IMU systems (widely used in surveying and airborne mapping) are coming with an independent clock, not synchronized to GPS, and thus, the implementation of the GPS time-tagging that may vary over a large range. These systems must be calibrated for highprecision application.

Latency error can be minimized if the motion sensor manages time-tagging thanks to the GPS Pulse Per Second (PPS) signal input.

Most survey data acquisition softwares can compensate for such latency errors, but in practice, the latency setting is mostly left for the end-user. This latency should not only represent the IMU latency, but the IMU-LiDAR latency, that we shall call the total latency: It will be defined by the time difference between the instant of IMU attitude physical measurement and the instant of LiDAR measurement. More importantly, the total latency may be affected by user software settings, and by acquisition computer hardware settings, including communication devices. In [ Habib et al. 2010], IMU-LiDAR timing error are identified as a source of error, and a maximum latency accuracy of $0.1 \mathrm{~ms}$ is suggested in order to meet high-quality standards of the airborne LiDAR surveys.

Calibration procedures are based on geolocalized survey data the which may be corrupted by errors from survey sensors, environmental perturbations, and data integration procedures. Timestamping errors may also affect the temporal coherence between sensor data, and in particular between LiDAR ranging data and IMU orientation data. These errors may become significant in case of undesirable high dynamics of the kinematic survey platform. If it is actually the case, latency errors may contribute significantly to the non observability of calibration parameters. Kinematic LiDAR surveys are performed from a wide variety of platforms (aircrafts, helicopters, trucks, and vessels). Some of these platforms (in particular small survey craft performing harbour inspection or coastal erosion monitoring) may be affected by fast motion dynamics, and thus sensitive to IMU-LiDAR latency.

\section{LIDAR-IMU LATENCY CALIBRATION PROCEDURE}

In this section, we propose a method that can be used for estimating the inertial motion unit latency with respect to a ranging system, connected to a acquisition software. Latency between a ranging system and an IMU can be determined by applying a controlled rotational motion to the ranging system and by estimating the position shift of a spherical target induced by a rotational motion. Hereafter, we shall describe a possible set-up in the case of a LiDAR coupled to a motion sensor. For doing so, it is required to get the following data:

- Position of the ranging system optical center through time;

- Orientation of the inertial motion unit frame with respect to the navigationframe. It is to be mentioned that the orientation bias between the motion sensor frame and the LIDAR is not required at this stage, and will be investigated later;

- Scan lines (e.g. set of detection points) from the LIDAR;

- Angular velocities of the LIDAR-IMU system. 
Angular velocities provided from the IMU are submitted to the same latency that we would like to estimate. Therefore, it is preferable to use an external source of angular velocity. We chose to use a 3D motion simulator capable of measuring angles with high accuracy, and to control very precisely angular velocities. In the following, we suppose that angular velocities are available with very high accuracy.

Let us denote by $n=(N, E, D)$ the navigation frame with origin at the motion simulator center of rotation, by bS the kinematic LiDAR body frame, and by bI the inertial motion unit frame. Let us first observe that latency estimation is not affected by orientation bias from the IMU frame and the kinematic LiDAR frame. Let us denote by $M$ a LiDAR detection point, referenced from its optical center $\mathrm{O}$ in its own frame $\mathrm{S}$, and $x_{f}=O M_{f}$ in a frame $\mathrm{f}$. In the navigation frame, we can write for a static (or quasi static) kinematic LIDAR detection point

$$
x_{n}=R_{b I}^{n} R_{b S}^{b I} x_{S}
$$

where $R_{b I}^{n}$ and $R_{b S}^{b I}$ are direction cosine matrix from frame (bI) to (n) and (bS) to (bI).

Now consider the same scene, but seen from the kinematic LiDAR in rotational motion. The principle of the method is to consider that point $M$ has been detected by the LiDAR, but shifted in the navigation frame. Let M' be the image of point $\mathrm{M}$, the kinematic LiDAR being in rotational motion. Denoting by $x_{f}^{\prime}=O M_{f}^{\prime}$, we can write

$$
x_{n}^{\prime}=R_{b I}^{n}(t-d t) R_{b S}^{b I} x_{S}
$$

From (1) and (2), we deduce that

$$
x_{n}=R_{b S}^{b I} R_{b I}^{n}(t-d t) x_{n}^{\prime}
$$

Assuming that the rotational motion is with a constant angular velocity, and after some manipulations, we obtain the relationship between latency and the displacement vector $\Delta_{n}=x_{n}-x_{n}^{\prime}$ due to the rotational motion:

$$
d t=\frac{\left\|\Delta_{n}\right\|}{\left\|\omega_{b I / n}^{b I} \wedge x_{n}^{\prime}\right\|}
$$

where $\omega_{b I / n}^{b I}$ denotes the angular velocity of the LiDAR-IMU with respect to the (n) frame, expressed in the IMU coordinate system.

\section{EXPERIMENTAL RESULTS OF THE LATENCY CALIBRATION METHOD}

The problem is now to define a reference point $M$ that can be defined from a LiDAR scan. A good candidate for such a point is the center of a spherical target. Indeed, this center can easily be fitted by LiDAR returns from the sphere surface with a very high accuracy. By an iterative leastsquare procedure, one can accurately estimate a sphere center from surface points [GrejnerBrzezinska, 2011]. In figure 2, we plotted LiDAR return from a spherical target used in our experimental set-up. 

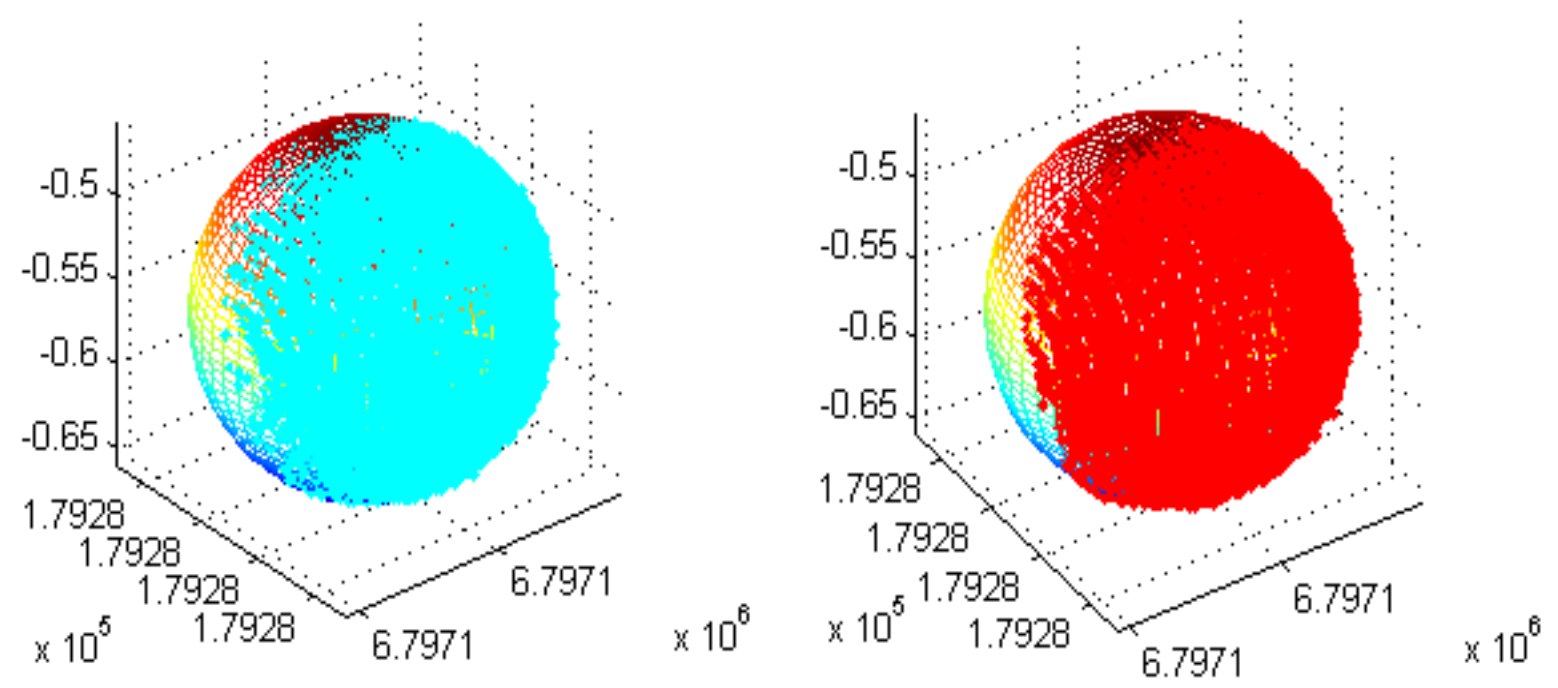

Figure 1: Spherical targets scans. Right side $7 \mathrm{deg} / \mathrm{sec}$ scans, left side -7deg/sec scans. Position shift of the centers has been estimated with a precision of $0,04 \mathrm{~mm}$.

Our method aims at being a laboratory test and will not require any positioning device, which will therefore not propagate positioning errors in the calibration itself. The experimental set-up that we realized is formed by a Leica HDS6200 Laser scanner, coupled with an OCTANS 4 Attitude sensor (they are mounted in the same mechanical bracket). The IMU and the LiDAR have been installed on an IX-Motion TRI30 motion simulator, capable of achieving rotational motions with a high precision and accuracy (about $0.001 \mathrm{deg} / \mathrm{sec}$ ).

Figure (2) shows the mechanical mounting of the LiDAR-IMU on the motion simulator, the control panel of the acquisition software Qinsy, and the control panel of the 3D motion simulator that have been used during our tests. A spherical target of diameter $20 \mathrm{~cm}$ was placed at a distance of 2.5 meter from the laser scanner optical center. It should be noted that in our approach, a relatively short distance to the target is not a limiting factor. Indeed, an increase of the distance to the target (denoted by $x_{n}^{\prime}$ in the latency estimate equation) would generate a larger position shift of the target when viewed at several angular speeds, but would deteriorate the quality of estimation of the sphere centres from ranging measurements.

A reasonable choice of the target range should be based on ranging precision considerations, in order to get a good estimate of the target center. This choice can be balanced by a relatively high value of the angular velocity which amplifies the target center shift. 


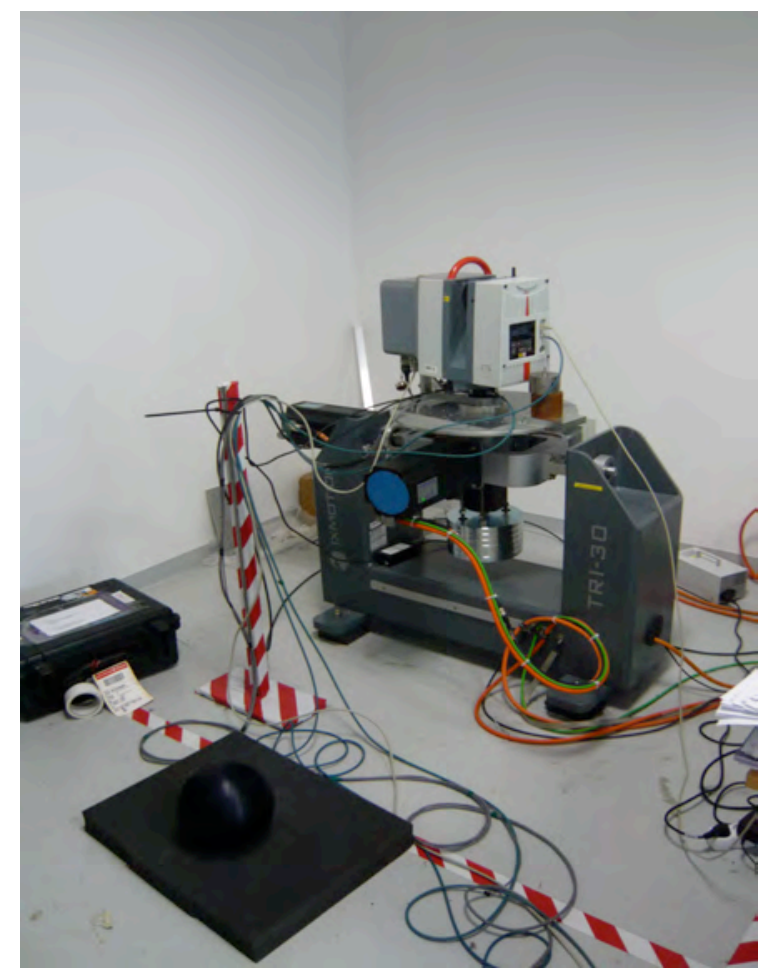

Figure 2: Experimental set-up for latency calibration: The Leica HDS6200 and the IxSea Octan4 are mounted on a IXMotion TRI30 motion simulator, scanning a sphere of precision.

Both LiDAR and IMU data were gathered by the Qinsy acquisition software. It should be mentioned that our method estimates the total latency between the IMU, the LiDAR and the acquisition PC. In order to check for the latency induced by the PC acquisition buffer size, we made several tests with different software configurations. Indeed, as the OCTANS4 was not connected to a Pulse per Second signal, and data were transmitted through a serial link, the size of the serial link buffer might impact the total latency. Data from these tests are given in table (1).

The latency of the OCTANS 4 , when connected by a serial link, is around $2,35 \mathrm{~ms}$ with $0,2 \mathrm{~ms}$ uncertainty. The latency due to buffering should be added, and the latency due to data assimilation by Qinsy in order to get the total latency. Table (1) gives the results we obtained with several buffer configurations, in order to check the impact of various buffer size and our latency estimate resolution.

One can check that the residual latency (e.g; the latency due to the acquisition software and data assimilation is quite constant, with an accuracy of $0,2 \mathrm{~ms}$. Note that figures given in table (1) are averaged values of a serie of runs, which returned the latency estimate with SD values of about $0.01 \mathrm{~ms}$. We can conclude from these tests that the method is able to find IMU latency with an accuracy of $0,2 \mathrm{~ms}$ and a precision of $0,01 \mathrm{~ms}$.

Table 1: Latency estimation results

\begin{tabular}{|l|l|l|l|l|l|}
\hline $\begin{array}{l}\text { FIFO } \\
\text { buffer size }\end{array}$ & $\begin{array}{l}\text { Sphere } \\
\text { center SD }\end{array}$ & $\begin{array}{l}\text { Total } \\
\text { latency }\end{array}$ & $\begin{array}{l}\text { OCTANS } 4 \\
\text { latency }\end{array}$ & $\begin{array}{l}\text { Buffer th. } \\
\text { latency }\end{array}$ & $\begin{array}{l}\text { Residual } \\
\text { latency }\end{array}$ \\
\hline 0 & $0.041 \mathrm{~mm}$ & $2.82 \mathrm{~ms}$ & $2.35 \mathrm{~ms}$ & 0 & $0.47 \mathrm{~ms}$ \\
\hline 8 bytes & $0.044 \mathrm{~mm}$ & $3.31 \mathrm{~ms}$ & $2.35 \mathrm{~ms}$ & $0.69 \mathrm{~ms}$ & $0.27 \mathrm{~ms}$ \\
\hline 14 bytes & $0.042 \mathrm{~mm}$ & $3.97 \mathrm{~ms}$ & $2.35 \mathrm{~ms}$ & $1.22 \mathrm{~ms}$ & $0.40 \mathrm{~ms}$ \\
\hline
\end{tabular}


It is also very important to mention that this method applies to any IMU connected to an acquisition system, and do not depend of the ranging device (LiDAR of MBES). Therefore, hydrographic survey systems and IMUs latency can be estimated by using this method, which is a positioning error free calibration method.

Table 1: Latency estimation results

\begin{tabular}{|l|l|l|l|l|l|}
\hline $\begin{array}{l}\text { FIFO } \\
\text { buffer size }\end{array}$ & $\begin{array}{l}\text { Sphere } \\
\text { center SD }\end{array}$ & $\begin{array}{l}\text { Total } \\
\text { latency }\end{array}$ & $\begin{array}{l}\text { OCTANS } 4 \\
\text { latency }\end{array}$ & $\begin{array}{l}\text { Buffer th. } \\
\text { latency }\end{array}$ & $\begin{array}{l}\text { Residual } \\
\text { latency }\end{array}$ \\
\hline 0 & $0.041 \mathrm{~mm}$ & $2.82 \mathrm{~ms}$ & $2.35 \mathrm{~ms}$ & 0 & $0.47 \mathrm{~ms}$ \\
\hline 8 bytes & $0.044 \mathrm{~mm}$ & $3.31 \mathrm{~ms}$ & $2.35 \mathrm{~ms}$ & $0.69 \mathrm{~ms}$ & $0.27 \mathrm{~ms}$ \\
\hline 14 bytes & $0.042 \mathrm{~mm}$ & $3.97 \mathrm{~ms}$ & $2.35 \mathrm{~ms}$ & $1.22 \mathrm{~ms}$ & $0.40 \mathrm{~ms}$ \\
\hline
\end{tabular}

\section{LIDAR-IMU BORESIGHT ANGLES CALIBRATION PROCEDURE}

The approach we present here is devoted to LiDAR-IMU boresight calibration procedure independent of any positioning data; namely, we do not want positioning errors to corrupt the calibration procedure.

\subsection{Principle of the method}

The procedure we propose for LiDAR-IMU boresight angle calibration is motivated by the fact that we would like to eliminate the influence of positioning errors on the misalignment angles computation. The procedure we propose can be achieved in a laboratory, and requires to make a serie of static scans of a tripod (see figure (1)) target from several points of views.

Let us suppose that the LiDAR and the IMU are rigidly mounted in a mechanical bracket. We start by a first static scan of the tripod. The major advantage of this type of target lies in the fact that its orientation can be determined only from the knowledge of the intersection points $\left(C_{1}, C_{2}, C_{3}\right)$ between the LiDAR scanning plan and the tripod itself. Points $\left(C_{1}, C_{2}, C_{3}\right)$ can be determined by fitting the center of the ellipse produced by the intersection of the LiDAR scanning plan and the tripod cylinders. By using notations defined in figure (1), it can be readily shown that for all $i, j \leq 3 ; i \neq j$ we have

$$
d_{i j}^{2}=d_{0 i}^{2}+d_{0 j}^{2}-2 d_{0 i} d_{0 j} \cos \theta_{i j}
$$

These three non linear equations can be numerically solved for $\left(d_{0 i}\right)_{i=1 . .3}$, with prior knowledge of the three angles forming the tripod. Then, we can estimate the tripod center $O$, being the intersection of three spheres of centers $\left(C_{1}, C_{2}, C_{3}\right)$ with radius $\left(d_{01}, d_{02}, d_{03}\right)$. 


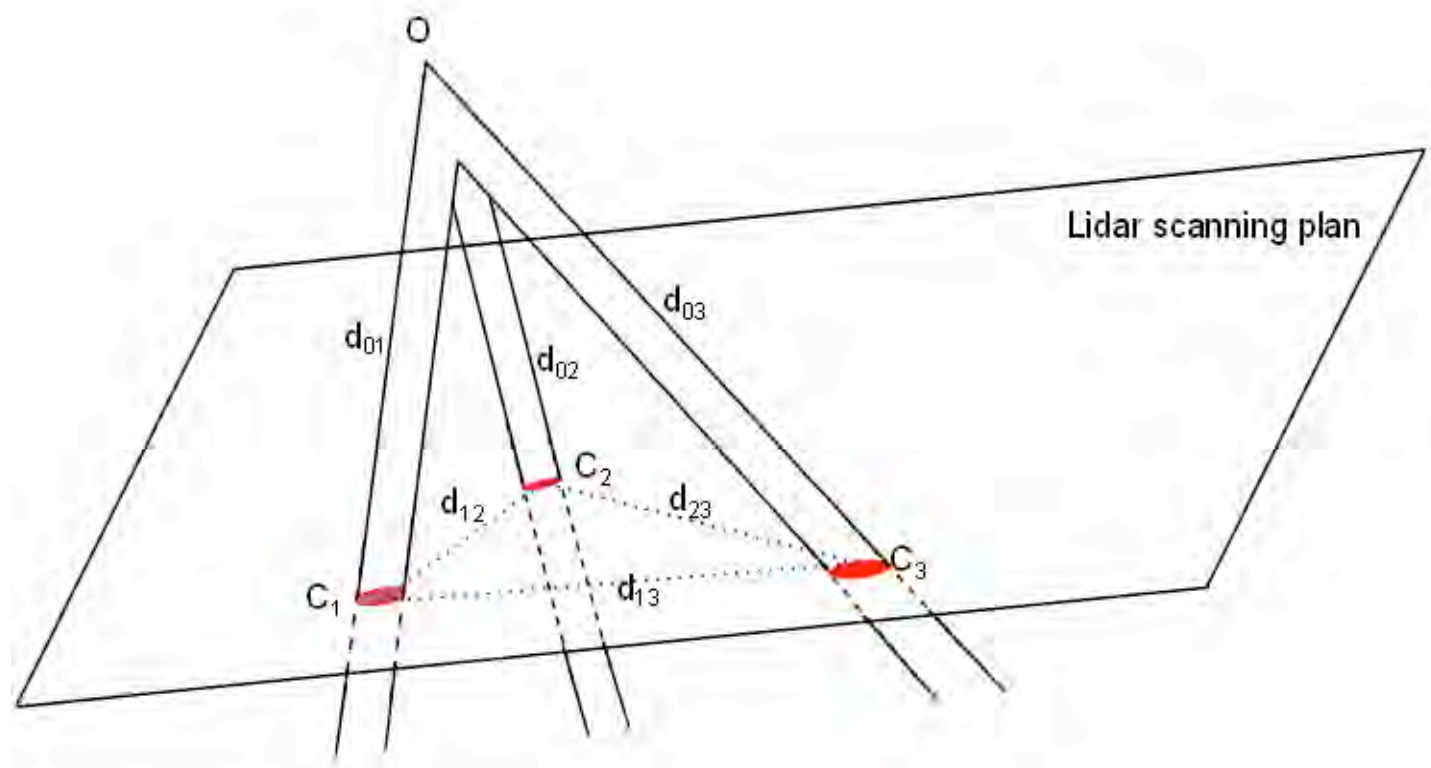

Figure 3: Geometric view of the bore-sight calibration target

Let us denote by $\left(x_{0}, y_{0}, z_{0}\right)$ the coordinates of point $O$ in a frame attached to the Lidar scanning plan, and $\left(x_{i}, 0, z_{i}\right)$ the coordinates of points $C_{i}$. Then, we have

$$
\left(x_{0}-x_{i}\right)^{2}+y_{0}^{2}+\left(z_{0}-z_{i}\right)^{2}=d_{0 i}^{2}, i=1 . .3
$$

this last system being explicitly solved for $\left(x_{0}, y_{0}, z_{0}\right)$ by

$$
\begin{aligned}
& \left(x_{0}-x_{1}\right)^{2}+y_{0}^{2}+\left(z_{0}-z_{1}\right)^{2}=d_{01}^{2} \\
& 2 x_{0}\left(x_{2}-x_{1}\right)+2 z_{0}\left(z_{2}-z_{1}\right)=d_{01}^{2}-d_{02}^{2}+x_{2}^{2}-x_{1}^{2}+z_{2}^{2}-z_{1}^{2} \\
& 2 x_{0}\left(x_{3}-x_{1}\right)+2 z_{0}\left(z_{3}-z_{1}\right)=d_{01}^{2}-d_{03}^{2}+x_{3}^{2}-x_{1}^{2}+z_{3}^{2}-z_{1}^{2}
\end{aligned}
$$

We observe that $y_{0}$ has two solutions, which express the fact that the tripod center may be located in the two half space separated by the Lidar scanning plane. Knowing the coordinates of point $O$, we can reconstruct the directions $O C_{i}$ of each tripod foot in the Lidar scanning plane.

Let us now suppose that two different static scans of the tripod have been performed, for two different Lidar orientations. For a given orientation $i$ let us denote by $X_{b S i}=O C_{i}$ the tripod foot vectors coordinatized in the LiDAR frame bS. Note that each of these vectors can be uniquely attached to a given footprint whenever the diameters of the foot tube are different.

\subsection{Derivation of the bore-sight calibration equations}

Consider now two different foot vectors, $X_{b S 1}, X_{b S 2}$ obtained from two orientations of the LiDAR scanning plan towards the tripod. Let us denote by 
- $R_{b S}^{b I}(\varphi, \theta, \psi)=\left(\begin{array}{ccc}c \psi c \theta & c \psi s \theta s \varphi+s \psi c \varphi & -c \psi s \theta c \varphi+s \psi s \varphi \\ -s \psi c \theta & -s \psi s \theta s \varphi+c \psi c \varphi & s \psi s \theta c \varphi+c \psi s \varphi \\ s \theta & -c \theta s \varphi & c \theta c \varphi\end{array}\right)$ the direction cosine matrix defining the rotation from the LiDAR frame $b S$ to the IMU frame, namely, the boresight angle direction cosine matrix parametrized by Euler angles $(\varphi, \theta, \psi)$;

- $\left(\varphi_{0}, \theta_{0}, \psi_{0}\right)$ an a priori estimate of the boresight angles;

- $\quad R_{b I}^{n}$, the direction cosine matrix from the IMU frame to the navigation frame $n$ (e.g; the local geodetic frame (North, East, Down)) a from the point of view $i$.

The basic principle of our method is to express that in the navigation frame $n$, the tripod foot vectors $R_{b I_{i}}^{n} X_{b I_{i}}=R_{b I_{i}}^{n} R_{b S}^{B I} X_{b S_{i}}$, coordinatized in the navigation frame are invariant for each LiDAR static scan. Therefore, the fundamental equation for this calibration method is

We start with

$$
R_{b I 1}^{n} X_{b I 1}=R_{b I 2}^{n} X_{b I 2}
$$

$X_{b I i}=R_{b S}^{b I} X_{b S_{i}}:=g\left(\varphi_{0}, \theta_{0}, \psi_{0}\right)$. In considering a linear approximation of this equation, we obtain: $g(\varphi, \theta, \psi)=g\left(\varphi_{0}, \theta_{0}, \psi_{0}\right)+g^{\prime}\left(\varphi_{0}, \theta_{0}, \psi_{0}\right) \cdot\left(\varphi-\varphi_{0}, \theta-\theta_{0}, \psi-\psi_{0}\right)^{T}$, which leads to the following linear system

$$
R_{b I}^{n} g\left(\varphi_{0}, \theta_{0}, \psi_{0}\right)_{1}-R_{b I 2}^{n} g\left(\varphi_{0}, \theta_{0}, \psi_{0}\right)_{2}=\left(R_{b I}^{n} g^{\prime}\left(\varphi_{0}, \theta_{0}, \psi_{0}\right)_{1}-R_{b I_{2}}^{n} g^{\prime}\left(\varphi_{0}, \theta_{0}, \psi_{0}\right)_{2}\right)(\Delta \varphi, \Delta \theta, \Delta \psi)^{T}
$$

In combining three observation sites, we obtain nine equations, which can be solved by a weighted least square ${ }^{1}$ which returns approximated values of $(\varphi, \theta, \psi)$. Then, by updating $\left(\varphi_{0}, \theta_{0}, \psi_{0}\right) \leftarrow(\varphi, \theta, \psi)$, we create a sequence of estimated boresight angles. Convergence of this process is not guaranteed but generally occurs after a few iterations.

\section{ANALYSIS OF THE BORESIGHT CALIBRATION METHOD}

\subsection{Description of the simulation set-up}

In order to study the robustness and performance of the boresight calibration method, a simulation of the whole estimation process has been performed for checking the boresight angles values with respect to some uncertainty on the ellipse center estimates. In this set-up, we considered a tripod with a 60 deg angle with respect to its vertical axis, and we generated a sequence of 3 LiDAR scanning plans given by the following rotations in roll, pitch and heading :

$$
(\varphi, \theta, \psi)=[-20,0,30],[0,20,120],[20,-20,240]
$$

\footnotetext{
${ }^{1}$ The weight matrix depending on the confidence on the estimation of the coordinates of the foot vector (which comes from the ellipse center estimate) and from the precision of the IMU which delivers the direction cosine matrix.
}

${ }^{1}$ The weight matrix depending on the confidence on the estimation of the coordinates of the foot vector (which comes from the ellipse center estimate) and from the precision of the IMU which delivers the direction cosine matrix. 
The uncertainty on the ellipse center was estimated by a statistical analysis of the leastsquare residuals and was set to $1 \mathrm{~mm}$ and $1 \mathrm{~cm}$ for a tripod tube of diameter $10 \mathrm{~cm}$.

\subsection{Performance and Robustness analysis}

From figure (4) and (5), it can be seen that our estimation method is unbiased. One should mention that the method presented in [Grejner-Brzezinska, 2011] induced a biais in the boresight matrix estimation since this method is based on a composition of micro-rotators which is no more a true direction cosine matrix representing a rotation matrix.

The following result show frequency distribution graphs of the roll, pitch and yaw errors for several ellipse centre distribution errors. It can be seen figure (5) that for a realistic error distribution on the ellipse centers (about $1 \mathrm{~mm}$ ), the boresight angle errors are less than 0,01 deg on pitch and roll, and 0,05 deg for the heading angle. Our simulation results indicate that this method converges in a few iterations, generally less than five. The robustness of the method can be checked in figure (4): even in the case of $1 \mathrm{~cm}$ (this error is clearly over estimated) of ellipse center error, boresight angles are quite well estimated, with an error of less than $0,1 \mathrm{deg}$ for pitch and roll and less than $0,5 \mathrm{deg}$ for heading.

From these simulation results, we observe that the estimation procedure including ellipse detection uncertainty, geometric reconstruction of the tripod foot vectors, and boresight matrix estimation is unbiaised and very accurate, in comparison of classical surface matching methods which cumulate latency errors due to kinematic survey, positioning errors, and surface modeling errors.
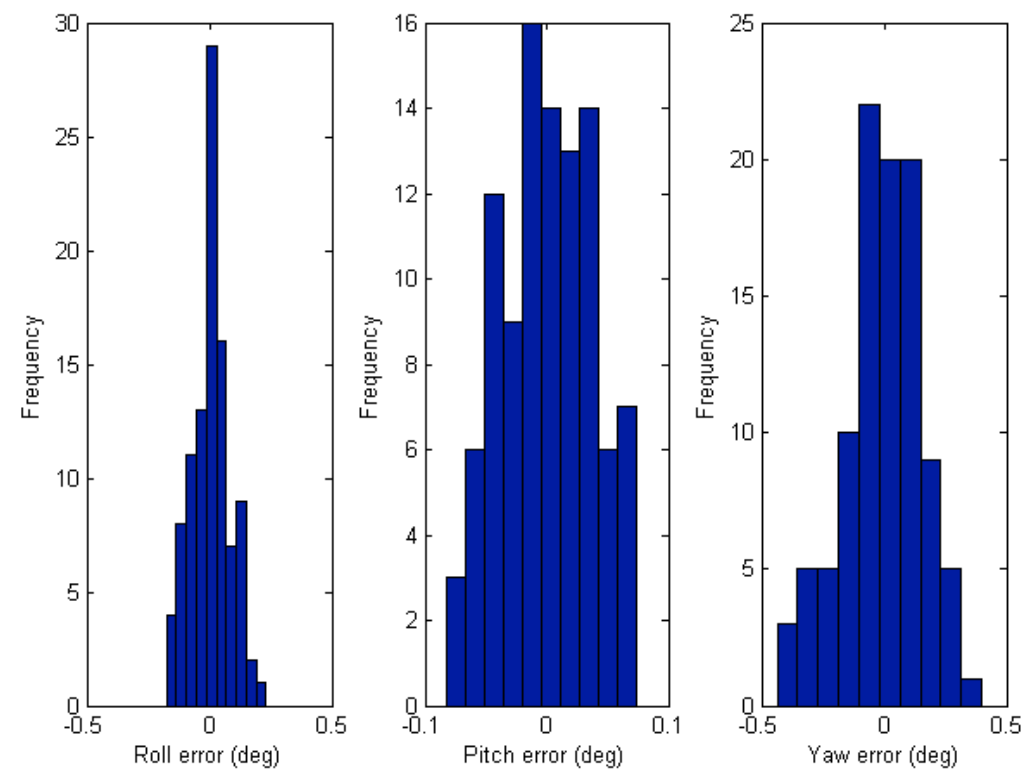

Figure 4: Boresight errors with $1 \mathrm{~cm}$ uncertainty on ellipse centers 

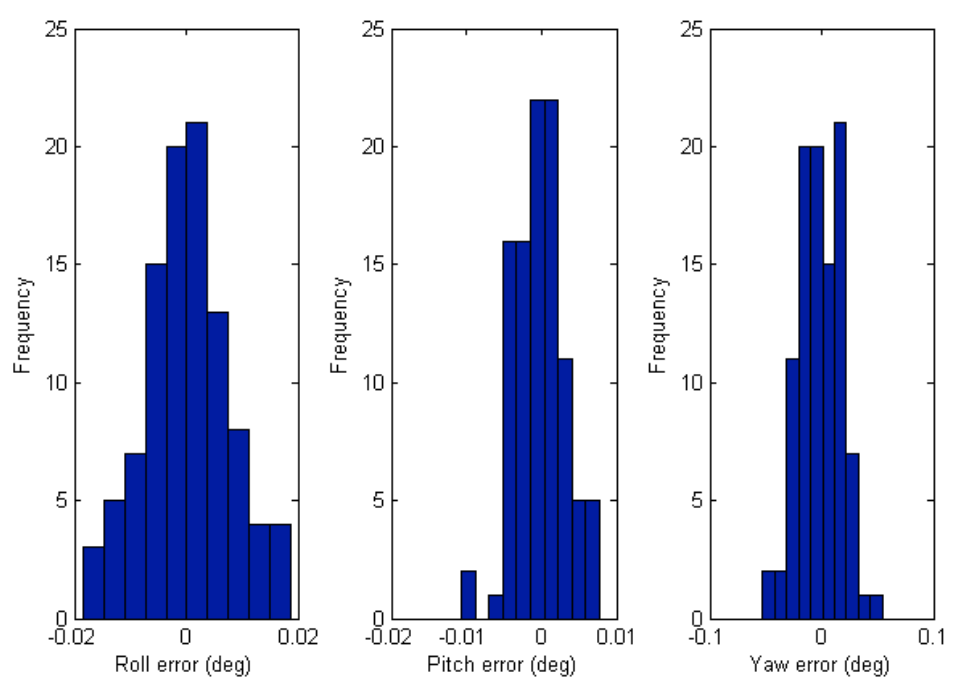

Figure 5: Boresight errors with $1 \mathrm{~mm}$ uncertainty on ellipse centers

\section{CONCLUSION}

The LiDAR calibration methods we propose offer many advantages in comparison of field calibration methods: they save survey mobilization time, they are free of any positioning errors, which is not the case of surface matching methods and target methods. They also avoid the classical obstruction and loss of accuracy due to calibration on edged targets. The boresight calibration method we propose is also free of inertial measurement errors due to eventual fast dynamics motion, as it only requires a serie of static scans.

The latency calibration approach may be applied to any IMU and acquisition software, independently of the ranging sensor (LiDAR or MBES). The boresight calibration procedure is for the moment limited to LiDAR, but should be also adapted to MBES calibration.

\section{REFERENCES}

[Barber, D., Mills, J., 2006] Geometric validation of ground-based mobile laser scanning system. ISPRS Journal of Photogrammetry \& Remote Sensing 68, 123-141.

[Burman, H., 2002] Laserstrip adjustment for data calibration and veri_cation. International Archives of Photogrammetry and Remote Sensing 34(3A), 67-72. 
[Clarke, J. H., 2003] Dynamics motion residuals in swath sonar data: Ironing out the creases. International Hydrographic Review 4(1), 6-23.

[Filin, S., 2003] Recovery of systematic biases in laser altimetry data using natural surfaces. Photogrammetric Engineering \& Remote Sensing 69, 1235-1242.

[Filin, S., Vosselman, G., 2004] Adjustment of airborne laser altimetry strips. In: ISPRS Congress Istanbul, Proceedings of Commission III.

[Glennie, C., 2007] Rigorous 3d error analysis of kinematic scanning lidar systems. Journal of Applied Geodesy 1, 147-157.

[Grejner-Brzezinska, D. A., Toth, C. K., Sun, H., Wang, X., Rizos, C., Nov 2011] A robust solution to high-accuracy geolocation: Quadruple integration of gps, imu, pseudolite, and terrestrial laser scanner. IEEE Transactions on instrumentation and measurement 11,3694-3708.

[Gruen, A., Beyer, H., 2001] Calibration and Oritentations in Computer Vision. Springer, Ch. System Calibration through Self-Calibration., pp. 163-193.

[Habib, A., Bang, K., Kersting, A., Chow, J., 2010] Alternative methodologies for lidar system calibration. Remote Sensing 2, 874-907.

[Jaakkola, A., Hyppa, J., Kukko, A., Yu, X., Kaartinen, H., Lehtomaki, M., Lin, Y., 2010] A low-cost multi-sensoral mapping system and its feasibility for tree measurements. ISPRS Journal of Photogrammetry \& Remote Sensing 65, 514522

[Kumari, P., Carter, W. E., Shrestha, R. L., 2011] Adjustment of systematic errors in als data through surface matching. Advances in Space research 47, 1851-1864.

[Mettenleiter, M., Oberteiber, N., Hartl, F., Ehm, M., Baur, J., Frohlich, C., 2008]

$3 \mathrm{~d}$ laser scanner as part of kinematic measurement system. In: Internation Conference on Machine Contol \& Guidance.

[Morin, K., Naser El-Sheimy, N., 2002] Post-mission adjustment methods of airborne laser scanning data. In: FIG XXII Int. Congress, Washington DC.

[QPS, 2007] Timing in Qinsy. QPS BV, The Netherlands.

[Schenk, T., 2001] Modeling and analyzing systematic errors of airborne laser scanners.

Tech. rep., Department of Civil and Environmental Engineering and Geodetic

Science, The Ohio State University, Columbus, $\mathrm{OH}$ 
276 | Hydrol 2 


\title{
Towards more attractivity for hydrographic surveying course through international joint diplomas
}

\author{
Nicolas SEUBE, France \\ Ecole Nationale de Techniques Avancés Bretagne
}

Maude Audet MORIN, Canada

Centre Interdisciplinaire de Développement en Cartographie des Océans

Topic: The hydrographic profession

\begin{abstract}
This paper proposes some possible actions in order to enhance the attractivity of category A programmes. The possibility of double diploma is presented through two types of experiences: double diploma between hydrography course, and double diploma in hydrography and oceanography. The paper also outlines the need of support from the industry in order to stimulate applied research in hydrography through 3 semester master thesis.
\end{abstract}

\section{INTRODUCTION}

Among the eighteen running courses in Hydrography recognized at category A against the FIG/IHO/ICA S5 norm for standards of competence of nautical Hydrographers, ten are university courses, eight are under Navy or Hydrographic Offices umbrella ${ }^{\mathrm{i}}$. It is now well recognized that the education and training capacity (both at category A and B) is largely under the increasingly demand of qualified hydrographers.

In some regions (Scandinavia, Eastern Europe, Middle East, Africa, Australasia for instance), no category A course in hydrography is available. Another observation is that among the sixteen countries hosting a category A programme in hydrography, only seven of them host university courses and the remaining nine countries offer education in hydrography through Navy courses. It is worthwhile mentioning that navy operated course have a capacity limited to their national needs and have a limited access to international students. University courses are in general hosted by medium or large institutes, which priorities are not only focused on education capacity in hydrography. Difficulties to maintain high standards of education are varied, and may be a lack of students applying to the course with regards to the running costs, or the opposite scenario, a lack of means and staff to run the course.

Another influencing factor is the fact that hydrography education at category $\mathrm{A}$ is not related to a given and agreed university level. Some category
A courses are BSc degrees, some others are MSc in one or two years, some others are National degrees which do not fit with international standards.

Hydrography as a discipline is related to a wide variety of subjects like Geodesy, GIS, Physical Oceanography, GIS, Remote Sensing, Positioning, the specificity of it lying in Bathymetry, Water levels, Marine Geophysics, and Hydrographic Surveying. New challenges in hydrographic applications, from the historical safety of navigation (which is still a prominent activity), to environmental monitoring (coastal erosion, habitat mapping), ultra low scale marine infrastructure inspection, regional scale bathymetry by remote sensing, the use of LiDAR or Satellite data, shift the competence of Hydrographers to a wider class of operation fields and methods.

We feel that for all these reasons, courses in hydrography should be networked with other disciplines, interconnected at the international level to optimize the use of infrastructures and to contribute to a broader education. This paper relates and discusses some actions that are currently undertaken by the ENSTA Bretagne and the CIDCO.

\section{FRAMEWORK}

The ENSTA Bretagne (former ENSIETA) host a programme in hydrography since 1971, recognized at category A against the FIG/IHO/ICA S5 norm 
[Seube et al. 2011]. Before 2005, this course was operated by the SHOM, and since then, the ENSTA Bretagne coordinates the course, with the aim of a tight cooperation with the private sector both at the national and international level.

The ENSTA Bretagne is a French "grande école ${ }^{\mathrm{i} i \text { " }}$ and deliver a French "Diplôme d'ingénieur", which is well recognized at the national level, but not well understood at the international level. The "Diplôme d'ingénieur" is equivalent to a MSc, but is not a MSc. In this context, linking the ENSTA Bretagne course with other courses in hydrography was not easy.

In 2011, the French ministry of education gave accreditation to the ENSTA Bretagne for delivering a "MSc in Hydrography", a slightly modified version of the two years course of the "Diplôme d'ingénieur". This new Master Degree in Hydrography is mainly devoted to foreign students, and can be followed by non-french speaking students.

The CIDCO (Interdisciplinary Center for the Development of Ocean Mapping) is a research center located in Rimouski (Québec) which develops expertise in topo-bathymetry, remote bathymetry, and hydrographic system analysis. The CIDCO and the ENSTA are regularly cooperating on research project on joined actions. No courses in Hydrography are available in Québec. In Canada, Hydrographic Office personnel training is done through a continuing education scheme [Kian Fadaie 2012].

\section{DOUBLE DIPLOMAS}

ENSTA Bretagne is in the process of creating a double diploma in Hydrography with HafenCity University (HCU, Hamburg, Germany), which also offers an English spoken, two-years Master degree in hydrography, recognized at category A. MSc at ENSTA Bretagne and HCU have the same structure: three semesters devoted to course modules, and one semester devoted to the Master thesis. Both of these courses are opened to foreign students.

The double diploma enables students to perform a part (one semester) of their studies in ENSTA Bretagne or HCU. Double diploma add some constraints on the course design and scheduling (exchange semesters have to cover the same topics), and the graduation rules must be fulfilled from each side (grading harmonization, semester validation procedures). But the double diploma is a framework which gives flexibility to students, as the framework for graduation is fixed in a common agreement, instead of applying the two side graduation rules in the case of a simple exchange without double diploma.

From the student point of view, beyond the cultural benefit of discovering two countries, two educational systems, the opportunity to practice hydrography in two different places with different equipment is a real added value. Surveying the port of Hamburg and the Brest Bay Area is a quite different experience. Moreover, student will have access to the two institutes networks in terms of placement for training periods, Master thesis, and jobs opportunities, and will have the possibilities to learn from research project in both sides.

\section{HYDROGRAPHY AND RELATED FIELDS}

Another challenge is to give to student a set of competence that goes beyond hydrographic surveying, but should include advanced studies in related topics like physical oceanography, remote sensing, or integrated costal management.

Since 2005 ENSTA Bretagne developped a double competence curriculum on both hydrography and physical oceanography. Beyond descriptive oceanography (a minimum requirement of the S5 norm), students have a heavy background on ocean modelling at various scales, sediment dynamics, and remote sensing oceanography. It has been observed that in giving the opportunity to hydrography student to complement their category A curriculum by an related field like oceanography make the course more attractive and open different paths to students that are really motivated by hydrography or by oceanography.

Based on this encouraging experience, we are in the process of setting-up a double diploma with the Université du Québec at Rimouski (UQAR) which have a 2 year master programme in oceanography (physical, biological, chemical, geological).

This project aims to open in 2013 a joint ENSTAUQAR in hydrography and oceanography.

The first motivation is to give the opportunity of studing two interconnected fields, in order to give them more profesional opportunities. Indeed, we observe that more and more environmental regulation of coastal construction project for

\section{8 | Hydrol 2}


instance will create new opportunities for young people having both skills in oceanographic modelling, oceanographic instrumentation, development of local observatory networks, and hydrographic surveying.

The second motivation is to enable students to perform a 16 months period of master thesis (as it usually the case in Canada) which can be used for complementing their knowledge of oceanography and to perform an active mid-term research project. Therefore, after completing 3 semesters at the ENSTA Bretagne, student will embark for another 3 semester period of research/course modules. Students will gain a double French/Canadian graduation and a double competence which can be a real added value for their future career.

The CIDCO, hosted by the UQAR will be the framework of student research project. Being in particular the hydrographic survey technology provider of major environmental research project in Québec, the Cidco will contribute to the immersion of student research in mixed hydrography/ oceanography projects. In addition, students will find in the research axis of the CIDCO (BathyLiDAR, autonomous bathymetry, hydrographic systems and data uncertainty) opportunities for working on subjects of interest for the hydrographic community.

The double diploma we propose contributes to developing research in hydrography. It seems that with regards to the EU industry need, the EU capacity in $\mathrm{PhD}$ students in hydrography is too low. Recruiting $\mathrm{PhD}$ students in hydrography is quite a risk since their employability is generally limited to the public sector (universities, hydrographic offices). It is the authors' belief that three year Master programmes, offering the possibility for a three semester of applied research could be beneficial to the hydrographic community. This type of programme cannot be developed without the implication of the industry and will benefit to the industry. The concept of a "short" $\mathrm{PhD}$ consisting in a 3 year Master program including 3 semesters of research could be an answer to some industrial problems in hydrographic surveying, and will doubtless contribute to the quality of our category A hydrographers.

\section{CONCLUSION}

This paper proposed three types of possibilities for increasing the hydrography education capacity and attractiveness: Double diplomas between courses having compatible curriculum, double diploma with hydrography allied disciplines, jointly with the call for mid-term junior research-ship that could be a opportunity for developing students skills and autonomy together with industrial problems solving.

\section{REFERENCES}

[Fadaie, K. 2012] Training Multi-Disciplinary Hydrographers at the Canadian Hydrographic Service, Kian Fadie, Canadian Hydrographic Conference, Niagara.

[Abbott, V. and Seube, N. 2008] Hydrography at MSc and Category A Level: a European perspective, Hydro8, Liverpool.

[Boeder, V, Egge, D., Schenke H.W., Schiller, L., Schiewe, J., 2010] Certified Hydrography Courses in Germany- FIG/IHO/ICA category A (HCU) and Category B (TECHAWI), Hydro2010, Rostock, Germany.

[Seube, N. Debese, N., Moitié, R, 2011]

Hydrography at Master and IHO cat-A Level at ENSTA Bretagne, International Hydrographic Review.

[Johnston, G, Egge, D. 2010] The FIG/IHO/

ICA Standards of Competence for Hydrographic Surveyors and Nautical Cartographers, Hydro10, Rostock.

iLet us mention that two courses are recognized at category A against the FIG/IHO/ICA S8 norm for standards of competence of nautical Cartographers.

ii A French « grande école » is not part of a university. Historically, this is a institute which students are selected through a competitive exam, a part of them having a contract with a Ministry as they are admitted. After graduation, these student are working for the state. At the ENSTA Bretagne, 20\% of student are in contract with the ministry of defense, and two graduated hydrographers per year join the SHOM after graduation. 
$280 \mid$ Hydrol 2 


\section{International Cooperation in Education: The VASSIVIERE Erasmus Intensive Training Program (2011-2013) on Hydrography and Geomatics}

Nicolas SEUBE, Thomas TOUZÉ, Nathalie DEBESE, Rodéric MOITIÉ and Irvin PROBST, France ENSTA, Ocean sensing and mapping Lab

Alain DE WULF, Timothy NUTTENS, Cornelis STAL, Belgium

Ghent University, Department of Geography, 3D Data Acquisition Cluster

Volker BÖDER, Germany

HafenCity University, Lab Marine Geodesy

Maude Audet MORIN, Canada

CIDCO

\section{SUMMARY}

In the framework of the European Union Erasmus Intensive Program which aims at sponsoring intentive courses jointly proposed by european universities, ENSTA Bretagne (France), Ghent University (Belgium) and HCU University (Germany), and the CIDCO (Interdisciplinary Centre for the Development of Ocean Mapping) (Canada), as an associate partner, organised a hydrographic and topographic surveying camp. This project took place in Lake of Vassivière, one of France's largest artificial lakes exploited by EDF, France's global energy company. Five teams of students were tasked to achieve the survey instructions given by EDF like in a real professional context. The main objective was to survey this $10 \mathrm{~km}^{2}$ lake to focus on points of interest like dam infrastructures, ports, bridges and to open navigation channels for a given level of the lake. A survey boat from the ENSTA Bretagne and land survey equipment from all universities have been mobilised for this purpose. The project received sponsorship from the industry (Boskalis, Netherland) which is interested in the concept of educating students at an international level. Both land and bathymetric surveys has been conducted using a large variety of equipments. This paper will analyze the educational benefit of international cooperation in the field of hydrographic and land survey training.

Topic: The hydrographic profession

\section{INTRODUCTION AND BACKGROUND}

The Erasmus Intensive Program in Hydrography and Geomatics mobilized 43 students, 12 supervisors from three European countries and an associate partner from Canada (CIDCO, Québec). For the first time in Europe, a fieldwork involving a large number of students and international teams was experienced. The aim of this paper is to explain the benefits of this action in order to encourage such international cooperation in the field of hydrographic survey training.

The ENSTA Bretagne in Brest and the HafenCity University in Hamburg offer programs in hydrography and have both recognition from the
FIG/IHO/ICA as category A course in Hydrographic surveying. They both offer a two years Master level program in hydrography. Ghent University offers a two years Master program in Land Surveying, which includes a short introduction to Hydrographic surveying.

The ideas underlying this project were to:

1. Give the students an opportunity to learn in an international context by making international teams;

2. Make them work both on hydrographic and land surveying problems and face challenging topobathymetric surveys of infrastructures;

3. Make them use a wide variety of equipments 
(LiDAR, sonars, TLS, etc.);

4. Give the students the responsibility of a whole survey, including hydrographic instructions interpretation, survey planning, quality assessment and reporting to the client.

Only last year, Master students were involved in this program because the aim was not to provide a first experience of practical survey but a more comprehensive work filling up the requirements for FIG/IOH/ICA category A hydrographers, namely a capacity to work, plan and report independently in a quite difficult environment.

The Lake of Vassivière environment offers many challenges for survey. The following features enable us to confront the students with difficult situations:

- A low level of the lake due to an exceptional dry weather in France in 2011 (4 meters below the normal level);

- The presence of sediments especially soft mud in some areas;

- A time varying water column environment because of the dam turbine running during the survey;

- Very shallow water areas;

- The presence of infrastructures (dam, water outflow, ports) which required high accuracy and precision surveys;
- The presence of GPS multipath environments due to surrounding woods or bridges and a relatively poor coverage of GPS permanent stations, located at more than $60 \mathrm{~km}$;

- A very long coastline to survey (more than 47 $\mathrm{km})$;

- The presence of submerged infrastructures (roads, bridges, houses, mills, walls) dated from before than 1951 (date of construction of the dam).

\section{APPROACH}

\subsection{Context of the project}

The Lake of Vassivière is an artificial lake, located in the Creuse district, in the center of France (Figure 1). The lake has an area of $10 \mathrm{~km} 2$, with an average depth of 11 meters and a nominal volume of 110 million cubic meters. Hydroelectric installations of Vassivière Lake are operated by EDF, Unité de Production Centre, by a hydraulic plant of $63,7 \mathrm{MW}$. Hydroelectric facilities are located in the northwest part of the lake. A minimum flow of the Vienne River is used to cool down the Civaux nuclear power plant, located $200 \mathrm{~km}$ away from Vassivière. The touristic activities and navigation are managed by the Lake of Vassivière authorities. The creation of the dam in 1951 contributed to increase the tourism activity (coastal footpath and many nautical

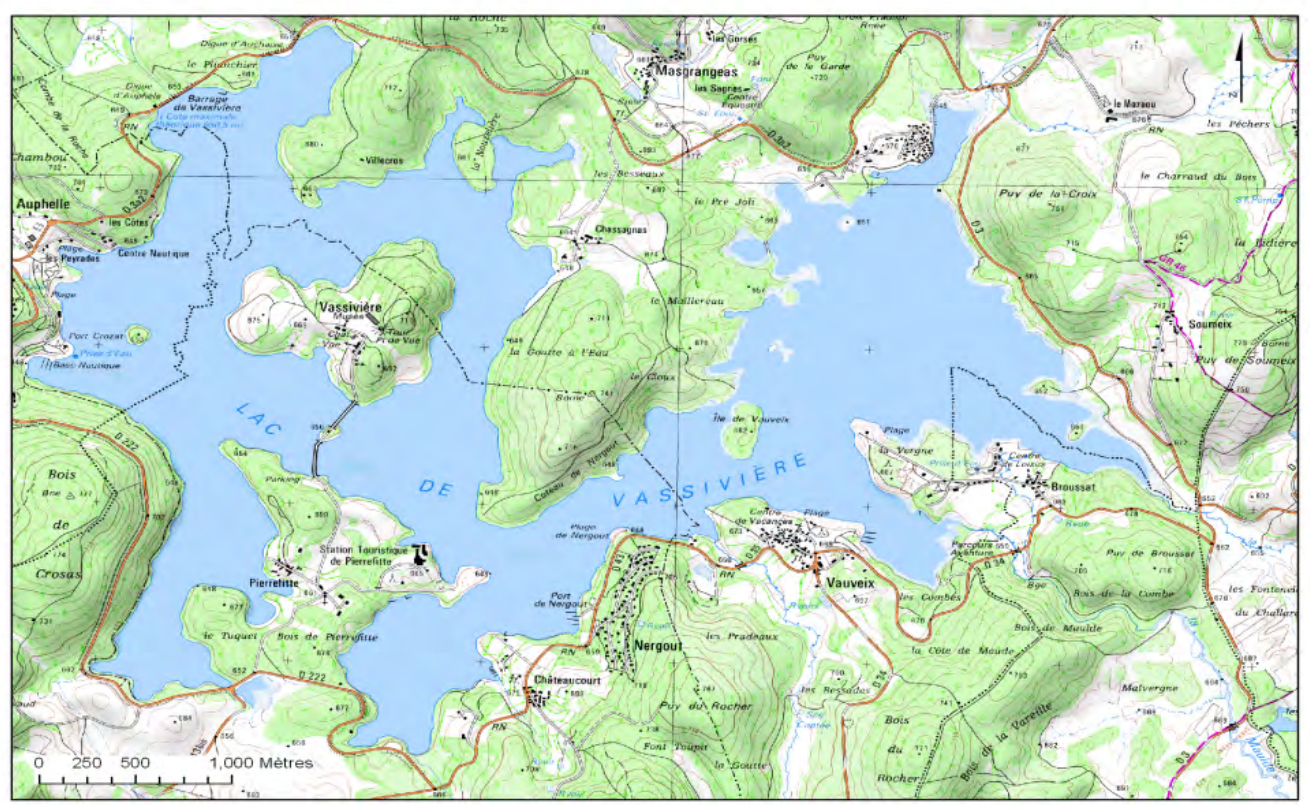

Figure 1: Localisation of Lake of Vassivière, France 
activities) in the area with an average visitor number of 70000 persons per year.

During summer, EDF have to maintain the lake level between $647 \mathrm{~m}$ and $650 \mathrm{~m}$ in order to guarantee the possibility of nautical activities and the operation of taxi boats, used in order to minimize car traffic around the lake. To face low water levels (the minimum envisioned lake level is $643 \mathrm{~m}$ ) due to climatic changes and to guarantee a minimum flow in the Vienne valley, an accurate bathymetric map is required in order to plan lake infrastructure modifications (ports, channels).

\subsection{Hydrographic instructions}

Hydrographic and topographic instructions were given by EDF and the Vassivière Lake authorities. The main objective of the project was to produce a full coverage high resolution map of the Vassivière Lake. Instructions given by EDF included the survey of specific areas for infrastructures monitoring and navigation purposes. A total coverage at Order 1 (S44 , OHI standards) was done for bathymetric chart and volume computations, and for infrastructures monitoring and navigation purposes, a total coverage at Special Order was conducted. One of the objective was to check for any problems or obstacles to navigation that may exist in case of low rating operation of the reservoir at $643 \mathrm{~m}$. The TPU (Total Propagated Uncertainty) imposed by EDF was $15 \mathrm{~cm}$ for a 95\% confidence level and a gridded DTM with cellsize of $1 \mathrm{~m}$ for navigation areas and $0,5 \mathrm{~m}$ for infrastructures areas (dam, outflow).

\section{3} Fieldwork organization

During the twelve days of the training, the students were divided into five subgroups, all tasked to perform both bathymetric and topographic survey works. The lake was divided into four survey areas, each area being divided in five subareas, planned to be covered in 2,5 days. During fieldwork, each group had to manage in order to overcome each of the tasks of bathymetry, surveying and data processing. The presence of such a large number of students has maximized the productivity and the data control during the fieldwork. All the data acquired were compared to control points to ensure data accuracy which is a major contribution to hydrographers education.

During the first week of the project, students were assigned to reach a high level of productivity in land surveying. They had to find a way of using the equipment that was allocated (total stations, GPS, TLS) in order to get the most relevant land survey information : data for control points with the 2D laser scanner, data for beach modeling, profiles, etc. Every day, the students had to report the density of topometric point that had surveyed and their quality estimation (Figure 2).

\section{$2.4 \quad$ Staff organization}

The role of the staff was limited to provide technical assistance for topographic measurement tools, for bathymetric work supervision, for data processing and for coordination of geodetic work. All teams had to manage independently and also had to make daily
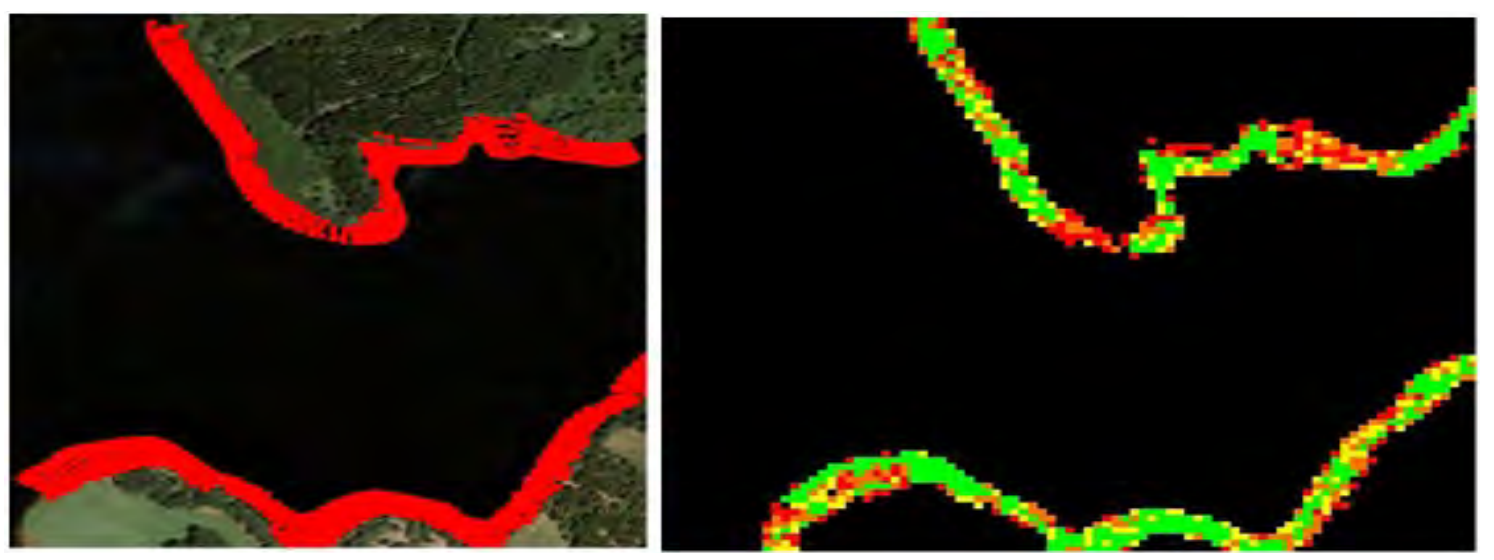

Figure 2: Example of temporal evolution of topometric point density 
reports to the staff. Moreover, the staff managed to give a series of lectures on specialized topics.

\section{PROJECT RESULTS}

\subsection{Geodesy and positioning}

Before the camp, all the benchmarks located around the lake were examined by the staff of the ENSTA Bretagne. Several positioning methods have been used:

- The TERIA permanent RTK network (with limited accuracy due to the fact that the closest base station of the French permanent geodetic network is located $40 \mathrm{~km}$ away from Vassivière), which requires GSM (Global System for Mobile Communications) communication;

- Two base stations installed by students using TERIA RTK averaging;

- Angle and distance measurements by total stations.

The coherence of all position measurements was the first activity planned for the students. Students had the opportunity to study from an experimental point of view the performances of each system to be used during the survey. For the project, three vertical reference systems were considered:

1. GRS80, ellipsoidal heights provided by GPS measurements;

2. IGN69, normal heights (altimetric French official system);

3. NGF-Lallemand, orthometric (old French official system) used by EDF.

The grid RAF09 defining the transformation between GRS 80 and IGN69 were used, as the geoid elevation varies of about $20 \mathrm{~cm}$ from one side of the lake to the other.

Students were tasked to create and make 3D adjustments of a local geodetic network of ten reference points, referenced from a IGN geodetic points, measured by total stations, and compensated by using a 3D least-square adjustment software.

\subsection{Topo-bathymetry surveys}

Before starting the camp, a particular attention has been undertaken in the calibration of the MBES (Multi-Beam Echo-Sounder), the VML (Vessel Mounted LiDAR) and their Inertial Measurement Unit (IMU) to know precisely the boresight angles and lever arms between the various sensors. A special attention was devoted to the minimization of the TPU through very accurate instrument calibration.

The calibration of the VML/IMU was made in laboratory on a sphere scanned from several points of view in order to replicate the movements of roll, pitch and heading. Before the calibration, the VML and the IMU were installed on a permanent mounted bracket. The assembly remains the same for the

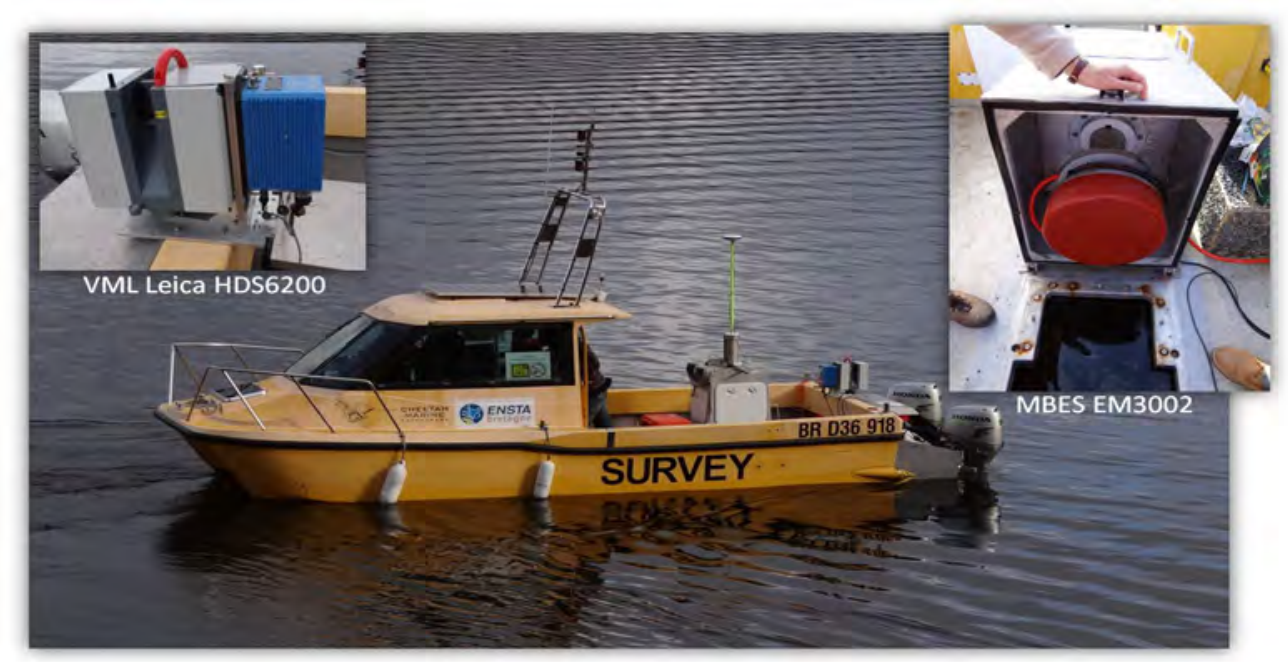

Figure 3: Topobathymetric works 
transport of the instrument and when mounted on the boat. For calibration of the MBES, a patch test was conducted on the lake a few days before the beginning of the fieldwork.

To perform the topo-bathymetry surveys, the ENSTA Bretagne team had deployed their catamaran.

The boat has a capacity of five persons on board including three workstations. One workstation was to control the sonar, the other for the VML and the last for the quality control in real-time. The boat was equipped with a MBES Kongsberg EM3002, from Boskalis, a VML Leica HDS6200 and a sidescan sonar (Figure 3). Mounted on a survey vessel, each component of the integrated system was coupled with an IMU (Ocatns 4 from IxSea). Robust georeferencing and motion compensation enable the production of precise map of the lake from a combination of MBES and VML equipments.

For the land part of the fieldwork, students had access to several devices such as GPS, total stations and TLS (Figure 3).

\subsection{Data post-processing}

All VML and MBES data has been acquired by using the QPS/Qinsy software. Data were exported in xtf file format for processing under CARIS HIPS and SIPS. The main data post-processing tasks were to identify the presence of sound velocity profile problems, of wrong positioning data due to GPS multipaths and wrong soundings due to soft sediments. Quality checks, object detection, georeferencing of obstructions, data cleaning have been also performed under the CARIS HIPS/SIPS environment.

\section{$3.4 \quad \underline{\text { Infrastructure surveys }}$}

An important part of the project was devoted to the dam and to the outflow inspection surveys. For these tasks, the staff imposed a TPU of $5 \mathrm{~cm}$. The infrastructures were surveyed with the VML and compared to a set of control points (Figure 5). TLS scans have also been performed, for the sake of comparison with VML data.

\subsection{Chart production}

After the project, the students were tasked to create a nautical chart of the lake by using the CARIS S-57 Composer. They designed a chart devoted to safety of navigation, considering the importance of traffic on the lake during the summer. The result is a 1/10 000 compilation scale chart, referenced to the vertical datum 646m (IGN69). Coastline was determined by using VML data and topographic data. Obstructions have been identified in order to design safe isobaths.

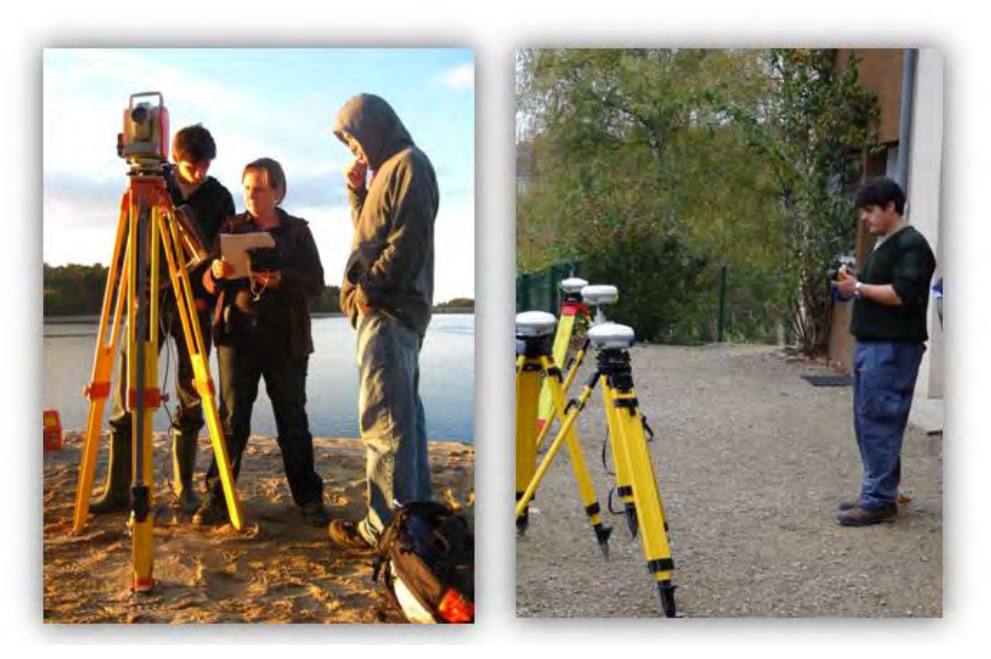

Figure 4: Land surveying works 


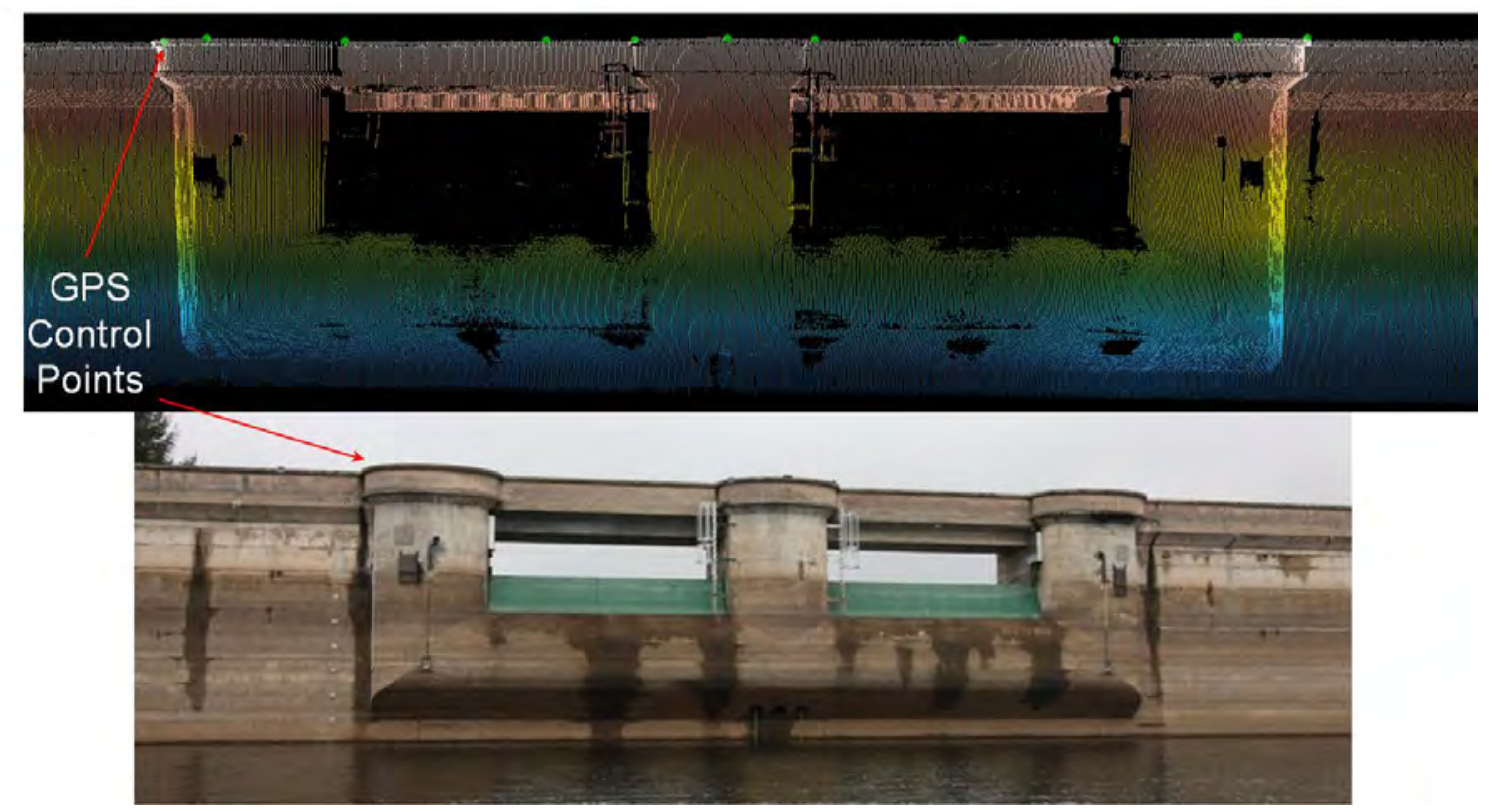

Figure 5: 3D view of the Vassivière dam, obtained from VML datasets

\section{DISCUSSION}

\subsection{Interest of international cooperation}

The added value of an international cooperation for such a large survey training project lies in:

- The usage of a wide variety of equipment provided by the participating institutes;

- Student work in international teams, in an unknown location;

- The possibility of a large scale project, motivated by the industry (EDF);

- A multidisciplinary team from several countries which allows us to plan a wide variety of fieldworks and post-processing activities.

\subsection{Interest of the project for the industry}

Due to the size of the project, its outcomes are subject to client approbation, therefore the industry contributes to student work evaluation. Our project has been sponsored by the Royal Boskalis Westminster company. They provided equipment

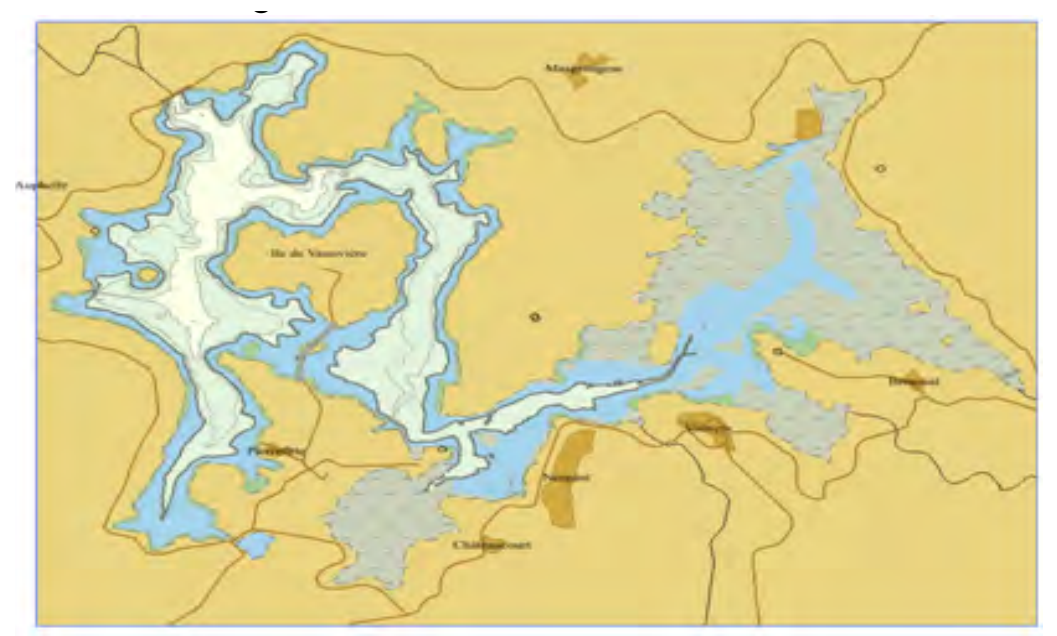

Figure 6 : Nautical chart of Vassivière Lake, France 
for the project, visited the project location, made a presentation of the industry needs and made a feedback evaluation after the project. The conclusions from this evaluation were very positive and a company as like Boskalis has a clear interest in such large scale projects that are organized at an international level.

\section{CONCLUSION}

International cooperation for the education of hydrographer's added value is very high for the students, the staff and the industry. Such a large project is quite difficult to set-up and coordinate but offers the possibility to address a variety of topics in surveying and post-processing. Moreover, it allowed students to use and compare different equipments. The level of autonomy of Master 2 level students increased and they were able to produce high quality results that will be used for the management of the Lake of Vassivière. Moreover, the amount of data that we got from the lake could be used to feed research projects and as a basis for another project in the same area. Indeed, the Lake of Vassivière offers an ideal environment for hydrographer's education.

Special Thanks to Boskalis (Sponsor of this project), CARIS, QPS for providing free software licences, and EDF for help and assistance during the project.

\section{REFERENCES}

[1] D. DODD, G. JOHNSTON, A. HOGGARTH. The Economic Impact of Appropriate Education in Hydrography, 7th FIG Regional Conf.; Hanoi, Vietnam, Oct 2009.

[2] V. BODER, D. EGGE. Hydrographic Education (Cat A) at the Newly founded Hafencity University, Hamburg (HCU).6th FIG Regional Conf.; San José, Costa-Rica, Nov 2007.

[3] D. EGGE. Education and Training in Hydrography --- Status and Perspectives. International Symposium on Application of Marine Geophysical Data and Undersea Feature Names, Seoul, Korea 2009.

[4] J. GREENFELD. Surveying Body of Knowledge, FIG Congress, Sydney, Australia 2010.
[5] N. SEUBE, N. DEBESE, R. MOITIE.

Hydrography at Master and IHO Cat-A Level at the ENSTA-Bretagne, International Hydrographic Review, May 2011.

\section{CONTACT DETAILS}

Nicolas Seube, Thomas Touzé, Nathalie Debese,

Rodéric Moitié, Irvin Probst

ENSTA Bretagne

2 rue François Verny

Brest

FRANCE

Tel. +33(0)298348888

Fax +33(0)2 98348846

Email: nicolas.seube@ensta-bretagne.fr

Web site: http://www.ensta-bretagne.fr

Maude Audet Morin

CIDCO

310, rue des Ursulines, C.P. 3300

Rimouski (Québec) G5L 3A1

CANADA

Tel. +1 4187251732 \#1722

Fax +1 4187241401

Email:maude.audet-morin@cido.ca

Web site: www.cidco.ca

Volker Böder

HafenCity University Hamburg (HCU)

Hebebrandtr. 1

D - 22296 Hamburg

GERMANY

Tel. +49 (0)40 428275393

Email: volker.boeder@hcu-hamburg.de

Alain De Wulf

Ghent University

Geomatic Engineering, Surveying

Departement of Geography

Krigslaan 281, S8

B-9000 Gent, BELGIUM

Telephone: +32477664983

Email: Alain.DeWulf@UGent.be

Web site: http://geoweb.ugent.be/data-acquisition-3d 
288 | Hydrol 2 


\section{Lowest Astronomical Tide in the North Sea derived from a vertically referenced shallow water model, and an assessment of its suggested sense of safety}

Cornelis SLOBBE and Roland KLEES, the Netherlands

Delft University of Technology

Martin VERLAAN, the Netherlands

Deltares

Leendert DORST, the Netherlands

Hydrographic Service of the Royal Netherlands Navy

Herman GERRITSEN, The Netherlands

Deltares

Topic: Vertical references

\section{INTRODUCTION}

Water level reduction with GNSS [FIG Commission 4 Working Group 4.2 2006, Dodd and Mills 2011] requires the availability of the ellipsoidal heights of CD, i.e. the Lowest Astronomical Tide (LAT) as adopted by the International Hydrographic Organization [International Hydrographic Organization, 2011, Technical Resolution 3/1919]. LAT is defined as the lowest tide level to occur under average meteorological conditions and under any combination of astronomical conditions. Ideally, the ellipsoidal heights of LAT are derived from the analysis of time series of observed water levels relative to a reference ellipsoid at tide gauges, GNSS buoys, or satellite radar altimeter crosstracks. Here, radar altimeter data are crucial in case one aims to derive an area covering surface, since only these data have a homogeneous spatial coverage. In shallow water, however, the limited temporal resolution of radar altimeter data does not allow to resolve all relevant tidal constituents. Hence, in order to obtain an accurate, area covering realization of the ellipsoidal heights of LAT in these waters, LAT values determined at tide gauge stations are complemented by LAT values derived from a shallow water tide model after adding the modeled LAT values to an altimetry-derived MSL model [e.g., Simon, 2001, Turner et al., 2010] including some interpolation procedure to bridge the gap between tide gauge stations and MSL data from satellite radar altimetry. Here, the MSL represents the water level under average meteorological conditions and is identified as the model's reference surface. This procedure, however, cannot be applied in coastal regions and estuaries, since these regions lack reliable radar altimeter data (i.e. information about MSL). Here we develop an alternative procedure for LAT realization in coastal waters that does not rely upon MSL data from satellite radar altimetry. The procedure will be used in the future to realize LAT in Dutch coastal waters, the Wadden Sea, and the Western and Eastern Scheldt estuaries.

In this study, LAT will be modeled relative to a geoid, after which the ellipsoidal heights of LAT will be obtained by adding geoid heights to the modeled LAT values. The use of a geoid instead of MSL has the advantage that the former can be realized everywhere and does not leave a gap along the coast as satellite radar altimetry does. Modeling LAT relative to a geoid is realized by i) the explicit modeling of the average meteorological and steric conditions as required by the definition of LAT and ii) referencing the hydrodynamic model to the chosen geoid. Another advantage of this approach is that it is conceptually consistent; unlike MSL, both the geoid and the model's reference surface are equipotential surfaces. Moreover, this approach allows for the inclusion of temporal variations in the definition of the average meteorological conditions. The latter reason follows from a precise interpretation of the LAT definition that the average meteorological conditions in spring and those in fall should be included separately.

For the user of LAT, its definition may suggest that instantaneous water levels will hardly drop 
below LAT. On the other hand, it is well-known that meteorological conditions have a significant influence on the water level in the North Sea.

Besides the issue of obtaining an accurate representation of the ellipsoidal heights of the LAT surface using hydrodynamic models, obtaining insight into the probability of a water level lower than LAT will be the other major topic of this paper. Similarly to Slobbe et al. [2012a], the model used in this study is the Dutch Continental Shelf Model version 5 (DCSM), which is a 2D tide-surge model that we extended to account for the horizontal variations in water density.

In this article, we will first introduce the extended DCSM 2D tide-surge model and describe the data sets used in the numerical experiments. Next, we will present and discuss the results of an experiment designed to investigate the capability of the hydrodynamic model to determine LAT relative to the geoid by including the average month-to-month variations in meteorological and steric conditions. Next, we will present the probability that the instantaneous water level drops below LAT, and propose a probabilistic method to realize a Chart Datum. Finally, we conclude by emphasizing the main findings and by some concluding remarks. A more extended analysis is presented in Slobbe et al. [2012b].

\section{EXTENDED DCSM MODEL AND DATA SETS}

In this study we will model LAT relative to the European Gravimetric Geoid 2008 (EGG08) [Denker et al., 2008], which is the state-of-theart geoid model for Europe. Furthermore, we will compute the probabilities that the instantaneous water level drop below LAT. In all our experiments, we will model the water levels with a time step of 10 minutes over the period January 1, 1984 to January 1, 2004.

\section{The extended Dutch Continental Shelf Model}

The numerical model used in this study is the extended Dutch continental shelf model (DCSM) described by Slobbe et al. [2012a] (the original DCSM model is described by Gerritsen et al. [1995], Verlaan et al. [2005]). DCSM was developed to make tide and surge forecasts over the full nodal cycle in order to support operational management of the Eastern Scheldt storm surge barrier. The model is based on the WAQUA software package [Leendertse, 1967, Stelling, 1984] for depthintegrated flow. WAQUA includes the non-linear surge-tide interaction and is based on the depthintegrated shallow water equations. DCSM covers the area of the northwest European continental shelf to at least the $200 \mathrm{~m}$ depth contour, i.e. $12^{\circ} \mathrm{W}$ to $13^{\circ} \mathrm{E}$ and $48^{\circ} \mathrm{N}$ to $62.3^{\circ} \mathrm{N}$, and has a horizontal resolution of $1 / 8^{\circ} \times 1 / 12^{\circ}$ (approximately $8 \times 9 \mathrm{~km}$ ) in longitude and latitude, respectively.

Although in the original model formulation the water density was assumed to be uniform, here we will allow for horizontal variations in water density. In the North Sea, these variations induce a 3D flow structure that cannot be handled by a $2 \mathrm{D}$ shallow water model. Hence, the water density is treated as a diagnostic variable computed from temperature and salinity values derived from a 3D hydrodynamic model using the international thermodynamic equation of seawater 2010 (TEOS-10) [IOC, SCOR and IAPSO, 2010]. In the model equations this contribution shows up by the depth-averaged baroclinic pressure gradient terms.

In order to obtain a unique solution of the equations, a set of boundary conditions is prescribed. Through closed boundaries, where neither inflow nor outflow can occur, the flow velocity normal to the boundary is set equal to zero. At the open sea boundaries, water levels are prescribed referring to the EGG08 geoid as discussed in detail in Slobbe et al. [2012a]. As shown by Slobbe et al. [2012a], in this way we obtain a model that provides water levels relative to the geoid. Note that in case water enters the model domain, the prescription of water level is supplemented by the condition that the velocity parallel to the open sea boundary is zero.

\section{$\underline{\text { Wind and Mean Sea Level pressure }}$}

As meteorological input data we used the publicly available data derived during the interim reanalysis project ERA-Interim, performed by the European Centre for Medium-Range Weather Forecasts (ECMWF). ERA-Interim covers the period from January 1, 1979 onwards and provides 3-hourly grids with a spatial resolution of $1.5^{\circ} \times 1.5^{\circ}$; the 
data are available from the ECMWF data server. For a description of the model, the data assimilation method, and the input data sets used in ERA-Interim we refer to Dee et al. [2011].

$\underline{\text { Monthly mean salinity, temperature and water levels }}$

Salinity and temperature fields used to compute the density variations and hence the depth-averaged baroclinic pressure gradients, are obtained from the Atlantic- European North West Shelf- Ocean Physics Hindcast performed by the Proudman Oceanographic Laboratory (POL), hereafter referred to as POL's hindcast [Holt et al., 2005]. This hindcast over 45 years (1960 - 2004) was performed with the Atlantic Margin Model, a coupled hydrodynamic-ecosystem model. Its hydrodynamics are supplied by the POL 3D baroclinic model (POL3DB) [Holt and James, 2001, Holt et al., 2001], which is part of the POL Coastal Ocean Modeling System, while the ecosystem component is supplied by the European Regional Seas Ecosystem Model [Blackford et al., 2004]. The model fully covers the northwest European continental shelf, its domain ranging from $20^{\circ} \mathrm{W}$ to $13^{\circ} \mathrm{E}$ and $40^{\circ} \mathrm{N}$ to $65^{\circ} \mathrm{N}$. The horizontal resolution is comparable to that of DCSM, $1 / 6^{\circ} \times 1 / 9^{\circ}$ in longitude and latitude, respectively. The model has 42 terrain-following coordinate levels in the vertical.

\section{MODELING LAT RELATIVE TO EGG08}

In this experiment LAT relative to EGG08 will be computed by forcing the model with astronomical tide and the average monthly variations in the meteorological forcing and steric forcing contributions. The LAT value per grid point is

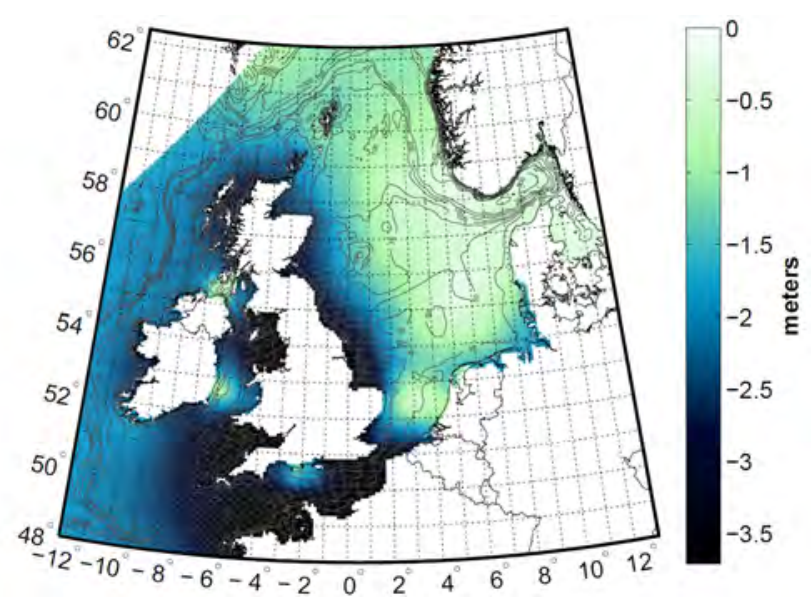

derived as the minimum modeled water level over the entire time series. The average monthly variations in the meteorological and steric contributions are computed by averaging for each calendar month, all available forcing fields over a period of 20 years (1984-2004). The obtained yearly time series have been used for the twenty year model run. In order to avoid jumps in the modeled water levels in the transition from month to month, the obtained time series are interpolated to 3-hourly values (the original temporal resolution of the meteo data) using a cubic spline interpolation. Here, we assigned the monthly means to the mid-epochs of each month. The meteorological and steric forcing contributions to the tidal water levels prescribed at the open sea boundaries are obtained in the same way as was used to derive the average monthly variations. For more details about the experimental setup we refer to Slobbe et al. [2012b].

The modeled LAT surface is shown in Fig. 1. Many of the features shown in this map are consistent with oceanographic expectations like coincidence of the locations where the modeled LAT values approaches zero with the well-known amphidromic system in the northwest European continental shelf. The minimum and maximum differences between the LAT surface obtained in this experiment and the one obtained using the original approach [Slobbe et al., 2012b, Experiment I] are -15.8 and $5.7 \mathrm{~cm}$, while the RMS is $5.5 \mathrm{~cm}$. The largest differences are observed west of the Danish coast.

\section{$\underline{\text { Validation }}$}

The obtained LAT surface is validated using LAT values at 92 onshore and 10 offshore tide gauges.

Figure 1: Lowest Astronomical Tide relative to EGG08 computed over the full simulation period January 1, 1984 January 1, 2004. The grey lines in the map show the contour lines of the bathymetry. The data will be made publicly available by the Hydrographic Service of the Royal Netherlands Navy. 
Between 95 and 103 constituents are estimated depending on the station. The length of the time series varies between 2.5 years and 20 years. The set of constituents used to derive the observed LAT values is that set for which the RMS of the differences between the observed water levels and the reconstructed astronomical tide is lowest. The obtained differences between observed and modeled LAT reveal a mixture of errors in both model and observations. In Slobbe et al. [2012b], we found that systematic errors in the representation of the tidal amplitude dominate. After correction for all known systematic differences, the average difference between observed and modeled LAT equals $-9.1 \mathrm{~cm}$ with minimum and maximum deviations of -53.6 and $15.1 \mathrm{~cm}$, respectively. Using the standard deviations of the differences between observed and modeled tidal minima, we performed a test to evaluate the statistical significance of these differences. For three stations, the observed differences are statistically significant at the $99 \%$ confidence level. These are located in the Irish Sea where DCSM representation is known to be lower than average. In Slobbe et al. [2012b], we also showed that the choice of the set of tidal constituents for each tide gauge has a significant influence on the estimated LAT value at this station. Whether the sets used in this study are a good choice is further investigated.

\section{THE SAFETY OF LAT AS A CHART DATUM ASSESSED}

Besides the fact that all predicted tidal water levels become positive in sign, another main motivation to use LAT as CD is that LAT provides an indication of the minimal water depth that can be expected under average meteorological conditions and hence provides a sense of safety. Indeed, any surface above LAT results in charted depths that are occasionally larger than the true depth, which might lead to a false sense of safety. However, it is well-known that meteorological conditions can result in water levels below LAT, especially in shallow waters. Hence, the sense of safety evoked by the use of LAT as $\mathrm{CD}$ is only justified in case the probability that the instantaneous water level drops below LAT is low.

In this study, the probabilities that the minimum instantaneous water levels in periods of tidal minima are below LAT are computed using time series of the modeled instantaneous water levels. In Slobbe et al. [2012b], we show that in the eastern part of the North Sea, these probabilities appear to be in the order of once per month to once per week. As could be expected, these probabilities are largest in winter, followed by spring, fall and summer. The probabilities in winter and summer differ, approximately, half an order of magnitude. The varying probability that the water level is below LAT motivated us to propose a CD definition as the probability that the actual water level falls below the defined level. Without attempting to prescribe how large the probability should be, we realized $\mathrm{CD}$ using this approach for different probabilities and quantified the differences to LAT. As shown in Slobbe et al. [2012b], even for a probability of once per year, the probabilistic CD would be below LAT by several decimeters.

\section{CONCLUSION}

In this paper, we have modeled the LAT surface relative to the European Gravimetric Geoid 2008 (EGG2008) using the extended and vertically referenced DCSM model. The data will be made publicly available by the Hydrographic Service of the Royal Netherlands Navy. In addition, we performed an assessment of the suggested sense of safety of the LAT Chart Datum.

A comparison of the obtained LAT surface with the one obtained using the original approach reveals significant large differences. The obtained differences between observed and modeled LAT reveal a mixture of errors in both model and observations. Significant improvements are expected when the successor of the DCSM version 5 model is used. DCSM version 6 provides a much better representation of the tide due to, amongst others, increased spatial resolution and incorporation of more physics.

From our experiment aimed to investigate whether the sense of safety evoked by using LAT as CD is justified, we conclude that this is not the case; in the eastern part of the North Sea we found that actual water level drops below LAT during periods of tidal minima once per month to once per week. The results suggest that a probabilistic CD definition

\section{2 | Hydrol 2}


better suits practical needs. Such a definition has the additional advantages that it offers an opportunity to realize $\mathrm{CD}$ unambiguously and is much easier to validate.

\section{REFERENCES}

Blackford, J., J. Allen, and F. Gilbert. Ecosystem dynamics at six contrasting sites: a generic modelling study. J. Marine Syst., 52(1-4):191215, 2004. ISSN 0924-7963. doi: 10.1016/j. jmarsys.2004.02.004.

Dee, D. P., S. M. Uppala, A. J. Simmons, P. Berrisford, P. Poli, S. Kobayashi, U. Andrae, M. A. Balmaseda, G. Balsamo, P. Bauer, P. Bechtold, A. C. M. Beljaars, L. van de Berg, J. Bidlot, N. Bormann, C. Delsol, R. Dragani, M. Fuentes, A. J. Geer, L. Haimberger, S. B. Healy, H. Hersbach, E. V. Hólm, L. Isaksen, P. Kållberg, M. Köhler, M. Matricardi, A. P. McNally, B. M. Monge-Sanz, J.-J. Morcrette, B.-K. Park, C. Peubey, P. de Rosnay, C. Tavolato, J.-N. Thépaut, and F. Vitart. The ERAInterim reanalysis: configuration and performance of the data assimilation system. QJ Roy. Meteor. Soc., 137(656):553-597, 2011. ISSN 1477-870X. doi: 10.1002/qj.828.

Denker, H., J.-P. Barriot, R. Barzaghi, D. Fairhead, R. Forsberg, J. Ihde, A. Kenyeres, U. Marti, M. Sarrailh, and I. Tziavos. The Development of the European Gravimetric Geoid Model EGG07. In F. Sans 'o and M. G. Sideris, editors, Observing our Changing Earth, volume 133 of International Association of Geodesy Symposia, pages 177-185. Springer Berlin Heidelberg, 2008. ISBN 978-3-54085426-5. doi: 10.1007/978-3-540-85426-5 21.

Dodd, D. and J. Mills. Ellipsoidally referenced surveys: issues and solutions. Int. Hydrogr. Rev., (6):19-29, 2011.

FIG Commission 4 Working Group 4.2. FIG Guide on the Development of a Vertical Reference Surface for Hydrography. Technical Report 37, The International Federation of Surveyors (FIG), Frederiksberg, Denmark, 2006.

Gerritsen, H., H. de Vries, and M. Philippart. The Dutch Continental Shelf Model. In D. R. Lynch and C. N. K. Mooers, editors, Quantitative Skill
Assessment for Coastal Ocean Models, Coastal Estuarine Stud., volume 47, pages 425-467. AGU, Washington, D. C., 1995.

Holt, J. T., and I. D. James. An s coordinate density evolving model of the northwest European continental shelf, 1, Model description and density structure. J. Geophys. Res., 106:14015-14034, 2001. doi: 10.1029/2000JC000304.

Holt, J. T., I. D. James, and J. E. Jones. An s coordinate density evolving model of the northwest European continental shelf, 2, Seasonal currents and tides. J. Geophys. Res., 106:14035-14054, 2001. doi: 10.1029/2000JC000303.

Holt, J. T., J. I. Allen, R. Proctor, and F. Gilbert. Error quantification of a high-resolution coupled hydrodynamic ecosystem coastal ocean model: Part 1 model overview and assessment of the hydrodynamics. J. Marine Syst., 57(1-2):167188, 2005. ISSN 0924-7963. doi: 10.1016/j. jmarsys.2005.04.008.

International Hydrographic Organization.

Resolutions of the International Hydrographic Organization. available at www.iho.int, 2011b. Publication M-3, 2nd ed., 2010, Updated to August 2011.

IOC, SCOR and IAPSO. The international thermodynamic equation of seawater - 2010: Calculation and use of thermodynamic properties, 2010. Intergovernmental Oceanographic Commission, Manuals and Guides No. 56, UNESCO (English), 196 pp. Available online at: http://www. teos-10.org/pubs/TEOS-10_Manual. pdf (accessed September 29, 2011).

Leendertse, J. J. Aspects of a Computational Model for Long-period Water-wave Propagation. Rand Corporation, Santa Monica, 1967.

Slobbe, D.C., M. Verlaan, R. Klees, and H. Gerritsen. Obtaining instantaneous water levels relative to a geoid with a $2 \mathrm{D}$ storm surge model. Submitted, 2012a.

Slobbe, D.C., R. Klees, M. Verlaan, L.L. Dorst, and H. Gerritsen. Lowest Astronomical Tide in the North Sea derived from a vertically referenced shallow 
water model, and an assessment of its suggested sense of safety. Submitted to Marine Geodesy, $2012 b$.

Simon. B., Niveaux caractéristiques et coefficient de marée: calcul direct à l'aide des constantes harmoniques, volume 2 of Rapport d'étude - Service hydrographique et océanographique de la marine. Service hydrographique et océanographique de la marine, Paris, FRANCE, 2001.

G. S. Stelling. On the construction of computational methods for shallow water flow problems. $\mathrm{PhD}$ thesis, Delft University of Technology, Delft, 1984. Rijkswaterstaat Communications 35.

J. F. Turner, J. C. Iliffe, M. K. Ziebart, C. Wilson, and K. J. Horsburgh. Interpolation of Tidal Levels in the Coastal Zone for the Creation of a Hydrographic Datum. J. Atmos. Ocean. Tech., 27:605-613, 2010. doi: 10.1175/2009JTECHO645.1.

M. Verlaan, A. Zijderveld, H. de Vries, and J. Kroos. Operational storm surge forecasting in the Netherlands: developments in the last decade. Philos. Trans. Royal Soc. Math. Phys. Eng. Sci., 363:1441-1453, 2005. doi: 10.1098/rsta.2005.1578.

\section{BIOGRAPHIES}

Cornelis Slobbe is a Dutch Geodetic Engineer from the Delft University of Technology. He currently works at a PhD-project at Delft University of Technology that aims to develop a procedure that enables to derive a consistent set of vertical reference frames. He also participates in the EU Interregion IVB project BLAST.

Martin Verlaan studied applied mathematics at the University of Twente and obtained his $\mathrm{PhD}$ at Delft University in 1997 on the topic of data-assimilation for storm surge forecasting. He is currently working at Deltares and TU Delft. His research interests are data-assimilation and operational forecasting of sealevel and waves. He is involved in the EU research projects: Jerico, MyWave and Sangoma. During storms he works for the Storm Surge Warning Service in the Netherlands (SVSD).

Leendert Dorst is a Dutch Geodetic Engineer from the Delft University of Technology. He is employed at the Netherlands Hydrographic Service as Head of the Department Geodesy \& Tides. In 2009, he obtained a $\mathrm{PhD}$ degree from the University of Twente, on the estimation of sea floor dynamics using time series of bathymetric surveys, to improve the resurvey policy of the Netherlands.

Herman Gerritsen studied applied mathematics at the University of Twente and obtained his $\mathrm{PhD}$ at Twente in 1982 on the topic of accurate boundary forcing in tidal flow modeling. He is currently working at Deltares. His research interests are data-assimilation and methodologies for quality assessment of numerical models and their use.

\section{CONTACT DETAILS}

D.C. Slobbe (Delft University of Technology)

PO Box 5048, Delft, The Netherlands

Tel.: +31 15 2784543, Email: D.C.Slobbe@tudelft.nl 


\section{THE SBW FIELD MEASUREMENT PROGRAM}

Bart SPELT and Herman PETERS, the Netherlands

Rijkswaterstaat

Ivo WENNEKER, the Netherlands

Deltares

Magiel HANSEN, Andre JANSEN, Hans MIEDEMA, Peter VERBURGH, Albert HUISMAN, Paul

KRAMER, Marco PETERS, Arjen PONGER, the Netherlands

Rijkswaterstaat

Topics: Accurate hydrodynamics, Hydrography in the Benelux

\section{INTRODUCTION}

The safety of the Dutch primary water defences must be assessed every six years for the required level of flood protection. In this assessment, Hydraulic Boundary Conditions (HBC) in the form of extreme water levels and wave conditions are required. They are based on wind, waves and water levels measured in open water, extrapolated to extreme conditions, followed by the transformation of the estimated extreme wave conditions from open water towards the shallow areas near the water defence structures using the SWAN spectral wave model.

Validation material for SWAN is obtained in a dedicated SBW (Strength and Loading of Water Defences) field measurement program in the Netherlands, which carries out field measurements during each storm season in the following three areas:

- Dutch Wadden Sea: a complex area enclosed by a series of barrier islands and the Dutch mainland coast, featuring ebb tidal deltas, tidal channels and shallow tidal flats.

- Petten coastal area: a bathymetric profile typical for the open Dutch coast, starting offshore (> $20 \mathrm{~m}$ deep) and gently sloping, including some sand banks, towards the dike.

- Lake IJssel: a large $\left(20\right.$ x $\left.60 \mathrm{~km}^{2}\right)$ and relatively shallow ( $4 \mathrm{~m}$ deep) lake.

The information requests from research studies determine the strategy of the campaign, which gives researchers an explicit chance of gaining complete data sets for model evaluation and development. Waves are measured using buoys and wave measuring instruments installed on measuring poles. In addition, the essential SWAN input quantities (seabed topography, water level, wind and currents) are measured as well. The use of X-band radars to obtain spatial wave, current and depth data is under investigation in the Wadden Sea. The three SBW measurement sites combined have been evolving over the past 10 years or so into one of the largest campaigns in Europe for high-quality on-line measurements of physical parameters such as waves, winds and water levels.

This paper aims to give a short overview of the SBW field measurement programme. The background and goals of the measurements are explained. Furthermore, the paper gives insight in the layout of the three measurement sites (which instruments are employed where and why), the experience acquired with the instrumentation and the site logistics, and how the data is processed and disseminated.

\section{BACKGROUND AND GOAL OF THE MEASUREMENTS}

Water defence structures protect the Netherlands from flooding from the North Sea, the major rivers and the large inland lakes. The Dutch Water Act ('Waterwet, 2009') stipulates that these primary water defence structures must be assessed once every six years with regard to their statutory prescribed level of safety for representative extreme water levels and waves. For the coastal regions the representative wave conditions in deep water (with an occurrence probability of once in a few thousand years) required for this assessment are estimated on the basis of wave statistics derived from measurements over the last 30 years at five 
permanent wave measuring stations in deep water. These estimated extreme wave conditions offshore are then transformed from deep to shallow water near the water defence structure using the SWAN spectral wave model. On the inland lakes the wave growth is fetch-limited in storm situations. Therefore main emphasis there is on calibrating the wave model for short fetch conditions. It is essential that SWAN accurately reproduces the essential physical processes so that reliable extreme wave conditions (that we will probably never encounter in our short measuring programs of only a few decades) can be calculated near the water defences. Reference is made to Groeneweg \& Van Dongeren (2002) and Hoekstra \& Hoitink (2002), who already dealt extensively with the relevant parameters for the wave processes under investigation.

Consequently the main purpose of the field measurement campaign is to produce data that can be used to check the validity and robustness of the SWAN wave model under relatively mild to stormy conditions in order to gain trust in its usefulness under very extreme, not yet encountered situations. Current focus is on wave measurements during storm conditions, because in such conditions waves are the parameter with the highest uncertainty. In addition, until recently hardly any wave data were available in certain areas like e.g. the Wadden Sea. Consequently, in the field measurements main emphasis has been on the processes of wave growth, propagation and dissipation. It is also necessary to monitor near the water defence structures several other hydraulic and meteorological parameters required for issuing reliable HBC. For, in the unlikely event that SWAN should produce substandard wave predictions, such measurements could provide valuable short term statistics of storm conditions occurring near the defence structures. In addition to the above mentioned measurements devoted to the HBC, specific instruments have been installed at the Petten dike to measure wave run-up and wave overtopping on the dike. The data acquired with these instruments are helpful for better assessing the strength of such a dike under extreme conditions.

All the above mentioned measurements are carried out within the framework of the SBW program set up by Rijkswaterstaat (a division of the Dutch Ministry of Infrastructure and Environment) specifically to fill any remaining knowledge gaps in the areas of HBC and of failure mechanisms of water defence structures.

\section{INFORMATION REQUIREMENTS}

In general, water levels are monitored on a routine basis at a large number of stations and, when combined with the hydraulic WAQUA or Delft3D model, they are believed to be adequate for estimating the extreme water levels. Wind information is a very important parameter for reliable wave hindcast studies. Thus more wind measuring locations were needed in addition to the already existing stations, because an inventory has shown that the existing (predominantly landbased) wind measuring stations gave in the areas of interest insufficient spatial coverage and were also not representative enough for the wind field over open water. Therefore, it has been decided to install several new semi-permanent wind measuring stations (conform KNMI quality standards) in open water. Furthermore, it is investigated whether additional current information can contribute to an improvement of the HBC. This applies not only to the current-wave interaction process as modelled in SWAN, but also to the calibration and validation of the WAQUA model. In most cases, current vector profiles over the water column are needed. In addition to local point current measurements, there is also a need for measured current maps with the perspective of supplying complete spatial coverage of the area. For the moment, however, it is decided to limit the current measurements to a few point measurements. For reliable wave calculations accurate and up-to-date information about the bottom topography is necessary. Since ship borne depth sounding and airborne laser altimetry campaigns are very accurate, yet also time consuming and costly, a lot of effort has been devoted to optimizing these campaigns.

\section{MEASURING STRATEGY AND TECHNIQUES}

A large number of wave buoys is deployed in the Wadden Sea and at Petten and, because these buoys are very flexible in their deployment position and can also become operational quite readily and quickly. Given the very small water depth no wave buoys are deployed in the large inland lakes, but measuring poles are used. They are (considering 
their structural strength, continuous power supply and on-line telemetry to a land-based receiving station) universal measuring platforms and thus well suited to serve as (semi-)permanent measuring platforms, especially because we are mainly concerned with measuring (wave) events in extreme weather conditions. Such poles can be equipped with a suite of sensors, like e.g. radar level sensors, step gauges, current meters, wind sensors etc. and are thus very well suited to measure (simultaneously and at the same location) a large number of important hydraulic and meteorological parameters, like e.g. water level, current, wind, air pressure etc. This enables us to put the measured wave processes in a broader physical perspective. Contrary to anchored buoys the wave sensors on a pole can measure the water level and the very low frequency wave energy (e.g. surf beat and seiches), which are also very interesting under storm conditions. However, the measuring instruments are often bothered by water droplets in the air (e.g. the capacitive and resistive gauges, the radar level sensors etc.) and sometimes by air bubbles in the water (e.g. all under water acoustic sensors like ADCP's). This holds especially for the near shore measuring poles at Petten, where wave breaking occurs. Moreover, the accuracy and the ability to measure short waves is deteriorated for underwater wave sensors (e.g. current and pressure sensors) by the attenuation of the wave orbital kinematics signal with depth.

\section{REGIONAL MEASUREMENT PROGRAMS}

\subsection{Wadden Sea}

In the Wadden Sea area the emphasis is on following the waves from the deep North Sea via the tidal inlets between the islands to the shallow water near the sea defence structures, primarily to validate and (if necessary) to improve the wave model SWAN in such a complex area.

The SBW measurement program in the Wadden Sea started in 2003. The measurement strategy was developed based on a priori SWAN model hindcasts, field knowledge and expert judgement. The general information requirements for the model had to be matched with possible wave measurement

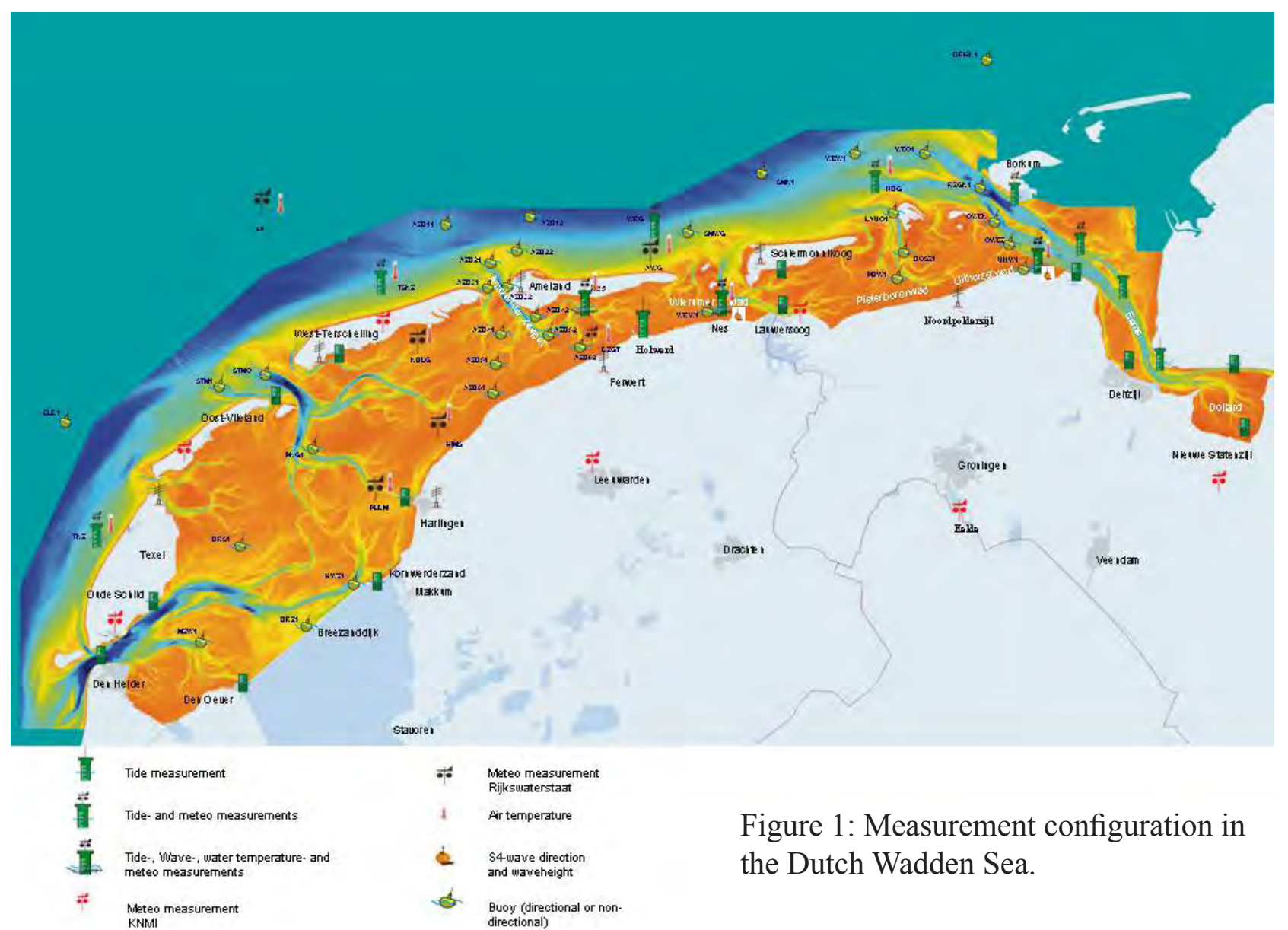



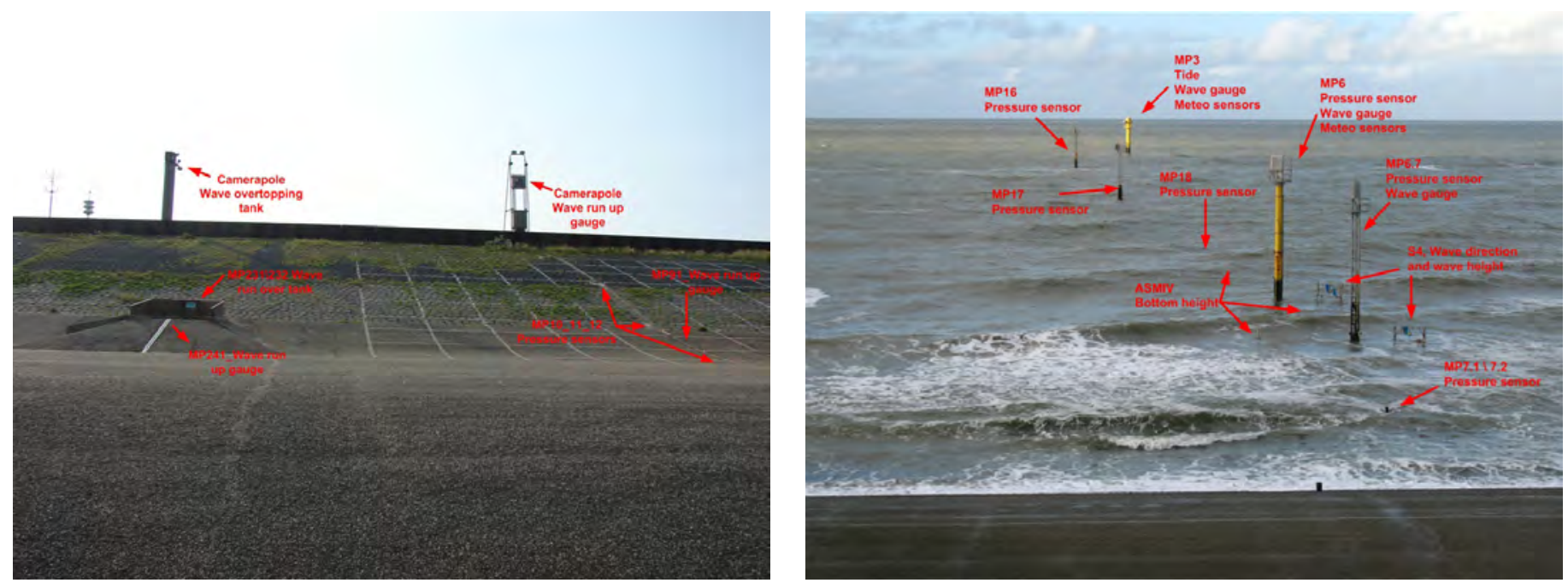

Figure 2: Measurement configuration in the Petten transect (left, a) and on the dike (right, b).

methods and available measurement locations. Reference is made to Zijderveld and Peters (2008). At the moment the wave-measuring configuration in the Wadden Sea is mainly confined to a rather large number (about 25) of wave measuring (non-) directional Wave riders buoys. These buoys were spread out inside as well as outside the Wadden Sea area in such a way that a rather good spatial coverage over the entire Wadden Sea area is accomplished. A number of buoy locations were chosen to provide information of the wave conditions as close as possible to the dikes (e.g. at the Afsluitdijk at the border of Lake IJssel). The buoys in the two transects at the Ameland tidal inlet yield information about the wave penetration through the inlet, both in the channels and over the tidal shoals. Nine buoys perform wave measurements in the eastern part of the Wadden Sea near the Groningen coast, while five additional buoys were deployed in the Western Wadden Sea to measure wave conditions there.

In addition, in the summer of 2008, three long-term measuring poles became operational; one south of Ameland (Nes), the second in front of the Frisian coast (Wierumerwad) and the third (Uithuizerwad) in front of the Groningen coast. The poles are measuring a suite of parameters such as waves, wind, water level and current. They were planned near the dike in order to measure the short-term (10 years or so) wave statistics and thus to estimate the credibility of the (with SWAN) calculated wave conditions near the sea defence using a couple of mild to severe storms. Furthermore, four additional poles were installed at Pollendam, Kimstergat,
Dantziggat and Noorderbalgen specifically for wind measurements. Also, wind sensors were placed on several already existing poles belonging to the National Water Monitoring Network ('Landelijk Meetnet Water' or LMW).

\subsection{Measurement programme at the Petten sea dike.}

The measurement campaign (since 1995) at Petten is devoted to measuring the $\mathrm{HBC}$ at a specific site along the Holland coastline. This is accomplished by a number of measuring stations (poles and buoys) in a transect (see Figure 2a) more or less perpendicular to the dike. Note that the two buoys are too far (resp. 3 and $8 \mathrm{~km}$ offshore) from the coast to be seen in Figure 2a. In addition, since 2007, the Petten measuring site is also equiped to measure the process of wave run-up and wave overtopping on the sea dike by using several dedicated sensors installed in or on the Petten sea dike itself. This can be seen in the right panel (b) of Figure 2. For the purpose of relating the measured run-up and overtopping to the incoming wave height instead of the total wave height, special measures have been taken for measuring the wave reflection coefficient in the transect using electromagnetic current sensors.

\subsection{Measurement programme in Lake IJssel and Lake Marken.}

Since 2005, in the large inland lakes IJssel and Marken measurement poles are measuring waves, but also a lot of other parameters like wind and water level. As discussed, this is done in order to establish a reasonable estimate of the HBC in such 


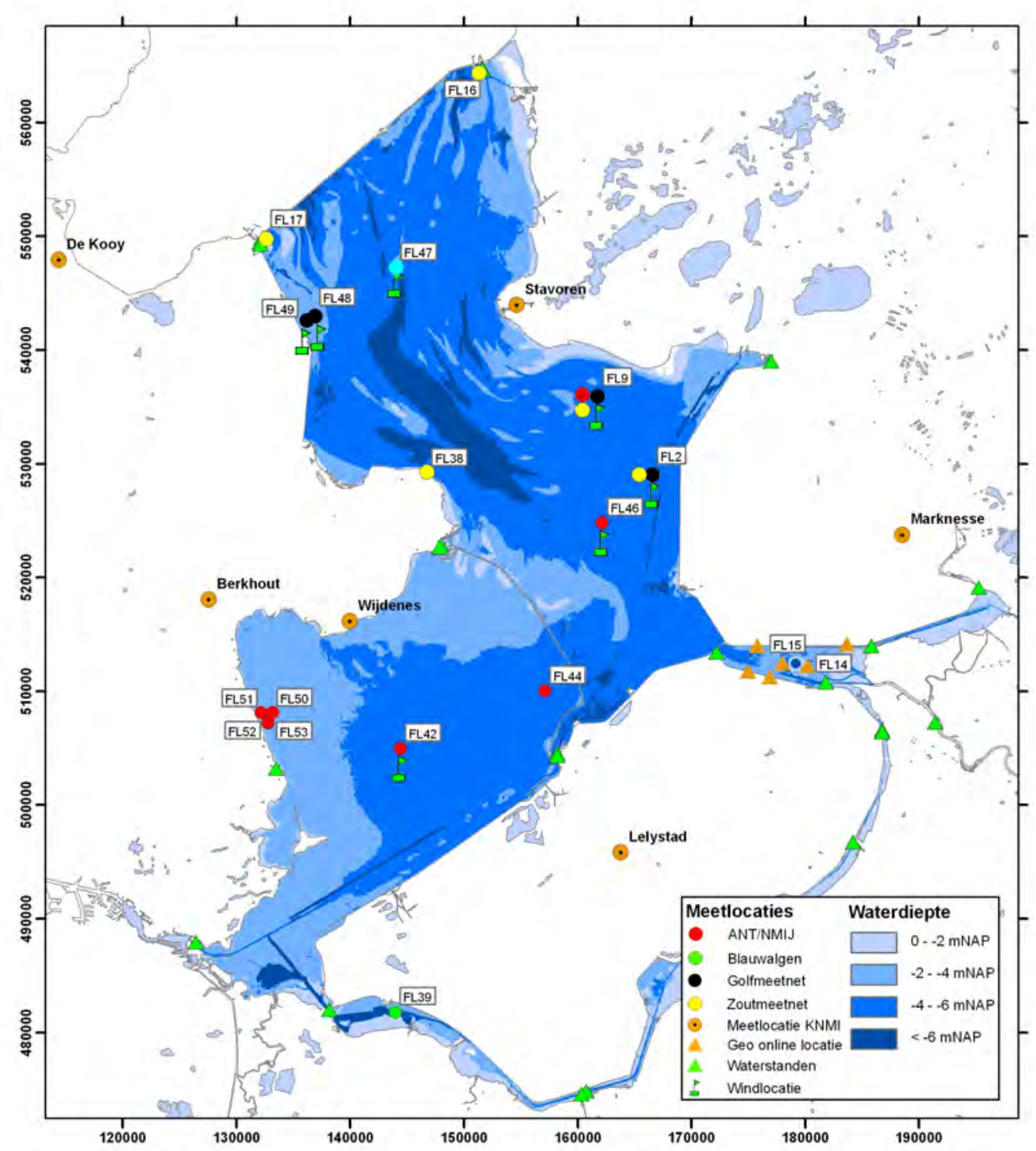

Figure 3: Measurement configuration in Lake IJssel and Lake Marken.

confined and shallow lakes. Note that the fetch in lakes is much smaller than at the sea sites of Petten and the Wadden Sea. On these lakes an efficient measurement configuration has been created by combining the poles for the HBC with other poles installed for the ANT (Autonome Neerwaartse Trends) and NMIJ (Natuurlijk Markermeer/IJmeer) projects. Moreover, some of the poles have an operational purpose (like FL2 for ship guidance) as well. Due to their small size and weight the poles can be placed and removed easily, which is advantageous when the measuring locations have to be altered or when the poles have to be removed in the winter before an emerging period of frost in order to prevent possible damage by moving ice packages.

\section{DATA MANAGEMENT}

All the data (from poles and buoys) is transmitted by radio links in real time to a few land-based receiving stations and from there to a few central computer stations. There the wave data is processed in time and frequency domain with the so-called SWAP (Standard Wave Analysis Package) software module belonging to the central processing systems of the National Water Monitoring Network or (in a kind of stand-alone configuration) with the socalled WAVES package, that was originally only intended to process the Petten wave data. All the other hydrological and meteorological data are processed there as well. With automatic validation algorithms the data are checked for possible outliers and staggers. Moreover, a visual check is performed 
on a regular basis with respect to the time series and the calculated parameters e.g. wind speed and wave spectra. Thus a quality control system exists in the form of a procedure for sensor status surveillance and data validation. For validating the important wave parameters use is made of the so-called WAVIX neural network, which (after a preliminary learning stage using a reliable initial data set) has managed to establish robust relations between the wave parameters at neighbouring measurement stations and the local wind conditions. In case of data loss the operational measuring and information divisions of Rijkswaterstaat are contacted with the request to repair the malfunctioning equipment (measuring sensors and/or data communication links) as soon as possible. Thus downtime of the measurement site is minimized. Immediately after an interesting storm an extraction is made from the database of relevant storm data. These data are combined in a so-called storm report. Furthermore, monthly reports (describing the overall data availability) are generated on a regular basis and finally encompassed in a storm season report. After the monitoring and validation steps the validated wave and other data is stored in the Rijkswaterstaat national data base DONAR. This thoroughly backed-up data base guarantees the integrity of all the measurement data.

\section{FUTURE DEVELOPMENTS}

Unfortunately the measuring site at Petten will vanish within a few years, because a major sand supply is envisaged for this part of the Dutch coast. However, if the information requirement for such data persists, we should look for an alternative site, which could in due course deliver comparable data. It is now foreseen that the wave measurement programme in the Wadden Sea will include more measurement locations in the Eems-Dollard estuary. This area can encounter very high water levels in severe storms, such as November 1st, 2006. Another interesting aspect is that in 2009 a software package has been connected to the microwave marine traffic surveillance radar on the Ameland lighthouse. This SeaDarQ software package has shown promising results in displaying wave patterns, current fields and bottom features, see Gautier et al. (2012). Such remote sensing techniques are envisaged to image the spatial wave and current fields in specific areas of the Wadden Sea. Furthermore, the possibility exists that a new measuring site will be created in the Western Scheldt in the South-western part of the Netherlands.

On the long term the whole SBW measurement campaign will be transformed into a monitoring campaign, to fulfil the information need of several stakeholders. One of the stakeholders is the Dutch Storm Surge Warning Department (SVSD) that is responsible for accurate storm surge warnings for the coastal areas. It is planned to include wave information in these warnings in the future.

\section{REFERENCES}

Gautier, C., H. Peters and J. van Heesen (2012). "Hydrodynamic data from radar observations", Hydro12.

Groeneweg, J. and A. van Dongeren. 2002, "Campaign Wadden Sea, Module: What to measure", Delft Hydraulics report H4174 d.d. October 2002.

Hoekstra, P. and T. Hoitink. 2002, “Design measuring campaign wave conditions Wadden Sea, Module: where to measure", IMAU report R 02-01, d.d. November 2002.

Zijderveld, A. and H. Peters. 2008, "Measurement programme Dutch Wadden Sea”, ICCE 2008. 


\title{
Deep Water Dredging and Maintenance in the Offshore Industry
}

\author{
Ellen STUIFBERGEN MSc, the Netherlands \\ RESON B.V.
}

Topics: Innovations in acquisition techniques, Subsea positioning, Cost-effective solutions

\section{INTRODUCTION}

The demand for high accuracy operations and positioning in bathymetric surveys is a current requirement in deep water dredging and construction projects. It is expected to become even more important in the future.

Removal and relocation of soil at depths as deep as $2,500 \mathrm{~m}$ is a challenge. Reef Subsea Dredging \& Excavation, formerly known as Scanmudring located in Norway, is involved in deep water projects. Their deep water hydraulic excavator is especially designed for those projects.

Operated from the vessel the excavator crawls its way over the seabed. The excavator removes soil and places soil around the legs of rigs with high precision. It is also used to maintain offshore facilities or to tear down the object in an environmental safe way.

Depth and required accuracy puts a lot of strain on both the subsea equipment and the operator.

Reef Subsea Dredging \& Excavation requested RESON to assist in the development of the monitoring system.

Since this excavator is operated and controlled from the surface, it is very important that the operator monitors the system in real time and can trust the visualized information. Furthermore the software has to be intuitive and easy to use.

This paper describes the challenges of deep water operations and the different tools used to make high accuracy deep water dredging and construction a reality. The system has been operational since February 2012 when the first sea trials proved successful.

\section{VARIETY OF UNDERWATER OPERATIONS}

The Deep Water Excavator is used for a variety of underwater operations: Seabed preparation, material removal, trench dredging, soil removal from templates, pipes or other objects. The realisation of the project is complex as objects in the work area should not be damaged during dredging / construction operation. Damage could result in costly repairs or environmental damage.

A stable platform is a requirement for accurate operations. Standing on the seafloor the system has a high stability and can be used for precise handling of equipment and objects. For this reason the excavator is equipped with different sensors making accurate operation in deep water possible.

\section{POSITIONING OF THE EXCAVATOR}

High accuracy is not only important in shallow water bathymetric surveys, but also in deep water dredging and construction. It is expected to become even more important in the future as more work is carried out in deeper waters. Challenges at deep water are obviously the water depth, but also the accuracy required at that depth. This is of course, not only a challenge for the equipment and dredge tools, but also for the positioning and monitoring software and the operator. The operator is at the surface and he will fully rely on the information that is visualized through the monitoring software.

In this case RESON software PDS2000 is used to monitor the system operations. An USBL positioning system is used for the initial excavator positioning during the descent and touch down. USBL positioning accuracy has improved a lot in the last decade, but still not always accurate or stable enough to perform the operations at the high accuracy required. So once the excavator is near its operation location, the excavator position is recomputed using known reference points on the seabed. This provides a better position than the USBL position alone. This new recomputed position will then be used in the software as a fixed reference position. 
Various sensors are placed on the excavator to monitor changes in the position and height of the excavator. The excavator is equipped with accurate inclino sensors. The sensors are used to measure the excavator's boom, stick and bucket angles. Both inclinometer size and accuracy are equally important. RESON has carried out performance tests of different inclinometer brands to be able to supply the most suitable sensor. Other sensors as depth sensor, height sensors, roll/pitch and heading sensors complete the sensor configuration.

\section{MONITORING THE OPERATION}

The positioning sensors together with PDS2000 software and additional tools such as SeaBat Forward Looking systems and Multibeam Echosounders are used to monitor and improve accuracy of deep water operations.

The various sensors monitor height, roll and pitch of the excavator. These values are important to the operator, because they are an indication of the system stability. For example a weak seabed may cause the excavator to shift / tilt and reposition of the excavator may be required. The operator will see the position change in the $2 \mathrm{D}$ and $3 \mathrm{D}$ views. Additionally alarms can be generated when a sensor passes a certain threshold value.

As Figure 1 shows the software visualizes objects on the seabed as 3D shapes in the $3 \mathrm{D}$ view and in the topview. Alarms will be generated when the excavator is too close to one or more of the objects. Alarms can vary from a general warning to a signal which is generated that stops the excavator immediately to avoid collision.

An inspection ROV can also be used to monitor the excavator activities. To visualise and monitor both the ROV and excavator in the same 3D view, the ROV can simply be added to the PDS2000 configuration. Figure 2 shows both the excavator and $\mathrm{ROV}$ in the same $3 \mathrm{D}$ view.

When visibility is good the camera on the excavator is used, but when visibility degrades the operator will have to rely on the Forward Looking Sonar

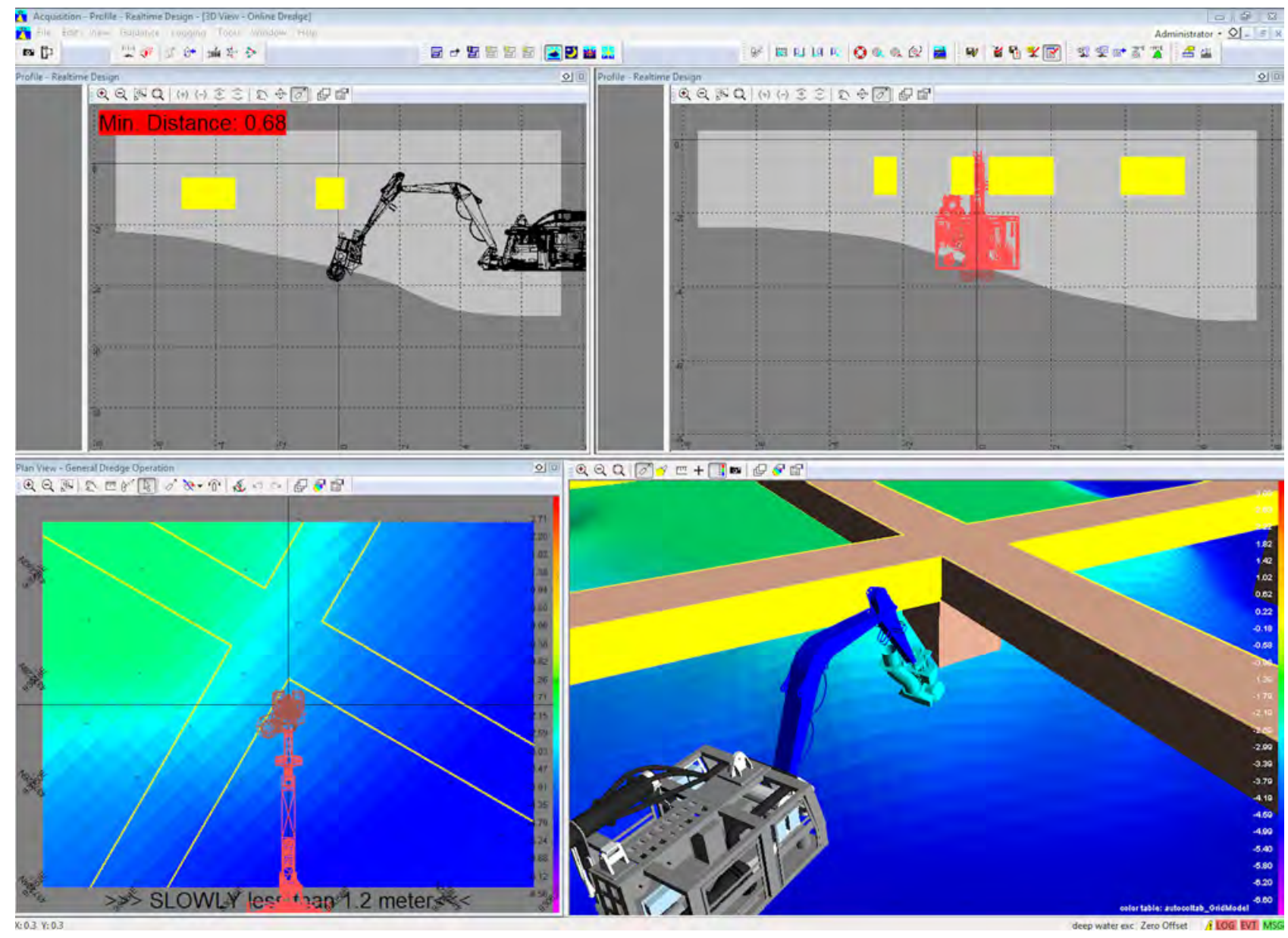

Figure 1. Simplified example of object avoidance 


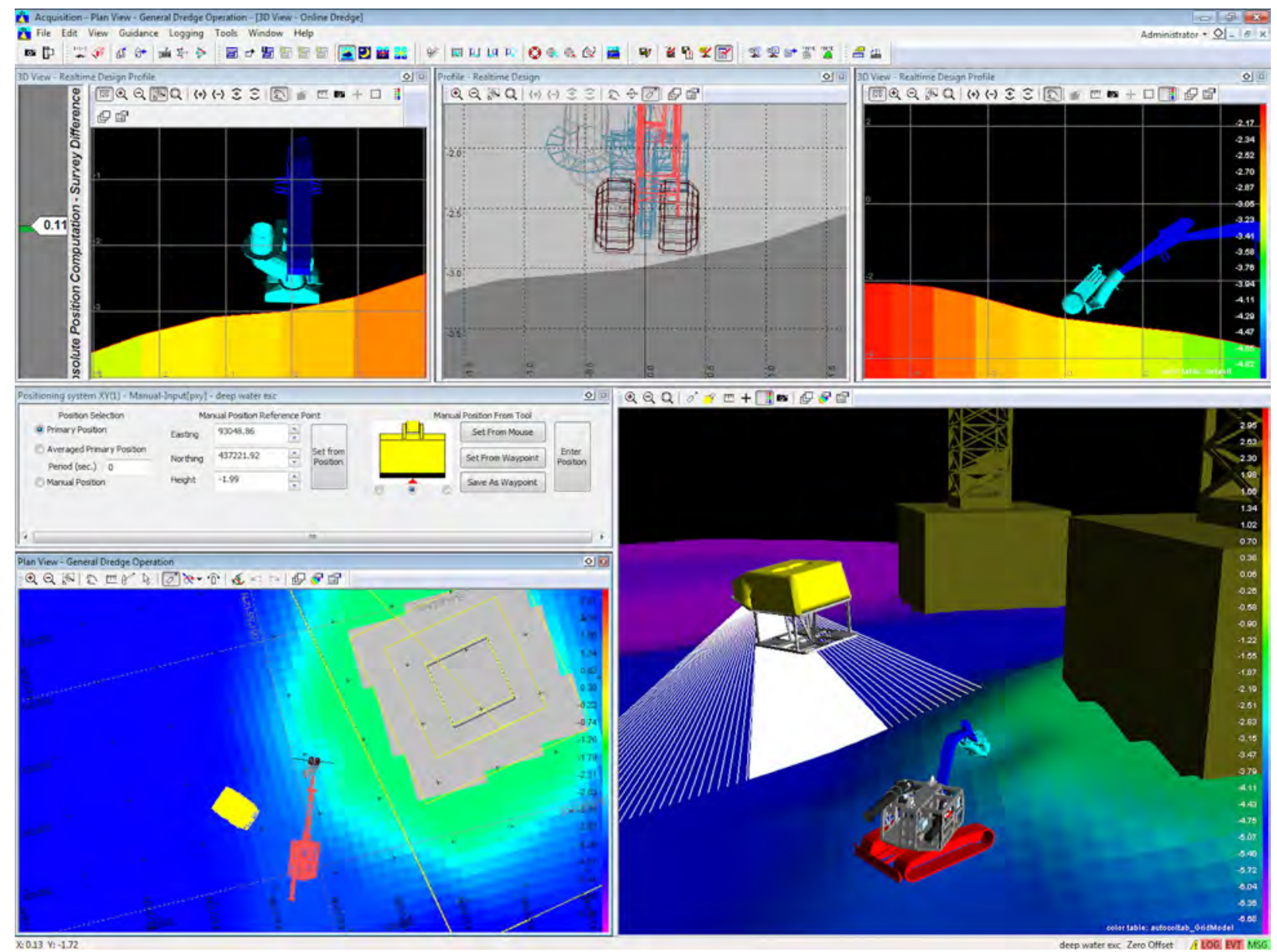

Figure 2. Excavator and ROV

(FLS) and PDS2000 monitoring software. The forward looking sonar SeaBat 7128 shows the details of the seafloor and objects in high resolution (Figure 3 and 4) The FLS image will also show the excavator tool movements and thus helps the operator in poor visibility situations.
During dredge operation PDS2000 monitors and updates the dredge progress in an As-Dredged gridmodel using the information of the sensors installed on crawler and excavator. A multibeam survey can be carried out during or after dredge activities to verify the work carried out. The multibeam data is used to update the As-Dredged Gridmodel

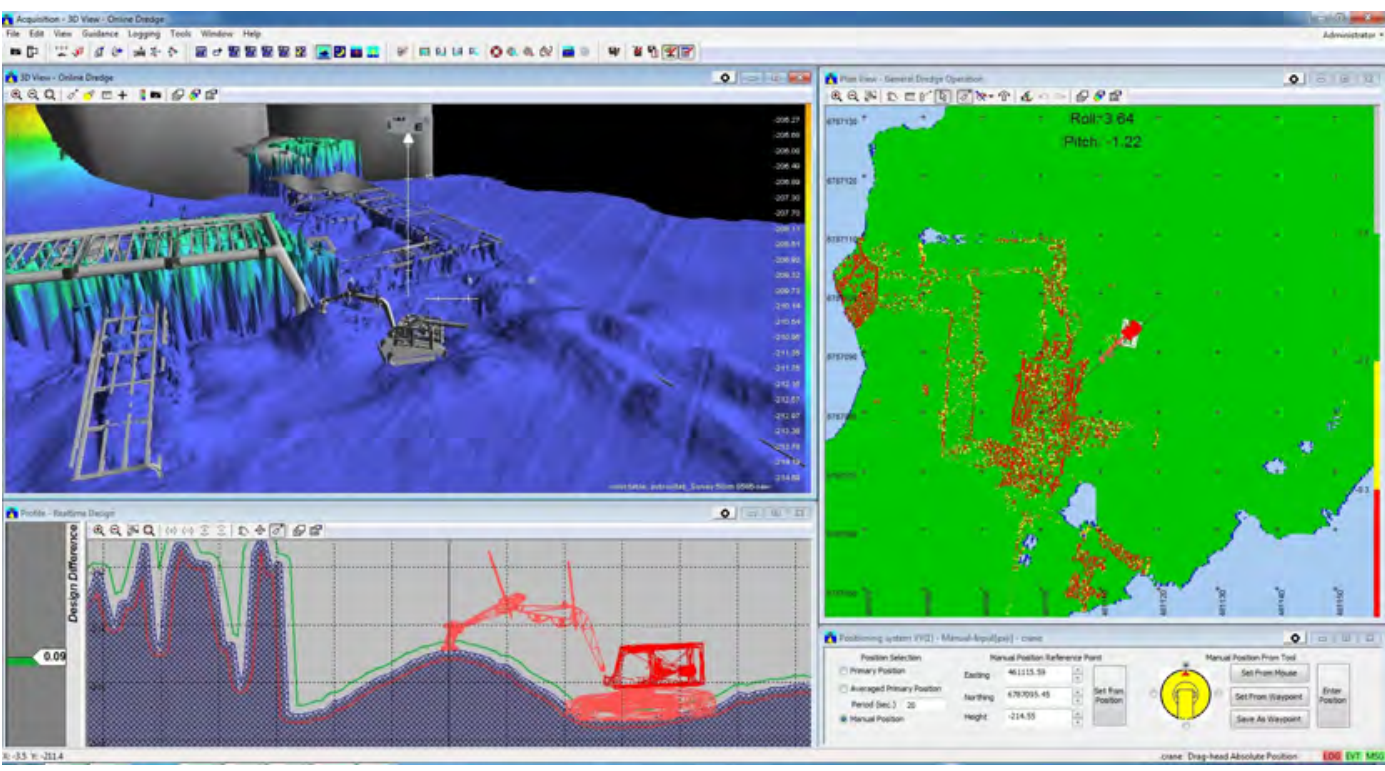

Figure 3. Excavator in operation at a depth of $240 \mathrm{~m}$ 


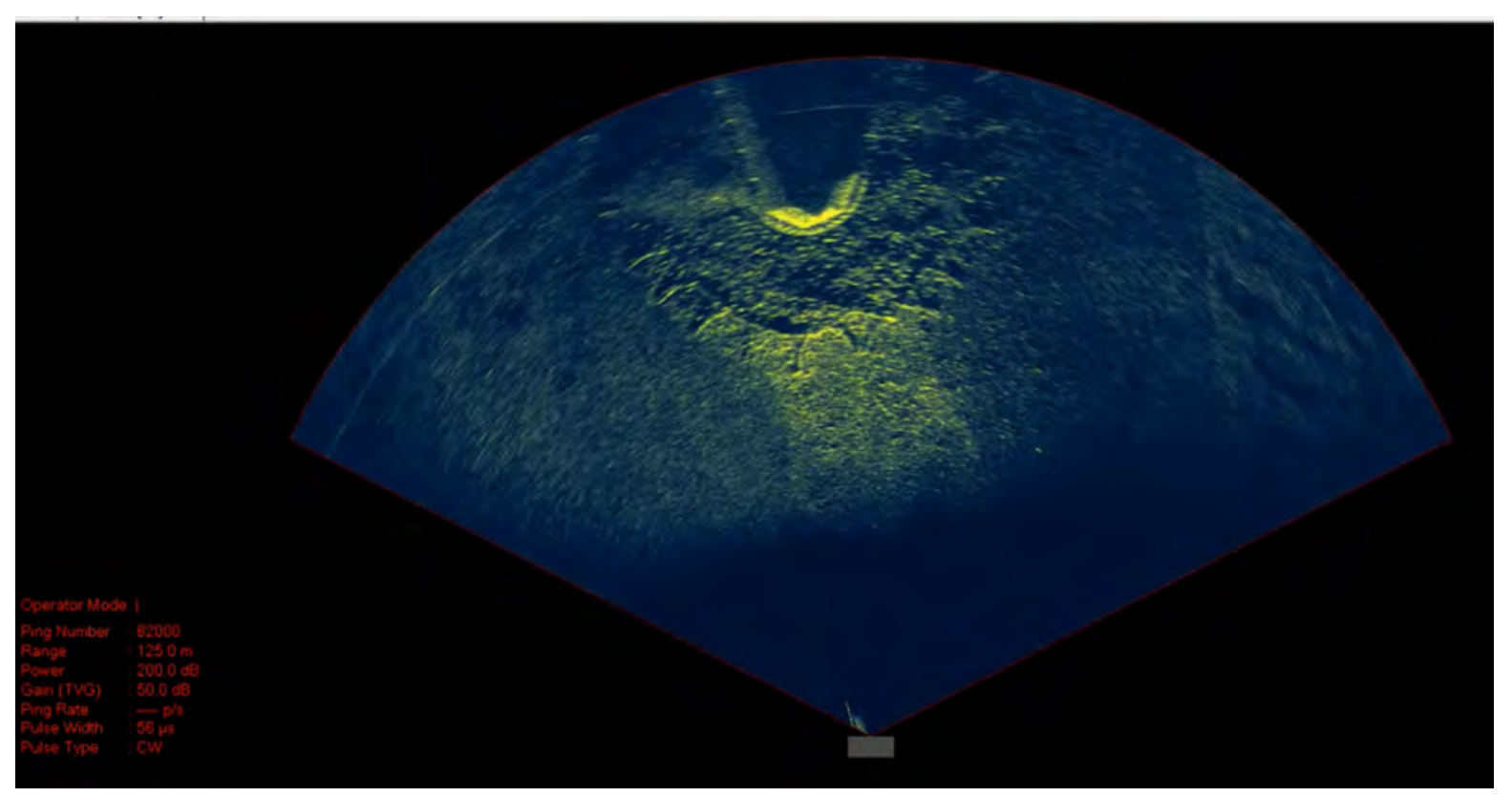

Figure 4. Forward looking SeaBat 7128 at a pillar at a range of $125 \mathrm{~m}$. (400 Khz)

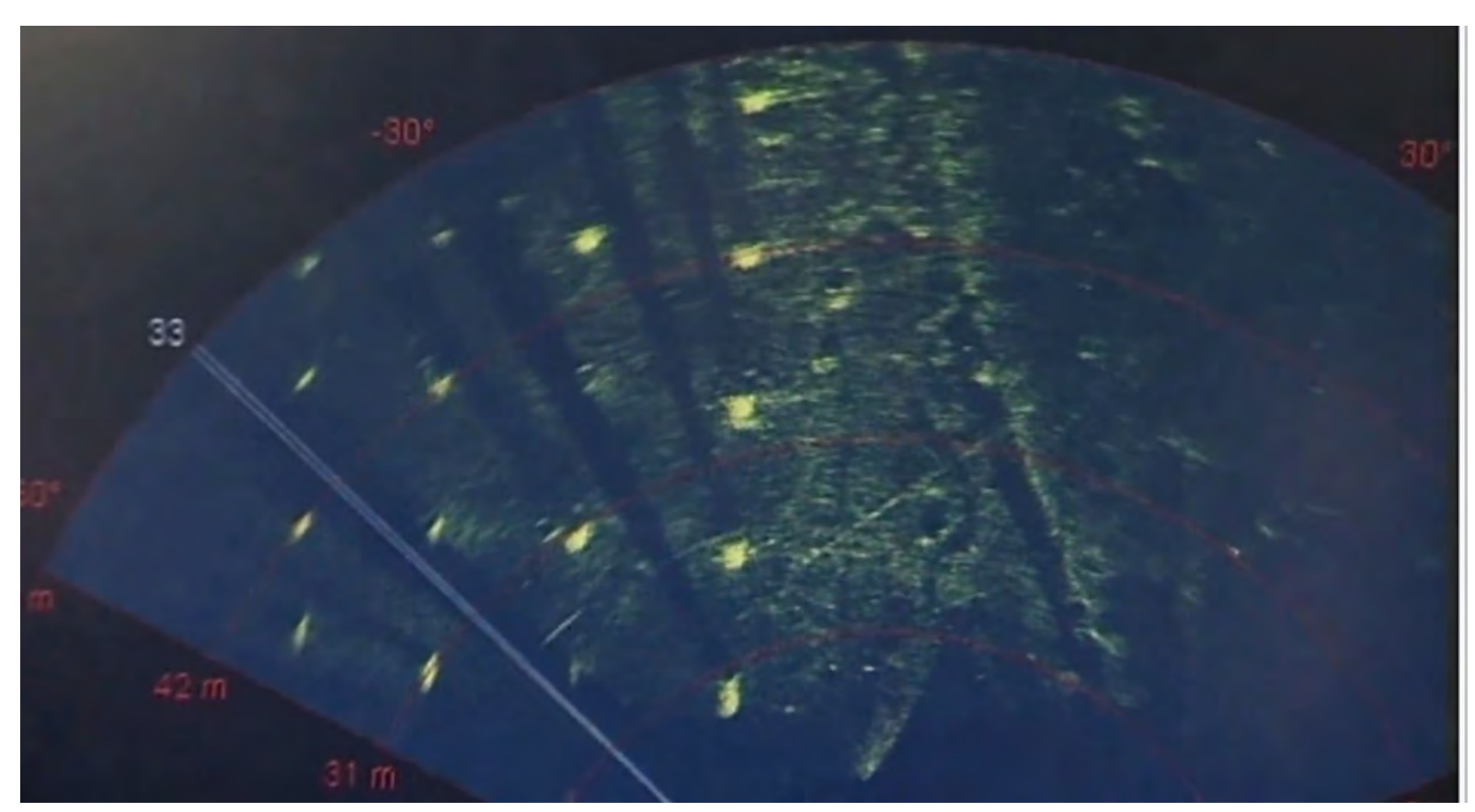

Figure 5. SeaBat 7128 forward looking at piles at a distance of $50 \mathrm{~m} .(400 \mathrm{Khz})$

It is also possible to monitor the dredging operation while dredging. Figures 6 and 7 show these results.

\section{CONCLUSION}

The demand for high accuracy information in deep water dredge and construction projects is very important and will become even more important in the future. The use of monitoring software with different sensors, such as USBL, inclinometers and the use of existing known positions on the seabed, allows work to be carried out quickly and safely. This is thanks to the real time excavator visualization in $2 \mathrm{D}$ and $3 \mathrm{D}$ views. User configurable alarms provide an extra level of security. Acoustic imaging systems such as FLS help the operator in poor visibility conditions and multibeam echosounders provide verification during and after the dredge operation.

The combination of different sensors, acoustic positioning systems and reliable monitoring software makes it possible to achieve and work with higher accuracy in deep water.

\section{4 | Hydrol 2}



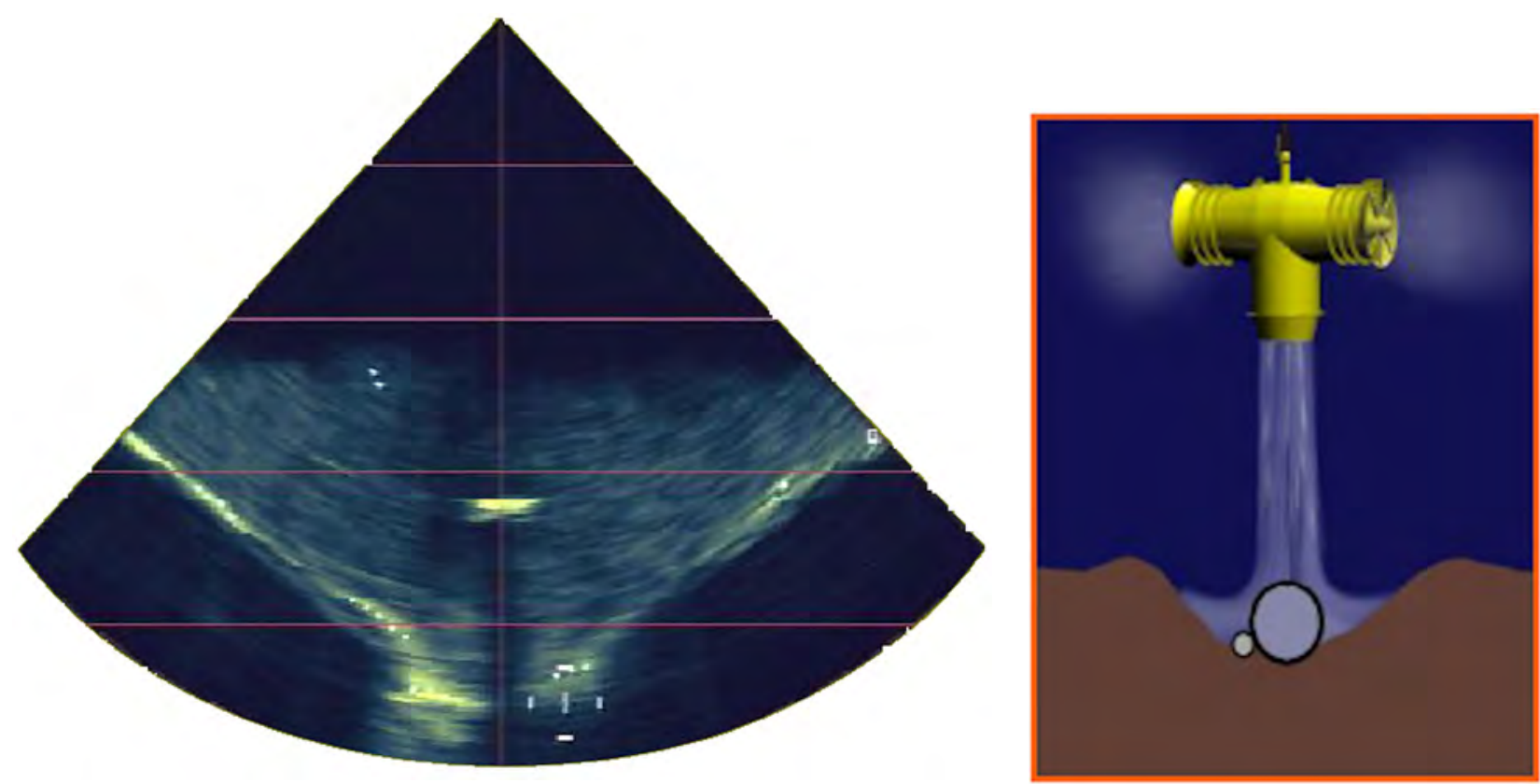

Figure 6. Monitoring the dredge activities with a Multibeam FLS system

\section{BIOGRAPHIES}

Ellen Stuifbergen, Sales Manager Software Systems at RESON B.V.

Started as geodetic surveyor at NeSA, a RACAL Company in 1993 and graduated as MSc Geodesy at the Technical University in Delft.

RESON is manufacturer of SeaBat Multibeam and Forward Looking Systems as well as the Software PDS2000. Next to that RESON also manufactures and supplies sensors to measure the movements of the various dredge tools. A combination of these tools are used to improve the monitoring of the deep water operations as well as the accuracy of the operation.

\section{CONTACT DETAILS}

Ellen Stuifbergen

RESON B.V.

Stuttgartstraat 42-44

3047 AS Rotterdam

The Netherlands

Tel.: +31 102451500

Fax: + 31102451555

Email: ellen.stuifbergen@reson.com

Web site: www.reson.com

Twitter account: @PDS2000
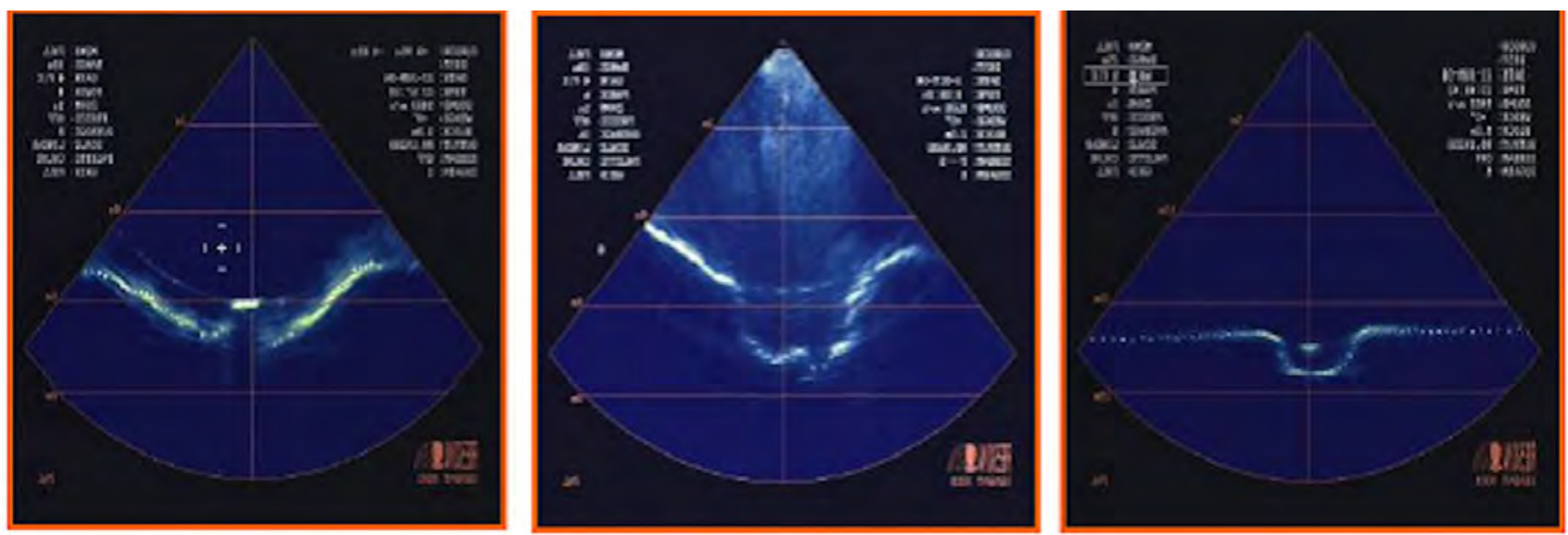

Figure 7. Monitoring the dredge activities with a Multibeam FLS system 
306 | Hydrol 2 


\section{Degrees of success: Meeting professional standards through distance e-learning}

Richard THAIN and Anthony JENKS, United Kingdom

Hydrographic Academy, Plymouth University

Andrew McNEILL, United Kingdom

Fugro

Don VENTURA, United States of America

Fugro-Pelagos Inc.

Topic: The hydrographic profession

\section{INTRODUCTION}

Higher education programmes for those wishing to enter the hydrographic surveying profession are generally available on an attendance basis at a limited selection of academic institutions. The number of places available on such courses is not sufficient to satisfy demand from the offshore industry, with the result that there has been a particular shortage of appropriately qualified personnel in the hydrographic survey, positioning and inspection fields. Shell's Chief Surveyor recognised this fact in an article in the trade press in April 2008, in which he expressed the industry's concern over the "current shortage and future supply of qualified, experienced and competent surveyors, which does represent a 'pinch-point' for the UK oil and gas industry" (Whitcombe, 2008).

By the nature of the work involved, the offshore hydrographic survey industry workforce is deployed frequently for extended periods in remote locations, often at sea aboard ships. Despite advances in technology, communications bandwidth is very expensive and thus usually limited to operational transmissions. There is very little opportunity for individuals to access the internet through a broadband connection on a regular basis, and sporadic plain text emails, and occasional satellite phone calls are all that are normally available. In this high-value, short-staffed industry, it is not normally viable for companies to release their personnel for, say, 12 months for full-time study to gain a postgraduate qualification and appropriate professional body recognition. Workforce development for the offshore hydrographic survey industry is, therefore, a challenge, and even the largest survey and geomatics companies have very few opportunities to engage with the higher education sector.

Plymouth University (School of Marine Science and Engineering), Fugro and the Royal Navy's Hydrographic School at FOST HM ${ }^{1}$ formed a working partnership to address the issues outlined above, with Fugro acting as 'industry advisers' and the Royal Navy agreeing to provide advice and assistance as required; especially useful as they already run recognised and accredited courses for working professionals. Funding was provided initially through the UK government, in the form of a grant from the South West Spoke of the National HE STEM $^{2}$ programme, and The Hydrographic Academy (HA) project commenced formally from January 2011.

\section{METHODS}

Distance e-learning is well established as an effective method of delivery of teaching and learning materials in higher education. Examples are numerous, and include the offerings from the UK Open University, and the Royal Veterinary College's MSc programme. This report does not aim to give a comprehensive review of the literature relating to the design and provision of distance and

${ }^{1}$ Flag Officer Sea Training, Hydrography and Meteorology

${ }^{2}$ Higher Education, Science Technology Engineering Mathematics 
e-learning, however, some of the key teaching and learning considerations relating to the design of the Hydrographic Academy's e-learning environment and course materials are as follows (adapted from Porter, 2004):

- To facilitate an individual's learning

- To bring together students from diverse locations, with individual interests, skills and needs to form learning communities

- To state expectations clearly

- To set and maintain rigorous academic standards, and communicate expectations clearly

- To be adaptable with regard to a learner's needs

- To communicate clearly and effectively

- To make consideration of the different abilities and learning styles of students

- To encourage discussion, debate and critical thinking

Early research also indicated that all learning materials would have to meet the learning styles and preferences of different types of students, be able to be used by students across platforms and differing levels of technology, be portable; and also all learners would have to be supported by a tutor, available regularly to individual students for advice and to deal with subject specific and general academic queries. It was decided to use balanced approach of constructivism and behaviourism, whereby students are 'lectured' in some way and are then exposed to practical applications and activities. With these considerations in mind, a 10 credit introductory module was developed, representing an entry point for both potential undergraduates and postgraduates. This module was accredited through Plymouth University's Continuous Professional Development (CPD) framework as a stand-alone unit.

With the medium of e-learning in mind, a coherent suite of learning materials was developed for the first HA module. This collection of materials has been dubbed the Total Learning Package (TLP), and was designed carefully by the learning technology team at Plymouth University to provide an easily navigable route through the module. Presenting a familiar HTML-type, web browser environment makes it second nature for anyone familiar with the internet to navigate. Seamless integration with online materials can be achieved as and when an internet connection is available. Critically, the entire TLP was packaged onto discrete media (in this case, an 8GB USB memory stick), and physically send to the student. The complete materials for the first module could be contained within one stick, and it thus represents a convenient method for students working offshore to take their learning environment with them.

The student experience when engaging with the TLP is typically as follows:

- Listen to a series of short, narrated PowerPoint lectures of typically less than 20 minutes each

- Complete a selection of challenging self-test formative questions

- Conduct some directed background reading, which may be supplied as part of the TLP or may have to be downloaded when internet connection allows

- Research and write a short essay or report on a subject related to a lecture or series of lectures

- Compile the essays and reports into a coherent portfolio which is directly related to professional practice, and is submitted for marking at the end of the module

In total, the TLP for Module 1 (10 academic credits at Level 4) represents 100 student study hours. A group of twelve students, all Fugro employees and sponsored by Fugro was enrolled electronically at the University in January 2012 to study the first module offered by the Hydrographic Academy. This 10 credit level 4 (first year undergraduate) module was run over a 10 week period, with evaluation being conducted throughout.

\section{RESULTS}

Significantly, the development time for the Hydrographic Academy's first module was found to be typical of the investment required to create a high-quality, accredited distance learning programme. It is estimated that approximately 4,500 man hours were expended in creating the teaching and learning materials for this module alone.

As expected, the majority of the students did not have a broadband internet connection for much of the time they were enrolled on the module (Figure 2), but importantly, $100 \%$ of the students replied affirmatively that the "format and style in which the module was presented was an effective way to learn". The tutor support provided to the students was also seen as a critical element of success. Support was not provided on a $24 \mathrm{hr}$ basis or at

\section{8 | Hydrol 2}


weekends, and limited to the normal working day, although a response within two working days or sooner was guaranteed. The student group found this element extremely useful, with the majority of individuals contacting their tutor on a weekly basis. Additional qualitative feedback was sought through the Creative Learning Journey (CLJ) model. It has been used as a means to facilitate and capture the collaboration and learning processes between partners engaged in a project, and has been employed successfully by the Manchester Beacon at the University of Manchester ${ }^{3}$. The overall CLJ for the first module can be viewed on the Creative STEM website ${ }^{4}$. A shortened version of this film can be found on the HA website, www.plymouth. ac.uk/hydro.

\section{DISCUSSION}

The trial of the Hydrographic Academy's first module has been a remarkable success. There has been positive quantitative and qualitative feedback from Fugro, the group of trial students, the professional bodies, from Plymouth University management and from those prospective students who continue to register their interest. Quotes received from students completing the first module appear below:

- "I have quite literally searched the world for an institution that offers this kind of tertiary education and from Australia to Europe I have been unsuccessful so thank you for your efforts! It's a huge step in the right direction!"

- "The course syllabus looks great! Establishing the Hydrographic Academy is a great initiative!"

- "It's great to have all the materials to be able to access the lectures and notes as and when I have time. It's very comprehensive, there are a lot of materials and it's a great opportunity for me to be able to study like this."

- "The content is easy to navigate through and it is very impressive. I was thinking there may be some key areas where I would need some extra information but that wasn't the case. I am very impressed with the course content and materials"

- "The Hydrographic Academy has given me the chance to fill a gap in my CV and develop my theoretical knowledge whilst helping me to progress my career within the industry" Significant developmental work remains in designing and producing elements of the Hydrographic Academy's future modules, in particular, the practical study elements. Practical hydrographic surveying will be predominantly taught through two residential sessions, although significant efforts are being expended to incorporate practical elements (data processing and survey planning, for example) within the e-learning materials.

\section{CONCLUSION}

E-learning is a well-proven method of providing higher education opportunities for busy working professionals, although it had not been applied in a comprehensive sense within the hydrographic survey industry before the developments introduced by the Hydrographic Academy at Plymouth University. There are numerous challenges posed by the unique nature of the offshore survey business, including limited internet access for the majority of prospective students. This aspect, together with the variable and on-call nature of the industry has meant that there have been very limited opportunities for workforce development, for employees to gain Higher Education level qualifications and professional body recognition.

As a partnership between industry and academia, the Hydrographic Academy project has successfully developed and trialled a short academic module for those working at sea or in remote locations. Feedback from learners has been extremely positive, and the quantitative and qualitative feedback received has indicated that learning outcomes can be met through distance e-learning. The project team is continuing to engage widely with the UK higher education sector to ensure that the latest developments in best practice are brought to the Hydrographic Academy, thus ensuring that the needs of the learners, employers and the professional bodies are met.

\footnotetext{
${ }^{3}$ Www.manchesterbeacon.org

${ }^{4} \mathrm{http}: / /$ www.creativestem.co.uk/
} 


\section{REFERENCES}

Lynette R. Porter, Developing an online curriculum. Technologies and Techniques. (London: Information Science Publishing, 2004)

David Whitcombe, "Recruit, Train and Retain," Hydro International April (2008): 26-27

\section{BIOGRAPHIES}

Richard Thain has been working for Plymouth University since 1999, following a spell of employment in the offshore industry as a hydrographic surveyor. Until 2008, he contributed to the development and delivery of programmes in oceanography, underwater acoustics and meteorology for Plymouth University at Britannia Royal Naval College; and also worked as an Associate Lecturer with the Open University. A founding member and the Education Coordinator for the Centre of Excellence in Naval Oceanographic Research and Education (CENORE), and working closely with the Royal Navy, industry and academia on military-orientated academic research, Richard is now deployed full-time as the Director of the Hydrographic Academy.

Tony Jenks is an e-lecturer in Plymouth University's the Hydrographic Academy, where he brings a wealth of experience gained during 37 years in the Royal Navy. As a specialist hydrographic surveying officer he has conducted surveys all over the world from a variety of ships and boats, as well as fulfilling two key appointments on the staff of the RN hydrographic training school.

Andrew McNeill is Global Learning \& Development Manager for Fugro. Andrew has a BSc in Topographic Science from Glasgow University and an MBA from Robert Gordon University, and has worked in the offshore industry since 1983 progressing through various offshore and onshore technical and management positions, ultimately as Chief Surveyor for Fugro's Offshore Survey Division. He was part of a team that setup the Fugro Academy in 2006 and has managed it in his current position since 2009 .

Don Ventura has been involved in hydrography since 1983 , when he embarked on a 20 -year service with the UK Royal Navy's Hydrographic Squadron. Don's time in the RN saw him gain considerable atsea and professional experience in a number of ships and disciplines ranging from coastal hydrography for nautical charting, ocean mapping, physical oceanography and deep ocean geophysical surveys. Latterly, Don has supported numerous programmes in his post-Naval career, including operational roles with NOAA's National Data Buoy Center, the joint USACE/NAVOCEANO Joint Airborne Lidar Bathymetry Technical Center of Expertise (JALBTCX) and more recently with Fugro's awardwinning bathymetric Lidar services worldwide. Don lives in the United States with wife Jane and his 2 children.

\section{CONTACT DETAILS}

Dr Richard Thain,

Director, Hydrographic Academy

Plymouth University,

School of Marine Science and Engineering

Drake Circus, Plymouth. PL4 8AA

rthain@plymouth.ac.uk 


\section{Utility of Airborne Lidar Bathymetry in Extreme Coastal Environments: Planning Considerations, Results and Lessons Learned}

Don VENTURA, United States of America

Fugro Pelagos Incorporated

Topic: Innovations in acquisition techniques

\section{INTRODUCTION}

Over the past two years, Fugro Pelagos has undertaken Airborne Lidar Bathymetry (ALB) surveys in two particularly diverse environments: the high temperature, tropical, complex coralline Red

Sea coastline of the Kingdom of Saudi Arabia; and the near-freezing, Arctic summer conditions found in the Northern Territories of Canada. These surveys, conducted on behalf of the General Commission for Surveys of Saudi Arabia (GCS) and the Canadian Hydrographic Service (CHS) respectively, were required to attain very similar accuracies and degrees of coverage to support national nautical charting requirements to international standards.

Although the outline requirements from the two agencies were similar in many respects, the polarity of the respective survey area environmental conditions necessitated a completely different response to the factors affecting successful conduct of the projects. Airborne operations can be affected by a plethora of issues, ranging from platform support, logistics and maintenance; climatological and oceanographic trends and events; through to ALB system and personnel performance and workload under differing operational pressures.

This paper will describe the projects in outline, the requirements of the surveys, system and aircraft parameters, and the different issues determined for both survey environments, together with the solutions to these issues. The paper will aspire to compare and contrast the various factors that need to be taken into consideration when operating ALB in such diverse environments whilst still trying to attain the same final product accuracies and standards.

\section{OUTLINES OF THE SURVEY AREAS}

\section{$\underline{\text { Saudi Arabian Red Sea Surveys } 2010}$}

In 2009, a hydrographic charting project The Red Sea Coastal Zone, Area between "Sha'ab Naza"
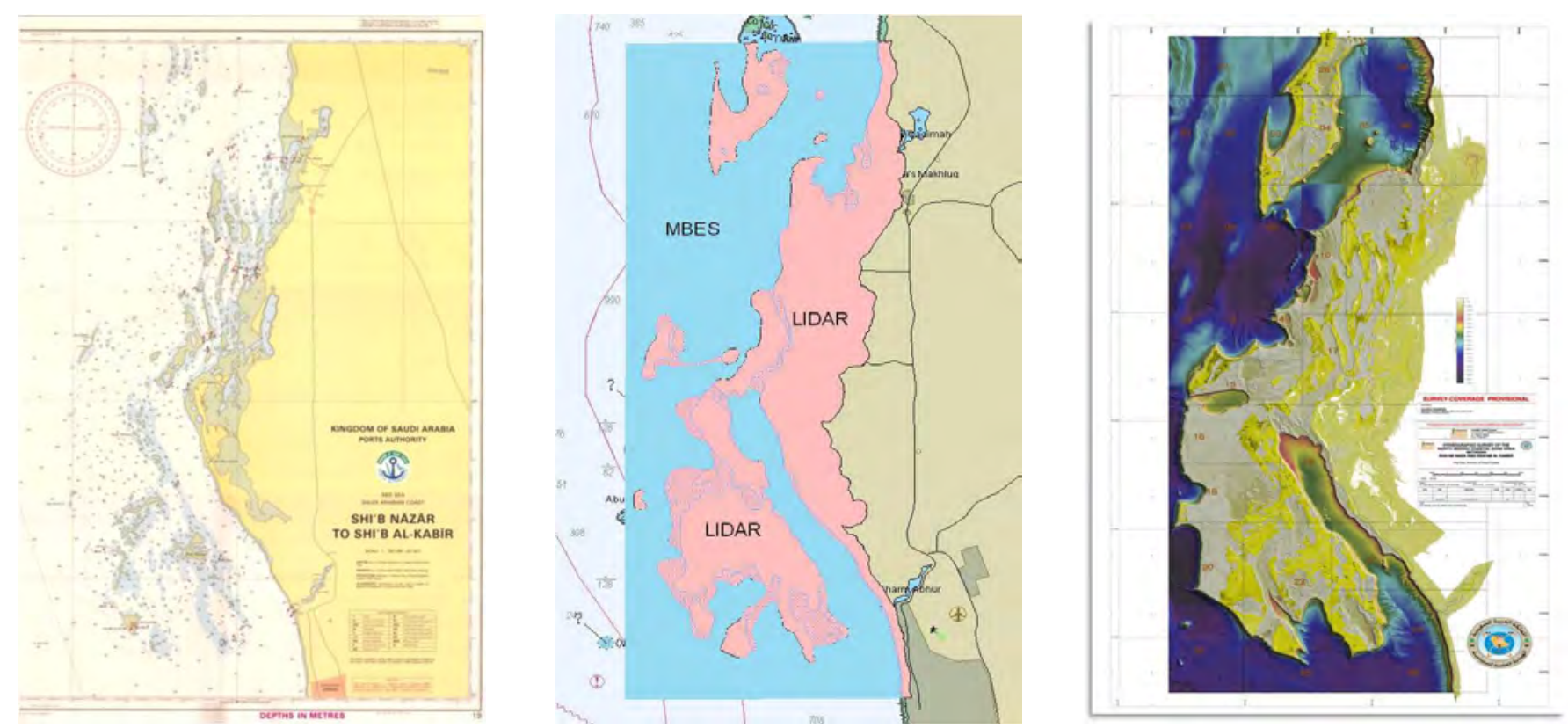

Figure 1: North Jeddah combined MBES/LiDAR survey area. (From left) Original Saudi chart, project-designation between LiDAR/MBES, and final combined acquired MBES/LiDAR survey results 
and "Sha'ab Al Kaber" was generated by Saudi Arabia's General Commission for Survey (GCS) and opened for tender for an IHO S44 Order 1a \& 2 survey suitable for ENC/charting use. A focus of the programme was to assess the level of effective hydrographic data acquisition in a typically diverse Saudi marine area, not least the dynamic requirements of the Kingdom's main Red Sea port at Jeddah. A Fugro bid won the contract based on a comprehensive combined LiDAR/MBES programme.

Initial designated assignment of the survey polygons was established based on the operational efficiencies and limitations of the main bathymetric technologies. Data density requirements, particularly for LiDAR, were pre-calculated in order to achieve the appropriate seabed coverage and target detection criteria specified in the associated contract specifications. This generated a data density based on a $3 \mathrm{~m} \times 3 \mathrm{~m}$ spot spacing pattern conducted at a minimum of $200 \%$ coverage $(60 \%$ effective runline overlap) to create a nominal density of LiDAR data sufficient to guarantee the target detection criteria required for IHO S-44 Order 1a. LiDAR was optimized in all areas where navigation hazards and/or shallow water were considered significant to either crew and vessel safety or operational efficiency (due to reduced swath coverage) of the MBES systems. By accepting a conservative limit for LiDAR penetration but equally conservative for ship safety, a healthy data overlap was assured and this facet of operations, subject to amendment as the survey progressed for the reasons provided below, greatly aided the complex data merge operation during the final processing stages of the survey.

Subsequently, GCS issued instructions for this to be carried out and the UKHO-supervised IMO submission for the Approaches and Routes to the new King Abdullah Port were presented before the IMO in July 2010.

\section{Canadian Arctic Surveys 2011}

Fugro was contracted during August 2011 by the Canadian Hydrographic Service (CHS) to conduct an airborne bathymetric LiDAR survey in specific areas of the Canadian Arctic at various times and locations and deliver fully processed and verified hydrographic survey data. The goal of the project was to investigate the feasibility of the implementation of bathymetric LiDAR into the hydrographic survey program in Canada. The airborne LiDAR survey was conducted with the SHOALS-1000T system for data collection to the extents provided by the CHS.

In this case, the airborne bathymetric LiDAR survey was planned to achieve IHO SP-44 Order $1 \mathrm{~b}$ category of survey coverage and accuracy. This

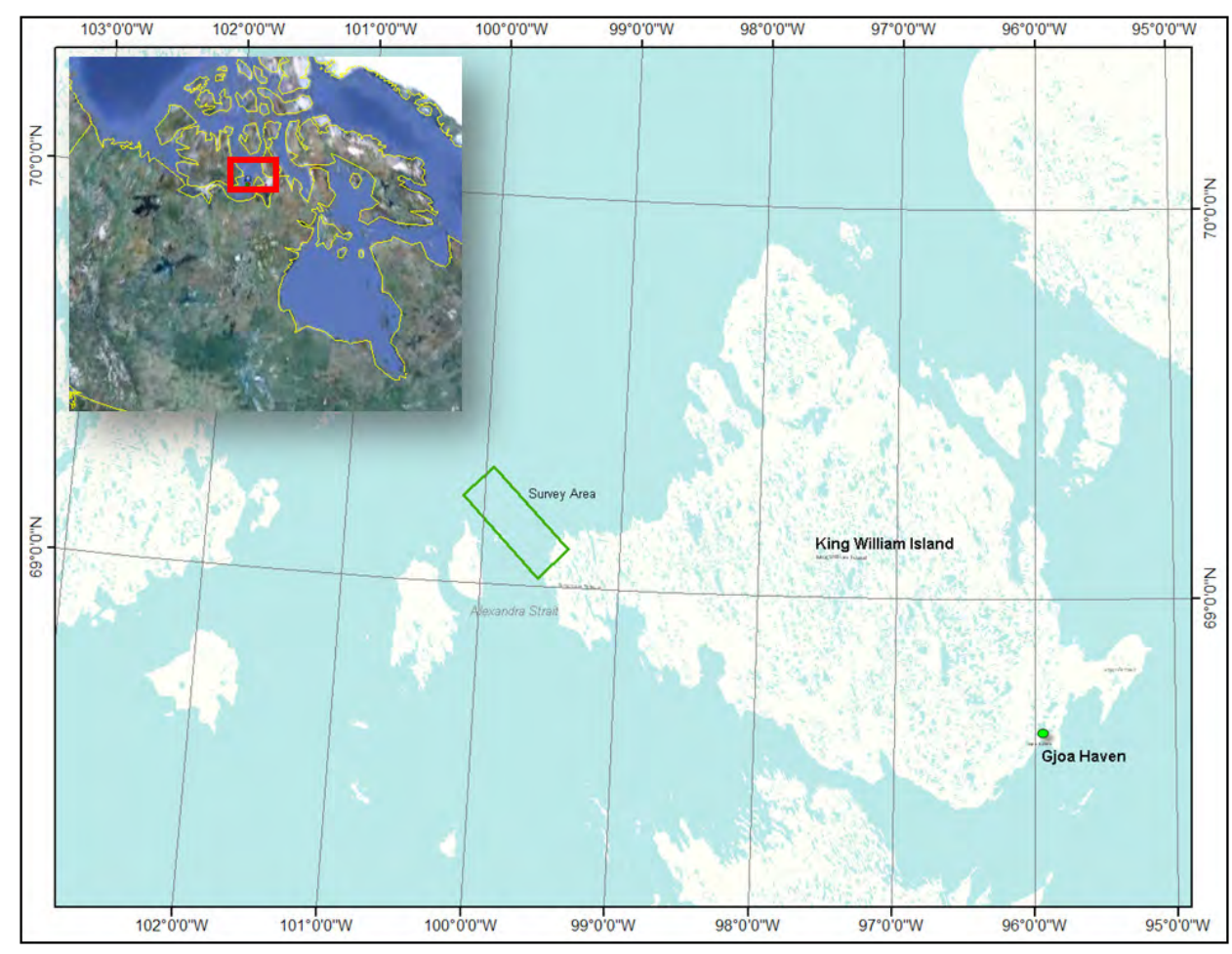

Figure 2: One of the CHS LiDAR Survey Areas (Alexandra Strait)

\section{2 | Hydrol 2}


was accomplished by combining a $5 \mathrm{~m}$ x $5 \mathrm{~m}$ spot spacing (flying at $400 \mathrm{~m}$ altitude and speed-overground of approximately 160 knots) with a $100 \%$ coverage plan. Planned line spacing provided 30 $\mathrm{m}$ of sidelap. The reduction in point density for this survey compared to the Red Sea survey did not affect in any way the individual point accuracy criteria, with both projects meeting S-44 Order 1 horizontal and vertical accuracy standards.

\section{TECHNICAL AND LOGISTIC COMMONALITIES BETWEEN THE SURVEYS}

Both surveys were flown with sufficient options, made available to the airborne operator, to devise a best 'plan of the day' for climatic and water quality considerations, such that successful data collection was possible in both shallow and deep regions of the areas under consideration. Operator assessments included reconnaissance of areas for water turbidity issues and wind direction and strength affecting survey parameters which were highly variable due to the predominant climatic factors being experienced on any given day.

The survey acquisition operations collected data from the following sources:

- Bathymetric LiDAR data from the SHOALS1000T system.

- Digital Aerial Photography from the SHOALS1000T.

- Dual frequency GPS data at several ground control stations

GPS base stations were installed in or near the vicinity of the survey areas such that the range of operations from the base stations did not exceed current standard operating procedures for this type of survey (typically $<70 \mathrm{~km}$ ). Base station data were typically collected every day from each station when a flight mission was planned. Back-up secondary stations at each location were set up for redundancy purposes.

Surveys in both regions were conducted from the same type of aircraft and indeed from the same provider; this in itself also created a standardised operational 'style' or paradigm, with the aircrew providing a uniform level of service and conduct of air operations.

\section{TECHNICAL AND LOGISTIC DIFFERENCES BETWEEN THE SURVEYS}

Whilst few if any technical differences existed between the survey approaches from a bathymetric LiDAR perspective, which shared the same types of survey equipment, sensors and even aircraft type, considerable logistic differences were evident between the projects. These included mobilization distances, local population centres providing logistic and other support services, shipping and transit considerations, accommodation, storage and victualling/refuelling arrangements. Although none of these aspects directly affected the end result of the survey or nature of the data collected, it is worthy of mention if only to recognise that these differences did exist.

\section{HANDLING EXTREMES - ENVIRONMENTAL}

As the main topic of this paper suggests, the mitigation of the primary environmental factors required for the successful prosecution of these surveys was considerable in both regions and equally necessary. The extremes of these climates highlighted the need for different approaches and planning to address a common set of issues on which successful airborne bathymetric LiDAR operations depended. These were: temperature and humidity; cloud cover and ceiling; precipitation; winds;

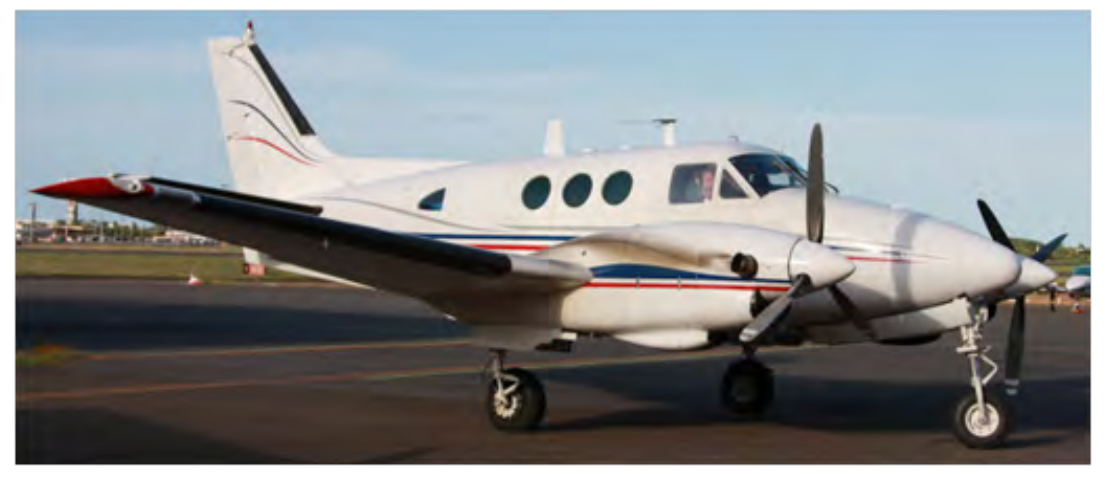

Figure 3: Beechcraft King Air A90 
surface waves; tidal streams and currents; and water clarity/turbidity. We will discuss these effects on bathymetric LiDAR operations in turn and compare the effects as they pertain to these two regions.

\section{Temperature and Humidity}

With respect to the typical bathymetric LiDAR sensor, high ambient air temperatures and humidity necessitate air-conditioning in an aircraft conducting such operations with today's technology, not just for personnel comfort. The aircraft cabin atmosphere thus needs to be conditioned in order to maintain Lidar system temperatures within design specifications. Low ambient air temperatures can also cause system operation parameters to be exceeded, with stability of the laser triggering mechanisms and electronics similarly affected. The mitigation is the same; to provide a stable, controlled airflow to the primary sensors to ensure consistent performance and reduce the likelihood of environmental stress on the main and most sensitive components.

From a platform standpoint, air temperature affects density, lower atmosphere turbulence and therefore operational performance of the aircraft. Thermals generated near a coastline are often very violent due to the different refractive heat indices that water and land (especially dry land) generate. Katabatic effects of descending cold air from nearby steep terrain can cause similarly unpredictable and unstable operating conditions. Severe turbulence can render an otherwise optimal data collection scenario almost impossible to conduct safely. Heat haze can also diffract the laser energy in the air column, resulting in reduced depth of penetration results

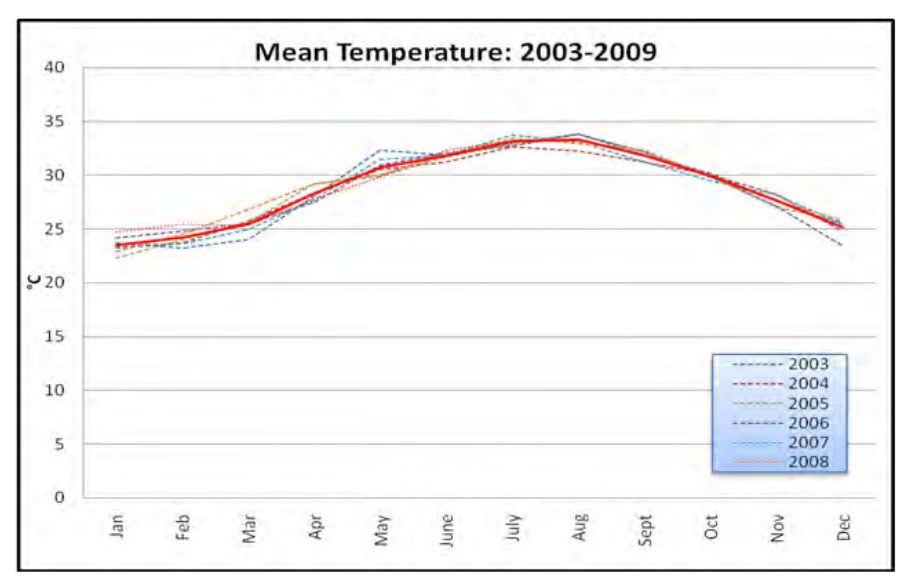

compared to that expected in an otherwise clear water scenario.

In these examples, mean temperatures in the Red Sea area were lower than $30^{\circ} \mathrm{C}$ from November to March, while humidity was lower from April to November, indicating that the optimum data collection based on just this factor would be during the winter months. Conversely for the Canadian areas, the average temperatures throughout the year varied from $-30^{\circ} \mathrm{C}$ in January to $7^{\circ} \mathrm{C}$ in July. Only the brief summer hiatus, where temperatures are above freezing, provided conducive conditions for the efficient collection of quality LIDAR data given the low altitude flying and requirements to have an icefree survey and safe aircraft operating environment.

High humidity, irrespective of temperature, can affect the performance of the sensor, potentially causing condensation or corrosion in the equipment. Humid conditions, admittedly usually in concert with higher air temperatures, can also create a hazy environment and absorption of part of the laser energy being returned to the detectors/receivers.

\section{$\underline{\text { Cloud Cover and Ceiling }}$}

Cloud cover, and specifically the ceiling altitude, can affect airborne hydrographic LIDAR operations. LIDAR bathymetry data collection is typically planned to be collected from an altitude of between 300 and $500 \mathrm{~m}$ or so. This means the ceiling for cloud, haze or fog must be at least this high. This aspect of the environment is seldom a major issue in the Red Sea, although other unusual phenomena affecting visibility through the air column, namely

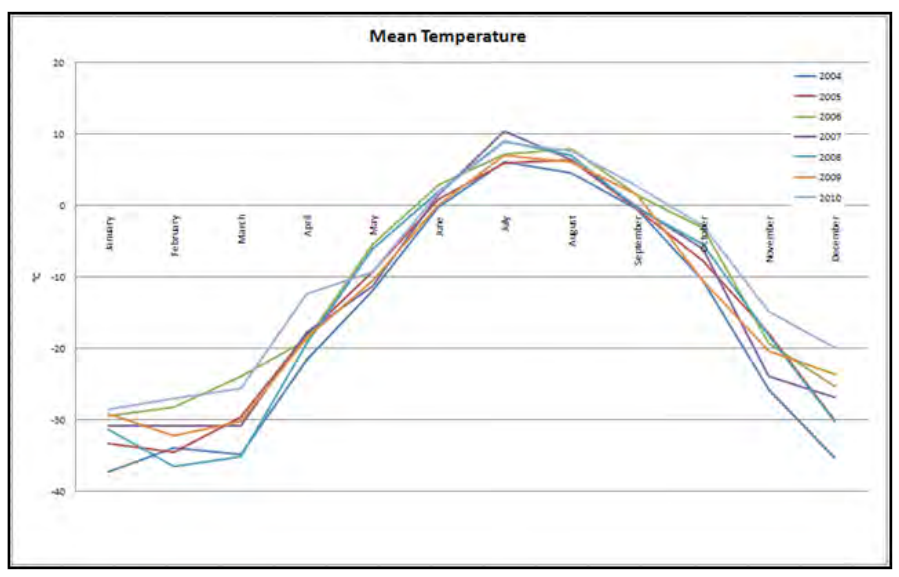

Figure 4: Mean temperatures: Red Sea (Jeddah) and Canadian Arctic (Gjoa Haven)

\section{I 4 Hydrol 2}


dust storms, were an issue that were harder to predict until sufficient local knowledge regarding the prevalence of high winds combined with local terrain capable of providing the particulates was understood. In the Arctic however the degree of low cloud cover was a regular phenomenon, particularly in coastal areas where advection created low cloud or fog. In circumstances like these a real risk of aborted data collection missions exists and there is very little mitigation possible unless the survey is sufficiently expansive to allow for alternative areas to be selected when the preferred area is not possible to survey.

\section{$\underline{\text { Precipitation }}$}

Rainfall can be a problem for hydrographic Lidar operations in two ways. Firstly, there is a significant loss of laser energy as the light scatters off raindrops in the atmosphere. Secondly, localized run-off from a rain event will often negatively impact water clarity in and around the coastal margins.

As one would expect, the selected regions in this paper again highlighted the maxima and minima effects of this factor on operations. Whilst it was not a major factor in the Red Sea as expected, precipitation in the form of ice, snow and rain was experienced in the Arctic. This not only affected the sensor performance but, in extremis, affected safe air operations when heavy overnight snowfalls were encountered making use of the local airport runways more hazardous than usual. Additionally, the higher albedo effect from falling snow creates glare issues for a bathymetric laser system, especially with a highly contrasting dark surface such as rock or water surface viewed under expansive cloud cover. If predictable (such as in some tropical conditions), then the effects of precipitation can be easily mitigated with carefully timed sorties, or provision of alternative data collection sites when the intended area is unsuitable.

\section{$\underline{\text { Winds }}$}

High winds can impact the aircraft's ability to remain reasonably level and fly straight lines. As a general rule of thumb, winds generally need to be less than $20 \mathrm{kts}(37 \mathrm{~km} / \mathrm{h})$ for an aircraft conducting bathymetric LiDAR operations to safely and effectively conduct an aerial survey.
Such scenarios can exist in any part of the world and coastal areas, regardless of latitude, are particularly susceptible to local increased wind effects. Both examples highlighted here created operational issues due to excessive periodic winds. This is typically mitigated by a carefully chosen survey line direction to minimise the significance of the wind force vector on the platform stability and operational (air) speed, and/or timing of the airborne sorties to avoid more predictable wind events (such as the build-up of onshore winds in the tropics created by dissimilar surface heating of land and sea. The more inclement general weather patterns of higher latitudes were less predictable, but just as frequent, as the former phenomenon experienced regularly during the Red Sea surveys, so similar downtime or interruption is experienced in completely disparate regions.

\section{$\underline{\text { Surface Waves }}$}

Winds can also cause breaking waves, which creates air pockets in the water column and may prevent the laser beam from reaching the seabed. Breaking or cresting waves could be caused by extreme winds, in which case the aircraft would probably not be flying for safety reasons anyway. If the wave is breaking at the land / water interface, this could also create turbidity from disturbed sediments in the surf zone. The increased turbidity will decrease water clarity and may prevent the laser beam from reaching the seabed. Irrespective of the region, these effects are common to the water medium and the only mitigation is to avoid such areas during survey and to have alternate, leeward shores available as substitute areas until local conditions change.

\section{Tidal Streams and Currents}

It is possible for tidal streams and wind-generated currents to affect a hydrographic Lidar collection. If the current is extreme, it can create turbidity from disturbed sediments because of the high laminar velocities. The increased turbidity will decrease water clarity and may prevent the laser beam from reaching the seabed. If the flow is tidally influenced, surveying at slack tide can mitigate the problem, as the current is reduced at that time.

These phenomena did affect both surveys, with different drivers creating the problems. In the Red 


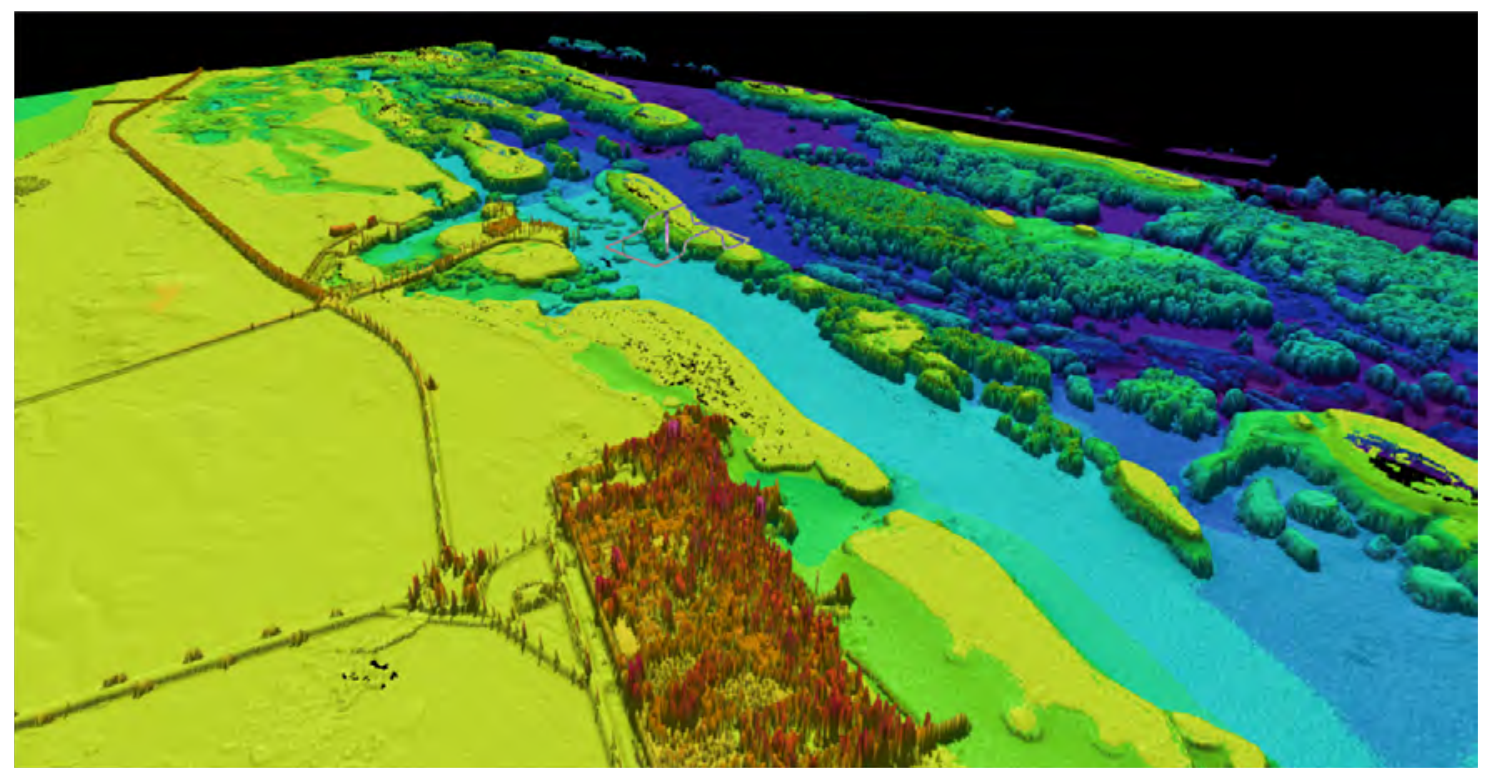

Figure 5: Complex reefs in Saudi Arabia generated accelerated local tidal streams and inshore turbidity issues

Sea, tidal ranges were seldom greater than $0.6 \mathrm{~m}$, but the propensity and complexity of the steep-sided reefs throughout the survey areas created barriers to the regionally induced tidal forces and had the effect of accelerating water flow through the deeper, narrow channels between the reefs. Closer inshore where higher levels of sediment were prevalent on the seabed, this created localised turbidity events which were predictable with the state of the tide and therefore reasonably comfortably mitigated. In the Arctic surveys, the stronger tidal forces and greater ranges experienced created similar patterns of turbidity but these were more regional in extent and longer in period, more closely associated with the spring and neap tidal cycles. In this latter scenario, data acquisition can be interrupted for much longer periods and in extreme conditions, no data collection may be possible at all until a major phase change in the tidal cycle occurs.

\section{Water Clarity/Turbidity}

As is very evident from above, the maximum depth of penetration on an airborne bathymetric LIDAR Survey depends on a number of factors, but ultimately the most important is the clarity of the water during acquisition. Systems in use today typically operate at the $532 \mathrm{~nm}$ wavelength and between 3 and $5 \mathrm{~mJ}$ of output energy; this provides a theoretical maximum penetration of two to three times (depending upon bottom reflectivity) that of normal human visual acuity (often expressed in terms of Secchi depth results or a light transmissometer ( $\mathrm{k}$ ) factor), up to a maximum depth of penetration of approximately $50 \mathrm{~m}$. The combination of output energy, diffusion of the laser 'spot', and operating altitude is designed to comply with international human eye safety regulations but is considered equally safe for all fauna illuminated by a pulse. All commercially available airborne hydrographic LIDAR systems will achieve approximately the same maximum penetration in the same waters during the same survey period.

Many of the factors above, in isolation or combined, can lead to localized or area-wide turbidity issues, and so the amalgam of all these factors must be considered carefully. Additionally, biologic and subsurface events can also create turbid conditions in the water; these include algae blooms, major biomass concentrations (especially during a spawning event), freshwater or other dissimilar liquid seeps from the seabed etc. Industrial activity and waste and other human activity such as fishing and dredging operations must also be factored into the assessments if such activities are known to occur during otherwise optimal conditions. In the examples selected, only the natural phenomena - climatic and biologic - affected turbidity in the Arctic regions, but major dredging operations in one area of the Red Sea survey seriously hampered effective data collection in a specific coastal strand and effective management of the options on when and where to survey had to be enforced.

\section{HANDLING EXTREMES - OPERATIONAL}

One of the main operational factors which differed between the surveys, tied closely to the primary environmental parameters which have been focussed

\section{6 | Hydrol 2}


on above, was the brevity of the Arctic mission day compared to that experienced the previous year in Saudi Arabia. The airfield proximity, fuel availability and transit leads were radically different between the projects which in turn limited the operational flexibility available to the acquisition team in the Canadian Arctic. These elements blur into a logistical definition but more directly affected the style and tempo of field data acquisition than the other factors mentioned above once the survey was underway. Local customs and sensitivities also factored into the operational pattern to a degree; whilst this was less true for the Arctic mission, restrictions were applied to the weekly operational tempo in Saudi Arabia and no flying was conducted on holy days. Conversely, the excellent logistic support provided which allowed un-interrupted 24-hour operations for 5 days of the week more than compensated for the no-fly restriction, which actually allowed a regular maintenance routine to occur on these days and so avoided any additional down-time.

\section{CONCLUSIONS}

Irrespective of the location, airborne bathymetric LiDAR operations must be well planned in order to be well executed; in this they are therefore no different from any other type of data acquisition mission. The factors on which this success depends however, and the importance of these factors compared to other hydrographic survey techniques, are radically different. A great many historic sources of environmental information are available to make the initial determinations on which a robust survey plan depend, but ultimately the awareness and flexibility of the surveyors in the field is essential to maximize the opportunities to acquire god quality data. The medium of light rather than sound as an energy source has both advantages and disadvantages, but successful use of the former demands an understanding of the various environmental factors on which we have focussed in this paper.

\section{BIOGRAPHY}

Don VENTURA is a hydrographic surveyor with Fugro Pelagos Inc. of San Diego, CA. A 22year Royal Naval officer veteran, he has been involved in hydrography for over 28 years and has planned, conducted and assessed hydrographic, oceanographic and geophysical surveys throughout four main ocean basins. 
3I8| Hydrol 2 


\title{
Suitability mapping for renewable energy potential in the North Sea- results from the BLAST project
}

\author{
Els VERFAILLIE, Alain DE WULF and Michel GOETHALS, Belgium \\ Ghent University (UGent) - Department of Geography
}

Stefaan GYSENS, Belgium

Flemish Government, Agency for Maritime and Coastal Services, Coastal Division

Ellen MEIRE and Philippe DE MAEYER, Belgium

Ghent University (UGent) - Department of Geography

Topics: Smart data management, Careful marine planning

\section{INTRODUCTION}

The Interreg IV B BLAST project (www.blastproject.eu) has a primary focus on "Bringing land and sea together", by harmonizing and integrating data between land and sea. Work package 6 of the BLAST project aims to develop new common policies and a web based decision support system (DSS) supporting Integrated Coastal Zone Management (ICZM) under the emerging climate change. One of the indicators of climate change of the DSS is renewable wave energy potential. In the search for optimal spaces to produce renewable energy (RE) important aspects are available power, investment costs and the spatial impact. Due to the high demand for land and sea use by different actors, especially in the coastal zone, a long-term dynamic spatial planning strategy becomes more and more important and could result in space reservation for future activities (e.g. adaptation and mitigation measures).

This paper describes the methodology to obtain suitability maps for wave energy parks in the BLAST North Sea area. The suitability maps are made by a GIS based multi-criteria decision analysis approach. Two different time-scales (19601989 and 2070-2099) and corresponding climate change projections of wave energy are used for the suitability maps presented in this paper. More results from this study in the framework of the BLAST project are given in the BLAST report (Verfaillie et al., 2012).

For this study, wave energy projections have been used. The projections are based on the medium emission (A1B) scenario (Nakicenovic et al., 2000) of the Intergovernmental Panel on Climate Change (IPCC). The medium emission scenario describes a world that has rapid economic growth, quick spreading of new and efficient technologies, and a global population that reaches 9 billion mid-century and then gradually declines. It also relies on a balance between different energy sources (Lowe et al., 2009).

\section{GIS BASED MULTI-CRITERIA DECISION ANALYSIS APPROACH}

To select a suitable location for wave energy within the North Sea, different location based criteria have to be compared and weighted against each other. Such a location based multi-criteria analysis is called a GIS based multi-criteria decision analysis approach (GIS-MCDA) (Malczewski, 2006). Recent GIS-MCDA studies for wave energy suitability analysis have been done by Prest et al. (2007), Ydens and Meirschaert (2008), Nobre et al. (2009) and Beels (2009). To find a suitable location for wave energy, a balance between minimal cost and maximal production has to be found by balancing wave power resource potential, economical considerations, technological specifications, environmental and social conflicts (Beels, 2009). The criteria for a GIS-MCDA consist of constraints and weighted factors (Figure 1). Restrictions on the study area are called 'constraints' (e.g. shipping channels) and in the restricted areas no exploitation of wave energy is allowed. The result of all constraints in a study area is an extractable wave energy potential map. 'Factors' are parameters with a variable level of suitability (e.g. distance to the harbour - the closer to the harbour, the more suitable for wave energy; wave energy power - the more power, the more suitable). The factors are evaluated for their impact on the installation of a wave energy 
farm (score $c_{i}$ ) and are weighted according to their relevance (weight $\mathrm{W}_{\mathrm{i}}$ ) (Figure 1). As a result, each grid cell from the study area receives a number that indicates its suitability. The result of the factors applied on the study area is a physical wave energy potential map.

The final suitability map of this study will be a combination of the physical wave energy potential map with the extractable wave energy potential map. A third step in this process could be an economical step, to define an economical extractable potential, but this is beyond the scope of this research.

The study area for this study corresponds with the North Sea area with the exception of France. Limited data are available from the United Kingdom because no active partner participated to Work Package 6 from the BLAST project. Still, some countries provided -incomplete- constraint datasets from the United Kingdom. Factor datasets were available from all countries.

\section{$\underline{\text { Constraints }}$}

Constraints are restrictions on the study area that do not allow exploitation of wave energy, because activities take place there that are legally allocated (e.g. aggregate extraction, shipping,...). As such, no space is available for wave energy convertors. By combining constraints, some locations are still free for wave energy extraction. For this study, the starting point constraints are taken from report D3.1 from the WINDSPEED project (van der Wal et al., 2011) and from the studies of Beels (2009) and Ydens and Meirschaert (2008). For this study, the following constraints were taken into account:

- Wind mill parks or wind mill park concession zones

- Shipping routes

- Oil and gas installations

- Military zones Pipelines

- Cables

- Nature zones

- Aggregate extraction zones

In Figure 2, the result from the combined constraints in the North Sea area are shown.

\section{Factors}

Next to the constraints, weighted factors are taken into account as well. Factors for this study are:

- wave energy

o 2 unperturbed projections (Ortega and Monbaliu, 2012)

- From 1960 to 1989 (baseline or past period), and

- from 2070 to 2099 (far future projection).

- bathymetry

- distance to the harbours

- distance to the coastline

- substrate type

- benthic value

For this study, the suitability analysis does not take into account specific device dependent or economical information, in contrast to the study of Ydens and Meirschaert (2008) and Beels (2009). The weights that are assigned to the different factors are the following:

The weights have been assigned based on the study of Beels (2009) and expert judgement. Each factor map has been classified into relevant classes and each class has received a score ci. The highest scores are given to the most suitable classes of the factors

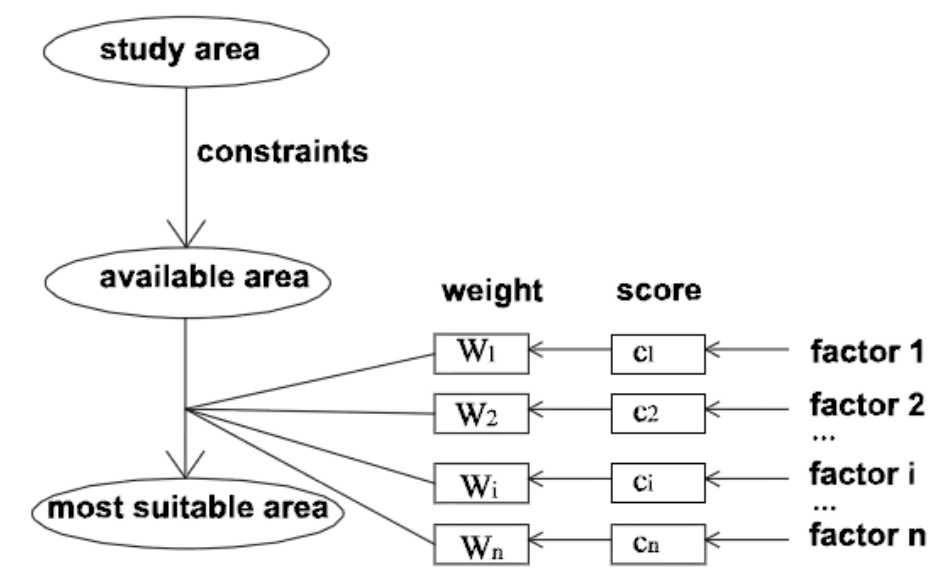

Figure 1: To find a suitable location for wave energy, a GIS-MCDA is performed on the BLAST study area. The suitability depends on constraints (restrictions) and weighted factors (source: Beels (2009)) 


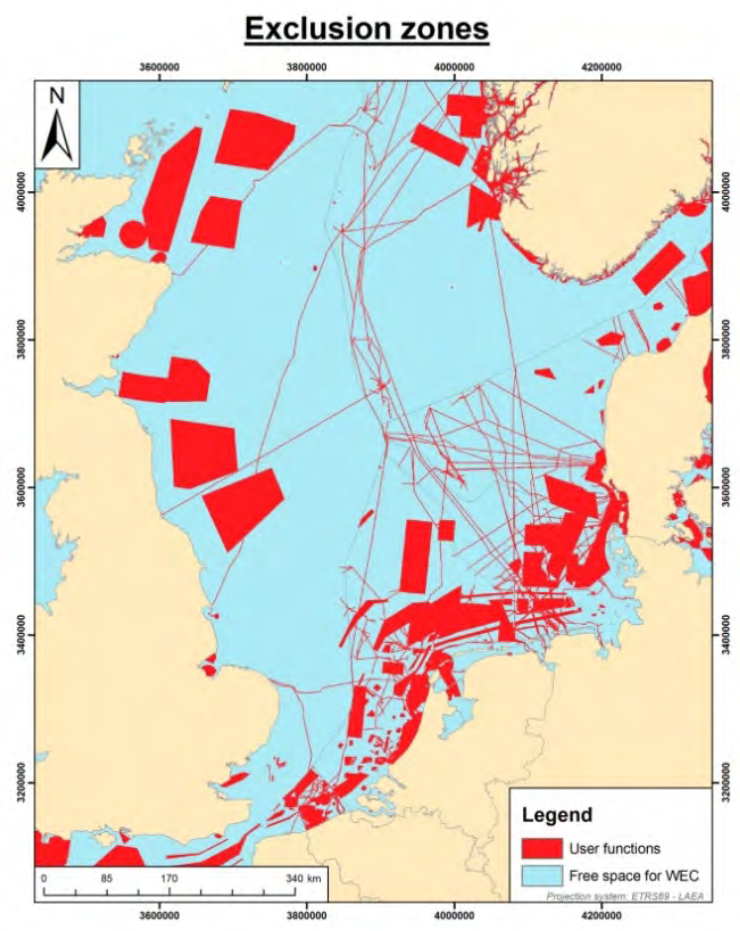

(e.g. high wave energy power, close to the harbours) and the lowest scores are given to the least suitable classes of the factors.

The combination of the weighted factor maps of the BLAST areas are called physical energy potential maps. These maps are shown in Figures 3a, 3b, $4 \mathrm{a}$ and $4 \mathrm{~b}$. Figures $3 \mathrm{a}$ and $4 \mathrm{a}$ show the physical energy potential maps from respectively the baseline situation and the far future projection. In Figures $3 \mathrm{~b}$ and $4 \mathrm{~b}$, the constraints are also shown on the maps. The difference between the baseline maps (Figures $3 \mathrm{a}$ and $3 \mathrm{~b}$ ) and the far future projection maps based on change calculations as explained in Ortega and Monbaliu (2012) (Figures 4a and 4b) indicate that a possible suitability shift can be expected as a result from climate change. There is an expected suitability shift from North to South and from the more remote areas in the Northern part of the North Sea to the more coastal areas in the South-Western part of the North Sea. At the same time, most of the sea activities take place within these coastal zones. The maps are indicator maps, meaning that they can not be interpreted as 'truth', because the uncertainty within the wave projection datasets depends on different criteria (e.g. choice of climate scenario, boundary conditions of wave models). They give an indication about possible suitable locations for wave energy potential within the North Sea. The main aim of the suitability maps is to show spatial planners and decision makers that the current situation
Figure 2: Extractable wave energy potential map after exclusion of all the constraints of sea activities. of spatial allocation in the North Sea should be considered in a flexible way. Spatial planners and decision makers should take into account that climate change can have effects on the most suitable locations for wave energy and other forms of RE. Maybe they should consider that certain 'fixed' sea activities (the 'constraints') could be combined with other sea activities. Win-win situations could

\begin{tabular}{|l|l|}
\hline Weight [\%] & \\
\hline wave energy power & 53 \\
\hline bathymetry & 5 \\
\hline distance to harbours & 10 \\
\hline distance to coastline & 20 \\
\hline substrate type & 9 \\
\hline benthic value & 3 \\
\hline
\end{tabular}

be created by combining different sea activities (e.g. wave energy and wind energy in 1 common renewable energy park where all the gained energy can be transported to the mainland by 1 single energy transmission system). Wave energy convertor systems are at the moment still in a prototype phase, but it is expected that the ecological impact from this type of energy gain is low (e.g. benthos, fish, seabirds, sediment). 

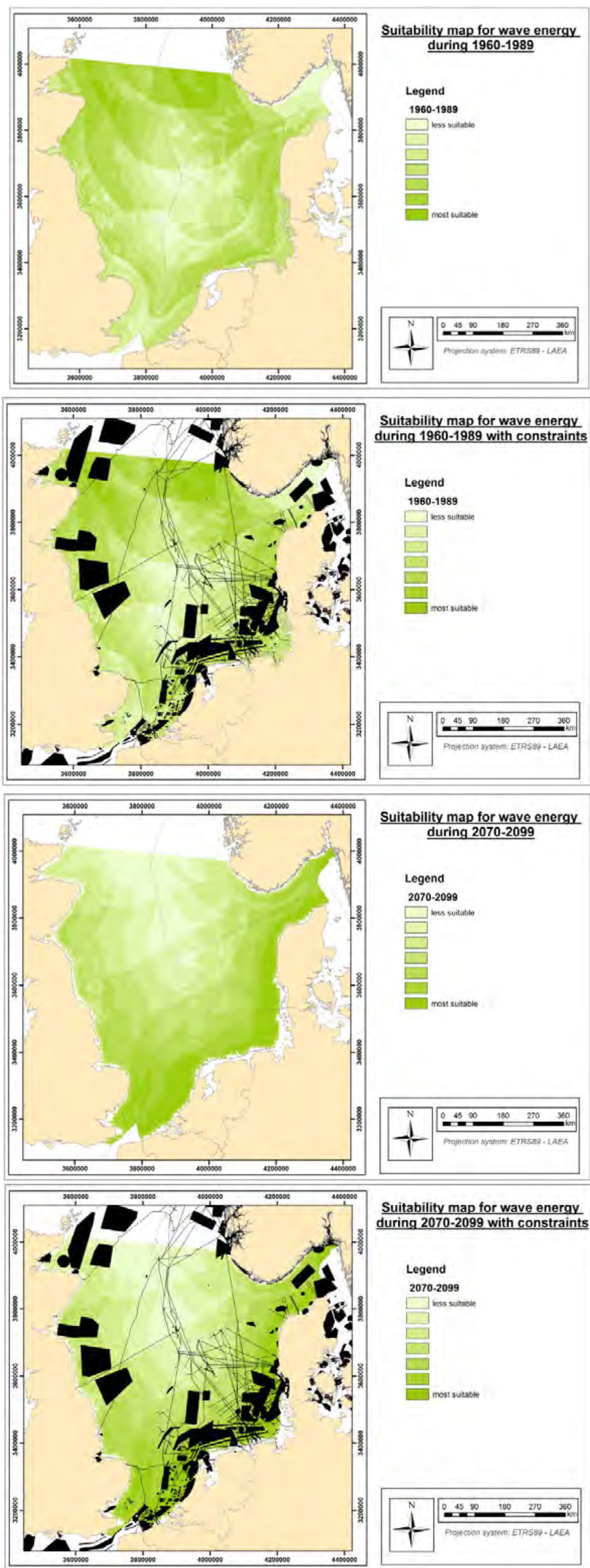

Figure 3a: Suitability map for wave energy parks (baseline situation)

Figure 3b: Suitability map with constraints for wave energy parks (baseline situation)

Figure 4a: Suitability map for wave energy parks (far future projection based on calculations of wave energy change (Ortega and Monbaliu (2012)).

Figure 4b: Suitability map with constraints for wave energy parks (far future projection based on calculations of wave energy change (Ortega and Monbaliu (2012)) 


\section{REFERENCES}

Beels, C., 2009. Optimization of the Lay-Out of a Farm of Wave Energy Converters in the North Sea Analysis of Wave Power Resources, Wake Effects, Production and Cost, Unpublished $\mathrm{PhD}$ thesis Ghent University, Ghent.

Lowe, J.A., Howard, T.P., Pardaens, A., Tinker, J., Holt, J., Wakelin, S., Milne, G., Leake, J., Wolf, J., Horsburgh, K., Reeder, T., Jenkins, G., Ridley, J., Dye, S. and Bradley, S., 2009. UK Climate Projections science report: Marine and coastal projections. Exeter: Met Office Hadley Centre.

Malczewski, J., 2006. GIS-based multicriteria decision analysis: a survey of the literature. International Journal of Geographical Information Science, 20(7): 703-726.

Nakicenovic, N., Swart, R. and (Eds.), 2000. Special Report on Emissions Scenarios. A Special Report of Working Group III of the Intergovernmental Panel on Climate Change. Cambridge University Press, Cambridge, UK and New York, NY, USA, 599 pp.

Nobre, A., Pacheco, M., Jorge, R., Lopes, M.F.P. and Gato, L.M.C., 2009. Geo-spatial multi-criteria analysis for wave energy conversion system deployment. Renewable Energy, 34(1): 97-111.

Ortega, H. and Monbaliu, J., 2012. Effect of climate change on North Sea wave energy potential based on UKCP09 Climate Projections - BLAST deliverable from WP6 (www.blast-project.eu).

Prest, R., Daniell, T. and Ostendorf, B., 2007. Using GIS to evaluate the impact of exclusion zones on the connection cost of wave energy to the electricity grid. Energy Policy, 35(9): 4516-4528.

van der Wal, J.T., Quirijns, F.J., Leopold, M.F., Slijkerman, D.M.E., Glorius, S.G. and Jongbloed, R.H., 2011. Inventory of current and future presence of non-wind sea use functions - Second edition, WINDSPEED WP3 Report D3.1.

Verfaillie, E., De Maeyer, P., De Wulf, A., Goethals, M., Gysens, S. and Meire, E., 2012. The renewable energy indicator: wave energy potential - BLAST deliverable from WP 6 (www.blast-project.eu).
Ydens, I. and Meirschaert, V., 2008. Onderzoek naar een economische exploitatie van het golfenergiepotentieel in de Noordzee m.b.v. ArcGIS, Unpublished MSc dissertation, Ghent University.

\section{CONTACT DETAILS}

Els VERFAILLIE

Ghent University (UGent) - Department of

Geography

Krijgslaan 281 - S8 B-9000 Gent

Belgium

Current address:

Ghent Port Company ampc

John Kennedylaan 32 - Haven 3000 A, B-9042 Gent Belgium

e-mail: els.verfaillie@havengent.be 
$324 \mid$ Hydrol 2 


\section{Monitoring Silt Content In Sediments Off The Dutch Coast}

Koos DE VRIES, the Netherlands

Medusa Explorations BV

Johan DE KOK, the Netherlands

Deltares

Ronald L. KOOMANS, the Netherlands

Medusa Explorations BV

John DE RONDE, the Netherlands

Deltares

Marcel J.C. ROZEMEIJER, the Netherlands

IMARES Wageningen UR

Waterdienst, Rijkswaterstaat

Topics: Geophysics of the marine environment, Hydrography in the Benelux

\section{ABSTRACT}

Silts, present in sand extraction sites, can potentially mobilize in the water column and result in increased turbidity of the North Sea. The main knowledge gap in assessing this potential risk is the capacity to buffer silts in the sandy sediments. To assess this buffering potential, Rijkswaterstaat and Stichting LaMER started a Monitoring and evaluation program (MEP Sandmining) to monitor, amongst others, the concentration and variation of fines in the sediments off the Dutch Coast.

We monitored the concentration of fines in the sediment along 3 cross-shore tracks, ranging from 0-9 $\mathrm{km}$ off the coast, with the Medusa system and by taking sediment samples. The Medusa system results in continuous measurements of the silt content of sediments along a line, the samples have been used for validation purposes.

In the period September 2009 - Oktober 2010, 6 campaigns have been conducted. Measurements show that, although the silt content is very low $(<5 \%)$, the silt content can vary strongly on small spatial scales. Temporal variations show how the silt content along the profiles change. Comparing silt concentrations to the daily averaged wave height before the measurements, indicates that the silt contents increase with declining wave height.

\section{INTRODUCTION}

Silts, present in sand extraction sites, can potentially mobilize in the water column and result in increased turbidity of the North Sea. Computer models predict that this potential effect will not have significant consequences for ecology exploiting current quantities. However, the assumptions of these models have to be verified by a monitoring and evaluation program (MEP Sandmining) (Ellerboek e.a., 2008). The main knowledge gap in assessing this potential risk is the capacity to buffer silts in the sandy sediments. Fine silts present in the water column will settle during calm weather and will be stored in the upper decimeters of the sediment bed. During events, like a storm, these fines will go in suspension. The time scales involved in these processes and the behavior of the fine material in the upper layer of the sediment are part of the MEP of Stichting LaMER and Rijkswaterstaat. Other topics of this MEP relate to the significance of increased suspended silt and decreased amounts of algae on the growth of shellfish like Ensis directus. Apart from the sediment-based research presented in this paper, also measurements of concentrations 
of Suspended Particulate Matter (SPM) in the water column are conducted by taking water samples and by in-situ measuring CTD, suspension concentrations and chlorophyl.

This paper focuses on monitoring changes in the content of fines in the sediments that can (re)suspend into the water column.

\section{MAPPING SEDIMENT COMPOSITION}

\section{The Medusa survey system}

Traditionally, silt content in the sediment bed is determined by taking sediment samples by (box) coring or taking grab samples. These measurements give accurate information on one spot, but spatial variation in the silt content e.g. due to the presence of small-scale morphological features as ripple structures can result in data that is not representative for large areas. Spatial variation can be mapped by taking large amounts of sediment samples, which is often too expensive.

Different hydrographic methods exist to map the variation in the composition of the sediments on the seafloor. Analysis of the acoustic signals of multi-beam and single-beam echosounders or sidescan sonar, gives high-resolution images of the composition sediments. This information helps to zone the seafloor in classes with one type of acoustic

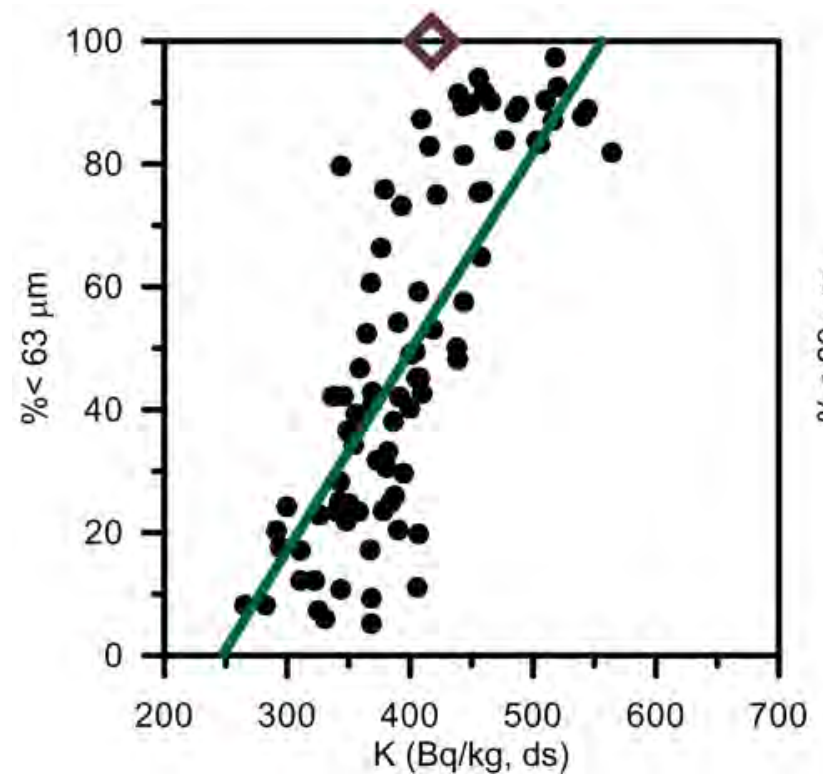

reflection that can be related to a certain type of sediment. It is though not possible to determine absolute concentrations of silt and sand or absolute values of grain sizes of the sediment bed [du Four et al, 2005]. We propose a method that directly measures some chemical constituents of the seafloor sediments, that can directly be related to sediment composition. This relation is established by a calibration in the laboratory.

This system (named Medusa) is towed over the seafloor behind a vessel. Each second, the system measures concentrations of the natural occurring radionuclides of the seafloor. These radionuclides $\left({ }^{40} \mathrm{~K},{ }^{232} \mathrm{Th}\right.$ and $\left.{ }^{238} \mathrm{U}\right)$ are present in rocks and sediments since the origin of the earth and can be measured with a gamma spectrometer. The system measures the background radiation that is emitted by soil and sediments. Various research projects have shown how silt, sand and heavy minerals contain different concentrations and ratios of radionuclides [de Meijer, 1998]. This method is also used to measure median grain size in the field [Nederbracht and Koomans, 2005] and to map the concentration of silts in sediments [Venema and de Meijer, 2001].

The advantage of the proposed system over traditional sediment sampling, is that the detailed maps of sediment composition determine the spatial variation at a small scale. Moreover, it is a cost effective method for monitoring purposes.

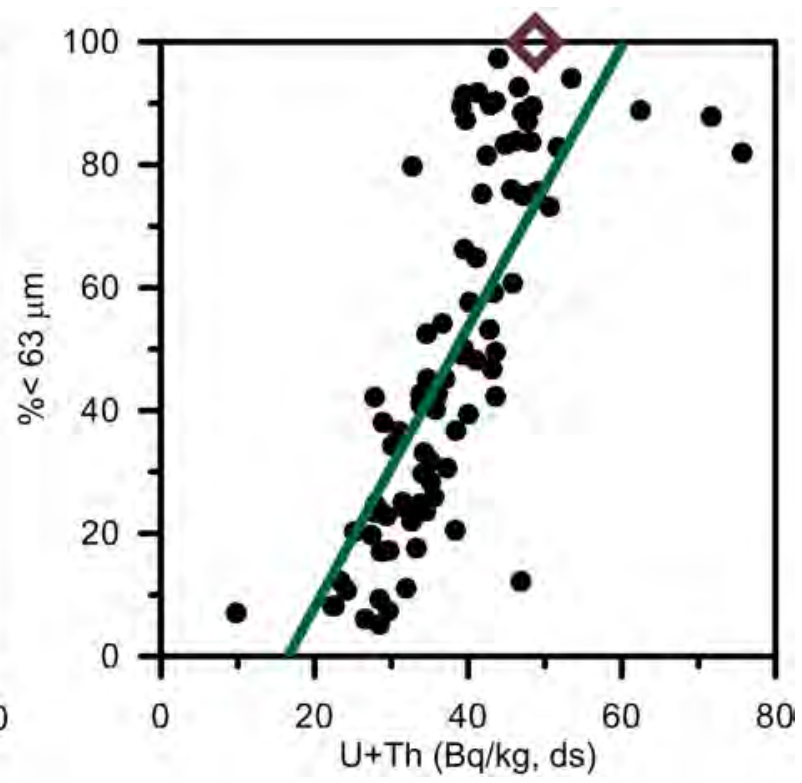

Figure 1: scatterplots of silt content $(\%<63 \mu \mathrm{m})$ vs potassium and $\mathrm{U}+\mathrm{Th}$ for sedimentsamples from various projects around the North Sea.. The resulting numbers of clay fraction are derived from different systems (Malvern, sieving). The brown datapoint is based on measurements of SPM. Only datapoints with a silt fraction $>3 \%$ are plotted.

\section{6 | Hydrol 2}




\section{Defining the benchmark}

The specific concentrations of radionuclides for each sediment fraction (also called fingerprint) allows the measurements of the radionuclides in the sediment to be translated into maps of sediment composition. To determine fingerprint of the material that will end up in the water column as SPM, we need to 1) define the grain size fraction of the SPM; 2) define the content of SPM in sediments from the site.

SPM has been sampled in the field and was analysed with a Malvern particle sizer [Blok, 2010]. These sediments were not pre-treated to remove organic matter or carbonates. Part of the SPM consists of organic matter. We estimated the carbonate content in the sampled material at maximum $10 \%$, the $\mathrm{OM}$ content in the sediment samples is $\sim 1 \%$. It is not clear how much of the OM is involved in the soilwater interaction. The sediment samples located on the position of the PSM samples have been analyzed with the Malvern particle sizer. Because our investigation focuses on the finest fraction of the sediments, the grains $>90 \mu \mathrm{m}$ have been removed. The sediment samples have been pre-treated to remove carbonate and organic matter.
The sieve analyses of these samples from the water column show that $90 \%$ of the SPM is $<35 \mu \mathrm{m}$, with a median grain size of $16 \mu \mathrm{m}$. The analysis of the sediments show a more bimodal type grain size distribution with a slight increase around 10-20 $\mu \mathrm{m}$ (be ware that due to the pre-sieving on $90 \mu \mathrm{m}$, a part of the material might be removed. The closer to 90 $\mu \mathrm{m}$, the more has been removed).

To estimate the mass of fine material that potentially suspends into the water column, we decided to map the content of the fraction $<35 \mu \mathrm{m}$ in the sediment. Therefore, the fraction $<35 \mu \mathrm{m}$ is used as a benchmark for the Medusa measurements.

Previous studies have shown that concentrations of $\mathrm{K}, \mathrm{U}$ and Th differ between clay and sand (Figure 1). Despite the fact that the samples come from different projects and the samples were analyzed with different sieving methods, a clear correlation exists between silt fraction and radionuclide concentration. The concentration of $\mathrm{K}$ in clay is a factor of 2 larger than in sand, the concentration of the sum of $U$ and Th in clay is about a factor 3 larger than in sand. The fingerprint of SPM is determined by taking SPM samples from the water column and by measuring the concentrations of radionuclides of these samples. Also the radionuclide concentration SPM correlates well with the measurements on sediment samples.

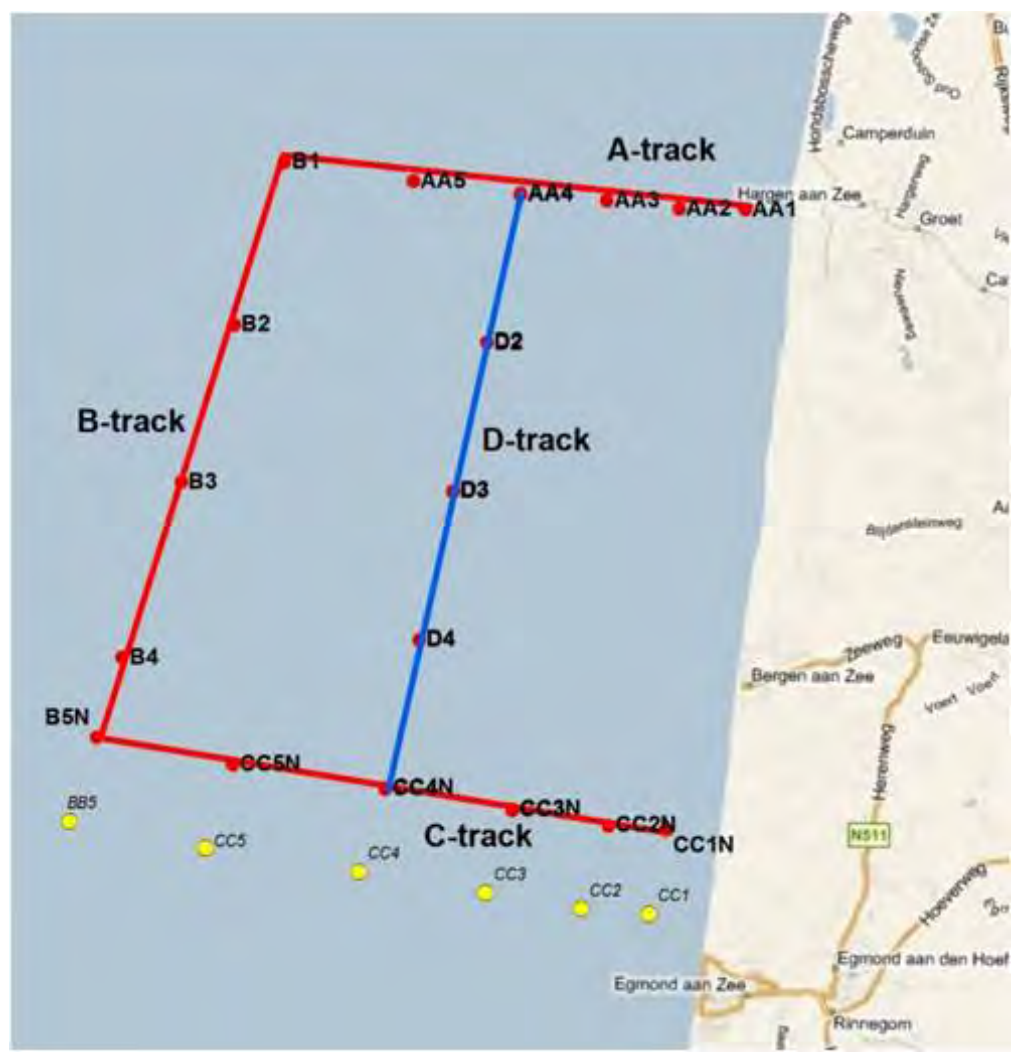

Figure 2: overview of the measured tracks. 

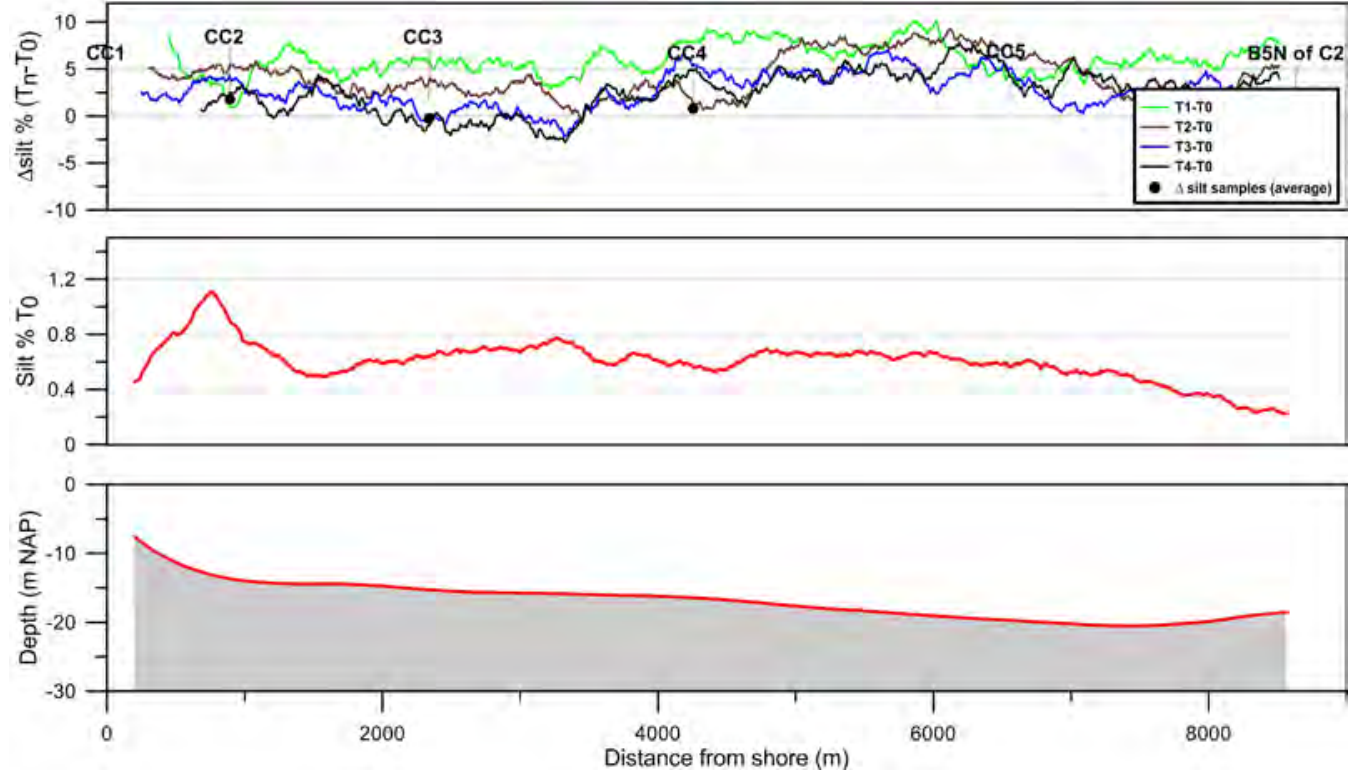

Figure 3: result of the monitoring of track $\mathrm{C}$, with the change in silt fraction, silt content in the T0 measurement and water depth.

\section{MEASUREMENT PROGRAM}

The program focused on two line measurements, with a length of $8 \mathrm{~km}$, perpendicular to the coastline (A and $\mathrm{C}$ track in Figure 2) and two lines, with a length of $10 \mathrm{~km}$, parallel to the coastline (B and D track in Figure 2). The site was located near Bergen aan Zee. In total 6 campaigns were conducted in the period of September 2009-Oktober 2010.

\section{RESULTS}

Figure 3 shows the results of track $\mathrm{C}$. The average silt content is $0.6 \%$ with an increased zone of $1.1 \%$ near the breaker zone around $500 \mathrm{~m}$ from the coast. Sample location CC2 is located in this elevated zone. Further seawards, starting at about $7 \mathrm{~km}$ from the shoreline, the silt-content in the upper layer of the seabed is decreasing to be less than $0.4 \%$.

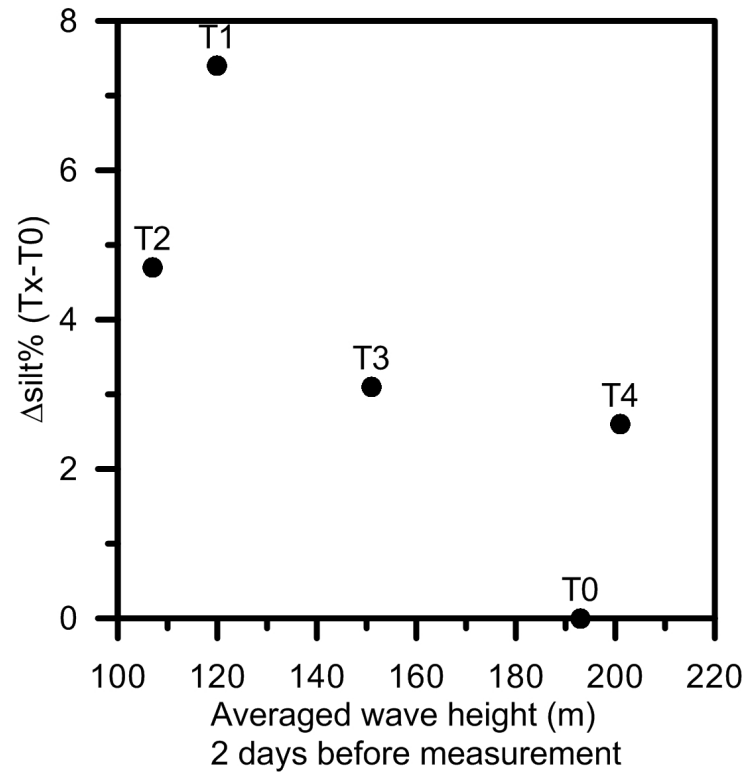

The change in silt content with respect to the T0 measurement of September 2009 is visible in Figure 3. Almost all measurements show a positive deviation from the September measurements, only the region 2000-3500 $\mathrm{m}$ shows a lower silt content in T3 and T4 measurements. The total deviation is between -2.5 and $5 \%$. On the average T1shows the highest changes in silt content and T4 the smallest changes.

\section{DISCUSSION}

The main goal of the study is to understand the buffering of SPM in the sediment. Since we expect that wave action is an important driving force in the mobilization of the fine material, wave heights of the periods before the measurements have been analyzed. As a first exploration, we compared the

Figure 4: change in average silt content as function of averaged wave height before the measurement. 
average wave height 2 days before the measurement with the averaged silt content in the sediment (Figure 4).

The comparison (Figure 4) shows how in the T1 and T2 measurements, silt content is $4-8 \%$ higher than in the T0 measurement. Prior to these campaigns, the wave height is $100-120 \mathrm{~cm}$, which is $80 \mathrm{~cm}$ lower than the wave height prior to the T0 campaign. This small dataset indicates that after a short period with lower wave height, the silt content in the sediment is higher.

\section{CONCLUSIONS}

An intensive study on the grain size distribution and chemical composition of SPM and fine sediments samples from the North Sea, show that the Medusa system is a powerful tool for mapping fine sediments in situ.

A two year monitoring of fine sediments off the coast near Bergen shows that the silt content of sediment changes in space and in time. A first assessment of wave height information and the measured content of fines in the sediment shows how a decrease in wave height, results in a higher silt content in the sediment.

\section{ACKNOWLEDGEMENT}

This project was initiated and funded by Stichting LaMER and Rijkswaterstaat.

\section{REFERENCES}

Blok, B. 2010. Meetvis, Medusa metingen van september en december 2009. 1201293-000, Deltares, Delft.

Du Four, I., Deleu, S., Darras, I., Roche, M., Koomans, R., \& Van Lancker, V. (2005).

Comparison between different seabed classification techniques and validation with sediment samples on two shallow-water dumping sites (Belgian continental shelf). Shallow Survey 2005 4th International conference on high resolution surveys in shallow water, Plymouth, Devon, UK.
Koomans, R.L. and de Meijer, R.J. 2004. Density gradation in cross-shore sediment transport. Coastal Engineering, 51: 1105-1115.

de Meijer, R. J. (1998). "Heavy minerals: from 'Edelstein' to Einstein.” Journal of Geochemical Exploration 62(1-3): 81-103

Ellerbroek, G., M.J.C. Rozemeijer, J.M. de Kok, J. de Ronde (2008) Evaluatieprogramma MER winning suppletiezand Noordzee 2008-2012. RWS Noord-Holland 16 juli 2008

Nederbracht, G. and R. L. Koomans (2005).

Nourishment of the slope of a tidal channel: from experiment to practice. Coastal Dynamics, Barcelona, Spain, ASCE.

Venema, L. B. and R. J. de Meijer (2001). "Natural radionuclides as tracers of the dispersal of dredge spoil dumped at sea." Journal of Environmental Radioactivity 55(3): 221-239.

\section{CONTACT DETAILS}

Koos de Vries

Medusa Explorations BV

Verlenge Bremenweg 4, 9723 JV

Groningen

the Netherlands

Tel.: +31 (0)505770280

Fax: +

Email:koos@medusa-online.com

Web site: www.medusa-online.com

LinkedIn account: http://nl.linkedin.com/pub/koosde-vries/6/5/902

Twitter account: medusaNews

Youtube: MedusaNews 
$330 \mid$ Hydrol 2 


\title{
Application of high resolution acoustics for determination of the physical properties of fluid sediments
}

\author{
Coen WERNER, the Netherlands \\ STEMA Systems
}

Topics: Innovations in acquisition techniques, Innovations in processing techniques, Careful marine planning, Geophysics of the marine environment

\section{INTRODUCTION}

For study of areas with fluid sediments, often a traditional low frequency echosounder is used. However, often this appears not to be reliable. The results consist of a single depth digitalisation value depending on the echosounder settings. The information is difficult to validate, because digital raw data are not included, digitalisation often is not stable and no information about physical properties of the seabed is derived.

The integration of high resolution digital seismic acquisition techniques with low frequency echosounder frequencies provides extensive opportunities for validation of acquired (raw) data. After calibration with geophysical point measurements this type of high resolution acoustics also can be a useful tool for characterization of the physical properties of fluid sediments.

A geophysical point measurement device usually derives a vertical profile with physical parameters versus depth. An example is the RheoTune, which appplies the tuning fork method and produces density and yield strength. Another device is the nuclear transmission/ backscatter [Van Craenenbroeck et al, 1998], that measures density.

This paper presents a case study, that illustrates the application of high resolution digital seismics (Silas system) together with geophysical point measurements using a RheoTune.

The general procedure of used method is described, together with the results that give insight in the potential capability of high resolution acoustics.

It is clear that a more thorough understanding of the physical properties of fluid sediments is important for economical reasons, e.g. for maintenance of the navigable depth. Also this type of information gives extra input to the study of geomorphological dynamics in an area.

\section{AREA AND METHODS}

$\underline{\text { Area }}$

The case study consists of 2 surveys in a channel of a tidal flat area in the Waddenzee (Northern Netherlands). The area can be characterized by significant tidal movements (between app. $+2 \mathrm{~m}$ $-2 \mathrm{~m})$ and related strong tidal currents.

\section{Methods}

Each survey was carried out using a $24 \mathrm{kHz}$ low frequency transceiver combined with a high resolution digital seismic system (Silas EBP-10). Followed procedure is described by Fontein, Byrd [2008].

The complete raw signal was recorded.Subsequently geophysical point measurements were carried out using a RheoTune device (fig.1.) This device measures the in-situ density and yield stress of water and fluid sediment together with depth (pressure), temperature and sensor orientation. The in-situ density is measured using the tuning fork principle [Werner,Fontein, 2010]. In this type of measurement the resonance frequency of the Tuning Fork depends on the density of the medium. The amplitude of vibration is controlled by the yield stress of the medium.

The surveys consist of a calibration survey and a regular survey. During the calibration survey in advance all parameters of the high resolution seismic system were determined during standard barcheck and soundvelocity probe procedures. Initially a number of high resolution seismic lines were run along the longitudinal axis of the area. Based on these recordings, subsequently locations were selected for geophysical point measurements which were carried out relatively shortly afterwards. The geophysical point measurements were situated 
preferably at locations with highest thickness development of fluid mud. At each of the selected points a depth/density/yield stress profile was obtained (fig.2).

The point measurements enabled the density calibration of the high resolution seismics. During this calibration at each location the seismic results (fig. 3A, 3B) are converted into a synthetical density profile (Fig. 3C) in an automated procedure by the software. This is done for different estimates of the arrival power of the signal, the power of the signal that arrives at the seafloor. The calibration ends at the arrival power where the match between the synthetical density profiles from seismic and geophysical point measurements (fig.3D) is optimal. The synthetical densityprofiles are calculated using standard acoustic laws, which relate arrival signal power and reflected power to the physical properties of the sediment [McGee, 1992], which can be described by the impedance, see formula (1).

Impedance $=\rho * \mathrm{v}(1)$

in which:

$\rho=$ density of sediment layer in $\mathrm{kg} . / \mathrm{l}$.

$\mathrm{v}=$ propagation velocity of $\mathrm{p}$-waves in sediment in meters/second
After this calibration, the seismic system produces calibrated synthetic densityprofiles for each seismic shot (fig.3 C) and the depth of a specific densitylevel on any location on the seismic lines.

The calibration was re-used 3 weeks later during a regular survey with the same seismic system for determination of the physical properties of the seabed. During this survey also the same system settings were used. Extra geophysical point measurements provided a check for the accuracy of the calibration.

\section{RESULTS}

\section{Calibration survey}

At the geophysical point measurement locations, high resolution seismic profiles and geophysical point measurements carried out in the same time interval (app. 90 minutes) provide two independend data sets for location of the top of the fluid sediment, the lutocline (table 1).

Explanation of table 1:

Column B: Time difference between seismic and geophysical point measurement (Minutes)

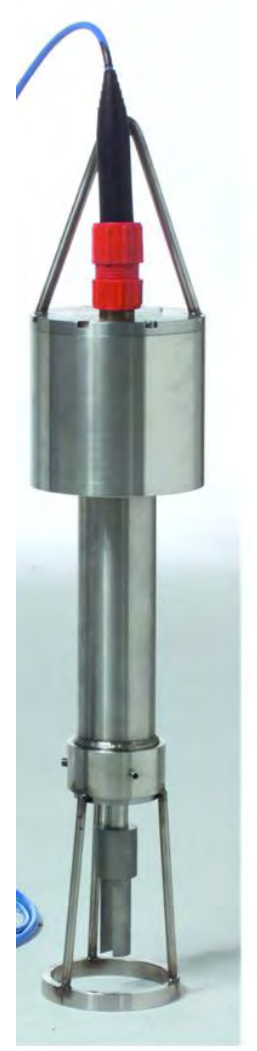

Fig. 1 RheoTune

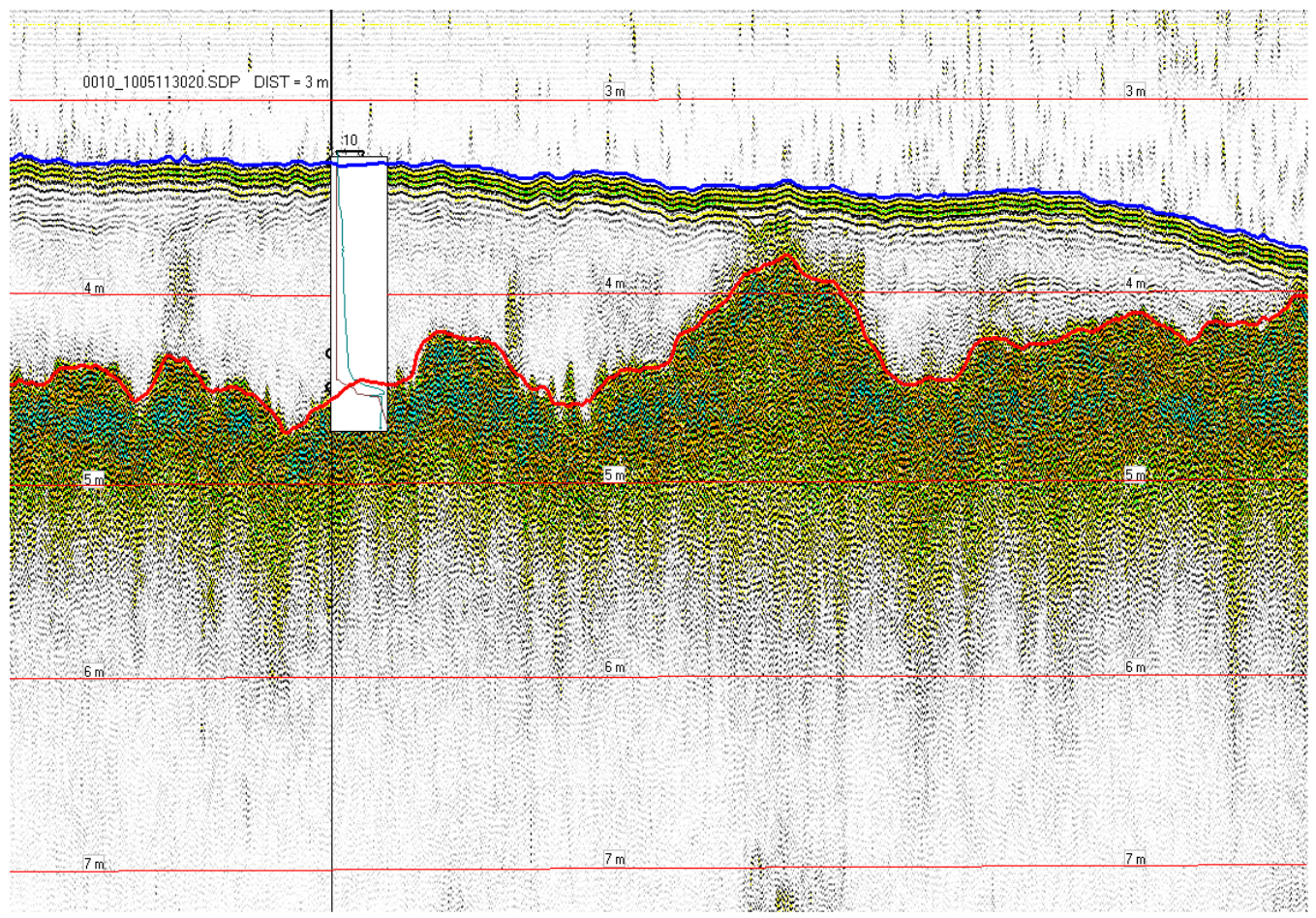

Fig. 2 : High resolution acoustical recording and location of a point measurement in fluid sediment in area of case study. See Appendix for Legend. 


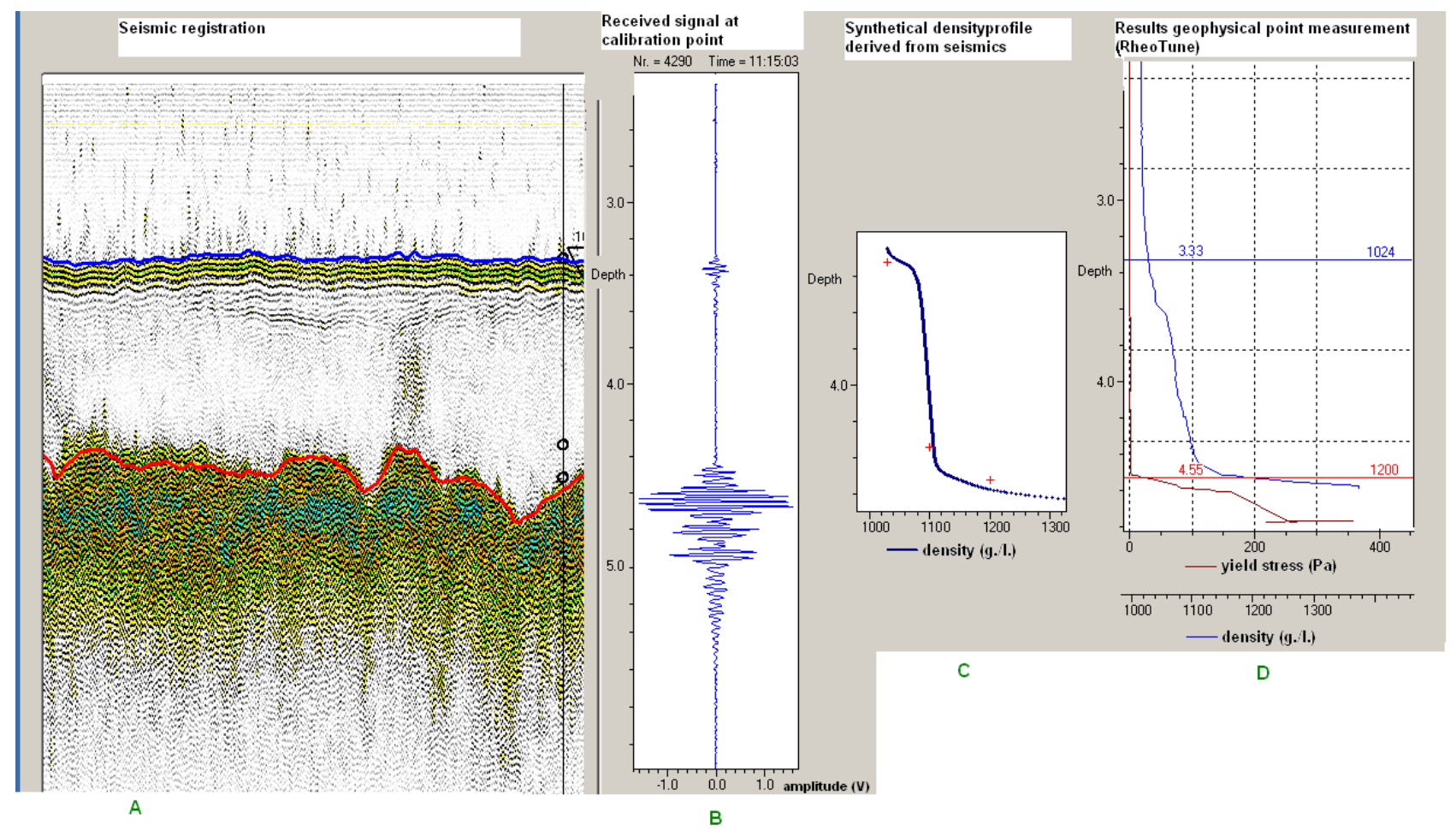

Fig.3 (To be rotated to fill entire page) Procedure of density calibration of high resolution seismics as applied by Silas.

$\mathrm{A}=$ Seismic registration, $\mathrm{B}=$ Received signal at calibration point, $\mathrm{C}=$ Synthetical densityprofile derived from seismics at calibration point, $\mathrm{D}=$ Results geophysical point measurement (RheoTune).

Column C: Distance between seismic and geophysical point measurement (m.)

Column D: Depth first reflector seismic (m. to N.A.P. )

Column E: Depth first density change according to geophysical point measurement (Tune) (m. to N.A.P.)

Column F: Difference between column D and E (m.)

Column G: Density above first density change in geophysical point measurement (g./l.).

Column H: Density gradient at first densitychange in geophysical point measurement in g./l. per $\mathrm{cm}$.
Column I: Length of first densitychange (m)

The relatively small values in Column F of Table 1 show that the location of the first reflector in the seismics corresponds with the first densitychange in the geophysical point measurement. The small values also show that the densitychange was detected by the seismics. Because above data confirm close correspondence between first reflector and first densitychange it is valid to use these measurements for density calibration of the seismics (method described in Section "Area and Methods").

\begin{tabular}{|c|c|c|c|c|c|c|c|c|}
\hline $\begin{array}{l}\text { A } \\
\text { Location } \\
\text { number }\end{array}$ & $\begin{array}{l}\text { B } \\
\text { Time } \\
\text { difference } \\
\text { (minutes) }\end{array}$ & $\begin{array}{l}\text { C } \\
\text { Distance } \\
\text { (m) }\end{array}$ & $\begin{array}{l}\text { D } \\
\text { Depth } \\
\text { seismic } \\
\text { (m.to } \\
\text { N.A.P.) }\end{array}$ & $\begin{array}{l}\text { E } \\
\text { Depth } \\
\text { (Tune) } \\
\text { (m to } \\
\text { N.A.P.) }\end{array}$ & $\begin{array}{l}\text { F } \\
\text { Depth Difference } \\
\text { D-E (m) }\end{array}$ & $\begin{array}{l}\text { G } \\
\text { Arrival } \\
\text { Density } \\
\text { (g./l.). }\end{array}$ & $\begin{array}{l}\mathrm{H} \\
\text { Density } \\
\text { Gradient } \\
(\mathrm{g} . / \mathrm{l} / \text { per } \mathrm{cm})\end{array}$ & $\begin{array}{l}\text { I } \\
\text { Inter- } \\
\text { val } \\
(\mathrm{m})\end{array}$ \\
\hline $0001 \_759$ & 63 & 2 & 3.58 & 3.47 & 0.11 & 1024 & 1.72 & 0.11 \\
\hline $0001 \_409$ & 67 & 4 & 4.00 & 3.88 & 0.12 & 1020 & 5.38 & 0.13 \\
\hline $0003 \_657$ & 71 & 2 & 4.09 & 3.98 & 0.11 & 1021 & 8.7 & 0.07 \\
\hline 0006_924 & 41 & 2 & 3.40 & 3.51 & -0.11 & 1026 & 0.45 & 0.11 \\
\hline $0007 \_724$ & 37 & 3 & 3.42 & 3.45 & -0.03 & 1026 & 1.18 & 0.16 \\
\hline $0008 \_211$ & 40 & 0 & 3.29 & 3.22 & 0.07 & 1027 & 0.27 & 0.40 \\
\hline $0009 \_614$ & 33 & 4 & 3.40 & 3.09 & 0.31 & 1023 & 0.55 & 0.25 \\
\hline 0010_020 & 15 & 3 & 3.32 & 3.33 & -0.01 & 1024 & 0.42 & 0.28 \\
\hline \multirow[t]{2}{*}{ 0011_449 } & 34 & 1 & 3.53 & 3.51 & 0.02 & 1027 & 0.43 & 0.16 \\
\hline & & & & & StDev $=0.12$ & $\begin{array}{l}\text { Average }= \\
1024\end{array}$ & & \\
\hline
\end{tabular}

Table 1. Results of calibration survey: Top of fluid sediment 
After calibration the geophysical point measurements provided an extra check for the accuracy of the $1200 \mathrm{~g} . / 1$. density level in seismic synthetical densityprofiles. The difference between densitylevels predicted by seismic and the level measured by the geophysical point measurement does not exceed $+-0.2 \mathrm{~m}$, with a standardeviation of $0.12 \mathrm{~m}$.. These variations are similar to observed variability at the lutocline (Table 1).

\section{$\underline{\text { Regular survey }}$}

The regular survey was carried out after 3 weeks in the same area. The same system settings and the calibration described above were applied to measure the location of the $1200 \mathrm{~g} . / 1$. level.

Geophysical point measurements finally provided a check for accuracy and validity of the re-used density calibration (see table 2). The difference between $1200 \mathrm{~g}$./l. densitylevels predicted by seismic and the level measured by the geophysical point (Tune) measurement does not exceed +-0.22 $\mathrm{m}$. (Standarddeviation $0.16 \mathrm{~m}$.). These values are slightly higher than during the calibration survey. Several point measurements could only be derived with time differences larger than 70 minutes and are consequently less representative.

\section{$\underline{\text { Results: Yield strength }}$}

The geophysical point measurements of the Tune indicate the yield strength of the fluid sediment is generally low and does not exceed 20 Pascal. The yield strength of the majority of the fluid sediment is lower than 5 Pascal. This makes the sediment more susceptible to currents and dynamic behaviour. In investigated area under the 1200 g./l. density level often a sharp transition is observed to yield strengths exceeding $100 \mathrm{~Pa}$.

It is important to notice that a lower yield strength will have less effect on vessel manouvrability. Consequently the yield stress is also an important parameter for maintenance of the navigable depth. How to integrate Rheological parameters (such as yield stress and viscosity) as extra criteria beside density for navigability is still under investigation.

\section{DISCUSSION}

\section{Calibration of seismic}

At the top of fluidized sediments the lowest density gradient is $0.27 \mathrm{~g} . / 1$. (Table 1 ) which is detected by high resolution seismics. This is however a single observation and possibly due to time mismatch between seismic and geophysical point measurement. After rejection of this single value, table 1 confirms a seismic detection capability for densitygradients of at least $0.4 \mathrm{~g} . / 1 \mathrm{per} \mathrm{cm}$.

There might be some influence on presented standdarddeviation values for accuracy of calculated synthetic densitylevels, because of:

- Time difference between seismic and geophysical point measurement

- Horizontal distance between location of geophysical point measurement and seismic line

\begin{tabular}{|c|c|c|c|c|c|c|}
\hline $\begin{array}{l}\text { A } \\
\text { Location } \\
\text { number }\end{array}$ & $\begin{array}{l}\text { B } \\
\text { Time } \\
\text { difference } \\
\text { (minutes) }\end{array}$ & $\begin{array}{l}\text { C } \\
\text { Distance } \\
\text { Seismics } \\
\text { and point } \\
\text { measure- } \\
\text { ment }\end{array}$ & $\begin{array}{l}\text { D } \\
\text { Depth } \\
1200 \text { g./l. } \\
\text { level seismic } \\
\text { (m. to } \\
\text { N.A.P. ) }\end{array}$ & $\begin{array}{l}\text { E } \\
\text { Depth } \\
1200 \text { g./l. } \\
\text { level (Tune) } \\
\text { (m to } \\
\text { N.A.P.) }\end{array}$ & $\begin{array}{l}\text { F } \\
\text { Depth Difference } \\
\text { synthetic } 1200 \\
\text { g./l. }-1200 \mathrm{~g} . / \mathrm{l} . \\
\text { (Tune) in } \mathrm{m} \text {. }\end{array}$ & $\begin{array}{l}\mathrm{G} \\
\text { Thickness } \\
\text { Fluid sediment above } \\
1200 \mathrm{~g} . / \mathrm{l} \text {. level in m. }\end{array}$ \\
\hline $005 \_607$ & 39 & 7 & 4.0 & 3.82 & 0.18 & 0.98 \\
\hline $003 \_848$ & -72 & 2 & 4.35 & 4.57 & -0.22 & 0.96 \\
\hline $001 \_453$ & -77 & 10 & 4.75 & 4.91 & -0.16 & 1.47 \\
\hline $06 \_214$ & -80 & 6 & 4.31 & 4.16 & 0.15 & 1.03 \\
\hline $011 \_632$ & 23 & 6 & 4.79 & 4.74 & 0.05 & 1.51 \\
\hline $012 \_438$ & 20 & 2 & 4.65 & 4.86 & -0.21 & 1.25 \\
\hline $013 \_242$ & 17 & 5 & 4.54 & 4.63 & -0.09 & 1.25 \\
\hline \multirow[t]{2}{*}{ 014_924 } & 13 & 2 & 4.70 & 4.70 & 0.00 & 1.38 \\
\hline & & & & & StDev $=0.16$ & \\
\hline
\end{tabular}

Table 2. Verification of results of regular survey: seismic synthetic 1200 g./l. Levels compared with 1200 g./l. levels resulting from geophysical point measurements (Tune). Smallest diferences are generally found at time differences under 24 minutes. Explanation:

Column D: Depth calibrated synthetic 1200 g./l. level seismic (m. to N.A.P. ) 
True values for accuracy could be better, but are difficult to verify. In order to improve seismic density calibrations presented a larger number of geophysical point measurements can be adopted.

\section{$\underline{\text { Area dynamics }}$}

Largest accummulations of fluid sediment occur in the $1.5 \mathrm{~km}$ long nearshore channel area in the center section. The situation however proved to be dynamic, because the surveyresults show significant changes in location of the top of fluid sediment layer after app. 90 minutes.

Short term changes at deeper levels in the fluid sediment such as the $1200 \mathrm{~g} . / 1$. density level, are less pronounced.

Most changes in the state of the fluid sediment layer could be related to sediment transport due to tidal currents.Occasionally also dramatic state changes in the fluid sediment were observed. In the majority of these occasions a relation with ship traffic was confirmed.

\section{CONCLUSIONS}

The presented information leads to following conclusions:

- The digital high resolution seismic registration provides more information than the results of a traditional echosounder and provides higher relability and more verification options.

- High resolution seismic proves to be a useful tool for characterization the physical properties of fluid sediments. The calibration survey indicates this type of the seismic can detect relatively small densitygradients of $0.4 \mathrm{~g}$./l. per $\mathrm{cm}$ in fluid sediment of low yield strength $(<5$ $\mathrm{Pa})$

- The application of the density calibration for the seismics proved to be valid for at least three weeks, with a standarddeviation of $0.16 \mathrm{~m}$. for the difference between 1200 g./.1. seismic synthetical densitylevels and 1200 g./.1. densitylevels of geophysical point measurements.

- The geophysical point measurements of the Tune indicate the yield strength of the fluid sediment in investigated area is generally below $20 \mathrm{~Pa}$. The yield strength of the majority of the fluid sediment is lower than 5 Pascal.

\section{REFERENCES}

1. K. van Craenenbroeck, J. Duthoo, M. Vandecasteele, J.A. Eygenraam and R. Van Oostveen, Application of Modern Survey Techniques in Today's dredging Practice (Terra et Aqua nr. 72, 1998). 6-8

2. W.F. Fontein and R.W. Byrd, The nautical depth approach, a review for implementation (WODCON XVIII Annual Dredging Seminar,2007)

3. R.G. Mc Gee, and Robert F. Ballard, An Acoustic impedance method for subbottom material characterization ( Hydraulic Engineering sessions at water forum, 1992).

4. C. J. Werner and W.F. Fontein,Tune systems: general principle of operation (STEMA, 2010)

\section{CONTACT DETAILS}

\section{Coen WERNER}

STEMA Systems b.v.

Poppenbouwing 52,

4190 CB Geldermalsen

NETHERLANDS

Tel.: +31345580395

Fax: +31345570649

Email:coen.werner@stema-systems.nl

Web site: www.stema-systems.nl 
336 | Hydrol 2 


\section{High-resolution geophysical survey for the exploration of near surface sand resources at the southern Kenyan coast using a multi source strategy}

Ane P. WIERSMA and P.J.F. FRANTSEN, the Netherlands

Deltares

P.N.W. VERHOEF, the Netherlands

Royal Boskalis Westminster N.V

Topics: Careful marine planning, Geophysics of the marine environment

\section{INTRODUCTION}

The nearshore coastal geology in large parts of the world is relatively unknown. However, economic interest in these nearshore areas is increasing, as valuable resources such as aggregates for harbour construction and mineral deposits experience increasing demand. The coastal zones were formed by large relative sea-level variations and changing sediment sources and supply. This results in an often complex setting with interacting depositional environments and associated morphology.

Nearshore coastal zones are often explored by carrying out shallow seismic surveys on a grid with a spacing of several hundred meters. The seismic data are then ground-truthed by a series of corings. This method works sufficiently in relatively uncomplicated areas with laterally continuous geology. In complex areas that have experienced periods of incision and deposition and consist of various sedimentary environments, working with a single geophysical method is not preferable as important indications for changing sedimentary environments are easily overlooked.

In this study we present the results of geophysical research in a previously unexplored area along the southern coastal zone of Kenya. This area has been assigned as a source area for the extraction of sand of sufficient quality for a harbour construction project nearby. The setting of the area is in front of a coral reef on a narrow passive continental shelf of 2 to 3 kilometers wide. Literature from the onshore area shows a complex geological history with periods of (relative) uplift and incision, and existing bathymetry charts suggest the presence of narrow valleys and submerged plateaus (Thompson, 1956; Oosterom, 1988; Abuodha, 2004). Because of the complexity and size of this area a geophysical survey was especially designed to explore near surface sand occurrences. The survey consisted of a combination of acquisition techniques and included a combined high-resolution swath bathymetry / side-scan sonar system and a chirp sub-bottom profiler. Using these methods, the area is mapped for potential sand occurrences.

\section{METHODS}

The equipment used for geophysical research of the southern coastal zone of Kenya consisted of a chirp sub-bottom profiler and a combined swath bathymetry - side-scan sonar system. All systems acquired simultaneously. Recent studies using both systems in one sweep, showed that interference between both the systems is negligible and that the quality of the collected data was good.

\section{$\underline{\text { Sub-bottom profiler }}$}

For this project an Edgetech SB512i sub-bottom profiler tow-fish was used. The system emits an acoustic signal of finite duration during which the frequency increases linearly. The acoustic signal is reflected by density contrasts within the shallow subsurface. Density contrasts are associated with changes in lithology. The received signal is transmitted to a computer system that processes and stores the data. The depth range below seabed that is covered by the signal depends on the material properties. A subsurface with high energy absorption leads to a smaller depth penetration. Maximum penetration in a sand body will be up to 7 meter, whereas in more fine-grained deposits the penetration can be up to over $20 \mathrm{~m}$. The result of the processed data is a profile that shows the primary reflectors with a minimum of noise. 
With a ping rate of two pings per second, and a surveying speed of 3 to 4 knots, the coverage of the surveyed area was about $1.0 \mathrm{~m}$ between each ping along the sailing line. A vertical resolution of $0.25 \mathrm{~m}$ and a maximum penetration of $18 \mathrm{~m}$ have been attained. The total track length of the survey was $780 \mathrm{~km}$.

\section{Bathymetry and side-scan sonar}

The bathymetry and side-scan sonar data were acquired with a Klein Hydrochart 5000 (HC5000) (Ai and Parent, 2011). This system can simultaneously collect high-resolution phase difference bathymetric sonar (PDBS) and high resolution multibeam side-scan sonar data. A CODA F185 motion sensor provided navigation and corrected the HC5000 data for ship motion. The specifications of the HC5000 indicate that the system is accurate up to depths below the fish of approximately 50 meters. We used a maximum swath range of 100 meters (total swath 200 meters), which provided accurate data for most depths.

\section{Ground truthing}

For ground truthing, a total of 79 vibrocores reaching a depth of up to 5 meter were executed. The sediment logs were used for the interpretation of the geophysical data.

\section{GEOLOGICAL SETTING}

The Kenyan coast is part of a passive continental margin. The continental shelf is $2-3 \mathrm{~km}$ wide with depths dropping off to over 200 meters within less than $4 \mathrm{~km}$ from the coastline in most places. Reefs run parallel to the entire shoreline at a distance of 1-2 km, only locally intersected by rivers. The coastal zone has experienced eustatic sea-level oscillations and/or isostatic and differential tectonic movements, which reflected by elevated coastal terraces onshore and submerged terraces offshore (Abuodha, 2004; Oosterom, 1988; Thompson, 1956).

The survey area is offshore of a fringing coral reef with shallow back-reef lagoons. In the north, the reef is interrupted by the entrance of the Mombasa creek systems, in the south the reef is interrupted by a River. The cliffed coast on the landward side of the lagoon mainly consists of Pleistocene reef limestones and back-reef deposits. Further, inland, the rock formations consist of a thick sequence of mainly shales, sandstones and conglomerates of Upper Carboniferous to Upper Jurassic age, gently dipping towards the coast (Rees et al., 1996). In such a setting, the sediments offshore are expected to be dominated by mainly carbonates derived from the reef / back reef system, and possibly siliciclastics from present day or ancient fluvial systems. The back-reef deposits will mainly consist of carbonate sand, silt and mud, while the slope in front of the reef will probably consist of coarser sediments, including reef limestone blocks, gravel and sand. More distal, these slopes may grade into sands and mud. Note that especially in the backreef environment, cementation can take place in relatively young sediments. Siliciclastics are mainly expected in areas with a sediment source from the inland catchments.

\section{RESULTS}

A series of 48 lines, with a spacing of $50 \mathrm{~m}$ were recorded parallel to the coast, and for correlation purposes, 99 cross-lines were recorded perpendicular to the coast, with a spacing of $250 \mathrm{~m}$. The $50 \mathrm{~m}$ spacing was chosen because of the expected complexity of outcrop systems and the $250 \mathrm{~m}$ spacing was chosen in order to obtain also sufficient coverage with the side-scan sonar in this direction.

\section{$\underline{\text { Seismics }}$}

Two reflectors were interpreted in the area of interest, the seabed reflector and a base sediment reflector (Figure 1). The seabed reflector was very strong, suggesting absence of soft material (e.g. mud) at the top. The second reflector was interpreted as the boundary between the base of unconsolidated sediments and the top of hardrock. This reflector varied from very strong to weak to invisible if the sediments on top of the hardrock were over 6 meter. The outcrops are characterised by an irregular surface appearance and a smudgy (scattered) reflection signal and lack of reflectors below the sea- floor reflector.

\section{Bathymetry and side-scan sonar}

After processing and editing of the bathymetric data, a bathymetric model of the survey area was

\section{8 | Hydrol 2}


constructed with a grid-cell size of $2 \times 2 \mathrm{~m}$. The depth is indicated in meters below Lowest Astronomical Tide (LAT). The model shows shallow areas of around 10 meters in front of the harbour entrance and in front of the coral reefs, a wider plateau with depth ranging from $35-45$ meters and a steep cliff going down to depths of more than 80 meters. Several areas clearly show a rough seabed morphology, with pinnacles, cliffs and steep-walled channels, while other areas show smoother terrain. The bathymetric model allows for a large-scale classification into morphological units.

The Side-scan sonar data were processed and mosaiced. On the resulting acoustic sea-bed images rock outcrops as well as the character of the sea-bed sediment (e.g. course or fine) and the presence of rubble and boulders can be identified.

\section{INTERPRETATION}

The sediment thickness model derived from the sub-bottom profiler data shows several areas with an unconsolidated sediment cover of several meters. Areas interpreted from the bathymetry data (Figure 2) and side-scan sonar data confirm the presence of these unconsolidated sediment bodies. The sidescan sonar provides additional information about the sediment character of these sediment bodies, while the bathymetry model provides information about the geometry and morphology of the sediment bodies. In combination with vibrocore data providing information about the sediment types, different geomorphological units could be identified in the surveyed near-coastal zone. Working with such units has the advantage that sediment composition (e.g. siliciclastic or carbonate), gradual variations in grain size and sorting, and potential threats for damage to dredging equipment can be predicted within the units.

The side-scan sonar images indicate that these areas have a smooth surface without notable rubble or rocky outcrops. Other areas show an irregular surface, consisting, e.g., of rock pinnacles and boulders and do not appear promising for sand extraction.

The combination of the acoustic systems applied in this study provides insight in the regional submerged near-surface geology and can be used to classify the study area in morphological units in front of the coast. In figure 2 the units that were identified in the area of interest are presented and discussed.

\section{Reef slope}

In front of the reefs, steep slopes are present. On the side-scan sonar images rubble and boulders can be recognized on these slopes, suggesting very coarse deposits. These slopes are interpreted as reef-front deposits consisting of eroded reef material. The deposits are expected to consist of badly-sorted carbonate components, ranging from sand to (very big) boulders.

\section{Submerged fans}

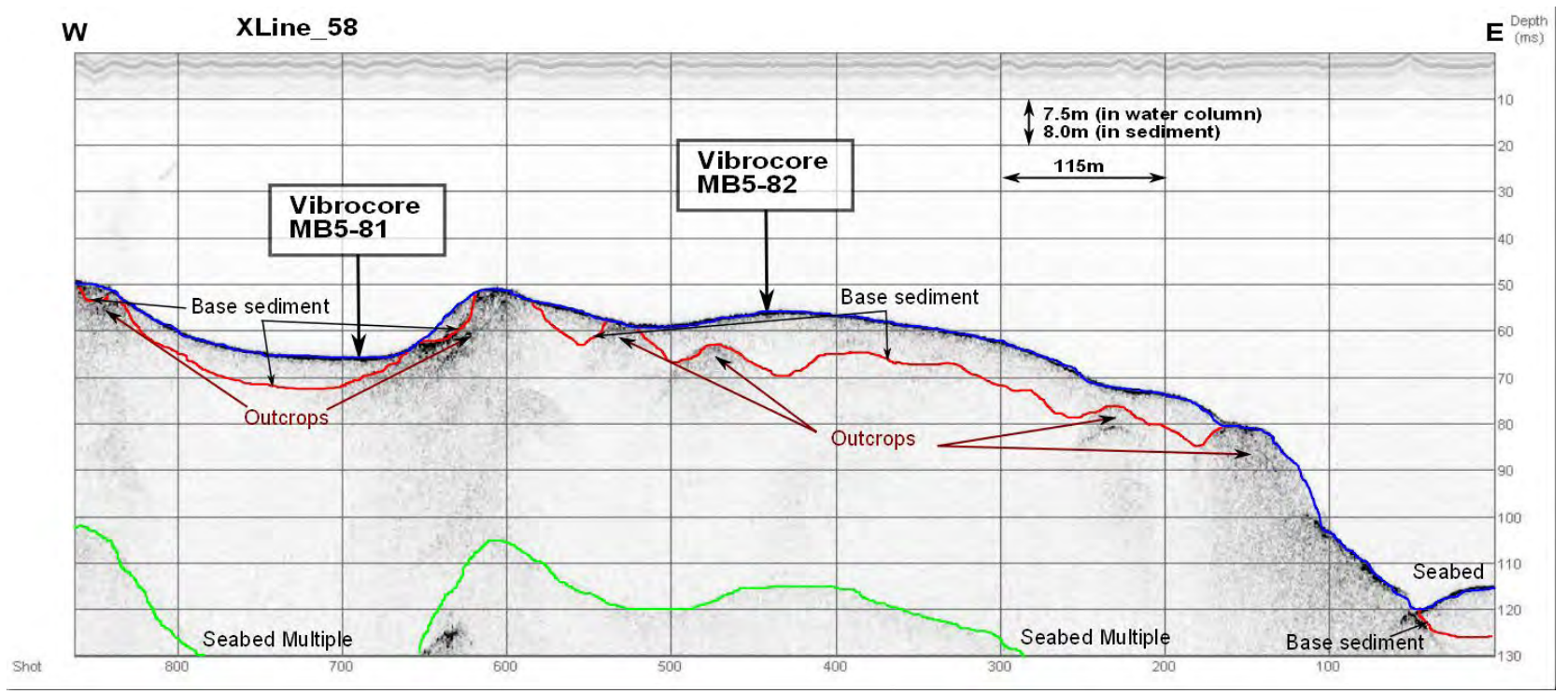

Figure 1. Example of an interpreted W-E seismic cross-section in the area, showing hardrock outcrops, locally covered by a sediment body, the base of which is indicated by the "base sediment reflector". 


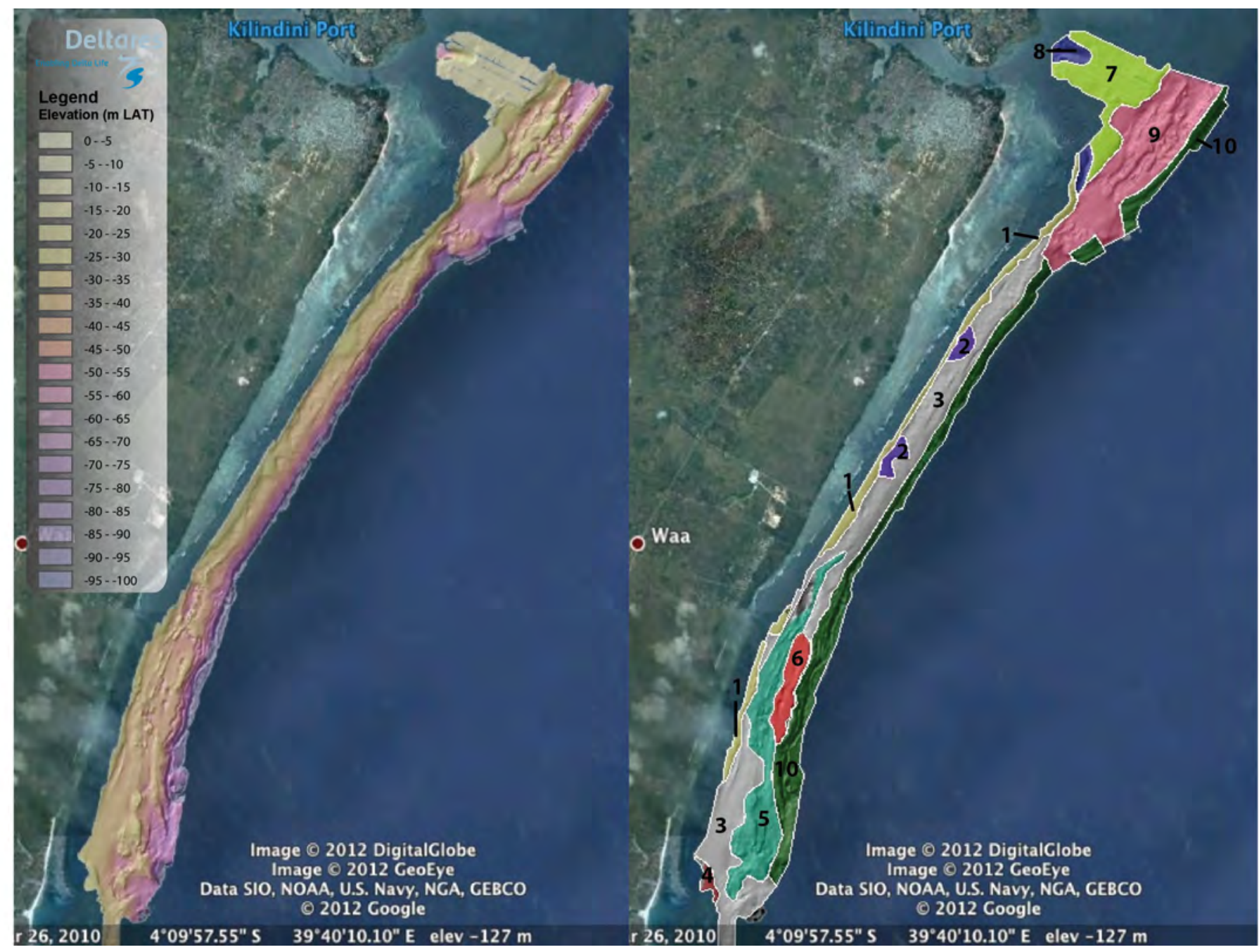

Figure 2. (left) bathymetrical model of the study area and (right) identified morphological units. The image is 15 kilometers wide and 22 kilometers high.

In certain areas, gently-dipping submerged fans are present. When plotted on air photographs, these submarine fans coincide with openings in the reef front. This suggests that the fans are fed by back-reef sediments that are transported seawards, probably during (storm) surges. The side-scan sonar images show a regular smooth surface at these locations, suggesting unconsolidated fine-grained sediments.

The back-reef deposits consist of calcareous (skeletal) sand, silt and mud. Therefore, the submarine fans most likely consist of the same material, but possibly sorting takes place during transport, leading to relatively finer sediment in the distal part of the fans.

\section{Submerged plateau:}

The submarine fans spread out on a submarine plateau with a depth of 35 to 45 meters below LAT. The seismic data suggest the occurrence of a thin layer $(<1 \mathrm{~m})$ of sediment on this plateau. A smooth area in the south appears to have a thicker cover. The side-scan sonar data and the bathymetry support this interpretation and show a surface with a sediment cover regularly interrupted by rocky outcrops, often aligned parallel to the coast. This plateau is interpreted as a drowned back reef environment, with patch reefs sticking through the surface sediments.

\section{Delta front}

In the south of the survey area, a river flows into the lagoon and through an opening in the coral reef. In front of this opening a submerged fan is present in the bathymetry and seismic data, interpreted as a delta front. Because the river catchment is mainly situated in shale and sandstone formations, sediments in the delta front are expected to contain terrestrial (siliciclastic) material. However, the side-scan sonar images at this location do not fully support this interpretation and indicate rubble on the sea-bottom. This suggests that also eroded reef material may be transported from the reefs and lagoons to be deposited in this submerged fan. The submerged plateau in front of this interpreted delta front appears to have a 
sediment cover of about two meter. These deposits do show a fine texture on the side-scan sonar images, and may also consist of the sediments transported by the river.

\section{Reef pinnacles}

The submarine plateau in the south is littered with steep pinnacles. We interpret these pinnacles that are often aligned as drowned patch reefs that may have kept in pace with sea level rise for a while. The tops of the pinnacles are up to 30 meters below the seasurface, and living corals may be still be present at this depth.

\section{Submerged back-reef deposits}

In front of the pinnacles in the southern part, an area covered with a sediment layer of several meters thick is present. This is evident from the sediment thickness map derived from the seismics, but also from the bathymetry map where a smooth blanket with some large scale scour holes is present. Also the side-scan sonar images suggest loose sediment at this location. This isolated sediment cover has no obvious source. Therefore, we tentatively interpret the sediment body as submerged back-reef deposits. Another explanation could be that the sediments are the remnants of former submarine fans (in front of the reefs producing the aligned pinnacles) deposited during a stage with lower sea levels, or eolian dunes formed during a lowstand period. An equivalent of the latter are also preserved onshore as the Kilindini Formation on a Pleistocene coastal terrace (Rees, 1996; Abuodha, 2004).

\section{Wave-cut platform}

In the northern part of the survey area, a shallow platform can be recognized with a depth of about 8 meters. The flatness of this unit suggests that it is a former wave-cut platform during a stage with lower sea-level. A submarine terrace with this depth was first recognized by Thompson (1956). The side-scan sonar images indicate a rocky surface littered with boulders.

\section{Incised channels}

Through the wave-cut platform, steep-walled meandering channels have been incised during low stand periods. The bottom level of these channels is currently about 40 meters deep. The bathymetric map and seismics suggest a sediment body overlying the base of the channel. Sediments in this unit are probably a mixture between carbonate material from back-reef deposits, and siliciclastic material from the river catchments and estuary inland of Mombasa.

\section{Incised platform}

In the north, the submarine plateau is incised by deep channels, with a base level of about 60 meters LAT. These channels were probably formed during a lowstand period and are the seaward equivalent of the narrow incised valleys around Mombasa.

\section{0. paleo-reef front}

Seaward of all units described here is a steep submarine cliff dropping from $40 \mathrm{~m}$ to over $80 \mathrm{~m}$ depth. This cliff may be a former fringing reef front that was drowned after a lowstand period. During the sea-level rise the coast stepped backwards and a new fringing reef was formed in front of the coast. The origin of this cliff is possibly also fault related, as the NNE-SSW orientation is parallel to the major faults in this area (Abuodha, 2004). Of these systems, we expect the Units 2, 3 (in the south), 4 and 6 to be the most promising for potential sand extraction. The incised channels of Unit 8 appear to have a sediment infill, especially on the seaward side, but the incised channels are very narrow in extent which may imply navigational complications while dredging. The sand extraction potential for the other units is very low, as big boulders may be present (Unit 1), abundant rock pinnacles may stick out from the sea bed (Unit 5), they consist of a rocky flat surface (Unit 7), they consist of deep channels flanked by steep cliffs with only patchy sediment pockets (Unit 9), or they consist of rocky outcrops flanked by a steep-walled cliff dropping to depths of over 80 meters (Unit 10).

\section{CONCLUSION}

A multi-source geophysical exploration strategy in complex areas facilitates the interpretation and allows the translation of geophysical data into geomorphological units. Working with geomorphological units enables a more comprehensive prediction of sediment character (e.g. grain size, sorting), sediment chemistry, lateral and vertical variations within units and the presence of potential hazardous objects for dredging equipment. Other areas can be discarded due to the presence of cliffs, rocky surfaces, large boulders or high content of fine sediments. Knowledge of these factors allows 
for an improved estimation and can reduce costs in later stages of the project. In addition, the enhanced knowledge of depositional environments can be used for reducing environmental risk.

\section{REFERENCES}

Abuodha, Pamela A. W. 2004. "Geomorphological evolution of the southern coastal zone of Kenya," Journal of African Earth Sciences 39: 517-525.

Ai, Yuhui and Parent, Marc. 2011. "Performance analysis using an uncertainty model for Hydrochart 5000," Sea Technology, June 2011 (ISSN 00933651).

(http://www.1-3klein.com/wp-content/ uploads/2008/05/Performance-AnalysisHydroChart-5000.pdf)

Oosterom, A.P. 1988. "The geomorphology of southeast Kenya," Ph.D. Dissertation. Wageningen Agricultural University, The Netherlands, 227p.

Rees, J.G., Williams, T.M., Nguli, M.M., Kairu, K.K. and Yobe, A.C. 1996. "Contaminant transport and storage in the estuarine creek systems of Mombasa, Kenya.” Report British Geological Survey, Keyworth, UK.

Thompson, A.O. 1956. "Geology of the Malindi area." Report 36, Mines and Geological Department, Ministry of Environment and Natural Resources, Nairobi, Kenya, 63p.

\section{CONTACT DETAILS}

Ane WIERSMA

Deltares

Applied geology and geophysics

Postbus 85467

$3508 \mathrm{AL}$

Utrecht

The Netherlands

Tel: +31(0)653171668

Ane.wiersma@deltares.nl 


\title{
Grid Models versus TIN: Geometric Accuracy of Multibeam Data Processing
}

\author{
Alain DE WULF ${ }^{1}$, Denis CONSTALES ${ }^{2,3}$, Timothy NUTTENS ${ }^{1}$, Cornelis STAL ${ }^{1}$ \\ ${ }^{1}$ Ghent University, Department of Geography \\ ${ }^{2}$ Ghent University, Department of Mathematical Analysis \\ ${ }^{3}$ Ghent University, Laboratory for Chemical Technology
}

Topic C: innovations in processing techniques

\section{INTRODUCTION}

Multibeam echosounder measurements serve to make a digital terrain model of the sea floor. The Delaunay triangulation is a widely appreciated and investigated mathematical model to represent the sea floor topography and is highly efficient for building triangular irregular networks (TINs) out of non-homogeneous data such as raw multibeam data.

Obtaining an accurate model of the sea floor is a major concern in dredging works. Contemporary hydrographical surveying tools, especially the multibeam echosounder, yield a very dense sampling of the sea floor. Consequently, this immense amount of data needs to be processed to generate an accurate terrain model, according to time and accuracy constraints imposed by the client. Modeling can be carried out in post-processing or in real-time, performing a real-time accountability which keeps track of the "cut" or "fill" volume changes realized at that moment. Most multibeam systems deliver equidistant interpolated data, allowing faster processing to be achieved by using equidistant grid modeling. Both modeling techniques (TIN and grid) yield their own advantages and drawbacks. In this paper, the standard deviation of the volume computed directly in a TIN model or indirectly by interpolating a (usually equidistant) point set in a TIN model is derived.

\section{SEA FLOOR MAPPING}

Obtaining an accurate model of the sea floor is a major concern in dredging works. Nowadays' hydrographic surveying tools, especially the multibeam echosounder, yield a very dense point sampling of the sea floor. The immense amount of data needs to be processed (e.g. filtering or data reduction), to form an accurate terrain model, according to some constraints imposed by the client. Modeling can be performed in post-processing or in real-time. Performing a real-time accountability will keep track of the haul, realized at some moment.

DTM (Digital Terrain Model) software for hydrographic purposes must meet the following four requirements:

1. Fast model creation: the purpose is to create the model as fast as the data is gathered, so that real-time control and verification are possible;

2. Editing (manual or automatic) of the model: adding data points as well as deleting data points (vertices) in the model are both required. When examining the theoretical model of a site, intervening directly in the model as it is displayed on the computer monitor is a prerequisite, by relocating, deleting or adding vertices. It should also be possible to replace data from resurveyed areas with more recent data, and to update the existing model with this new information;

3. To include the possibility of data reduction: reduce the large amounts of multibeam data to acceptable levels, keeping the sea floor model as accurate as possible, but the data set manageable for the used computers;

4. Data quality control: the final result in the form of volume calculations should be as close to the truth as possible and certainly not further away than acceptable, assuming that the acceptable quality level is realizable. In order to qualify the data, different statistical tools can be applied (Höhle \& Höhle, 2009). The final data model and the derived volume computation should give a correct approximization of the real situation. The acceptability of the model is related to the measurement device, as well as to the requirements of the client. Grid models and TINs are the most frequently used models in hydrography (Brouns, De Wulf and Constales 2001), offering different kinds of advantages and drawbacks. Both terrain representations are discussed with their advantages and drawbacks. Grid based filtering approaches (Wack and Wimmer 2002) and TIN based filtering approaches are intensively discussed in the field of airborne laser scanning, using similar techniques. The distinction between TIN based and grid based filtering 
techniques can be made by respectively an original point set filtering and a filtering based on interpolated equidistant cells.

In general, filtering techniques can be divided in four categories (Krzystek 2003);

- $\quad$ Least squares interpolation(Briese and Kraus 2003);

- $\quad$ Local slope based filtering (Vosselman 2000; Sithole 2001);

- $\quad$ Morphological filters (Zhang et al. 2003);

- $\quad$ Convex hull filtering (Krzystek 2003).

\section{GRID MODELING}

Nowadays, most multibeam systems offer equidistant grid data as default output of the on-line and on-board processing chain. The plane coordinate system used is generally a square grid with the axis parallel to the Easting and Northing axis of the grid coordinate system used. Since the use of GNSS (Global Navigation Satellite System) equipment, the universal transverse Mercator coordinate system (UTM) in relation to the ETRS89 datum (referencing the global ellipsoid GRS80) has established itself as the standard grid system in Europe.

Height/depth values can be related to a universal reference (e.g. the WGS84 and GRS80 ellipsoid, LAT, geoid...) or, in most cases, to a conventional reference plane. In the latter case, if the GNSS receiver onboard the vessel gives the height above the WGS84 ellipsoid, a conversion matrix between ellipsoid and the reference plane used should be given. Alternatively, the older technique of tide gauges can be used, in which case the measured depths are related to the water surface and the water surface is related to the reference plane by means of tide gauges. This leaves the grid interval distance as the unique and most important user-defined parameter.

The use of equidistant points allows to store only the depth values in computer memory and not the Easting and Northing values, since these values can be computed out of the row and column number of each point, assuming (for instance) that the point storage is performed in a row-wise manner in the computer memory. Memory use can be optimized by using arrays of integer values that, for dredging based surveys, can be limited to only 2 byte for each depth or point, giving a range of 216 or 65536 height/depth values, or a range of approximately $65 \mathrm{~m}$ with the $\mathrm{mm}$ as unit.

\section{TIN BASED MODELING}

\section{Principle}

It is a common practice to use the Delaunay triangulation (Brouns, De Wulf, and Constales 2003) to construct a TIN rather than other, less restrictive, triangulations. In a Delaunay triangulation, the circumscribing circle of any triangle contains no other vertices (Shewchuk 1996).

Triangles whose circumcircle does contain another vertex are invalid and need to be replaced by another triangle by a process called edge flipping; this principle is shown in Figure 1 (left, middle). The triangles $a b c$ and $a c d$ are not Delaunay triangles, since they contain respectively $d$ and $b$ in their circumscribing circles. After flipping the edge $a c$ to $b d$, the triangles $a b d$ and $b c d$ are created, which do not contain other vertices in their circumscribing circle. They therefore meet the Delaunay requirement.

Figure 1 (right) represents what is called edge completion: when four points are co-circular, the resulting quadrilateral is (arbitrarily) split in two separate triangles. This constitutes a degenerated case as either of the two diagonals can be constructed. 

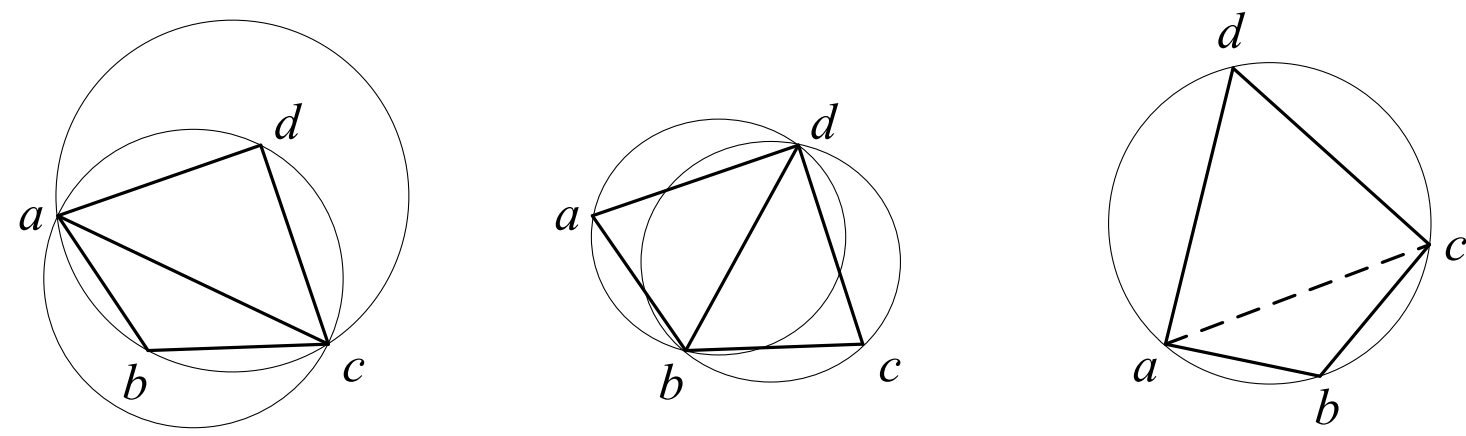

Figure 1: Delauney triangle principle

It can be proven (Shewchuk 1996) that the Delaunay triangulation of a set of vertices is unique; this is an important quality asset towards the client, as it allows him to repeat the calculations to verify the results independently.

\section{Advantages and drawbacks of grid models versus TINs}

It can be a requirement of the client of dredging/reclamation projects that the original measured points have to be in the digital terrain model from which the volumes are derived. This requirement allows the client to check the original results in a 3D modeling environment, which simplifies the validation of the point set. TINs are a favorite scheme to construct a DTM from a sea floor, measured at discrete spots. Grid models, compared to TINs, have three important drawbacks:.

1. It is generally impossible to have each sampled point of a TIN associated to one grid height/depth, since the measurements are not on a regular grid. Instead, the mutual distances depend on the survey ship's survey system (equally spaced measurements or not) and attitude (roll, pitch, yaw);

2. Grid values do not reflect the actual measurements, since gridding means either assigning interpolated values when the measurement density is inferior to the grid density, or resampling and loss of information, when the measurement density is superior to the grid size, the latter introduces unwanted "smoothing" in the DTM;

3. The grid model is not adaptive: whereas TINs will naturally represent areas with detailed relief information with a denser triangle pattern than areas with a smoother relief, grids will be far less flexible to cope with variable levels of detail.

TINs do not have these drawbacks, but they are more demanding towards computer memory and processing time. Moreover, the algorithms needed for geometric computations are more sophisticated.

\section{ACCURACY OF TIN BASED VOLUMES}

\section{Volume computation in a TIN}

Volume computations in TINs or grid models are quite straightforward. In a TIN model, a prismatic volume is computed between a horizontal reference level and each triangle, on the condition that in planimetry, the triangle is inside the area where the volume has to be computed. Furthermore, it is assumed that for hydrographic volume computations the most important stochastic error is the altimetric error and that the planimetric positioning errors can be neglected as the sea floor is rather flat. Quite often, especially when a difference of volumes has to be computed, an equidistant set of points is interpolated in the TIN(s): this allows to construct a difference model for which the height/depth of each point is the difference of interpolated heights/depths in both TIN models. Hereunder, a synthesis of the mathematical analysis of both cases is performed. We assume a set of $n$ original points that will be triangulated and, in a second step, a set of $m$ points interpolated in the TIN:

$$
\begin{gathered}
\text { TIN }=\left\{f_{i} \in A: A \subset \mathbb{R}^{3}: i=0 \ldots n\right\} \\
\text { Subset }=\left\{\widetilde{f}_{l} \in B: B \subset \mathbb{R}^{3}: i=0 \ldots m\right\}
\end{gathered}
$$

Figure 1: Delauney triangle principle 
The variance of the volume for both steps will be computed, based on a constant variance for each initial height/depth value $f_{i}$. We assume a stochastic error, implying that all systematic errors have already been corrected. With $A_{j}$ the planimetric surface of a triangle $j, f_{\text {ref }}$ the height of the horizontal reference plane and $f_{i}$ the elevation of the three vertices $i$ of the triangle, the volume $V_{j}$ generated by one triangle $j$ is equal to (Figure 2):

$$
\left(\frac{1}{3}\left(f_{1}+f_{2}+f_{3}\right)-f_{r e f}\right) A_{i}=V_{j}
$$

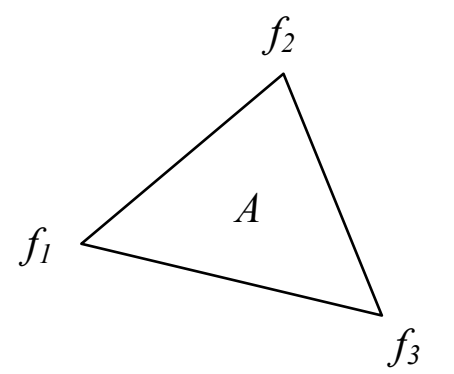

Figure 2: Triangle with elevations $f_{i}$ and surface $\mathrm{A}$

The total volume $V$ of the TIN is the sum of the volumes of all individual prisms, thus:

$$
\frac{1}{3} \sum_{i} f_{i}\left(\sum_{f_{i} \in A_{j}} A_{j}\right)-f_{\text {ref }} A_{\text {total }}=V
$$

If we call $B_{i}$ the sum of the surfaces of all triangles with point $i$ as vertex or:

$$
B_{i}=\left(\sum_{f_{i} \in A_{j}} A_{j}\right)
$$

Then we can write:

$$
\frac{1}{3} \sum_{i} f_{i} B_{i}-f_{\text {ref }} A_{\text {total }}=V
$$

Assuming that all $f_{i}$ are independent, the variance of the volume can be written, as we proved in De Wulf et al. (2012), in either of two equivalent ways:

or:

$$
\operatorname{Var}(V)=\frac{\operatorname{Var}(f)}{9} \sum_{i} B_{i}^{2}
$$

$$
\operatorname{Var}(V)=\operatorname{Var}(f) \frac{1}{n} A_{\text {total }}^{2} \cdot\left[1+\left(\frac{\sigma(B)}{\bar{B}}\right)^{2}\right]
$$


The question we have to solve here is "what is the variance (or loss of accuracy) when we base the volume computation on a set of $m$ random points interpolated in a TIN (Figure 3)?"

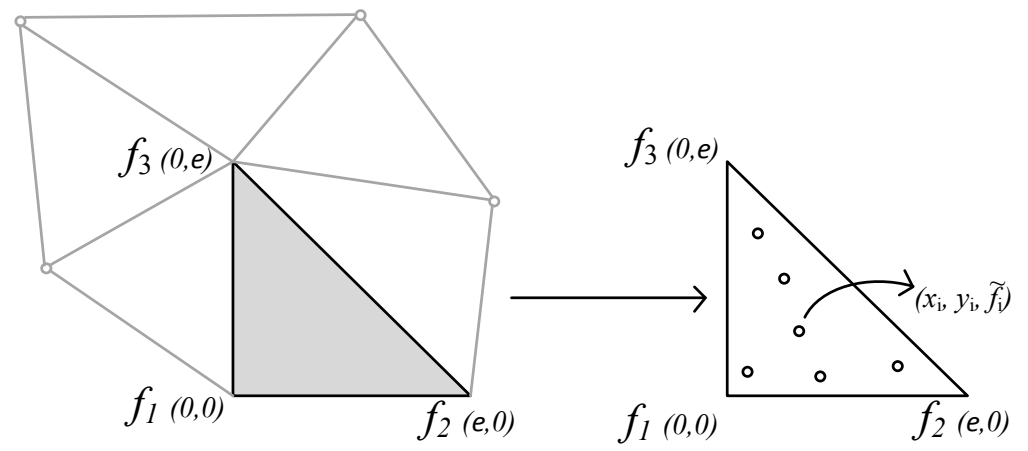

Figure 3: Assumed structure of a triangle with $m_{\Delta}$ points, having elevation values $\tilde{f}_{i}$

Without loss of generality, we can assume a rectangular triangle with corner points at the origin $(0,0)$, the point $(\varepsilon, 0)$ and the point $(0, \varepsilon)$. The result for non-rectangular triangles will prove identical. If the set of $m$ points are equidistant points instead of random points, the variance will be smaller, and the random case under study can be seen as a "worst case" scenario.

We assume that the true height over the triangle can be obtained by linear interpolation, but that the measurement is affected by an error term $\sigma(x, y)$ which is zero on average and whose square's expectation value is the general measurement error. The complete mathematical derivation will be published soon but leads to the result that

$$
\operatorname{Var}(V)=\sum_{\Delta} \frac{A_{\Delta}^{2}}{m_{\Delta}}\left(\frac{1}{4} \operatorname{Var}\left(f_{\Delta}\right)+\operatorname{Var}(f)\right)
$$

The variance is a sum over all triangles, where, within each triangle, $m_{a}$ the number of interpolated points, $\operatorname{Var}(f)$ the a priori assumed stochastic measurement error, $A_{A}$ the planimetric surface and $\operatorname{Var}\left(f_{s}\right)$ the variance of the heights of the 3 vertices.

Combining both steps, the construction of a TIN and computing the volume based on a new set of $m$ points interpolated in that TIN, the global variance becomes:

$$
\operatorname{Var}(V)=\sqrt{\operatorname{Var}(f) \frac{1}{n} A_{\text {total }}^{2} \cdot\left[1+\left(\frac{\sigma(B)}{\bar{B}}\right)^{2}\right]+\sum_{\Delta} \frac{A_{\Delta}^{2}}{m_{\Delta}}\left(\frac{1}{4} \operatorname{Var}\left(f_{\Delta}\right)+\operatorname{Var}(f)\right)}
$$

\section{CONCLUSIONS}

Multibeam echosounder data impose some specific requirements to the processing. These requirements have been identified and the different aspects of DTM construction by grid modeling and by Delaunay triangulation have been treated in this context and opposed to each other as two alternatives, of which the advantages and drawbacks have been discussed.

Editing the model is significantly more complex when TINs are used in comparison to regular spaced grids. The authors use an adapted merge-step in the divide-and-conquer algorithm to replace old data

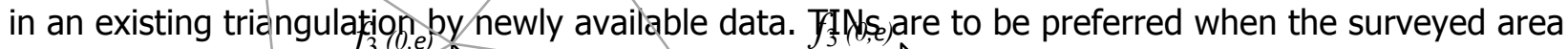
has a non-homogeneous cov rage.

Equidistant grid modeis are 1 fexible, but offer higher $\$$ lower memory requirements and

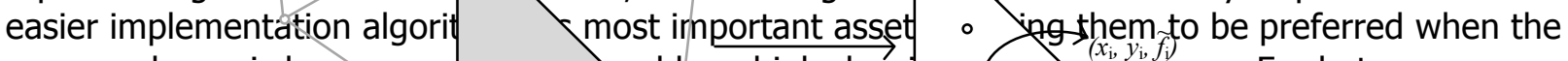
measured area is homogene red by a high-densi covered areas, typical for sin yeys, TINs are a $\quad \circ \quad \circ$ fferred option. A mathematical form for the standard devation of TIN bfased, volum $f_{1}$ co,mputations hafs been proposed, either based on irreqular spaced points 
Prof. Dr. ir. Alain De Wulf is professor, working on quality aspects of geodesy and land surveying in general. He also has a special interest in hydrography and is developing specialized software for the processing and quality assessment of hydrographic 3D acquisition sensors.

Dr. Denis Constales is a researcher both in the Department of Mathematical Analysis and in the Laboratory for Chemical Technology at Ghent University.

MSc. Timothy Nuttens is a teaching assistant at the department of Geography and PhD student working on the use of high accuracy terrestrial laser scanning for deformation measurements of newly built concrete tunnels ('Diabolo Project', Zaventem and 'Liefkenshoek Railway Connection Project', Antwerp, Belgium).

MSc. Cornelis Stal is a PhD student working on the combination of airborne and terrestrial laser scanning for 3D city modelling. His special interest is in the (automatic) generation of geometric, radiometric and semantic rich 3D models, derived from irregular point sets and other spatial datasets.

\section{CONTACT DETAILS}

Prof. dr. ir. Alain De Wulf

Ghent University - Department of Geography

Krijgslaan 281 (Building S8)

B-9000 Ghent, BELGIUM

Tel. +32 92644983

Fax. +3292644985

Email: Alain.DeWulf@UGent.be

Web site: http://geoweb.ugent.be/data-acquisition-3d

\section{REFERENCES}

Briese, C., and K. Kraus. 2003. "Laser-Geländemodelle: Zusammenspiel von Filterung und Datenreduktion". In Photogrammetrie-Fernerkundung-Geoinformation: Auf dem Weg zu operationellen Prozessketten in Photogrammetrie, Fernerkundung und Geoinformation Bochum, Germany: Publikationen der Deutschen Ges.ellschaft für Photogrammetrie, Fernerkundung und Geoinformation. 9 p. (on CD-ROM).

Brouns, G., A. De Wulf, and D. Constales. 2003. "Delaunay triangulation algorithms useful for multibeam echosounding." Journal of Surveying Engineering no. 129 (2):79-84.

Brouns, Gert, Alain De Wulf, and Denis Constales. 2001. "Multibeam data processing: adding and deleting vertices in a Delaunay triangulation." Hydrographic Journal no. 101:3-9.

De Wulf, A, D. Constales, C. Stal, and T. Nuttens. 2012. Accuracy ascpects of processing and filtering of multibeam data: grid modeling versus TIN based modeling. Paper read at FIG Working Week, 6-10 May 2012, at Rome, Italy: 6 p. (on CD-ROM).

Höhle, J., and M. Höhle. 2009. "Accuracy assessment of digital elevation models by means of robust statistical methods." ISPRS International Journal of Photogrammetry and Remote Sensing no. 64 (4):398-406.

Krzystek, P. 2003. "Filtering of Laser Scanning Data in Forest Areas using Finite Elements." International Archives of Photogrammetry and Remote Sensing no. 34 (3):6 p. (on CD-ROM).

Shewchuk, J. 1996. "Triangle: engineering a 2D quality mesh generator and Delaunay triangulator" In Applied Computational Geometry Towards Geometric Engineering, edited by L. Ming and M. Dinesh, 203-222. Heidelberg, Germany: Springer.

Sithole, G. 2001. "Filtering of laser altimetry data using a slope adaptive filter." International Archives of Photogrammetry and Remote Sensing no. 34 (3):203-210.

Vosselman, G. 2000. "Slope based filtering of laser altimetry data." International Archives of Photogrammetry and Remote Sensing no. 33 (B3):935-942.

Wack, R., and A. Wimmer. 2002. "Digital terrain models from airborne laser scanner data: a grid based approach." International Archives of Photogrammetry and Remote Sensing no. 33 (Part 3):293-296.

Zhang, K., S. C. Chen, D. Whitman, M. L. Shyu, J. Yan, and C. Zhang. 2003. "A progressive morphological filter for removing nonground measurements from airborne LiDAR data." IEEE Transactions on Geoscience and Remote Sensing no. 41 (4):872-882. 
Hydro 12 | 349 
350 | Hydrol 2 
$\begin{array}{lllll}\text { T. Kearns } & - & - & - & \end{array}$

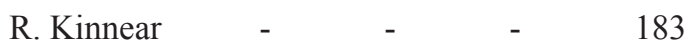

J. Aardoom $\quad-\quad$ - $\quad$ - 5

A. Annaert $\quad-\quad$ - $\quad$ - $\quad$ - 45

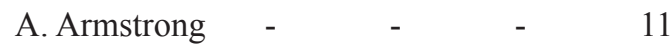

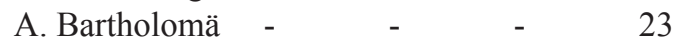

$\begin{array}{lllll}\text { U. Barjenbruch } & - & - & - & 99,247\end{array}$

\begin{tabular}{lllll} 
J. Beaudoin & - & - & - & \\
\hline
\end{tabular}

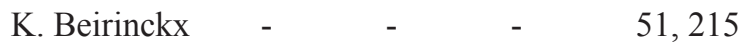

$\begin{array}{lllll}\text { A. Bijlsma } & - & - & - & 117\end{array}$

$\begin{array}{lllll}\text { C. Blasi } & - & - & - & 99\end{array}$

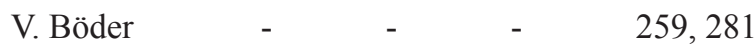

V. Bosselmann-Borsos $\quad-\quad\left[\begin{array}{lll}- & & 147\end{array}\right.$

$\begin{array}{lllll}\text { L.N. Brisson } & - & - & - & 105\end{array}$

O. Büchsenschütz-Nothdurft $\quad$ - 147

$\begin{array}{lllll}\text { O. Cantrill } & - & - & - & 17\end{array}$

R.M. Capperucci - $\quad$ - $\quad$ - 23

$\begin{array}{lllll}\text { F. Claeys } & - & - & - & 5\end{array}$

$\begin{array}{lllll}\text { S. Claeys } & - & - & - & \end{array}$

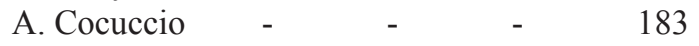

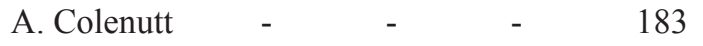

$\begin{array}{lllll}\text { C. Collins } & - & - & - & 35\end{array}$

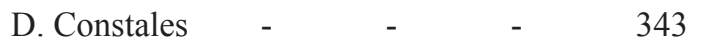

$\begin{array}{lllll}\text { R. Côté } & - & - & - & 41\end{array}$

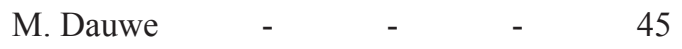

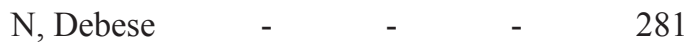

D. Depreiter $\quad-\quad 5 \quad-\quad 51$

$\begin{array}{lllll}\text { B. Dierikx } & - & - & - & 29\end{array}$

$\begin{array}{lllll}\text { T. van Dijk } & - & - & - & 57\end{array}$

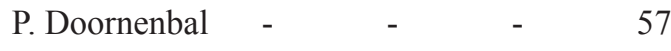

$\begin{array}{lllll}\text { L. Dorst } & - & - & - & 57,117,289\end{array}$

$\begin{array}{lllll}\text { M. Doucet } & - & - & - & 81\end{array}$

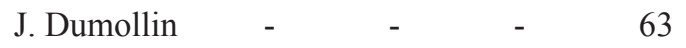

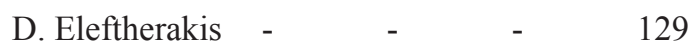

$\begin{array}{lllll}\text { K. Epke } & - & - & - & 195\end{array}$

S. Ni Fhlaithearta $\quad-\quad$ - 5

J.B. Ferriera Fontes $\quad-\quad$ - $\quad 69$

$\begin{array}{lllll}\text { P.J.F. Frantsen } & - & - & - & 337\end{array}$

$\begin{array}{lllll}\text { R. Furness } & - & - & - & 11\end{array}$

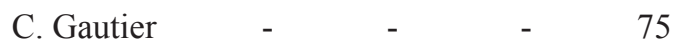

$\begin{array}{lllll}\text { L. Gee } & - & - & - & 81\end{array}$

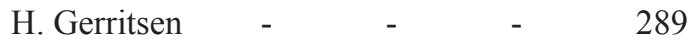

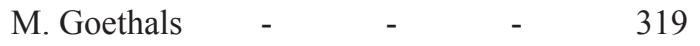

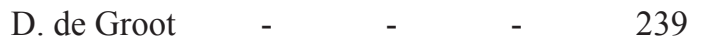

K. Gunning - $\quad$ - $\quad$ - $\quad 87$

$\begin{array}{lllll}\text { S. Gysens } & - & - & - & 319\end{array}$

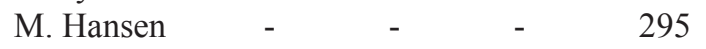

$\begin{array}{lllll}\text { S. Harper } & - & - & - & 87\end{array}$

$\begin{array}{lllll}\text { P.T. Harris } & - & - & - & 93\end{array}$

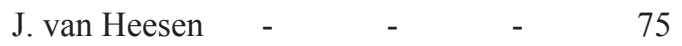

$\begin{array}{lllll}\text { H. Hein } & - & - & - & -\end{array}$

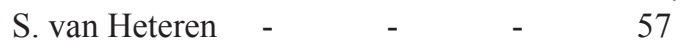

105,111

$\begin{array}{lllll}\text { T. Hiller } & - & - & - & 105,1 \\ \text { B. Hoogendoorn - } & - & - & 57\end{array}$

$\begin{array}{lllll}\text { M. Hounjet } & - & - & - & 117\end{array}$

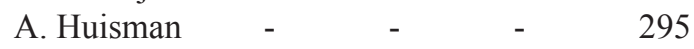

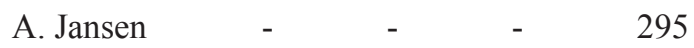

$\begin{array}{lllll}\text { A. Jenks } & - & - & - & 307\end{array}$

$\begin{array}{lllll}\text { G. Johnston } & - & - & - & 11\end{array}$

$\begin{array}{lllll}\text { C. de Jongh } & - & - & - & 63\end{array}$

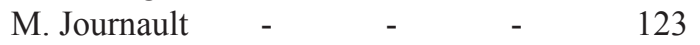

N. Kinneging - $\quad$ - $\quad$ - $\quad$ - 129

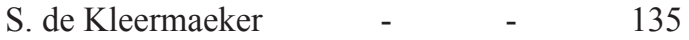

$\begin{array}{lllll}\text { R. Klees } & - & - & - & 289\end{array}$

$\begin{array}{lllll}\text { M. Kleuskens } & - & - & - & \end{array}$

$\begin{array}{lllll}\text { J.K. Klippen } & - & - & - & 141\end{array}$

$\begin{array}{lllll}\text { J. de Kok } & - & - & - & \end{array}$

$\begin{array}{lllll}\text { M. Kol } & - & - & - & 153\end{array}$

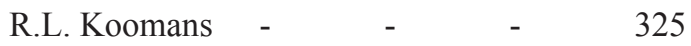

$\begin{array}{lllll}\text { F. Köster } & - & - & - & 147\end{array}$

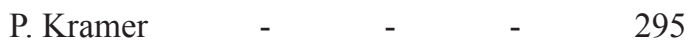

$\begin{array}{lllll}\text { J. Kroos } & - & - & - & \end{array}$

$\begin{array}{lllll}\text { D. Kruimel } & - & - & - & 17\end{array}$

H. Lekkerkerk $\quad-\quad$ - $\quad$ - 153

$\begin{array}{lllll}\text { M. Libert } & - & - & - & \end{array}$

$\begin{array}{lllll}\text { G. Liek } & - & - & - & 51\end{array}$

$\begin{array}{lllll}\text { R. Longhorn } & - & - & - & \end{array}$

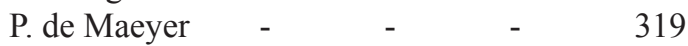

$\begin{array}{lllll}\text { S. Mai } & - & - & - & 99,247\end{array}$

$\begin{array}{lllll}\text { D. Mallace } & - & - & - & 165\end{array}$

$\begin{array}{lllll}\text { L. Maltais } & - & - & - & 41,123\end{array}$

$\begin{array}{llll}\text { R.M. Malyankar - } & - & - & -\end{array}$

$\begin{array}{lllll}\text { T. Mason } & - & - & - & 183\end{array}$

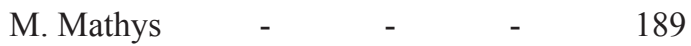

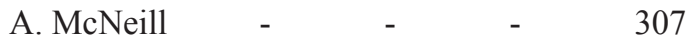

$\begin{array}{lllll}\text { E. Meire } & - & - & - & \end{array}$

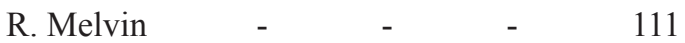

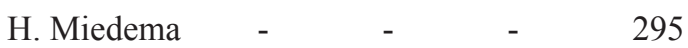

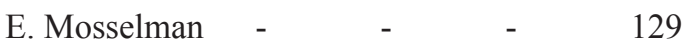

$\begin{array}{lllll}\text { R. Moitié } & - & - & - & 281\end{array}$

$\begin{array}{lllll}\text { M. A. Morin } & - & - & - & -\end{array}$

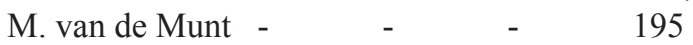

$\begin{array}{lllll}\text { S. Murthy } & - & - & - & -\end{array}$

$\begin{array}{lllll}\text { J. Nistad } & - & - & - & 265\end{array}$

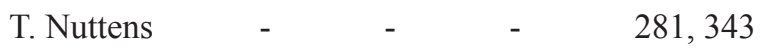

H.O. Odunsi $\quad-\quad \quad-\quad-\quad-\quad 209$

$\begin{array}{lllll}\text { D. Parker } & - & - & - & 81,183\end{array}$

$\begin{array}{lllll}\text { S. Paul } & - & - & - & \end{array}$

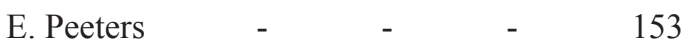

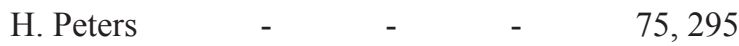

$\begin{array}{lllll}\text { M. Peters } & - & - & - & 295\end{array}$

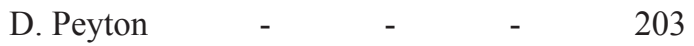

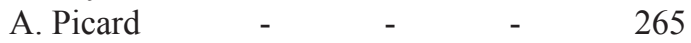

$\begin{array}{lllll}\text { Y. Plancke } & - & - & - & \end{array}$

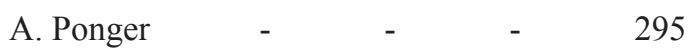

H. Poppe - $\quad-\quad$ - 5

B.M.J. Possel - $\quad-\quad-\quad-223$

$\begin{array}{lllll}\text { J. Pötrönen } & - & - & - & 229\end{array}$

$\begin{array}{lllll}\text { I. Probst } & - & - & - & 281\end{array}$

$\begin{array}{lllll}\text { V. Putans } & - & - & - & \end{array}$

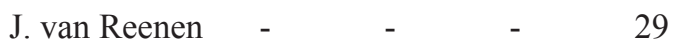

D. Rodriguez Aguilera $\quad$ - $\quad$ - $\quad 57$

$\begin{array}{lllll}\text { R. Roels } & - & - & - & 153\end{array}$

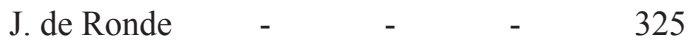

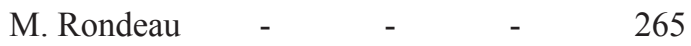

$\begin{array}{lllll}\text { F. Roose } & - & - & - & 189\end{array}$

M.J.C. Rozemeijer $\quad$ - $\quad$ - $\quad 325$

$\begin{array}{lllll}\text { B. Ruesink } & - & - & - & \end{array}$

$\begin{array}{lllll}\text { S. Rütten } & - & - & - & 247\end{array}$

$\begin{array}{lllll}\text { S. Salter } & - & - & - & 253\end{array}$

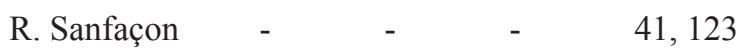




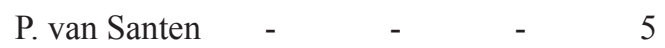

$\begin{array}{lllll}\text { M. Sas } & - & - & - & 51,189\end{array}$

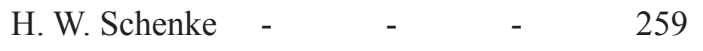

$\begin{array}{lllll}\text { L. Schiller } & - & - & - & 259\end{array}$

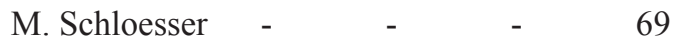

N. Seube

A. Sieben

D. Simons

C. Slobbe

M. Snellen

A. van der Spek -

B. Spelt

C. Stal

A. Steingrimsson

E. Stuifbergen

H. Swiegers

R. Thain

T. Touzé

L. Tsoulos

R. van der Velden

D. Ventura
$11,265,277,281$

129

129

289

129

57

295

281, 343

111

301

223

307

265, 281

11

195

307,311 $\begin{array}{lllll}\text { P. Verburgh } & - & - & - & 295\end{array}$

$\begin{array}{lllll}\text { E. Verfaillie } & - & - & - & 319\end{array}$

$\begin{array}{llll}\text { P.N.W. Verhoef - } & - & - & 337\end{array}$

M. Verlaan ～- $\quad$ - $\quad$ - $\quad$ - $\quad 117,135,289$

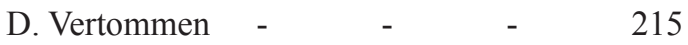

L. Vonhögen-Peeters $\quad$ - $\quad$ - 57

$\begin{array}{lllll}\text { G. Vos } & - & - & - & 215\end{array}$

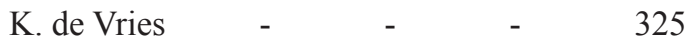

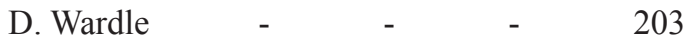

$\begin{array}{lllll}\text { T. Weber } & - & - & - & 81\end{array}$

$\begin{array}{lllll}\text { I. Wenneker } & - & - & - & \end{array}$

$\begin{array}{lllll}\text { C. Werner } & - & - & - & 331\end{array}$

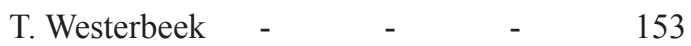

$\begin{array}{lllll}\text { D. Wells } & - & - & - & 87\end{array}$

A.P. Wiersma $\quad-\quad \quad-\quad-\quad-\quad 337$

$\begin{array}{lllll}\text { J. Wilhelmi } & - & - & - & 247\end{array}$

$\begin{array}{lllll}\text { S. Wright } & - & - & - & 105\end{array}$

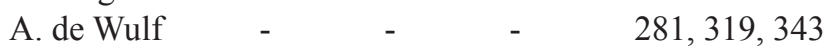

$\begin{array}{lllll}\text { T. Zenz } & - & - & - & 247\end{array}$

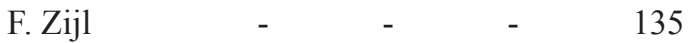




\section{Organisation Index}

\begin{tabular}{|c|c|c|c|}
\hline \multicolumn{3}{|c|}{ Alfred Wegener Institute } & 259 \\
\hline \multicolumn{2}{|c|}{ Allseas Engineering BV } & - & 195 \\
\hline Alten PTS & - & - & 57 \\
\hline ANTEA & - & - & 215 \\
\hline \multicolumn{3}{|c|}{ Antwerp Maritime Academy } & 45,215 \\
\hline Aqua Vision & - & - & 5 \\
\hline \multicolumn{3}{|c|}{ Canadian Hydrographic Service } & 41,123 \\
\hline CARIS & - & - & $17,35,63,147$ \\
\hline CherSoft Ltd & - & - & 253 \\
\hline $\mathrm{CIDCO}$ & - & - & $265,277,281$ \\
\hline \multicolumn{3}{|c|}{ Coastal \& Marine Union (EUCC) } & 159 \\
\hline \multicolumn{3}{|c|}{ Consórcio Draga Brasil Ltda } & 69 \\
\hline \multicolumn{3}{|c|}{ Delft University of Technology } & $129,135,289$ \\
\hline Deltares & - & - & $\begin{array}{l}57,75,117,129,135,289, \\
295,325,337\end{array}$ \\
\hline \multicolumn{2}{|c|}{ Earth Info Services } & - & 209 \\
\hline EdgeTech & - & - & 105 \\
\hline \multicolumn{2}{|c|}{ ENSTA Bretagne } & - & $11,265,277,281$ \\
\hline Esri Inc & - & - & 165 \\
\hline Eurosense & - & - & 5 \\
\hline \multicolumn{3}{|c|}{ Flanders Hydraulics Research } & 29,215 \\
\hline \multicolumn{3}{|c|}{ Flemish Dept. of Maritime Access } & $51,189,215$ \\
\hline \multicolumn{2}{|c|}{ Flemish Hydrography } & - & $5,63,215,319$ \\
\hline Fugro - & - & - & $223,307,311$ \\
\hline Geocon BV & - & - & 239 \\
\hline \multicolumn{2}{|c|}{ Geoscience Australia } & - & 93 \\
\hline \multicolumn{3}{|c|}{ GEO TAG Engenharia Ltda. } & 69 \\
\hline \multicolumn{3}{|c|}{ German Fed. Inst. of Hydrology } & 99,247 \\
\hline \multicolumn{2}{|c|}{ Ghent University - } & - & $281,319,343$ \\
\hline \multicolumn{2}{|c|}{ HafenCity University } & - & 259,281 \\
\hline \multicolumn{2}{|c|}{ Hamburg Port Authority } & - & 147 \\
\hline \multicolumn{2}{|c|}{ IIC Technologies - } & - & 11,203 \\
\hline \multicolumn{3}{|c|}{ IMARES Wageningen UR } & 325 \\
\hline
\end{tabular}

IMDC $\quad$ - $\quad$ - $\quad 51,189$

$\begin{array}{llll}\text { Jeppesen } & - & - & 141,177\end{array}$

Maritime Safety Queensland 17

Medusa Explorations BV - $\quad 325$

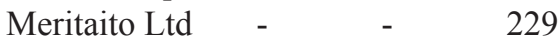

Nat. Techn. University Athens 11

NetSurvey Limited $\quad$ - 165

NOAA - $\quad$ - $\quad 11$

$\begin{array}{llll}\text { Nortek BV } & - & - & 75\end{array}$

Plymouth University $\quad$ - $\quad 307$

Port of Rotterdam _ - 29, 153

P. P. Shirshov Inst. of Oceanology 233

PUMA - $\quad$ - $\quad 153$

Quality Positioning Services, Inc. 81

RESON BV - $\quad$ - $\quad 301$

Rijkswaterstaat - $\quad$ - $\quad 29,51,75,129,135,295$, 325

Royal Boskalis Westminster NV 337

Royal Netherlands Navy - $\quad 57,117,289$

Senckenberg am Meer - $\quad 23$

STEMA Systems - $\quad$ - $\quad 331$

Teledyne $\quad-\quad \quad-\quad 111$

Thurne Hydrographic Ltd - $\quad$ 105, 111

$\begin{array}{llll}\text { TNO } & - & - & 57\end{array}$

UK Hydrographic Office - $\quad 81,87,183$

UK Maritime \& Coastguard Agcy. 183

UK National Oceanography Centre 183

UK New Forest District Council 183

University of Bremen - $\quad 23$

University of New Hampshire $\quad 81$

University of Twente - $\quad 57$

University of Southern Mississippi 87

University of Waikato - $\quad 23$

Venture Geomatics Limited 11 
354 | Hydrol 2 


\section{Topical index}

Innovations in acquisition techniques

Subsea positioning

Innovations in processing techniques

Smart data management -

Easy customer access to data and products

Careful marine planning

Cost-effective solutions

Geophysics of the marine environment

Vertical references

Accurate hydrodynamics -

Hydrography in the Benelux

The hydrographic profession
$69,75,105,111,153,207,227,245,263,299,309,329$

$111,195,237,299$

$17,35,41,57,81,99,117,123,129,147,153,165,251,329,341$

$41,63,87,141,147,159,165,177,221,251,317$

$41,87,123,135,141,147,159,165,177,183,221,251$

$23,51,57,69,159,165,183,251,317,329,335$

$81,87,129,141,183,221,251,299$

$23,29,51,57,69,189,213,231,323,329,335$

$117,251,287$

$5,99,117,135,213,245,251,293$

$45,51,63,117,129,135,153,213,293,323$

$11,45,201,257,275,279,305$ 
356 | Hydrol 2 